
Mason E. Hale, Jr.

7. duel

very rate?

Mason E. Lisle, Jr. 



\title{
LICHENOGRAPHIA EUROPEA
}

\section{REFORMATA.}

\author{
Premituntur
}

\section{LICHENOLOGIAE FÚNDAMENTA.}

\section{COMPENDIUM}

IN

THEORETICQUM ET PRACTICUM LICHENUM STUDIUM

$$
\text { " }
$$

CONSCRIPSIT

\section{EIIAS IRIES。}

Botanic. Demorsta, Prof. momise.

\section{LUNDE.}

TYPIS BERLINGIANis, M D C C X X X L

VENDITUR APOD E. MAURITIUM, GRYPHIE. 


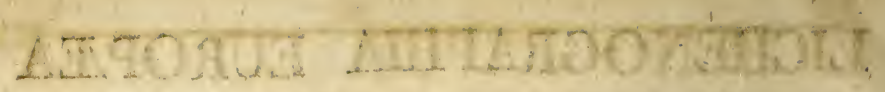

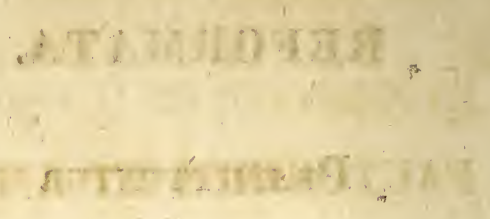

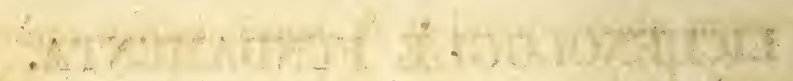

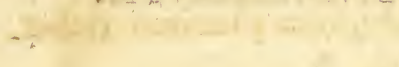

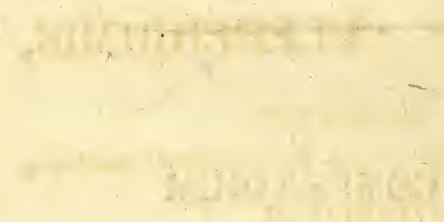

$$
2=1+4=9
$$

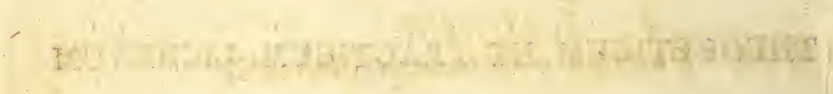

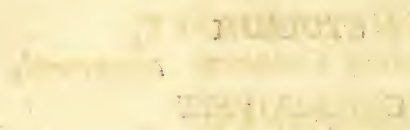

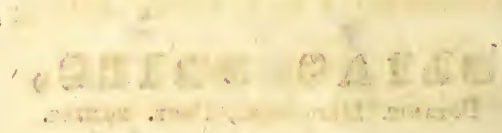

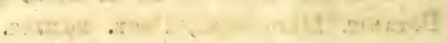

$$
\text { (1) }
$$

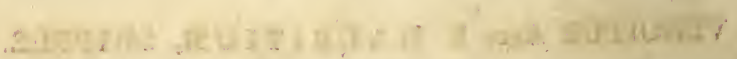




\section{FAUTORIBUS ET AMICIS,}

quorum observationibus \& speciminibus communicatis Lichenographia Europaea plurima debet, nominatim

\section{VIRIS CELEBERRIMIS,}

W. BORRER,

Lichenographiæ Britannic auctori,

L. DUFOUR,

Peregrinatori Hispaniæ insigni,

F. LAURER,

Plurima e Germania offerenti,

A. LE PREVOST,

Liberalitatem Gallicam impetranti,

I. SCHAERER,

Lichenologiz in Helvetia statori,

S. SOMMERFELT,

Scrutatori Norvegia acuto,

G. WAHLENBERG, Floræ Lapponicæ illustratori

gratiam, quam habet maximam, refert 


\section{RATIO OPERIS}

\section{VII,}

I. Theoria Lichenum.

I. Indicatio.

a. 1dea.

b. Expositio.

ic Associatio.

d. Summa.

II. Designatio

a. superior (Lichenosarum \& Phycear.) S. 5 .

b. proxima (Lichenum \& Byssacearum) \$. 6 .

c. collateralis (Fucacear. \& Ulvacear.) \$. \%

d Diagnoses. $\$ .8$.

III. Comparatio - p. xxxvi.

a. Plantarum perfectior, \$. 9.

b. Fungorum. \&. 10.

c. Phycearum. \$. 11 .

d. Systematica. \$. 12.

IV. Typus

a, vitce.

b. modi.

c. proventus.

d. existentice. $\quad$ S. 16.

II. Morphologia Lichenum,

V. Genesis

a. originaria. $\$ .17$.

b. per sporidia. S. 18 .

c. per gonidia. S. 19 .

d. Relationes. S. 20.

VI. Morphosis.

a. Nisus.

b. Forma.

c. Insertio.

d. Ordo.

VII. Metamorphosis.

S. 21.

§. 22 .

ค. 23 .

๑. 24.

a. Ratio. \$. 25.

b. Explicatio. \$. 26 .

c. Variationes. S. 27.

d. Leges. \$. 28.

p. IVIX. 
VIII. Anamorphosis

a. hypothalli. S. 29 .

p. Lxx.

b. thalli. \$. 30 .

c. apotheciorum. S. 31 .

d. Corollaria. S. 32 .

III. Geographia Lichenum.

IX. Medium.

a. Aër.

S. 33 .

p. Lxxx.

b. Calor.

f. 34 .

c. Humiditas.

d. Lux.

ऽ. 35 .

X. Sedes.

a. Habitatio. \$. $3 \%$.

b. Solurı. S. 38 .

c. Stationes. ... \$. 39.

d. Migrationes. \$. 40 .

XI. Regiones, - - p.

b. maritima (- occidentalis.) \$. 42.

c. continentalis ( - orientalis.) \$. 43.

d. alpina ( - - hyperborea.) \$. 44.

XII. Statistica.

$\begin{array}{ll}\text { a. climatum. } & \text { S. } 45 . \\ \text { b. sedium. } & \text { S. } 46 . \\ \text { c. regionum. } & \text { S. } 4 \%\end{array}$

d. $V$ is in constitutionem. $\$ .48$.

IV. Historia Lichenum.

XIII. Constitutio.

a. Principia.

b. Species.

c. Genera.

d. Systema.

S. 49.

p. xctx.

XIV. Colores

a. primarius. s. typicus.

b. secundarii. s. normales.

c. aberrantes.

d. peregrini.

S. 55.

S. 50 .

ऽ. 51 .

S. 52 .

XV. Qualitates,

a. duce natura. $\quad$ f. $5 \%$

S. 53.

p. xclit.

p. LXXXIY.

Lxxxvill. 
II.

XVI. Studium.

a. Epocha contemplationis. S. 61. p. cxv.

b. - descriptionis. S. 62 .

c. - dispositionis. S. 63 .

LICHENOGRAPHIA EUROPAEA.

I. Clavis dispositionis. $-\longrightarrow$ p. I.

II. Variationes systematis. - p. 7 .

III. Genera \&

IV. Species - - p. 15-458. Addenda \& corrigenda $\quad$ p. $15-458$. IND I CES.

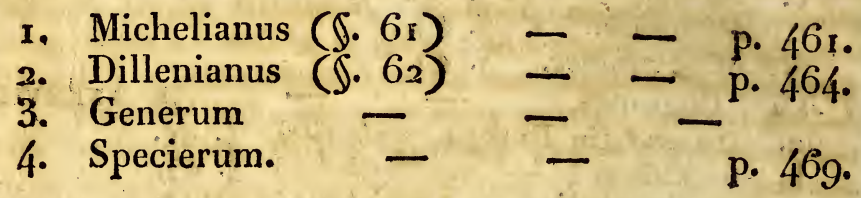




\section{RATIO OPERIS.}

Lichenum familia reliquis inter plantas Cryptogamas Linn. multiplici et insigni usu in technologia, medicina, oeconomia etc. antepollet; maxime spectabilem, procipue in septentrionalibus et alpinis, vegetationis partem efficit; physiologia egregie incepta solidaque experientioe basi suffulta eximie sese commendat. Singulare itaque videatur eam tam paucos habere cultores. Recentiora detecta ejus historiam plene reformantia plerisque Botanicis caput mortuum efficiunt, quare nova scripta etiam Lichenologica de his aut nullam aut imperfectam cepere notitiam. Cujus caussa videtur practici, ad specialia deducti compendii defectus, quem prosente opusculo tollere studui.

Deterruit multos a Lichenum studio late serpens opinio, hanc familiam adeo vastam et intricatam esse, ut singulari et monographico studio tantum coli possit. Est vero cum Fung is comparata specierum, generum etc. numero vicesies angustior. (Ingenue fatear me in Lichenum familia ne tertiam quidem laboris. partem deposuisse quam in unico genere Agaricorum, quorum synonymorum maxima pars ne collecta quidem erat, ut Lichenum, et ad quorum dispositionem omnibus tentatis viis plurima millia singularium observationum tantum in sporidiis necessaria erant). Vix crederem Lichenum species et 'genera difficiliora esse determinatu, quam Phanerogamarum, si hinc non mox ad omnino idealem et absolutam perfectionem tendamus illincque status normales et typicos, facile negotio discernendos, respiciam's. Si vero ad theoretica principia, parum sape suffragante natura, et perfectoe analogia leges uno gradu omnes species reformentur, vel singuli obvir status steriles, mutili, deliquescentes, decolorati $e_{\text {. }}$ s. p., ut scepius factum vidimus, pro veris speciebus describantur, vix aliquid practici, vix aliquid determinati sperare licet. Apparens illa in proesenti Lichenologia speciali barbaries ex eo potissimum pendere videtur, 
quod nimis sit diffusa, nimis dilatata et, ut ita dicam, supra mod:m exculta, id quod vulgo fit monographico studio, ubi Auctor non reliquas et procipue vicinas familias simul colit, sed unicam ad "stitum in statu" extollit. Novorum generum et specierum spes inter Lichenes Europaos saltim longe minor est quam in vicinis familiis. Dum v. c. ex unico Observatore per paucos menses in Europa decadem novorum generum et centuriam specierum inter Phyceas ultimis annis detectas esse accepimus, per ultima decem lustra vix unus alterve Lichen novum genus constituens ( $S$ iphula enim jam ab Ammano) in Europ a detectus est, specierumque novarum denarium numerum diligentissimus per annum non detegeret. Ut in proximis familiis nova genera et species quotannis emergunt, in Lichenologia prisca magis submergunt. Illoe magis in crescendo et multiplicando, hoec in maturando et contrahendo occupata est. In systemate ad prima Systematicorum principia redire necessitas magis magisque urget. Hinc quondam diximus Lichenologiam esse quasi civitatem institutionibus obrutam, cujus reformatio difficilior, quam nova constructio.

Ut in prosente rei herbaria statu maxime necessarium videtur opus practica Lichenum cognitioni inserviens, nescio an aliud magis difficultatibus obnoxium, anceps et periculosum. Omnia pare in dubium vocata sunt, multa vario modo reformata, de plerisque dissentitur. Temerarium foret studium omnium placitis placere; suam experientiam sequens nemini forsan satisfaciet. Summa de Lichenologia merita b. m. Achar $i \vec{i}$, cujus nunc ut rejecti regis errores tantum enumerantur, agnoscens, gavisus sum meas observationes in plerisque cum, admirandis studiis Schaereri, Wallrothi. $\boldsymbol{M}$ Teyer $i i$ etc. conspirare. Multas ineditas observationes has confirmantes amicis, procipue Dufoureo, debeo. Horum quoque auspiciis Lichenographice reformatce nomine usi sumus. - Omnia, quae de Lichenibus scripta mihi innotuerunt, sollicite consului; gratissimo animo hoc loco agnoscendum pluria et rariora scripta me amicorum liberalitati debere, literaturam Gallicam Lichenum Prévostio, ineditam Lichenographiam Britannicam Borrero, Stictarum Monographiam $D$ e liseo e. s. p. Quod vero ipse expertus sum (in 
montibus et silvis per majorem anni jartem vivens. nec eas obiter tantum sub excursionibus lustrans), id pracipue exponere volui. In iis tantum, qua ipse experiri non potui, v. c. de origine crustarum rosearum $M$ eyerum, optimam auctoritatem secutus sum.

Proeter terminologiam, generumque et specierum nomenclaturam, in quibus omnis immutationis molestiae vix umquam bene compensantur, reliqua proprio marte de novo elaborare studui, at simul ad recepta, quousque fieri potuit, me accommodare. Nulla auctoritas tueatur nomina sine maxime urgentibus rationibus mutata. Nomina ab Achario, quum minus cognita, adaquata etc. viderentur, rejecta, ubique iterum recepta; sed servent etiam ipsius, etsi genera paulo aliter limitentur, prioritatis jus. - Admiror constantiam terminologua Wallrothianae congruam, vix subtiliorem 'propositam esse lubens agnosco, at quamdiu idioma Deorum Olympicorum non est scientiarum, triviale et humanum, ut intelligar, sequi coactus fui. Quosdam in Mycologia receptos terminos, v. c. hypothallum, in Lichenologia recepi, cum ipsae partes, in utraque classe sibi invicem satis respondeant. Discreto illo monographico studio, quo familiae ex Algis et Fungis L. resolutce culta fuerunt, singuloe in scientia detrimentum priva elaborata est terminologia, guas ut conciliemus studebimus, cum plurimi termini communes esse debeant, ne diversa tribuantur nomina partibus non tantum functionibus prorsus identicis, sed adeo etiam similibus, $(v$. c. peritheciis $S$ phaeriae et Verrucariae,) ut discerni nequeant. Minus hoc loco respexerim terminorum nomina proter necessitatem multiplicata, sed facilem, in quem quisque ducatur, errorem diversos in diversis familits terminos veram indigitare differentiam; qua vero his cribratis ipsis magis indicaretur quam slescriptionibus.

Ut inductionem ad Lirhenum studium promittere necesse visum est fragmenta noniulla proelectionum nosirarum in plantarum familias, quatenus ad hujus libri materiem spectant. In genere vero generalia a singularibus, quantum fieri potuit, nolui separare; cum a singularium cognitione omnis ver a et fructuos a cognitio fluat, ad quam haud descendunt meri helluones summitatum rerum. Hloc studio multa corollaria justo nimis extenduntur; et de phy- 
s iologic is hanc maximam errandi fingo fuisse causam, ut verbis utar Haller $i$, quod paucis experimentis, aut demum multis, sed subjecta pro experimentis analogia, plerique usi sint - vel etiam his deficientibus quid explicatum censuerint qualitatibus occultis, qua, licet speciosa, ut obscura inter severiores naturae scrutatores vix ullos eximios sectatores numerant. - Qua de diversis vegetabilium seriebus, vita, morphosi etc. discrepantibus in praelectione prima plenius iterum repetii, omnium Botanicorum attentione digna videri vellem. Plura, quam hujus operis ratio tulit, ex his observationibus deduci posse fingo. Primitiae GeographicaLichenum in Europa distributionis in opere hujus indolis vix deficere potuerunt; sed paucissimus proparatis subsidiis minime absolvere licuit. Historiam succinctam $L i-$ chen ologiae tironibus magis proficuam credidi, quam nudam librorum citatorum explicationem. $e . s . p$.

Librum pandit dispositionis Lichenum recepta conspectus, qui simul rite intellectus pro affinitatis adumbratione, et artificio considerari possit, quem systematicum genium probantibus et Lichenes examinantibus haud displiciturum speramus. At ne tiro, quod cavendum censeo, unicce videndi rationi coce adhareat, plures variationes addidi. Physiologico magis, quam systematico respectu, addidi dispositionem thallinam, qualem tam incertum dispositionis fundamentum offert.

In generibus et speciebus diagnostice describendis tam brevis et acutus esse studui, quam rei perspicuitas et ipsarum protea indoles permiserit. Sunt s. d. diagnoses adminicula ad species ignotas delerminandas, non specierum criteria; nam sope deficiunt partes e. s. p. E logica methodica euim omnibus constat nos tantum definire ideas s. status typicos, quales excepimus, et solos Mathematicos absolute sua objecta definire. Multas nomine fere neglectas notas in auxilium vocavi. Varietates leviores, formas, lus s et reliquos titulos, quos diversa individuorum evolutiones gerunt, raro, nisi synonymorum gratia, curavi; hoc gry, tironibus frustranea crux, in libera natura magis confundit. Veris varietatibus inesse fingo primitivam differentiam, per varias modificationes constantem. Nullas species nisi a me visas in certarum zumerum recipere debui; species steriles tantum lec- 
tas $l$. alia ratione incertioris originis cruce ( $(t)$ nota$v i$; asteriscus $\left(^{*}\right)$ vero inter synonyma indicat statum singularem abnormem; post species formam insignem, procedentis tamen potius filiam, licet transitus directus non satis observatus sit. Sub protearum et difficiliorum specierum studio, singula sope hebdomadas et menses dicavi.

Stationes et loca, quoe milhi certa innotuerunt, plenius exponere conatus sum. Si illoe aliis regionibus aliter se habeant, ut plura cognita exempla suadent, res est attentione digna; quales in Scandinavia mihi obviam venerunt, $h$. $l$. indicavi. Patriam vix umquam, nisi speciminum fide, adscripsi, re vagam et erroneam repeterem; malui in his defectu, quam excessu peccare. Inventoris vel communicatoris nomen addidi tam in rei, quam grati animi testimonium. Subjunctas observationes non ut graphicas descriptiones, quibus protea Lichenum indoles cegre comprehenditur, consideratas velim, cum in hoc opere excursionibus dicato mallem tradere adumbrationem historice et rationum, quales se sub passivo studio mihi impresserunt. Hoc, ut ita dicam, specierum individualitas, Botanicis practicis delicioe, sub latiori et magis theoretica specierum constructione deteritur. Quibus modis geographicis differentiis in specierum determinatione uti licere censeam, suo loco exposui*).

Sequintur dem $m$ indices Lichenum Michelii et Dillenii, quos simul totius antiquioris literaturoe clavem sistunt, quare in hac, quamvis cara. mihi sit, ulterius regredi superfluum scepius duxi, nec non Index nom in um genericorum et specier um recentiorum. Ut hace (scilicet specierum) simul completa et compendiosa foret, ne sin-

*) Miretur forsan aliquis quare non potius Systema Lichenum universale conscripserim. Hoc sane nostros labores haud multum auxisset, cum exotice species nullis fere vexentur controversiis, omnesque Acharian a e, plurima Féei (ex ipsius auctoris munifcentia) e. s. p. nobis cognitre sint, magnaque accesserit copia novarum specierum. At primo exoticarum cognitio, indigenarum vacillante, secundi ordinis visa est; dein, multas mihi ignotas in herbariis Germanorum servari novimus, ut opus nostrum incompletum fuisset tandemque sub alia forma, magis objectisu graphica et analytica prodiisset, cujus prodromus opus, quale prasens, visum est necessarius. 
gulum nomen ob genericum non tantum apud diversos sed eundem etiam Auctorem ter quater varians, multoties repeteretur hujus nullam habui rationem, sed tantum nomina specifica minus varia attuli, quo. facilius, ut mihı persuasum habeo, investigabuntur: lllius adposui Auctoris nomen, qui speciem primus descripsit aut rite limitavit, quod majoris ponderis visum est, quam quis fortuito primus sub hoc vel illo nomine generico collocarit. Nomina compilationum quarundam, quas nemo amplius curat, ut Gmelini editionis Systematis natura, prorsus omisi, cum Auctor ipse plantam quam nomine suo designaret, sapius forsan ignoraverit.

Ceterum nostrum qualecumque judicium ubique sequens, haud necesse duxi aliorum recedentes videndi rationes simul refellere; potius evitavi discrepantias in exponendi aut determinandi modo ita proponere, ut nostrum quasi novum aut privurn quoddarn promineret; nolui in corrigendo poedagogi munere fungi videre. In synonymis citandis, de qua re mox infra plura afferentur, intelligo plantam ab Auctore descriptam, non vero Auctoris synonyma, quamvis to excl. syn. haud addiderim. Nostrum ceterum judlicium ex omni parte ut nostrum suffragium, vel, si dissenseris, ut meam exceptionem censeas velim. Multa aliter proponi posse facile video. Haud spes mihi fuit Lichenologiam Europaram absolvendi, sed desiderium indicem facilem tironibus tradendi et ex parte simul prostructionem, ad quam nova et ulteriores observationes referantur, donec perfectior exstruatur. Tale per decennium ab aliis exspectavi, at frustra; quare meum ante plures annos elaboratum tentamen non diutius supprimere debui metu, ne ab alio supprimeretur. Cautius sine dubio egissem, si alii primi periculi honorem relinquens, ipse demum supplendo et corrigendo prodiissem. Non nostrorum studiorum sed scientia caussa vovemus, velint lichenologi magis ad convergentes, quam divergentes videndi rationes tendere, sine quo nisu nil ubique recepti et stabiliti enasci posse vidéur; mere critica nil exstruunt, sed hypercritica provocant, ner parum ad hodiernam Lichenologiae disturbationem (at, quod non negligendum, regenerationem simul), et scientiae auctoritatem detractam contulerunt. Nam cum inter scientiae cultores tantum de nominibus $e_{\text {. }}$ s. p. disce- 
ptatur, omniaque continue commutantur, illi in "proeliminaribus" detinentur et ap"ld exotericos contemtus in ipsam tantum redundat. Aque evitanda sunt, monente $B$ acone, "immodicum studium duorum extremorum, antiquitatis et novitatis, quae temporis filice male patrissant: ut enim tempus prolem devorat, sic hoec se invicem; dum antiquitas novis invideat augmentis et novitas non sit contenta recentia adjicere nisi vetera prorsus eliminet et rejiciat," et "error se ostendens in modo tractandi doctrinam, qui est imperiosus et Magistralis, non ingenuus et liberalis, ita demum compositus, ui potius fidem imperet, quam examini subjiciatur" - "Qui de natura tamquam de re explorata, pronuntiare ausi sunt, sive hos ex animi fiducia fecerint, sive ambitiose et more professorio, maximis illi ecientias detrimentis affecere" *).

Primarius fons divergentium in singularibus judiciorum videntur diversa' species et formo, quas singuli sub eodem nomine ante oculos habuerunt. Sed in ipsis synonymis extricandis haud pauca prostare saltim debui cum mihi aperta fuerint omnia, quae quidem multa, Lichenophylacia Scandinaviae et pracipue cum per longam annorum seriem mihi contigerit consulere optimum fontem, 6. m. Acharium, qui mihi quotannis insigni liberalitate et humanitate, plurimas centurias Lichenum determinavit, multa communicavit omniaque mea de suis specierum ideis dilbia per literas solvit, ut ex his pleniorem quam ex herbario ipsius synonymorum Acharianorum mihi comparaverim cognitionem. A munificentia Cell. Lichenologorum insuper tulimus fere omnes species in Suecia, Norvegia, Ruthenia, Britannia, Helvetia, Hispania etc. detectas; a Botanicis Gallice, quorum cohortationibus excitatus hoc opus, utinam indignum non videatur, conscripsimus, pluribus completis diversarum hujus imperii regionum collectionibus condonati sumus liberalitate, numquam frustra provocata, sapius ultro oblata. Multa e Germania quoque largili suntHochstetter, Kunze,L aur er, E. Meyer,

*) Quod vero ad tenebras attinet, quibus imperiti hanc l. illam disciplinam obrutam queruntur, ea sapius magis subjective, quam objective censende. Id tempus sane inter Plantas Cryptogamas est proterlupsum, quo compilationilus, conjecturis e. s. p. quid ad harum cognitionem conferri possit. 
Schmaltz, Sclubbertet Wallroth; pudet me tamen leviorem esse meam cognitionem Lichenum hujus centralis Europoe regionis, quae tot classicas Lichenologicas numerat imagines, multasque species germanicas mihi esse ignotas. Hinc synonyma fere omnia ad exemplaria originalia determinavi et ubi erraverim hoc non raro exemplaribus ipsis tribuendum censeo. Qui diversas collectiones Lichenum lustravit, bene scit in his pro authenticis venditari specimina ad diversas species pertinentia. Sic v. $c$. in collectione b. m. Swartzi pro originali Lichene corneo With. adest Gyalect a cupularis, sed ad alia anglica exemplaria et ad nutum plurimorum auctorum illud synonymon ad Biator a $m$ mixta $m$ retuli e. $\left.s . p_{.}{ }^{*}\right)$.

Gratissima mente agnosco rarum favorem, liberalitatem et ingenuitatem, quibus priora mea scripta $a b$ omnibus, vix ullo excepto, recepta suint; huic operi eandem sortem exoptare, vix sperare, liceat. Ex iis vero, qua de Phyceis in 'Syst. Orb. Ve g., protulimus, et jam in Flora Ratisbonensi prius quam liber in Germania divulgatus erat, mea studia alieno et subinde contrario modo prolata sunt stili nostri et proponendi modi forsan dissensu, quem si nativo meo verborum et proponendi modi sensu restituendo plene tollere possem, valde loetarer, *). Aliorum optimorum

*) Ad synonyma figenda nil magis confert, quam fideles Exsiccatorum collectiones, sape majoris utilitatis quam libri describentes, quare ex his citavimus, quas ipsi Editorum sapius muñere possidemus nempe Desmazieri, Ehrharti, Plantas Cryptogamas et Phytophylacium, Flörkei (priores fasciculi mihi desunt), Mougeotii et Nestleri, Schaereri et Sommerfelti $i$. E Flot owi $i$ tot citavi, quot vidi numeros; $S$ Schrader $i$ numeros dispersos tantum vidimus. $F$ unki $i$ apud amiciss. Hornschuch pervolvi, at numeros adnotare negligebam. Reliquas non vidimus; inter has dolemus numerandas $R$ eichen $b a$ chi $i$. Cum amicis Stenhammar, Ljungstedt et Ahnfelt ipse curavi Collectionem Lichenum Suecic, ulterius continuandam, quam eam tantum ob causam primam citavimus, quod operis nostri basin quasi subministrat. A me et sub meis auspiciis 70-80,000 Lichonum Suecanorum exemplaria distributa sunt, qua ad synonymiam stabiliendam aliquantulum collatura esse sperare liceat.

**) Que in libro allato r. 2.20-223 ad classem Algarum, latiori sensu sumtam, attulimus, ad dispositionem in singulis familiis referenda non esse, re propius perpensa, vix ullus dubitet; adt singulas familias me dispositiones e thallo haud sequi posse verbis expressis notavimus. Singularis fuisset contradictio, sidispositionem, ip- 
si inscribens "e fructificatione," e thallo tradere voluissem, pracipue cum hanc primariam thallina dein confirmare studuerim. Ibidem $p$. 323, s. exposui, quare receptas distinctiones e thallo articulato et contiguo etc. e mea videndi ratione sequi non licuerit, sed tam leviter, et modo studio resignante a proposita via discessi, ut nesciam an non plures eorum, qui dominantis astimati sunt sectatores, longe magis. Equidem crederem, omnibus Botanicis, quibus studia mea innotuerunt, notum esse, me seinper dispositiones carpologicas, re et verbis, in Lichenum, Phycearum etc. fumiliis ursisse, cum vix in alia re a Cel. Botanicis magis dissenserim. Idem sponte fluere crederem toto genio dissertationis et vexbis meis in flora Ratisbonensi 1826. p. 558 in integritatem restitutis, licet in primis lineis contraria sententia quantum salva persuasione mea licuit concedere voluerim: Unter den Phyceen ist die Fruchtbildung so vom Thallus zurückgedränst, "dass es eweifelhaft ist, ob sie sich jetzt daselbst einführen lässt. Dass sie gleichwohl aber endlich zu diesem Ziele kommen werde, ist meine subjective Ueberzeugung, und war es um Einförmigkeit in der ervähnten Arbeit zu gewinnen dass ich genöthigt wurde ein systematische Anordnung darnach zu versuehen e. s. p. - Hepaticas ad Algarum classem numquam referendas diximus, ne umquam guidem in mentem mihi venit, consulto dicenti (minime ordinem Algarum L. cum omnibus spuriis formis, jam ad finem seculi Linnaani exclusis, sed) " $L$ innaei Algarum ideam: Vegetabilia, quibus radix, folium ev caudex in unum, ls se seroandam, uta Jussia eo, W ahlenbergio aliisque acutis observatoribus factum vidimus, non ut familiam sed superiorem classem, ex quo sponte fluere mihi videbatur, ea vegetabilia esse exclusa, in qua e haec idea non cadit, nempe tam Hepaticas, quam Tremellinas, eo magis cum in mox sequente Algarum dispositione, et quidem in eadem plagula $(p, 58)$, ut sententiam non mutaverim, eas prorsus excluserim, cum in omnibus meis reliquis scriptis et quidem eodem tempore edito, illas ad Muscorum, has ad Fungorum classes immutate retulerimus, cum vix fingerem guemquam tam sbso. lete ratione mea verba interpretaturum. Id tantum addendum, $C h a-$ ram, licct illi idea accedere videatur, et a summis viris huc referatur a me Filicum classi propiorem haberi. - Lemaniam et oscillatoriam numquam proximas habui, sed ad eandem seriem s. tribum, multis tamen generibus distinctas, retuli; nolim v. gr. ut pari ratione dicatur, me Peltigeram et Gyalectam sibi invicem proximas habere. Codium ad Vaucherieas, Ectocarpum ad Conferveas, hujus affinitatem cum Confervis fueicolis indicans, retuli; Ectoc. to mentosum Codium "referre"s. analogum, non affine esse indicare studui; "nolim ut pari ratione credas me o. c. Gyalectam et Stereocuulon sibi proxime affines habere. Rationes nominis Ceramii prisco latiori propiore sensu servati l.c. indicavi, inter quas etiam quod novum et pracipue a me propositum evitare volui. Est miki fere inna- 
anonymice *) prolata; et cum plene de veritate Scopoliani: "nulli celari possunt errores" mihi persuasum sit, de his omnes contentiones evitare optime visum est, probe perspicienti quam viles et inanes tales passivis videantur observatoribus, quas melius sapientes ut leves aberrationes considerant et certe prorsus negliget, forsan cum nobis ipsis, futura dies. Mos denique est, ut Auctor observationes et correctiones expetat easque humaniter veritatisque studio propositas grate acceptas et aquo animo latas fore testetur. At illas, et sine suis precibus, haud defuturas satis persuasum habet, et quod ad modum attinet, hic ab unius cujusque genio et stilo pendet, quibus leges proscribere nec valet nec velit. Et dicendi genus ipsius, fastosum et diffusum evitare studentis, leve nimis forsan videatur; si quid amphiboli et lemerarii sub calamo cum Typotheta certante, plus temporis in natura fruenda quam libris compilandis consumti, invite irrepserit, ab ingenuis

ta, nimia forsan, antiquiorum nominum reverentia, quce ne et in prasente libro simul offendat, vovemus. Limites Fungorum, Lichenum, Byssacearum, Zoophytarum etc: cum Phycearum ita confines, ut haud mirum videatur me varia genera, v. c. Alcyonidium, exclusisse, vel alio loco, ю. c. Byssocladium, auctorite simul vulgo suffultum, collocasse.

*) Ut unicus in Flor. Ratisb. 1826. n. 25. mea studia exposuit neglexi, eum tantum ob caussam, quod plurima ullata a d publi cum, nec meum, judicium pertineant v. c. me nil nisi inutiles immutationes ad systematicam fungorum cognitionem contulisse e. s. p. Si verum videatur, ab omnibus threniis Lectori parcam. Cum vero fere omnes qui his studiis deinceps incubuerunt, etiam ii, qui proprias vias aperuerant, nostrum Systema Mycologicum secuti sint, licet, non negante Auctore citcto, in singularibus usque reformatum sit et six uliud in inferioribus plantis majoris ambitus et difficultatis, - velim ut audiatur et altera pars, Fl"ra Ratisb. l. c. Ea, quum Auctorem plane nesciam, contendente, Systema nostrum fungorum in omnibus essentialibus $N$ e es io, Lichenum Eschweilero deberi, id tantum observare decet, mei lineamenta utriusque esse antiquiora; ceterum de his perbene scio aque ingriuorum ac acutorum Neesi $i$ b E senbeck et $E s c h w$ e $i$ le $r i$ judicium. Cum incidit in errores, quos evitundos promonui, genium Systematis nostri sublatum reddere ei quidem contigit; tale vero panes me non vivere scio. Ut prafiscini dicam vix aliud vidso sincorum quam ad finem prolatum, sed adhuc frustratum, desiderium alios in mea studia lacessendi. (Me quid arovvpws in re herbaria nec scripsisse, nec umquam scripturum vix est quod moneam, cum haud necesse mihi videatur alii, quam qui sine rubore alios carpere l. se ipsum laudare cupit). 
et vere liberalibus lectoribus éxcusatum novit; $a b$ aliis frustra hoc loco peteret. Qui ipse fateatur se verba auctoris haud rite intellexisse, nullam suorum studiorum rationem habere mallet, quam ut sententias e nexu disruptas ita tantum proferat, ut paradoxae et obscurce promineant. Objectiones vero in rem ipsam eo cariores sibi agnoscit Auctor, cum eis vel errores suos corrigendi vel rationes plenius exponendi occasio subministretur. Cum per omnem vitam cum omnibus lites et rixationes ipsi contigerit evitare et omnia polemica a genio suo aliena sentiat, in his exponendis, rem ipsam tantum respiciens, formam eristicam semper evitabit. A sua sententia jucundius ipsi videbitur posse discedere, quam rei gratia coacto tueri, iis tantum vindiciis erecto se nil nisi severe et integre veritatem ambiisse; et latitia, . quod bene latens sibi ipsi non frustra vixeret. His auspiciis restat tantum, ut exoptet h jus scientia cultoribus perennem illam felicitatem et verum in natura gaudium, quae in ipsum ex harum stirpium studio redundarunt.

Lunda Calendis Decembris 1830. 


\section{PRALECTIO I. Theoria Lichenum:}

Non fingendum aut excogitandum, sed observandum, quid natura faciat \& ferat. - Baco.

Caput I. Indicatio Lichenum s. Iocus in Systemate of Vegetabilium serie.

D. I. Inter quattuor orbis vegetabilis provincias, Dicoityledonearum, Monocotyledonearum, Heteronemearum \& Homonemearum I), hæc infima, optime a Linkio primo sub Anandrarum nomine separata, maxime naturalis, bene a reliquis abscissa $8 x$ certe inter vastissimas numeranda. Cum in his vis formativa ad certum typum nondum fixa, sed in formas externa facie \& proveniendi modo diversissimas evagari videatur, primo obtutu vix fingeres, id quod vera ratio tamen est, omnibus 2) in maxime essentialibus eandem esse vegetationis \& fructificationis theoriam. Omnibus nempe Systema vegetativum evasculare, deficientibus tam vasis spiralibus, quam propriis, absque interno necessario partium nexu, mere cellulare, cellulis irregularibus sphæroideis vel cylindricis subfloccosis, omnibus externis organis confusis, quorum incrementum mera partium ex-

1) Cfr. Systema Orbis Vegetab. 1. Plantae Homonemene, ubi antecedentia \& ea, quæ infra tangenda sunt, plenius indicavi.

2) Nulla formationes autonoma vegetatione carentes v. C. Phylleriacece, Entophyta \&c. h. I. sunt. Ceterum quam plurimæ aliæ Homonemeis adscriptæ sunt tantum status aliarum degeneres. 
tensio aut aggregatio. Systema fructificationis; nisi plane deficeret, a vegetativo primitivo immediate, metamorphosi simplici 3), enatum, cum eodem subcontiguum, flore et distincto sexu destitutum; cellulis collabentibus in sporidia, qua germinantia, nulla testa relicta, ipsa prolongantur in fila vel discreta vel in corpus homogeneum confluentia. Tot rationibus conspirantibus difficile videtur summum commune dispositionis principium eruere, quale vero, quantum equidem perspicio, offerunt celluloe subsphoricce, vivaces, gelatina in organisationem tendente farctoe, reproductivo, herbacea, normaliter virides (qui color tamen subinde magis incenditur), re ipsa natura gemmacea, quæ in altera Homonemearum parte (Algis) præsentes, in altera (Fungis) deficientes omnes, \& quidem insignes, vegetationis \& propagationis differentias determinant. Harum indolem inter Lichenes primus plene exposuit Wallroth 4), cujus denominationem gonidia igitur recipiamus; sed etian reliquis Algis competunt \&, quod summi videtur ponderis, hæc -differentia. totum fere Orbem vegetabilium percurrit, quæe exinde in duas collabitur series, Morphosi, Biologia \&c. diversas, quarum altera primaria gonidiis l. gemmis instructa, altera secundaria eisdem destituta. Videntur hac ratione hæe

3) Hæc facile primaria differentia. Cfr. sequ. Cap. 3 . Omnes Nemeæ absque fructificationis metamorphosi ipsæ valde protex.

4) Wallrothi Flechtenk. 1. p. 46. A nobis olim dictæ fuerunt cellula vegetoe Syst. Orb. Veg. 1. p. 225., a Cel. Meyer bene gemmulx, cum non tantum conditio sint gemmarum necessaria, sed earum etiam prototypicus status. De analogo, sed valde ręcedente, organò Fungorum in Mycol. Theoret. disserendum. 
differentia clavem Morphologix \& Physiologia discrepantium, funditus exceptarum, offerre 5). Chlorococcum 6) est gonidium liberatum, per se vegetans.

5. 2. Hæ duæ series, Fungi \& Algce, ex habitu antiquitus distinctæ fuerunt, 7) \& hac differentia confirmatæe videntur. Fungi in systemate vegetativo (IMycelio dicto), omni viridi \& herbaceo, omni radicis veræ, caulis \& folii analogo destituti, defectu nempe gonidiorum verorum, horum organorum prototypi. Est mycelium fructificationi tam subjectum, sæpe in hac ita absorbetur (velum fructificationi tantum offerens), ut in descriptione practica 8) vix respiciendun sit, quare Fungus ipse, cœnotocus Ehrenb. saltim, ob defectum gonidiorum nullius vegetativarum partium explicationis compos est, sed, ut ita dicam, e gemma primaria (velo) præformatus extremitatibus determinatis, omnibus organis simul explicatis \& definito tempore perituris emergit. Totus Fungus pro mera fructificatione habendus est. Hinc Veteres

5) Hujus expositionem proferendi alius forsan locus nobis subministrabitur.

6) Hunc statum per latas plagas regnantem proprio collectivo nomine designare utile duximus, minime tamen pro autonoma stirpe sumentes aut 'ad definitan quandam referentes. Oritur tam a Lichenosis, quam a Phyceis, immo ab infusoriis. Duplex ejus status progressivus, primarius (Palmella botryoides Lyngb.) \& regressivus, secundarius (Protococcus Ach.).

7) Fungi semper ordine distincti fuerunt, Algæ plurimæ ante Linnæum Muscis 1. Plantis submarinis adnumerabantur.

8) Cfr. Link. Phil. Bot. p. 435. Quanti vero ponderis sit mycelium s. velum Fungorum in in theoria vegetationis exponenda in Linn. 1828. p. 196 indicare studui. Curn plantis perfectioribus comparatum meras sistit rhizinas. 
jam bene Fungos definiebant: Vegetabilia sine radice, caule et follis \& altius forsan divinans Rajus "nec color ipsis herbaceus aut folium proprie dictum, nec reliqua textura analoga (cum gemmulis conjuncla) adsit - Algx autem, vegetativo Systemate (Thallo dicto) gaudent herbaceo, colore viridi 9) aut læto, herbacearum partium evolutione e. s. p. ob gonidiorum (foliorum elementarium) præsentiam. Thallus non velum tantum, sed truncum fructificationi offert. Est itaque thallus Algarum "radix, folium \& caudex in unum" \& sæpe in formam foliaceam tendit. At non phytographicas tantum differentias gonidia determinant, sed simul onnes biologicas tam insignes, ut viri acuti ingenii Fungos ex orbe vegetabiliun exclusos voluerint 10). Deficientibus enim gonidiis, nutritionem absorbentibus \& præparantibus, Fungi a matrice tantum nutritionem hauriünt, nec umquam in saxo, ligno prorsus exsucco, cortici incolumi peregrinæ absorptioni resistente e. s. p. occurrunt. Deficientibus gonidiis, foliorum analogis aut vicibus fungentibus, Fungi oxygenium non exhalant; hujus nutritionis processus defectu numquam herbaceo-virescentes i i) azoticum spargunt \& odorem non herbaceum sed

9) Lichenes, ut trunci arborum, extus decolores ob stratum corticale apparent.

10) Hoc a nobis non probari posse e sequentibus facile patet; ut vero aliter judicantibus, e nostro studio, in media via obviam eamus, concedamus Vegetabilia in duas series, Herbaceam \& Fungosam abire. Si ponitur character Vegetabilis in successiva evolutione, totam Fungosam seriem excludere omnino constans est. Cfr. Theophr. Hist. p. 1. \&c.

11) Occurrunt quiidem Fungi virides, sed horum color non herbaceus, sed magis metallicus, ut plurimi Fungorum solores. 
virosum (ad animalium magis accedentem); eorumque chemicæ qualitatés magis fere animalium, quam herbarum. Deficientibus gonidiis, seu gemmulis, e velo primario egressis nulla successiva 12 ) partium evolutio. Has omnes discrepantias persequi, hoc loco nimis longe deduceret, quare subsistamus in iis, quæ Fungorum \& Algarum differentias confirmant. Algae, gonidiis s. gemmulis reproductivis instructe, successive explicantur, nutritionem a cingente medio absorbent \& preparant \&c.; hinc minus a loco pendent \& præcipue saxis \& locis, quos Fungi fugiunt, insident. Sunt hoc respectu non vere parasitæ. Inde quoque pendet Fungorum normalis propagatio per sporidia 13), Algarum frequentior \& in infimis unica per gonidia.

§., 3. At hæ discrepantiæ non inter Homonemeas continentur, quo facto Fungos e Vegetabilium censu forsan excluderes, sed etiam ad summas Vegetabilium provincias extenduntur. Ut supra allatæ Fungorum \& Algarum differentiæ clarius illucescant reique ipsi major attentio tribuatur, plantas perfectiores, inter quas omnes ra-

12) Haud obstat, quod Mycologi vulgo singulum Fungum, ut Botanici vulgo Monotropas \&c. ex eadem basi ortas, licet plures per intervalla idem mycelium enitatur, pro individuo habere solent, cum sæpe mycelio evanescente divulsæ a se invicem vegetent. Inter Myxogastres, qui ceterum vegetatione a reliquis fungis eximie differunt (Cfr. Syst. Myc. III., ubi hanc pæene ignotam vegetationem exposuimus) silva individuorum, inter se haud connexarum, sæpe ex unica matre s. placenta fugaci orta \& formata est.

13) Varios fungos epiphyllos v. c. Rhytismata \&c. verno demum tempore fructificare \& sporidia elastica ejicere, cuique Mycologo jam cognitum est. Cavendum ne res, quæ manu fere prehendi possunt, in dubium vocemus. 
tiones evidentiores sunt, respicere liceat. Inter Vegetabilia cotyledonea Fungorum typum exprèssum vidimus in plantis, Fungasis vulgo dictis 14), gemmis veris reproductivis, ideoque etiam caule \& radice distinctis veris foliis e. s. p. destitutis. Tota harum morphosis etiam præformata est; nulla observatur successiva metamorphosis aut evolutio novarum partium, sed emergunt extremitatibus determinatis \& onnibus partibus præparatis, quæ dein in luce tantum magis amplificantur \& discernuntur. In Balanophoris, Aphyteia Linn., nomine apto, pluribusque formis, præcipue tropicis, hoc perevidens est; sed etiam in melius explicatis v. c. Monotropa, Lathraea e. s. p. vidimus individua omnibus organis præformatis emergere, v. c. flore terminali, dein tantum magis discretis. Gemma primaria, si sic dicatur, omnes partes explicandas, veli instar fungorum, includit; ob defectum foliorum verorum nutritionem praparantium \& promoventium emissione Oxygenii retenta color viridis ut in Fungis desideratur, odor idem virosus 15 ) e. s. p. Eadem caussa semper parasitica evadunt. Radice vera discreta carent, basi tuberosa aut rhizinis tantum, Fungorum instar, instructæ. Plantas perfectiores folii veri analogo privatas nutritionem præparare non posse patescere videtur a Cuscuta, licet hæc non nisi secundarie parasitica in evolu-

14) Comparationem harum vegetationis cum fungorum instituimus in Linnæa 1830. p. 499.

15). Singulare exemplum offert Ichthyosma Wehdemanni Schlecht. Linn. 1827. t. 8. Hanc iconem mihi inspicienti mox in mentem venit singularis \& perfecta hujus gemmæ primarix \& Agarici squarrosi veli similitudo; dein legebam idem spargere odorem piscinum; etiam Agarici squarrosi piscinum bene dixit Persoon. Plura alia exempla adsunt. 
tionis serie a supra allatis longe recedat; hæc enim in terra germinans absorpto nutrimento in semine deposito perit, nisi aliam offendit stirpem, e qua nutrimentum hauriat. His rationibus pæne oppositas esse plurimas vere cotyledoneas I6) stirpes notissimum est. - Harum omnium differentiarum rationem inquirentes in defectu aut presentia gemmularum reproductivarum inveniendam fingimus, quas inter Plantas Homonemeas indicatas vidimus in gonidiis, que in perfectioribus plantis accedentibus metamorphoseos gradibus in gemmas exseruntur \& in folia explicantur. Nec desunt evidentissima testimonia, gonidia etiam in Algis v. c. Cladoniis squamosis, Sticta pulmonacea \&c. in folii figuram excrescere, at physiologice considerata non vera folia sunt, sed novus thallus. Eædem enim sunt harum partium functiones primariæ, \& differentiæ pendent a novo , accedente metamorphoseos gradu, quo singula plantarum provincia distinguitur. Hunc enim superiorem magis essentialem differentiam habeo; sed licet in metamorphoseos prototypica \& successiva evolutione discrepantia observetur, typica de identitate non dubitamus. Series sic indica-

16) In tota serie Fungosa deficiunt veræ cotyledones, indeque Acotyledonex sunt; hac plurimisque urgentibus rationibus ductus (Syst. Orb. Veg. 1. p. 31) plantas vulgo Acotyledoneas dictas Nemeas vocavi. - Omnes stirpes gonidiis aut gemmis successive evolutæ Chlorophyta quoque dici possent. Heteronemex, quantum nobis innotuit, omnes sunt Chlorophyta, Equiseti arvensis enim scapus est tantum ò vegetationem præceps \& a natura ipsa revocatum experimentum \& Buxbaumia aphylla, a primis inventoribus ad Fungos relata, foliis analogam metamorphosin percurrit. Nam si Filix aut Muscus vere vegetatione fungosa gauderet, a Fungis vix esset limitandus. Rafflesiam e Filicum vicinia rejiciendam esse, non est quod dubitetur. 
tæ non tam stricte limitatæ. ut in systematicim usum Vegetabilia in duas diversas cohortes hinc sejungere liceat, multo minus alteram seriem excludere; etiam physiologico respectu non prætervidenda multa puncta intermedia, quibus se invicem tangunt. Nobis sufficiat hoc loco indicasse extremitates, cum Morphologia, Biologia Plantarum \&c. vulgo alteram tantum perceperint. In systema fructificationis enim hæ differentize haud pariter agunt. Cum ejus differentiæ, præcipue seminum \& germinationis, summa sint systematis naturalis principia, cum Cel. Schlechtendahlio I7) velim, ut ex fructificationis principiis suæe evolutionis sphæræ subsumantur.

5. 4. E supra indicatis magis, quam expositis, ut ratio præsens jussit, differentiam summam Algarum \& Fungorum patescere spero - \& sic excepta Algarum idea, quæe etiam Linnæana est, Lichenes non possunt non ad Algarum seriem referri, cum omnis earum vita vegetabilis in gonidiis (viridibus) deposita sit \& reliqure differentiæ optime conspirent, Physiologicæ, Biologicæ, inmo Chemica, quæ omnia e sequentibus plenius illucescant. Alia quæstio est, utrum hæc differentia etiam systematico sensu summa sit, an potius in fructificatione superior reperiatur differentia, ex qua subdividantur \& utriusque seriei formæ dispescantur, ut inter perfectiores plantas fit. E facie externa enim forsan quis potius compararet infimos floccosos \& filamentosos Fungos \& Algas (Phyceas), Lichenes \& perfectiores Fungos (Elvellaceas \&c.). - Tale vero nullum ab aliis propositum nec ipsi invenimus principium; diligentior disquisitio potius magis magisque edo-

17) Linnoea 1828. p. 196. Cel. Trattinick ib. phanerogama fungosa jungere mavult. 
cuit, communem omnibus his esse theoriam tam vegetationis, quam fructificationis, exceptis differentiis e gonidiorum defectu \& presentia deducendis, quæ deinde ab externis momentis, licet constantibus, varie temperantur. Hoc plurimis exemplis e ceteris plantarum familiis facile illustratur; sed hoc loco tantum addimus, quod primarium nobis videtur (concedentibus omnibus ea quæ serie contigua in eodem metamorphoseos gradu inter se cohærent a se invicem non esse divellenda, \& ea, quæ sub evolutione in inferioribus statibus eosdem evolutionis gradus percurrunt, eandem efficere seriem), tam Algarum, quam Fungorum seriem esse contiguas, licet sub evolutione sæpe analogas; Lichenes in statu elementari ab Algisisaquaticis charactere vix discerni posse (quare isæpe inter Algas aquaticas recipiuntur), exsistere familiam inter Lichenes \& Algas aquaticas ita intermediam, ut utriusque cultores, eandem in diverso statu sibi vindicent e. s. p. Inter diversas autem familias Algarum \& Fungorum nullus umquam directus progressivus transitus, tantum apparens sub Algarum morphosi regressiva, thallo disparente e. s. p. Sed haec primarias differentias non tollunt 18 ).

\section{Caput II. Designatio Lichenum, s.} affinitas de differentia.

5. 5. Expositis Algarum idea ex mente Linnæi \& rationibus, quæ Lichenes ad earum evolutionis sphæram cogunt, ad ipsorum designationem progrediamur. Hæc, cum omnes Algarum sectiones mire inter se intricate sint, minus facilis est, quam facie externa videtur; nam cum vita submersa \& emersa primarium offerat momentum,

18) Jam in Syst. Myc. I, p. XIX, hujus rei conspectum indicavi. 
diversas evolutionis series determinans, e theoria sequitur, quod experientia nimis probat I), Algas amphibias inter diversas series ambigere. Hinc pendet, quod tot formæ \& inter Algas submersas \& inter emersas recipiantur; equidem, ne entia præter necessitatem multiplicentur, mallem ut tantum e statu perfectissimo normali determinarentur. - Quarum vita submersa, e densiori minusque variabili medio nutritionem absorbent, quocum connexa sunt vita contigua, fabrica distinctior, conformis, magis filamentosa, apothecia aut nulla - aut clausa, excipulo thallo semper homogoneo \& reliquæ in fructificatione sæe evidentiori differentiæ. Quarum vita emersa, nutrimentum e medio tenuiori majoribusque vicissitudinibus obnoxio absorbent, unde vita interrupta 1. per intervalla retardata, fabrica magis confusa, cellulis quibusdam exsuccis \& demortuis heterogenea (leprosa), apothecia in perfectis semper præsentia (in fructificationem mediante luce apertam nituntur) excipulo passim simul heterogeneo, sporidiis minus gemmaceis (ad quam naturam semina submersa semper tendunt), normaliter cellulis elongatis propriis (Ascis dictis) receptis, in paucis modo jam primitus pulveraceo-collapsis siccis (nec submersárum more gelatina involutis). Ha rationes non parum forsan illustrarentur comparatione aliarum plantarum in eodem evolutionis gradu positarum, quarum altera emersa, altera submersa, v. c. Lycopodii \& Isoëtis, Equiseti \& Charae, Ceratophylli \& Hippuridis e. s. p. Hoc loco vero nimis a re alienum censeo; ceterum a-

1) Confr. Collemata, Lichina, \& Byssacex facile omnes, Segestrella rubra, ut taceam quam plurimos atypicos status v. c. Chlorococcum, Byssaceas spurias, minime fungosas \&c. 
deo evidens, ut harum stirpium naturam perspicientem vix fugiat. Fructificationem ipsam in luce magis apertam esse, in aqua v́ero inclusam, æque notum ac necessarium. Ipsum ascorum defectum diversamque sporidiorum indoleın inde facile deduceres. Oscillatio Algarum Aquaticarum mutatis momentis hanc theoriam confirmat 2). Denique maxime essentialis observatur discrepantia in ipsius vegetationis typo, licet in perfectissimis tantum seriei utriusque sectionibus, vere perennibus, evidenter expressa sit; Aërece exogeneæ 3), Aquaticae endogenea. (Ex hoc principio progrediendum, si supra allatam Algarum ideam sublatam velimus. Argumenta tamen "pro \& contra" sollicite perpendimus).

§. 6. Lichenos a dicuntur Algæ emersæ, quarum differentia a submersis e supra allatis sequitur. Veri Lichenes illarum typo plene respondent; thallo gaudent stratis distinctis \& discretis; corticali 4) homogeneo, decolori (non viridi), humi-

2) Hæc caussa cst mutationis apotheciorum \& nuclei in Lichina.

3) Etiam inter Plantas Cotyledoneas Exogenearum \& Endogenearum differentia tantum in truncis arboreis clare expressa est. Consideramus igitur Exogeneas ut vel vere exogeneas, 1. typice tantum exogeneas s. heterogeneas, quales etiam plantae perennes v. c. Linnoea; \& Endogeneas ut vel evidenter \& vere endogeneas, vel typica potentia tantum endogeneas s. homogeneas; successivos harum in illas transitus \& caussas hoc loco mittamus; ipsam distinctionem ad Lichenes designandos necessariam tantum indicantes. - Mihi saltim Fucaceas examinanti perspicuum visum truncum esse subhomogeneum centro vero molliorem (subgelatinosum) \& juniorem in ambitu magis induratum; in Lichenibus perevidens est -stratum gonimon, corticali proximum, esse junius \& mollius. Gfr. Dec. Syst. Nat. 1. p. 122. Syst Orb. Veg.p. 225.

4) In Lichenibus in cortice tenuiori lævigato arborum 
do subgelatinoso, sicco subcartilagineo \& medullari. Hujus superiorem partern constituunt cellulæ vegetæ sphæricæ (sæpissime virides) s. gonidia, vulgo in stratumr contiguum stipata, reliquam exaridæ decolores, s. lepra. Gonidia Lichenum differentiam essentialem a Fungis, lepra a reliquarum Algarum sectionibus offerunt. Infimum (aut in formis verticalibus subcylindricis intimum) stratum vegetum cum medullari sæe confusum constituunt vulgo cellulæ filamentosæ, quæ tamen maxime mutantur \& in infimis obliterantur 5). Hæ trunci Lichenis expansionem aut prolongationem variam determinant, quare de earum magis ludente indole plenius sub Morphosi Lichenum disseramus. Hoc loco tantum adnotandum statum Lichenum elementarem, in quo hac strata adhuc confusa sunt, dici hypothallinum - \& cellulas cylindricas in Lichenibus horizontalibus, vel in foliaceis rhizinarum instar sæe prolongatas (at nutrimentum, non haurientes) vel, in crustaceis præcipue, matrici arctius adglutinatas, sæpe ultra thallum pronascentes, dici hypothallum, cum thalli fulcrum seu basin efficiant. - Proxime ad Lichenes accedunt formationes, quæ constanter ut ita dicam in statu hypothallino 6 ) permanent, ideoque a veris Lichenibus separandæ sunt, nem-

\& foliis tropicis natis strati corticalis sæpe vicibus fungitur matricis epidermis a Lichene assimilata, sed v. c. in Pertusaria communi eandem fere structuram vidi strati corticalis tam proprii, v. c. in saxis, quam ex epidermide arborum transmutati.

5) Præcipue in supra memoratis hypophloeodibus \& formis secundariis.

6) Inferiores Byssaceæ hypothalli faciem omnino præ se ferunt, exstantque formæ, de quibus dubitetur utrum hypothallus Lichenum mutatus an antonomæ sint Byssacex. 
pe Byssacea 7), quæ alteram Lichenosarum sectionem efficiunt. In his nullum formatur stratum leprosum, stratum corticale \& medullare omnino confuşa sunt, hinc tota fabrica similaris gelatinosa aut filamentosa, gonidiis sparsis nec in stratum collectis, omnino ut in infimis Algis aquaticis (Ulvaceis), cum quibus etiam congruunt prin-

7) His sine dubio adnumerandx Collemacex. Cfr. Syst. Orb. Veg. 1. p. 300. \& Linn. 1830. p. 535. Hanc bene definitam, ut mihi videtur, \& certe naturalissimam familiam, quam primum ab aliis negotiis otium mihi concedatur, plenius exponere in animo est; tum simul concedatur occasio, totam vegetationem elementarem $\mathrm{Ne}$ mearum sub Byssi nomine complexam tractandi. Donec hoc factum sit, vellem Lectores de ista familia judicium suspenderent. Complectitur quidem formas thallo $U n$ dince, Ulvae, Conferva \&c., sed ita inter se formis intermediis intime cohærentes omnibusque characteribus vegetationis \& fructificationis, physiologicis, biologicis \& chemicis (si superficialibus e forma externa locum debitum s. ultimum tribuatur) conspirantes, ut divelli sane nequeant. Perfectior ejus vegetatio tropica est, in qua observantur genera ex thallo Confervacea v. e. $\mathrm{Ci}$ licia (forte Dichonema Nees eadem sterilis), Coenogonium e. s. p. Ut unicum exemplum hoc loco addam, quo modo collocationem ultimi distorti, jam a Plumiero picti generis, inductione designaverim. Fungus non est ob gonidia filis inclusa, totamque indolem ideo herbaceam. Phycea non est ob vegetationem vere emersam, præcipue ob apothecia, omnino genuina \& priva ut proxima genera luculenter testantur, ascis sporidiisque instructa. Lichen non est, licet apothecia exacte Biatore, ob thallum strato corticali \& leproso destitutum. In omnibus vero respondet idex Byssacearum; thallus Ulvacearum, apothecia Lichenum. Thallus hypothallum variorum Lichenum refert, \& prorsus analoga Thermutis facillime hinc abit in tenuissima Collemata, illine in hypothallinum statum Parmeliæ triptophyllæ, ut sub Collemate velutino tam tenuissima Collemata, quam Biatoræ citatæ statum confusum viderimus. Per Ciliciam facilline Conogonium cum Byssaceis thallo contigio jungitur. 
cipiis chemicis, vilioribus \& colore virescente, a Lichene rite evoluto alieno. Paucis, e thallo vix differunt $a b$ infimis Algis, sed fructificatio, ob vegetationem in perfectis saltim emersam, adest perfecte Lichenum, quare summi tam Lichenologi genere ab his distinguere dubitarunt, quam Phycologi inter Algas aquaticas receperunt; sic tam in Systernate, quam in natura, cimphibioe. Mihi videntur sectionem a Lichenibus diversam, nec eis immiscendam, versus Algas aquaticas intermediam sistere. Hæ sunt rationes præcipuæ: I) Characteribus, præcipue e fabrica systematis vegetativi (primaria facile sectionum Homonemearum differentia) desumtis luculenter \& acute a Lichenibus recedunt, nec negligenda diversissimæ chemica qualitates \&x.; II) Diversum definitum sistunt evolutionis gradum. Lichenibus inferiorem; III) Inter omnes Byssaceas stirpes, inclusis Collemaceis, aftinitas longe evidentior, quam cum ullo Lichenum, quibus si eas immiscere velimus, intime connexas formas in diversissimas Lichenum sectiones dissipare cogimur \& naturali nexu divulso inter diffinia intrudere 8); IV) Analogia Algarum aquaticarum, quarum summa, meo sensu, divisio ex momentis prorsus analogis pendet. Objici potest Lichenes in statu hypothallino a Byssaceis ægre aut vix 9) discerni posse, at pen-

8) Exemplo sint ; Ephebe ad Usneaceas referenda, Collema ad Parmeliaceas (a Parmelia ipsa vero fructificationis structura abunde differre docuit Eschweiler), Coenogonium inter Lecidinas, Lichina inter Sphærophoreas, Nostoc emend. inter Endocarpeas collocanda. (Nulla vero adest analogia cum generibus Myco-Lichenum, cfr. p. 13) Accedunt alia genera fructu imperfectiori cum nullo genere Lichenum facile comparanda, sed a Byssaceis non separanda.

9) Plura hujus rei exempla in ipsa Lichenographia. 
det hoc a communi naturæ lege, ex qua superiores sectiones ejusdem seriei inferiorum status primitus percurrunt, \& ad-tollendam separationem hocce argumentum nimium demonstrat, cum v. c. etiam Algas aquaticas a Lichenibus non esse separandas convinceret. Utrum vero Byssaceæ pro autonoma familia sumendæ sint, an ut peculiaris sectio $\mathrm{Li}$ chenum (qualem efficiunt Collemaceæ $=$ Lichenes homoeomerei apud Wallrothium), res est, de qua hoc loco non egimus.

5. 7. Algas aquaticas, Patrum \& Acharii auctoritate ducti, sub communi nomine Phycearum io) comprehendimus. Quibus rebus a Li-

Racodium vero rupestre \&c. cum his lubenter associassem, sed adhuc nulla probabilitatis species mihi oblata est idem ad Lichenem quendam pertinere, quare cum similibus inter Byssaceas (vegetum atrovirens est, fere ut pulvinuli Umbilicarice pustulatoe 1 . Stictoe glomeruliferox; Byssaceæ secundariæ productiones in perfectis Lichenibus). Majori jure Wallrothius omnes nostras generis Byssi spec. pro gonidiorum Lichenum metamorphosi habet, de qua re vero plenius in Byssacearum historia disserendum.

10) $\Phi v$ ros apud Theophrastum latiori quidem sensu sumitur, sed huic notioni optime respondet. Inter multa, quæ memorat genera (Hist. Pl. IV. c. 7) etiam distinguimus Ulvas ( $\beta^{\prime}$ t $\varrho \iota v \nu$, rectus legendum credimus $\beta \varrho v ́ o \nu$ ), Conferveas ( $\left(\varrho \iota \gamma^{\prime} \varphi v \nu \lambda \lambda o \nu\right)$ \&c. Commentatores semper $\varphi v$ vos per Algam vertunt, duce forsan Plinio, qui observat, de Algis agens "non habet lingua alia nomen, quod Græci Phycos vocant" (Hist. Nat. XIII. c. 25). - Maluere cel. Viri Phyceis tantum Algarum nomen servatum. Servatæ vero Algarum ideæ ad definitionem Linnæi, primi determinatoris, restictæ nomen quoque servare nobis cum Jussiæo, Wahlenbergio \&c. justius visum est. Plinius quoque Algæ nomen, primus in Hist. Nat. introducens, Licheni (Roccellae tinctoria) quoque tribuit, Ulvas vero (Bryon Hist. Nat. XVII. c. 8) ab Algis distinguit. Ordinis aut generis, ejusque determinatoris, nomen non rejicimus ob unam alteramve formam exclusam. 
chenosis differant, jam notavimus. Ulteriorem earum dispositionem hac vice sicco pede transeuntes, sectiones primarias, e nostra sententia, hand paucis observationibus passivis in natura ipsa nisa, comparationis gratia tantum addimus, Systema Agardhianum, ut in Syst. Orb. Veg. p. $3_{2} 3$ indicavimus, pro fundamento \& basi assuméntes I I). - Probe licet perspicientes alias disponendi rationes aliis scopis aptiores esse, nos duas primarias differentias in vegetatione \& multiplicandi modo tantum respicimus. Altera Phycearum pars thallum habet extus induratum, epidermide sæpius tectum, gonidia saturatius colorata, apothecia \& sporidia vera (Fucacece, Floridece \&c. Syst. o. v.); altera thallo similari instructa, apotheciis sporidiisque veris (h. e. novo metamorphoseos gradu ortis) caret, \& unice,

11) Hac de caussa ad idem, quantum nobis licuit, accedere studuimus nec ut essentialem reformationem proposuimus, quod sectiones a thallo articulato \& continuo \&c. neglectæ fuerint vel genera quædam aliorsum a nobis relata. In Syst. Orb. Veg. p. 325 obiter indicavimus differentias e thallo corticato \& ecorticato (rectius epidermide instructo \& destituto, nam a Lichenum strato corticali mutatis mutandis differt ut epidermis palmæa cortice arboris Dicotyledoneæ), articulatione nobis magis essentiali viso, \& ex apotheciis veris - \& jam tum persuasum habui, in his latere distinctionem fundamentalem, ex qua ordines sumerentur. Quam cum a Cel. Reichenbach (Consp. Regn. Veget. p. 25, 27) jam propositam viderim, nec dissentientem Cel. Rudolphi audiverim, hoc fundamentum grati recipimus, nec tamen priorem nostram dispositionem ejusque principia eo sublata esse, sed, ut Cel. Reichenbachii dispositio testatur, gradum ulterius progressa censemus. Familias Nostochincrum \& Confervacearum Reichenb. equidem alia ratione e diversa nempe gonidiorum indole, neglecta thalli forma, distinxeram ad Cel. Agardhii Diatomearum limitationem accedens. 
quantum equidem experiri potui, gonidiis viridibus aut decoloratis 12) (hinc proteis sæpe) multiplicâtur. (Reliquée plurimæ veræ Phyceæ). Illam sectionem Fucaceas sensu latiori 1. cum Cel. Reichenbach Ascophycas, hanc Ulvaceas s. Gongylophycas 13) dictas vellem. Illæ absolute marinæ (Thalassiophyca), hæ tantum generatim spectatæ necessarie aquaticæ, sæpius aquæ dulcis cives 14). Estque hæc distinctio Phycearum, quam inde a Dioscoride omnes fere usque ad Linnæum in mente habuisse videntur 15).

12) Tam s. d. sporidia Ulpacearum, quam granula Diatomearum mihi gonidia videntur.

13) Vix quemquam dubitaturum fingo superiores sectiones, diversis rationibus consideratas, diverso salutari posse nomine v. c. Endogeneas, Monocotyledoneas e. s. p. In inferioribus sectionibus oritur alia terminologia realis (Cruciferce Pleurorrhizeae siliquosa), alia nominalis (Arabidea).

14) Eodem modo loco separata Mollusca; altera series absolute marina, altera aquarum dulcium etiam species habet marinas. An altera series, ut supra limitata, in mari etiam sal aquæ marinæ imprægnata absorbeat \& præparet, nescimus; non præparat saltim principia haloidea v. c. jodinum.

15) Vidimus jam supra Theophrastum sub $\varphi v ̛$ ' Phyceas in genere complecti; jam vero Dioscorides Lib. IV. c. 99. Bov́ov $\Theta a \lambda \alpha \sigma \sigma \iota \nu$, (Conferveum) \& qúxos $\Theta \alpha-$ $\lambda \alpha^{\prime} \sigma \sigma \iota \nu \nu$ (Fucaceum) separat. Bryon Plinii Ulva. Commentatores dein sub Musco comprehendunt Ulvaceas, sub Fuco Fucaceas.' Rajus aliique illas ad Muscorum', has ad Submarinarum classem retulerunt, at limites omnino strictos non posuerunt. Dillenius Fucaceas separatas voluit; Ulvaceas vero, Byssaceas \& Lichenes cum Muscis conjunctas, unde illarum expositio in Historic Muscorum derivatur. Admixta quidem una alterave forma peregrina, sed e textu ipso facile colligitur, Confervas \& Tremellas=Ulvas ipsi fuisse Phyceas sporidiis \& apotheciis destitutas, qua nota a Lichenibus \& Fucaceis distinguit. - At licet Veterum studiis lubenter débita tribuam, quo mihi nemisin devincere vellem, nova 
5. 8. Sint itaque harum sectionum characteres essentiales:

Biologicus Lichenum: Algæ 16) aëreæ, perennes, interrupte vigentes, exogenex, sensim stratum leprosum deponentes, sporidiis gonidiisque multiplicatie.

Byssacearum: Algæ aëreæ aut amphibiæ, perennes, per intervalla in vegetatione retardatæ, heterogeneæ, nulla strata discernentes, sporidiis gonidiisque multiplicatæ.

Fucacearum: Alga aquatice (in aqua salsa), perennantes, continue vigentes, endogener, extus vulgo induratæ (epidermide normaliter tectæ), sporidiis (gonidiisque?) multiplicatæ.

Ulvacearum: Algæ aquaticæ sæpe annuæ, continue vigentes, homogeneæ, mere gonidiis multiplicatae.

Phytographicus Lichenum: Apothecia nucleo ascigero, raro primitus pulveraceo-collapso. Thallus strato gonimo infra corticale discreto. Byssacearum: Apothecia ascigera, raro in ascos dissoluta. Thalli strata, corticale \& medullare, confusa.

Fucacearum: Apothecia I7) e thallo formata, sporidiis peridiolis aut muco involutis. Thalli stra-

clariorique exorta luce lætus \& gratus fruor. Non tantum recentiora de Phyceis opera, sed etiam locupletissimas collectiones, quas debeo amicissimis viris HoffmannBang, Lyngbye, Greville, Chawin, Gaillon, Desmazières, Rudolphi, J. Vahl, b. m. Aspegren, \&c., in usum convertere studui.

16) Memoria simul tenendi sunt characteres biologici Algarum v. c. gonidia nutrimentum e cingente medio absorbentia \& præparantia, morphosis successiva \&c.

17) Duplicis fructus in his eadem ratio est, ac si cephalodia, soredia \&c. Lichenum pro altero fructus genere sumantur. 
tum exterius, haud discretum, corticans, gonidiis sparsis.

Ulvacearum: Apothecia \& sporidia nulla. Thal- lus absque stratis dissimilibus \& discretis, gonidiis sparsis, sporidiorum vicibus fungentibus i 8 ). Chemicos plene exponere non audemus, videntes licet differentias admodum prominentes, ut e nullo alio percipiendi modo sectiones allatæe magis confirmentur. Duæ inferiores, Bysśaceæ \& Ulvaceæ nulla principia perfectiora preparant, gelatinam tantum cum chlorophylli rudimento; omni itaque vi nutriente \& restaurante, omni materia tinctoria \& glutine amylaceo carent.Reliquæ longe nobiliora principia præparant, Fucaceis haloideum jodinum insigne; gelatina saccharatam indolem passim assumit, indeque nutriens evadit e. s. p., quæe vero vires in $L i$ chenibus adhuc magis pollent, glutine amylaceo aut albuminoso nutriente, restaurante \&c., hi simul enituntur nobiliora principia vegetabilia, v. c. Erythrinum 19) ad resinas proxime accedens, unde ditissima materia tinctoria derivatur.

Typicus Lichenum: Stirpes radice (cellulis fistulosis), trunco (lepra) \& foliis (gonidiis) in unum corpus corticatum confusis, sed in stratis discretis, fructificatione metamorphosi simplici enata.

Byssacearum: Stirpes radice, trunco \& foliis cum strato corticali confusis, nullis stratis discretis; fructificatione simplici metamorphosi enata. Fucacearum: Stirpes radice \& foliis in corpus

18) Vesiculæ Codii, Vaucherioe \&c. vero apothecia non sunt, sed cum vesiculis Mucorinorum, quæ non vera peridia, comparandie.

19) Götting. Gelehrt. Anzeig. 1830, N:o 141. 
truncosum aut frondosum confusis, strato corticali nullo, sed extus compactiores \& epidermide vulgo tectæ, fructificatione metamorphosi simplici enata.

Ulvacearum: Stirpes radice \& foliis in unum corpus homogeneum \& simulare confusis; metamorphosi ad sporidia formanda nulla -20).

\section{Caput III. Comparatio Lichenum, s. analogia of dignitas.}

5. 9: Quo clarius percipiatur character typicus ultimo loco datus, elementa Algarum, in Lichenibus jam in strata discreta, sub perfectiore evolutione in superioribus provinciis persequamur. In proxima Heteronemearum primitus observatur thallus Homonemearum sat similis, sed accedente novo metamorphoseos gradu, provincias distingùente, abit in Rhizoma ( radix \& caulis in unum), sed gonidia exseruntur in folia, e quo thalli \& rhizomatis differentia patet. (Idem quodammodo fieri in Cladoniis \& Lichenibus thallino respectu summis, supra indicavimus, ubi gonidii in folium explicatio facillime observatur). Hac nova metamorphosi fructificatio perfectior, nempe duplici metamorphosi prodit. Plante colyledoneæ tam radicem, quam truncum \& folia normaliter hăbent discreta, triplicique metamorphosi fructificationem, adhuc nobiliorem, enituntur. Foliorum rudimentum primitivum est gonidium \& granula chlorophylli i) cum Protococco $=$ gonidio

20) Gemmulas s. gonidia metamorphosi vera orta, indeque heterophana, tantum sporidia dicimus.

1) Sic demonstratum etiam ex infimis plantis, quod Cel. Agardh in Organographia $p$. - acute indicavit gemmam primitus esse atomon. 
comparat Cel. Agardh. - Multa hoc loco alia comparationis puncta in functionibus se offerunt; addendum tantum, plantas sub metamorphosi regressiva fructificationis eandem seriem inversam repetere. Tot embryonis in genere involucra, quot diversi peracti metamorphoseos gradus; Homonemearum sporidia embryones nudi, absque omni testa. - Lubrica magis \& anceps 2) quæstio est, an sexus analogia etiam in Lichenibus \& Homonemeis in genere prodeat. Sexualitatis tutores sexum masculinum in velo fungorum, in cellulis solutis Algarum quæsiverunt: jam vero harum partium differentia tanta est, ut, s. d. fructificatione foeminea simillima, alterutrum necesse erroneum sit; utrumque falsum esse, vix quemquam effugere potest considerantem, has partes ad omnino diversum systema pertinere, vegetationis nempe, diversosque metamorphoseos gradus; sexualitatis vero polaritas in eodem \& coætanee se divellat. Hrec vera est ratio s. d. marium (rei enim adhuc dubia, ut gemmæ progerminant \&c.) inter Muscos, ut etiam ascorem inter Homonemeas. Miramur sexualitatis tutores fugisse, plures evidentes rationes ut reticeam, insignem illam similitudinem, quæ his partibus intercedit; ad eundem metamorphoseos gradum pertinent asci \& sporidia, nec ulla alia sane adest pars, qua sexum masculum adumbrare posset, quam asci. A-

2) Hactenus enim certus demonstrandi modus deest. Hypothesis supra allata conspirat cum ill. Decanclollei (Organogr. II. p. 161), qui problematicam indolem indicavit. - Equidem omnibus Nemeis verum \& foecundantem sexum facilius denegarem, cum sexus differentia in tertio metamorphoseos tantum gradu prodeat, ad quem non adscendunt Nemeæ; copulatio vero nematum germinantium re ipsa est idem metamorphoseos gradus. Cfr. Syst. Orb. Veg. 1., p. 31 . 
scos esse altioris significationis ex eo quoque demonstratur, quod in diversissimis ceterum generibus similes prodeunt. Si igitur sexualitatis анаlogon assumatur, in ascis, ut anthera, quærendum est. Ex ipso elemento Homonemearum vegetationis, omuibus partibus conjunctis systematis vegetativi \& morphosi simplici necesse fit, ut discreta non possit prodire. In Fungis saltim vidimus ascos refertos liquore s. aura (foecundante?), quæ maturascentibus sporidiis absorbetur. Quæ hoc loco familiariter communicata volui, mere hypothetica esse quisque facile videt 3 ). At si mares, magis obstantes, Muscorum agnoscamus, constans est sexum Homonemearum sic excipere. Lichenum ceterum nulla adest vera anajogia cum familiis superiorum provinciarum (cum Hepati-

3) Quando asci inter Plantas Homonemeas obliterantur 1. deficiunt, fructificatio in cingente medio fluxili nascitur (nisi nimia siccitate primitus collapsi fuerint). Hæc ratio est $\mathrm{Phycearum} \&$, si ascos pro antheræ analogo haberes, eorum obliteratio bene compararetur cum plantis cotyledoneis vere aquaticis, inter quas etiam sexus masculi vis \& evidentia supprimitur \& semina magis ad gemmaceam naturam accedunt. (Dec. Organogr.t. 2 . $f$.5. e. Fungorum analogon capillitii). Inter Fungos, exclusis quibusdam atypice ut inter Lichenes collapsis aut nimia humiditate accedente dissolutis, communis est lex, quod fructificatio ascigera via sicca, ascis destituta via humida oriatur. Si quid de tam problematicis rebus proferendum sit, vidisse videor liquorem, in quo sporidia nuda gignuntur, eundem esse cum vapore ascis incluso. Via sicca formatur fructificatio Hymenomycetum, inde Ascigerorum; recedentibus tantum Tremellinis, idque eo magis per gradus definitos evidentissime quo magis primitus fluxiles; Pyrenomycetes ascigeri primitus habent nucleun ceraceum siccum, ut Verrucariæ; ascis vero destituti primitus fluxiles sunt, Gasteromycetes ascis destitutos fructificationem primitus habere fluxilem notissimum est. Sed hoc alio loco plenius exponendum. 
cis præcipue deneganda); nam ista cum Muscis citata tantum est typica ex utriusque evolutioné intra suam sphæram regressiva, adeoque ad Cap. 4. 5. 16. pertinet.

5. Iо. Eo plura vero puncta comparationis offerunt Fungi, ut ejusdem provincie altera series, tam cum Algis in genere quam cum Lichenibus in specie ob fungorum primitivam discrepantiam in charactere typico ( Fungi=Stirpes radice vera, caule \& foliis carentes, fructificatione simplici morphosi orta). Hrec analogia, exceptis quibusdam infimis confluentibus formationibus Ulvacearum \& Hyphomycetum, non in Systemate vegetativo, sed in fructificativo expressa est. Hoc vero respectu tanto antepollent Fungi, quantum vegetatione impares \& deteriores. Omnium horum sectionum-fastigia, v. c. Pileati, Phallodei \&c. \&c., nil omnino analogi inter Algas habent. Nullum exstat prototypum inter Algas fructificationis, quod non ectypum habet inter fungos perfectius evolutum; in fungis insuper accedunt inter Lithophyta adumbrata, v. c. Agarici, Boleti. Cum genera \&c. e fructificatione polissimum pendeant, Fungorum genera non tantum plura sunt sed etiam longe evidentiora quam Algarum, specierumque numerus etiam multiplo major. (Inde vero neutiquam deducenda major quædam horum studii dignitas, si hæc res umquam in contentionem venire posset.) - Lichenum omnis analogia inter Elvellaceas inferiores et Pyrenomycetes 4) continetur, nec adest Lichenum genus

4) Cfr. Syst. Myc. Vol. III. sect. post. ubi Auctor, qui in studio vero characteres maxime essentiales (S. o. v. p. 26) \& primitivas differentias inquirendi ab anonymo in FI. Ratisb. 1826, non percellitur, Elvellaceas demonstrabit (quidquid e externa facie judicetur) ut transitum 
autonomon cum aliis fungis comparandum. At quam parum evidentes sunt modificationes fructificationis inter Lichenes, si cum fungorum citatis sectionibus comparantur? Omnium generum Gymnocarporum Lichenum ectypos reperimus in Stictide \& Peziza (Parmeliacearum in Pezizis Lachneis, Lecidinarum in Phialeis); Sphærophorearum in Thamnom yce \&c.; Endocarpeorum \& Verrucariarum omnia genera minorem partem tantun tribuum Sphæriæ generis compensant. Cum Limborieas inter Lichenes tantum ut singularem \& facile spernendam aberrationem pronimus, inter Pyrenomycetes in sectionem insignem efflorescunt. Ceterum harum classium perfectior comparatio Mycologiæ theoreticæ, cum inter Fungos omnes rationes evidentiores, reservanda est.

f, I r. Quamvis Algarum sectiones primari$æ$ ultimo cum statione cohærere videantur, unde singulæ privus typus, non fingendum eas esse accidentales, ut gonidium aut sporidium v. c. Lichenis in Phyceam, aut versa vica, excrescere aut transmutari posset. Non tóntum singulæ sectioni, sed speciei etiam, priva est idea, primitiva differentia, quæ mutatis externis momentis personari, non tolli potest. At in affinibus naturæ corporibus sub iisdem aut diversis momentis ortis hæc differentia in constante, communi aut recedente, omnium partium typo adumbratur. Ex hac lege dijudicanda analogia inter diversas Algarum sectiones. Primo obtutu patet Lichenes Fucaceis, Byssaceas. Ulvaceis respondere; inter

Hymenomycetum in Pyrenomycetes propositas, re ipsa esse alteram tantum Pyrenomycetum seriem, a Pileatis longe diversam. Indicabitur ibidem qua ratione hoc modo Systema suum perfectius ejusque principia ut constantia manifestiora reddere conetur. 
priores vero nulla simul adest affinitas propior, cum Lichenosarum \& Phycearum differentia in duabus elementaribus, maxime conterminis, sensim jam determinata fuerit. Inter Lichenes \& Fucaceas eadem observatur differentia ac inter Arbores Dicotyledoneas \& Palmas; utrisque, Dicotyl. Arboribus \& Lichenibus, vita perennis interrupta, unde stratum interius discretuni sensim exaridum 5) extime tantum prope stratum corticale vegetum e. s. p. nec negligendurn Lichenes simul resince speciem (Erythrinum) præparare. Fucaceæ vero ut Palmæ perennantes, contigue vigentes in medio temperaturam sat æqualem servante, unde nulla strata discreta, centrum junius \& mollius e. s. p. Summam simul in horum morphosi esse differentiam vix est monendum, sed potius præmonendum, ex simili concentu in Systemate diversarum provinciarum limites transgrediendos non esse 6).

5) Lepra offert ideo lignum Lichenum.

6) Non e calculo quodam, sed e naturæ ipsius monito deducitur, superiorum sectionum differentias, licet minus discretas, jam in inferioribus esse significatas. Non vero ob hanc rationem singulam seriem extra suam provinciam deductam vellem, v. c. Phyceas, ab ejusdem evolutionis gradus Lichenibus divulsas, cum Heteronemeis, $E$ quisetum cum Coniferis e. $s$. p. in infinitum conjuncta. Ubi hoc modo indicatio evidentior est, utique primo obtutu arridet; in systemate vero objectivum \& definitum, ut constans, tantum receptum velirn. Altera via subjectiva est \& facile labitur in excessum; non idem omnes, sed plus vident alii, qui imaginatione pollent. $S i$ ad extremum hanc dispositionis rationem deducimus, prensando rerum imagines, sequentes licet ipsæ intricatæ sint series radicales oriuntur (Cfr. $\int$. 16. n. 11):

I. Endogenea: Phycex. Filices. Monocotyledoneæ.

II. Exogenea: Lichenes. Musci. Dicotyledonex.

III. Syngeneoe: s. Hysterophyta: Fungi. Acotyledoneæ sensu nostro.

At non spernenda videtur harum rerum s. umbrarum at- 
5. I2. Quam denique dignitatem (Classis, Familiæ, Ordinis \&c.) diversis sectionibus tribuamus, e definitione ipsarum notionum earumque comparatione unice pendet. E terminologia Systematis Decandolleani Homonemece (certe non Nemea) clássem, Alga subclassem, Lichenes familiam s. ordinem, ejusdem dignitatis ac $R a-$ nunculacea, Rosacea e. s. p. (minime altioris dignitatis) efficiunt 7). Ad eos in plures familias resolvendas omnes desunt rationes sufficientes; sistunt quidem plures sectiones bene sat discretas, sed singula ex unico fere charactere pendet, $\&$ præcipue in evolutionis gradu tam perfecte analogæ sunt (quod mihi primarium videtur veræ familiæ criterium, ut optime videre licet in Decandolleanea Cruciferarum expositione) ut non dubium mihi videatur has, æque ac Fuceas \& Florideas, ejusdem familiæ diversas tantum esse series 8). Rem vero subjectivam \& pæne adiaphoram censeo, si dein dixeris, nominum notionibus mutatis, aut Homonemeas omnes classem, aut

tentio; easdem equidem secundo ordine dispositione symmetrica excipere studeo, ita vero ut sectionibus ipsis naturæ congruenter limitatis \& definitis illam pro ingenio suo quisque attendere aut negligere possit. Cfr. ceterum Systematica.

7) Equidem potius, ad notionem inferiorem Classis vulgo receptam, Classes Decand, ut quattuor summas sectiones in Systemate Zoologico Cüvieriano dictas vidimus, provincias dicerem; proximas (ut Mammalia, aves, amphibia, pisces Vertebratorum; insecta, arachnidea, crustacea \& annulidea Articulatorum e. s. p) classes nuncuparem. Si distingueretur inter familias \& ordines, illas superiores dicerem v. c. Lichenosas familiam, Lichenes \& Byssaceas ordines.

8) E supra allatis elucere fingo nullo respectu Fungos \& Lichenes ut pares evolutionis gradus considerari posse. Est quasi Rosaceas cum Monocotyledoneis comparares. 
Lichenosas \& Phyceas Classes. Non nomina, sed res ipsas respiciamus. Si has Classes dictas malles, Fungi etiam in plures classes essent distribuendi. Algæ \& Fungi sunt sectiones pari dignitate, licet in his formarum copia \& fructificationis varietas aperte major sit. Sed nec e formarum nec e sectionum subsumtarum copia superioris dignitas pendet, sed ex organorum evolutionis gradu \& e superioris divisionis principio deducetur.

\section{Caput IV., Li chenum typus, s. vita of rationes normales.}

5. 13. Sub typica Lichenum origine hypothallus est organum primarium, vegetatione autonoma, partes involutas continens quoque ceteras; ejus nisus cellulas elongandi extensionem \& formam thalli determinat. Illis vero discretis ejus incrementum, nisi in ambitu l. apice, supprimitur, \& in multis formis a gonidiis immediate ortis desideratur. Ejus vita eadem ac adulti Lichenis, tantum obscurior. - Vis vitalis perfecti Lichenjs in extimis cellulis cylindricis \& præcipue in gonidiis deposita est. Nullo interno nexu inter se communicant gonidia, licet in stratum vulgo stipatæ, in formis nimis extensis tantum discretæ. Horum stratum (normaliter viride) functiones foliorum in perfectis plantis peragunt! 1) Stratum corticale sub periodıs vegetationi faventibus subgelatinosum mechanico modo humores atmosphæræ absorbet; sed gonidia nutrimentum præparant $\&$ assimilant.

1) Illustr. Decandolle (Organ. Veg. 1. p. 381.) primus observavit e strato gonimo oxygenium in luce exhalari ut in perfectioribus plantis. Fidem debetur prima attentio ad stratum gonimon ut characterem Lichenum primarium; paucis primaria momenta in Lichenum Biologia \& Physiologia. 
Cfr. ceterum Lichenum Morphologiam. - Ob horum vim continue reproducendi Lichenum vita indefinita, longissima, nullam in se gerens mortis caussam; sed externis injuriis tantum finienda. Vegetant vero Lichenes jove modo pluvio vel irriguo; siccissimo aridi sunt, fragiles, quasi emortui; sed iterum humectati vita sua nova mirifice delectantur, ut in montibus \& silvis sub novis pluviis videre licet 2). Tenacitas vitæ tanta est, ut quasdam species (Parmeliam ciliarem ex gr.) ultra annum intra tecta servatas, aëri atmosphærico iterum expositas reviviscere viderim. At ob hanc vitam interruptam incrementum simul admodum lentum, quod tamen non tantum in diversis speciebus, sed in eadem etiam ad externa momenta variat 3). Morphosis vulgo demum in thallo adultiori apothecia attingit; quo magis hæc precipitata, eo magis ad Fungos descendunt. Hac ratione Lichenes physiologico respectu in duas phalanges, Myco- \& Phycolichenes (Cfr. p. 12) colligere licet.

J. I4. Morphologico porro respectu Lichenum statum typicum considerantes citemus pri-

2) Species, quæ exsiccatæ, ægre discernuntur, (v. c. Peltigeræ, Lecideæ ut $L$. albocoerulescens, contigua etc.) in hoc statu individualitem suam optime patefaciunt, quare sub pluviis harum vegetationem præcipue observavi. Colorem thalli in hoc statu normaliter respeximus.

3) Exempla ob loci angustiem addere non licet. Plura instituit \& exposuit Cel. Meyer, quem ut etiam quæ de tardo incremento Biat. rivulosae attulit Flotow in Fl. Ratisbon. conferas. In Lapponia experientia docuit, depastum campum Cladoniae rhangiferince non ante septimum annum novum pabulum offerre, \& decimo quarto demum justam attigisse magnitudinem. Præcipue vero attendendum hoc Lichenum incrementum e diversis climatibus adinodum oscillare; tardius quoque in campis progredi, ocius $\&$ in silvis $\&$ montibus irriguis. Lichenum crustaceorum incrementum longe serius. 
mo communem naturæ corporum legem: ea numquam supra statum suum typicum adscendere 4) posse, scepe vero infra hunc in evolutione subsistere. Lichen nullus (perfectus) gonidiis, crusta, apotheciis \&c. caret, sed sæpe deficiunt; apothecia ob serotinam evolutionem multasque caussas eorum evolutionem supprimentia. Crusta per senium vulgo obliteratur, persistentibus apotheciis, ut in Lecideis, Verrucariis, Opegraphis; in Caliciis 5) apotheciorum evolutione præcipitata passim omuino latet. - Stratum corticale efficiunt. cellulæ rotundatæ arcte conglutinatæe. Nullus Lichen strato corticali proprio 1. spurio destitutus normalis status videtur; paucissimi, qui exstant, thallo tantum leproso valde suspecti sunt. - Typice omnes Liclienes apotheciis instructi, \& quidem ascigeris, sed in Calicieis \& Sphaerophoro normaliter primitus fructificatio tota pulveraceodissoluta. - Prorsus delenda sunt, ut status atypici, genera fructificatione mutila, confusa, aut ex acervis gonidiorum formata ; Coniangium \& Conioloma, licet atypica, ut inquirenda tantum attulimus, quum eorum origo nondum absolute fuerit declarata. In statu normali porro omnes Lichenes subtus 1. puncto basilari matrici adnata sunt; ab hac vero divulsi multi foliacei \& filamentosi vigere pergunt, qualia individua precipue in campis arenosis a ventis agitantur l. in silvis sarmentosa aut pendula occurrunt; omnes horum status primarii (Usneæ, Everniæ \&c.) fruticulosi erecti sunt.

4) Quando enim Pertusarix Parmeliaceum discum acquirunt, tota stirps evidenter morbosa. e. s. p.

5) Caliceas veros esse Lichenes $\&$ ne remotissimam quidem cum Gasteromycetibus habere affinitatem vix est quod amplius demonstretur. 
S. 15. Typicus Lichenum omnium proventus est in aëre \& luce. Propagati in aqua tantum formas Ulvaceas infimas imitantes (Chlorococcum, Palmellas etc.) enituntur; Lichen evolutus in aqua demersus perit. Nomnullæ vero infimorum generum species loca passim irrigua seligunt \& saxa, parte anni saltim ex aqua emersa, vegetatione Lichenosa haud destituta sunt. Lichenes vero crustacei his locis peculiarem formarum seriem crusta tersa, levigata, decolorata e. s.' p. sistunt. (Cfr. p. 146 \&c.) Locis nimis irriguis, umbrosis, nimia gonidiorum luxurie strati corticalis formatio supprimitur, quare his locis sub Chlorococci specie vulgo late regnant. Ex altera parte locis nimis siccis absconditis, v. c. in cryptis rupium apotheciis destituti in lepram vulgo fatiscunt. Nullus Lichen occurrit locis luce prorsus privatis. Proventus in statu typico dijudicando semper respiciendus. Singularis est vis $\mathrm{Li}$ chenum matricis substantiam assimilandi. In mere corticolis, passim quoque in aliis, strati corticalis vicibus fungitur arboris epidermis tenuior; hi aliis locis proprium haben' stratum corticale, plurimi vero, si succedaneo destituantur, crustam vere leprosam in hoc statu offerunt. In saxis calcareis thallus mere crustaceus vulgo cum matricis substantia in compaginem subcalcaream concrescit; in saxis arenosis e contrario crusta vulgo evanescit; etiam color ex oxydis variis aut quisquiliis externis mire sæepe mutatur, quæ vero differentiæ vix urnquam species distinguunt. Multi perfectiores Lichenes, ut Evernix, vix nisi in proventu normali veris apotheciis gaudent. Cfr. ceterum Geographiam Lichenum. Addendum modo h.l. Lichenes, licet sæe arborei sint, pro parasitis veris non esse habendos, cum nutritionem ipsi ex 
aëre absorbeant \& præparent. Etiam evolutio alia ac in Fungis, a quibus hoc respectu recedunt, ut Viscum a parasitis Fungosis. Tantummodo quidam infimi Mycolichenes, in climate præcipue tropico sedem infra epidermidem quærentes minus exaridam, duplicem explicationem admittunt, cujus rationes in sequ. \$. indicandæe 6)

S: r6. Typum denique Lichenum historice respicientes, quem ordinem teneant in totius orbis vegetabilis evolutionis serie exponamus. Hic longe alius est quam locus systematicus; rejicienda omnino est sententia, naturam a simplicibus ad perfectiora simpliciter progressam. Hæc Phytogeneseos 7) pars mere speculativa (qua talis ex hoc opere rejicienda esset) forsan videatur, sed, præter adminicula, quæ historia vegetationis emortux subministravit, varia attentione ad momenta presentia inductione vera, licet res ipsa idealiter excipienda, elici posse videntur \& systematica præjudicia tollere. Ex eo enim, quod inveteravit contemplatio natura corporum evolutionis, ut serialis, sive unica series fingatur, sive plures simplices, oritur maxime divergens discrimen a via naturæ, quæ, hac ratione excepta, in procreando libera quocumque progreditur, nec in unum latus ut in Systema necesse fit. Ramorum instar e trunco aut velut continue scissi radii a eentro 8) naturæ corpora, quo perfectius evoluta

6) Evitavi in precedentibus omnem divergentium judiciorum tetricum examen; nain si nobis theoriam nostram ita, ut perspicua \& probata sit, exponere, non contigerit, aliorum refellere, quo ingratius opus nescio, nolui. Quisque "idolis fori \& theatri". plus minus ducitur, nesciam ipse, quantum equidem eis inhæream.

7) Syst. Orb. Veg. 1. S. 10.

8) Inter Systema mathematicum \& philosophicum ea 
eo mag is discreta, sed diversarum serierum evolutionis gradus sinul \& coætanee exstiterunt. Seriem Chlorophytorum ut in evolutione necesse antecedentem 9) hac ratione diximus Protophyta, Fungosam Hysterophyta. Per illam a Phyceis, \& quidem suecessive, primum indicando \& demum divellendo, adscendit, ad hanc vero descendit natura formatrix, quod tamen non ita capiendum est, quasi totus orbis vegetabilis ad hanc descendisset. Faeile enim in omni fere evolutionis sphæra seriem progressivam separare licet 10 ).

intercedit differentia, ut in illo infima, in hoc summum pro centro sumatur.

-9) Cfr. Syst. MYyc. 1, p. XX, XXI. Syst. Orb. Veg. 5. 10 .

10) Quando vegetabilia ut a simplicissimis ad perfectissima adscendentia, aut versa vice, exponere volumus, necesse est series regressivas \& collaterales separare. Præter biologicas differentias (actiones vitæ in progressiva vivaciores), plura adsunt criteria phytographica (ut taceam chemica \& typica), quibus series progressivas \& regressivas per omnem provinciam distinguere possumus. Progressiva piæcipue in systemate vegetativo luxuriat, regressiva in fructificationem magis nititur. Progressiva tam cum inferioribus, quam cum superioribus affinitate cohæret (Ulvacea cum Heteronemeis, Filices $\operatorname{cum~Mo-~}$ nocotyledoneis, Monocotyledonea Hydrophyta \&c. cum Dicotyledoneis); regressiva autem, charácterem provinciæ acutius in unam partem explicans s. ad extremum ducens nec cum inferioribus, nec cum superioribus provinciis vera affinitate hectitur, sed in formas inter se maxime affines rigescit, ut Lichenes $\backslash$ Algarum (\& adhuc magis Fungi), Musci Heteronemearum, Gramina Monocotyledonearum \&c. In his tribus ultimo citatis adest insuper indicatio quædam Dicotyledoneæ indolis, cum series progressiva Monocotyledoneam evidenter monstrat. Hoc inter Algas jam fusius exposuimus; sed non minus evidens in reliquis. De Filicilus satis sit notare III. Decandolle eas ad Monocotyledoneas ducere. Musci truncum habent in centro \& ambitu induratum, stratum his intermedium mollius, truncum insuper ramulosum, situm 
Sic inter Homonemeas Algæ ex uno latere novis accedentibus morphoseos gradibus extra suam provinciäm in Chlorophyta perfectiora adscendit; intra hanc ad Fungos, et quidem plurimis punctis II) descendit; in Algarum vero classe Phycece sunt series progressiva, Lichenes regressiva ad Fungos. Lichenes, quo perfectiores, eo magis ad Phyceas per Byssaceas accedunt, eo evidentius Protophyta, eo serius fructificant; quo imperfectiores autem, eo magis ad Fungos \& hysterophytam naturam 12) degenerant; eo prococior \& magis discreta fructificatio, usque dum hæc in infimis, loco sed non charactere Hysterophytis (Verrucariis quibusdam, Strigzula) tam preceps evadat, ut Systema vegetativum sepe excludat, limitesque horum versus Fungos non minus obliterentur, quam perfectiorum versus Phyceas. Præceps \& prototypica morphosis est qua præprimis Hysterophyta supra designavimus. Nec cuiquam attente observanti anamorphoses tam $\mathrm{Al}$ garum, quam singularum partium, v. c. apotheciorum Lichenum, latere potest has omnes, pro Fungis vulgo habitas, præcipitata evolutione ortas. Etiamsi durationes addentur infinitæ, Fungus, primitus gonidiis carens, numquam in $\mathrm{Al}-$ gam adscendere potest; sed Alga deficientibus gonidiis, in formam fungosam facile degenerat 13 );

foliorum dicotyledoneum e. s. p. - Quo propius familia aut genus seriei adscendentis ideali linex, ut ita dicam, positum est, "eo magis diversas provincias aut classes conjungere videtur vo c. Chara Filicum, Algis \& Najadeis simul contermina.

11) Hac ratione originem formarum analogarum utriusque elassis facile perspici posse fingerem.

12) Vulgo absolute corticolx, hypophloeodes, \& ad saxa vix nisi in formatione recentiori!, in qua Phyco-Lichenes vulgo tantum degenerati, obviam veniunt.

13) Omnes formæ secundariæ Algarum ad Fungos re- 
planta foliis carens, numquam folia fert; in planta vero foliosa, ut apud nos vulgo hieme, passim deficiunt. Nil supra suam ideam adscendit, sed facile infra hanc subsistit! "non potest crescere, ex Seneca, quod plenum est." Quibus omnibus consideratis facile concessum fingerem seriem regressivám, licet magis mágisque imperfectam, progressiva esse seriorem in evolutionis serie, idque eo magis cum imperfectiores in perfectioribus parasitari soleant 14). Frustaneum est fere oppositas vias in Systemate complecti velle. - Hoc enim modo non e cavis spatiis descendendo, sed per passivam natura, contemplationem accedimus ad Platonicam, paulo temperatam, videndi rationem, perfectissimas ideas, licet sensim \& succes-

latæ hac nota aberrant. Minime vero exinde inconstantia characteris! Omnes quærelæ de characterum inconstantia abessent, si primo ipsos recte, dein scientiam vere scientifico modo (h. e. ideali) amplecteremur.

14) $\mathrm{Si}$ quid hypothesi geologicæ tellurem primitus totam aqua fuisse obrutam superstruere liceat, Phyceoe essent Primigenitæ, scopulisque denudatis, ipsæ nova metamorphosi accedente, in Filices \&c. progressæ, at intra Algarum classem in Lichenes regressæ, tandemque infra suam classem in Fungos. (Abstrahendum vero ab omni uniseriali evolutione). Atmosphæra densior, quam primo evo tribui vidimus, cum thallo luxuriante anteriorum Lichenum ( $\&$ in genere cum Systemate vegetativo luxuriante emortuæ vegefationis) bene convenit. Sed plura accedunt geoponica momenta, v. c. crganica destructa nutrire Systema fructificationis. Quo minus hæc ingrediuntur eo magis Protophyta plantæ; Hysterophyta, tantum organicis destructis nutrita, mox in fructificationem præcipitant. Hinc Fungorum \&c. formæ citius fixæ, nec tam versiformes quám Algarum thalli vacillante lusu. Etiam ob pauciora momenta sub Algarum primitiva evolutione præsentia harum pauciores sunt formæ constantes quam Fungorum, totius vegetationis perfectæ hæredum e. s. p. Qux vero singula peculiari commentario exponenda essent: 
sive explicatas, esse primigenitas 15) \& formas imperfectiones laterali evolutione, æquilibrio successu temporis magis magisque turbato, aberrantes sæepius etiam ratione existentix esse secundarias. Quod in ingenii humani poësi maximesublime, id nature ipsius, rite exceptæ adhuc sublimioris, de cujus veritate numquam dubitandum, proxime accedere videtur 16 ).

\section{PRELECTIO II. \\ - MORPHOLOGIA LICHENUM 1).}

Naturæ non imperatur, nisi parendo - - At qui formas novit, is nature unitatem in dissimillimis complectitur. - Baco.

\section{Caput V. Genesis Lichenum.}

§. 17. De Lichenum generatione originaria ipsi experientix via nil comperimus 2). Gene-

15) Monas summa in potestate, etiam non evoluta, summam involvit tamen ideam.

16) Notæ de his antitheses ita solventur, ut ingenii humani dotes non obtrectemus, sed nec falso admiremur; utrumque ne veram suam facultatem naturam, unicum verum prototypum, parerdo amplectendi negligat.

1) Præcedens prælectio ob varias collaterales comparationes, ipsa e nexu divulsa, addendas, justo magis extensa fuit. Hanc \& sequentes facilius absolvemus, cum liber ipse earum plenior sit commentarius. Sic v. c. pp. 208212. Cladoniarum morphologiæ dicatæ sunt; \& ceterum Wallroth \& Meyer, in manibus omnium Lichenologorum, quæ ad Morphologiam spectant, exposuerunt.

2) Quamvis pulchre vitce originem per inorganicum chemismum explicatum viderimus, mihi tamen obscura \& perceptu diflicilis permansit, cum ipsum tamen prineipium defuisse modusque observandi dubius visa fuerint. Generationi æquivocæ s. originariæ hodiernæ parum credo nec inter alia naturæ corpora, quam quort $m$ vita ab antegressa derivatur. Sed campus ille transcendentalis generationis originariæ, absolute nec relative exceptæ, s. judicia de primis rerum staminibus \& caussis, materies est tam lubrica \& versatilis, ut oppositæ sententiæ pari successu. \& pari fragilitate defendantur; quas foveat quisque, ex 
ratione reproductiva ortos Lichenes facile persecuti sumus; sed huic momento singularem attentionem licet dicaverimus, per quattuor lustra nulla observatio, nullum experimentum successit, unde mihi absolute concludere licuerit generationem originariam s. equivocam aut individuum aut novam speciem, quod facile sequitur a generatione originaria continuatd, produxisse. Plantas perfectiores subito vidimus emergere locis, quibus antea non visæ fuerunt 3 ), non vero Lichenes.

idiosyncrasia vulgo pendet. Si fingimus nempe cum Epicureis apud Lucretium:

"Jamque adeo fracta est atas effetaque tellus"

"Vix animalia parva creat, quae cuncta creavit" "Sed quia finem aliquam pariundi debet habere"

"Destitit, ut mulier, spatio defessa vetusto" naturæ viribus jure objicitur quæstio, quæ quondam a Luciano Iovi ceterisque Diis: Cur tot olim genuerint liberos, nullos autem intra hominum memoriam? An lege Pappia contra senum nuptias lata constricti? Ut constanter dicam, haud adeo evictum videtur inveteratum judicium materiem brutam produxisse vitam, ut ei certo superstruatur; possemus forsan æque bene urgere materiem esse activitatis vitæ residuum. Prius idolis microcosmi melius respondet, posterioris plura offert testimonia macrocosmus. Annales lapidei telluris ipsius adhuc testantur, integras regiones, vasta terræ strata \&c. esse corpora organica in caput mortuum redacta; quousque hac via, computando durationes infinitas, actiones \& reactiones mitatas, non regredi posses? Chémismum inorganicum nec materiem augere, nec nova simplicia corpora producere expertum est, quæ de vita vero comperta. Neutrum statuens, hoc ideo observatum volui, cum acceperim inorganici chemismi vim ad vitam enitendam, ut rem haud controversam, propositam, eamque generationem originariam, etiam ubi hæc a præcedente vita non derivetur, continuatam urgeri. Res non est levis momenti determinare, admissa generatione æquivoca, (?) quousque \& qualiscumque recipienda. Facili nimis labore alias nos edoctos sentimus.

3) Crf. Novit. Fl. Suec. p. 203. 
Nec facile agnoscimus generationem istam Lichenum hypermorphosi ortam e transmutatione $M u$ scorum, Phycearum ltc., cum ejus expositio, licet insignes numeret tutores, faciliori \& naturæ constantix convenientiori modo excipi possit.

5. 18. Sporidia Lichenes propagare diu, ut videtur bona harmoniæ naturæ fide, raro frustrata, receptum fuit; primus Cel. Meyer 4) directis \& urgentissimis experimentis extra dubium posuit, cum quibus ex omni parte congruunt nostræ observationes 5). Id tantum addere debeo me

4) De sporidiis expressis verbis loquitur Meyer Flecht. p. 170. \& sq.

5) Meas observationes de Lichenibus in genere magis fuisse passivas, quam activas monendum est, cum has, publicis negotiis abrupto, plene continuare sæpitis non licuerit; sed et activa experimenta recentiora ne levissimum quidem dubium de sporidiorum germinatione reliquerunt, quibus additis plurimis observationibus de Lichenum evolutione natura ipsa duce, plenam horum morphoseos cognitionem mihi comparatam puto. - Omnium familiarum fungorum germinationem \& evolutionem e sporidiis plene observavi, quales a-Michelio plures, ut delendum sit, quod etiam in classicis recentioribus Botanicis scriptis, neminem veram eorum germinationem observasse, fertur. Accidit in re herbaria, ut in Geographia antiquorum: in qua ignotis regionibus portenta \& phxnomena naturæ legibus opposita tribuebantur, \& illarum cognitione aucta magis magisque ad regiones adhuc exteriores incognitas transferebantur. Tales multis Botanicis videntur Plantæ homonemex, in quibus collocant Cornari theoriam de transmutatione plantarum phanerogamarum, generatione æquivoca \&c. Adsunt quædam facta, quæ ad hanc vel si mavis originariam non denegandam (v. c. inter Ulvaceas \& Hyphomycetes) cogunt, at ex altera parte sæpe luculentissime vidimus, multa ejusmodi gravissima æenigmata pleniori cognitione prorsus evanescere - vel etiam ejusmodi plantas non esse veras plantas, sed peregrina residua! - exanthemata tantum, orpana monstrosa, qualia Uredines, Phylleriacede e. s. p. Rem glenius tractabo in Mycologia Theoretica; sed hoc loco 
originem Lichenum per sporidia exacte talem vidisse, qualem eorum generationem originariam describit acutissimus Vir, ut, si experientiæ meæ indulgeam, facile concluderem etiam huic sporidia subfuisse. Duplici ratione observari potest Lichenum propagatio per sporidia: vel active, sporidia disseminando \& experimenta dirigendo, vel passive, novorum individuorum ortum in matricis vicinia persequendo. Illa necessaria, donec plane evictum erat sporidia germinare \& individua hac via orta $a b$ aliis discerni posse; hæc facilior plenius ad metam ducit, cum ex ea normalem evolutionem melius vulgo comperiamus. Sed et prior minus difficilis est, quam ob sporidiorum subtilitatem primo crederes obtutu, si lamina matura maceratur in aqua pura, qua dein loco idoneo caute effundatur. Sporidia germinantia omnino ut in reliquis Homonemeis in fila prolongantur, vel matricem intrantia, vel eidem adpressa, anastomosantia sæpius arcte conglutinata vix discernenda, sæpe radiantia, e. s. p. Adulta maculæ instar expallentis aut nigricantis apparent vel in pulverem subtilem collapsa. Ut et optime Meyer "ubi confluunt, ad novam plantulam accrescent" 6). Hæc sunt, quæ explicata vul-

non possum non testari, me infimarum plantarum propagationem, quousque nempe rite me intellexisse puto, æque normalem \& legibus definitam ac inter perfectiores plantas invenisse.

6) Cfr. ceterum Meyer l. c. p. Hoc loco insuper addendum, nematum incrementum climate, temperie, statione \&c. admodum 'temperari, adeo ut sæpe quoque in evolutione subsistant. Dum aliæ species v. c. Parmelia plumbea \& Biatora vernalus (in genere species hypothallo insigniori) citius explicantur, alix, præcipue saxicolæ, tardius. Ceterum tot differentias offerunt \& tot generum adhuc ignota, ut præceps foret pleniorem expositionem generalem tradere. Multa experimenta prorsus 
go hypothallum primarium efficiunt, de quo in capite sequente.

ઈ. 19. Facilior observatu \& a Michelio 7) (qui gonidia pro veris seminibus habebat) exposita Lichenum propagatio per gonidia, quæ tamen, considerata eorum geinmacea natura, nulla alia est ac Salicum \&c. per gemmas \& turiones. Go, nidia sæpe in ipso thallo, imprimis foliaceo, in nova foliola facile explicantur \& præcipue in Cladoniis, inde squamosis. Sic densissime foliolis Stictam pulmonaceam, Ramalinam fraxineam, Umbilicarias e. s. p. prolifero-obtectas eaque e thallo primario in nova individua excrescere luculenter vidimus. Sed etiam gonidia a matrice discreta in nova individua excrescere certissimum est. Locis humidis aut statione abnormi in genere hrec propagatio prepollet; ubi gonidiorum eruptiones luxuriant, apothecia cum sporidiis excluduntur, cujus analoga exempla non desunt inter plantas perfectiores 8). Quod vero non tantum a statione pendet, sed sæpe magis a climatis differentiis, qua in Geographia Lichenum respi-

frustrantur, sed exstant etiam phanerogamæ plures quas naturæ solum seminibus propagare succedit, ut varix Orchidex, Salices, Populi e. s. p. Ascos sporidiis destitutos in podetiis Cladoniarum forsan comparabis cum Dentaria bulbifera abortante e. s. p. At ejusmodi rationes abnormes nullo modo ad theorias exstruendas sufficiunt. Sunt quoque alia momenta in germinatione sporidiorum non prætervidenda v. c. prolongatio nematum una aut oppositis directionibus (Mono- \& Dinemex) qux in presenti ob obser vationes insufficientes reliquere cogimur. 7) Huc spectat quoque Observatio Cassini Opuscul. Phyt. 11. p. 391 .

8) Hæc est caussa cur Lichenes pulverulentos aut sorediis tectos sæpius steriles invenimus; cur Evernioe sarmentosa \&c. raro fructifere; cur $E$. vulpina in ligi is fabrefactis apotheciis caret e. s. p. 
cièndà - At ínsignis vulgo obśervatur differentia : in individuis e sporidiis \& e gonidiis ortis; illa statu hypothallino incipiunt; hæe conglutinando plura gonidia immediate in thallum explicantur, quæ differentia tamen et in perfectioribus, plantis exstat, cum individua a semine enata primo statum cótyledonarium (nemata $=$ cotyledonum analogon) offerant, e gemmis vero orta mox in normalem herbam explicentur.

5. 20. Accedunt alii magis accidentales propagationis modi, qui vero ut modificationes priorum tantum considerandi. Hypothalli vis individua propagandi non deneganda; continet enim gonidia in potestate. In montibus Sueciæ occidentalis, in quibus Lichenum crustre ad usum technicum frequenter derasie, facile est visu eas ex hypothallo, precipue versus juniorem ambitum, reviviscere. Huc quoque referendum Schcereri experimentum ex ipsis rhizinis Umbilicariæ nova individua excrevisse. - E duobus vero normalibus Lichenum propagandi modis ex analogia luculenter constat sporidiorum esse typicum \& primarium; gonidiorum succedaneum \& secundarium. Non ideo negandum inter Phyco- Lichenes propagationem per gonidia frequentiorem multis locis, \& solam in regionibus, in quibus vera apóthecia non proferuntur variarum specierum v. c. Evernice vulpina in septentrione, pluirium Americanarum in Europa occidentali-meridionali 9). - Alia vero ratio Myco-Lichenum, quod non ex affinitate tantum majori cum fungis, apotheciis sem-

9) Hoc vero sporidiorum veram seminalem indolem non magis tollit, quam Dentaria bulbifera, Allium arenarium e. so,p. unice per bulbillos apud nos propagata. Contra alteram sententiam, sporidia esse frustranea, citari possunt verba Theophrasti: Causs. Pl. I. c. 1. 
per præsentibus! \& sporidiis vulgo perfectioribus concludo, sed e frustratis experimentis gonidiis eas propagandi (Cfr. quoque Meyer l. c.). Si e Caliciis quibusdam \& Opegrapha varia, in ligno alneo infra corticolam hac ratione orta, concludere liceat, nemata in his matricem intrant, unde vulgo crusta primitus hypophloeodes \& entoxyla, quare evolutionem difficile persequimur 10). Sed situm hypophløeodem generationem originariam certo non indicare, e variis experimentis, circa Fungos locis similibus obvios didicimus. Ceterum inter Lichenes eadem lex, qua inter omines plantas, valet; sporidia speciem propagare, ut ex his plures diversæ formæ (n. b. ejusdem tamen speciei) enasci possint; gonidia vero, ut turiones, $m a$ tris individualitatem servare. Hinc oritur singulare illud factum, quo individua locis speciei maxime privis, ubi sporidiis vulgo oriuntur, magis multiformia evadunt, quam ubi degenerata e gonidiis orta, v. c. Leprarix, Isidia \&c. sæepius latissime maxime conformia regnant. Individua hoc modo e gonidiis orta matris statum non superant, sed facile infra eum subsistunt. Protococcus viridis facile a Lichenibus locis humidis solutis oritur, sed ut status secundarius hoc modo, latissime licet expansus, numquam ad Lichenem perfectum adscendit, Hoc autem accidit Palmellæ botryoidi, magis primitivæ, in Biatoram vernalem \&c. facile explicatæ.

\section{Caput VI. Morphosis Lichenum 1).}

§. 2r. Ulterior thalli evolutio aut una cum

10) Occurrunt hi quoque ad saxa friabilia calcarea \& arenaria vulgo, ut Opegraphoe, nec ullam vidi Verrucariam in saxis primævis durissimis, nisi locis irriguis. Matris etiam substantiam vulgo assimilant.

1) Cum morphosis \& metamorphosis fundamentum sint 
aut ex hypothallo est segregatio organorum, qua in illo involuta latent, nec metamorphosis. Duplex est thalli adolescentis nisus, centrifugus \& centripetus; 2) hic producit thallum normaliter a matrice verticaliter assurgentem (adultiorem sæpe pendulum); ille typice horizontaliter expansum, qui quidem subinde adscendit, sed hypothallo infero denudato 3 ) a primitus verticali dignoscitur. In Cladoniis \& Stereocaulis duplex adest thallus; e primario horizontali enascitur verticalis, podetia dictus; gonidiorum evolutione podetia iterum sæe horizontali adspersa. - In thalto verticali cellulæ cylindrice centrum normaliter occupant \& sursum prolongantur, circa quas velut circa axen communem cellulæ sphæricæ congeruntur. In thallo horizontali cellule cylindricæ, si adsunt \& discerni possunt, paginam inferiorem occupant \& extrorsum prolongantur 4),

totius specialis expositionis, hoc loco pauca tantum momenta ad summam rei formulam notantur.

2) Hæ directiones non polariter oppositæ, sed centrifuga constricta in centripetam abit. Cetrarioe media ratio est. Sic præcipuam differentiam in rhizonate nisus contrifúgus \& contripetus fere ubique offert. Inter Muscos exinde, oritur differentia acrocarporum \& pleurocarporum; inter. Filices hactenus prætervisa, sed insignior quam ulla alia e fronde deducta; centrifugum inter Filices est rhizoma repens; centripetum in Struthiopteride e. s. p.; unde ex hoc oriuntur plurimi caudescentes. Etiam diversas Monocotyledonearum classes e diversa reproductione rhizomatis facile distinguimús.

3) Cum cellula cylindric sunt aut nudo oculo non discernuntur, hypothallus deficere dicitur. Etsi timendum fuit, ne a subtiliori eruditione minus correctæ expressionis redargueremur, ad monitum acutiss. Linkii, malui semper descriptiones practicas, quam theoreticas tradere.

4) Præcipue in crustaceis cellulæ cylindricæ in ambitu nudx observantur, unde thallus fibrilloso-radians. Si- 
supra quas velut supra basin cellule spharica coacervantur. In hỏ pagina inferior vulgo discolor \& heterogenea; subinde vero etiam subtus adest stratum corticale.

4. 22. Obiter indicaturi externam thallivariam formam ab infino gradul progrediamur, segregantes differentias magis abnormes \& a loco potissimum pendentes. Thallus horizontalis ivel crustaceus est vel foliaceus. Inter has species; whabitu facile discernendas, nulli omnino acuti limites poni possunt.m Prater differentem formam \& adhæesionem, thallus foliaceus a crustaceo recedit coetanea \& majori luxurie cellularum cylindricarum, ut sphærice denum supprimantur (tatis contextus stuppeus dicitur), substantia tenuioni, nec rigida, friabili, subtartarea thalli crustacei. Sed his rationibus non pauciores transitus, quam in ipsa forma. Thallus crustaceus normaliteri $u$ niformis, sæpe vero, junior præcipue, in ambitu aut, per atatem, totus tam effiguratis est, ut facile pro foliaceo sumatur; thallus foliaceus tam explicatione impedita, quam anamorphosi sepe crustaceus fit; immo hic etiam, non minus quam crustaceus, deficere potest. (Male ólim omnes acrustacei Lichenes ad crustaceos numerati; sape a foliaceis orti). Plures sunt thalli crustacei varietates: simplicissimus est thallus æqualiter ex hypothallo explicatus \& concretus (thallus contiguus; per ætatem rimulosus aut vage rimosus passim evadit; nota raro cujusdam ponderis). Huic proximus thąllus binc inde conglobatus ex hypothallo 5) proveniens, vel hypothallo innatus (thal-

mile in Phyceis vidimus, \& in utriusque fanilix morphosi insignis analogia.

5) Præsente nempe hypothallo; ; alias matrix ejus vicibus fungitur. 
Jus areolatus) vel ab hypothallo magis discretus (thallus granulosus; granula insuper magis globularia, areolae applanatæ). Tam areolas, quam granula equidem primitus semper rotunda vidi; forma præcipue illarum angulata (sæpius $4-7-$ gona) oritur e mutua pressione, ubi discretre, vel inorganica. lege, ubi plures confluentes iterum in areolas diffranguntur. Granula \& areolæe lobatce e pluribus coalitis ortæ sunt. Hoc modo thallus granulosus \& areolatus in crustaceo-squamulosum (Psoræ Hoffm. Squamariæ Dec.), ob nisum in formam foliaceam, facile transit. Quando thallus primitus crustaceus \& contiguus, at cum cellulis cylindricis (sæpe rudimentis tantum) concretus, junior in ambitu plicalo-radiosus, in formam foliaceam tendit (Placodium Hoffm.), sed adultior, vegetatione cellularum cylindricarum suppressa, in crustaceam similarern indolem regreditur ; etiam passim diffractus. Utraque hæc thalli crustacei varietas in speciebus maxime affinibus occurrit \& transitus plurimos in foliaceum offert. - Thallus foliaceus vel in ortu (ex hypothallo) compositus; squamulosis, qualis præcipue caute distinquendus a crustaceo-squamulosis, v. c. Parm. trib. IV.: stellatus : imbricatus \&tc. - vel magis simplex, monophyllus, \& ubi frondosus (magis integer, concaviusculus, vulgo admodum latifolius) semper persistens, minus variabilis. - Thalli verticalis duplex lusus, compressus (subfoliaceus) \& teres (fruticulosus) 6); filamentosus est utriusque

6) Etiam inter thallum subfoliaceum \& filamentosum limites levissima modificatione sæpe obliterantur; nam foliaceus facile ita angustatur, ut teres fiat (Ramal. calicaris, Evernia villosa, flavicans); \& thallus fruticulosus solidus subtus compressus subcanaliculatus \& discolor evadit v. c. Usnea homalea, Sphaerophori sp. \& fistulosus in folium supra canaliculatum dehiscit. 
degeneratio, qualis etiam a thallo foliaceo maxime angustato oritur.

5. 23. Infimi sunt Lichenes, quorum thallus matrici est innatus. In multis Caliciis vidi thallum ipsum intra lignum primitus ortı $m$, in aliis vero hypophlœodem. Horum hypcthallus byssino-canescens, ligno intertextus, a reli quorum Lichenum recedit; re ipsa accessorius videtur. In omnibus crustis hypophœodibus (Verrucariis, $\boldsymbol{O}$. pegraphis \&c.) hypothallus deficit. Thallus horum, vulgo parum conspicuus, e cellulis novis juxta positis \& adglutinatis formatur. Attamen inter thallum hypophloeodem \& superficialem nulli definiti sunt termini, variæ species utraque ratione variant. Crustaceus pagina inferiori adnatus est; effiguratus vero a matrice plus minus sæpe solvitur. In his prima adsunt rudimenta cellularum cylindricarum cum thallo ipso conjunctarum. In foliaceis thallus a matrice discretus est, sed quædam cellulæ cylindricæ in fibrillas, quibus adhæret, excrescunt. Mihi hypothalli species sunt. Lichenes frondusi puncto centrali vulgo adfixi, passim cuneatim fere inserti, quod etiam inter Stereocaula, Usneas e. s. j). observatur. Stictce privum est sæpius in pagina inferiori propria habere receptacula gonidiorum (cyphellas); in omnibus aliis Lichenibus horum proventus'accidentalis est. Inter Peltigeras cellula cylindricæ venas in pagina inferiori efficiunt. - In thallo verticali cum cellulæ cylindricæe thallo inclusæ sint nullæe observantur fibrilla.

5. 24. Quamquam thallus seepissime est proe$\operatorname{cox}$ s. apotheciis (tum serotinis dictis) tempore antecedit; sunt tamen quidam status normales, in quibus crusta serius explicatur, quam apothecia precocia. h. e. thallus serotinus. Plures vero 


\section{Metamorphosis Lichenum.}

sunt, in quibus crusta \& apothecia $c c$ Utraque aberratio tântum inter infimos Licı observatur. De hac re conferatur dispositio thal. lina p. 12-14., hoc loco inserenda. - Abnorme est, ubi thallus mox abit in apothecia, thallo discreto suppresso, quod in statione abnormi observatur. Insignior est hæc ratio gonidiis in alieno thallo insertis \& ex eo nutritis, mox in apotheciis mutatis, cujus exemplum Lecid. Ehrhartiana a. Perfectiores Lichenes omnes longam annorum seriem percurrunt priusquam metamorphosin ad apothecia formanda subeunt 7).

\section{Caput VII. Metamorphosis Lichenum 1).}

5. 25. Expositis thalli genesi ejusque incremento restat apotheciorum formatio, unica normalis metamorphosis inter Lichenes. Apothecia repetunt intra angustiores limites organa elementaria thalli, sed magis nobilitata \& definita. At priusquam hoc exponamus, apotheciorum partes indicare necesse est. Harum structura \& denominationes eædem ac Fungorum. Primo discernenda sunt thalamium, seu fructificatio ipsa, \& ex-

7) Reliqui termini, quibus utimur, cum ceteris plantis communes sunt vel ex ipso verbo intelliguntur. Thallus crustaceus compendii gratia dicitur crusta. Crustæ tartareæ typum nobis offert Parm. tartarea L. h. e. crusta e granulis coacervatis, conglobato-concretis formata, inæquabilis, minus cartilaginea: a qua separamus crustam amylaceam, pulveraceo-compactam.

1) Nomen metamorphosis vario sensu sumitur; partim pro degeneratione in status atypicos (anamorphosis Wallr.); partim pro alterius plantie in alteram, specie \&c. diversam (hypermetamorphosis). Ab utraque ratio diversa est explicatio normalis novi status ab eodem individuo, in quo organa præcedentis sub nova \& mutata forma redeunt. 


\section{MOŔPHOLOGHA.}

, thalamiun recipiens. In thalamio dis„mus ascos, cellulas subverticales elongatas, in Lichenibus perfectioribus (obsoletiores vulgo) cylindricas, clavatas \&c., in inferioribus ellipticocylindricas - \& sporidia, cellulas rotundas ascis inclusas. Basis thalamii, valgo é cellulis rotundis sterilibus contexta, a Cel. Eschweiler hypothecium dicitur. Occurrunt quoque in thalamio. cellulie elongatæ subfloccosæ, ad perféctos ascos rion evolutæ, quales s. d. paraphyses fungorum. Minime enim partes fructificationis semper justam attingunt evolutionem; præter status infra sub anamorphosi notandos in disco nimis extenuato tam asci ipsi deficiunt, quam steriles tantuın \& vacui occurrunt. Ex altera parte asci quoque passim intra se ascos, idque precipue thalamio, non explanato nucleiformique; sed non nova individua speciei, qui sporidiorum finis, reproducunt 2). Excipulum vel thâllo concolor est \& similare (exc. thallodes), vel discolor \& heterogeneum (exc. proprium). Subinde utrumque adest; at typice vix umquam neutrum 3). Thalamium apertum hoc vulgo marginat. Per retatem tamen sape supprimitur, passim a thallo ipso non dif-

2) Plurimæ in his partibus observantur modificationes, sed sine iconographica simul expositione haud facile clare explicandæ; ceterum practicæ Lichenologiæ minuś inserviunt. Præcipuæ \& classicæ in hac parte sunt analyses Eschweileri v. 'c. in Martii Lich. Bras. - Infusoria fructificatio Homonemearum interna organa per plures gradus sæpe repetit, id quod jam de Fungis expósitum est.

3) Verrucæ Pertusarice non minus, quam cupulæ Parmelicirum, excipula dicendæ. Biatorce omnes, quantúm vidi, normaliter marginatæ; contrarium forsan exhibetur e commutatione Parmeliarum degenerum v. c. Lecid. cyrtelloe Ach. - Eadem ratio Cladonix. 
ferre videtur. Velum est excipulum thallodes admodum tenue, discum tegens, facile disparens.

5. 26. Excipulum thallodes, cum nullam metamorphosin subierit, utpote thallo prorsus simile, ad thalli partes referendum fuisset, nisi apotheciorum caussa ortum esset \& serie contigua cum excipulo proprio conjungeretur. Sticta, Parmelia, Stereocaulon, Biatora \&c. evidentissima offerunt exempla excipuli thallodis, magis libera$\mathrm{ti}$, indole \& colore discum assimilando in proprium abeuntis. Etiam excipulum pulviniforme e thallo quasi erumpens, discolor (stroma ex Cel. Meyer) nil aliud est, quam thallus ipse thalamiorum vi protuberans, strato corticali (vulgo epidermidis spurio) destitutus 4). At excipulum vere proprium, sæpius carbonaceum, licet limites poni nequeant, considerata ejus indole in Caliciis, Verrucarieis, Opegraphis, Lecideis \&c., in quibus sape a thallo discretum est 5), insignius apparet. Ut meám suspicionem aperte dicam, mihi videtur hypothallina magis indolis. Cujus hæc sunt indicia: excipulum vere carbonaceum sæpe infra thallum oritur, optime ex hypothallo ipso tam deficiente crusta, quam hac præsente inter areolas; etiam prusta contigua, primitus vulgo cum hypothallo connecti vidimus, \& si dein a crusta elevatur \& sustentatur - anamorphosi, v. c. in Umbilic. pustulata, in formas hypothallinis simillimas degenerat - deficiente crusta in Parmeliis quibusdam hypothallo nigro, v. c. $P$. ferruginea, cerina, excipulum facile nigrescit. Spo-

4) Etiam exstant Pertusariae status nucleis in stromate pulverulento nidulantibus.

5) Hoc evidentissime videre licet in Caliciis \&c. - In Verrucaria nitida, in Carpino præcipue, e. pl. apothecia infra crustam oriuntur. 
ridia germinantia in hypothallum vulgo abeunt, sed in Caliciis \& Opegraphis in primordia excipuli carbonacei. (Ex hac re patet ratio apothec. coxtaneorum \& præcocium). Si porro ad excipuli variationes e varia origine apotheciorum in Parmel. trib. IV. attenditur, patescere videtur, excipulum proprium esse speciem hypothecii, quod ipsum cellularum rotundarum, non vegetarum, indole lepræ thalli respondet. Cellulas cylindricas thalli in ascos abeuntes empirice facile persequimur; e primo obtutu iconum tantum (v. c. Nees Syst. d. Schw. f. 7r, Grev. Cr. Scot. t. 242 \&c.) horum organorum typica identitas facile patet. Cum cellulis cylindricis thalli id porro commune habent, quod non nova speciei individua, sed pares suas tantum producunt 6). - Sporidia denique gonidiorum metamorphosi orta esse, multis rationibus comprobatur. Primo enim origo e cellulis cylindricis eadem, dein forma convenit tandemque utrumque horum sistit vera Lichenum organa reproductiva. Exstant insuper formationes metamorphosi incompleta, v. c. Coniocarpon, in quibus cellula rotundæe vegetæ medium tenent locum inter gonidia \& sporidia. Est itaque singulum apothecium thallus integer in nuce, partibus nova metamorphosi subtilioribus, sed definitis, nobilitatis \& declaratis, ut herbæ in flore.

5. 27. Jam progrediamur ad variationes apotheciorum in proveniendi modo, situ \& forma. Quo modo oriantur apothecia haud difficile persequi; sed quare ipsa, \& quæ momenta, præeter nisum ipsius naturæ, eorum evolutionem diversam determinent, vix nisi theoretice excipi po-

6) Defectus cellularum cylindricarum thalli coætanei facile declarari posset ex hypothalli primitiva metamorphosi in apotheciorum, vere luxuriantium. - 
test. Vidimus quidem eam a differentiis climatis pendere, cum multæ late diffusæ species in definitis modo regionibus apothecia exserant. Nexum horum cum luce divinamus, cum præcipue in pagina superiori s. luci obversa (ap. antica), rarissime in lobis terram spectantibus (ap. postica) 7) proveniant. Quo imperfectior Lichen, eo profundius in genere oriuntur apothecia; in $\mathrm{Ca}$ liciis, Verrucariis \&c. in matrice, etiam infra crustam; in plurimis in strato cellulari; in optime evolutis etiam in strato corticali. Offert hoc momentum sæpe eximios characteres. - Quoad nexum cum thallo variant immersa \& superficialia - s. innata, adnata, sessilia (in ambitu tota libera) \& elevata. Fulcrum apotheciorum vel $\mathrm{ab}$ excipulo thallode forinatum (podicellus, apothecia podicellata) vel e proprio (stipes, ap. stipitata). Alteruter terminus videtur superfluus, sed differentia maxime essentialis. Cladontiarum podetia cum podicellis comparantur, sed longe insigniores sunt. - Forma typica - est rotunda; apothecia difformia raro normalia, qualia tamen oblonga, linearia, compositione passim ramosa (ap. lirellceformia). Excipulum proprium clausum dicitur perithecium; cui vel ob differentiam ab apotheciis in Trypethelio \&c. proprium nomen necessarium. Omisimus reliqua diversa nomina e levi quavis apotheciorum modificatione; addentes tantum urceolata dici apoth. valde excavata, ambitu constricto; scutelliformia concaviuscula, elevato-marginata; peltceformia dilata-

7) Forsan hæc semper atypica, suadente Cetr. cucullata. In specimine Peltigerce resupinatoe vidi apothecia juniora marginalia, integra, scutelliformia, quæ vero, ut in Cetr. glauca subinde fit podicello dehiscente', infera evadint. 
ta, plana, absque margine prominente; cephaloi. dea, convexa, marginem (passim reflexum) reprimentia. Disciformia inter scutellata \& peltæformia; tuberculata inter eadem \& cephaloidea media sunt.

5. 28. Leges, quas sequuntur apothecia \& præcipue thalamia sub successiva evolutione, faciles sunt. Omnia primitus clausa, plerunque conniventia (raro globosa velo obducta), thalamio incluso conglobato gelatinoso-ceraceo, ascis convergentibus, s. nucleiformi 8). Persistentibus clausis apotheciis, s. excipulum proprium sit s. thallodes, thalamium nucleiforme deliquescit, ut sporidia gelatinosa per ostiolum 9) proflunt. Apotheciis dehiscentibus thalamium subdisciforme vel in laminam explanatur rigescentem \& persistentem, vel mox pulveraceo-collapsum. Quando status thalamii nucleiformis tam cito absolvitur, ut lamina jam primilus non clausa, ne marginibus quidem conniventibus sese offerat, apothecia aperta dicuntur. Hoc præcipue fit in apotheciis e strato corticali enatis, in quibus discus punctiformis prodit, prius quam excipulum formatum est; vel in apotheciis a thallo magis dis-

8) Nondum certa mihi est differentia inter nucleum contiguum, qui excipulo aperto in discum collabitur \& nucleum laminarem connivendo-involutum, qui excipulo aperto in laminam expanditur. Hic in genere competeret Gymnocarpis, ille Angiocarpis, etiam Thelotremati. Sed cum Pertusarice \&c. nucleus denudatur, in laminam expanditur? vel potius symphycarpeo-láminaris? Lamina, ex Achario, totum thalamium; discus ejus síperficies, unde facile intelligitur, quare colorem sub disco sæpe diversum dixerit.

9) Ostiolum vel poro tantum pertusum (Ost. simplex) 1. papilla pertusa nigra prominet (Ost. papillatum) Nucleo thallo profundius immerso in collum attenuatur. Papilla excipulo heterogenea discreta dicitur. 
cretis. - Inter Angiocarpos passim plura thalamia eidem insunt excipulo (apothec. composita); passim plura in unum confluunt. Eadem est ratio disci in Hymenothalamis, plurimis discis in unum confluentibus (apoih. symphycarpea); hoc modo, frequentiori forsan, quam observari potest, Biatoræ abeunt in Parmelias. Cfr. Parm. trib. IV. \&c. Præcipue in apotheciis excipulo carbonaceo discus in plures minores solvitur. Plurimas hujus indolis formas s. apothecia composito-conglomerata, quasi prolifera, habemus Lecidearum, Opegrapharum e. s. p.; etiam Parmelice cenisece. Singularem, sed rarum admodum, lasum offerunt Calicia slipitata, in quibus offendi nóva stipitata apothecia, podetiorum more in Cladoniis, tam e disco, quam margine excipuli surgentia. Hæc prolificatio magis imperfecta prodit duplicatione marginis in multis Graphideis \& Lecideis. Tales vero lusus omnes accidentales sunt, nec ad species discernendas sufficiunt; attamen, ubi hic nisus antepollet, non prætervidendus. Hoc loco demum citanda suo loco fusius exposita apothecia $U m b i$ licarice. Ea typice esse simplicia, scutelliformia aut lirellæformia Io), nemo dubitat, sed earum luxuries gyrosoplicata (plicis deficientibus discus ipse rimosus) tam normalis est, ut, accedentibus aliis notis, non possint non in Systemate, theorie non serviente, tam a Lecideis, quam ab Opegraphis separari.

10) In ipsa Umb. Mühlenbergii rarius visa sunt apoth. scutelliformia. Brown Schrift. ed. Nees 1. p. 531. Eadem ratione multæ Opegraphoe exacte Lecidinæ sunt lectx; Calicia Lecidina e. s. p. Valde ambigo an non ex hoc modo tractandi omnia genera Lichenum confluerent. Equidem minus characteres respiciens tam hrec, quam Fragarias" \& Potentillas e. s. p., separo. 


\section{Caput VIII. Anamorphosis Lichenum.}

5. 29. Plantarum Homonemearum investigatoribus non sine jure objici fingerem, quod status atypicos (formas tam sub evolutione impeditas, quam præcipitatione degeneres) nimis \& attenderint \& neglexerint; illud, cum omnia Algam Fungumve referentia pro autonomis plantis vulgo descripserint; hoc, cum descriptorum nexum cum matrice \& prole, primo obtutu sæe latentem, non inquisiverint I). Quo factum est, ut formis, e diverso fonte derivandis, congestis non Systema tantum frustranee obfuscatum fuerit, sed et irrita corollaria de harum stirpium natura \& generatione orta sint. Plurima exempla dedimus in Syst. Orb. Veg. 1., quibus jam alia accesserunt. Quæe de præcipuis Lichenum anamorphosibus 1. c. attulimus, ea eodem tempore ab aliis aculissi-

1) Hoc præcipue evenit, postquam singulæ familiæ tantum monographice, anamorphosi quasi scientiæ, tractari coperunt. Singularum cognitionem hac via eximie sæpe excrevisse non diffitendum est, sed stolonibus etiam resecandis luxuriavit, quare vulgo non nisi retractata in commune scientiarum caput adsumenda est; raro fundamentis pariter firmata, ac ambitu adaucta fuit. Proximis familiis valedicendo, egit potius reprimens in universalem disciplinarum nexum \& tractandi modum, singula non in plura latera, nec pluribus conjunctim expolitis. Auctor, qui unico puncto oculos infigit, non potest non multa oblique intueri; qui cunctis viribus in unius disciplinæ reformationem tantum nititur, facile ad nimia proferenda, nimia subvertenda, ut attentionem excitet, deducitur. Hoc modo commune scientiæ ingenium non paritur; si a singulari ad universale saltu transscendatur, e fulgore fumus potius, quam e fumo lumen oritur. Minime monographias impugno, sed studium monographicum, singulas familias ut disjecta membra tractans magisque iatricans. 
mis observatoribus eximie commonstrata sunt 2), ut res ipsæ (quo magis lætor quam prioritatis commentum curo), a pluribus autonomis \& passivis observatoribus libere observatæ, ab hospitibus quibusdarn in dubium frustra vocari videantur. Primo attendamus anamorphoses hypothalli, hactenus neglectas \& præ ceteris fallaces, cum Lichenosam faciem prorsus exuant \& Byssaceas (hypotballus enim, per se consideratus, est planta Byssacea) referant. Simpliciter locis siccis $\&$ solis fervori infestis collabitur (unde ex hypothallo nigro Byssus antiquitatis L.); locis vero humidis, ad terram; saxa irrigua e. s. p. in floccos sæepius cespititios, sed statura admodum varios repullulant. Quorum originem, latas plagas irriguas sape licet occupantium, ab hypothallo lichenum in montibus Sueciæ facile persequimur, v. c. a Lecidea atrovirente, atroalba, milliaria, Biatora uliginosa, Parmelia cinerea. Ut excrescentice fortuite apud Lichenologos passim notantur 3); apud Phycologos, ni fallimur, inter Con-

2) A Wallrothio ingenioso \& maxime, prominente modo, graviter \& populariter a Meyero, observationibus larga manu a Dufoureo diffusis, quæ in Historia Lichenum plenius indicanda sunt. Nec negligamus prævias observationes plurimorum Auctorum Lichenologiam ad hoc maturitatis stadium ducentes.

3) Sæpe vero etiam alienis speciebus tribuuntur; v. c. "pulvinuli sparsi atri hispidi" Lecan. coarctatæ Lich. univ. $p .353$ ad Lecideam quandam pertinent. Nam in rupibus irriguis, quibus innascitur, vulgo adest ferrago Lichenum mutilorum. Vide Lich. Europ. p. 292. Sed Conferva incrustans, sub Lich. leucolepide Wahl. Flor. Lapp. n. 781 memorata, hujus est hypothalli progenies. - Rhizocarpon Ram. \& Dec., exacte Byssocladium referens, ut adnatum, spontaneitate nondum prævalente, ratio media est. De Racodio rupestri \&c. conferatur p. XXXI. not. 9 . 
ferveas recipiuntur. Hujus saltim loci esse credimus v. g. Confervam nigram Roth., C. ebenéam Dillw. C. pannosam Web. \&-Mohr., Scytonema repens \& minutum Ag., sed inter tantam copiam synonyma certarum specierum absolute determinare non ausi sumus. Conferva pulveria Dillw. e cellulis cylindricis luxuriantibus quidem oritur, sed his insperse simul sphærice, unde habitus magis Leprarie. Tanta exstat harum formationum analogia cum pulvinulis tomentosis Stereocauli locis udis obviis, ut eosden cum allatis potissimum comparem; adscendendo a Lecidece milliarioe per Cladonice papillarice pulvinulos floccosos series contigua oritur. In medio relinquam utrum pulvinuli byssacei in thallo Parmelice glomeruliferce, Umbilicarice pustulatce e. s. p. pro proilificationibus thalli, sed in statu hypothallino degeneratis, an pro apotheciorum lúxurie habendi sint. Collata metamorphosi, etiam $\int_{0} \cdot 3_{1}$, intei has differentia facile evanescere videtur.

f. 3o. Magis multiformes sunt anamorphoses thalli, sed thallina indole servata in Lichenum familia permanserunt, cum hypothallince vulgo ad Phyceas translatæ fuerunt \& apotheciorum ad Fungos declinant. Quæ ratio horum organorum typum, qualem proposuimus, etiam confirmat. E corporis Lichenosi deliquescentia totali in pulverem oriuntur status leprosi, tam e lepra, quam gonidiis compositi. Videntur hi omnes ex autonomorum Lichenum censu delendi; expurgationem hanc acutiores Lichenologi diu in animo volverunt, sed plene sapere non ausi sunt. Vulgo steriles tautum occurrunt, quare genus Leproe, aut melius Leprarice, subministrarunt. Non tantum Lichenes crustacei, sed foliacei etiam, 4) im-

4) Quam plurima exempla in Lichenogr. videas, qux 
mo verticales 5) Leprarias efficiunt, vita tamen non omnino exstincta. - Si lepra, immixtis gonidis, in acervos discretos pulverulentos (Soredia diclos) prorumpit, Lichen simul vulgo sterilescit 6). tichenes crustacei diversissimorum generum in hoc statu Variolarice genus sistunt. Variolaria ulla, ut normalis Lichen, in natura minime existit. Vulgatiores a Parmeliis (etiam foliaceis, ut egregie Meyer) \& Pertusariis originem ducunt. Lichenes sorediiferos thallo foliaceo aut fruticuloso persistente, quod minus constans, licet recte factum sit, a suo genere non separarunt Auctores v. c. Variolarioideas ITsneam hirtam, Ramalinam farinaceam; sed ne varietates quidem efficiunt hi status. Ceterum in prorumpendi modo sorediorum maxima observantur differentia: nunc e

hoc loco non repetam; foliacex originis testimonia offerunt P'arm. parietina, Lanuginosa, pulverulenla, subfoliacex P. triplophyilla, effiguratæ P. murorum e. s.p. Leprar. incana, a diveisissimis speciebus orta, optina a Clacloniis, Biatora byssoide e. s. p. (Non commutanda cun Lepr. alba, e Lecid. sanguinaria, milliaria e. s. p. deliquescentibus). Cavendum enim, ne ejusmodi nomina ad definitam speciem referantur; sed locis, quibus diutius moratus surn, nulla mihi obvenit forma, quam non ad suam, speciem certissime referre contigerit. Byssos v. c. B. auream, Jolithum, odoratam, cobaltigeneam Wulf. \&c. a Leprariis separo \& sub Byssaceis exponam.

5) V. c. Ramalina pollinaria Leprariam Parm. orostheo similem. Flotow. in Fl. Ratisb. 1828.

6) Horum analogiam cum Uredinibus, olim a nobis annotatam, minus probatam vidimus; mutatis vero mutandis ratio eadem est, nec Uredineae, ut a cellulis plantarum solutis tantum ortæ absque propria reproductiva prupagatione, meo sensu, pro autonomis plantis sumendx. Illustr. Link, hanc analogiam simul perspiciens, Variolarias optime pro Leprariis "parasiticis" (hæc expressio tantum nobis minus placet) declaravit. 
margine thalli, nunc e pagina superiori, nunc ex inferiori proveniunt; hae diversitates majoris ponderis sunt, quam corum defectus aut præesentia, quod cyphelloe testantur. "Ad singularum specierum historiam plenior expositio relegata est. Antecedentes thalli anamorphoses cum reliquis Algis communes sunt; Lichenibus vero propria videntur excrescentix corallina, stipatæ, subcylindricæ, passim ramulosæ, qua itidem thallo crustaceo ad peculiare genus, Isidium, elevatæ 7), cui vero "generi" ne unus quidern restat autonomus $\mathrm{Li}$ chen 8). Maxime licet personatus his efflorescentiis thallus crustaceus appareat, identicos status thalli effigurati, v. c. isidiophoros Parm. saxatilis, olivacece, Everniae furfuracea, a typicis lævigatis genere separare nemini in nientem venit. At hac formatio Isidii non speciebus ceterum affinibus, ne generibus quidem omnibus est communis, ut simul e thalli $\&$ apotheciorum indole pendens. Desideratur inter IMycolichenes; PhycoLichenes thallo segregato; in genere Parmeliaceis \& Endocarpeis priva est. In statu isidiophoro quoque vulgo desiderantur perfecta apothecia; sed passim adsunt in apice ramulorum rudimenta, metamorphosi gonidiorum ut in Spi-

7) Analogæ sunt Pliylleriacece, plantarum perfectiorum proles. Notatu dignum illas, ut Isidiis Lichenibus, arboribus dicotyledoneis fere privas esse. Si attenditur ad nexum gonidiorum \& chlorophylli, tam Uredinearum, quam Phylleriacearum rationes evidentiores prominent.

S) Omnes Isidii species in ipso libro suæ matri subscripsimus. Ceterum variæ sunt Isidii formationes; spurix thalli prolificatione ortæ, v. c. Isidium gonatodes, oculatum, stalactiticum (in quo areolæ ipsæ cylindricoelongatæ); thallus passim ramulosus Lecid. milliariae. In duabus hyperboreis Parmeliis thallus isidio-morphus normalis status videtur. 
lomatibus quibusdam incompleta, pro apotheciis descripta 9).

ઈ. 3 r. Definitæ magis, ut semper ex evolutione suppressa pendentes, sunt anamorphoses apotheciorum, eo majori vero atténtione digna, cum multa Lichenum spurid genera, immo species fungorum, subministrarint. Jam sub metamorphosi indicavimus singulares quasdam formas Spilomatis, semicompleta gonidiorum morphosi apothecia imitantes, Reliquæ præcipua sunt:

a. Status Angiocarpi Gymnocarporum, in quibus horum supra descripta normalis evolutio abrumpitur, \& Endocarpeas \& Verrucarias referens subsistit; sape atypica evolutione magis degenerat. Ad priores referendæe sunt variæ species v. c. Endocarpi, Porinae, plurimæ Sagedice A. ut a Parmeliis imperfectis orte; Sagedia candidissima A, varix Pyrenulce Schleicher, Lecidinarum abortus. Apotheciis in strato corticali oriundis, nuclei magis exseruntur, nigrescunt (in apotheciis excipulo proprio simplici abortu), perithecia Verrucarix aut Sphæriæ (Sphceria Lichenum Rebent., Endocarpon athallum Spreng. \&c.) referunt \& hac ratione oritur thallus nigro-punctatus 10). Hoc

9) Priscis nominibus generic. Lepra, Variolaria, Isidio ut terminis utor. Nimis ceterum in singularia deduceret, multas alias thalli prolificationes, plus minus suppressas, hoc loco exponere. In his semper apothecia aut nulla aut mutila. Externa facie sæpe admodum a thallo primario recedunt v. c. Lich. parasiticus E. B., cui simillimas proles in variis Imbricariis, præter Parm. saxatilem, vidimus. Ad eundern typum, inter alia, pertinent verruca centralis Parm. gelidae; maculæ determinatæ, applanatæ, fuscescentes in Parm. cinerea. Color fuscescit ex hypothallo prædominante.

10) Hinc ad characterem specierum nil valet, v. c. inter Parm. physodem \& encaustam, Parm. conspersam \& centrifugam. Harum priorem luxuriantem omnino e- 
quidem modo plurimi Gymnocarpi mutantur varioque pro singuli generis diversa indole 1 i). Hec anamorphosis ad typum primarium magis spectat, sequens mere mor phologica.

b. Quamvis diversa a præcedentibus appareant cephalodia s. apothecia Parmeliacearum monstrosa, thalamio solo erumpente nec ullo excipulo thallode religante explanata, quare convexa $\&$ subimmarginata, - iisdem valde affuia sunt, ut agre limitentur 12). Erant status Angiocarpi monstrositates Gymnocarporum in Angiocarporum evolutione retenti, sunt cephalodia abortus Parmeliarum, quibus priva, Lecidinarum apothecia imitantes 13). Quo magis discus normaliter extenuatus, eo magis cephalodia ab eodem habitu recedunt, v. c. Usnea, Ramalina, Imbricaria-

punctatam, sterilem! vidi ; hanc in apotheciorum vicinia sæpius nigropunctatam. Hæc puncta nigra pro apotheciis abortivis habenda vel sola Parm. cinerece forma, quæ Lecan. multipunctata A. Lich. univ., luculenter demonstrat. Sed occurrunt etiam puncta nigra aliæ indolis, v. gr. in Parm. erinacea e fibrillis abortivis, e. s. p.

11) Opegraphæ juniores normaliter facile Verrucariam referunt. Verruc. byssacea $\mathrm{Fl}=$ Calicium abortivum. Caticiis insuper competit alia degeneratio, excipulo dilatato \& inciso, cum Limboria non confundenda.

12) Unicum exemplum sufficiat. Puncta Verrucarioidea nigra Parmel. saxatilis in ejus prole, Lich. parasitico E. B., in cephalodia vulgo exseruntur \& explicantur.

13) Lecidinis normalia sunt apothecia cephaloidea; ex allata Parmeliacearum anamorphosi præcipua oritur difficultas has, ceterum evidenter diversas, tribus acute limitandi. Dicuntur igitur cephalodia Parmeliæ simul formce Biatorince. Cephalodia in Usneis, Ramalinis \&c. re ipsa esse anamorphosin apotheciorum, nec thalli, evidenter videre licet in Ramalina calicari; ceterumque serie contigua cum formis Biatorinis Parmeliarum, de quarum nexu cum apotheciis nemo dubitat, cohærent. 
rim; quo crassior vero discus persistit, eo magis conveniunt apothecia \& cephalodia v. c. Patellariarum. Ad cephalodia proxime accedunt apothecia degenerata Sticta pulmonacece, in pagina thalli inferiori sæe prorumpentia, quorum margo \& reliqua diversa facies a disci origine infra stratum gonimon pendet I 49 .

te. Arthonia Ach. s. apothecia macularia, sæpius difformia, immarginata, excipulo omuibusque internis partibus confusis. Aniecedentes status inter perfecliores Lichenes s. Phyco-Lichenes pracipue observantur, hic vero \& sequens in inferioribus s. IMyco-Lichenibus. Oriuntur præcipue a Graphideis \& Verrucarieis, rarius a Lecidinis \& Parmelieis infimis. Arthoniæe nidulantur in cortice arborum tenuiori 15), ob cujus celere incrementum evolutio normalis quieta turbatur \& initia apotheciorum cum epidermidis extensione dilatantur, ut partes internæ discerni nequeant. Pendet itaque hre anamorphosis a statione, sequens vero a precipite evolutione.

d. Spiloma Ach., in quo apothecia primitus in pulverem, sporidia referentem nuda, tota dissolvuntur. A genuinis Lichenibus disco collapso

14) Omnes anamorphoses mutuos fines ita invadunt, ut tantum sub primariis rationibus colligantur. Medium statuin inter apothecia vera \& cephalodia sistit discus soredio exceptus, vulgo magis tumens \& gelatinosus, hinc facile corruptus. Similia sunt apothecia in morbosis disciferis Pertusaris, quarum discus etiam cephalodiis facile adnumérandus. Diu experiri conatus sūm Sclerococci originem a cephalodijs Lichenum (ut Illosporit s. Ticti rosei Schreb a gonidiis), at hactenus frustra. Eadem est ratio theorix Wahlenbergiane de origine Calic. turbinati ex ostiolis Pertusarix.

15) Alio loco verx Arthonix desiderantur; deficiunt etiam status Arthonioidei Verrucariarum saxicolarum \& sub epidermide nidulantium. 
Spiloma recedit excipuli defectu. Communis harum formarum caussa sunt vicissitadines in medio cingente nimis acutæ; quo infervescente cito in pulverem subtilem solvuntur àpothecia v. c. in saxis calcareis soli jnfestis (Spiloma reticulatum Chaub.), lignis \& corticibus exaridis (Conio. carpon nigrum ex p. Dec.); hinc præcipue in calidis regionibus obviæ sunt, in summo septentrione deficientes. Solo vero passim inundato aut irriguo apothecia evadunt scabrida, subpulverulenta, pejus evoluta floccosa 16 ), ad nematum naturam accedentes, ut pro apotheciis viviparis haberi possint. Anamorphosibus hypothallinis tam similes sunt, ut sæe æegre dignoscantur. Sic anamorphosis apotheciorum ad hypothalli revergit.

§. 32. Quamdiu morphoseos \& anamorphoseos proles non distincta, clare percepta \& sobrio modo explicata, frustraneum omne systematicum studium, quod dubiis tantum principiis, suspenso gradu, quæritur. Nam quod in observatione indefinitum \& vagum, in constructione fallax \& infidum est. Lichenum ananjorphoses minus forsan numerosæ, saltim versiformes; quam adhuc inferiorum familiarum vibrationes; tamen systematis ariadneum filum, nec mere ingenii ense, nec comtemplatus solum nisu extricandum, adrnodum innodarunt. Hic locus maxime conveniens videtur ad primaria systematis Lichenum fundamenta inquirenda. Hrec ab apotheciis pendere

16) H. I. Spiloma tuberculosum Engl. Bot., Spil. verrucosum Fl. \&c. Similes formæ in rupibus udis Scandinaviæ non raro cum anamorphosibus hypothalli prope connexæ. Indicationem hujus status sistunt apothecia disco scabroso, quæ itidem abnormia sunt. Cfr. Lecid. Spiloma microclonum optimum ex ascis Stictid. parallelce locis udis pariter protruditur. 


\section{'Anamorphoses Lichenum: ' LXXIX.}

plerisque Lichenologis tam evictum visum fuit ${ }^{7} 7$ ), ut contrariam sententiam vix tetigerint, quo neglecto tamen hæc, benevolo studio externam faciem reconciliandi, adhuc late serpit. Contra principium negantes non sufficit citare canonem Linnæanum "orthodoxos Systematicos e fructificationis vero fundamento dispositionem desumere." Externa vero facies parvi est momenti, analogiam nec affinitatem indicat, quarum differentiam illiusque inferiorem vim post editionem Syst. Myc. I. (p. XV. \&c.) ab omnibus agnosci vidimus. Rem morphologice considerantes, apothecia inter Lichenes potiora esse facile videmus, cum veram affinitatem sequantur; cum hæc sola series discretas superiores limitent; cum nobilius, scilicet altioris methamorphoseos, sint organon \& præcipue, cum eorum evolutionis series sit definita \& limitata 18). Quibus omnia contraria in thallo, qui nullum constans primarium discrimen, in characterem familiæ non receptum, offert. Præcipuam vero rationem, ob quam thallus ad Systema objectivum se cogi non patiatur, sistunt morphoses \& anamorphoses numquam definitx; thallus semper in novas \& mutatas nititur formas; ut $-i$

17) Schradero, Turnero \& Borrero, Wahlenbergio, Flörkeo, Aleyero, Wallrothio, \&c. .. Etiam Acharius a dispositione thallina in carpologicam abit \& Eschweiler nuperius rationes thalli magis congrue quam ceteri, etiam in limitandis generibus, neglexit.

18) Ex hoc ipso pendet, quod omnes comparationes hac in parte cum animalibus claudicant, quod omnes horum partes melius recipi possunt. Animal suos metamorphoseos gradus peregit \& deposuit, priusquam completum prodit; hac ratione fructificatio tantum, vitæ periodo extremitatibusque definitis, cum animalium imaginibus comparari potest. Folia \&c., licet functiones in utroque orbe differant, sunt tantum status persistentes larvati -floris, veræe plantarum imaginis: 
continue occupatus in evolutione, tum demum ejus variationis series absoluta, quando accidentaliter-in novissimo statu dissolvitur in primiliva gonidia, in novam prolem progerminantia.

PRALECTIO III.

\section{GEOGRAPHIA LICHENUM 1).}

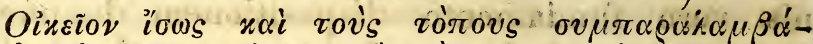

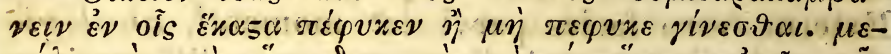

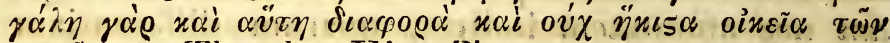

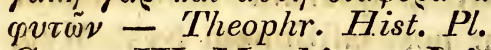

CaputIX. Medium Lich num s. limites d. vegetationis conditiones.

§. 33. Quousque aër, medium sistens omnium Lichenum commune, in solum libere agit, latissima Lichenum patet patria. Extenditur a circulo rquinoctiali ad summa alpium cacumina, quæ rarescentibus aut evanescentibus aliis plantis peculiarem offerunt zonam, Lichenosam dictam; Ad utrumque vegetationis terminum, stus (ut in desertis Africes) \& frigoris, ultimi desinunt. Sunt tantum duo limites, quos non transcendunt, aqua nernpe \& nivis perennis 2 ). Ubi vero solum, maxima anni parte tam aqua, quam nive submersum, denudatur aëri, mox $\mathrm{Li}$ chenes, licet sæpius sub personata forma, hospitantur. Inter reliquas Lichenum conditiones $l u x$ est primaria, quare addi possit tertius terminus, non transcendendus, tenebrarum perpetuarum. Sic limitata Lichenum patria, considerandx aêris vicissitudines, quæ primarias vegetationis discre-

-1) Adhuc in incunabilis latet, ne omnis quidem Europæ inchoata; de peregrinarum regionum adsunt tantum fragmenta. Minus igitur hanc materiem absolvere in spe est, quam in votis, ut novis \& conjunctis Lichenologorum studiis plenius exponatur.

2) Limes verticalis Lichenum in genere ideo non indicandus, sed in singularibus speciebus, utique attendendus, est. 
pantias determinant. Sunt calor, humiditas, raritas cum varia lucis intensitate, multis modis inter se complexe. Generalem harum vim in vegetationem e Geographia plantarum universali cognitam anticipamus.

S: 34. Galor absolutus infirmior Lichenibus est stimulus, quam reliquis plantis 3), at eum tamen esse momentum valde efficax, facile intelligitur multis tam speciebus, quam generibus regionibus tropicis privis. Sed calor per se vegetationem non promovet, nisi conjunctus cum humidate; hac pari ratione presente major specierum videtur numerus in tropicis regionibus, quam in:frigidis; sunt in zona magis temperata regiones quiedam specierum ditiores, quam in septentrione. Præcipue species corticols cum calore evidenter decrescunt. Frigus, s. temperaturam humilem, ut sæpe fingitur, momentum esse Lichenum vegetationi favens omnino erroneum censemiss; individuorum luxuries locis frigidis ex aliis caussis pendet, nempe minori siccitate aëris \&c. Nec negligenda tarda Lichenúm vegetatio, quæ a lætiori \& fortiori semper supprimitur; quare non mirandum in regionibus tropicis ob eximiarn \& perennem plantarum perfectiorum vegetationem Lichenum individua rarescere. Praecipue: notabilis est caloris vis in apotheciorum formatioinem: apothecia composita, stromate discolori gaudentia, in tropicis communia, in frigidis desiderantur. Intra Europam vero calor absolutus minus specierun indolem \& numerum mu-

3) Aqua calefacta, non fervida autem, suffusa non necantur. Experimento perfacili, at neglecto, aqua diversæe temperaturæ Lichenibus infundi posset \& sic explorari, quem caloris gradum sustineant. Intensissimum frigus alpinás saltim species haud necare novimus. 
tat, quam ejus distributio inter diversas anni ter. pestates; clima temperaturam magis cequalem servans Lichenum vegetationi magis favet quam oscillans; maritimum magis, quam continentale. Multæ species, vulgo australes habitæ, juxta mare occidentale ad oras Lapponie, hieme satis miti ob mare haud congelatum fruentes, procedurt? in Europa Sclavorum, æstati siccissimæ \& hiemi frigidissimæ infestorum, prorsus desideratæ. In illis incrementum individuorum celerius quoque videtur, sed hoc momentum cum humiditate aëris ita conjunctum, ut rite segregari nequeat.

5. 35. Cum Lichenes jove tantum rorido \& tempestate pluviosa vegetent, facile intelligitur, quare Lichenes ab humiditate aëris magis pendeant, quam omnes aliæe plantæ. In regionibus aëre sicco admodum rarescunt, humido vero luxuriant. Sic v. c. ab amic. Doct. Sundewall accepimus vix ullum Lichenis vestigium conspici in planitiebus Orientis 4), cum in irriguis Americe silvis admodum luxuriant. Inde etiam derivanda est magna specierum copia in regionibus occidentalibus \& maritimis, in quibus ob temperaturam magis æqualem aër humidus, autumnus longus, hiems ex magna parte pluviosa; plures privarum specierum Europæe occidentalis, ex America quasi oriundæ, in hujus demum regionibus calidioribus fructificant. Humiditati : aëris, nec frigori, \& aliarum stirpium defectui debetur insignior Lichenum vegetatio alpina, rore sæpe contigue lretificata. Sed \& huic perniciosum videtur clima continentale; queritur Gel. Wahlenberg Carpathos, solum licet aptissimum individuis offerentes, Lichenologicas suas spes specie-

4) Species collect $x$ admodum minutx, infimorum generup, Graphidearum, Porodothii Eschw. \&e. 
Jum yariorum aut privarum fefellisse. Alpes maritimæ præstant; Pyrenaei, individuorum copia haud admodum pollentes, rariorum specierum hortum quasi offerunt. - Venti, vi tam exsiccandi, quam irrorandi, cum humiditate aëris ita conjuncti sunt, ut haud separandi videantur, sed insignis est convenientia inter regiones campestres \& alpium juga denudata, ut hanc stationem seorsim considerenus. Ventus quoque mechanice agit in crustarum faciem, inde tersam ac levigatam, \& facile multas species arboreas, in terra obvias, a sede sua originaria primitus divulsit.

f: 36. Lucis momentum 5), ut ubique, sed occultius, agens, minus perspicitur; ex eo vero pendet omnis justa Lichenum explicalio, ut facile videre licet, ubi nimis rárescit aut deficit. Ưt vero calorem intensiorem non omnes species ferunt, hinc regionibus polaribus privæ, sie nec lucem intensiorem species quadam loca umbrosa semper quærentes. Hic vero effectus non ut caloris ad diversas zonas extenditúr, nec ut humiditatis ad diversas regiones, quare in Geographia Lichenum minus notabilis fit, $\&$ in variis terris singularibus maxime rationibus pollet. Ejus vim in colores alibi exposuimus. In genere forsan dici posset citrinum colorem esse tropicum, fuscum montanum, ochroleucum alpinum. Magis familiariter proponenda est suspicio, a præsentibus vero subsidiis evidenter indicata (Cffr. Cladon. \&c.), seriem citrinam pracellere in America, fuscam in Europa, ochroleucam in Asia quæ si vera, facile deduceretur ab Americæ insigni

5) Quid directe aëris raritas conferat ad mutandam vegetationis Lichenosæ faciem ad corollaria quædam colligere nondum licuit. Vidimus tamen in summis alpibus multas formas turgescentes, quasi inflatís e. s. p. 
vegetatione Lichenum tropica, in antiquo orbe magis succumbente; sed novus orbis splendido a vium e. s. p.colore itidem insignis est ceterumque etiam e frigidiori America duplex citrinarum specierum numerus, cum regionis Europæ comparatus, vulgo reportatur. (Clad. cocciferce in America boreali 12, in Europa 6 species, ommes simul Americanas, enituntur.) Computatis vegetationis Lichenosæ rationibus hæc nascitur theoria: Summa est specierum accumulatio, locis calidioribus 6), simul vero humiditate aëris scatenti. bus; summa autem individuorum locis, in quibus ob cali solive asperitiem reliqua vegetabilia rarescunt.

\section{Caput X. Sedes Lichenum s. solum of stationes.}

5. 37. Cum solum nutritionem Lichenibus non offerat, sed fulcri loco inserviat, diversissime \& fere omnis generis sunt Lichenum sedes. Inhabitant quacumque corpora emortua \& perennia, tam inorganica, quam organicæ originis v. c. humum, ligna, ossa I); porro partes plantarum vivarum perennes, aëri expositas, ne foliis quidem exceptis, tantum omnibus partibus annuis 2). Sed ob diversum proveniendi modum \& quod inferiores substantiam matricis sæpe assimilant, non singula species quolibet solo obviam venit; pluri-

6) Calcis vis calorem absorbendi \& vegetationem $\mathrm{Li}$ chenum stimulandi non est dubitanda. Variæ species, v. c. Biatora decipiens, in Europa australi vagantes, in septentrionali solo calcareo tantum obviam veniunt.

1) Corpora durissima \& polita nidulartibus Lichenibus diu resistunt v. c. metalla, vitrum. Vidi tamen Liche-: nes tam in ferro, quam in fenestris antiquissimi templi oppiduli Falsterbo in Scania.

2) Has vero emortuas v. c. folia, cæspites graminum incrustant. Muscos vivos incrustando necant. 
mi Mycolichenes certo solo adscripti sunt. Quo perfectiores species, eo magis in genere vágantur \& a matrice separatæ; in plerisque solum normale bene discerui potest. Alii magis a solo v. c. plurimi crustacei, alii magis e statione v. c. Umbilicariae, Cladonice, mutantur. Quo magis diversa loca non fastidiunt species, eo magis vulgo etiam proteæ sunt v. c. Parm. varia. Ha vagaintes dicuntur, a quibus distinguantur incrustantes, quarum idem individuum supra diversa corpora (terram, muscos, ligna, saxa \&c.), primitus vernicis instar, profusum est. Hic proveniendi modus inter Biatoras, v. c. B. vernalem, passim normalis est.

5. 38. Diversissimum solum referendum est ad tres classes primarias: solum arboreum, terrestre, saxatile; reliqua matrices aberrantes sunt, nec species privas habent. In singula classe separandie species solo indicato absolute adscripte, aut normaliter tantum, in reliquas vero vagantes. Verrucarice hypophlœedes, Opegrapha erumpentes \&c., sunt absolute \& necessario corticoIæ; Usnea barbata, Evernia prunastri \&c. normaliter arboree, sed in terra \& saxis simul occurrunt. Verrucaria epigcea \& paucæ aliæ (harum enim numerus minimus est) absolute terrestres; Cladonice, Peltigerce \&c. normaliter. In regionibus frigidis plurimæ sunt absolute saxicolæ; v. c. Umbilicarice, Verrucariae \& Lecidece permultæ; major vero in tropicis numerus absolute corticolarum. Sunt verô plures modificationes, has. differentias magis tollentes; lignum denudatum induratum facilius recipit species saxatiles, quam cortex; saxa formationis junioris corticolas facilius, quam granitica \& durissima; formæ muscicolæ in genere semper suspectæ, vix umquam 
sunt primariæ, licet incrustantes bene efformatæ sint. Ceterum quoad solum maxime notabilis est differentia inter calcareum \& graniticum, tam terrestrium, quam saxicolarum; utrique plurimæ privæ species. 1 . non nisi in altero accidentaliter vagantes, inter quas præcipue notabiles sibi invicem respondentes, ut facile conjiceres differentiam primitivam a solo pendere, v. c. Parmelic badia \& cervina, $P$. surdida \& repanda, $P$. cinerea \& calcarea, Verrucaria nigrescens \& umbrina. Sxe quoque ex eadem soli differentia insignes \& fallaces oriuntur varietates.

6. 39. Differentiæ soli \& matricis insuper temperantur a diversis stationibus; adhuc magis sæpe ipsius speciei facies. Matricem normalem plurima optime servant in statione montano-silvatica, maxime mutant in campestri. Parmelia subfusca v. c. in agro Femsjonensi absolute corticola, in Scania campestri frequentior in saxis \& in summis alpibus ad terram. Eadem ratio permultarum specierum arborearum in maritimis saxicolarum v. c. Parm. ciliaris, parellae, Evernice prunastri; hæc, ut Ev. furfuracea, Usnea barbata, Imbricarice \&c., in campis quoque arenosis vagatur. Plurimæ formæ saxicolarum l. arborearum muscicolæ \& terrestres, vulgo juga denudata alpium inhabitantes in campis maxime perflatis \& siccis simul reperiuntur v. c. Parmelia tartarea frigida, $P$. pallescens Upsaliensis, $P$. scruposa bryophila, $P$. subfusca epibryon, $P$. ferruginea Jungermannice, quarum tantum primam in pineto-montanis legi, jdque loco diversissimo, nempe in paludibus turfosis profundis, in his regionibus maxime campestribus. - Sed ex altera parte saxicola Parmelia, quæ inde nomen tulit, \& plures similes in ligna frequenter 
adscendunt; neque hoc in regionibus silvaticis vidi. Major adhuc forsan vis ventorum exsiccandi in oris mediterraneis, cum ex iis ipsam Parm. murorum corticolan habeam. - Reliqua stationes minus notabiles; paucre admodum species sunt qux in humida, rupibus nempe irrigatis 1. juxta aque limites, tantum proveniunt v. c. $S e-$ gestrella rubra, Verrucariae graniticola, Endacarpon fluviatile (quod inde ortum facile censeas), Biatora microphylla; plures, quæ stationem cariem aut uliginem servantem non deserunt $v_{\text {. }}$ c. Biatora icmadophila, decolorans, uligino"sa, Calicium brunneolum. Multæ species, stationè ceterum varia, non nisi in umbrosa \& rorida (adeoque non nisi in silvatico-montanis) fructificant v. c. Stictce, Cetraria glauca, Evernioe fere omnes, Lecidea panceola. Cladouriæ pyxidatæ in eadem apothecia normalia, edunt, in statione aprica, præmature forsan exsiccatæ, vix nisi symphycarpia. At facile jam videor nimis in specialibus versari.

5. 40. Lichenum migrationes a normali solo \& statione in peregrina 3 ), specie ipsa normali persistente, in præcedentibus tetigimus; hoc loco, in anamorphoseos complementum, tantum colligemus loca \& stationes præternaturales, in quibus species vix umquam justam evolutionern attingunt \& a tironibus probe sunt discernendx.- a. In ramulis ienellis arborum nulla normales formoe occurrunt; Imbricarie in formas leptophyllinas, tenellas, dissectas, v. c. P. parietina in " $L e$ can: candelariam", abeunt; Physcioe in formas adscendentes, hispidas, fornicatas 1 . cucullatas, v. c.

3) In regionibus calcareis species calcarex sxpe etiam in saxis graniticis leguntur, numquam vero in mere granitieis regionibus. 
"Borrera tenella"; Patellarice ecrustaceæ evadúnt (Cfr. p. 175); Myco-Lichenes abeunt in formás Arthonioideas. - b. Lignum, procipue fabrefactum, vix umquam est matrix primitiva (exceptis tamen Caliciis \& Lecideis affinibus); nullibi frequentiora individua crusta, immo apotheciis, mutila qua probe a typis discernenda quam in ligno fabrefacto. - c. Lichenes in aliis parasiti normaliter nulli genuini; de Caliciis duobus res adhuc sub judice est. - d. Saxa formationis recentioris inter Phyco-Lichenes nullas privas normales species enituntur, sed peculiarem seriem formarum degeneratarum, v. c. saxa cotacea 4); calci proprii in primaria perfectiores, strato corticali integro, v. c. Parm. calcarea contorta in calce primitiva, $P$. ccalc. farinosa in juniori, sed in utroque solo variare possunt. - e. Omne solum nimis singulare (e. gr. "Musci cranii humani") prorsus non attendendum. Omnem stationem perumbrosam it perhumidam status degeneres producere ex Lichenum idea patet. Utrique peculiaris formarum specierum series, ut in latebris montium \& juxta lacus, saxis circumseptos, ubi similes formæ tersæ, lævigatæ, decoloratæ peculiarem zonam aquæ periodicæ occupant (in Suecia ab Urceol. Acharii deterninatam; solæ Verrucarice in hac perstant normales) videre licet.

\section{Caput XI. Regiones Lichenum.}

5. 4I. Speciebus plerisque trivialibus ab hoc ad illum Europæ angulum vagantibus, primo obtutu vegetatio Lichenosa admodum uniformis apparet. Est quoque talis in Europæ regione me-

4) Murales species, \& calcareæ \& granitic $x$, non primarix; Muri Lichenosa vegelatione cum saxis forwmtionis junioris congruunt. 
dia, continentali, inferalpina, paucis bene evolutis \& privis formis insigni. Hanc igitur undequaquam cum reliquis confluentem mittentes extremitates evidentiores designare studebimus. In his exponendis Europam tantum respicere licuit; videntur tamen exoticæ eædem, modo acutius distinctæ; tropica enim leve indicium tantum est regio (Europoe) australis; Americance occidentalis. - Primo separanda, ut e calore pendens, Regio australis, oras mediterraneas tantum leviter attingens prodromis generum tropicorum v. c. Chiodecto, Dirina. Inquirere operæe est pretium quænam species reliquæ Europæ ibi deficiant; suspicorParmeliam tartaream, Lecid. sanguinariam, Umbilicarias \&c., cum has numquam inde aeceperimus. In illa regione Europæ tantum lectæ sunt Evernia villosa, intricata, Ramalina pusilla, Cladonia endiviafolia, Parmelioe plures e. s. p. Graphidex australes in ea frequentiores sunt, sed adhuc occurrunt in plaga australi regionis sequentis. Ceterum in genere major hic est luxuries specierum saxi calcarei \& corticolarum, \& maxime characteristicæ, ut huic regione privæ, sunt crustæ roseo-tinctæ.

5. 42. Præcedenti omni modo contigua est regio maritima (atlantica in Europa) s. occidentalis, e temperatura minus oscillante \& aëre rorido pendens," specierum privarum dives; nam per totam hanc regionem, licet ab Hispania ad Finmarkiam extensam, communes sunt Ramalina scopulorum, Sticta, Parmelia Borreri, aquila, plumbea, rubiginosa, cartilaginea, carneolutea, optima Parm. erythrocarpia, Verrucaria maura e. s. p. Species latifolize, Stictæ, Amphilomata \&c. in hac precipue fructificant; citata duo genera centrum habent in insulis oceanicis. Sed e ca- 
lore medio separanda in duas plagas, australem \& borealem, inter quas Roccella (genus maritimum) optime forsan limites indicat, nam curn hac species regionis australis, secus mare occidentale diutius persistentes, valedicunt, ut Sagedia aggregata, Endocarpon Guepini, Verrucariece \& Graphidea plures. In plaga boreali difficilius est hujus regionis species privas ab alpinis discernere, cum v. c. in Scandinavia occidentali Lichenes pro maxime alpinis habiti regiones litorales comitentur v. c. Parmelia gelida, Biatora atrorufa, Endocarpon phylliscum, Umbilicarice! Aliæ ad totam occidentalem zonam pertinent v. c. Biatora rivulosa, Parmel. muscorum. Ad hanc nec ad alpinam regionem insuper referendæ plurima species a Wahlenbergio in Finmarkia detectæ; plures jam in australiori Norvegia \& Hallandia lectæ. Denique tam australi, quam böreali plagæ hujus regionis proprium est, species privas, quas illa cum regione mediterranea, hrec cum alpina non communes habent, copiosius \& perfectiores in America reperiri, quales in plaga auśtrali Parm. leucomela, chrysophthal$m a$ (in continentem longius intrans), cinnabarina, Sticta aurata (etiam silvatica non nisi in America vera apothecia profert), Evernia flavicans, Parmel. Borreri, sinuosa, ut crustaceas minus limitibus definitas taceam; in plaga boreali $\boldsymbol{P}$. straminea, aipospila, molybdina. (Similia exempla plura inter Pyrenomycetes).

§. 43. Antecedenti regioni variis rationibus opposita est regio montana, quam ideo continentalem s. orientalem diceres, quod maximam partem Ruthenia, quantum e collectionibus Weinmanni \&c., concludere licet, offert; sed etiam majorem Sueciæ partem in planitiebus silvosis, sæ- 
pe vero cum occidentali confluens, occupat. In Europa australiori regiones subalpinas, immo alpinas, magis continuat, ut ibi ab alpina limites difficilius ponantur, in Europa boreali-occidentali vero ab occidentali, in qua tamen non reperiuntur Parmelia Fahlunensis, Cladonia bellidiflora aliæque regioni montanæ characteristicæ. $\mathrm{Ob}$ variam vero indolem difficile significatur, cum longe alia sit multarum specierum ratio in Europa australi, ubi limites magis obliterantur, quam in Scandinavia, ad specierum distributionem observandam ideo præcipue accommodata, quod hæ in planitiebus segregatæ non ita congeruntur \& stipantur ut in subalpinis. Præcipuæ hujus regionis species sunt Umbilicarioe, Parmelia \& Lecidea fuscescentes, Parm. cinerea, centrifuga, incurva, tartarea, ventosa, Lecidea sanguinaria; $\&$ in septentrione Peligera arctica, Cetraria odontella \&c. Ceterum in hac regione Lichenes longe insigniorem partem vegetationis sistunt quam in precedentibus; Cladonice, Cetrarice \&c. denso agmine terram sterilissimam tegunt. Numerus vero specierum non pariter augetur, evanescentibus multis arboreis, calcareis aliisque Europæ medire speciebus v. c. Lecidea canescente, epigar, Cladonia alcicorni. Quo longius a mari occidentali recedimus, eo magis evanescunt species latifoliæ, Stictoe, Amphilomata, ut in regione maxime orientali nil lætius \& ocius vegetans restare videatur 2). Utrum truncorum putridorum copiæ, an climati adscribenda sit Caliciorum luxuries, ambigitur. In regione montana, silvis denudata, facies magis alpina.

2) Lichenes hac ratione plantis perfectioribus oppositi -sunt, nec mirum: illi æstate temperata, hieme miti; hæ rstate calida præcipue gaudent. 
5. 44. Ultimam demum alpinam regionem, quæ polos yersus cum planitiebus requatur s. hy perborea, in Flora alpina saltion speciali subdivisám vellem, quod cum hoc loco fieri non potuerit, singulas potius alpes consideremus. Alpes Lap. ponice individuorum, precipue Cladoniarum, numero ditissimæ sunt, sed tam specierum absoluto, quam specierum privarum (exclusis nempe septentrionali-maritimis), Helveticis \& Pyrenaicis inferiores, cum in his, simul cumuletur vegetatio Lichenosa regionis montanæ, in septentrione infra alpes sæpe desinente (v. c. Umbilicaria pustulata, Evernia vulpina, Parmelia sordida \&c.) aliæeque accedant formæ australiores. Harum nonnullæ jam adsuit in alpibus australioribus Norvegie, v. c. Parmelia chrysoleuca, oreina, Lecidea armeniaca, conglomerata - \& in convallibus Parmelia speciosa. Adhuc alpibus Scandinavire prive restant Evernia divergens, Biatóra placophylla aliæeque recentius detectre. Siphulam Ceratitem communem habent cum alpibus Uralensibus, de quibus ceterum tantum novimus terram Evernia ochroleuca, Cetrariis, Cladoniis \&c. obtectam, unamque accepimus privan speciem, Everniam fertilem. De alpibus Britannicis specialiora mihi haud innotuerunt; convenire videntur cum Norvegire maritimis. Specierum numero precipue eminere videntur Pyrencei, nisi ob elegantissimas inde receptas collectiones fallor multaque priva. Defectu specierum maritimarum \& occidentalium in alpibus centralibus Eu-ropæ, typo Helveticis, deprimi videtur numerus, (sed accedunt aliae privie); etian, ex Wahlenbergio, individuorum copia. Hoc respectu, eodem Auctore, Carpathi magis pollent; quod vero ad species attinet, hi infimi videntur. - Exstat ita- 
que differentia etiam Lichenologica inter alpes Earopa borealis \& australis; in illis major individsorum numerus at minor privarum specierum, qualis Siphula. Plurime insigniores species Alpibus australioribus communes sunt, in septentrione desiderate, vo c. Umbilicaria atropruinosa (e Carinthia insuper misit Laurer), variae $L e$ cidece, Biatora testacea, Parmelia Lagasia, gypsacea. Per omnes Europæ alpes communes Evernia ochroleuca a,'Peltigera crocea, Parmelia physodes encausta, $P$. chlorophana, Biatora globifera, atrorufa, Liecidea Wahlenbergii \& plurès ejusdem generis. Denique notandum in regionibus alpinis multas species ad regiones inferalpinas passim descendere:

Caput XII. Statistica Lichenum.

5. 45. Cum exterarum regionum Flora Lichenosa tam parum cognita sit, ut in speciali computatione foret infida, indicatis, qua in Flora Europæa deficiunt, hanc tantum respiciamus. Omnes Lichenum tribus cognitie omnibus regionibus sunt communes; multa vero inferiorum genera tropica ex Europa exsulant vel tantum in australı parte ut hospites proveniunt - v. c. Trypethelium, Pyrenastrum, Porodothium Eschw., Leucogramma Mey: Gyrostomum - Chiodecton, Dirina, Strigula, Ustalia. Preterquam horum copia úbertate Stictarum, Graphidearum, Verrucariearum, specierum epiphyllarum \& in genere Zichenum arboreorim tropicis regionibus suus ab Europa diversus character. - In zona ${ }^{\circ}$ frigidioni -australi-redeunt quidem Europæa genera, immo maxime arctica Peltigera, sed etiam priva plures Sticta, Spharophora; Usnea \& Cladonia melanocarpa oninino proprix hemisphærio australi videntur. In genere versus polum aucti 
videntur Phyco-Lichenes, versus æequatorem $M_{y}$ co-Lichenes, quasi ob calorem majorem refugium sub epidermide arborum quarerent. $\mathrm{Ca}-$ licia nulla tropica novi. Ceterum species, quae in Europa maxime ubiquitarix, v. c. Usnea barbata, Parmelia subfusca, Cladonia pyxidata, Lecidea parasema \&c. eredem undecumque terrarum nobis allatæ; definitæ veró Euro? pæ zonæ adscriptæ e peregrinis terris vel desiderantur, vel in aliis analogis terris tantum degunt: - Vires Lichenum in frigidis prepollent.

- 5.46 . Indicantes diversitates sedis \& regionum de specierum in his distributione jam egimus; hoe loco magis earum relationes respiciemus. Multæ sunt species, eæeque vulgatissimæ; que omnes regiones simul inhabitant, qua a litore marino ad summa alpium juga adscendunt $\mathrm{v}$. c. Cladonice. Plurimæe privie videntur regioni tropicæe \& alpinæ, sed vere alpinæ regionis specierum numerus inde non augetur, deficientibus arboreis aut terram petentibus. Lichenes arborei, etsi vix definitæe arbori adscripti, cum certa quadam sæpe versus septentrioíem crescere desinunt, v. e. in Suecia Biatora rosella, Pertus. Wulfenii a, Thelotrema lepadinum cum Fago; normalis Opegrapha herpetica, Coniocarpon cinnabarinum cum Carpino, Opegrapha scripta cum Corylo, Opegraph. varia a. cum Fraxino, Acere, Pertus. Wulfenii $\beta$, Kerrucaria gemmata cum Quercu. - At maxima observatur discrepantia specierum terrestrium-\& saxicolarum inter regiones prorsus diverse geologicxe constructionis, v. c. mere graniticas \& mere calcareas 1 ) inter quas

1) Exemplum optimum prxbent confines in Suecia provincix Smolandia, tota granitica, \& Ölandia, tota calcarea; illa insuper píneto-montana, hæc campestris. Do- 
etiam juxta positas quoad singulas species \& formas differentia major, quam inter regiones Europee borealis \& australis ceterum pares. - - Cum regiones silvaticæ \& alpinæ apud nos sint contiguæ, minus mirum alpinas species in illas descendere, \& quidem sæpe alveos fluviorum sequentes ( $P$. melanaspin, $P$. elegant primariam), quam proventus multarum alpinarum specierum tam in ölandia, quam in Scania, a regionibus alpestribus saltum facientium (nam in regionibus silvaticis intermediis desiderantur), ut Cetrarice nivalis \& cucullato, Endocarpi pusilli, Lecidece sabuletorum in Scania 2), Sagedia cinerece, "Lichenis (Clad.) vermicularis" variarumque specierum calcarearum in ölandia. At ölandia Biatora decipiens, Cetraria juniperina terrestris e. s. p. majorem monstrant similitudinem cum alpibus Helveticis, quam Lapponicis. Hæc omnia ad ventorum effectum referenda sunt. Neque itaque mirum Suecize Biatoram campestrem in summis demum asperrimis jugis Vogesorum lectam esse; nec complures Liclienes in Europa australi

lemus quod nobis non licet integras harum provinciarum Floras Lichenologicas communicare. Ne unica quidem Verrucaria saxicola eis communis est; e Placodiis Parmeliarum nullum præter $P$. saxicolam; in Smolandia P. gelida \& coarctata; in Ölandia Parmelia crassa, murorum, fulgens. Nulla Psora in Smolandia, in Ölandia Parm. circinata \& cervina. In ölandia vix ulla Umbilicaria adest, sed Collematum copia in Smolandia desideratorum. Diversus character prominet $\varepsilon$ diversis varietatibus, sub quibus etiam communes species occurrunt. In ölandia crustæ a carbonate calcico, in Smolandia a ferro inficiuntur. Sed corticolæ communes.

2) Egregius. amicus Stenhammar, cui tot eximias observationes omnis generis in nostrum librum debeo, idem in Ostrogothia campestri observavit; præterque plurimas allatas Parmeliam Hypnorum, Sagredicum clopimam. 
alpinos esse, qui in Suecia campestres Lapponiam vix attingunt:

5. 47. Computantes distributionem Lichenum 1) per diversa Europæ regna, diversas regiones complectentia, minorem numeri differentiant inveniemus, cum climatis oscillatio in australioribus per alpes æquetur. Facile perspicientes tabulas in vegetationis relatione exponenda esse profundendas, unicam tantum addimus excerptam e Florulis Lichenum diversarum Europæ regionum, quas in nostrum tantum usum, præcipue ad specimina visa, conscripsimus.

1) Quamquam recentioribus detectis communium specierum admodum auctus est numerus, minor re ipsa tamen est, quam ex hactenus recepta species determinandi ratione crederes, nam v. c. Usnea barbata, Evernia ochroleuca \& jubata in 10 species divisis, totidem pro tribus communibus oriuntur. Ex 18 circiter speciebus, quas Parmelia varia, \& 25, quas $P$. cinerea Recentioribus subministrarunt plurimæ etiam communes sunt. Iń sequente tabula species ad nostri opusculi determinationes computavi.

2) Pro ratione numerus specierum Scandinaviae justo major, partim quod optime cognitæ, partim quod omnes Botanici ad species a nobis ipsis lectas agnoscendas promptiores sumus. Varia Calicia, Lecidece \&c. in reliquis simul facile occurrunt, licet specimina nobis non obvenerint. Exclusa Norvegia Sveciæ ipsius numerus admodum deprimitur. - Dein optime mihi cognita Flora Lichenum Gallice, ditissimæ Europæ regionis; porro Helvetiae. Prior numerus indicat species cum Scandinavia communes, posterior in hac non lectas. Utriusque rationis majo r copia in Gallia, quam Helvetia, e defectu hujus multarum specierum maritimarum, occidentalium \& australium. Illæ quidem adsunt in Britannia, cui vero desunt variæ species continentales \& alpinæ; hujus vero index incertior. Multas quidem ex Hispania accepi; tamen species in Suecia non lectas tantum numeravi. ( $\mathrm{Li}$ chenum Graecorum collectionem, a liberali Bory missam, haud advenisse dolemus.) 
Species:

Usneacex (excl. Cetr.)

Cetrarix

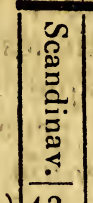

Peltigeræ

- 10

11

Stictex

Parm. Imbricarix -

- Physcix -

- Amphilom. \& Psoromatis

- Placodii \& Patellarix

- Psora \& Urceo.

Dirinæ

Gyalectr - - 2

Stereocauli - 8

Cladonix - -23

Biatoræ cum Bæom:

Lecidex - - 40

Umbilicariæ - -

Graphidearum - 8

Coniocarp. \& Conian. 2

Galiciearum - - 27

Spherophori - 2

Siphuix = - 1

Endocarpi - E 4

Sagedix
Ghiodecti
Pertusar \&

Pertusar. \& Thelotr. 7

Veriucariearum - 16

Limboriearum - 4

Summa

Summarum

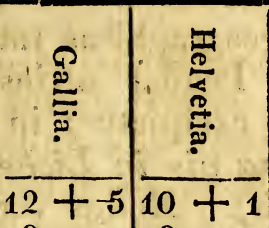

$9-$

$10-10-$

$6+125+314+1$ 年

$7+16-6+1+2$

$9-$

$8 ?+1$

$28+1327+826+1 ?+7$

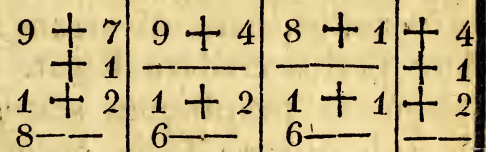

$22+119+120--1$

$20+618+217+2+4$

$27+828+822+2+3$

$7+16+1$

$8+66+17+5+5$

$2+122-12= \pm 1$

$2+11+12+1+1$

$3+1$

$3+13+13+1+1$

$\frac{3}{4}+1$

$43+1013+513+6+4$

$4 \frac{4--33+1|4-|+1}{247+73|229+41| 225+27 \mid+48}$

314| 320 | 270 | 252 1- 
5. 48. Laudatúr ab his, rejicitur ab illis attentio ad geographicas rationes in specierum \&c. limitatione. Pendet utriusque sententice veritas a modo, quo excipiatur; in genere vero statisticae est magna vis in Lichenum historiam et constitutionem 5). Modus vero observandi pro diversorum generum indole diversus est. Solum inter Verrucarias summi, inter Parmeliaceas nullius est ponderis. Qui inter has duas formas externa facie recedentes, cum altera in saxo, altera in cortice; altera in granite, altera in calce; $l$. illa in alpibus, hæc in planitiebus tantum occurrat, specie distinguendas fingit, evidenter in errore versatur, cum diversam faciem ex eo ipso pendere potius credere liceat. Res eadem est, si distingueres propinquos status, cum in diversis terris sub diversa facie occurrant; plurium Lichenum mos est in vera tantum patria rite explicat ri, extra hanc mutilos \& steriles per gonidia propagari 6). Inter duas vero bene \& typice explicatas formas, licet affines, diversus proveniendi modus differentiam specificam eximie confir-

5) Idea speciei, immo generum, ex harum attentione nova luce disserenat; qux comparatur ex herbario vel e singula regione, nimis vulgo angusta \& restricta est. Plenior est notitia speciei, sub diversissimis rationibus centies observatæ vel quam singulari adscriptam esse compertum habemus, quam semel modo, ignotis limitibus, obvix e. s. p. Hinc ad generale temperamentum species excipere consueto, quæ ex unico alterove specimine aut forma pendent, \& varietates infinitæ omnem vim \& dignitatem amittunt.

6) Promiscuus proventus v. c. "Stereocauli paschalis \& Cladonice papillarice," "Lecid. atroalbce \& geographicoe" nulla est ratio species conjungendi, nec analogæ in analogo loco degenerationes v. c. "Parm. parietince, aurantiacoe, murorum", P. physodis \& Evernice furfuraceee". 
mat. Videndum v, c. an species in omni statione a proxima tute distinguatur, an utrique propria anamorphoseos series, an utraque in illa regione promiscua sine transitu, cum altera in hac excludatur, ut Biatora rosella versus septentrionern, accumulatis formis $B$. vernalis proximæ, e. s. p. Aberratio, inter duas species ambigua, ad earn sæpius referenda, cum qua geographice convenit. (Ad genera ipsa inter Graphideas hoc, non omnibus sine dubio annuentibus, extendi. Lich. Eur. p. 35g.) De multis speciebus v. c. Parmelia gelida, coarctata, in vera patria legitima tantum comparatur idea. Plurimæ sunt pro singula specie variæ rationes, quas observatione potius quam regulis in naturæ gremio acquiescens addiscit.

\section{PRELECTIO IV. \\ HISTORIA LICHENUM.}

Natura semina nobis scientiæ dedit, scientiam non dat. Senecc.

Caput XIII. Constitutio Lichenum 1).

§. 49. Quæ sint rei ipsius (naturae), quæe formæ (artis), in omni constitutione exponenda primarium est separare. Illa licet essentiam, hæc putamen facile dicamus, forma tamen non perinde est; cum idea sub definita forma tantum comprehendi possit. Omnis forma, ut constructio quasi corporea \& oculis subjecta, essentiam ut ideam non plene capit; sic et nulla naturæ constructionem. Id vero nemo dubitet in scientiis

1) Obsequuntur quidem Lichenes eidem constitutioni quoad sectiones, genera, species \&c., quæ reliquis orbis vegetabilis provinciis præposita; sunt tamen eisdem, ut cuique familiæ, quædam rationes privæ. Mihi ipsi \& plerisque in multis nimis trivialis videar, sed consulto, cum alii quæ philosophicam constructionem redolent nauseant. 
rerum naturalium materiei summam normam es. se naturam, forma vero proponendarum rationem 2). Nescimus igitur quo pacto in dubium vocari possit in singularibus observandis unice empirice, in hac methodo inventis ordinandis $\mathrm{phi}$ losophice potissimum esse progrediendum. In principio, e quo ut rami e trunco scientia explicatur, summa sit necessitas, in singularibus natura duce summa libertas, quatenus illud formam, hoc materiem respicit; inversa est ratio conditoris scientiæ., Mysterium est, optime demonstrante $W a h$ lenbergio (in Suea V.), discere, quousque naturam sequi possimus, quandoque ars subveniat. Species unice \& proximæ sectiones ex maxima parte sunt nature, in sectionibus superioribus ars jam subvenit, in Systemate præpollet, non vero, interprete Bacone, aranearum sed apium 3). Quæ in specie ad constructionem Lichenologiæ spectant, a supra jam expositis facile deducuntur, v. c. thallum precipue in speciebus distinguendis, caute $\&$ occulte in generibus, neutiquam in Syste-

2) Logica ad scientiarum materiem inveniendam inutilis, in inventis ordinandis primaria. Hac simplicissima restituta veritate novus ex Linnæo nascebatur ordo. Systema \& quæcumque disciplina a regulis logicis, h. e. perceptionis humanæ, aberrans nullo modo rite constructa esse potest.

3) Benevolos illos nisus naturam l. artem unice amplectendi frustraneos esse facile demonstratur. Ob harmoniam vero naturæ ad se invicem properant; neutra tollenda, conjunctæ valent. Scientia sine principiis construi nequit; oppositum si quis contenderet, ipse sequitur tamen occulta, ipsi non clara, hinc facile vaga. Natura, constantia \& ratione prosequenda, est varium \& mutabile, Penelopes instar continue texens \& retexens; procos suos credulos ambigua deludit spe donec ratio expergefacta, Minervæ instar cachinantes principes Ulyssi tradit. 
mate esse consulendum e. s. p. Externa facies inter Lichenes fallacissima est. Anamorphoses ejusdem generis \& speciei magis dissimiles sunt, quam normales species \& genera.

5. 5o. Utrum species sint constantes naturæ quantitates, an vagæ \& confluentes, hoc loco non exponendum; illam sententiam nos profitemur 4). Inde sequitur dilatatio notionis speciei, inter Lichenes saltim. Formæ typo familiæ repugnantes species veras non sistunt. E statibus typicis hæ optime determinantur. Non characteres tantum, sed tota historia respicienda. (Cfr. \&. 48.) Characteres non efficiunt species, sed ad ignotas determindas sunt adminicula. Quo minutiosius characteres acuuntur, eo magis non raro a natura aberratur. Eque facilis error in nimia contrahendo, quam distinguendo 5). Malo insignem evidentem statum distinguere, quam eum cum alia specie confundere. In insigni formarum greg? passim juvat series quasdam constantiores \& historia discrepantes ut diverticula distinguere \& novo examini commendare. Re plene explorata veritati debita tribuentur. Caute ex analogia concludendum. Non idem ubique cha-

4) Indiciá contrarii judicii e Lichenologia petita a prisca laxa specierum limitatione pendent. At concedendum transitus observari inter species vere distinctas, sed pendet vel ex harum thallo concrescente, quasi hybriditate, (Cfr. p. 292) vel ex apotheciis in peregrino thallo ortis (5. 24) vel e formis tam mutilis ut verus character non promineat. Hos dicimus transitus indirectos; directos vero quibus altera forma in alteram explicatur. Falluntur, qui non e statu normali, sed e formis transitoriis species dijudicant.

5) Ultimus locus in utroque latere ambiguus honos. Puerile est novis tantum speciebus, senile harum reductione tantum gaudere. Qui alterutrum, nec passive tantum veritatem, quærunt, necesse labantur in excessum. 
racter fallax, nec ubique constans. Maxime mutabilibus sæpe proximæ species parum variæ. Nihil ceterum pollet positiva lex, aliquantulum sensus integer, plurimum naturæ sedulum \& acutum examen. Cum ipsæ proteæ sint, observator Protei instar præteritum \& futurum statum simul noverit.

5. 5r. Nitentur genera typica apotheciorum indole. Si genera unice e characteribus, in nullo statu variis, determinares, plurima confluerent. Characteres generici ob typicam apotheciorum congruentiam sepe parum prominent; hinc affinitas præcipue, morphosis \& occulte thallus cousulendi in limitandis generibus. Non idem character in diversis tribubus idem valet 6). - Difficilior \& ex idiosyncrasia pendens est questio, quousque ad sectiones naturales generis nomen extendatur; utrum sectiones Parmeliacearum \&c. genera an subgenera (tribus) dicenda sint. Si attendatur ad notionem generis naturalis, concessum fingerem, generis ideam post speciei in historia naturali naturalissimam esse debere, ut ejus species magis inter se, quam cum aliis aliorum generum affines sint; at conjunctis omnibus generibus Parmeliaceis perevidens est, infimas magis Lecideis, Biatoris, Pertusariis \&c. esse affines, quam v. c. Usneis \& Ramalinis 7). Et sic in ceteris,

6) Pulchrius, quam verius urgetur genera ex eodem fructificationis principio ubique esse distinguenda - "hceresin summam Botanices" dixit Linnæus. Nec fit, nec fieri debet. Cfr. v. c. Polygonum \& Cruciferas, genera Lichenum \& tribus Sphoriarum. Est potius singulæ familix privum quoddam characteres eorumque dignitatem moderans \& pendens, v. c. inflorescentia, astivatio - inter Algas thallus.

7) Si omnia genera Parmeliacea conjungimus, nulla adeșt ratio sufficiens reliquarum tribuum, re ipsa inferio- 
de quibus suis locis agendum; hoc loco de principiis.

5. 52. Principia, quæ in Homonemeis disponendis S) secuti sumus, aliis locis exposuimus. Pleraque ab aliis quoque probatissimis recepta vidimus, ut hoc loco repetere superfluum foret, nec connivemus ad id, nempe symmetricam formam,

ris dignitatis, servandi. Characteres horum, ut carpologici propositi, sunt tantum thallini personati \& quidem minus constantes quam thallus ipse in primariis Parmeliacearum sectionibus. Verum quidem est Parmeliaceas, cum centrum totius familiæ efficiant \& formarum copia reliquas fere æquent, seriem sistere magis contiguam, quod in omni naturalissima sectione fit; æque vero bene cognitis tropicis generibus inter Trypethelium cum affinibus \& Verrucarias, inter Graphidearum genera $\& c$. limites haud fore acutiores, at ipsa nulla præsente differentia thallina primitiva distinctu difficiliora, varia jam presentia exempla testantur.

8) Diversas disponendi vias in Syst. Orb. Veg. 1. p. 7-10 exponere studuimus, quarum altera, similia \& affinia colligens, sectiones varia ratione circumscribens, negligit commune dispositionis principium; altera hoc commune fundamentum pertendit. Utraque artificialis (illa si analogiam, hæc si characterem pro affinitate sumit) \& naturalis esse potest. Illam methodum, hanc systema diximus, minime pro lubitu, sed e recepta systematis definitione \& ad usum consuetum. Sic Linnæus semper dixit dispositionem sexualem systema, familias suas plantarum methodum. Minus bene de alteriusutrius viæ exclusivo pretio disputatur; sunt diversæ ideæ in natura æque fundatx \& æque necessarix, ad se invicem referendæ ut syntheticum \& analyticum; ut subjectivum \& objectivum; ut democratia \& monarchia; ut spes \& fides, quas jungit veritatis studium. Tantum igitur abest, ut sibi invicem inimicæ sint, ut potius altera, quo magis ad alteram accedat, eo perfectior ; methodus systematis fundamentum; systema methodi scopus. Cavendum ne a se invicem separando \& opponendo systemata ut monarchix in despotismum, ut fides in fatalismum, - methodi ut democratiæ in anarchiam, ut spes in diffidentiam degenerent. 
quod ab aliis minus bene exceptum vidimus 9). - Qure ad Lichenes in specie spectant, hoc loco tantum alleganda sunt. Affinitas Lichenum, more naturalissimarum familiarum, undequaquam tam implicata, ut eorum methodum mere empiricam, uniserialem \& omnes affinitates complectentem \& simul claram, definitam \& practica cognitioni inservientem dare impossibile sit, etiam si plura ex allatis postulatis mittamus. E nostris principiis primo inquirendæ differentiæ primarix \& maxime essentiales; secundariæ symmetrica dispositione excipiendre sunt. In his ducant principia seu ars. Parıneliæ transitus sursum æque facilis est in Stictam, Peltigeram, quam in Cetrariam \& Everniam; deorsum non minus Dirinam \& Gyalectam, quam Biatoram \& Lecideam, tam Glyphidem \& Ustaliam, quam Endocarpon \& Pertusariam tangit. Sed hec principia deducta sint e sedula naturæ contemplatione. Novis methodis l. nove systemate vel sine amplissima speciali cognitione vel sine novarum idearum manifestatione nil exstat inanius. At proponendi forma, principio alio aut aliter excepto, facile tempera-

9) In Syst. Myc. III. sect. 11. demonstravimus: a) contrariam in Flor. Ratisb. 1826. n. 26. argumentationem nullam esse, utpote nec principiis nec naturæ examine, sed præjudiciis nixam: b) verum refutandi modum \& apparentia dubia: c) perperam exhiberi me numerum quaternarium solum urgere (Cfr. S. Orb. Veg. 1. $p$. 21. h.): d) falso, cujus nullum apud me præceptum, ad genera extendi \& caussas: e) veram rationem adeo ut impossibile sit nubem s. numerum quendam pro idea amplecti;f) eamque cum libertate naturæ optime perstare, nisi tantæ libertati faævemus, ut verum tantum in exlege agnoscamus. Si inservies principio: principiis obsta, aliorum obliviscaris quæso, consulas naturam; me comitem forsan habebis. 
tur 10). Quæstioni, utrum ab infimis an a summis sit progrediendum, in abstracto propositge indifferenti, sine respectu ad finem expositionis responderi nequit. Alteri alterum optimum \& necessarium. Practico, ut legitime Linnæus, a proximis \& optime cognitis progredi præstat. Inter Homonemeas precipue infima tam vacillantia \& aníphibola, ut nullam certam basin exstructioni offerant; plurimi sic excepti Lichenes jam ut anamorphoses deleti. Nec Strigula \&c. genuinam \& veram Lichenis ideam offerrent. Systema licet definitum \& probatum velimus, non ideo denegemus omni sublimiori naturæ, ut religionis, studio inesse elementum quoddam mysticum, quo mens se divinitus natam sentiat eaque naturæ mysteria divinet, qua experientia nondum comperit; quod vero donec factum fuerit, hac via inventa pænes se ipsum, fatorum Cassandræ memor, quisque servet.

\section{Caput XIV. Colores Lichenum.}

5. 53. Nullius variationis in singulari $\mathrm{Li}$ chenum historia frequentior usus, quam coloris. Hic primo obtutu tam vagus \& illusorius videtur, ut non miremur, si quis considerans, quam

10) Prisci passim Botanici, non minús quam Scholastici Theologi, de singula formæ variatione disputabant. Vidimus et recentiora symptomata 1 . s. c. De his Linnæus': "Hinc ortus fuit tantus rumor inter systematicos Botanicos \& diversas sectas, tot jurgia \& opprobria; credidere methodis naturalibus addicti, se tenere methodum naturalem, reliquos omnes errare; alias vero propugnantes methodos regerunt illam difficillimam esse, suam vero facillimam, certissimam; uno verbo, nescia quid fascinat homines, ut non possint alteram methodum videre absque perturbatione - - optandum itaque foret, tirones omnibus adsuescerent methodis, ut nuga istæ semel evanescerent." 
multæ species spuriæ ex eo ortæ, quam impossibile singulas leves modificationes sequi, minoris eum faceret. At in infinita varietate vidisse nobis videmur typos quosdam primarios facile discernendos \& solos indicandos, cum plurimæ species intra singulam ex his ortam seriem pari ratione facile mutentur 1). Nativus et primitivus color, ut in tota serie protophytarum (optime

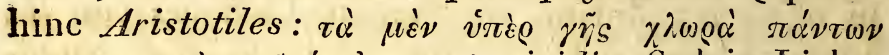

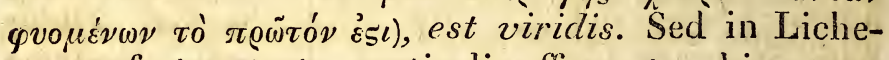
ne perfecto, strato corticali efformato, hic purus \& persistens, exceptis gonidiis s. vitæ principio 2), desideratur. Hoc tamen in statu humido translucente viridés apparent variæ Stictoe, Parmelice e. s. p., sed in siccis viride evanescit $\&$ vera series indicatter.

5. 54. Color hypothalli, ubi hic distinctus percipitur, vel expallet (hypoth. albus) vel nigrecit $(h$. niger $)$. Hic quidem in luridum, coerulescentem e. s. p. simul passim vergit, sed plures series definitas recipere non licait. - Thalli color, in affinitate determinanda primarius, strato corticali tantum inhæret; lepra semper fere alba est, sed ut Lepraria efflorescens thalli colorem plus minus mutuatur. Et thallum e primario viridi expallentem 1. saturatius coloratum vidimus (at non

1) Sunt hæ series, ubi distinctæ, tam insignes, ut species forma diversissimæ, sed colore normali congrux, re ipsa inter se magis affines vidcantur, quam quæ forma conveniunt, sed colore normali differunt. Cfr. Lich. Eur. p. 5\%. Posses facile Lichenes glaucos \& citrinos, ut Fuceas \& Florideas separare, sed directo lucis stimulo eorum color magis variat.

2) Inter chlorogonidium \& chrysogonidium limites acuti vix ponendi. Vidi Byssum candelarem L. flavissimam \& viridissimam. Videas de Leprariarum colore 5. 54 . 
nigrescentem), sed tinctura accedente lutescente in quatuor bene limitatas abit series: e læte viridi-glaucam - e flavoviridi ochroleucam - e saturate viridi fuscam l. olivaceam - e liteoviridi citrinam 3). Quanti practici usus, videas in Lich. Europ. p. I-5. Plures, apud nos saltim, non invenimus colores normales, nec horum, caussas, ut omnium differentiarum primitivarum, a nisu nature ultimo pendentium, inquirimus, reliquorum vero aberrantium indicabimus. Color thalamii, e nexu forsan cum erythrino, typicus est ruber, sed per gradus haud palpabiles cum majori induratione in rufum, fuscescentem \& nigrescentem 4), oxydationis processu deustum, abit. Exstant quidem exceptiones tam normales, ut characteres distinctivos offerant, sed haud difficile ad typum reducuntur 5). Color vero thalli evidenter disci temperat, præcipue ubi hic extenua-

3) Facile crederes arctiorem intercedere nexum inter series duas lutescentes \& non lutescentes; aliud vero suadet specierum affinitas. Cfr. v. c. Lecideas. In Lichenophylacio nostro larvæ insectorum per Eichenes fuscos \& citrinos, nec reliquos, avide pascunt.

4) Hanc seriem eadem species, idem individuùm sæpe percurrunt,"v. c. Parmel. subfusca, varia, Biatora decolorans, vernalis. Parm. sordidae discus primitus \& Parm. cinerece locis irriguis rubescens. Cladonice cocciferce vegetæe exsiccatx apothecia rubiginoso-atra offerunt. Etiam maxime deustæ Lecidex discum rufum sæpe monstrant v. c. Lecid. alboccerulescens - L. sanguinaria, sabuletorum, enteroleuca - immo maxime carbonacea $L$. contigua.

5) Color disci expallens vel ex ipso disco nimis extenuato, sxpe sterili, oritur ut in Usnea, Ramalina, vel e statione humidiori \&c. pendet v. c. Biat. vernalis. Sed Ramaline apud nos, Usnea in America fiequenter disco rubello occurrunt, quo colore simul imbuta cephalodia. Niger color in generibus fungis proximis dominatur, ruber in Lichenibus centralibus. 
tus \& a thallo immediate receptus est; in apotheciis discretis v. c. Cladoniarum 6) purior est. Color viridis, æruginosus \&c. numquam normalis est, nec cœeruleus nisi a pruina ortus. - Color sporidiorum primarius videtur hycilinus, qualis in thalamio nucleiformi persistit; in disco aperto ad hujus colorem passim accedit.

f. 55. Aberrant vero thalli colores variis modis, quorum caussas \& nexus probe attendat practicus Lichenologus. Primo notandi Lichenes hypophloeodes, in quibus color ab epidermide matricis pendet \& cum hujus indole mutatur, quare, primo observante Flörkeo, species non discernit. At epidermidis color non immutatus, sed a Lichenis insita vi in diversis arboribus varia ratione mutatur. Nec genuinus color prodit thallo cum matrice lapidea coalito. Ob has caussas series coloris inter $M y$ co-Lichenes non definiti; in Caliciis inferioris dignitatis. - Aliæ mutationes e statione pendent; humidiori magis virides, raro typice evolute; justo siccioribus albescentes

6) Possumus ad scalam allatam sæpe facile explicare colores recedentes, computando typicum rubrum cum colore thalli \& disci crassitie, v. c. in Imbricariis, Placodiis. "Unico exemplo sit Parm. olivacéa, cujus discus sterilior thallo concolor, perfectior inter colorem thalli \& rufum colore intermedius; rufus in disco crassiori P. Acetabuli prodit. In Parmeliis citrinis discus subaurantiacus; thallo vero tenuiori apotheciisque magis liberatis saturatior fit ( $P$. cerina $c_{\text {. }}$ ) \& rubet ( $P$. parietina $\beta ., \quad P$. aurantiaca \&c). Inde facile intelligitur Parm. varice saxicolce \&c. discus crassus ruber, macer lutescens, sterilis virescens; cum semper crassus Parm. straminece, ventosae \&c. seriem normalem constanter sequitur. Hinc porro formæ Biatorinæ, v. c. Parm. badioe, trium priorum serierum rufo-fuscescunt $\&$ hæc caussa est cur infimas proles $P$. subfusca, varioe \&c. discernere non liceat. Lucis wis in disci colorem fere nulla est! 
formæ leguntur. Color albus ex omni serie oritur, sed normalem numquam inveni. $C f r$. $\int s q$. Series glauca tamen magis candicat, fusca in griseum vergit, ochroleuca albescit. Occurrunt quoque formæ lutescentes, potius in ochraceum quam virescentem vergentes Lichenum glaucorum v. c. Parm. subfusce, frustulose, qua vero deliquescentes in lepram albam abeunt 7). E vario lucis stimulo thallus tam expallet, quam saturatur, sed hoc sub certa lege comprehendere non licuit; alia species v. c. Parm. chrysophthat ma, chlorophana in luce expallent, in qua $P$. parietina \& murorum intensius coloratæ evadunt. Mulı quidem in tropicis eximiis nitent coloribus; aliæ vero quo nagis occultis \& frigidis locis occurrunt, eo intensius coloratæ, v. c. Biatora lucida, Parmelia chlorophana, Lecid. Wahlenbergii, Calicium corynellum, ut calori \& luci unice haud tribuendum sit. Singulæ seriei variationis cyclus ex usu optime addiscitur; in genere glauca pallide viridis, glaucus, coerulescens, stanneus, albus; fuscae saturate viridis, olivaceus, cinereus, griseo-fuscus, badius; ochroleuca flavovirens, ochroleucus, albescens; citrince viridi-luteus, aurantius, miniatus.

§. 56. Magis adhuc fallaces colores prorsus peregrini, quibus multa individua tota imbuta \&

7) Cum color thalli nativus in Parmeliis personatus sit, normalis tamen vulgo in excipulo thallode prodit.

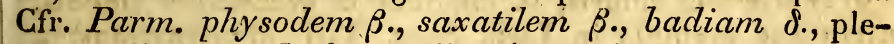
rasque citrinas. In hac serie color typicus tam fugax est, ut non nisi rarissime observetur v. c. in Parm. ferruginea, Evernia villosa, quare e disci tutius dignoscitur. Hypothallum in colorem thalli agere perevidens est; ab illo vulgo pendet niger. Parm. physodes $\beta, P$. stygic $\beta$, \&c. totæ passim nigrescentes, pagina superiori exclusa, monstrant tantum thallinam. 
larvata occurrunt 8). Primi inter hos citandi ab oxidis inorganicis pendentes, quæ colorem normalem (\& subinde formam; legimus "Endocarp. sinopicum" crystalla ferri prorsus referens) ab majorem affinitatem ad thallum Lichenum prorsus tollunt. Experimentis directis \& passiva observatione hæ rationes sane extra dubium positæ sunt. Ex his præcipuæ: a) oxidi ferrici aut ferrosi, s. potius hydratis, a quo omues crustæ rubro- \& ochraceo-ferruginosæ pendent 9) - b) oxidi mangani, e quo; teste Meyero,. derivantur crustee rosea \& purpurascentes 10) - c) carbonatis calcici, causse crustarum cretaceo-albarum in saxis calcareis vulgatissimarum, sæepius connexarum cum statu thalli atypico amylaceo. Etiam ad latera umbrosa rupium, ubi oxygenii exspiratio lucis defectu impeditur, crusta anylacee \& lacteæ. - Vix minus frequentes decolorationes a Byssis (S. O. V.) parasitantibus, e quibus color crustarum rubellus, ruber, rarius aureus, sed siccus semper æruginoso-canescens. Infestant præcipue corticolas, v. c. Opegraphas, sed etiam Liecideas, qualis status Lecid. Dilleniana. E Wallrothio Byssus ipsa est anamorphosis gonidiorun. - Porro sæpe thallus vel ab hypothallo stio

8) Hanc materiem copiose \& eximie tractavit Meyer. Miror acutissimum Wallrothium de oxydatione, re a plerisque perspecta, licet in speciali expositione haud recepta, dubitare. Cfr. Lich. Eur. p. 329.

9) Varietates coloris, \& chemice \& mechanice imbuti, (utriusque exempla in Lich. Suec. XIII divulgavimus) a diversa oxidationis forma pendent. Color peregrinus mechanice imbutus etiam in ligno observatur, simul vulgo apothecia obducens; chemice decornpositus tantum in sa$x$ is apotheciis immutatis; quem hactenus in specc. hypothallo nigro tantum vidi.

10) Smith, autonomiam primus negans, ab urina adspersa deduxit. Transact, Linn. Soc. II. p. 11. 
soluto vel a lepra peregrina, chlorococco e. s. p. inficiuntur. Omnia harum exempla libri practice parti reservata sunt. - Tandern e succo profluente arborum, v. c. Parmeliam saxatilem, $O$. pegrapham variam, rufofuscas tinctas vidimus. (Chemicas coloris mutationes in usum technicum ad sequens caput reservamus). - In summa, vitæ color inter Lichenes est viridis, qui sub aspero calo tristiori, sub lætiori vero splendidiori involucro vulgo obducitur; fructificationis ruber in nigrum regressivus; thalli vero morientis niveus, ut ipsius naturæ in optima Lichenum patria. Caput XV. Qualitates Lichenum 1). 5. 57. Sub frigido Arctois cœlo, cujus sole obliquis radiis brevi visente natura vix reviviscit, inhospita tesqua aborigines incoluere nomades, quorum, vitam tantum tolerantium, universa facile oeconomia Rangifero (Cervo tarando), omnia ad victum amictumque subministrante, nititur. Vescitur vero hic præcipue, \& per quattuor quintas anni partes unice, Lichenibus, inter quos uberrima Cladonia rangiferina celebratissima, licet reliquas species fruticulosas, filamentosas \& foliaceas non spernat, a quibus ultimis orbis vegetabilis colonis itaque pendet ultimas terras esse habitabiles. (Linn. Fl. Lapp. n. 456). At in regionibus montanis omne boum genus, tam ferum (Buffon Hist. Nat. XIV. p. 333), quam mansuetum Lichenibus non victitat tantum, sed

1) Hanc libelli potius materiem absolvere non in animo est, sed tantum conspectum historice proponere. Plura collegerunt Hagen in Hist. Lich. Pruss. Amoureux sur l'utilité des Lichens. Lyon 1787, Hoffmann de vario Lichenum usu. Erlang. 1786, Luyken Histor. Lich., Retzius in Flora Oeconomica Suecix Lund. 1806, Westring Svenska Lafvarnes färghistoria, Stockh. 1805. \&c. 
mire etiam pinguescit (Cfr. Scopol. Ann. Hist. Nat. 2. p. (1 12!) 2). Errantes quoque sine oeconomia Indiani Americre borealis ipsi demum Lichenibus, speciatim Umbilicariis, vescuntur. ( $\mathrm{Kalm}$, Richardson). In naturæ igitur oeconomia, private fundamento, Lichenes summi sunt ponderis; facile insuper adderes eosdem prima stamina humi, futuræ vegetationis subsidia, parare (Linn. Amcen. Ac. II. p. 25); plantas tenellas alpinas tueri; ad arenam volatilem coërcendam conducere (Lidbeck de aren. vol.); aviculis nidos, insectis refugium (Gleditsch Forstw.) offerre. An $\mathrm{Li}_{-}$ chenes arboribus sint detrimento, quastioni a Lid. beck speciatim tractatæ, sæpeque repetitæ plane negando non respondendum.

5. 58. Debiles hyperboreos attingunt sollertiores gentes, vita etiam frui studentes; quare naturæ adhuc acerba, non vero noverce ingenii vires frangentis, vincendæ gratia ad agendum potissimum stimulantur \& naturæ dona, inter quæ Lichenum copie, periculis \& experimentis in practicum, magis complicatum, usum convertere studuerunt. Hinc fere omnia, hac via de Lichenum usu inventa, Germano-Scandinavis debentur. Usus Lichenum in tinctoriis primarius \& multiplex antiquitus in Scandinavia cognitus fuit; primo exposuit Linder (Färgkonst Stockh. 1718), dein Linnceus (ölänska \&c. Resa), varia addidit Holmberger, tandemque innumeris experimentis auxit Westring (Svenska Lafvarnes Färghistoria). In Europa australi vim tinctoriam Roccelloe \& Parellae ut cognitam jam Patres memorant. Sed etiam in aliis technologiæ partibus pollent, v. c. igelatina Lichenosa in arte texendi, atramentum

2) Etian in desertis Africæ Antilopæ Lichenibus victitant. $C f r, p .212$. 
sinense ab Umbilicaria pustulata præparatum e. s. p. Olim e Lichenibus pulvis cyprius parabatur. Ceterum memorantur tanini Lichenum usus ad corii præparationem, principium amarum Stictce pulmonacea ut humuli succedaneum (Gmel. Russ. Reis. 3. p. 426) aliaque minus probata. - Sed prestantissimam ad panem cibumque esse Cetrariam Islandicam, quod Islandis (etiam alias species usitantibus) primum innotuit, certissimum est, æque ac eandem specificum esse remedium in febri hectica, tabie \&c., diu in Suecia probatum. Sed Parmelia parietina laudes suas ut Cinchonæ plenum succedaneum, auctore Sanders, apud Medicos nostros baud sustinuit. Vis tamen febrifuga variarum specierum, novis experimentis exploranda, vix dubia est.

5. 59. Sub ea solis zona, in qua natura ipsa est continua \& almæ varietatis lusus, inter lautiora naturæe munera Lichenes ser se parum momentosi, sed incolæ, ad vitam jucundam a natura ipsa invitati, prími ad rerum caussas \& nexus cognoscendos expergefacti prima scientiarum semina sparserunt. Non offendat, quod prima stamina in nudam speculationem aberrarunt; nec quod invaluit apud primos Botanices restitutores symbolica naturæe contemplatio s. physiognomistica, a Neapolitano Porta in systema absoluta, per quam naturæ ipsius, ut ita dicam, homceopathia plantarum vires eruere sluduerunt. Inde ortæ sunt perhibita vires Peltigerce aphthosa, ob soredia, contra aphthas, Pelt. canince contra hydrophobiam, Usnece barb. hirtce ad capillos firmandos, $U$. $b$. plicato contra plicam polonicam, Lichenum citrinorum contra iclerum e. s. p., quarum fontes ideo tantum apesire placuit, quod ad nostrum usque ævum in scriptis philantropico boianicis re- 
petuntur 3). Ex idearum sympatheticarum connubio cum superstitiosi ævi, Paracelso duce, ortæ sunt portentosæ vires "Musci cranii huma$n i "$ 4); nec longe abest vis venenata Evernice vulpinae, septentrionalibus tantum cognita, cum apud eos in templis tantum obveniat. Ut esca ad lupos necandos superstitiosa sapit.

5. 6o. Nullius denique regionis sunt "scientiarum tropæa," experientixe fructus in formans theoreticam concinnati. Earum est rationem rerum explorare, leges exponere, vera a falsis discernere. Pandit in hac parte viam Decandolle \& vix alia familia ejus theoriam magis restimat, quam Lichenum; exclusis nempe Collemaceis \& Byssaceis et hac ratione contrariis. Odor nullus ("Violarum" quibusdam adscriptus a Byssis parasitis oritur); paucissimis Stictis rancidus. Sapor stipticus, amaricans, Roccellae \& Ramal. scopulorum, e statione facile maritima, subsalsus. Materia tinctoria omnes in potestate pollent, at non pari gradu; deficit fere in tenuioribus \& subgelatinosis v. c. Ramal. calicari; abundat in magis crustosis, tartareis, etiam coriaceis v. c. Roccella, Ram. scopulorum. Specialiora mittamus. "At, quod maxime insigne, coloris quantitas, immo indoles, maxime mutatur 5) in diversis evolutionis

3) Solius Stictoe pulmonacere vires thoracicas, hac via inventas, v. c. a Scopolio confirmatas vidimus.

4) Vix aliquis rite cognovit, ut lapis fuisse videatur medicorum. Icones fictitixe v. c. Tabern. Kreut. 11. 288. Parkins. $p$. 1313. Tillands. Ic, $t$. 160. Dillenịo Parm. saxatilis, Linnæo (Mat. med. p. 174). P. omphalodes. Sed etiam Hypnis adscriptus est; vires, ex auctorum sententia, e loco classico.

5) Hinc fere nullus harum rationum in speciebus limitandis usus. Analogxe aberrationes diversarum specierum vi tingendi inter se isepius magis conveniunt, quam cum 
stalibus; ditissimæ sunt formæ isidioideæ, sequuntur variolarióideæ; pauperrimæ pulverulentæ, gonima \& hypothallinæ. Pendere videtur ex erythrino, resinæ specie, in aqua regre licet solubili, Lichenibus priva. Colores præbet rubros, purpureos, fascos; maxime diversos e diversa tractandi methodo. Lacmus e Lichenibus cum principio animali paratur. - Vis nutrieus, restaurans in glutine amylaceo deposita est; cum principio amaro conjuncta magis medica, febrifuga (purgans?). Plenior virium Lichenum exploratio omni altentione digna.

\section{Caput XVI. Studium Lichenum 1).}

5. 6I. Ea est progressus disciplinarum natura ratio, ut exigua initia a mera corporum contemplatione ad accuratiorem descriptionem s. distinctionem \&, rerum copia aucta, ad dispositionem transeant. Variis tentatis methodis ad criticain nature contemplationem reditur, essentialia separando, varietatum leges inquirendo, quæ reformationem secum ducunt. Diu inter Lichenes pirvaluit epocha contemplationis, cujus externus character prominet defectu scientificæ formæ, habiluali tantum objectorum designatione, sæpe simul nativo naturalis sensu. Primi Lichenum collectores eos cum Muscis \& Phyceis prorsus commiscuerunt, donec Tournefortius \& ipsos accuratius limitavit \& nornen receptum 2) eisdem

speciebus e quibus ortæ. Inde nomina "Parelle" \&c. adhuc incerta. Arcanum est, e qua specie \& quo modo Lacmus paretur; Parmelia tartarea \& sordida corallina e Suecia in Hollandiam præcipue exportantur.

1) Cfr. Luyken Historia Lichenum in genere. Grotting. 1809. fida, sine ira \& studio. Omnia singularia Lichen. Europ. reservans, genium diversum scientix levi manu tantum adumbrare volui.

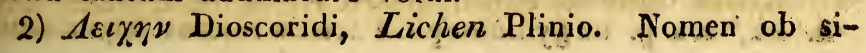


adfixit. Licet non spernenda sint studia Moriso ni, Raji, Vaillantii \&c., omnem hujus epochæ literaturam, parum fructuosam, assimilavit Dillenius, ut raro ultra ipsum regredi opus sit; si exceperis Michelium, cui ob majorem subtilitatem minus favebat. Michelius, hujus epochæe fastigium, disjecta membra in sectiones eximias redegit, (Cfr. p. 46r), fructificationem analytice examinavit, plures nitide delineandas curavit, sed ad ævi Tournefortiani genium species \& formas accidentales non distinxit, nullas adjecit descriptiones, ut plurimæ phrases caput mortuum sistant. At Michelii merita de omnibus plantarum Homonemearum familiis eo magis præfulgent, quod a proximis non visebantur.

§. 62. Ex herculeis Michelii laboribus cuique rem Lichenologicam pertentanti manifestum erat, prisca via non sufficere progredi, sed novam specierum accuratiori limitatione $\&$ definitione 'esse aperiundam. Provocabant igitur suurn oppositum, epocham descriptionis ( $1740-179^{\circ}$ circiter), qux omnes nervos, captivo subinde ingenio, ad species religiose limitandas earumque characte. res eruendos tendebat. Evidens prodit hæc oppositio in Dillenii Historia Muscorum (\& Algarum) Oxon. I $74 \mathrm{r}$, opere classico, hujus epochæ oraculo Lichenologico semperque fundamento, cui paucas habemus pares monographias, sive accuratum naturæ examen, sive plenum literaturæ ap

militudínem crustaceorum \& usum simul ad morbum, Lichenem dictum, sanandum ( $(5.59)$. Physiologia sub hac epocha vix orta. Porta, physiognomista idem, qui sporidia Hymenomy̆cetum primus vidit, Lichenum prima stamina, Michelius gonidiorum reproductionem observarunt. Mera phantasmata, v. c. Lichenes explicati per 'm teriem excrementitiam terræ, petris \& arboribus in'ditam," e. s. p. ut gymnosophiæ tristia restant monumenta. 
paratum, sive denique ceneam ipsius diligentiam in iconibus concinnandis spectaveris. Genera tria \& dispositio ex operis clave (p. 464-468) perspiciuntur. Hoc ævo novus in septentrione oritur Botanices sol, qui in Lichenes radios quoque spargit. Nativa ingenii affinitate ideas Michelii curn definito apud Dillenium conjungebat Linnceus 3). Hos antesignanos sequentes assecla in specierum justa limitatione versantur, nulla essentiali formæe variatione suscepta. Priecipue notandi: Haller (magis autonomus), Scopoli, Gouan, Hudson, Necker, Weiss, Schreber, Lightfooth, Weber, Hagen, Ehrhart, Dickson, Villars, Swartz, Smith \& precipue Wulfen. Theorematum, magis propositorum, quam demonstratorum, sub hac epocha faciem fideliter adumbrat Hagen. (Lich. Pruss.). Ut ideæ Lichenum proğressus notanda preciptie separatio a Muscis.

5. 63. Auctis specierum copiis prisca Linnæana simplicitas amissa est, molestiæque examinantis tam multiplicatæ sunt, ut sine plena confusione hac via pergere non liceret. Plura genera \& hæc ordinantem ideam necessitas urgebat, justitiam accuratior fructus analysis, duce Hedwigio, evincebat. In his inquirendis cardo novae epochæ (circiter $1799-1825)$, hinc dispositionis dictæ, vertebatur. Sunt quoque omnes hanc spectantes rationes tam depugnatie, ut recentiores

3) Sexualitem, generis integritatem \&c. cum Micheliò statuit; Calicieas Mucoris \& status leprosos Byssi species dixit. In specialibus ultra Dillenium raro digressus est, at multa apud illum eximia neglexit. Magis hine formam, quam materiem spectant Lichenum studia Linnæana. Sectiones Linnæanæ: Leprosi tuberculati, scutellati, Imbricati, Foliacei, Coriacei, Umbilicati, Scyphiferi, Fruticulosi, Filamentosi. Paulo mutavit, Byssos subjungens, Haller. 
pro novis, auctis licet \& emendatis, modis tantum habendæ sint 4). Jam pridern generum nonullorum distinctionem tentaverant Hill $\left(I_{75} \mathrm{I}\right) \&$ Adanson ( 1763$)$, sed altioris indagationis \& suc. cessus erant supra laudati Weberi (Flor. Hols.), Willdenowii (Flor. Ber.) \& Humboldtii (Flor. Friburg.) conamina, quibus varia genera perennia debentur. Plenam vero reformationem primus moliri cepit G. F. Hoffmann; non sine coætaneorum applausu, at methodus fere nulla est, ge. nera vaga \& thallina, demum vero (Deutschl. Fl. 1795) Persoonii \& Schraderi studia adjecit. Hi nempe veræ reformationı fundatores censendi; primi genera, quæ perennabunt, dispositionem, quæ reviviscit, e vero fructificationis principio deduxerunt. Eximiis iconibus de Lichenologia bene meritus est Hoffmann 5). Pre ceteris laude inclaruerunt Acharius \& Flörke, quorum ille hanc disciplinam, omnia otia Lichenibus determinandis dicans, maxime, \& nimis facile, auxit;

4) Ad conspectum facilitandum dispositionum varietates ad has classes referri possunt:

a. Thallus primarius. (Dillenius, Linnoeus). Acharius in Prodromo. Agardh. Delise. Chevallier.

b. Apothecia sectiones quasdam superiores segregant, reliquis e thallo dispositis. Hoffmann, vere Angiocarpos a Stellatis separans. Decandolle, Graphidea's, Verrucarias \& Pertusariam sub Нypoxylorum familia cum Pyrenomycetibus jungens. Eschweiler Syst. Lich. - F'ée. Cfr. Variat. IV.p. 12.

c. Excipulum primarium. Wahlenberg (FI. Lapp. p. 400). Acharius meth. \& Lichenograph. univ. Cfr. Var. II. p. 10.

d. Thalamium primarium. (Michelius). Persoon. Schrader. Luyken. Fries. Mever.

5) Nimis brevi obfuscata sunt Hoffmanni merita, pro parte forsan ob modum minus aptum, quo solidiora studia supprimere studuit. Cfr. Schrad. Journ. Bot.1799. 
hic, Lichenographiæ in Germania stator ibidemque renatæ Pater, naturam diligentissime observavit 6). At non horum tantum studiis, sed plurimorum observatorum cura species admodum adauctæ sunt, v. c. Wahlenbergii (multos revi errores evitantis), Turneri \& Borreri, Ramondii, Decandollei, Dufourei, Sommerfeltii 7). Cum vero specierum limitatio ex ipsius æevi genio secundi ordinis facta esset, ejus notio simul nimis relaxata est. Prestantissima hujus epochæe in parte theoretica collegit Luyken l. c.; alia quædam pericula, sub physiologia nomine collaudata, in quibus nomina \& res quasdam notas offendimus, sed sub peregrino involucro, ad veram se habent, ut narrationes s. d. Wawerleyanæ ad veram historiam. Hujus epochæ corollaria censenda: Lichenes a Phyceis diversam sistere familiam, eosdem in plura necesse collabi genera, partium accuratius examen, dispositionis fundamenta e. s. p.

6) Flörkeana studia nobis parum cognita esse dolemus. De Acharianis, non beneficiorum tantum memor, sed persuasionis caussa omnino assentimur cel. Fée "quelquesunes critiques sont trop severes, quelques autres sont injustes." Ex se singmhum ærum judicabitur. Nondum scientiæ evolutio tam maturitatem accelerata, ut plene. sapere licuerit; multa nobis sunt indicia Acharium nova via præiisse nisi in molimine "Histarioe Lichenum" (minime "Victoriæ Lichenum," ut exclamatum vidimus) scientiæ ereptus fuisset. Sublimis est omnis historiæ veritas excessum involvere emendationem \& magis condolescamus, quam vituperemus, quorum int egris studiis scientiarum genius ad illum perficiendum utitur. Laudanda mihi videtur separatio Isidii, Variolarioe, Arthonice e. s. p. a formis typicis; jain hæc progressus erat, veræ Historiæ necesse antecedens.

7) Omisimus hoc loco eximias symbolas specierum extra-europearum cura Acharii, Delisei \& præcipue Féei. Spolia Brasiliensia Martii nondum plene distribuit Eschweiler. 
5. 64. Salva presentis sæeculi erga antecedens fide \& religione facile predicemus Lichenographiam sub his auspiciis magis ambitu, quam fundo, crevisse, præcipue cum plurimi ejus cultores ipsi perspexerint ejus statum, qui non felix erat. Inde orta est presens epocha reformationis, non quasi hrec uno gradu aut adulta (adhuc in adolescentia est) nata esset; nam dispersa \& accuratissimæ supra laudatorum virorum, Schaereri, \&c. observationes, Eschweileri analyses collatæ \& in integrum fusæ ad receptæ constitutionis emendationem \& ad naturæ contemplationem, priorum errorum exemplo edoctam, necesse reducerent, \& quidem ad eadem materiei corollaria, sed in diversis ingeniis diverso modo refracta. Vera sunt natura, errores cuique Auctori tantum privi. At eis nos decet gratulari, eos ut naturam amare, quibus hrec ut clientibus adyta sua aperuit. Ut hujus epochæ heroes in republica Lichenologix eminent $W$ allroth \& Meyer; sed plenius, facile prematurum, judicium suspendo, cum sæpe demonstratum sit, neminem eorum, quorum ipse se partem fuisse fingit, integram conscribere posse historiam, quod periclitetur tam suis symbolis nimium tribuere, quam, eliam si se $\alpha \pi \alpha \vartheta$ ov sentiret, thermometrum tantum, ad mutatas rationes oscillans, plus minus grati in collegas animi sistere. Varias symbolas attulerunt Stenhammar, Flotow, Laurer. Est syus reformationi character in studio physiologix \& morphologiæ funditus excipiendarum, primariorum a secundariis, distinctione, in nisu genera \& species ad naturam reducendi. Sed cum precedenti epochæ cautela in separando commendanda esset, nostræ ob oppositum genium in conjungendo; hic enim vi rerum in alterum excessum, quo quidem in diem imperatur sed contrareformationis semina sparguntur, vulgo tendit. At futura Lichenologix fata latent. Speramus fore, ut tenera, amabilis instar sponsæe, scientiæe amabili fructifera efflorescat. Vovemus, ut hujus cultores, quibus in hæreditatem \& principatum tradita est natura, insitæ huic obsequendi \& imperandi simul virtuti non diffidant. 


\section{CLAVIS}

\section{dispositionis Lichenum Europæorum.}

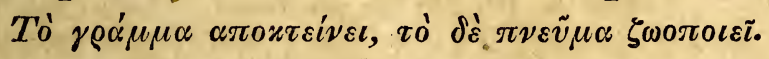
Ord. I. GYMNOCARPI. Schrad. (p. 15). CHAR. Apothecia aperta, discifera. Trib. I. PARMELIACEE. Discus subrotundus, persistens, ab excipulo thallode marginatus. (p. 15).

A. Usneacea Eschw. Discus apertus. Thallus subverticalis (aut pendulo-sarmentosus), centripetus, hypothallo destitutus.

I. USNEA. A pothecia orbiculata, peltata ; discus apertus, strato medullari filamentoso impositus. - Stratum thalli corticale a medullari filamentoso secedens. (p. 17).

Spec. n. 1. (p. 18. glauca).

II. EVERNIA. Apothecia orbiculata, scutelliformia ; discus apertus, strato medullari floccoso impositus, coloratus - Thallus stuppeus, fistulosus aut strato medullari floccoso contiguo farctus. (p. 19).

1. Cornicularice. Dec. fruticulosæ (aut sarmentosæ) apoth. lateralibus. Spec. fuscae. n. 2, 3.-ochroleucae 4, 5. - citrina. 6. (p. 20-23)

2. Duf fourea. Ach. fruticulosæ, inflatæ, apoth. terminalibus. Sp. ochroleucae n. 7. \& * (p. 24).

3. Physcice. Dec. foliaceo-compressæ, (flamentosæ semper steriles) subtus canalicul. Spec. glaucae 10, 11 - ochroleucce 8, 9. - citrince 12, 13. (p. 25-28.) III. RAMALINA. *) Apothecia orbiculata, scutelliformia;

*) Deest in Europa hujus sectio Cornicularia, sed tam hanc, quam priorum generum species e seriebus coloris in Europa deficirneibus extrueuropteas habemus. 
discus strato gonimo (viridi) impositus subconcolor. Thallus subcartilagineus, undique fertilis et similaris. (p. 28).

1. Dufourea. ut supr. Sp. ochroleuca. n. 16. (p. 29).

2. Physcice ut supr. Sp. glauca n. 16-18. (p. 20-32).

IV. ROCCELLA. Apothecia orbiculata, scutelliformia; discus strato carbonaceo impositus, ater pruinosus - Thallus cartilagineo-coriaceus. (p. 33).

Spec. glaucae n. 19, 20. (p. 33, 34).

V. CETRARIA. Apothecia oblique marginata, peltæformia, nuda. Thallus adscendens, subtus glaber. (p. 34).

1. Cartilaginea, suberectæ. Sp. fuscae n. 21-24. ochroleucae 25, 26. (p. 34-38).

2. Membranacea, steriles depressæ. Sp. glauca n. 27, fusca n. 28, ochroleuca (p. 40, 410) citrinoe n. 29, 30. (p. 40).

B. Parmeliece. Eschw. Discus clausus, dein discoideo-apertus. Thallus horizontalis, centrifugus, hypothallo instructus!

VI. PELTIGERA. Apothecia peltæformia, innata, vel infera vel velo membranaceo secedente obtecta. Thallus frondosus, coriaceus, subtus villosus, sapius venosus, sine cyphellis (p. 41).

1. Nephroma. Ach. peltis posticis. Spec. fusca $n$. 32. ochroleuca. n. 31. (p. 42).

2. Peltidea. Ach. peltis anticis. Spec. subglauca n. $33-39$. (p. 43-48).

3. Solorina. Ach peltis discoideis. Spec. glauca n. 41 , crocer 40 . (p. 48, 49).

VII. STICTA. Apothecia nuclei instar infra stratum gonimon oriunda, dein prorumpentia disciformia, nuda, excipulo thallode subdiscolori. Thalius frondosus, coricceus, subtus villosus, avenius, sapius cum cyphellis. (p. 49).

* Cyphellis normalibus luteis. Sp. n. 42. (p. 50).

*** - - maculaform. spurius. Sp. n. $43,44,46 .(p .51,52)$.

***** - accidentalibus aut o. Sp. n. 47, 4s. (p. 54, 55).

VIII. PARMELIA. A pothecia scutelliformia, primitus clausa, margine thallo concolori. Stratum carbonaceum sub disco nullum. Thallus foliaceus aut crustaceus, subtus discolor $l$. adnatus, absque venis et cyphellis. Ulterius ex apotheciis dividendum; 
quo vero in præsenti noǹ satis plano emendavi tantum receptas sectiones ( $\mathrm{Cfr}$. p. 56).

Sect. I. Thaillo foliaceo discreto adnatus hypothallus.

1. Imbricaria. Discus membranaceus, nudus, strato gonimo impositus. Thallus foliaceus, membranaceus, imbricatus. (p. 57).

* Glaucescentes. Sp. 49-56.(p. 58-64).

** Oliqaceo-fusca. Sp. 57-61 (p.65-68).

*** O chrole u ca. Sp. 62-66 (p. 69-71).

***** Citrina. Sp. 67, 68. (p. 72-75).

2. Physcia. Discus ceraceus, subpruinato-velatus, strato medullari impositus. Thallus foliaceus, stellatus, var. adscendens. (p. 76).

Spec. $69-78$. (p. 76-86).

Sect. II. Thallus foliaceus membranaceus, dein granuloso-conglobatus. Hypothallus fibrillosus matrici adnatus. Plurimoe spec. sunt Biatoroe personatce.

3. Amphiloma. Thallus platyphyllinus. Excipulum thallodes accessorium. (p. 87).

Spec. 79-81. (p. 87, 88).

4. Psoroma. Thallus minute squamulosus. Apothecia biformia; e squamulis orta margine thallode; ex hypothallo margine proprio. (p. 89).

* Glaucescentes. Spec. 82-86. (p. 90-94).

** Olivaceo-fuscae. Spec. 87-89. (p. 95-97).

**** Citrina e. Spec. 90, 91. Vere Parmel. (p. 98).

Sect. III. Thallus crustaceus, squamuloso-aut in ambitu effiguratus. Hypothallus glaber.

5. Placodium. Apothecia plano-scutellata, disco immarginato nudo. Imbricariis et Biatoris accedentes. (p. 99).

* G la uc e scentes. Spec. 92-100. (p. 99-105).

** Olivaceo-fuscescentes. Sp. 101-106. (p. 106-109).

*** Ochrole uciae. Sp. 107-112. (p. 109-113).

**** Citrina e. Sp. 113-118. (p. 114-121).

6. Psora. Apothecia ex urceolato scutellata, disco marginato normaliter cæsio-pruinoso. Physciis et Lecideis affines. (p. 112).

* Glaucescentes. Spec. 119-123. (p. 122-125).

** Olip a c e o-fusc. Spec. 124-126. (1). 126-128).

*** O chrolé uca. Spec. 12\%. (p.129).

**** Citrina. Spec. 128. (p. 130).

Sect. IV. Thallus crustaceus, uniformis.

7. Patellar ia. A pothecia plano-scutellata, disco immarginato, haud cæsio-pruinoso. Placodiis Biatorisque acced unt. (p. 131). 
Glaucescentes. Spec. 129-13\%. (p. 132-145).

** Olivac eo-fusc. Spec. 138-145. (p. 146-152).

*** Ochroleuca e. Spec. 146-153. (p. 153-161).

**** Citrina e. Spec. 154-160. (p. 161-172).

8. Urceolaric. Apothecia immersa, suburceolata aut tuberculoso-protuberantia, disco submarginato cæsiopruinoso. Psoris et Lecideis affines (p. 170).

Spec. subglaucoe 171-175. (p. 177-193).

Appendix: Thallo obliterato. (p. 173-176).

IX. DIRINA. Apothecia scutelliformia, primitus tuberculosa, margine thallo concolori. Discus strato carbonaceo receptus. Thallus crustaceus (p. 193).

Spec. 176. (p. 194).

X. GYALECTA. Apothecia urceolata, primo clausa, dein varie dehiscentia, limbo libero colorato cingentia discum e gelatinoso rigescentem. Thallus crustaceus. (p. 194).

Spec. 177-181. (p. 195-199).

Trib. II. LECIDINE. Discus subrotundus, persistens, excipulum proprium primitus apertum demum subobtegens, cephaloideus. ( $p$. I.98).

XI. STEREOGAULON. Apothecia turbinata, demum cephaloidea, solida, podetiis solidis intus filamentosis suffulta. (p. 200).

Spec. 182-189. (p. 201-205).

XII. CLADONIA. Apothecia scyphuliformia, mox cephaloidea inflata, nuda (sæpe symphycarpeo-difformia), podetiis fistulosis inanibus suffulta. (p. 205). Thallus primitivus squamulosus (Sp. 190-210) aut crustaceus (211-213).

* Gla uce scentes. Apoth. rufis. Spec. foliacea 190-192. (p. 212 -215.) et thallo crustaceo. Sp. 213. (p. 245).

** Fuscescentes. Apoth. fuscis. Sp. thallo squamuloso: 193-201. (p. 216-231) et crustac. evanido: $n .211 .(p .243)$.

*** O ch roleucae. Apoth. carneo-pallidis. Sp. squamulose: 202204 (p. 232-235.) et crustucea: n. 212. (p. 294).

**** Coccifer a e. Apoth. coccineis. Sp. 205-210. (p: 236-241).

XIII. BROMYCES. A pothecia globosa, immarginata, inania, velata, basi stipitem arcte amplectentia. Thallus mere horizontalis crustaceus. (p. 246).

Spec. n. 214. (p. 246).

XIV. BIATORA. Apothecia discoidea, solida ceracea, nuda, margine proprio ceraceo (disco pallidiori) sæpius demum excluso cephaloidea. Thallus mere horizontalis (foliaceus l.) subcrustaceus. (p. 247). 


\section{DISPOSITIONIS.}

[A. Foliacece, thallo membranaceo, demum conglobato, perfectissimæ simul margine thallode instructæ. Zeora. p. 86. sub Parmelia.

Spec. n. $79-89 .-$ (p. 87-97).

B. Crustacece. Biatoræ veræ].

Sect. I. Thallo effigurato.

* Glauce scentes. Spec. stipitatre: n. 224-226. (p. 256, 257.) l. sessiles: $215-21 \%(p .251,252)$.

** Fu sc escentes. Spec. 218-223. (p. 252-255).

**** (Citrinae. Spec. 116-118. p. 118, 119).

Sect. II. Thallo crustaceo, uniformi.

* G la ucescentes. Spec. 227-238. (p. 258-270).

** Fuscescentes. Spec. 239-244. (p. 271-276).

*** Ochroleucat. Spec. 245-248. (p. 277-279).

(**** Citrinae. Spec. 156, 158, 160. p. 164, 165, 170).

XV. LECIDEA. Apothecia primitus aperta, patellæformia aut hemisphærica, excipulo proprio carbonaceo aterrimo marginata. Discus contiguus, æquabilis, raro papillatus, corneus (aut ceraceus, margine atro). T'hallus crustaceus. (p. 281).

Sect. I. Thallo effigurato.

* Glauce scentes. Spec. 249-254. (p. 284-287).

** Fuscescentes. Spec. 255-257. (p. 288, 289).

*** Ochroleuca. Spec. 258. ( $p .290)$.

**** Citrina e. Spec. 259, 260 . (p. 291).

Sect. II. Thallo uniformi.

Trib. I. Areolatoe. Hypothallus niger. Crusta subinnata. Apothecia in statu perfectissimo patellata. (p. 293).

* Gl auc escentes. Saxicola. Spec. 261-267. (p. 295-308). Corticole, $S p$. 285-287. ( $p$. 329-331).

* Fuscescentes, in cinereum etc. quoque decolorate. Sp. 268274. (p. 310-319). Cfr. n. 394. c.

*** Ochrols uca e. Sp. 275-280. (p. 320-324).

**** Citri na a. Sp. 281-284. (p. 325-327).

Trib. II. Granulosae. Hypothallus pallidus. Crusta libera, perfecta granuloso-tartarea. Apothecia perfecta hemisphærica (p. 334).

* G la u c a e, candicanics. Sp. 2S8-292. (p.334-338). C fr. n. 402.*.

** Fu sc a e, cinerascentes. Sp. 293-296. (p. 339-344).

*** Ochroleucale. Sp. $297-299$. (p. 344, 345).

***** Citrinae. Sp. 300 et $+(p .346)$.

UMBILICARIA. n. XVI.

Trib. III. GRAPHIDE $\mathbb{E}$. Discus difformis, sæpius lirellaformis, excipulo (in nostris) proprio (aut nullo). Tribus artificialis, nostrce Lecidina de generata (p. 359).

XVI. UMBILICARIA. Apothecia varia, primitus clausa, 
mox aperta, excipulo carbonaceo. Discus rimosus aut sæpius in gyros lirellasve dehiscentes abiens. Thallus horizontalis, frondosus, umbilicato-affixus, subpellatus. Genus Leeidinum personatum. (p. $347-359)$.

Spec. $301-308$. (p. 350-358).

XVII. OPEGRAPHA. Apothecia lirellæformia, excipulo proprio subcarbonaceo (atro), libero, primitus conniventi-clauso, rima longitudinali dein aperta, disco canaliculato. Thallus crustaceus. (p. 361).

* Apoth. superficialibus, excipulo thallode 0. Spec. 309-313. (p. 361 -369).

** Apoth. erumpentibus, margine thallode spurio distante. Sp. 314316. (p. 370, 371).

Accedunt abnormes excipulo cum disco confuso, Ustaliis exoticis affines.

Spec. 317, 318., (p. 372, 373).

XVIII. LECANACTIS. Apothecia difformia, elongatave, excipulo proprio carbonaceo (atro) semper aperto cum thallo connato; disco planiusculo pruinoso-velato. Thall. crust. (p. 274).

Spec. 319-322. (p. 275-277). Cfr. n. 166.

* CONIANGIUM. Apothecia adpressa, difformia, suboblonga, immarginata, lamina persistente sporos coloratos obtegente. Thall. crust. - Genus atypicum. (p. 377).

* CONIOCARPON. Apothecia adpressa, difformia, lirellæformiave, lamina rumpente in soros spororum coloratorum fatiscentia. Genus forsum spurium. ( $p$. $378)$.

Trib. IV. CALICIE E. Discus globosus aut orbicularis, in sporidia nuda collabens, excipulo proprio. Lecidinarum quasi degeneratio proecipitata. (p. 38ז.)

XIX. CONIOCYBE. A pothecia sphærica, stipitata, immarginata, e vertice fatiscentia, excipulo suberoso. (p. 382). Spec. 323-326. (p. 382-384).

XX. CALICIUM. A pothecia crateriformia, excipulo proprio carbonaceo marginata, disco in sporidia nuda colJapso. (p. 384).

Sect. I. Substipitata.

* Apoth. glaucopruinosis. Spec. 327-331. (p. 386-389).

** Apoth. fuscescentibus. Spec. 332-336. (p. 389 393).

*** Apoth. flavo-viridi-pruinos. Sp. 33\%-340. (p. 393).

**** Apoch. nudis, aterrimis. Sp. 341-344. (p. 398). 
Sect. II. Innata. Sp. 345-348. (p. 400).

* TRACHYLIA. Apothecia sessilia, convexa, immarginata, excipulo carbonaceo, disco pulveraceo. (p. 402).

Varii abortus priorum \&c. disco pulveraceo; Spiloma. Ach. Gfr. p. 380, 443. e. s. p.

Ord. II. ANGIOCARPI. Schrad. (p. 403). CHAR. Apothecia clausa, nucleifer .

Trib. I. SPHAROPHOREA. Excipulum mere thallodes clausum, lacero-dehiscens. Thallus vèrticalis.

XXI. SPHAROPHORON. Apothecia terminalia, sphærica, lacero-dehiscentia, nucleo pulveraceo atro (p. 404). Spec. n. 349-351. (p. 404, 405).

XXII. SIPHULA. A pothecia in apicibus thalli tumescentibus \& lacero-dehiscentibus, nucleo ceraceo-gelatinoso disparente colorato.

Spec. n. 352. (p. 406).

Trib. II. ENDOCARPEE. Excipulum mere thallodes, aut thallodes mutatum simul, clausum, ostiolo pertusum. Thallus horizontalis, primo genere excepto crustaceus. (p. 407).

XXIII. ENDOGARPON. Apothecia thallo inclusa, excipulo membranaceo pallido (thallode mutato) cingente nucleum gelatinosum coloratum. Thallus foliaceus (p. 407).

Spec. 353-358. p. (408-411). Cfr. n. 48, 101, 145, 140.

XXIV. SAGEDIA. Apothecia thallo immersa, excipulo membranaceo cum nucleo gelatinoso nigricante. ( $p$. 412).

Spec. $359-365$. (p. 412-416). Cfr. n. 137, 140. XXV. CHIODECTON. Apothecia verrucæformia, e strato thalli medullari erumpente formata, nucleos ceraceogelatinosos nigricantes includentia. ( $p$. 417).

Spec. 366. (p. 418).

XXVI. PERTUSARIA. Apothecia verrucæformia, e thallo formata, includentia nucleos $(1-00)$ nudos ceraceo-gelatinosos coloratos. p. 417.

Spec. n. $387-372$. (p. 420-426) Cfr. n. 169, 170.

* THELOTREMA. Apothecia verrucæformia, e thallo formata, dein aperta, includentia nucleum collapsodisciformem velatum. (p. 427). 
Spec. n. 373. Cfr, n. 169, 136.

Trib. III. VERRUCARIEA. Excipulum proprium, clausum (perithecium) ostiolo contiguo pertusum, nucleo deliquescente subhyalino. Thallus crustaceus.

XXVII. SEGESTRELLA. Stroma thallodes nullum. Perithecia denudata, ceraceo-membranacea, (colorata), ostiolo simplici. (p. 429).

Spec. $374-375$. (p. 429, 430).

XXVIII. VERRUCARIA. Stroma thallodes nullum. Perithecia solitaria, prominula, carbonacea (aterrima), ostiolo simplici. (p. 430).

Spec. terrestres. 376, 377. (p. 431, 432).

- saxicolae. 378-394. (p. 432-442).

- corticolae. 394-401. (p. 443-448).

Trib. IV. LIMBORIEA. Excipulum proprium carbonaceum clausum (perithecium), dein varie \& irregulariter dehiscens. Thallus crustaceus. (p. 448).

XXIX. PYRENOTHEA. Perithecia carbonacea, clausa, ostiolo pertusa, nucleum subgelatinoso-fatiscentem protrudentia, dein dehiscentia. (p. 449).

Spec. 402-404. (p. 450-452).

XXX. CLIOSTOMUM. Perithecia carbonacea, clausa collapsa rugoso-plicata, rugis demum dehiscentibus.

Spec. 405 . (p. 455).

XXXI. LIMBORIA. Perithecia carbonacea, clausa, demum a centro versus ambitum in lacinias stellatim dehiscentia. (p. 455.)

Spec. n. 406.

XXXII. STRIGULA. Perithecia carbonacea, clausa, disco collabentia. Subepiphylla. (p. 457). Sp. 407. (p. 458).

\section{Variationes Systematis.}

Systema naturale non actu, sed potentia existít. Link.

I. Minus curans singulares, pro diverso tempore \& ratione, modificationes hoc systema Schaderianum dictum vellem, cum a principiis a cel. Schradero propositis deductum sit. Hæc eadem sunt quæ secuti Luyken, Meyer \& nos ipsi, antecessorum studiorum tum nescii. Hoc loco ita propositum, ut practico Lichenum examini 
potissimum inverviat. Theoretice vero consideranti facile patet, Sphorrophoreas ab Endocarpeis haud magis differre, quam Usneacece a Parmelieis sens. strict., \& tantum ob seriem abruptam distingui; unicum genus vere e Lichenum familia fructificatione Lichince Agardh hunc liatum tolleret; porro Limborieas \& Calicieas, typice contemplatas, meras aberrationes, illas Verrucariearum, has Lecidinarum; demumque Graphideas, additis nempe generibus exoticis, esse quasi ultimas degenerationes diversarum serierum, ita facie externa inter se implexas, ut $x$ gre quidem removeantur tam a se invicem, quam a diversarum serierum generibus, cum quibus 'facile confluunt. Earum forma primitiva etiam rotunda est, secundaria elongata a variis causis (non parum a situ, teste Cenangio, inter rimas epidermidis comprimentes) derivari potest; ceterumque Umbilicarice, Parmelia ventosa \&c. testantur, quam facile apothecia typice scutelliformia in lirellas degenerent; Lecanactides, Opegrapha cerebrina \&c. Graphideas in Lecidinas (nec desunt paria exempla exoticarum ad Parmeliaceas e. s. p.) revergentes sistunt. Practico fini eas separare tamen non inutile; licet omnes systematicas differentias v. c. excipulum thallodes \& proprium, clausum \& apertum, nucleum rigescentem, deliquescentem \& fatiscentem negligant. - Quibus consideratis operæ pretium duximus, nullo charactere præcepto, Lichenum analogiæ \& affinitatis series ex statu normali et perfectissimo apotheciorum inquirere \& ad normam III. Decandolle. Cruciferarum, in series parallelas disponere, quo facto præcedens dispotio sic resolvitur:

\section{Thalamium}

A. Discoideum, receptum ab excipulo

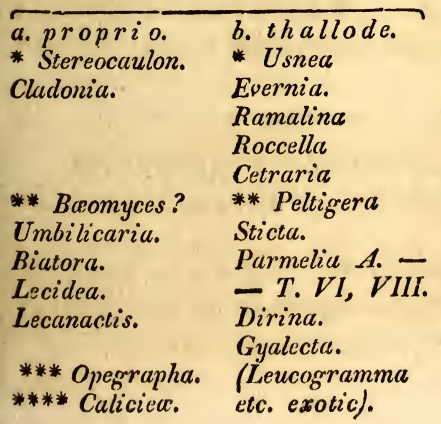

\begin{abstract}
B. Nucleiforme, receptum ab excipulo
\end{abstract}

a. thallode. b.proprio.

* Spharophoron.

Siphula.
Endocarpon.

Pertusaria.

Sagredia.

Chiodecton.

Thelocrema.

(Exot.)
** (Exotica)

Segrestrella.

Vurrucaria

Pyrenothea

Limboria.

*** (Oxystoma)

***** Strigula. 
Hoc loco Parmeliaceam seriem, ut centralem, in medio posui simulque ut ideam traderem dispositionis $\mathrm{Per}$ sooniance ad recentiores progressus accommodatx. Quo inferius descendimus eo evidentior analogia, ut hac ratione, perspecto nempe nexu, Graphideas divellere possimus. Ceterum analogia inter genera utriusque seriei tam excipulo proprio, quam thallode evidentior est, quam ex thalamio disciformi \& nucleiformi, quod sequente dispositione exponitur.

II. Si vero optaveris Systema magis physiologicum, thalamii evolutionis gradus stricte sequens, quales in Physiologia Lichenum exposui - genera omnia in simplicem seriem adaptata, ut singulum inter duo proxima, quæ aut evolutione suppressa aut supra normalem explicata refert, intrudatur - minus curans si superius collocata genera in eadem sectione re ipsa imperfectiora sint - tale facillime proponitur ad excipuli indolem, quæ thalamii evolutionem determinat. Hoc est fundamentum Systematis Achariani, quod, neglecta omnino erronea Homothalamorum sectione, sic exponendum est:

A. COENOTHALAMI. Ach. Excipulum thallodes

a. mox apertum. Thalamium semper disciforme, explanatum, immutabile. Usneacex.

Usnea. Evernia. Ramalina. Roccella. - Cetraria.

b. clausum, dein discoideo-apertum. Thalamium primitus connivente-nucleiforme, ceraceo-gelatinosum, mox explanatum, rigescens. Parmeliex.

Peltigera. Sticta. Parmelia. Dirina. Gyalecta - Thelotrema.

c. semper clausum, ostiolatum. Thalamium nucleiforme-persistens, ceraceo-gelatinosum, deliquescens. Endocarpeæ.

Pertusaria. Chiodecton. Sagedia. - Endocarpon.

d. clausum lacero-diffractum. Thalamium e nucleiformi disciforme fatiscens aut disparens. Sphxrophorex.

Sphærophoron. - Siphula.

\section{B. IDIOTHALAMI. Ach. Excipulum proprium}

a. primitus apertum, ascigerum. Thalamium ut in prioris a. Juecidinæ.

Stereocaulon. Cladonia. Bæomyces. Biatora. - Lecidea. b. clausum, mox dehiscens. 'Thalamium ut in prioris b. Limboriex reform. 
Umbilicaria. (Pyxine!) Opegrapha. Limboria. Cliostomum.

c. semper clạusum ostiolo pertusum. Thalamium ut in prioris c. Verrucarieæ.

(Genera exot. pl.) Segestrella. Verrucaria. - Pyrenothea.

d. disco fatiscens, ascis destitutum. Thalamium ut in Sphorophoro pulveraceo-solutum. Calicium. Coniocybe.

Hujus dispositionis explicatio in morphosi thalamii proposita est. Vix crederem simpliciorem, paucioribus abeirationibus obnoxiam, dispositionem uniserialem proponi posse. Perinde est utrum via progressiva, an regressiva, ut hoc loco factum sit, an paucioribus subdivisionibus, conjunctis v. c. a. \& b., proponatur. Offendit primo obtutu e recepta videndi ratione Angiocarpos \& Gymnocarpos commixtos esse, sed hoc ex eorum morphosi facile explicatur. Genera fructificatione simillima, sed excipulo proprio aut thallode (excepta nondum rite limitata Biatora, cum hujus excipulum sit thallodes mutatum) discrepantia numquam inse invicem permutari possunt v. c. T'rypethelium \& Pertusaria, Calicium \& Sphaerophoron, Limboria \& Thelotrema, S'tereocaulon \& Usnea. - Sed apothecia omnium Canothalamorum in ortu Endocarpea sunt; Parmelieoe sensu strictiori tardius ex hoc statu normalem attingunt, quare multæ harum formæ minus explicatæ pro Endocarpis, $S_{a}$ gediis \& Pertusariis adhuc habentur, ut Sticta, Parmelioe; Usneacex, ut perfectiores, hunc statum tam subito absolvunt, ut apothecia explicata primum observatori sese offerant. E contrario etiam veræ Endocarpece, typicum suum statum superantes, in Parmeliaceas abeunt, qui nisus in Thelotremate prædominatur, in Pertusariis, Endocarpis \&c., fatiscente strato corticali perfectiorem thalamii evolutionem retinente, quoque præpollet. Eadem est ratio Idiothalamorum; primitus 1 . abortiva omnium apothecia Verrucariea, \& ut Endocarpeæ evolutione ultra normalem in formas Parmeliaceas degenerant, sic etiam Verrutcaria maura, Pyrenothea leucocephala \&c. usque in Lecidinas transmutari possunt. - Formationes Isiidii omnes ad Cocnothalamos pertinent; omnia genera Fungis analoga ad Idiothalamos. e. s. p.

III. Ex ipsorum demum thalamiorum indole, immutata persistente, deliquescente, rigescente \& fatiscenbe 
Lichenes disponi possent. Cum vero e physiologica Lichenum expositione constet nucleum primitus esse ceracengelatinosum, dein vel deliquescere, vel magis explanato-disciformem rigescere aut ita obiter statum primitivum absolvere, ut immutabilis appareat, \& thalamium fatiscens tantum esse atypicun statum, cujus genera v. c. Sphcerophoron \& Calicium non, meo sensu, comparari debent, hæ aliis notis simul suffulciendæ sunt. Hinc ad Lichenes (Idiothalamos) thalamio rigescente tantum genera apotheciorum forma degenerata referenda credidi \& ad Coniothalamos Calicieas apotheciis apertis. Hac ratione omnia genera aberrantia a typicis (thalamio regulari, persistente vel deliquescente) separantur. Hanc Schraderiani Systematis modificationem in Vet. Ac. Handl. 1821. \& Syst. Orb. Veg. proposui; sed cum ex ejus operis ratione omnes differentias simul amplecti debuerim, quas hoc loco resoivi, Schraderianum ipsum magis logicum \& simplex est. - Cel. Meyer ita recedit, ut Lichenes Hymenocarpos in duas bipartiatur sectiones disco regulari rotundo \& deformato elongato, omniaque genera thalamio primitus fatiscente ad Coniocarpos refert. Cel. Sprengel Meyerianum systema ita mutavit, ut $M y e-$ locarpos Meyeri (nucleo subdeliquescente) supra Hymenocarpos collocarit, quod vero stirpium ipsarum indoli \& affinitati, ta:n thalli quam apotheciorum morphosi mihi contrarium videtur.

IV. Dispositiones e thallo vulgo malæ notæ sunt, meritoque si e thalli forma tantum 1. externis notis sumuntur. At physiologico \& phytogenetico respectu, ut a Cel. Fée, quare hoc Systema Feeanum dixerim, percepto, minime inutile videtur thalli evolutionis gradus systematice proponere \& hinc Systema thallinum simul periclitari. Acute quoddam limitatum non exspectandum est; analogia sæpe pro affinitate sumenda. Progrediendum in hoc via mathematica, sensu Linnæi, incipiendo ab infimis, sed cavendum ne fingas naturam ipsam in' $\mathrm{Li}-$ chenibus enitendis sic progressam. (Vide Syst. Orb. Veg. §. 10). Perfectiores Lichenes a Phyceis adscendant, quo imperfectiores sunt eo magis ad Hyslerophyta descendunt. Myco-Lichenes hinc dicti vulgo quoque occurrunt tantum vel in lignis putridis, vel absolute corticolæ vel in saxis præcipue formationis recentioris, v. c. Opegraphce, Verrucarioe, \& ut Fungi magis loco definito adscripti, cum Phyco-Lichenes vagantur, nullas fere privas speci- 
es habent in saxis formationis recentioris, sed varietates ad typum crustæ Myco-Lichenum deformatas plures.

\section{MYCO-LICHENES.}

Thallus e cellulis mere sphæricis constitutus, haud effiguratus, passim deficiens, serotinus aut coætaneus, subinnatus. Series chromaticæ confusæ. Excipulum thallo discolor. Thalamium: nucleus contiguus deliquescens aut collapso-disciformis. Ad Pyrenomycetes thalli obliteratione descendunt.

Trib. 1. Thallo frustraneo, serotino, primitus subentoxylo, ab apotheciis discreto. Hypothallus byssinocanescens. H. 1. Calicieae, Lecidece n. 296-299.

Trib. 2. Thallo superfluo, coætaneo, vulgo hypophloeode aut innato, nil ad peritheciorum, primo clausorum, formationem conferente. Hypothallus niger aut nullus. H. I. Limboriece, Verrucaria, Sagedia, $n$. 365, Opegrapha.

Trib. 3. Thallo necessario, hypophloode, biformi, nempe coætanæe cum thalamiis in horum stroma (discolor) protuberante \& apothecia formante. Hypothallus o. Repetitio prioris tribus in climate magis tropico; limites vix ulli. H. l. Trypetheliacese Eschw.; paucissimoe Europoece v. c. Asterisca Meyer. (n. 316), Chiodecton - \& forsitan Dirina.

\section{PHYCO-LICHENES.}

Thallus, cellulis quibusdam sæepius in cylindricos productis, in formas varias tendens, pracox, normaliter superficialis. Series chromaticæ distinctæ. Excipulum e thallo enatum, sæpe concolor. Thalamium in nucleum convolutum?, sæpius disciformi-expansum. A Phyceis adsceridunt. Trib. 4. T'hallo oequali, uniformi, horizontali ant adscendente, cum apotheciis contiguo.

* Thallo crustaceo aut foliaceo, in ortu composito, convexo aut plano, subtus undique æqualiter adhærente. H. l. Segestrella p. p., Sagedia *, Pertusaria, Thelotrema, Lecidea, Baomyces, Biatora, Gyalecta, Parmelia. 
* Thallo frondoso, in ortu simplici, concaviusculo, puncto basilari adfixo. H. 1. Endocarpon, Umbilicaria, Sticta, Peltigera, Cetraria.

Trib. 5. Thallo monostelide, uniformi, verticaliter assurgente, puncto basilari adfixo, demum subpendulo aut libero sarmentoso. H. l. Siphúla, Sphcerophoron, Roccella, Ramalina, Evernia, Usnea.

Trib. 6. T/2allo segregato ab apotheciis podetiis verticaliter assurgentibus a primario horizontali. H. I. Stereocaulon, Cladonia.

Quo perfectior Lichen, eo magis serotina sunt apothecia. Myco-Lichenes crusta passim, non apotheciis; Phyco-Lichenes apotheciis carent, non crusta, nisi hxc, ut in Lecideis, per senium vulgo obliterata; nam in Parmeliis acrustaceis excipulum saltim crustæ pars. Tribus 1-3 facile est cum Fungis confundere (non cum Phyceis) earumque nexus inter se evidentissimus. Trib. 4-5 \& 6 evidenter, quoad thallum nempe, jungunt Cetraria \& Siphula; plurirnæ enim Cetrariæ etiam variant fruticulosæ ut Siphula \& fistulosæ ut Cladoniæ, licet vulgo in frondis formam dehiscant, unde pendet forma canaliculata. Cladonice podetia, normaliter fistulosa, variant in frondem canaliculatam dehiscentia; \& forsan thallum $\mathrm{Cl}$. turgidae Cetrarioideum hac ratione explices. Tribus 4-6 in statu. elementari tarn progressivo (Palmelloe \&c. cfr. Segestrellam rubram) quam regressivo (Conferva pulveria Dillw.) cum Phyceis facillime commutantur, nam charactere non differunt; insuper metamorphosi præternaturali enituntur varias formas secundarias \& Fungis \& Phyceis (sub Algis Byssaceis ex parte a me receptas) adnumeratas.

Singularis mihi videtur existimatio refutandas necesse esse singulas diversas dipositionis rationes ad receptam tuendam. Cum ob multifariam generum affinitatem singulum Systema, quale in charta depingitur, omnem indicare nequeat, quibus rationibus varia propius ad hanc metam ducant, inquirendum credidi. Tantum e re variis rationibus considerata plena nascitur cognitio. Verum \& pulchrum sub variis formis manifestatur. Qui se unicum \& summum justum in generalibus plene amplexum esse fingit, se \& alios fallit. 


\section{Lichenes Europæi.}

Conspurcavit magis: Botanicen varietatum introductio quam alia res ulla, ut nisi brevi medela, actum fuisset de scientia; Linné.

\section{Ord. I. GYMINOCARPI.}

Apothecia aperta; discifera. Lamina proligera explanata, excipulo thallode aut proprio recepta, normaliter persistens ascigera, subinde prinitus pulveraceo-collapsa (numquam deliquescens).

Duo ista genera Caliciea, disco primitus pulveraceocollapso ordine facile separes, dispositionis fundamento a disci indole sumto, unde hic ordo in Hymenothalamos \& Coniothalamos dissolvitur. Præsentis vero operis scopo convenientius visum est haud separare; cum 1) Coniothalami paucas tantum offerant autonomas formas, quare pro singulari aberratione facile habeantur; 2) verissimi Hymenothalami plures offerant status abnormes, disco pulveraceo collapso, a Coniothalamis charactere non separandos; 3) eadem differentia redeat in Sphærophoro sequentis ordinis, cum Calicieis tribu haud conjungendo, ni mere artificialem dispositionem construere velimus; nam Sphcerophorece cum Endocarpeis; Caliciece vero cum Lecidinis \& Graphideis affinitate naturali nectuntur; 4) discus persistens etiam in Coniothalamis observatus sit, immo asci tam in Caliciis quibusdam, quam in Sphærophoro, ut horum defectus inter Lichenes character atypicus sit, \& e dissolutione sub ipsa evolutione explicari possit. Nam asci, licet plus minus evoluti varient, numquam deficiunt nisi disco pulveraceo-collapso; at cum discus pulveraceus abnormis est, in statu normali semper adsunt asci.

\section{Trib. I. PARMELIACE E.}

S. genus superius LICHEN. Walenb.

CHAR. Apothecia thallo contigua, subrotunda, e concavo explanata, scutelliformia, raro peltata. Discus subceraceus, persistens, excipulo thallode marginatus.

I. Hæc Lichenum tribus vastissima \& centralis unicam \& thallo \& apotheciis contiguam seriem efficit, ut pro unico genere superiori (Syst. Orb. Veg. 1. p. 277) haberi posset \& ex systematicis principiis fere deberet. 
Ne Peltigera quidem sectio est reliquis dignitate superior; at Sticta plerisque inferior. Genere hoc latiori sensu sumto nulla adest ratio Lichenis nomen genericum rejiciendi; cum tres quartas partes specierum Linnæanarum colligat omniaque Lichenum genera evidentius recedentia vel ad alia genera a Linnæo relata fuerint vel ei prorsus ignota v. c. Caliciea, Verrucariea, Limboriea. Si ob tam levem decimationem omnia nomina generica essent rejcienda, quæ tum persisterent? Conspirat sine dubio magis cum genio methodi naturalis genere antiquo, v. c. Geranii, ad familix dignitatem promoto, centro hoc nomen relinquere. Hoc sensu, levioribus tantum discrepantibus, Lichenis nomen servatum vidimus a viro sedem \& genium Linnæi tenente \& ad Lecidinas simul extensum ab Herbarii Linnæani possessore. Generi latiori illo sensu restituto, male, me judice, Parmelize nomen substituitur. Mihi perinde erit, utrum sequentia Parmeliacearum subgenera ut autonoma genera, an tribus consideraveris; utrum Lichenem (Usneam) barbatam an Usneum barbatam dixeris. Proponendi modo nimia sæpe mihi tribui videtur attentio, rei ipsæ justo vilior, quare quidam magis ad arbitrarias immutationes \& novas denominationes, quam novas observationes tendunt!

II. At non pauca offert commoda sectiones primarias Parmeliacearum (perspecto scilicet omnium nexu, ne heterogenea e thalli analogia immisceantur) ronsiderare. Levioris videatur forsan ponderis ingens specierum numerus, nam additis speciebus extra-Europæis v. c. ipsa Stic$t a$ ad 50 adscendit, at memoriam \& specierum cognitionem admodum sublevat. Si plura genera non admittuntur, unicum servatum subgenerum, tribuum, sectionum, subdivisionum \&c. copia nimis intricatur, ut adhuc Parmelia ulterius potius, at e notis magis fidis, quam hactenus factum vidimus, subdividenda. Majoris vero momenti sunt plura genera, si ad genium vicinarum familiarum \& genera sequentium tribuum re ipsa inferioris dignitatis attendamus. Præcipue vero fere necessaria sunt, quando de Lichenibus in genere, de Lichenum structura, vegetatione, geographica distributione e. s. p. disserendum est. Malui hinc contra regulas systematicas peccans, quam nimis correcti studiosus, videri, Cfr. ceterum quod supra de generibus dictum est. 


\section{U S N E A.}

Usneæ spec. Dill. - Hoffm. - Eschweil. - Wallr. Usneæ \& Ramalinæ spec. Ach. Lich. univ. et syn. Usnea. Fries S. O. V. p. 234.

CHAR. Apothecia orbiculata, peltata. Discus semper apertus, nudus, strato medullari filamentoso impositus. - Thallus primitus erectus, suffruticulosus, (adultior passim pendulus, filamentosus), strato corticali crustaceo a medullari filamentoso subdiscreto; undique similaris.

Inter Lichenis subgenera Usnex thalli filo centrali tenaci, structurce filamentosa, facillime dignoscitur, licet in quibusdam speciebus exoticis, semper fruticulosis, cortex minus discretus sit. In specie autem subfoliaceo-compressa omnium maxime discretus èst. - Duplex in Vet. Ac. Handl. 1821 proposui Lichenum fastigium, Usneas \& Peltigeras, illas caulescentium, has frondosorum \& horizontalium, quæ de loco principi certant. In genere vero caulescentes perfectiores \& agmine ab his ducto series oritur magis contigua \& naturalis. Hinc cum Linneo Usneis summum vindico locum, quem quoque singulari sua structura, Exogeneis fere analoga, facile tuentur. - Unica tantum certa species Europæa, \& quidem e Lichenum glaucorum serie, quam in plures species ante me omnes divulsisse Lichenologos, potius mirandum, quam refutandum censeo. Consentientem habeo Wall rothium. Sed in exteris terris, \& præcipue hemisphæra australi, plures exstant nobiles Usneæ, \& quidem etiam e serie spadicea (Usnea lorea Fr. l. c.), ochroleuca (Usnea dichotoma Fr. l. c.) \& citrina. Ex his vero facile elucet characteres Usneæ adscriptos plurimos fallaces esse; variat nempe thallo tereti \& plano; apotheciis lateralibus \& terminalibus, obsolete \& distincte marginatis, disco valde discolori \& concolori, in quo statu homothalamus, qualis discus non exstat, perperam dictus est. Nec radii apotheciorum in nostra Europæa paucisque aliis in characterem ingredi debent, nam, optime observante Wallrothio, omnino atypici sunt. Hoc vero, ex mea horum verborum notione, non impedit, quo minus in speciebus quibusdam normales sint, etian si in una alterave forma ejusdem speciei magis obliterentur v. c. in Usnea jamaicensi Ach., meo sensu ab Ussea barbata non distin- 
guenda. Multa enim nobis obviàm veniunt exempla notam in genere aut specie esse normalem, quæ ex superioris sectionis typo atypica videatur, nec ex typica proposita idea naturam corrigere ejusque libertatem perstringere nobis licitum sit.

- 1. USNEA barbata, thallo tereti irregulariter ramoso glauco, demum annulatim ruplo, apotheciis subimmarginatis radiatis, disco pallido. Fries Sched. Crit. 9. p. 34.

Usnea coralloides. Wallr. Flechtenk. 2.

a. florida, suffruticulosa, ramosissima, elatior, scabrida, apotheciis amplissimis. Dill. Musc.t. 13.f.13. Lichen floridus. Linn. et Auct. - Engl. Bot.t. 872. Fl. Dan. t. 1189. Usnea. Hoffm. Pl. Lich. t. 30. f. 2. et Ach. - (Lichen comosus. Ach. in Vet. Ac. Handl. 1795. t. 8. f. 1. sine orbillis).

Exs. Lich. Suec. n. 120. Moug. et Nestl.n. 260. Flörke n. 178.

b. hirta, suffruticulosa, ramosissima, pumila, sæpius verrucoso-pulverulenta. Dill. l.c. f. 12. Lichen hiitus Linn. et Auct. Usnea hirta. Hoffm. (at PI. Lich. t. 30. f. 1. potius priorem sterilem exhibet).

Exs. Lich. Suec. n. 150. Flörke n. 179.

c. plicata, pendula, elongata, subdichotoma, implexa, lævigata, pallescens. Dill. Musc. t. 11. $f$.1. Lichen plicatus Linn. et Auct. - Engl. Bot. t. 25\% accedit. - Westr. Färghist. t. 8. Usnea. Hoffin. et Ach. Fl. Dan. t. 135\%. - Usnea gracilis \& filaris Ach. formæ minores.

Exs. Lich. Suec. n. 270.

d. dasypoga, pendula, elongata, filamentis subsimplicibus, fibris lateralibus patentibus. Dill. $t .12 . f$. 16. Lichen barbatus. Linn. et Auct. Engl. Bot. t. 258. Usnea barbata. Hoffm.

Exs. Lich. Suec. $n .119$.

Per omuem Europam vulgatissima ad arbores \& ligna; rarior \& degenerans in saxis, campis arenosis. Forma a. precipue in arborum frondosarum coronis; b. ad sæpes \& ligna fabrefacta; c. in silvis densis irriguis, apprime abiegnis; $d$. ad truncos arborum, copiose in pinetis. 
Typus speciei est forma florida, optime fertilis \& fruticulosa; reliquæ parcius \& rarius fructificant; b, quia Variolarioidea; reliquæ ut nimis protensæ \& filamentosx. In $\mathrm{d}$. fibrillas laterales ad typum Isidii pertinere bene censet Wallroth; vidimus autem $b$, vere Isidiophoram. Notavi hoc loco, pro more, formas vulgatissimas \& celebratissimás, adsunt vero simml plurimæ his subjungendæe aut intermedix, exoticas ut reticeam, v. c. Usnea ceratina Ach. (Moug. \& Nestl. n. 465); U. plicata Moug. \& Nestl. n. 166 inter a \& d, præcipue accedens ad illam formam subalpinam Europæ australis, qux pro verissima Usnea barbata habetur (in Suecia vero non lecta, indeque non Linn.), præcipue singularis apotheciis, ciliis detersis, in ambitu subnudis, at juniora evidenter radiata vidimus transitumque evidentem. Cum hac facile confluit Lichen articulatus Huds. s. Usnea Hoffm., quæ tamen non varietas, sed monstrositas articulis magis discretis inflatis. Ex his omnibus nominibu's trivialibus servavi Linnæanum primarium, omuibus formis adæquatum, (nam plurimis speciebus junctis novum formare nomen impium mihi videtur), præcipue cum in omnibus fere linguis vernaculis, ut etiam a scientiæ Patribus, Muscus barbatus s. Barba arborum dicitur. In hac specie frequenter simul observantur cephalodia e carneo-pallido fuscescentia, primitus tenuiter marginata, quæ, e metamorphosi apotheciorum, nec ut Wallrothio thalli, orta mihi videntur; nam formas exacte medias vidi in speciminibus americanis apotheciorum disco incarnato, ceterumque Ramalinæ calicaris simillima sunt, quorum ab apotheciis veris transformationem quisque observare potest. Hæc "apothecia accessoria" Ach. cum multis formis Biatorinis Parmeliarum facile comparem.

Obss. Solum Usneam longissimam Ach., thallo tereti-compresso filumentoso subpulveraceo simpliciuseulo, fibrillis horizontalibus tecto diversam et in Europa orientali ad Silesiam! et Saxonium! obviam, tuto huc referre non ausus sum, licet formis d. sape simillima. Forte hujus stutus typicus in Oriente reperiundus sit; simillima glabra specimina e Nepaul vidimus. Ut in Europa semper sterilem hoo loco seorsim proponere non debui.

\section{E V E R N I A.}

Usneæ \& Lichenoidis spec. Dill. - Usneæ \& Lobariæ spec. Hoffm. Cornicular. \& Physciæ spec. Derand. Evernia, \& specc. plurr. Dufoureæ, Alectoriæ, Cor" niculariæ \& Borreræ. Ach. Lich. univ. 
CHAR. Apothecia orbiculata, scutelliformia, marginalia, a thallo marginata. Discus primitus connivens, strato medullari floccoso impositus. Thallus subtus at margine nudus, primitus erectus, intus stuppeus uniformis, sape inanis. Discus coloratus.

Medium inter Usneas \& Cetrarias in evolutionis serie tenent locum Evernix, sed apotheciis subconniventibus (non autem vere clausis) eorumque forma Parmeliis adeo affines, ut ægre admittantur ut peculiare Lichenis subgenus. At thallus primitus erectus, nec horizontalis, quxe differentia ubique valde insignis, \& defectus omnis hypothalli differentiam urgent. Cfr. sectiones Parmeliarum, quarum exstant quidam formæ adscendentes, minime autem vere erectæ demumque pendulæ. Apothecia sessilia \& podicellata, lateralia \& terminalia aliæque notæ, ad genera distinguenda laudatæ, nimis incertæ sunt. Ceterum thallus, ut in Usneis \& sequentibus, variat teretiusculus fruticulosus (in abnormibus formis filamentosus \& sarmentosus) \& compresso-foliaceus, adultior pendulus, at inter has differentias nulli stricti \& naturales limites. Lichenes filamentosi penduli vix umquam typici sunt. Apothecia in hoc subgenere rarissima.

* Thallo tereti, undique similari, fruticuloso aut in formas filamentosas sarmentaceo-pendulas degenerato.

2. EVERNIA jubata, thallo tereti lævi nigro-fusco (pallenteque), apicibus simplicibus, apotheciis innato-sessilibus integerrimis, disco nigrofusco. Fries Sched. Crit. 9. p. 33.

a. bicolor, thallo erecto fruticuloso ramosissimo divergente, apicibus cinerascentibus. Dill. Musc. $t$. 13. f. 6? Lich. bicolor Ehrh. - Ach. Vet. Ac. Handl. 1803. t. 4. f. 6. Engl. Bot. t. 1853. Usnea Hoffm. Cornicularia. Ach. Lich. chalybeif, var. Wahl.

Exs. Lich. Suec. n. 264. Moug. et N'estl. 167. Ehrh. Crypt: n. 40.

b. chalybeiformis, thallo subfilamentoso sarmentoso rigidulo divergente ramoso, apicibus sæpius pallidi- 
oribus. Dill. t. 13. f. 10. Lichen chalybeif. Linn. et Auct. Usnea. Hoffm. Alector. jubatæ var. Ach. Exs. Lich. Suec. n. 266.

c. implexa, thallo filamentoso pendulo ramosissimo implexo molli, apicibus concoloribus. Dill. t.12. $f$. 7. Lich. jubatus. Linn. et Auct. Engl. Bot.t.1880. Usnea implexa, jubata, ramulosa Hoffm. Parmelia \& Alect. jubata Ach.c. pl. varr. - Schrad. Journ. Bot. 1799. 1. t. 3. f. 4. Cornicularia. Dec.

Exs. Mougeot et Nestl. n. 261. cum scutellis! Lich. Suec. 265.

d. setacea, thallo filamentoso longissimo pendulo subsimplici, passim incrassato. Lich. setiformis Ëhrh. - Alect. jubata v. setacea. Ach.

Per omnem Europam vulgaris. Var. a. ad saxa inter muscos, præcipue locis montosis; $b$. ad saxa aprica, sæpes (ubi tenuior) - c. \& d. vulgatissime ad truncos \& ramos arborum.

De nexu specifico varietatum b. c. d. non amplius dubitatur, tantum de $L$. bicolori Ehrh. Cel. Wallroth ut peculiarem Usneæ speciem citat, reliquis formis, utique atypicis, ad Ramalinam calicarem relatis. At has formas ab omni $\boldsymbol{R}$. calicari diversas esse, apothecia \&c. abunde demonstrant; Lich. bicolorem earum esse statum typicum luculentissimis speciminibus facillime evincam. Adsunt non tantum plurima intermedia, qualis forsan Lich. heteromallus Engl. Bot. t. 2246, etiam fructifera, quæ ad a. aut b. pro lubitu referas, sed etiam ipsius Lich. bicoloris, cujus apices in ipsissimum L. chalybeiformem prolongantur. Differunt itaque varietates allatæ hand aliter ac a nalogæ Usneæ barbatæ, Everniæ ochroleucæ \&c. - In c. \& d. axillæ subcompressæ, color, naturali expallescente, lividus, canus \&c. Omnibus apothecia minuta, plana, integerrima, thallo concolora (formæ expallidæ semper steriles), sed rarissima. Soredia, in b-d precipue frequentia, exigua.

3. EVERNIA divergens, thallo angulato castaneo albo-punctato, apicibus attenuatis furcatis concoloribus, apotheciis innato-sessilibus crenulatis, disco castaneo.

a. thallo erecto fruticuloso turgido, ramis brevibus suberectis. 
b. thallo fruticuloso-sarmentoso tenuiori, ramis elongatis divergentibus. Lich. chalybeiformis. Fl. Dan. $t$. 262 ex analogia prioris b. - Cornicul. divergens. Ach. - meth. Lich. t. 6. f. 1. Lichen. Wahl. Lapp. p. 439.

Exs. Lich. Suec. fasc. XII.

Ad terram sterilem muscosam alpium Scandinaviæ frequens.

Totus unicolor, nec basi discolor, ut in concolori Cetrar. aculeata, a qua ceterum abunde diversa thallo solido, numquam denticulato, apotheciis \& toto habitu. Potius cum sequente nigrescente comparanda, sed notis indicatis constanter recedit. Apothecia hujus quoque rarissima. - Desunt formæ arboreæ, sarmentosæ \& pendulæ.

4. EVERNIA ochroleuca, thallo teretiusculo ochroleuco (pallenteque), axillis compressis sublacunosis, apicibus attenuatis ramulosis, apotheciis innato-sessilibus demum repandis, disco livido-fusco. - Cfr. Schrad. Journ. Bot. 1799. I. $t$. 3. f. 3.

a. rigida, thallo fruticuloso rigido ochroleuco, apicibus reflexis nigricantibus. (Planta mortificata tota subinde nigrescit.) Lich. ochroleucus. Ehrh. - Usnea. Hoffm. Parmelia s. Cornicularia. Ach. - Fl. Dan.t. 1879. $f$. 1. L. rigidus. Vill. ex Ach.

Exs. Lich. Suec. n. 330. Moug. et Nestl.n.853.

b. cincinnata, thallo sarmentoso complicato rigidulo ochroleuco, apicibus concoloribus. - L. sarmentosus. Engl. Bot. t. 2040. - Cfr. Sommerf. Lapp.p.115.

c. sarmentosa, thallo filamentoso sarmentoso-pendulo molli ochroleuco pallidove, apicibus prælongis concoloribus. Mich. nov. gen. pl.t. 39. f. 2. Lich. sarmentosus. Ach. in Vet. Ac. Handl. 1797. t.8.f.2. Usnea dichotoma. Hoffm. - Pl. Lich. t. 72. Parmelia s. Alectoria sarmentosa $A c h$.

Exs. Lich. Suec. n. 269.

d. crinalis, thallo filamentoso tenui pendulo præalongo molli pallescente, vix ochroleuco.

Exs. Lich. Suec. n. 268. - Moug. et'Nestl. n. 755 vix differt.

In Europa silvatica, præcipue montosa \& bo- 
reali. Var. a. ad terram in campis alpinis \& subalpinis; b. ad rupes in montanis; c. ad truncos pineos, ramos fagineos \&c. d. in Abiete, Junipero \&c.

Specificam identitatem omnium varietatum extra dubium positam censeo; b. Lich. ochroleucum \& sarmentosum adeo luculenter, ut nil evidentius, conjungit. In formis degeneratis color quidem mutatur, sed nomen antiquissimum satis aptum; tantum ochroleuca fructificat. - Thallus demum inanis; apothecia primo suburceolata, margine tenui inflexo cincta, demum ampla (præcipue in $\alpha)$, repanda, disco semper saturate colorato adeoque, etiam sensu Acharii, nulla ratione homothalamo.

5. EVERNIA arenaria, thallo tereti ex ochroleuco lacteo, axillis lacunosis, apicibus æequalibus ramosis, apotheciis sessilibus integerrimis, disco pallido.

a. thallo fruticuloso, ramis rectis brevioribus.

b. thallo sarmentoso-complicato, ranis longioribus curvato-complicatis.

Exs. Lich. Suec. n. 114.

In Gallia, Silesia (Flotow) \& Suecia meridionali; a. ad saxa cotacea; b. in campis arena volatilis.

Ad præcedentem Flotow, ad Ramalinam calicarem Wallroth spectare suspicati sunt. Apothecia, licet rarissima, ab utraque evidenter distinguunt. Hæc superficiali-sessilia, nec ut in præcedentibus innata, minuta, plana, integerrima, tenuissime marginata, disco pallescente, nec ut in omnibus præcedentibus saturate colorato. Si vero hujus detegantur formæ arborex, steriles \& pendulx, eas a prioris distinguere difficile forsan erit.

6. EVERNIA vulpina, thallo ramosissimo angulato lacunoso citrino, apotheciis sessilibus, disco badio-fusco. Ach. Lich. univ. p. 443.

a. Iæte flava, subnuda, passim longissima filamentosa. Hall. helv. n. 1794. L. auratus. Vill. L. citrinus. Schrank. L. vulpinus. Wulf. - Jacqu. Misc. 2. 
t. 10. f. 4. Usnea. Hoffm. Cornicularia. Dec. Fr.2. p. 329 .

b. flavo-virescens, granuloso-pulverulenta, semper fruticulosa. Lich. vulpinus. Linn. Suec. $n$. 1129. Fl. Dan. $t .226$.

Exs. Lich. Suec. n. 142. Fl. Deutsch. n. 70.

In truncis Pini, pracipue Cembre, in alpestribus Europie mediæ; b. vero ad ligna fabrefacta (tecta imbricata, sæpes \&c.) Europæ borealis.

Thalli, numquam sarmentosi, indole \& colore (intus stuppeo, albo) a præcedentibus longius distat, quam a sequentibus, at in thallo undique similari nil foliacei adest. Vulgo b. pro primaria forma habetur, sed hæc, cum Usnea barbata $b$. analoga, semper sterilis tantum occurrit \& loco haud naturali obviam venit. Superficies granuloso-pulverulenta idem testatur.

* T\%hallo suffruticuloso erecto undique similari, molli, intus st:ppeo subinani, ramis obtusis; apotheciis subterminalibus. Dufourex. Ach.

Hæc sectio potissimum Extra-europæa, cujus species etiam e serie glauca, spadicea \& citrina cognitæ sunt; nostræ tantum e serie ochroleuca.

7. EVERNIA fertilis, thallo suffruticuloso laciniato-ramoso molli lacunoso ochroleuco, apicibus obtusis, apotheciis subterminalibus sessilibus cyathiformibus, disco badio.

In montibus Uralensibus ad rupes. Dedit b. m. Swartz.

Everniæ divaricatæ affinis, sed valde singularis, copiose fructificans, licet pumila, erecta, 1-2 unc. tantum alta, anguloso-compressa, irregulariter \& laciniato-ramosa, superficie valde lacunosa, ut ipsa apothecia extus reticulato-scrobiculata; ceterum tota structura molli sequentium, intus flocculosa alba. Apothecia pro speciei magnitudine ampla, in apicibus ramorum obtusiusculis sessilia, sed apicibus non immersa, cyathiformia, primo urceolato-conniventia, margine tenui integerrimo, disco tenui badio, demum pro more rugoso. Species suæ sectionis habitu deliquescente, sequenti propior. 
* EVERNIA madreporiformis, thallo suffruticuloso dichotomo turgido molli noduloso ochroleuco, apicibus obtusis - - -

Parmelia mollusca. Clement. nec Ach. Dufourea madreporiformis. Ach. Lich. univ. excl. syn. Cladonia papillaria. Dec. syn. nec Ach. Clad. madreporif. Schaer, spic. p. 43. - Exs. $n .85$.

Ad saxa, rupium fissuras ipsamque terram in alpibus Europæ mediæ, inque Hispania.

$\mathrm{Ob}$ fructum ignotum inter Lichenes rite cognitos inserere non debui, at certe hujus, nec Cladoniæ generis. Ad Ev. prunastri, fere ut prior ad Ev. divaricatam, accedit ; vidimus illius specimina saxicola satis similia, Etiam differentia a præcedente haud certa est.

*** T/lallo compresso, subfoliaceo (in macris filiformi), adulto et fructifero pendulo, subtus canaliculato subdiscolori, apotheciis lateralibus.

8. EVERNIA divaricata, thallo subfoliaceo molli ochroleuco, demum articulato, laciniis linearibus dichotomis lacunoso-rugosis acutis, apotheciis sessilibus scutelliformibus, disco badiorubro. Ach. Lich. univ. p. $44 \mathbf{1}$.

Dill. Musc. t. 12. $f$. 5. Lich. divaricatus. Linn. Usnea flaccida. Hoffm. - Pl. Lichen. t. 67. f. $1,2$. Decand. fr. 2. Parmelia divaricata. Ach. meth.

Exs. Lich. Suec. ined. - Moug. et Nestl. n. 545.

In Europæ montanis ad arborum acerosarum truncos \& cacumina.

Transitum ad sequentem, cujus varietatem urgent recentiores, nullum inveni genuinum. Epidermide rupta medulla stuppea cohæret, ut thallus articulatus evadat, instar Usneæ barbatæ. Variat ceterum thallus longissimus subfilamentosus \& brevior latior magis divaricatus. Color pro more seriei ochroleucæ in album \& virescentem ludit. Apothecia scutelliformia, planiuscula. .

- 9. EVERNIA prunastri, thallo subfoliaceo stuppeo contiguo ochroleuco, laciniis linearibus, subtus canaliculatis albis, apotheciis subpodicellatis cyathiformibus, disco badio-rubro. Ach.l.c. 
Vaill. pảr.t. 20. f.11. Mich. gen. t. 36. f. 3. Dill. musr;: $t$. 21. f. 55. $A$. (ceternm apud Dill. confusá species). Lich. prunastri. Linn. et. Auct. - Engl. Bot. t. 859 (\& L. stictoceros ib.t. 1353). Westring. Färglafv.t. 11. Lobaria Hoffm. Physcia. Decand. Parmelia Ach. meth. - Lich. corniculatus. Rell.

Exs. Lich. Suec. n. 141. Flörk. Deutsch, n. 92. Moug. et Nestl. n. 355 .

b. arenaria, laciniis longioribus angustioribus utrinque concoloribus. Dill. Musc. t. 21. $f .54$. Lich. arenarius. Retz. Scandl.

Ad arbores \& frutices Europæ omnis copiose; rarior ad saxa; b. præcipue in campis arenosis.

Fructifera semper elongata, pendula, in silvis densioribus montanis tantum obvia. Apothecia cyathiformia, demum podicellata. Sorediis albis frequenter adspersa. Ceterum admodum variat thalli statura; etiam coloris intensitas; sulphuream legi ad rupes marinas Hallandiæ - b. præcedenti similis, at transitum nullo modo efficit. Huic quoque proximum unicum specimen Borrerce calamistratoe Herb. Acharian.

- 10. EVERNIA furfuracea, thallo subfoliaceo stuppeo glauco (sæpius cinereo-furfuraceo), laciniis linearibus dichotomis, subtus canaliculatis nigricantibus, apotheciis podicellatis, disco rufescente. Marn. Lich. Boh. p. 105.

Buxb. Cent. 2. t. \%. f. 1, 2. Mich. gen. t. 38. f. 1 . Dill. Musc. t. 21. $f .52$. Lich. furfuraceus. Linn. et Auct. Engl. Bot. t. 984 . Lichenoides s. Lobaria. Hoffm. - Pl. Lich t. 9. f. 2. Physcia. Decand. Parmelia s. Borrera. Ach.

Exs. Lich. Suec. n. 140. Moug. et Nestl. n.63. Fl. Deutsch. n. 173.

b. ericetorum, laciniis angustioribus, supra candicantibus, nudis. Borrera camtschadalis. Ach.non differt. Per omnem Europam in truncis, lignis, saxis; $b$. in ericetis borealibus.

Fructifera semper pendula; apothecia ex omni capite prioris similia, vixque magis podicellata, ut qua ratione sectione ab priori removeri potuerit non video. At 
ab omnibus affinibus discrepat pagina inferiori nigricante, quo ad Parmelias accedit. Vegetatio vero a Parmeliis adscendentibus prorsus discrepat. Filiam esse $P$. physodis omnino erroneum censeo. Refutat insuper optime b. fruticuli, \& fere Cladoniæ rhangiferinæ, facie, in ericetis nostris obvia. Status normalis nudus rarior est, ut vulgatissimus isidiophorus nomen facile subministret; novum enim nomen magis, quam haud prorsus aptum, mihi displicet.

I1. EVERNIA intricata, thallo ramosissimo subcartilagineo glauco (sæpius pubescente), laciniis linearibus subtus canaliculatis albidis, apotheciis sessilibus planis, disco nigricante. Mich. gen, t. 38. f. 3. glaber. Dill. Musc. $t$. 21. $f$. 51. pubescens. Lichen intricatus. Desfont. Fl. Atl. t. 253. f. 3. Parmelia s. Borrera atlantica. $A c h$.

Ad cortices \& ramos arborum in regione mediterranea, Italia!, Hispania Dufour! - (accepi quoque ex Anglia; num ibidem natum specimen dubitetur).

A proximis abunde distincta. Apothecia marginalia, exigua, primo innata, dein sessilia; margine obtuso integerrimo, hand elevato; disco crasso, plano, fere atro \& primitus nudo, ob quem aliasque rationes a $P$. $P / h y-$ sciis diversam habeo. Thall, proximorum quoque brevior, angustior, subinde filaris, in cæspitem densum intricatus; verum hoc forsan variat. Vidi specimina tum pubescentia, quum glabra.

12. EVERNIA villosa, thallo multifido subcartilagineo villoso glauco, laciniis subtus canaliculatis pallidioribus, apotheciis podicellatis scutelliformibus, disco cerino.

a. thallo subfoliaceo. Mich. gen. t. 38. f. 2. Dill. Musc. t. 21. $f$. 53. Parmelia s. Borrera solenaria. Ach. - Parmel. s. Borrera villosa Ejusd.

b. thallo filiformi. Borrera s. Parmelia ephebea. Ach. Ad ramos arborum in Europæ regione mediterranea. In Lusitania Link! Holl!; Hispania ad Cadix alibique Dufour!; Gallia meridionali Fee!, Italia. Micheli. 
Denso cxspite nascitur, præcedente major'; semper villosa lecta, ut pubes in hac normalis videatur, at proximos omnes tum puberas, quam glabras vidi. Fibrillæ autem radicantes Parmeliarum prorsus desunt. Præter omnes notas thallinas Everniæ \& Parmeliæ, etiam apotheciorum a $P$. chrysophthalma adscendente (Borrerce mente Acharii) differt ; in $E_{v}$. villosi discus strato medullari albo impositus est; in P.chrysophthalma immediate strato gonimo viridi, hinc non potui non contra Wallrothium distinguere. At ad seriem citrinam pertinet, licet thallus sit decoloratus.

13. EVERNIA flavicans, thallo cæspititio subcartilagineo ramosissimo vitellino, laciniis linearibus compressis, subtus subcanaliculatis concoloribus, apotheciis scutelliformibus, disco aurantiaco. Swartz. Fl. Ind. Occid. 3. p. 1908. Lichen.

Hujus americanæ speciei, tam glabræ (Borrera flavicans Ach.), quam pubescentis (Borrera pubera c. peruensis $A c h$. ) variæ, in Europa maxime occidentali tantum habemus varietatem sterilem, quæ

$\beta$. crocea, thallo flavo-vitellino glabro, laciniis anguloso-teretibus.

Dill. Musc. t. 13. f. 16. Lich. flavicans Engl. Bot: t. 2113. Borrera flavicans. $\beta$. Ach. Cornicularia crocea. Ejusdem (magis pumila). Physcia flavicans Decand. Ad truncos \& inter muscos in Hispania Fee!, Pyrenæis Dufour!, Gallia occidentali Mougeot!, Anglia Acharius!

Specimina Europæa magis angustata, divaricata, lætius colorata, sorediis pallidis lateralibus sæpe adspersa. Specimina L. flavicantis Swartz, ab ipso accepta, etiam puberula sunt. - Analoga est hæc species cum Evernia vulpina, sed abunde diversa.

\section{R A M A LIN A.}

Lichenoidis spee. Dill. Lobarix. Hoffm. Physcix. Decand. Ramalinæ \& Alectoriæ Ach. Lich. univ. Evernix. Eschweil. Ramalina. Fries S. O. V. (ut aberratio Evernix). 
CHAR. Apothecia orbiculata, scutelliformia, æqualiter marginata, utrinque sparsa. Discus apertus, strato gonimo impositus. Thallus primitus erectus, undique similaris a concolor (adultior subpendulus \& passim filamentosus). Discus thallo subconcolor.

Subgenus Ramalinarum re ipsa aberratio tantum videtur Evernix, at tam thalli habitu \& substantia, quam apotheciorum indole facile distinctum, ut merito peculiarem sectionem efficiat, præcipue cum multæ adsint species exoticæ eximiæ eisdem gaudentes differentiis, v. c. $\boldsymbol{R}$. gracilenta Fries Mscr, thallo rigido filiformi subramoso glauco, costis elevatis longitudinalibus anguloso, apotheciis lateralibus, disco lacteo; e China, facie Alectoriæ Ach. Nostræ autem species Europææ, prima excepta, adeo affines, ut omnes conjungere sæe in animo fuerit. Consideranti vero mili diversam vegetationem, locum \& præcipue usum technicum, cui Botanicus practicus obviam venire debet, potius seorsim tractandæ mihi videntur. Sic v. c. $R$. calicaris utilissimum subministrat gluten, nullam autem materiam tinctoriam, qua R. polymorpha \& scopulorum pollent e. s. p. Non igitur negaverim eas ex eodem typo primitus enatas forsan esse, quamquam non credam nos nunc ubique species absolutas statuere posse. Melius sapiens Linnæus multas distinxit species, quæ ipsi affinium filiæ videbantur, cum eminentes \& constantes apparerent, 1. scientiæ practico scopo inservirent. - Triplex quoque hujus subgeneris sectio, cum prioris prorsus analoga; e prima filiformi pendula nulla species Europæa; ex altera, Dufourece sensu Acharii, tantum $R$. pusilla; reliquæ cum tertia Everniarum sectione analogæ sunt.

"14. RAMALINA pusilla, thallo cespititio molli ochroleuco, ramis difformibus inflatis turgidis, apotheciorum disco apicibus angustatis immer- so, concavo, pallido. Prev.!

Ad ramos Juniperi in insulis Stoechadibus. Primus detexit \& communicavit Cel. $A$. le Prevost.

Thallus mollis \& membranaceus, cæspitose nascens, plerumque in pulvinulos irregulares unciales circiter conglomeratus. Rami perbreves, sed admodum inflati, in- 
anes, turgidi, difformes, obtusi, simplices aut brevius divisi, rugulosi, hinc inde fissi \& lacero-aperti. Apothecia nulla discreta; discus semper apertus, urceolato-concavus, tenuissimus; margine elevato, acuto, integerrimo, e disco simul formato.

* 5. RAMALINA calicaris, thallo subfoliaceo ge- latinoso cartilágineo rigeseente lacunoso glauco, apotheciis podicellatis elevato-marginatis, disco plano pallido. - Westring Färglafv. $t$. 12. Lich. fraxineus.

- a. fraxinea, laciniis longioribus, latioribus, fertilibus planis, apotheciis lateralibus. Mich. gen. t. 36. $f$. 1. Dill. Musc. t. 22. f. 59, Lich fraxineus Linn. et Auct. Engl. Bot. t. 1181. - Fl. Dan. t. 1187. Platisma. Hoffin. Pl. Lich. t. 18. $f, 1$, 2. Lobaria. Hoffm. Germ. Physcia Decand. Parmelia, dein Ramalina. Ach. Ramal. stictæformis. Scheich. Cat.

Exs. Lich. Suec. n.71. Ehrh. Crypt.n. 88. Moug. et Nest. n. 158.

b. fastigiata, laciniis brevioribus, fastigiatis, compressis aut inflato-cavis. Vaill. Bot. par. t. 21. f. 2. Dill. l. c. 62. C. t. 21.f.55. B. Lichen populinus. Ehrh. Lobaria. Hoffm. Lichen fastigiatus. Pers. - Ach. Vet. Ac. Handl. 1799. t. 9. f. 1. A. - F. Physcia. Decand. Pármelia, dein Ramalina. Ach.

Exs. Lich. Suec. n. 263. Ehrh. Crypt. n. 276.

c. canaliculata, laciniis angustioribus, fructiferis canaliculatis, apotheciis ex apicibus reflexis appendiculatis. Column. ecphr. t. 337. Moris. hist. 3. sect. XV.t. 7.f. 5. Dill. Musc. t. 23. f. 62. A. B. Lichen calicaris Linn. et Auct. - Ach. l. c. f. G-K. Lobaria Hoffm.

Exs. Lich. Suec. n. 72.

d. thrausta, laciniis angustissimis filiformibus teretibus. Alectoria thrausta. Achar.

Exs. Lich. Suec. n. 267.

Per omnem Europam vulgatissima ad truncos arborum \& ligna.

De nexu omnium formarum nullnm dubium restat - a. \& b. in eodem cæspite legi. Ad b. proxime accedunt specimina in silvis densis abiegnis lecta, quæ tubulosa, gracilia, ramosissima, cribroso-pertusa, apotheciis 
terminali-sessilibus, quxe primo obtutu ad $R$. pusillam referas. d. autem Evern. ochroleucam c. assimilat, sed ab hac specie omnino oritur \& c. immixta crescit. Margo e disco simul formatus est, excipulique thallodis margo strato gonimo plerumque destituitur. Vidi apothecia lactea margine thallode omnino destituta. Ejusmodi apothecia facile in cephalodia carnea transmutantur. Singulæ varietatis ceterum occurrit forma sterilis aut parcius fructificans, sed sorediis farinaceis inquinata. Tales status varr. a. \& b. ad $R$. pollincriam vulgo referuntur, ut synonyma dispescere difficile sit. Cum thallus subtus albidior sæpe sit, Dillenius ejusmodi specimina cum $L$. prunastri confudit. A var. c. in statu sterili \& sorediifero non differt: Lichen farinaceus Linn. \& Auct. Engl. Bot. t. 889. Lobaria Hoffm. Physcia Decand., Parmelia, dein Ramalina Ach. Ram. splendens Schleich. - Dill. Musc. t.23.f.63. Sterilis plana quidem est; ubi vero in eisdem speciminibus apothecia adsunt, mox canaliculata evadit. s. Parm. farinacea v.canaliculata Clem. "Sexu" tantum differre jam suspicatur Dillenius \& sub L. rostrato jungit Scopoli. Hæc forma traditur in Lich. Suec. n. 75. Moug. et Nestl. n. 356. Ehr. Crypt. n. 107.

i6. RAMALINA pollinaria, thallo subfoliaceo membranaceo flaccido corrugato glauco, sepius maculis pulveraceis adsperso, apotheciis podicellatis incurvo-marginatis, disco concavo pallido.

Vaill. par. t. 20. f. 15. ex habitu. Dill. Musc.t.21. $f$. 57. Lichen squarrosus Pers. Lobaria Hoffin. Lichen pollinarius. Ach. Vet. Ac. Handl. 1796. $t$. 11. f. 2. Parmelia, dein Ranalina. Ach.

Exs. Lich. Suec. n. 143. Moug. et Nestl. n. 346. Flörk. Deutsch. n. 40.

Rarior species. Optima ad rupes, a Pyrenæis ad Sueciam; sed etiam ad truncos, ejusmodi vero specimina a priori caute distingnenda.

Sub recentioribus nominibus sxpe venduntur specimina pumila, squarrosa, sorediffera prioris; quæ ne commutentur, distinxi. Thallus, ad prioris modum, forma mire variat, at semper tenuior, moilior, flaccidus habitu crispato, siccitate flavescente. Ob tenuitatem sopedia 
vix enititur, sed, præcipue versus apices, maculas puilverulentas; hinc bene Dillenius, cujus synonymon perperam ad sequentem citatur: "id peculiare habet, quod foliorum laminæ utraqne parte hinc inde a substantia interiori fungosa abscedant \& maculas candidas relinquant." Apothecia magis quam reliquarum urceolata sunt, margine incurvo.

17. RAMALINA polymorpha, thallo cespititio - cartilagineo-rigido longitudinaliter costato-rugoso glauco, apotheciis podicellatis elevato-marginatis, disco concavo pallido. Ach. Lich.univ. p. 600 .

Lichen tinctorius. Weber, Ehrh. - ex spec. Wallr. Lobaria $H_{o f f m}$. Lichen polymorphus. Ach. in $V$ et. Ac. Handl. 1799. p. 270. t. 11. f. 3. Parmelia. Ach. meth. Physcia. Dec. fr. Supl.

Exs. Lich. Suec. n. 144. Ehrh. Crypt. n. 276. Fl. Deutsch. n. 40.

Ad rupes \& saxa Europæ, præcipue maritimæ.

Thalli ramificatio \& forma pro more variæ, at habitu proprio facile distincta. Soredia sæpius præsentia, nunc distincta capituliformia, nunc lacunis thalli longitudinalibus immersa, nunc solum thallum pulverulentum reddunt. Sapor nauseosus. Gelatinam parcam continet, sed materia tinctoria abundat; "aqua calida perfusa purpurascente statim tingit colore." Hoffm.

18. RAMALINA scopulorum, thallo cespitilio coriaceo-cartilagineo rigido polito glauco, apotheciis podicellatis, margine mox reflexo, disco convexo pallido. Ach. Lich. univ. p. 6o4.

Moris. Hist. Sect. XV. t. 4. f. 4, 5. Dill. Musc. t. 17. $f$. 38. Lichen siliquosus. Huds. Lich. calicaris. Fl. Dan. t. 959. Engl. Bot. t. 688. Ach. in Vet. Ac. Handl. l. c. t.9. f. 2. non Linn. Lich. scopulorum. Retz. \& Auct. Westring Färglafv.t. 23. Parmelia. Ach. meth. Physcia Decand.

Exs. Lich. Suec. n. 300. Funk. Crypt.

Ad scopulos marinos a Lapponia ad Hispaniam copiose.

Maxime caspititia, latas plagas scopulorum obdu- 
cens, quasi e communi crusta orta. Thalli figura varia, sed ob rigiditatem \& crassitiem, fere Roccellæ, foliaceam faciem vix assumit; nunc teres, nunc compressa; demun scabrosa. Sapor amarus. Materia tinctoria præstat.

IV. R O C C E L L A.

Roccella. Veterum. - Decand. - Ach. - Eschw.

CHAR. Apothecia orbiculata, scutelliformia, lateralia, a thallo marginata. Discus primitus apertus, strato carbonaceo impositus. Thallus primitus erectus, demum pendulus, cartilagineo-coriaceus, fere calcareus, intus stuppeus. Discus nigrescens, plus minus casio-pruinosus.

Et hoc subgenus typice Everniæ degeneratio, sed habitu \& characteribus facile distinctum. Stratum carbonaceum abnorme censent Cell. Meyer \& Wallroth, in utraque vero specie frequentissime obvium indeque, meo sensu, normale dicitur. Speciem utramque cum Wallrothio conjungere diu in animo fuit, at dissuadent autoptæ, \& hinc, ex huius opusculi ratione, neglecta omni theoretica speculatione, experientix tantum fidendi, Dillenium, Linnæum \&c. distinguentes sequi debui.

19. ROCCELLA tinctoria, thallo coriaceo tereti undique similari subfiliformi glauco, apotheciis subinnatis sparsis, disco convexo nigricante, margine evanescente. Ach. Lich. univ. p. 439 . Pluken. Alm. t. 205. f. 6. Dill. Musc. t. 17. f. 39. Lich. Roccella. Linn. et Auct. - Engl. Bot.t. 211. Parmelia. Ach. meth.

In rupibus maris mediterranei, præcipue Archipelagi, sequenti rarior \& magis australis; extra Europam vulgatior.

Adulta longissima, pendula, parce ramosa. Apothecia juniora pruinosa, sed adulta subnuda.

20. ROCCELLA fuciformis, thallo cartilagineocoriaceo compresso dichotome laciniato glauco, apotheciis marginalibus sessilibus, disco planiusculo casio-pruinoso, margine subpersistente. Ach. Lich. univ. p. 440. 
Dill. Musc. $t .22$ et 23. $f$. 61 . Lichen fuciformisa Linn. - Engl. Bot. t. 728. Roccella. Decand Parmelia. Ach. meth.

Ad rupes marinas Europæ meridionalis \& maxime occidentalis, præcedente frequentior. In Gallia etiam ad arbores lecta.

Variat plus minus plana, subtus concolor \& fuscescens, pumila \& elongata; frequenter sorediifera. Pruina disci in hac magis persistit. Ad hanc ut formam pumilam, minus planam, sorediis valde inquinatam, pertinet Dill. Musc. "t. 22. $f$. 60. Lichen fucoides. Dicks. Roccella phycopsis $A c h$., licet sub hoc nomine etiam viderimus $\boldsymbol{R}$. tinctoriam, eadem ratione deformatam.

\section{C E T R A R I A.}

Lichenoidis spec. Dill. Lobariæ spec. Hoffm. Germ. Corniculariæ \& Cetrariæ spec. Ach. Lich. univ. Cornicularix \& Physcia spec. Decand. Cetraria. F'ries Syst. orb. Veg. - Schaer. spic. p. 9.

CHAR. A pothecia peltæformia 1. e scutellato peltata, apicibus thalli (ramis lobisve) oblique adfixa, hinc quoque oblique marginata. Discus tenuis, apertus, strato medullari impositus. Thallus primitus adscendens, fertilis suberectus, cartilagineus aut membranaceus, lobis teretiusculis aut foliaceis supra concaviusculis.

Mediurn exacte inter Lichenes primitus erectos \& horizontaliter expansos tenet Cetraria; illis magis accedit prior sectio (ad genus Usneæ Wallr. ab Auctore relata); his posterior, ut, nisi apothecia nimiusque cum prima sectione nexus obstarent, ad eas facile referres. Thallus adscendens in hoc subgenere normalis est; in Parmeliis abnormis \& e loco pendens; differunt ejusmodi adscendentes Parmelix thallo subtus canaliculato, apotheciis e lamina thalli enatis \&c.

* Thallo cartilagineo, suberecto. Thallus fruticulosus aut canaliculato-foliaceus.

21. CETRARIA tristis, thallo fruticuloso corneocartilagineo rigido solido distiche dichotomo 
piceo, ramis fastigiatis teretibus, apotheciis terminalibus plano-convexis, disco fusco-nigro.

Dill. Musc. t. 17. f. 37. Hall. hist. t. 47. f. 1. L. radiatus. Huds. L. corniculatus. Lightf. Lichen fucoides Wulf. in Jacqu. Coll. 3. t. 12. f. 3. Lichen tristis Weber Gött. t. 5. f. 1-3. Engl. Bot.t.72n. Fl. Dan. $t$. 1126. $f$. 2. Gornicularia. Hoffm. Pl. Lich. t. $34 . f .1$. et Ach. Lobaria rigida. Hoffm, Germ.

b. tenuior. L. rigidus. Wulf. in Jacqu. Coll.2.t.13. $f .5$.

Exs. Lich. Suec. n. 329. Ehrh. Crypt. n. 10. Moug. et Nestl. n. 646.

In rupibus alpinis \& subalpinis siccioribus Europæe fácile totius.

E basi communi, Fucorum more peltato-dilatata, plures adscendunt! rami tenaces, piceo-nigri. Sub disco stratum crassum, album. In septentrionalibus major nasci videtur. Apothecia variant integra \& radiata.

22. CETRARIA odontella, thallo fruticuloso cartilagineo rigido solido palmatim ramoso spadiceo, ramis planis dentatis, apotheciis terminalibus planis, disco fusco. Ach. syn. p. 230.

Lichen odontellus. Ach. Prodr. - Wahl. Fl. Lapp. n. 815. Suec. n. 1592. Cornicul. spadicea var. Ach. Lich. univ.

Exs. Lich. Suec. n. 113.

Ad saxa \& latera rupium irrigua in alpinis \& borealibus Scandinaviæ, nec infra Upsaliam lecta.

Cum formis tenuissimis C. islandicae vulgo commutatur ob colorem similem, at plurimis notis differt; loco, crescendi modo \&c. nec non apotheciis (in Norvegiæ subalpinis tantum lectis) cum priori potius convenit. Tota ccncolor, denso cæspite, jam primitus solida \& plana oritur. Rami erectiusculi, haud ciliato-spinulosi. Apothecia facie prioris, sed tenuiora, satis ampla.

23. CETRARIA aculeata, thallo fruticuloso cartilagineo rigido subfistuloso irregulariter ramosissimó spadiceo, ramis divaricalis flexuosis nigro- 
spinulosis, apotheciis terminalibus peltatis denticulatis, disco spadiceo. Fries Sched. Crit. 9. p. 32.

Vaill. par. t. 26. f. 8. Dill. Mlisc. t. 17.f. 31. Lichen hispidus. Lightf. - Engl. Bot. t. 452. L. spadiceus. Roth in Bot. Mag. 2. t. 1. t. 1. L. aculeatus. Ehrh.! Schreb. Coralloides. Hoffm.pl. Lich. t. 5. f. 2. Lobaria Hoffm. Germ. Cornicularia aculeata, spadicea, \& muricata. Ach. meth. t. 6. f.2. Exs. Lich. Suec. n. 261. Fl. Deutsch. n. 116-118. Moug. et Nestl. n. 168, 766.

Ad terram sterilem, siccam in montanis, uliginosam in planitiebus; item ad ligna putrida \&c. vulgaris.

Sequenti affinem \& congenerem semper habui, at vix cum Recentioribus varietatem dicam. Diversa vegetatio, diversa geographica distributio. Variat quidem utraque, ut omnes sequentes Cetrarix, tubuloso-fruticulosa \& foJiacea (cfr. var. $\beta$.), ita vero, ut in hac status fruticulosus normalis, in sequentibus foliaceus. Utriusque vidimus insignem seriem a tubulosa in foliaceam transeuntem, ubique luculenter diversam; immo in statu analogo distinctissimæ apparent. Basis tamen et in hac pallidior, subsanguinolenta. Rami apud nos normaliter fistulosi aut medulla laxa farcti, nisi justo tenuiores aut casu compressi ; sursum dilatati in peltas amplas, podicellatas, liberas, a sequentis speciei prorsus diversas.

$\beta$. hiascens, thallo in frondes ramosissimas dehiscente, apotheciis terminalibus liberis maximis. - Mich. gen. t. 39. f. 7.?

In alpibus Norvegicis detexil Blytt.

Thallus multo tenuior quam prioris.

24. CETRARIA islandio $x$, thallo cartilagineo foliaceo canaliculato laciniato ciliato-spinuloso olivaceo-castaneo, apotheciis oblique scutellatis lobis anticis adnatis integerrimis, disco badio. - Schaer. spic. p. $\mathbf{1}$.

a. Camer. epit. p. 783. f. 2. Buxb. Cent. 2.t.6.f.1. Mich. gen. t. 44. f. 4. Dill. Muss. t. 28. f. 111. Hall. helv. n. 1978. Lich. islandicus, Linn. et Auct. 
Wulf. in Jacqu. Coll. IV. t. 8. f. 1. Fl. Dan: t. 155. Eingl. Bot. t.1330. Sv. Bot.t. 34. Westring Färglaf. t. 16. Lichenoides. Hoffm. Pl. Lich. t. 9. f. 1. Lobaria. Hoffm. Germ. Cetraria. Ach. Physcia. Decand.

Exs. Lich. Suec. n. 174. Fl. Deutsch. n. 136. Schaer. Helv. n. 22. Moug. et Nestl. n. 15\%. b. platyna, latior, planiuscula, undulata. Hall. helv. n. 1979. Cetr. platyna. Ach. syn.

- c. crispa, angustior, crispata, laciniarum marginibus conniventibus. B xb. l. c. f. 2. Dill. Musc. t. 28. f. 112 .

Exs. Schaer. Helv. n. 23.

Ad terram sterilem \& glareosam in regionibus borealibus \& alpinis copiose.

Basis subsanguinolenta. Color intensitate variat. Inter reliquas formas præcipue insignis subtubulosa, divisione ceterum vulgaris, erecta, parce ramosa, sutura (thalli dehiscentis vestigio) ciliato-spinosa. Hæc semper sterilis \& ab omni Cetr. aculeata diversa.

25. CETRARIA cucullata, thallo cartilagineo subfoliaceo sinuato-laciniato ochroleuco, marginibus conniventibus undulatis, apotheciis lobis posticis adnatis, disco carneo-pallido. - $A c h$. Lich. univ. p. $5 \mathrm{r} \mathbf{1}$

Dill. Musc. t. 21. f. 56. 'B. Lichen cucullatus Bellardi. - Smith. Transact. Linn. Soc. 1. t. 4.f. 7. Platisma. Hoffm. Pl. Lich. t. 66. f. 2. Lobaria Hoffm. Germ. Physcia. Decand.

Exs. Lich. Suec. n. 173. Schaer. helv. n. 18. Moug. et Nestl. n. 544 .

Ad terram in alpinis \& montanis ; in Europa boreali in campos arenosos planitierum etiam descendit v. c. Scaniæ.

"Media quasi inter priorem \& sequentem" Smith. Basis subpurpurascens. Laciniæ læves, haud ciliato-spinulose. Apothecia prorsus Nephromatis Ach. (nec cucullata, sed lacinix fertiles cucullatæ) \& carneo-pallida (nec fusca) in plurimis speciminibus a me visis, tam e Norvegia, quam ex Europa Australi. - Adsunt quoque specimina prorsus tubulosa, ad qux quoque referenda videtur Duf. arctica. Laurer. 
- 26. CETRARIA nivalis, thallo subcartilagineo foliaceo lacunoso lacero-laciniato ochroleuco, laciniis canaliculato-patulis crispis, apotheciis marginalibus crenulatis flávescenti-carneis. - $A c h$. Lich. univ. p. 5 o.

Linn. Lapp. n.446.t.11.f.1. Dill. Musc. t.21.f.56. A. Lichen nivalis. Linn. et Auct. Vill. Delph. $t$. 55. Fl. Dan. t. 227. Sv. Bot. t. 384. Engl.Bot.t. 1994. Lobaria. Hoffm. Physcia. Dec.

Exs. Lich. Suec. n. 172. Schaer. helv. n. 19. Sommerf. Norv. n. 76. Ehrh. phyt. 60.

Patria \& loco cum priori prorsus convenit. Thallus ad basin plerumque flavescit; rarissime tubuloso-inflatus. Laciniæ scrobiculatæ, passim denticulis nigricantibus adsperse. Apothecia ampla, terminalia aut lobis anticis adnata.

** Thallo membranaceo, sterili subdepresso. Habitu ad Imbricarias valde accedunt, sed laciniæ concaviusculæ, fructiferæ suberectæ, apothecia terminalia, adulta peltata; discus strato albo impositus. Variant omnes marginibus laciniarum nudis \& pulverulentis.

27. CETRARIA glauca, thallo membranaceo foliaceo expanso sinuato-lobato adscendente glauco, subtus nigricante, laciniis fertilibus elongatis, apotheciis terminalibus peltatis e rubro spadiceis. Ach. Lich. univ. p. 509 .

a. fertilis, laciniis elongatis canaliculatis utrinque albicantibus, aut tantum maculatis. Mich. gen. $t$. 37 . Dill. $M$ sc. $t$. 22. f. 58 Lichen fallax. Weber. Platisma. Hoffm. Pl. Lich t. 46. Lobaria. Hoffm. Germ. Cetraria. Ach. meth. Physcia. Dec. - Lich. glaucus. Wulf. in Jacq. Coll. 4. t. 19. f. 2. degener, absque scutellis veris.

Exs. Lich. Suec. n. 112. (a \& b). Mougeot et Nestl. n. 156. (a).

b. sterilis, laciniis brevioribus latioribus subdepressis, subtus fusco-nigris. Moris. sect. $X V . t .7 . f .4$. Dill. Musc. $t$. 25.f. 96 . Lichen glaucus. Liinn. et Auct. Fl. Dan. t. 598. Hoffm. en. Lich. t. 20.f. 1. Lobaria. Haffm. Cetraria. Ach. meth. Physcia. Decand. 
Ad truncos arborum, rarius ad saxa \& terram in ericetis, per omnem Europam frequens; a. vero tantum in silvis montosis irriguis ad $\mathrm{Abi}$ etes, Betulas \&c.

Thallus subtus glaberrimus est, nec margine, licet sepe fimbriato, denticulato-ciliatus. Hujus monstrosa progenjes, cum Lick. parasitico Engl. Bot. fere comparanda, thallo diminuto vesiculas proferente, ut jam in icone citata Wulfenii videre licet, est Dill. $t .24 . f .82$. Lichen ampullaceus. Wulf. in Jacqu. Coll. 1. $t$. 4. f. 3. Platisma Hoffm. Pl. Lich. t. 13. f. 2. Apothecia ampla, facile deformia.

Præter formas allatas, synonymorum caussa potissimum memoratas, alix exstant magis notabiles, semper vero steriles, ut separatim describendas non censeam. Sic in saxis frequenter obviam venit paulo minor, magis laciniata, olivaceo-fuscescens. Ab hac discerni nequit Cetr. hypocarpa Pers.! marginibus albo-pulverulentis discrepans, ad cortices \& ligna obvia. Ejusmodi formæ pro Cetr. sapincola v. ulophylla sæpius venduntur. - Conferenda Parm. perlata.

28. CETRARIA sapincola, thallo membranaceo foliaceo adscendente laciniato e viridi olivaceofuscescente, subtus pallidiore, laciniis planis fertilibus brevibus, apotheciis lobis antice adnatis disco saturatiori. Ach. Lich. univ p. 507.

Lichen scutatus. Wulf. in Jacqu. Collect. IV. t. 18. f. 1. Lich. sxpincola. Ehrh. - Hedw. Stirp. Crypt. 2. t. 2. f. 1-10. Hoffm. enum. Lich. t. 14. f. 1 . Platisma. Hoffm. Pl. Lich. t. 14. f. 1. Lobaria. Ejusd. Germ. Lichen s. Peltigera chlorophylla. Willd. Exs. Lich. Suec.n. 170. Ehrh. Phytoph.n.90. Schrad. Crypt. n. 122. Flörk. n. 48.

Ad sapes, truncos, ramulos apprime juniperinos, Europæe precipue montosæ.

Præcedenti longe minor, apotheciis minoribus magis regularibus plerumque obtecta. Variat rarius sterilis, margine pulverulento (var. ulophylla), sed sub hoc nomine sxpe confunduntur status analogi Cetrariae glaucae \& Peltigr.a resupinatce. - Transitum ad Parmeliam olivaceam, cujus var. polycarpa auct. Flotow, non vidimus; differt quoque apotheciorum struetura. 
Hoc loco inserenda videtur Cetraria, statura C. sæepincolæe \& juniperinx, sed ochroleuca, ad ligna vetusta quercina in agro Femsjonensi obvia, sed cum sterilis tantum visa sit, tute distinguere non potui.

29. CETRARIA juniperina, thallo membranaceo foliaceo suberecto lacero-laciniato utrinque flavissimo, laciniis concavis nigro-denticulatis, apotheciis lobis antice adnatis acute marginatis, disco fusco-badio. Ach. Lich. univ. p. 506. $\alpha$. Lichen juniperinus. Linn. et Auct. Hoffm. en. Lich. t. 22. $f$. 1. Squamaria. Pl. Lich. t. 7. f. 2. Lobaria. Ejusd. Germ. Physcia. Dec. Fr. Usnea. Wallr. Cetraria Tilesii. Ach. syn. forma terrestris.

Exs. Lich. Suec. n. 171.Schaer. Helv. n. 20.

In Europa boreali vulgaris ad ramos Juniperi; ceterum in alpibus totius fere Europæ ad terram \& fruticulos varios.

Lepra (gonidiis Wallr.) Ixte flava hæc \& sequens ab affinibus facillime dignoscuntur. A sequente differt: colore saturate flavo, non virente, thallo rigidiori adscendenti-erecto, lacunuloso, repetito-laciniato, laciniis angustis, subcanaliculatis, laceris, margine nigrodenticulatis, apotheciisque. Variat vero etiam hæc marginibus leproso-pulverulentis, licet sæpissime nudi sint; \& in campis petrosis sterilissimis ölandiæ copiosissime obviam venit forma sterilis, prorsus erecta, tubulosa, anguloso-scrobiculata, maxime pulverulenta. Lich. juniperin. $\gamma \cdot$ alvarensis. Wahl. Suec.

3o. CETRARIA pinastri, thallo membranaceo foliaceo depresso rotundato-lobato viridi-fla vo, laciniis planis inermibus, apotheciis marginalibus obtuse marginatis, disco flavescente-badio. Sommerf. in Vet. Ac. Handl. 1823. p. 117.

Lichen pinastri. Scop. et Auct. Hoffm. en. Lich. $t$.

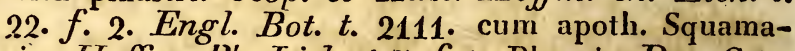
ria. Hoffm. Pl. Lich. t.7.f.1. Physcia Dec. Cetr. juniperina. $\beta$. Ach. Parmelia pinastri. Sommerf. Suppl. Lapp. p. 113.

Exs. Lich. Suec. fasc. XII. Schaer. Helv. n. 21. Ad cortices \& ligna arborum variarum, Be- 
tulce, Quercus, Pini silvestris \&c.; priori magis versus austrum descendens \& inferalpina, multisque locis, ubi illa prorsus deest, v. c. in agro Femsjonensi, vulgatissima.

Quamdiu hanc tantum sterilem margine pulverulentam, qualis sæpius occurrit,' \& priorem margine nudam legeram, de utriusque unione non dubitavi; jam vero, C. pinastri margine nudo \& $C$. juniperina pulverulenta visis, physiologice earum differentias explicare non potui, indeque, neutra in alteram directe transeunte visa, ex hujus operis principio, nil conjungere quod aperte et directe confluere non vidi, distinguere coactus fui, præcipue cum harum differentiis neglectis multas species, ab omnibus receptas, v. c. Cetr. nivalem \& cucullatam, conjungere coactus fuissem. - Priori tenerior est, e viridi lutescens, thallo depresso lævi, simpliciter lobato; lobis latis, planis, rotundatis, marginibus etiam nudis, numquam nigro-denticulatis. Thallum depressum, ut reliquas notas, e lepræ effusione non pendere testantur omnes Lichenes, cum lepra prorumpente non deprimantur, sed erigantur, sicut ipsa quoque $C$. juniperina. In Siberia frequentius fructificat. - Nihilo tamen minus pro prioris filia facile habeam.

\section{P EL T I G E R A.}

-Lichenoidis Dill. ser. III. div. 1. huc ex maxima parte. Peltigera. Hoffm. Decand. - Schaer. - Fries S. O.V. - Meyer. Peltidea. Ach. Meth. Peltidea, Nephroma, Solorina Ach. Lich. univ.

CHAR. Apothecia peltæformia, thalli lobis marginalibus, rarius disco, innata. Discus primitus clausus, aut inferus (in lobis posticis) aut velo thallode fugaci primitus obtectus. Thallus centrifugo-expansus, coriaceus, frondosus, subtus liber villosus, sappius venosus, cyphellis destitutus.

Thallo evidentissime distinguitur hoc subgenus; in genere quoque apotheciis, licet tam versus Cetrarias, quam Stictas \&c. limites acuti prorsus evanescant. Apothecia enim occurrunt omnino scutelliformia I. leviter modo obliqua, velum in speciebus apotheciis posticis saltim de- 
sideratur; eædem differentiæ in Sticta, Parmelia \&c. redeunt. Lecan. limbatam Sommerf. ab hoc genere removere nequimus. Nulla sane adest evidens ratio, hoc subgenus ut altioris dignitatis considerandi, quam Cetraria \& alia genera Parmeliacea. Nec bene ex media suarum proxime affinium serie divellitur.

* Apotheciis posticis, thalli lobis adnatis, reniformibus. Velim nullum. Thallus subtus avenius. Facile ut peculiare subgenus inter Cetrarias \& Peltigeras medium consideratur. Nephroma. Ach.

3. PELTIGERA arctica, thallo coriaceo-membranaceo glabro ochroleuco, subtus avenio nigricante, apotheciis posticis reniformibus aurantiacis. - Wahl. Lapp. p. 448.

Lichen arcticus. Linn. et Auct. Fl. Dan.1430. L. grönlandicus. Fl. Dan.t.466. L. antarcticus. Jacqu. misc. 2. t. 10. $f$. 1. Peltidea, dein Nephroma polaris. Ach. Exs. Lich. Suiec. n. 180.

Ad terram muscosam Scandinaviæ; Norvegiæ totius; in Suecia ab alpibus ad Ostrogothiam $\&$ Westrogothiam descendens.

Thallus pallide sulphureus, amplissimus, ut maximus fere sit Lichen in orbe, hinc Norvegis Jättebröd s. Placentæ gigantum; subtus adpresse tomentosus, dein nudus, in ambitu pallidior. Peltæ unciam latæ.

32. PELTIGERA resupinata, thallo cartilagineomembranaceo glabro subspadiceo, subtus avenio pallido, apotheciis posticis reniformibus $\mathbf{e}$ rufo fuscis. Ach. meth. p. 289 .

Mich. gen. t. 44. ord. XIII. $f .1,2$ habitu peregrino. Dill. Musc. $t$. 28. $f$. 105 . Lichen resupinatus. Linn. et Auct. Fl. Dan. t. 764. Wulf. in Jacq. Coll. 4. t. 12. f. 1. Peltigera tomentosa. Hoffm. Germ. Nephroma. Ach. Lich. univ.

b. papyracea, thallo tenuiore, subtus lævi nudo demum nigricante. Peltigera papyracea. Hoffim. Germ. Peltidea, dein Nephroma parilis. Ach.

Exs. Lich. Suec. n. 17y. (a. b.) Sommerf. Norv. 69. (a.) 70. (b.) Moug. et Nestl. n. 252.

c. levigata, thallo crassiore nitente, subtus nudo la- 
cunoso pallido, lobis fertilibus distinctis. Nephroma lævigata. Ach. syn. Peltidea Sommerf. Lapp.

d. helvetica, thallo subtus fusco-tomentoso, marginibus, prrcipue loborum fertilium, dentibus confertis fimbriatis. Nephroma helvetica. Ach. Lich. univ. Per omnem Europam, saltim montosam, ad bases truncorum \& rupium latera; b. locis irriguis ; c. alpinis ; d. valde umbrosis, optima ad ramos Pinuum in silva nigra regni Würtembergici. Hochstetter!

Priori longe minor, obscurior, magis complicata \& varians; transitus omnium varietatum evidens est; c. loevigata ceteris insignior ad Nephr. cellularem Ach. thallo reticulato-scrobiculato diversam accedit; var. helvetica e prolificationibus marginalibus tantum pendet, facie recedit. E colore disci, ex rtate \& loco plus minus obscuro, haud distinguendx varietates, multo minus species. - Variat porro thallo sorediifero \& marginibus pulverulento. Dill. l. c. f. B. C. Engl. Bot. t. 2360. Moug. et Nestl. n. 838.

* Apotheciis antice thalli lobis productis, raro margini, adnatis. Velum in plerisque evidens, in ultima specie ægre observandum, in exoticis v. c. Pelt. Gröndaliana (Sticta Ach. Erioderma po!ycarpa Fée) desideratum, sed omnibus thallus simillimus subtus venosus, hygrophanus h. e. e statu udo \& sicco colore mutabilis.

Species valde affines, at in speciminibus perfectis facile discernendæ, optime a Dillenio \& Wulfenio propositæ \& pictæ. Cavendum ne e thalli magnitudine, lobis in omnibus crispatis \& in plerisque pulverulentis visis - vel ex apotheciis majoribus \& minoribus, sessilibus aut elevatis, solitariis aut polydactylis e. s. p. distinguantur species. Forma quoque apotheciorum caute adhibenda; etiam in Peltig. canina, rufescente, polydactyla \&c. primitus rotundata \& ex apice, quod evidentissimum in P. malacea \& aphthosa, revoluta sunt. Ex his tanien, si pauciores optaveris species, quattuor primarias distinguere poteris 1. P. malaceam et aphthosam; ?. $P$. caninam, rufescentem et polydactylam; hæc vero simul accedit ad 3. P. horizontalem. 4. P. venosam. Disci color semper e carneo-rufo fuscescens aut nigrescens, intensitate varia, in diversis spiciebus tamen sat 
constante, at non characteres tam evidentes offerente, ut in definitionibus specierum recipere potuerim.

33. PELTIGERA malacea, thallo spougioso molli lævi livido-fusco (cinerascente), subtus tomento denso nigrescente, versus margines incano, avenio foveolato, apotheciis anticis adscendentibus orbiculatis crenulatis. Ach. syn.p. 240. Exs. Lich. Suec. n. 177. Fl. Deutsch. n. $13 \%$.

Ad terram inter muscos in campis sterilibus $\&$ ad montium latera; e plurimis Europæe plagis vidimus.

Est inter evidentissimas, nec rariores, ut mirandum sit eam apud Veteres Auctores non aut obiter tantum esse memoratam. Sequenti, nullo pacto $P$.caninae aut $r u-$ fescenti, proxima. Ab omnibus differt tomento pagina inferioris densissimo spongioso crasso, unde totus thallus insigniter crassus \& spongiosus, ex maxima parte in vegetis nigricante, in siccis \& versus marginem incanescente, venas obliterante; proprie enim venæ tomento ita dilatantur ut omnem superficiem inferiorem æequaliter occupent, relictis tantum foveolis quibusdam albicantibus. Hac tomenti indole impeditur fibrillarum evolutio, ut sæpissime prorsus nullæ adsint, nec nisi rarius illarum fasciculos nigros sparsos vidimus. A sequente insuper vegeta e longinquo dignoscitur thallo semper verrucis destituto \& fragillimo, valde obscuro livido-fusco aut nigrescente, lobis superne subtomentosis, ceterum nudo, apotheciis pulchre crenatis, numquan quantum vidimus revolutis, obscurioribus, siccis eleganter badioatris.

34. PELTIGERA aphthosa, thallo coriaceo molli verrucoso lætissime viridi (glaucescente), subtus venis nigrescentibus reticulato fibrilloso, apotheciis anticis adscendentibus rotundis, margine lacero. Hoffm. Germ. 2. p. 107.

Dill. Musc.t. 28. $f$. 106. Lichen aphthosus. Linn.et Auct. Fl. Dan. t. 767. f. 1. Wulf. in Jacqu. Coll. IV. p. 266. t. 17.! Engl. Bot. t. 1119. Peltigera s. Peltidea Hoffin. Pl. Lich. t. 6. f. 2. - Ach. - Sv: Bot. t. 318. L. veriucosus. Web. 
Exs. Lich. Suec. n. 178. Flörke Deutsch. n. 49. Schaer. Helv. n. 29. Moug. et Nestl. n. 251. Ad terram supra muscos in campis sterilibus \& silvis Europæ totius abunde.

Colore vegetæ lætissimo, subflavescente, verrucis in pagina superiori, ceterum lævi \& glabra, impressis, apotheciis vix umquam elongatis, revolutis tamen $\&$ verticalibus simul obviis, \& tota facie eminus dignoscitur. Thallus amplns, minus quam prioris, magis quam sequentium fragilis, subtus ad oras incanus, fibrillis paginæ inferioris, ubi loco magis adnatus, minus evidentibus; apothecia e carneo rubra.

35. PELTIGERA canina, thallo membranaceo flaccido scrobiculato tomentoso fusco-viridi (cano), subtus venisque albis, fibrillis ambitus candidis, apotheciis anticis adscendentibus rotundatis, demum semirevolutis verticalibus. Sched. Crit. 4. p. 23.

Vaill. par. t. 21. $f$. 16. Dill. Musc. t. 127. $f_{\dot{J}} 102$. Lich. caninus. Linn. et Auct.plurr. Wulf. in Jacqu. Collect. IV. p. 260. t. 14. f. 1. pro more optime. Engl. Bot. t. 2299. Peltigera canina. Hoffm. Ach. meth. $\alpha$. $\beta$. $\gamma$. Mart. P. leucorhiza. Flörke. P. canina albescens. Wahl. Lich. univ.

Exs. Lich. Svec. n. 111. Lichen. Flörk. Deutsch. n. 153. Moug. et Nestl. 154. Schaer. Hielv.n.28. saltim ex meo specim.

b. pusilla. Dill. l. c. $f$. A. B. C. D. Pelt. spuria. Ach. meth. - Dec. fr. ex spec.!

Exs. Moug. et Nestl. n. 83\%.

Ad terram \& saxa inter muscos, vulgaris.

Thalli tenuitate \& laxitate, ut inter venas superne scrobiculatus sit, pagina superiori præcipue in statu sicco tomentosa venisque paginæ inferioris vegetis carneo pallidis, primo obtutu dignoscitur. $\mathrm{Ob}$ hanc thalli indolem veras polydactylas formas aut margine crispalo-pulverulentas, quantum vidimus, numquam profert. Fibril$l_{\mathfrak{r}}$ vetustiores fuscescentes. Apothecia inter prioris \& sequentis media. - Speciem semper habitu proprio distinctam inveni, nec cum sequenti jungam, ob, venas mortificatas subinde obscuriores \&c. P. spuria Ach. certe ad hanc, licet icon sequentem fere referat. 
36. PELTIGERA rufescens, thallo coriaceo molli lævigato subtomentoso cinereo-virescente (cinereo, subrufescente), subtus venis nigrofuscis reticulato fusco-fibrilloso, apotheciis anticis mox verticalibus oblongis revolutis. Sched. crit. l. $c$. Mich. gen t. 44. ord. 12.f. 2. Dill. Musc. t. $2 \%$. f. 103. Lich. rufescens. Necker et Auct. Engl.Bot.t.2300. Peltigera. Hoffm. Germ. - Ach. meth. P. canina s. crispa. Ach. Lich. univ. P. canina var. malacea. Wahl. Suec. (minime P. malacea Ach.). Pelt. ulorrhiza. Flörke. P. obseura. Schaer. - forma polydactyla: L. polydactylus. Wulf. in Jacq. Coll.IV. p. 262. t. 14. $f .2$. Pelt. polydactyla. var. spuria: Flörke. Exs. n. 74.

Exs. Lich. Suec. n. 110. Fl. Deutsch. n. 154.

Cum priecedente, qua fere vulgatior est; etiam ad saxa \& truncos.

$\mathrm{Si}$ affinitas duarum specierum ad eas conjungendas sufficiat, hæc sane cum priore jungatur, at si habitui constanter diverso \& diversæ in natura vegetationis historiæ major vis tribuatur, utique separanida; nec umquam vidi specimen, quod quo referrem, dubitavi. Secutus itaque sum Patres, qui in speciebus distinguendis magis plantam ipsam, quam characteres, contra Recentiores, respiciunt, speciatim Dillenium, quem audiamus: "Magna huic cum priori intercedit similitudo, ita ut, nisi ab exercitato, non facile distinguatur. Differt autem ab illa his præcipue notis: primo foliis crassioribus, rigidioribus \& minoribus, in angustiora \& profundiora segmenta divisis marginibus introflexis sinuosis \& crispis (sæpe pulverulentis); dein colore, qui huic obscurior est, per siccitatem rufescens; tandem superficie inferiore magis villosa \& radiculis nigricantibus bievioribus magisque cirrhosis." Insuper tota vegetatio alia in speciminibus perfectis: in priori lobi uniformes, ambitus rotundato-lobati peltiferi ; in hac ambitus explanati laciniati steriles, discoidei erecti angustiores fertiles. Apothecia, in hac frequenter polydactyla, obscuriora, mox magisque revoluta, elongata \&c.

- 37. PELTIGERA polydactyla, thallo papyraceo lævi glaberrimo nitido plumbeo-virescente (cæsio, fumoso), subtus nudiusculo venis, fuscis re- 
ticulato, apotheciis anticis adscendentibus, adultis revolutis. Fl. Deutsh. Lich. 9. p. ro.

a. Dill. Musc. t. 28. $f_{\cdot} 107,108$. Lich. polydactylus Necker. Peltigera s. Peltidea. Hoffm. Pl. Lich. t. 4. $f$.1. Ach. cum varr. P. canina v. rufescens. Wahl. Suec.

Exs. Lich. Suec. n. 109. Fl. Deutsch. n. 175, 192. Schaer. Helv.n. 30. Moug. et Nestl.n.633. b. scutata, subobscurior, apotheciis primo transversim oblongis, demum erectis revolutis. Lichen rufescens. Wulf. in Jacqu. Coll. IV. p. 263. t. 15! Peltid. hymenina. Ach. meth. (dein sub P. horizontali). P. rufescens. Schaer.! spic. p. 15. in adnot. $-\&$ minor: Mich. t. 44. f. 6. Lich. scutatus. Engl. Bot. t. 1834. - Peltid. scutata \& collina. Ach. P. canina. v. glabra. Ach. syn. P. glacialis Schleich. P. horizontalis. v. collina. Wahl.

Ad terram inter muscos, ad basin truncorum Europæ totius, minime rara.

De nexu omnium, quas huc retuli, formarum certus sum, nec a. \& b. stricte limitari possunt. A proximis singulis thalli partibus eximie differt. In umbrosis omnino-membranaceus evadit. Fibrillæ vulgo desiderantur; si adsunt, accidentales, fuscæ fasciculatim inter venas spongiosas sparse. Apotheciorum ruforum, dein fuscorum, situs dactylinus non constans est, sed in hac specie frequentior. In genere inter præcedentes \& sequentes media, his propius fere accedens. - Controversias synonymorum omnes solutas spero. Lichenoides digitatum rufescens Dill. p. 203 certe est prior; ex unico, lapsu exorto, verbo "glabro" huc perperam relatum. Lich. rufescens Wulf., cum eodem a plerisque confusus, a Flörkeo ad sequentem relatus, revera est præsens. Cfr. descr. apothec. l. c.

38. PELTIGERA horizontalis, thallo coriaceo lacunuloso glabro nigro-virescente (cinereo-rufescente), subtus venis nigris reticulato, apotheciis anticis transversim obiongis planis horizontalibus. Hoffm. Germ. 2. p. 107.

Michr t. 44. ord. 12. f. 1. Dill. musc. t. $28 . f$. 104. Lichen horizontalis. Linn. et Auct. Wulf. in Jacq. Coll. IV. p. 263 t. 15. Engl. Bot.t. 888. Fl. Dan. 
t. 533. Peltidea. $\alpha_{.}$\& $\gamma$. Ach. syn. P. muscorum. Schleich. Cat.

Exs. Lich. Suec. n. 209. Schaer. helv. n. 2\%. Moug. et Nestl. n. 345 .

Ad rupes udas silvaticas, inter muscos, Europæ totius vulgaris.

Prioris b. cum qua sola confundi potest, tam thalli indole, quam apotheciis demum erectis revolutis facile dignoscitur. - Exstat tam hujus quam duarum præcedentium formæ margine pulverulento.

39. PELTIGERA venosa, thallo coriaceo flabelliformi simplici læte viridi (cinereo), subtus albo venis ramosis divaricatis fusco-nigris variegato, apotheciis lobis anticis adnatis rotundis horizontalibus. Ach. Lich. univ. p. 5 r 4. Mich. gen. t.44. ord.12. $f$. 3. (f. 5. apotheciis rubris). Dill. m'sc. t. 28. $f$. 109. Lichen venosus. Linn. et Auct. Wulf. in Jacq. Coll.1V.p. 271. Engl. Bot. t. 887. Fl. Dan. t. 1125. f. 1. Peltigera. Hoffm. Pl. Lich. t. 6. f. 2.

Exs. Lich. Suec, n. 176. Ehrh. Crypt.n. 29. Schaer. Helv. n. 26. Moug. et Nestl. n. 153.

Ad terram nudam montosam Europæ totius, at non ubique.

Distinctissina, mimima, unciam vix superans, apotheciis a prioribus recedens; hæc enim non lobis propriis metamorphosi mutatis, sed ipsi thallo adnata sunt; velum obsoletum; forma oblique scutellata, exacte Cetrariæ; margo subtus liber \& decorticatus ut in Stictis optimis. Thallus autem verum locum designat.

*** Apotheciis subrotundis, lamince thalli adnatis, maculaeformibus, velatis. Margo e velo formatus fugacissimus. Solorina. Ach. Lich. univ.

40. PELTIGERA crocea, thallo coriaceo lobato obscure viridi (cinnamomeo), subtus croceo! venis ramosis anastomosantibus, apotheciis laminis thalli applanatis spadiceis. Wahl. Lapp. p. 445

Linn. Lapp. t. 11. f. 3. Dill. musc. t. 30. f. 120. Lichen croceus Linn. - Fl. Dan. t. 263. Thulf. in 
Jacq. Coll. IV. t. 11. f. 2, 3. Engl. Bot. t. 498. Peltiger. Hoffm. Pl. Lich. t. 41. f. 2-4. t. 42. f. 4, 5. Solorina. Ach.

Exs. Lich. Suec. n. 298. Schaer. Helv. n. 24.

Ad terram alpium Europæ totius; in Scandinavia boreali in planities descendit.

Venæ fere præcedentis, haud fibrillosæ. Apothecia subtus non radicant, hinc adultiora fere convexa; nec ullo modo saccato-immersa ut in sequente.

4r. PELTIGERA saccata, thallo membranaceo subimbricato læte viridi (viridi-cinerascente), subtus albo avenio fibrilloso, apotheciis laminæ frondis applanatis, mox saccato-depressis nigrofuscis. Dec. fr. 2. p. 408.

Mich. gen. t. 52. f. 1. Dill. Musc. t. 30. f. 121. Lichen saccatus. Linn. - Fl. Dan. t. 532. f. 3. Engl. Bot. t. 288. Peltid. Ach. meth. Solorina. Ach. Lich. univ.

Exs. Lich. Suec. n. 175. Ehrh. Crypt. n. 9. Schaer. helv. n. 25. Moug. et Nestl. n. 61.

Ad terram \& rupes, locis umbrosis irriguis, præcipue alpinis, Europæ totius.

Apothecia primo ut in priori superficialia, dein veto radicando peculiari modo depressa. - Duplex forma: a. vulgaris, tenuis, magis foliacea, nuda, sicca viridi-cinerascens; \& b. pruinosa, crassior, placodioidea, glaucopruinosa, sicca fuscescenti-cinerea. Hanc in Iföklack Scanix reperi, etiam e Germania habeo. Apothecia conveniunt. Limaces thallum sxpe devorant, reśtantibus solis apotheciis.

Hujus porro subdivisionis est: Lecanora limbata, thallo imbricato squamoso-phylloideo, lobis inciso-crenatis cinereis, apotheciis amplis lamina proligera urceolata badia, margine proprio (velo) integerrimo, accessorio foliaceo plano sublobato virescente. Sommerf. Lapp. p.105. t. 3. Sommerfeltia arctica. Flörke, locis similibus obvia, quam pro prioris individuis junioribus in crusta peregri-, na parasiticis potissimum habeo; at, negante inventore, cui optima specimina debeo, meum judicium suspendo.

\section{S T I C T A.}

Lichenoidis Ser. II. subdiv. 4. Dill. ex max. parte. 
Pulmonaria. Hoffm. Pl. Lich. Lobaria \& Sticta. Dec. Fr. Sticta \& Parmel. spec. Ach. - Fries. S. O. V. - Sticta. Delise Monogr. Stict. Paris. 1825.

CHAR. Apothecia scutelliforma, margini aut disco thalli adnata, margine (sæepe obliquo) subtus libero. Discus primitus clausus nuclei instar sub strato gonimo oriens, dein elevatus explanatus nudus, strato medullari impositus. Thallus e centro expansus, foliaceus, coriaceo-cartilagineus; subtus villosus, cyphellis maculisve discoloribus variegatus nec venosus.

Quamquam hoc subgenus, sensu emendato Cel. Delise, valde naturalem sectionem efficit, non parum miratus sum Cel. Meyer id contra sua principia, habitum prorsus negligendum jubentia, ut genus autonomon \& altioris dignitatis, quam reliqua genera Parmeliacea, considerasse. Characteres, quos laudat carpologicos, partim vagi, partim fallaces. Stricte enim haud dicas hujus apothecia magis disciformia \& submarginalia, quam multorum (v. c. Cetrarice), sub Parmeliis ejus comprehensorum. Lamina in eisdem non minus cornea, in multis autem præcipue junioribus Stictis carnoso-ceracea. Excipulum in optimis speciebus strato corticali non orbatum est 1 . thallo discolor, licet hunc characterem et nos tam in Stictis, quam verissimis multis Parmeliis eximium viderimus. Cyphellæ ad characteres carpologicos non referendæ, ceterunque exceptionem admittunt. Characteres carpologici revera difficiles, nisi genus mere in characterum favorem construere velis. Allatos magis essentiales censeo. Eximie confirmantur thalli habitu.

* Cyphellis perfectis, normalibus, luteis. Sectio tropica, vix in Europa fructificans.

42. STICTA aurata, thallo submembranaceo laciniato-lobato glauco-rutilante, subtus tomentoso cyphellis sorediiformibus citrinis adsperso, apotheciis marginalibus subpeltatis obliquis, margine citrino, disco badio-purpureo. Delis. Stict. p. 49. t. 2. f. 5,6 .

Dill. musc. t. 84. $f$. 12. Platisma crocatum. Hoffm. Pl. Lich. t. 38 . Lichen auratus Smith. - Engl. Bot. t. 2359. Sticta. Ach. sine fruct. Sticta croca- 
ta. Dec. Fr. Parmelia aurata. Eschw. Lich. Bras. t. 14. $f$. 1. nitidiss.

Inter muscos ad terram \& truncos Europæ maxime occidentalis, Hispaniæ!, Angliæ! Galliæ in Bretagne. Prevost! (frequentior in America, præcipue calidiori, ibique fructifera!)

Speciosa, cun alia Europæa haud commutanda, sed in peregrinis terris variæ affines. Thalli color variat, etiam fuscescescens \& virens; in sterilibus margines crispati pulverulenti. Apothecia prorsus Cetrarice, etiam strato corticali obducta. Cfr. Eschw. l. c.

Specimina STICT A CROCAP E Auct. (Engl. Bot. t. 2110) Europrece, ut jam observavit Meyer, a priori tute distingui nequeunt. ExtraEuropora vero adsunt exemplaria evidenter diversa. Suudente Smithio priori a ur at ce nomen servandum puto.

** Cyphellis perfectis, normalibus, albidis. Europæ occidentalis incolæ, valde affines.

43. STICTA silvatica, thallo coriaceo-membranaceo laciniato-lobato lacunuloso vireseentefusco, subtus pallidiori tomentoso, cypheilis urceolatis albis excavato ("apotheciis marginalibus peltatis rufofuscis"). Ach. Lich. univ. p. 454. Mich. gen. t. 43. ord. XI. Dill. Musc. t. 27. f. 101. L. silvaticus Linn. - Wulf. in Jacqu. Collect.IV. t. 12. f. 2. Engl. Bot.t. 2298. Pulmonaria. Hoffm. Pl. Lich. t. 4.f. 2. Peltigera. Hoffim. Germ. Sticta. Del. Stict. t. 7. f. $27 . A$.

Exs. Lich. n. 79. Moug. et Nestl. n. 155.

In silvis montosis, præcipue ad latera rupium muscosa irrigua, Europa occidentalis ab Austria \& Hispania ad Sueciam.

Pendet hujus differentia a Stict. fuliginosa unice fere ab iconibus Dillenii, Wulfenii, Hoffmanni \& Smithii, apothecia exacte Peltigeræ offerentibus, nam thallus hujus etiam quoad formam variat rotundatus minus laciniatus, \& granulis fusscis, quæ insuper characterem specificum offerre nequeunt, utraque adspersa occurrit. Acute suspicatur Cel. Delise, inventis normalibus apotheciis in speciminibus americanis, qux equidem ad S. fuliginosam referrem, apothecia hæc apud Dillenium a Peltigera quadam ortum ducere reliquosque sua ab eo mut uatos, sed ob auctoritatem præcipue accuratissimi auto- 
ptæe Wulfenii adhuc dubia superesse videntur. Dillenius quoque utramque accurate comparat. Re itaque ambigua, subjungenda est:

* STICTA fuliginosa, thallo coriaceo-membranaceo orbiculato rotundato-lobato rugoso lurido; subtus pallidiori tomentoso, cyphellis cancavis albidis adsperso, apotheciis sparsis sessilibus - orbiculatis rufis, margine decorticato pallidiori. Ach. Lich. univ. p. 454.

Dill. Musc. $t$. 2. $f .100$. A. Lich. fuliginosus. Dicks. - Engl. Bot. t. 1103. Sticta. Dec. Fr. 2. Delis. Stict. t. 6. f.20. S. silvat. $\beta$. Hepp. Würtzb. p. 26. Exs. Moug. et Nestl. n. 542. (fere S. sylvatica ipsa).

Cum pracedente rarior in Anglia!, Gallia Dufour!, Helvetia Schleich.', silva nigra regni Würtembergici Hochstetter! \& in oris occidentalibus Sueciæ, Norvegix Blytt!

Aegre in statu sterili a priori distingui potest thalli forma, colore obscuriori, efflorescentiis isidioideis frequentioribus, at genuinos characteres non offert. Apothecia vero, qualia Auctores citati prioris pingunt, tantum differunt, ut, nisi prioris erronea exhibeantur, vix conjungenda sint. In $S$. fuliginosa normalia certe sunt, in lamina frondis sparsa, sessilia, orbiculata, ob excipulum decorticatum Biatoræ similia, at vere thallinum est $\&$ primo clausum. - His porro accedit Sticta Dufourei Delis. Stict. t. 6. f. 22 , helvolo-fusca, at sterilis tantum lecta. 44. STICTA limbata, thallo membranaceo orbiculato lævi fusco (glaucescente), ambitu sublobato, subtus pallido tomentoso cyphellis urceolatis albidis adsperso, apotheciis sparsis adpressis ferrugineo-fuscis. Ach. Lich.univ. p. 236 . Dill. Musc. t. 20. f. 100. B. C. Lich. limbatus Smith. - Engl. Bot.t. 1104. Sticta. Delis. Stict. t.7.f.24. Inter muscos ad truncos \& rupes Europæ maxime occidentalis, a St. Sever Galliæ (Dufour!) ad Norvegiam (Blytt), frequentior in Britannia!, Armorica!, rarior in Helvetia (Schleicher!) \& Baden (Laurer!) 
Priori geminæ speciei affinis, at omnino diversa. Thallus minus lobatus vel omnino integer, lævigatus, pallidior, numquam illius efflorescentiis isidioideis, semper vero in Europa sorediis granulosis cinereo-cæsiis versus marginem adspersa. (Ex America normalem \& nudam vidimus). Apothecia ad prioris typum pertinent; ex Cel. Delise thallo immersa, convexa, immarginata.

*** Thallo, cyphellarum loco, subtus maculis nudis pallidis variegato.

45. STICTA scrobiculata, thallo coriaceo laxo scrobiculato plumbeo (glaucescente), lobis rotundatis subintegris, subtus tomentoso maculis nudis albis, apotheciis sparsis decorticatis e rufo fuscis. Ach. Lich. univ. p. 453.

Mich. gen. t. 49. ord. XXI. Dill. musc. $t$. 29. f. 114. L. scrobiculatus. Scopol. - Fl. Dan. t. 1007. Engl. Bot. t. 497. Lich. verrucosus, Huds. - Wulf. in Jacq. Coll. IV. t. 18. $f$. 2. Pulmonaria. Hoffm. Pl. Lich. t. 1. $f$. 1. Lobaria. Ejusd. Germ. Lich. plumbeus. Roth. Bot. Mag. 2. t. 1. f. 2. Parmelia scrobiculata. Ach. meth. Lobaria. Dec. Fr. Sticta. Delis. Stict. t. 18. f. 69 .

Exs. Lich. Suec. n. 78. Moug. et Nestl. n. 444. Inter muscos ad truncos \& rupes Europæ totius, at copiosior \& fructificans in occidentali $a b$ Italia ad Finmarkiam usque.

Thallus amplus, junior orbicularis, adultior \& præcipue fertilis sorediis adspersus. Apothecia in frondis lamina sparsa, integerrima, excipulum thallodes decorticantia, unde extus subfurfuracea, sæpe in ipsis sorediis sita, disco ceraceo.

-46. STICTA pulmonacea, thallo coriaceo laxo lacunoso-reticulato saturate viridi (subcervino), laciniis elongatis discretis sinuato-lobatis, subtus tomentosis maculis nudis albis, apotheciis submarginalibus decorticantibus rufis. Ach.Lich. univ. p. 449 .

Fuchs Hist. p. 633. ic. Mich.gen. t.45. Dill. musc. t. 29. $f$. 113. Lichen pulmonar. Linn. - Engl:Bot. t. 572. Westr. Färglaf. t. 20. Lobaria. Hoffm. 
Germ. Sticta. Delis. Stict. t. 14. f. 60-65. plur. formx. Pulmonaria reticulata. Hoffm. Pl. Lich. $t$. 1. $f .2$. Sticta linita. Ach. syn. p. 234.

Exs. Lich. Suec. n. 77. Moug. et Nestl.n.62. Flörke Deutsch. n. 179.

Ad truncos arborum vetustarum, raro rupes, Europæ totius, vulgatissima.

Nostratium amplissimos habet lobos; sorediis, immo frondibus prolificantibus, passim adspersa. Apothecia non perfecte decorticata, sed excipulum discolor, rimulosoverrucosum; discus ut in St. aurata corneus, nec ut in reliquis præcedentium mollior ceraceus, quare in his disci color magis mutabilis est. Variant autem deformata, tam in disco frondis, quam pagina inferiori erumpentia, nigricantia, sæpe immarginata \& corrugata. Pro Lecanora parasitante hæc habet Flörke, (potius pro fungosa haberem), at morphosi apotheciorum certe orta sunt, ut bene observavit Celeb. Delise.

*** Thallo subtus immaculato, (neglectis cicatricibus thallo adfixo a matre soluto ortis); cyphellis veris, sed accidentalibus et rarissime obviis. Thallus Imbricariarum more expansus \& adfixus.

47. STICTA glomerulifera, thallo coriaceo-cartilagineo adpresso lævi pallide viridi (glaucescente), laciniis e: ungatis sinuato-lobatis, subtus villosis, apotheciis sparsis, margine thallode inflexo persistente, disco e testaceo spadiceo. Delis. Stict. p. 129. t. 15. f. 54, 55.

Mích. gen. t. 46. ord. XVII. Dill. musc. t. 26. $f$. 99. Lichen glomerulif. Lightf. - Engl. Bot.t.293.

Lobaria Hoffm. Parmelia. Ach. L. amplissimus Scop. L. laciniatus. / uds. L. grandis. Pers. Ann. Bot. Exs. Lich. Suec. n. 327. Moug. et Nestl. n. 346. Ad rupes \& arborum truncos Europæ præcipue occidentalis, ab Italia \& Corsica Schleicher! ad Nordlandiam. Copiose in Suecia occidentali.

Orbes in statu perfecto maximos generis (tripedales usque diametro!) format, sed vulgo minor \& minus regularis. Laciniæ autem priorum longe angustiores (haud ultra $\frac{1}{2}$ unc. latæ) subimbricatx, normaliter certe læves, quamquam in senilibus sæpe insigniter transversim cor- 
rugatx. Colorem junioris tivido-virentem, in forma quadam, superficie pulveraceo-fatiscente, lacteum vidi. Subtus ex albido fuscescens, vix ochraceus. Maxime insignes sunt glomeruli (fruticulosi, subgeletinosi, pulverulenti, atrovirides), sæpius, non semper, e thallo, ad unciæ usque diametrum, enati (pro Collemate parasitico quoque habiti), quorum analogi inter Umbilicarias potissimum quærendi. Ex thallo certe hujus generis; cyphellæ veræ visæ sunt; lobi ad prioris typum apice oblique emarginati. Apothecia Parmeliæ faciem præ se ferunt, at mihi excipulo thallodi persistenti corticato 1 . decorticato parum tribuenti hujus generis quoque videntur. Primo enim mamillosa, pertusa, nucleo exacte Stictarum sub strato gonimo latente; dein elevata, scutelliformia in disco loborum sita, margine vere thallode tenui parum inflexo integro crenatove. Discus corneus, strato medullari impositus! At vidi in speciminibus quibusdam stratum gonimon duplex, alterum integrum sub disco, alterum s. normale centro perforatum, sub strato apotheciorum medullari.

48. STICTA herbacea, thallo membranaceo adpresso lævi obscure viridi (glaucescente, subfusco), subtus villoso!, laciniis sinuato-repandis apice rotundatis, apotheciis sparsis, margine thallode inflexo subdecorticante, disco rufo. $D e$ lis. Stict. p. 132.

Moris. Hist. III. Ser. 13. t. \%. f. 3. Dill. Musc. t. 25. $f$. 98. Lichen herbaceus. Huds. - Fl. Dan.t. 1127. Pיlmonaria. Hoffm. Pl. Lich. t. 10. f. 2. Lobaria. Ejusd. Germ. Parmelia Ach. (cfr. Syn. p. 341). - Lich. lætevirens Lightf. - Engl. Bot. t. 294.

Exs. Lich. Suec. fasc. XII. Ehrh. Crypt. n. 50. (Lichen mutabilis).

Ad rupes \& radices arborum Europæ præcipue occidentalis, ab Hispania! ad Norvegiam!

Priori minor, tenuior; humida herbacea, saturate viridis; sicca subcoriacea, in umbrosis glaucescens; in apricis fuscescens. Lobi breviores, sed latiores, numquam glomeruliferi; variant lævigati \& senio rugulosi, nudi \& glaucopruinosi. Apothecia juniora prioris simillima, sed in adultis stratum corticale sæpe exuitur, ut excipulum 
a thallo discolor sit, rimuloso-verrucosum; margo tenuis crenulatus.

\section{PARMELIA.}

Lichenoidis spec. Dill. Parmelia. Fries. S. O. V. exclus. Lobaria. Reliqua syn. infra.

CHAR. Apothecia scutell:formia, orbicularia, thalli disco horizontaliter adnata, margine thallode æquali. Discus primo conniventi-clausus subceraceus. - Thallus e centro horizontaliter expansus, bilateralis, forma varius, hypothallo suffultus.

De situ horizontali adnotandum, hunc ad matricem in situ horizontali positam referendum esse, indeque ficillime dignoscuitur ab Usneis, Evernïs, Ramalinis \&c., qux verticaliter a basi sua surgunt. Exstant quoque nonnullæ formæ aberrantes Parmeliarum foliacearum, a loco non horizontali pendentes, adscendentes, sed numquam erectæ evadunt vel ut genera citata locis similibus pendulæ. Differunt insuper hypothallo fibrilloso, strato corticali subtus nullo, apotheciis primitus clansis dehiscentibus \& præcipue eorum situ e. s. p. - In genere autem fatendum characteres carpologicos adhuc nimis subtiles \& negativos potissimum esse, at hxc difficultas tollitur, si vastissimum Parmelix subgenus in plura dissolvitur. Ad hæc vero stabilienda parum admodum confert thalli forma, in eadem specie sæpe foliacea, subeffigurata \& crustacea ; certiores \& cum habitu genuino (qui aliud est ac facies externa, sensu Linnæano, habitus a recentioribus plerumque dicta), conspirantes characteres offert disci indoles, ejusque situs vel supra stratum gonimon vel supra stratum medullare e. s. p. Omnes species, in quibus excipulum proprium sub disco adest, re ipsa e Lecidearum serie sunt, licet sæpe margine thallode spurio (cum thallo leproso plerumque conjuncto) circumvallentur. Ex principiis indicatis in adumbratione manuscripta Systematis Lichenum disposui; at ex hujus opusculi ratione, non omnes receptas opiniones uno ictu offendere, sed tirones ad novam constructionem sensim adducere, (reformationem enim, non revolutionem Lichenologice intendo), receptas sectiones a thallo foliaceo, crustaceo-effigurato \& crustaceouniformi, novis \& certioribus differentiis suffultas servavi. 
SEct. I. Thallo foliaceo, a matre discreto, cui adnatus hypothallus fibrillosus. Lobaria Hoffin. Imbricaria. Dec. Parmelia Ach. - additis speciebus apud omnes dispersis.

Trib. I. IMBRICARIA. Apothecia elevata, subpodicellata, regularia; disco tenu:ssimo, nudo, strato gonimo imposito!' Thallus imbricato-foliaceus, ex apoth. abortu sape nigro-punctatus. Tribus eximie naturalis, cui vero plures crustacex prorsus accedunt. - In hac \& sequentibus sectionibus, specierum divitibus optime observantur quattuor Lichenum memoratx series, glauca, olivaceo-spadicea, ochroleuca, citrina. Admiranda analogia inter species diversarum serierum intercedit, sed etiam maxime analogæ species v. c. $\boldsymbol{P}$. perlata \& tiliacea, $\boldsymbol{P}$. corrugata, $\boldsymbol{P}$. caperata c. s. p. non inter se, sed speciebus sux seriei proxime affines sunt. Sed hæc affinilas non in hac tantum sectione continetur, sed in sequentibus continuatur, ita ut species singulæ subdivisionis cum analogis suis sequentium sectionum seriem omnino contiguam efficiant. Hæe series quam maxime juvant ad agnoscenda specimina mutilata. - Glaucescentium series ceteris formarum ditior est, citrinorum pauperior. E principiis Wallrothianis hx analogx species ut formæ phcex, ochromatices \&c. facile explicarentur \& inter se colliderentur, sed in natura semper distinctissimas inveni, eodem modo ac Fucos, Ulvas, Confervas olivaceas, purpureas, virides, quarum distinctione in diversas series Lamourous. Phycologia reformationem fundavit. Confirmantur insuper lepræ, disci \& sporidiorum colore. Sic acutiss. Wallroth $P$. variam tantum pro forma ochromatica $P$. subfuscce habere videtur, mihi auten sunt analogx species diversarum serierum, majoremque $P$. varice video affinitatem cum Parm. saxicola (thallo orbata vix discernibili) quam cum $P$. subfusca. - Mutatur quidem color singulæ seriei, sed intra determinatos limites; v. c. ochroleucæ sapius e flavo-viridi albescunt, sed præsentibus formis dealbatis (semper atypicis) seriei glaucæ \& ochroleucæ diversam originem optime sentio, licet in earum differentiis exponendis calamus in verborum angustie titubet. Quod vero e Systemate non rejicit has differentias, cum omnes crustæ Lichenum dealbatæ morbosæ sint \& 
Systema statum naturalem tantum respiciat. - Quanta insuper vis harum serierum, patet e reductionibus recentioribus e transitibus indirectis ortis, v. c. specierum citrinarum; veteres jam Everniam vulpinam \& flavicantem conjunxerunt, Wallroth E. flavicantem \& villosam cum $P$. chrysophthalma, Flotow $P$. chrysophthalmam cum $P$.parietina, Meyer plerasque luteas species, etiam formas $P$. murorum proximas, ad $P$. parietinam retulit; quibus in summam redactis omnes citrini Lichenes sensu strictiori eandem efficerent speciem. Hoc studio, ex transitibus indirectis ornnia conjungendi, continuato, reliquis seriebus idem fatum auguramur.

* Glcucescentes. Lepra, si in soredia $\mathrm{l}$. in superficie efflorescit, cinerascenti-alba. Apotheciorum discus inter rubrum \& badium varians. Continuant species glaucas Stictce \& Cetrarice; continuatur series infra a Placodiis glaucescentibus.

49. PARMELIA perforata, thallo foliaceo-imbricato membranaceo viridi-glaticescente, subtus nigro atro-fibrilloso, lobis rotundatis ciliatis, apoth. disco rufo, demum perforato. Ach. Lich. univ. p. 459 .

Dill. musc. t. 20. f. 42, 44, t. 82. $f$. 3. Lichen perforatus. Jacqu. Coll. 1. p. 116. t. 3. Platisma. Hoffm. Pl. Lich.t. 13. f. 1. P. Fee Crypt. t. 32. f.3. Lich. proboscid. Scop. L. melanoleucos. Willd. Bot. Mag. 4. $t$. $1 . f \cdot 2$.

b. P. cetrata. Ach. syn. p. 198. P. crinita. l.c.p. 196. status Isidiophorus.

Ad truncos \& supra muscos Europæ australis, in Hispania, Italia, Helvetia Schleicher!

Speciosa, lobis (= iaciniis latioribus) pulchre nigrociliatis (ciliis raro detersis) facile distincta. Margines passim elevato-pulverulenti. Apothecia infundibuliformia, ampla, peculiari modo perforata, quod in innumeris Cetr. glaucae apotheciis, situ \& forma diversis, non vidi, nec hujus thallus subtus fibrillosus aut margine ciliatus. Pro hujus tamen varietate declarat Wallroth. - Extra Europam frequentior \& adhuc insignior occurrit. Varietas fulva Mich. Fl. Bor. Amer. p. 324. apud nos haud occurrit. Num etiam in Lusatia lecta sit, ut indicat Acharius, nescinus; saltim aliis locis v. c. sub Borr. vil- 
losa Ach. syn. p. 223. pro Lusatia Lusitania certe legendum est. At Germanice cives ex Hepp \& Fingerh. 5o. PARMELIA perlata, thallo foliaceo-imbricato membranaceo lrevi virescenti-glauco, subtus fusco-nigro obsolete fibrilloso, lobis rotundatis nudis, apoth. disco rubro, margine tenui. Ach. l.c. Vaill. par. t. 21. f. 12. Mich. gen. t. 50. f. 1. Dill. musc. t. 20. f. 39. Lichen perlatus Linn. et Auct. Wulf. in Jacqu. Coll. IV. p. 273. t. 10. Lobaria Hoffin. Lich. glaucus. Auct. Eur. austr. P. plicata. Pers.

Exs. Moug. et Nestl. n. 253.

Ad truncos \& saxa Europæ australioris vulgaris; at in boreali prorsus desideratur.

Priori affinis, notis allatis, thallo tenuiori apotheciisque haud perforatis piæcipue diversa. Sed sterilis formæ sterili Cetrar. glaucre, pro qua hæc in Europa australiori sæpe sumitur \& præcipue ab Auctoribus Lichenem fallacem, veram C. glaucam, ab hac distinguentibus, valde similis; distinguitur autem thallo orbiculari, regulari, imbricato, magis virente, subtus passim fibrilloso; facillime vero fertilis apotheciis in lamina frondis sparsis, figura prorsus Parmelix, cyathiformibus; lobis fertilibus ceteris conformibuc, planis, depressis, subtus fusco-nigris. Cel. Wallroth et hanc cum C. glauca jungit. Ubi utraque species promiscue nascitur, obviam venire transitus indirectos = specimina mutilata, sterilia, inter utramque ambigua, non dubitamus, sed nullum ad $P$. perlatam accedens vestigium in Suecia a me observatum esse certe novimus \&, an transitus genuini observati sint, ignoramus. Hinc, re a me ipso haud observata, contra unanimum Lichenologorum accuratissimorum seculi præterlapsi testimonium $P$. perlatam delere non ausus sum. - Variat tam sorediifera, quam sterilis marginibus elevatis pulverulentis, qualis var. $\beta$. olivetorum Ach. Lichen dubius Wulf. l. c. t. 19, f. 2.

5r. PARMELIA tiliacea, thallo foliaceo-imbricato submembranaceo levigato glauco-albicante, sæpius pruinoso, subtus fusço atro-fibrilloso, lobis sinuato-laciniatis, a poth. disco badio, margine integro. Ach. l. c. p. 460. 
Mich. gen. t. 45. $f$. inf. L. tiliaceus. Ehrh. Hoffm. en. Lich. t. 16. f. 2. Fingl. Bot. t. 700. Lobar. H: jusd. Germ. Lich. quercifot. Wulf. in Jaqu. Coll. III. p. 127. t. 9. f. 2. L. quercinus. Willcl. Berol. t. 9. f. 2. Imbricar. Decand. Lich., dein Parmelia scortea. Ach. ex p.

Exs. Lich. Suec. n. 169. Ehrh. Cr. n. 59. Moug. et Nestl. $n .445$.

Ad cortices, ligna, rupes Europæe fere totius, (a Cadiz Doufour! ad Lapponiam Sommerfelt!) at non ubique.

Lobis ad modum Stictce glomeruliferce sinuatis a prioribus facile differt; potius cavendum ne cum Sticta citata dealbata commutetur, ut jain Wulfenio accidit. $P$. scortea Ach. est forma normalis glabra, $P$. tiliacea frequentior pruinosa; ceterum non differunt. $P$. saxatili affinis, at simul $P$. aleuriti.

52. PARMELIA Borreri, thallo foliaceo-imbricato cartilagineo-membranaceo leviusculo glauco-cinerascente, subtus atro-fibrilloso, laciniis apice rotundatis utrinque nudis, apoth. disco nudo rubro-badio, margine integro. Turn. apud Ach. l. c. p. $46 \mathrm{r}$.

Lichen Borreri. Engl. Bot. t. 1780. (sorediis marginatis adspersa) P. scortea americana. Ach. syn. p.197. nuda nigro-punctata; P. rudecta $\alpha$. Ach. $i$. c. isidiophora.

Exs. Moug. et Nestl. n. 634 .

Ad cortices, ligna precipue Europæ occidentalis, ut in Norvegia Blytt! Anglia Turner!, Gallia meridionali-occidentali Dufour! Rarior \& sterilis in Vogesis Mougeot! Helvetia Schleicher!

Hujus potissimum americanæ speciei exoticam completam habemus formarum seriem, in Europa tantum sorediis rotundis marginatis lecta videtur, quibus ad formam $P$. saxatilis similia proferentem soredia, at elongata, accedit \& a $P$. cetrata, cujus ut plurimarum soredia immarginata, differt. Ceterum inter has medium fere tenet locum. Cum hac convenit thallo normaliter levi, lobis ambitus dilatatis subintegris subtus versus marginem nudis fuscis; cum illo thallog vetustiori subcartila- 
gineo (apices enim membranacei sunt), laciniato, subtus dense atrofibrilloso. Apothecia describuntur rubra, equidem badia vidi. - Accepi quoque pro Lobaria submarginali Mich. seu Parmel. submargin. Ach.

53. PARMELIA saxatilis $\alpha$. thallo foliaceo-imbricato subcartilagineo reticulato-lacunoso opaco glauco-cinerascente, subtus nigro atrofibrilloso, laciniis sinuato-lobatis retusis, apoth. disco badio, margine demum crenato. Ach. l. c. p. $46 \mathrm{~g}$. Moris. Hist. s. XV. t. 7. f. 6. Mich. gen.t.49.f. 1. Dill. musc. t. 24. $f$. 83 . Lich. saxatilis $L$. et Auct. - Hoffm. en. t. 15. f. 2. Wulf. in Jacq. Coll. IV. t. 20. f. 2. Engl. Bot.t.603. Westring Färglaf. $t$. 2. Lobaria, Hoffm. Imbric. retiruga. Decand.

Exs, Lich. Suec. n.168. Moug. et Nestl.n.349, 738. tenuior.

b. luxurians, laciniis discretis latioribus lævioribus adscendentibus sorediis elongatis marginatis adspersis, apotheciis raris minoribus. Vaill. Bot. t. 21. $f .1$. - at multo minor. P. scortea pr. p.

Ad saxá, ligua \& arbores Europæ omnis vulgatissima. b. Ad truncos tiliaceos Suecia \&c.

Species notissima, magnopere varians, sed formæ haud rite limitandx. Vetusta tota frequenter isidiophora vel tota in Isidium degenerans. In speciminibus, a $\mathrm{Cl}$. Graves ad Ermenoville Galliæ lectis, hujus Isidii apices globulo rubro terminantur. - Ad saxa quoque locis montosis e thallo pronascuntur phylla minuta, cæspitosa, e cucullato explanata, rotundata, lobata, læviora, e cœrulescenti-viridi glauca, cephalodiis hemisphæricis nigris frequenter adspersa. Paginæ inferiori P. saxatilis simillima sunt. Pro peculiari vegetabili habent Smith (Lich. parasiticus Engl. Bot. t. 1866, unde spec. non viso recepit Acharius sub Endocarpo parasitico Syn. Lich.p. 100) Sommerfelt (Lecid. Parmeliorum Suppl. Fl. Lapp. p. 176) plurimique; pro $P$. saxatilis prole Acharius in herb., Borrer, Meyer, quorum sententix eo potius accedo, cum non hanc tantum sxpissime, sed etiam prorsus analogas in $P$. omphalode, conspersa, recurva \&c. viderim, quarum singula matris colorem \& naturam participat. Cfi. Lich. Suec. exs. n. 326. - Lich. doe- 
daleum Engl. Bot. t. 2129 sileo, nam meam suspicionem specimine non viso in medium proferre temerarium videretur.

$\beta$. P. Omphalodes, thallo f. imbr. subcartilagineo læviusculo nitido æneo-fusco, subtus atro-fibrilloso, lac. sinuato-lobatis subtruncatis, apoth. disco badio, margine rugoso subalbicante. Ach. l. c. p. 460 .

Vaill. par. t. 20. f. 10. Mich. l. c. f.2. Dill.musc. t. 24. f. 80. Lich. omphalodes Linn. - Engl. Bot. t. 604. Westr. Färglafv. t. 7. non Wulf. - Lobar. Hoffm. Imbric. adusta Dec. Fr. - P. hispidula. Ach. syn. p. 468. spec. muscicola; fertilia in Suecia legi.

Exs. Lich. Suec. n. 108. Moug. et. Nestl. n. 348. Ad saxa \& terram glareosam præcipue in montanis.

Non is sum, qui species per secula notissima \& inconcussa lubenter deleam, sed certissima adsunt criteria $P$. omphalodem, ut jam observavit acutiss. Wallroth, prioris esse veram varietatem. Præter colorem atypicum, jam speciem suspectam reddentem, sed intra glaucescentium variationis terminum, ut Cetr.glauca, P. physodes \&c. testantur, haud essentialiter differentem, reliquæ notæ sæpe in utraque evanescunt. Ceterum seriei glaucæ adsunt omnia criteria; immo color normalis in excipuli margine demum prodit.

Eadem ratione, qua $P$. omphalodes a $P$. saxatili, differt ab utraque: P. pusilla ib. p. 472, thallo ruguloso, atro haud nitente; ad ligna tam raro et semper sterilis obvia, ut vix seorsim sit designanda. Autonoma plane non est; sed potius status emortuws et putridus.

54. PARMELIA aleurites, thallo foliaceo-imbricato membranaceo rugoso-plicato glaucescente, demum furfuraceo, subtus pallido fusco-fibrilloso, lobis apice discretis planis inciso-crenatis, apoth. disco hepatico, margine demum crenato. Ach. l. c. p. 484 .

Mich. gen. t. 51. ord. $X X X . f$. 2. Lich. diffusus. Dicks. Crypt. t. 9. f. 6. Placod. Hoffm. Pl. Lich. t. 65. $f$. 2. Lobaria. Ejusd. Germ. Lich. pallescens. Hoffm. En. Lich. t. 10. f. 1. L. aleurites. Ach.- 
Engl. Bot. t. 858. Imbric. Dec. fr. P. aleurites \& obsessa. Ach. syn.

Exs. Lich: Suec. n. 290. Moug. et. Nestl. n. 739. Precipue ad ligna frequens, rarior ad cortices \& saxa, Europæ totius.

Præcedenti cognata, sed minor, tenuior, diverso modo divisa, subtus pallida; nec superficies scrobiculatoreticulata, sed semper corrugata \& pulverulenta per $\mathfrak{x}$ tatem evadit vel tota granuloso-isidioidea. Hoc loco adnotandum videtur præsentian vel defectum sorediorum, formationis isidioideæ leprosæ e. s. p. vix umquain species distinguere, earum vero diversam indolem, ubi præsentes sint, maxime harum differentias \& affinitatem illustrare. Ceterum laciniis suis latis, primitus fere in thallum monophyllum coalitis, ut etiam colore apotheciorum prioris dilutiori, ad $P$. tiliaceam \&c. quoque accedit. Vulgo quidem apothecia fusco-nigra describuntur, sed equidem in vivis pallidiorem discum semper observavi, potissimum Parm. physodis!, inter rubrum, dilute badium, lividum, ne dicam luteolum, \& hepaticum varium. Ab omni $P$. ambigua, specie analoga seriei ochro. leucæ, expallente certe diversa. Parm. aleurites senio cinerascit.

55. PARMELIA sinuosa, thallo foliaceo-imbricato membranaceo lævi nidito glaucescente, subtus nigro atrofibrilloso, laciniis planis sinuatopinuatifidis, apotheciorum disco hepatico, margine integerrimo.

Lich. lævigatus. Engl. Bot. t. 1852. Parm. Ach.syn. p. 212. Lich, sinuosus (nomen aptius) Engl. Bot.t. 1852. Parm. Ach. syn. p. $20 \%$.

In Europa maxime occidentali; in Anglia Borrer!, Nornandia Gallix Prevost!; ceterum in America boreali.

Pulchra \& distincta, medium inter $P$. saxatilem \& physodem tenens locum; huic tamen proxima, licet laciniæ non inflatæ, e colore, superficie nitida, lævi, quasi molli, sorediisque immarginatis. Isidiophora 1. pulverulenta tota non visa est; passim vero cephalodiis nigropunctata. Sed etiam a $P$. physode certo dignoscitur laciniis explanatis, apice latioribus subemarginatis, subtis fibrillosis. Peculiari modo sinuato-laciniata est, sinubus 
plerumque latis circularibus. - Bene utramque speciem conjunxit jam Cel. Meyer, sed Achario vitio non vertendum, sed fonti potius Smithio, duas istas, neutra visa, ab ipso esse receptas.

56. PARMELIA physodes a. thallo foliaceo-imbricato subinflato lavi glauco-albescente, subtus glabro atro, laciniis linearibus sinuatis, apotheciorum disco hepatico.

Buxb. Comm. Petrop. III. t. 14. f:1. Dill. musc. $t$. 20. $f$. 49. Lich. physodes. Linn. - Wulf. in Jacq. Coll. III. p. 121. t. 8. P. ceratophylla Wallr. optime.

a. apicibus clausis. Mich. gen. t. 50. ord. $X X V \cdot f$. 1. L. physodes. Hoffm. en. Lich. t. 15. f.2. Engl. Bot. t. 126. Fl. Dan. t. 1186. f. 2. Lobar. Hioffm. Parm. Ach. Imbric. Dec. - P. distorta. Ach. syn. laciniis adscendentibus apice subvesiculoso-articulatis.

Exs. Lich. Suec. n.291. Moug. et Nestl.n. 159. b. apicibus pertusis. Mich. l. c. f. 2. Lobaria terebrata. Hoffm. Lich. pertusus Schrad. L. diatrypus. Ach. Engl. Bot. t. 1248. Parmel. Ach. Imbric, Dec. P. Terebrata Mart.

Exs. Moug. et Nestl. n. 65 .

Ad truncos, ligna, saxa ipsamque terram in ericetis \& arenosis.

Monstrositas tantum est b. ; ceterum insigniter plurimis haud stricte definiendis modis ludit; nempe thallo substellato, irregulari \& valde complicato (frequens in lapillis ad litora maris); laciniis totis aut apice tantum inflatis, convexis \& planiusculis, etiam nigro-vittatis (Parm. duplicata Ach. meth. Cfr. Wulf. l. c. fig. lat. dextra) \& cum color paginæ inferioris etiam in hac optime explicata forma passim superiorem occupet, non miremur, idem fieri in $P$. intestiniformi tota passim nigricante. - Ceteris formis insignior est rara v. obscurata Ach., quæ quoad colorem ab hac differt ut P. omphalodes a saxatili. - Omnes vero formæ a reliquis Imbricariis Europæis recedunt hypothallo non fibrilloso, sed verniceo nigro in pagina inferiori, quo fibrillarum defectu pagina inferior præcipue relaxatur. Monente jam Dillenio abit locis alpinis in formam angustatam, quæ

$\beta$. $P$. encausta, thallo stellato-multifido compli- 
catoque corrugato glauco - cinerascente, subtus nudo nigro, laciniis angustissimis compaginatis, apoth. disco badio. Dec. sub Imbric.

a. laciniis semiteretibus, demum verruculosis, disco dilatato. Squam. pulla. Hoffm. Pl. Lich. t. 32. $f$. 2. Lobaria. Germ. Lich. encaustus. Smith. Transact. Linn: Soc. 1. t. 24. f. 6. Engl. Bot. t. 2049. Westr. Färglafv. t. 19. Parm. Ach.

Exs. Ehrh. Cr.305. (Lich. multipunct.) Moug. n. 353.

b. laciniis teretiusculis, torulosis, vesiculoso-subarticulatis, disco minuto. L. intestiniformis Bellardi. Parm. Ach. - Sommerf. Lapp.

Ad saxa \& rupes Europæ alpinæ a Pyrenæis Dufour! ad Lapponiam. Wahlenberg!

Evidentissimi \& directi transitus inter $\alpha \& \beta$ exstant; L. intestiniformem Bell. hujus' esse statum angustatum Decandolle jam demonstravit. Etiam a subarticulata evadit: $P$. distorta Ach. Differt potissimum laciniis angustioribus, hinc minus inflatis, magis inter se contiguis 1 . caspituloso-complicatis, colore magis squalido ex aëre alpino; sed apices, ubi dilatantur, plus minus inflati. Color passim fuscescit aut æneus fit, ut in $\alpha \&$ proximis ejus seriei jam vidimus; totius vero nigrescit tantum in formis angustissimis, paginam superiorem quasi excludentibus. Tales cum analogis formis $\boldsymbol{P}$. stygioe facile commutantur, sed verus thalli color saltim in apotheciorum margine albido semper restat.

* Olivaceo-spadicea. Lepra, si efflorescit, subconcolor. Apotheciorum discus inter olivaceum æneofuscum nigrumque variat. - Continuationem efficiunt sursum Stictæ concolores, Cetr. sepincola; deorsum Placodia. **

57. PARMELIA Acetabulum, thallo foliaceo-imbricato membranaceo ruguloso viridi-olivaceo, subtus pallidiori nigrofibrilloso, lobis rotundatis repandis, apoth. disco concavo meo-rufescente, margine crenulato.

Vaill. par. t. 21. f. 13. Mich. gen. t. 48. f. 2. Dill. musc. t. 24. f. 79. Lich, acetabulum. Necker. FToffm. en. Lich. t. 18. f. 2. Wulf. in Jacqu. Coll. III. t. 9. f. 1. Lob. Hoffm. Imbric. Dec. fr. - L. corrugatus. Smith. Parmelia. Ach. 
Exs. Lich. Suec.292.Ehrh. Crypt. 127. Moug. N. 256. Ad truncos arborum frondosarum Europæ facile totius, summo septentrione excepto, at non ubique.

Thallus recens olivaceo-viridis, siccus subinde hine inde glaucescit. Multi Auctores subtus nigrum petunt, qui in meis spec. hand normalis color. Apothecia recentia item virescunt; sicca rufescunt. - Nomen antiquius utique parum apto Smithiano præferendum est.

- 58. PARMELIA olivacea, thallo foliaceo orbiculari membranaceo plicato-radioso umbrino-olivaceo, subtus pallidiori subfibrilloso, lobis planis rotundatis crenatis, apoth. disco plano concolori, margine demum crenato. Ach.syn. p. 200. Vaill. par. t. 20. f. 8. Mich. gen. t. 51. ord. XIX. Dill. musc. $t$. $24 . f .77,78$. L. olivaceus Linn. Hoffm. en. Lich. t. 13. f. 3, 4, 5. Lob. offm. Germ. Imbric. Dec. Parm. collematiformis Schleich. Cat. (Collema exasperatum Ach. etc. ex spec. Schl.) Exs. Lich. Suec. n. 260. Moug. et. Nestl. n. 161. Ad cortices, ligna, saxa Europæe totius vulgaris.

Forma vulgatissima, notissima simul est; ceterum tantum variat, ut ad proximos transitus indirecti non desiderentur. Subinde tam ampla ut ad præcedentem primo obtutu potius referas. Alia laciniis angustioribus, saxicola, $P$. fahlunensem satis refert. In sax is magis obscura, fuliginosa \& nigricans, vulgo cum $P$. pulta Ach. commutata, \& certe $L$. pullus. Schreb. - In silvis abiegnis irriguis pallide viridis, tenuissima. In rupibus juxta mare in Hallandia crassa, crustaceo-foliacea, olivaceo-cinerea, intus bombycina. Variat porro glabra, elevato-punctata, centro pulveraceo-granulosa \& tota in Isidium mutata. Apothecia normaliter sunt viridi-olivacea, sed spadicea in saxis \& $æ$ neo-rufa in corticibus occurrunt. Non itaque desunt indicia infinitarum formarum \& varietatum, sed nolui earum distinctione scientiam tantum diffusam \& tædiosam reddere. Non e descriptione sed ex usu optime addiscuntur. Qux natura hand limitavit, frustanei eis in Systemate ponuntur limites.

59. PARMELIA fallunensis, thallo foliaceo-imbricato subcartilagineo lævigato ex olivaceo. 
æneo nigricante, laciniis digitato-multifidis subcanaliculatis, subtus pallidioribus rare fibrillosis, apotheciis æneo-fuscis crenulatis. Ach. syn. p. 204.

Lich. Fahlun. Linn. - Hoffm. en. Lich, t. 12. f. 2. Wulf. in Jacq. misc. 2. t. 10. f. 3. Engl. Bot.t. 655. Squamaria. Hoffm. Pl. Lich.t. 36. f. 2. Imbric. Dec.

Exs. Lich. Suec. ined. Flörke Deutschl. n.93. Moug. et Nestl. n. 350.

b. sciastra, minor, margine apoth. subintegro. Dill. musc. t. 24. f. 81. P. sciastra. Ach. Lich. univ.

In Suecia septentrionali \& media copiose; Norvegia passim Blytt! dein per alpes omnes ad Carpathos Wahlenberg! \& Pyrenzos Dufour!

Color tam thalli, quam apotheciorum, locis umbrosis in olivaceum sæpe vergit; locis apricis magis nigrescit. Subtus revera pallidior est, tantum passim accidentaliter fuscescit; fibrillæ nigræ, raræ, subinde nullæ. Forma typica laciniis canaliculatis ab omnibus facillime dignoscitur; sed infimæ proles steriles \& angustatæ laciniis planioribus difficitius colore, laciniis minoribus, crispis, haud recurvis e. s. p. a sequente distinguuntur.

6o. PARMELIA stygia, thallo foliaceo-imbricato subcartilagineo nitido ex olivaceo-fusco nigro, laciniis convexis palmato-multifidis apice recurvis, subtus aterrimis obsolete fibrillosis, apotheciis concoloribus granulato-marginatis. Ach. l. c. Lich. stygius. Linn. - Hoffm. en. Lich. t. 14. f. 2. Squamaria. Pl. Lich. t. 25. f. 2. Parmel. Fl. Dan. 2007. $f .2$.

Exs. Lich. Suec. n. 166! Moug. et Nestl. n. 351. Ad rupes \& saxa Scandinaviæ facile totius; dein per alpes \& montes subalpinos usque ad Carpathos Wahlenberg! \& Pyrenæos Dufour!

Pagina inferior opaca, aterrima est, fere ex hypothallo lævigato adnato ut in $P$. physode analoga, sed adsunt simul, licet rarius, fibrillæ distinctæ, apice penicillatæ. Lacinix plerumque intertextæ sed semper lineares, tantum apice dilatatie. - Vidimus vero ad rupes 
juxta aquas singularem formam laciniis longioribus, discretis, semicylindricis, olivaceis fuscescentibus, nec nigris.

$\boldsymbol{\beta}$, lanata, laciniis setaceo-filiformibus teretibus intricatis fusco-nigricantibus, apotheciis concoloribus subgranulato-marginatis. Meyer Flechten. c. ic. opt.

Lich. lanatus. Linn. - Engl. Bot. t. 846. Lich. pubesc. Wulf. in Jacq. Coll. II. t. 9. f. 7. Cornicul. lanata. $A c h$.

Exs. Ehrh. Crypt.n.70. L. laneus. Moug. Nestl.n. $35 \%$. lisdem cum præcedente locis \& sæpe in eisdem cæspitibus.

Ad Parmelias hanc pertinere e situ apotheciorum \& vegetatione horizontali patet eandemque prioris esse statum maxime angustatum omnino cum Meyero persuasum habemus. Sed sub Lich. lanato Racodium rupestre \& diversarum stirpium degenerationes comprehenduntur v. c. a Leers \&c. Ev. jubatoe. (Dill. t. 13. f. 8. ramificatione \&c. ita cum specim. inter $L$. bicolorem \& chalybeiformem mediis convenit, ut ad hanc citaverimus); certe et, observante Wallrothio, Cetr. tristis, ut icones.Wulfenii svadent. Hinc forsan Hoffmann in tres speciess (Usneam lanatam, laneam, pubescentem) distribuit. - Cfr, quoque Lich. retieulatus Wulf. l. c. t. 9. $f$. 6,7. L. normöricus. Gunn. Norv. t. 2.f.9-11, qui C. tristis.

0 bs. Prorsus diversa thalli indole a $P$. styg $i$ a $\beta$. differt $L$. pube scens $L$., quem licet vere scutelliferum siderim, ad novam familiam inter Lichénes et Phyceas mediam, cum Collemate, Lichina etc. refero.

6r. PARMELIA dendritica, thallo foliáceo substellato stuppeo vinidi-atro, utrinque nudo nitidulo, laciniis convexis flexuosis digitato-multifidis apice subinflatis, apotheciis reneis in tegerrimis. Pers. in Act. wett. 2. I. p. 16.

P. pulla. Ach. syn. p. 206, ex ipso (sed Lich. pullus Schreb. potius forma P. olivaceae). Sommerf. Lapp. p. 112. - (P. Sprengelii. Flörke in Spreng. Mant. Hal. 2. p. 26. ex Ach.)

Exs. Lich. Suec. ined.

Ad montes Europæ borealis passim.

Minutam hanc speciem cum neutra precedentium conjungere potui. Substantia nec cartilaginea, nec membranacea. Color, Collematum more, humidus virescens, 
siccus niger, nec in fuscum, ut ipsius P. olivacese, vergit. Sæpius sorediis, P. caesioe similibus, adspersa. A P.olivacea insuper, differt thalla toto in lacinias angustas plano-subteretes flexuosas lacunulosas, apice subinflatas digitatasque diviso.

*** Ochroleucce. Vegetarum color pallide flavovirescens, siccarum \& fatiscentium plus minus intense ochroleucus, apotheciorum subbadius. Hinc speciebus ochroleucis priorum generum, illinc sequentium sectionum proxime affines.

\section{PARMELIA caperata, thallo foliaceo-imbrica-}

to submeinbranaceo ochroleuco, subtus nigricante parce fibrilloso, lobis sinuato-laciniatis apice subintegris, apoth. disco badiorubro, margine crenulato. Ach. Lich. univ. p. 457 .

Mich. gen. t. 48. $f$ 1. optime Dill. musc. $t$. 25. $f$. 97. ubi et syn. L. caperatus. Linn. - Wulf. in Jacqu. Coll. IV. p. 280. t. 20. f. 1. Engl. Bot.t. 654. Hoffm. en. Lich. t. 19. f. 2. Platisma. Pl. Lich. t. 38. $f$. 1., t. 39. f. 1., t. 42. $f$. 1. Lobaria Ejusd. Germ. Imbric. Dec. P. rudecta. $\beta$. Ach. syn. p. $19 \%$.

Exs. Lich. Suec. n. 293. Ehrh. Cr. n. 11\%. Moug. et Nestl. n. 255. speciosa.

Ad saxa \& truncos; frequentior in Europa media australi, rara in Ostrogothia Sueciæ.

Nostratium maxima evadit, regularis placentas eximie orbiculares sistens, coriaceo-membranacea fere ut Peltig. arctica, cui insuper omnium partium colore accedit. A P. perlata, corrugata \&c., tantum analogis, serie eam removeri mirentur affinitatem in forma externa quærentes, at non his, sed sequentibus affinis est; immo inter hanc \& sequentem exstant formx intermediæ, ex specc. imperfectis haud distinguendæ. Præter staturam ampliorem \& notas indicatas ab ea differt thallo molliori, in superficie haud polito, adultiori rugoso, sulphureo-pallido (junior lævis \& flavovirescens est) - nec umquam nigro-punctata visa.

63. PARMELIA conspersa, thallo foliaceo-imbricato submembranaceo polito stramineo-virescente, subtus fusco nigro-fibrilloso, laciniis sinua- 
tis planis, apoth. disco badio, margine integro. Ach. l. c. p. 486.

Dill. musc. $t$. 24. f. 75. Lich. centrifug. Auct. non Linn. Hoffm. en. Lich. t. 10. f. 3. Squamaria Pl. Lich. t. 16. f.2. Lobar. Ej. Germ. Lichen conspersus. Ehr. exs. - Wahl. Lapp. - Engl. Bot. 2097. Westr. Färglafv. t. 24.

Exs. Lich. Suec. n. 16\%. Moug. et Nestl. n.160. Fl. Deutsch. n. 34.

Ad saxa \& rupes Europæ totius, nec nisi fortuitu ad ligna, terram glareosam.

Sxpius quidem nigropunctata, unde nomen, sed exinde nullus character specificus sumendus; variat enim firequenter, præcipue locis humidis, omnino epunctata. Variat insuper isidiophora \& sorediifera, sorediis semper minutis planiusculis submarginatis; laciniis latioribus \& perangustis, adglutinatis regulariter expansis \& laxioribus complicatisve e. s. p. - Substantia semper tenuis, sed subcartilaginea; superficies, nisi isidiophora, polita. Valde affinis P. lophyrex.

* PARMELIA relicina $\beta$. thallo foliaceo-imbricato submembranaceo lævigato virescente stramineo, subtus atro fibrillis ramosis densissimis pannoso, laciniis sinuato-pinnatifidis apice inflatis. - Fries S. O. V. p. 283.

In saxis Galliæ occidentalis. "Foret de Briquebec" Despreaux. Misit A. Le Prevost.

$O b$ apothecia ignota adhuc dubia species, at a reliquis ochroleucae seriei diversa divisione thalli ad typum $P$. sinuosae, apicibus $P$. physodis instar inflatis, laciniis angustis lævibus subtus dense atro-pannosis. Laciniæe apice sorediiferæ aut pulverulentæ in speciminibus Gallicis visis, qua re ab exotica vera P. relicina tantillum differunt.

64. PARMELIA incurva, thallo stellato-imbricato globulifero stramineo-virescente, subtus nigro fibrilloso, laciniis angustissim is subteretibus apice recurvis, apotheciis spadiceis subintegris. Sched. Crit. 9. p. 3 ז.

Lichen multifidus. Dicks. Crypt. 3. t. 9. fig. \%. Lich. 
incurvus. Pers. - Engl. Bot.t.1375. Lobaria incurva. Hoffm. Parm. recurva. Ach. - Fl. Dan.t. 2007.f.1. Exs. Lich.' Suec. n. 259. cum apoth.

Ad saxa \& rupes, tam siccas, quam irriguas, Europæ potissimum borealis haud infrequens.

Vulgo cum $\boldsymbol{P}$. centrifuga commutata, at $\boldsymbol{P}$. conspersce (apotheciis spadiceis, thallo subtus nigro \&c.) magis affinis, inter quam \& $P$. ambiguam medium tenet locum, ceterum optime diversa \& parum variabilis. Præcipue dignoscitur sorediis, semper præsentibus, globulosis, elevatis, compactis, quales in alia specie non vidimus. - Specimen authenticum Imb. recurva Dec. non vidimus. Descriptio \& locus in rupibus calcareis aliquantulum recedit.

65. PARMELIA ambigua, thallo stellato-imbricato sorediifero stramineo-virescente, subtus fusco-nigro fibrilloso, laciniis linearibus applanatis multifidis, apotheciis adnatis rufofuscis integerrimis. Ach. Lich. univ. p. 485.

Lich. diffusus. Web. spic. Lich. ambiguus. Wulf. in Jacq. Coll. IV. p. 239. t. 4. f. 2. Psora Hoffm. Pl. Lich. t. 40. f. 2-4, 42. f. 2, 3. Lob. Hoffm. Germ. Imbric. Decand.

Exs. Lich. Suec. n. 295. Moug. et Nestl.n.449. b. albescens, scutellis obscurioribus. Wahl. Suec. P. hyperopta. Ach. syn. p. 208.

Ad ligna putrida, cortices, raro ad terram, fere ubique.

Laciniis latioribus planis haud recurvis, sorediis depressis farinosis adspersis, passim etiam totis pulverulentis, apotheciis prorsus sessilibus \& adnatis (in priori pro more subtus omnino libera), disco rufescente a præcedente facile dignoscitur. - Ceterum satis mutabilis; in cortice Pini passim laciniæ maxime discretæ venose serpunt. - b. est hujus status loco humidiori, ad ochroleucarum normam', expallens, nullo modo ad P. aleuritem accedens, cum qua præsens species tantum analoga est. P.hyperoptam Ach. ad istam formam pertinere optime observavit Cel. Flotow.

66. PARMELIA centrifuga, thallo ochroleuco, subtus albo fibrilloso, centro crustoso delabente, 
ambitibus concentrice dispositis foliaceo-imbricatis, laciniis linearibus convexulis, apotheciis periphericis rufofuscis. Ach. l. c. p. 486. Lich. centrifugus. Linn. nec Auct. Exter.

Exs. Lich. Suec. n. 48. Ehrh. Crypt. n. 116.

Ad saxa \& rupes juxta aquas, nec non ad ligna putrida, per omnem Scandinaviam silvaticam \& Rutheniam borealem Weinmann! vulgaris.

Nobilissima species, male cum $\boldsymbol{P}$. conspersa olim confusa, nuperque iterum conjuncta, forsan ob punetus nigros in utraque \& præsentes \& deficientes. Rarins quidem in $P$. centrifuga occurrunt, at, ubi adsunt, confertissima. In serie naturali medium certe tenet locum inter P. ambiguam \& stramineam. - Vegetatio prorsus singularis. Laciniæ vetustiores \& centrales concrescunt in crustam omnino tartaream tuberculosam, quæ vero magis incrassata a matre facillime \& semper solvitur \& delabitur; laciniæ vero ambitus persistunt \& extrorsum crescentes circulum magis magisque dilatatum, centro evanescente, formant. Intra hunc circulum iterum iterumque eadem lege novi nascuntur circuli, quare $\mathrm{Li}-$ chen perfectus e plurimis zonis concentricis pulcherrimus. Laciniæ foliaceæ latiores quam prioris, minus applanatæ, non vero semiteretes, ut in P. recurva. Nec globifera, nec sorediifera, nec isidiophora visa est.

**** Citrince. Color normaliter citrinus, sed variat virescens \& expallens. Discus apotheciorum semper luteus. Conferendæ species citrinæ priorum \& sequentium sectionum; ad has formis degeneratis etiam facile referendie.

67. PARMELIA parietina, thallo foliaceo squamulosove imbricato membranaceo sublobato luteo, subtus pallidiori obsolete fibrilloso, apotheciis elevato-marginatis integerrimis, disco luteo. Dufour ir. litt. 1818.

Dill. Musc. t. 24. f. 76. Lich. pariet. Linn.

* thallo nudo, haud pulverulento, apothecior. margine concolori.

a. thallo foliaceo flavo, humido virescente, lobis explanatis adpressis. L. parietinus. Vulg. - Engl. Bot. t. 194. Sv. Bot. t. 648 . Fl. Dan. t. 1005. Parm. parietina. Ach. 
Exs. Lich. Suec. n. 258. Ehrh. Cr. 146. Moug. et Nestl. n. 66. Desmaz. n. 143.

b. cuureola, thallo foliaceo zonatim subcentrifugo aureo-vitellino, lobis concretis plicato-ramosis. Parm. aureola. Ach. l. c.

c. ectanea Ach., thallo foliaceo stellari vitellino, laciriiis angustis adpressis sæpe recurvis.

d. rutilans, thallo foliaceo imbricato-complicato irregulariter laciniato (subcrustaceo). Lecanora, dein Parmelia rutilans. Ach.

e. laciniosa Duf.!, thallo lacero-dissecto squamuloso, laciniis adscendentibus nudis. Simillima L. candel. Ach.

f. polycarpa, thallo diminuto conglomerato, lobis complicatis, apotheciis confertissimis obtecto. Lich. polycarpus. E/hrh. Engl. Bot. t. 1795 magis explanat. Lecan. candel. $\beta$. Ach. certissime. Lec. polycarpa. Flörke.

Exs. Lich. Suec. n. 106. Fl. Deutsch. n. 90. Ehrh. Cr. 136.

g. lobulata, thallo obliterato aut lobis brevissimis adpressis apothccia minuta cingente. Lecanora lobulata Flörke. Lec. candel. v. lobulata. Ach. mscr. Parmelia parietina, thallo obliterato Duf. in litt.

Exs. Lich. Suec. n. 325. Fl. Deutsch. n. 14.

* subcrustacea, thalli marginibus pulverulentis, raro toto in pulverem fatiscente. Lich. candelarius vulgo, nec Linn. - Engl.Bot.1794. Westr. Färglafv. t. 5 .

Exs. Lich. Suer. n. 25\%. Ehrh. Crypt. n. 126. Moug. et Nestl.n. 743. Fl. Deutsch. n. 171. h. substellata Ach., thallo foliaceo substellato lacerolaciniato, laciniis expansis pulverulentis. - Westr.l. c. $f$. c.

i. concolor, thallo squamuloso lacero-laciniato, squamis confertis adscendentibus. Lec. candel. $\alpha$. Ach. eoque teste $\mathbf{L}$. concolor Dicks. 3. t. 9. f. 8 .

1. pygmoea, thalli laciniis teretiusculis erectis ramulosis complicatis. L. candelarius. Wahl. - var. Finmarkica. Ach. Borrera pygmæa. Bory \& Physcia culminalis. Lapyl. (Moug. 1. c. d. exs.).

m. Iychnea, Ach., thallo crustaceo lobulato-granuloso citrino-fulvo.

n. citrinella, thallo toto in pulverem viridi-flavescen- 
tem soluto. Verrucaria flava. Hoffm. Parmelia, dein Lecan. citrina. Ach. nempe corticola. Lepr. botryoides Auct. ex magna parte hujus loci.

Exs. Lich. Suec. n. 324. Fl. Deutsch. n. 108.

Per omnem Europam vulgatissima a. ad truncos arborum, saxa, ligna, locis subhumentibus; b. ad saxa aprica sicca, optima in scopulis marinis; c. \& d. in corticibus arborum levigatis, soli infestis; e. ad truncos in dumetis; f. $g$. in ramis \& virgultis tenuioribus. - h. in corticibus lævigatis; i. locis similibus scruposis, vulgatissime ad ligna; l. in saxis apricis, ventis valde perflatis, non Finmarkiæ tantum sed totius Europæ; m. priecipue ad parietes, prope terram; n. ad cortices, ligna \&c. locis humidis.

Qualem limitavit celeberr. Dufour, qui inter Recentiores species Lichenum veras physiologice primus definivit suasque observationes insolita liberalite anicis communicavit, equidem quoque naturæ convenientissimam inveni. Omnes allatæ formæ inter se absque omni limite confluunt, ut veras varietates vix dicas, \& e loco lepræeve effusione pendent. Formæ analogæ quoque occurrunt plurimarum v. c. $P$. olivacece, conspersa, quas etiam crusta prorsus pulverulenta legimus; nescio cur hæc tam infeliciter dilacerata sit. Contra principia mea hujus formas seorsim enumeravi, partim ob synonymiam, partim ut exemplum in vulgatissimo quodam Lichene protex thalli indolis, e quo tiro reliquorum addiscere possit. - Eximie quoque Cell. Wallroth \& Meyer hanc speciem illustrarunt, sed hic saltim, meo præfiscini sensu, limites longe nimis extendit. Quo modo reliquæ species huc relatæ, quas indirecte tantum in Parm. parietinam transire vidi, differant, suis locis notabitur. - Discus crassiusculus, non fuscescit.

p. Biatorina, thallo squamuloso nudo, apotheciis subconvexis intense fulvis, margine thallo discolori evanido.

In Gallia meridionali ad truncos. Le Prevost.

Ex mente Auctorum Lecidea foret, nam excipulum, licet a thallo sit formatum, diseo omnino concolor est. 
Hanc cum vulgari confluere non vidimus, sed ad eandem śpeciem pertinere minime dubitamus.

O bs. Parmeliu diversicolor Syn. p. 210, e Kamtskatka, media inter priorem, sequentem et P. eleg a ntem, etiam ex alpibus borealibus, in quibus terrestris, nobis allata est; verum illius historia haud tam plena, ut inserere potuerim. Homonyma stirps e novo orbe (P. fibrosa Syst. Orb.Veg.) ab omnibus allatis dive'sa est et ad sequensem tribum pertinet.

68. PARMELIA chrysophthalma, thallo subfoliaceo cartilagineo-membranaceo lacero-ramoso e vitellino albicante, subtus albido ad marginem fibrilloso, laciniis multifidis, apotheciorum disco aurantiaco. Ach. meth. p. 267.

a. thallo foliaceo depresso imbricato, apotheciorum margine integerrimo. P. contortuplicata Ach. syn. p. 210.

b. thallo foliaceo depresso subadscendente, apotheciorum margine nudo aut ciliato. Mich. gen. t. 26. $f$ : 4. Dill. Musc. $t$. 13. $f$. 17. Lich. chrysophthalmus. Linn. Wulf. in Jasq. Coll. 1. t. 4. f. 3. Engl. Bot, t. 1088. Platisma armatum (apoth: ciliatis) \& denudatum (apoth. nudis) Hoffm. Pl. Lich. t. 36 . $f: 4 ; 31 . f$. 1. Lobaria denud. Ejusd. Germ. Physcia chrysophthalma. Dec. Borrera Ach.

Exs. Moug. et Nestl. n. 455.

c. thallo subbimbricato adscendente, laciniis angustissimis, apotheciorum margine nudo. Physcia exilis Mich. Borrera. Ach.

Ad truncos \& ramos arborum in Europa australi \& occidentali. Vidi ex Italia, Hispania, Gallia, Helvetia, Anglia.

Fausto casu a Cel. Schleicher accepi ramum Pruni spinosce, in quo omnium formarum transitum evidentem observare contigit. In evolutionis serie priori analoga (ob substartiam magis cartilagineam pulverulenta non lecta est), quod jam de prioris f. \& hujus b. observavit Cel. Flotow ; sed omnino speciem efficit distinctam: thallo subcartilagineo, magis lacero-ramoso, colore in sole expallente (quo situ prior intensior subvitellina), laciniis prope marginem tantum fibrillosis, disco tenuiori, diversaque geographica distributione, in speciebus stabiliendis vix satis commendanda. - Forma primaria minus notata videtur ob habitum trivialem; e descriptione Imbric. 
chlorina Chev. par. p. 621. Thallum typice esse horizontalem, nec Everniarum more, primitus erectum, e fibrillis, quibus omnis Evernia destituitur, luculenter patet.

$\boldsymbol{E}$ definitione Borrer. solenariam ad priorem potissimum trahas, sed e fonte primario, a quo mutuata est, ad Ev. villosum pertinere patet. Dillenii figura pejor est, villo nimis rudi ad margines delineato, quasi fibrillosa esset. Alia denique planta, steritis tantum ad Lozere Gallice visa, ibidem pro Borr. solenaria kabita, ab utraque diversa est $=$ Borr. Boryi Fee! Pertinet ad primam sequentis tribus subdivisionem.

Trib. II. PHYSCIA (Syst. Orb. Veg. p. 242). Apothecia primo clausa, dein dehiscentia. Discus ceraceus crassiusculus, strato medullari impositus. Thallus normaliter foliaceus, adscendens aut stellaris, subtus fibrillosus.

Prioribus hactenus immixtæ, at maxime essentialiter differunt \& jam habitu dignoscuntur. Hujus loci sunt sic dictæ Physciæ subtus fibrillosa, omnes typice decumbentes \& horizontales. (Huc quoque pertinet Borrera furfuracea a. $\beta$. Hook. in Kunth syn. 1. p. 25, qux Parm. cirrhata S. O.V. \& ab E. furfuracea prorsus diversa). Harum paucæ, præcipue exoticx species, normaliter adscendunt; plurimæ meræ aberrationes specierum normaliter horizontalium. In omnibus formis adscendentibus fibrillx, matricem petendo, magis elongantur; $P$. erinacea insuper superne undique setis obsessa est.

* Normaliter adscendentes aut laxe decumbentes, apotheciis suboblique marginatis. Hagenia. Eschw.

Evernix foliaceæ differunt thallo primitus verticali, dein pendulo, utrinque strato corticali obducto, fibrillis prorsus nullis, apotheciis haud dehiscentibus, disco tenui \&c. - Thallus in his numquam crustaceus variat aut obliteratur, plerumque speciosus, cum sequentis subdivisionis species in abnormi statu tenellæ squamulosæ e. s. p.

69. PARMELIA leucomela, thallo cartilagineo glauco-albicante, laciniis angustissimis attenuatis adscendentibus, subtus canaliculatis subpulverulentis, fibrillis marginalibus tomentosis, apotheciis podicellatis margine patente radiato, disco plano nigrocæsio. Ach. meth. p. 256 . 
Clus. Hisp. p. 32,33 (Muscus in Ilice) Dill. Musc. t. 21. f. 50. Lich. leucomelas. Linn. - Swartz Obs. Bot. t. 11. $f$. 3. Physcia Mich. Borrera. Ach. Ad corticem Ilicis aliarumque arborum in Hispania. Clusius, Lagasca! (in utraque America copiosa).

Plerumque $2-3$ pollices alta, erectiuscula, raro decumbens, numquam stellato-adpressa. Laciniæ elongatæ, angustissimæ, sursum attenuatx, ramosx, acuminatæ. Fibrillæ dense fibrillosæ. Apothecia obliqua, eeterum regularia, margine patente integro, sed definite radiis $\mathfrak{x}-$ qualibus subulatis supra canaliculatis coronato. - A stirpe ejusdem nominis Gallica, Germanica abunde diversa videtur. Gfr. Parm. speciosa.

-70. PARMELIA ciliaris, thallo cartilagineo e viridi cervino-glauco, laciniis linearibus subadscendentibus subtus canaliculatis, fibrillis simplicibus ciliatis, apotheciis podicellatis, margine erecto demum lacero-dentato, disco plano nigrofusco subpruinoso. Ach. meth. p. 255. Moris. Hist. XV. t. \%. f. 6. Tournef. I. R. H. t. 325. f. C. D. Vaill par. t. 20. f. 4. Lich. ciliaris. Linn. - Fl. Dan.t.711. Hedw. Theor. Crypt. t. 32. Wulf. in. Jacq. Coll. IV. p. 244. t. 13. $f$. 1. Engl. Bot. t. 1352. Lichenoides Hoffm. Pl. Lich. t. 3. $f_{\text {. }}$ 4. Lobaria. Ejusd. Germ. Physcia Dec. Borrera $A c h$.

Exs. Lich. Suec.n.139. Fl. Deutsch. n.152. Moug. et Nestl. n. 64. Desmaz. Exs. n. 40.

b. tenella, surrectior. Borr. crinalis. Schleich.

Per omnem Europam ad cortices, saxa \&c. Thallus normaliter in situ horizontali laxe decumbens, in verticali adscendens; in hoc statu præcipue margo apothec. obliquus, adultior lacero-dentatus fimbriatusque. Variat insuper stellato-expansus, præcipue ad saxa. - Maxime notabilis forma ad scopulos nostros marinos vulgaris est: Thallo substellato-expanso, semper depresso, cervino-fusco, disco mox nudo (Cfr. Walll. Liap. n. 817. Lich. Suec. l. c. B), quæ in sequentem, optime monente amiciss. Stenhammar, facile abire videtur. Certe potius cum hac, quam cum P. obscura jungenda est. Frustra adhuc studui persuasum mihi redde- 
re vulgarem formam una cum Parm. sophode esse abeirationem $\boldsymbol{P}$. obscurae; dissuadet $\boldsymbol{P}$. ciliaris, ipsa passim stellato-expansa, $\boldsymbol{P}$. obscura major in statu adscendente (formæ sequentium adscendentes typo suo semper minores sunt), ut multos alios characteres taceam; dissua$\operatorname{det} \boldsymbol{P}$. obscura etiam passim Borrerx A. faciem induens, sed a $P$. ciliari valde diversam. Transitus directi non observati.

* Normaliter stellato-adpressa, apoth. aqualibus. Triplici statu omnes hujus subdivisionis species legimus, normali nempe, adscendente (Borrera Ach.), in quo priores valde referunt, \& crustaceo, in quo Lecanoræ Ach. - Eosdem nec specie, multo minus genere differre, observationibus a Cel. Wallrothio, Meyero \& me, illorum nescio, factis jam extra dubium positum est. Sagaciter quoque observat Meyer occurrere formas prorsus acrustaceas, y. c. $P$. stellaris, ad Lecan. Hageni rejectas. Similes porro vidi $P$. obscurae cum P. sophode, P. pulverulenta cum P. subfusca confusas. Testantur hæc exempla, in sequentibus magis magisque accumulata, dispositionem et genera e thallo (horizontali) foliaceo, subeffigurato, aut mere crustaceo nullo modo persistere posse. Sectiones, qux hinc oriuntur, certe minoris ponderis quam Fungorum pileatorum e pileo stipitato, sessili \& resupinato. - Variant insuper omnes foliacex formæ hujus sectionis laciniis, latioribus \& angustioribus, illis planis, his convexis, unde e singula duplex saltim species orta.

7r. PARMELIA aquila, thallo cartilagineo substellato nudo castaneo-fusco, subtus pallido ubique fibrilloso, apotheciis adnato-sessilibus, margine tumido erecto subcrenato, disco plano fusco-nigro mox nudo. Ach. Lich. univ. p. 488. Mich. gen. t. 51. f. 6. Dill. musc. t. 24.f. 69. Lich. pullus. Lightf. L. aquilus. Ach. - Engl. Bot. $t$. 982. Imbricar. Dec. - Parmelia crossophylla. Wahl. in Ach. Suppl. meth. Lich. fuscus Rutstr.

Exs. Lich. Suec. n. 208.

b. phrscioidea, laciniis adscendentibus torulosis aut tubuloso-inflatis (Borrera ex ment. Ach.) - Collema cristatum. Dec. fr. 2. p. 283. sec. spec., non vero syn. Lichen balaninus. Wahl. Lapp. $n$. 426 . 
c. crustacea, thallo iugoso-plicato, crustoso, uniformi, aut ambitu subradioso. Lecan. balanina. Ach. syn. p. 185 .

Ad saxa juxta litora marium fere omnium Europæorum, glacialis, baltici, atlantici, mediterranei.

Affinitate naturali præcedenti \& americanæ $P$. detonsa proxima; nec a sequente longe distat. Variat, ut hæc, marginibus laciniarum angustarum pulverulentis. Apothecia thallo fere immersa, primitus tantum pruinosa, disco opaco.

72. PARMELIA pulverulenta, thallo cartilagineo substellato e viridi fusco cinereo-pruinoso, subtus atropannoso, apotheciis sessilibus, margine tumido, disco plano nigro-fusco subpruinoso. Wallroth Flechtenk. p. 457 . P. allochroa.

* Thalli laciniis adpressis, margine nudis. Dill. musc. t. 24. f. 71. Lich. omphalodes. Wulf. in Jacq. Coll. 2. t. 15. $f$. 2. optima. L. pulverul. Schreb. Squamaria Hoffm. Pl. Lich. t. 8.f. 2. Lobar. Ejusd. Germ. Imbric. Decand. Parmel. Ach. Fl. Dan. t. 1719. Sturm. Deutsch. $f l$. 11. $t .8-$ (apotheciis margine squamuloso-foliosis: Mich. t. 43. f. 4.? Parm. venusta. Ach. meth. t. 8. $f$. 5. Imbric. Dec.) laciniis thalli angustioribus: Lich. angustatus. Hoffm. en. Lich. t. 11. f. 2. In muscis: Parm. farea ß. Ach. P. muscigena. Ejusd. pr. p.

Exs. Lich. Suec. n. 76. Ehr/h. Crypt. n. 187. (Lich. allochrous). Fl. Deutsch. n. 172. Moug. et Nestl. n. 162. Desmaz. n. 144.

* Thalli (magis cinereo-virentis) laciniis adscendentibus, subtus fibrillosis margine pulverulentis (vel omnino in pulverem granulosum solutis). Lich. pulverulentus. Ehrh. L. lanuginosus. Hoffm. en. $t .10$. f. 4. Lobar. pulveracea. Ejusd. Germ. Lich. griseus. Lam. Imbricar. Dec. L. pityreus Ach.-Engl. Bot. t. 2064. P. pityrea \& farrea a. Ach. Lich.univ. (Lepraria farinosa $A c h$. syn. ex p.)

Exs. Lich. Suec. 105, 204. Moug. et Nestl. n. 352. Fl. Deutsch. n. 47.

Ad cortices, ligna ubique copiose; etiam supra muscos, ad saxa \&c. 
Hic Lichen non minus variabilis quam $P$. parietina; habeo formas cum singulis hujus speciei analogas; inter has quoque Borreras Ach. \& Lecanoras Ach. (Lecan. chloroglauca. Flörk. ex Wallr.) prorsus referentes; at easdem, plurimis communes, nisi synonymorum gratia, enumerare prorsus tæedet. - Identitatém P. pulverulentoe \& venusta, $\boldsymbol{P}$. pityrea \& farrece harumque affinitatem, a me primo indicatas, ab omnibus jam agnosci video. Formæ pulverulentæ, præcipue si centrum thalli mere pulveraceum, ut mos est, sæpius steriles; fertiles mox ad statum normalem accedunt. Forma tota leprosa latas plagas truncorum irriguorum occupat, \& vulgo Lepr. farinosa dicitur; probe vero tenendum nullam Leprariam ad certam quandam speciem pertinere - Color humidi viridis, sicci fuscescens, sed e pruina cinerascens, hanc speciem facile distinguit. Nullum dubium Linnæum hanc speciem etiam sub Lich. stellari i ntellexisse (Cfr. Engl. Bot. $t$. 1997); sed ab hoc species omni respectu distincta manet.

73. PARMELIA speciosa, thatlo cartilagineo-membranaceo virescenti-glauco epruinoso, subtus lacteo, laciniis obtusis ciliato-fibrillosis, apotheciis subsessilibus, margine incurvo crenato, disco concavo rufofusco subnudo. Ach. Lich. univ. p. 480 .

a. thallo stellato, laciniis elongatis adpressis. Lich. speciosus. Wulf. in Jacq. Coll. IIT. p. 119. t. 7. Lobaria. Hoffm. Germ. Imbricaria. Decand. (Parmelia phyllocarpa. Pers. cum prioris statu, qui $\boldsymbol{P}$. venusta Ach., analoga).

Exs. Moug. et Nestl. n. 605 .

b. thalli laciniis brevibus adscendentibus, fibrillis longioribus. Borrera leucomelas. Bot. Germ. Gall. non Ach.

Ad cortices, saxa \& supra muscos Europæ montosæ, præcipue mediæ \& Galliæ occidentalis. Etiam ad Haakenăs in Tellemarken Norvegiæ Blytt!

Laciniæ in utraque forma lineares, planiusculæ, pinnatifido-divisæ, obtusæ, subtus niveæx subvillosæ, margine tantum ciliato-fibrillos ; variat ceterum a. etiam marginibus adscendentibus pulverulentis e. s. p. Color ve- 
geti Lichenis virescenti-albus, sicci lacteus \& ex Wulfenio subcœrulescens. Apothecia proximarum magis elevata, margine incurvo, mox crenato fimbriatoque. Discus concavus, mox nudus. Medium statum inter a. \& b. sistere videtur Lich. hispidus Wulf. in Jacq. Coll. IV. $t$. 6. $f$. a, b, c. Omnibus partibus b. a $P$. leucomela vera mihi diversa videtur, at specimina sub hoc nomine accepta e Grermania (v. c. ad Carlsruhe Laurer!), Gallia orientali (Mougeot!) \& occidentali (Guépin!) ad hunc $P$.speciosce statum, ut decet physcioideas, diminutum pertinent. Omnia sterilia fuere, sẹd ex America boreali similia adsunt fertilia, in quibus apothecia non definite radiata, sed margine incurvo dentato-lacero cincta, discus concavus. Ceterum hæc species in America vario modo mutatur, quod vero scopo præsenti magis alienum. 74. PARMELIA astroidea, thallo submembranaceo glaucescente epruinoso, subtus pallido nigricante-fibrilloso, apotheciis innato-sessilibus, disco plano nigricante subpruinoso, margine integerrimo.

a. thallo stellato, haud pulverulento, laciniis angustioribus. P. astroidea. Clement. Ens. vid. p. 302. P. sideralis. Ach. syn. p. $20 \%$.

b. thallo orbiculari (centro) granuloso-pulverulento, laciniis ambitus latioribus. Parm. Caricæ. Clement. l. c. Lecan. Ach. syn. p. 188. Parm. Clementiana. Turn. in Transact. Jinn. Soc. IX. t. 13. $f .1$. Ach. syn. p. 201. Lich. Eingl. Bot. t. 1779. (P. cineritia Ach. dubia ut sterilis, vix distincta).

Exs. Moug. et Nestl. n. 737.

c. laciniis adscendentibus squamulosis (Borreræ aut potiss. Lec. tribracioe A. facie).

Ad cortices arborum, præcipue Quercus, optima in Hispania Dufour!; ceterum, plerumque degenerata, in Gallia occidentali, immo ad Vogesos Mougeot!, \& Anglia Turner!

Species, quantum video, distincta e vicinia P. stellaris, speciosce \& pulverulentoe, cum qua eam formationum cyclo prorsus convenire apparet. Statum sub b. designatum ad $P$. speciosam jam retulit acutiss. Flotow eumque haud normalem esse, sed ad typum quendam haud granuloso-pulverulentum, ut $\boldsymbol{P}$. farrea A, ad $P$. pulve- 
rulentam, $P$. conoplea Ach. ad $P$. rubiginosam Ach., referendum, res est de qua non dubitetur. Hunc vero typum in $\boldsymbol{P}$. astroidea Clem. invenio, omnesque hujus formæ a priori differunt apotheciis magis adpressis, fere innatis, (in P.speciosa elevata sunt, immo subpodicellata,) margine erecto subintegerrimo numquam squamuloso-foliaceo, quo cum sequentibus convenit, disco fusco-nigro cesio-pruinoso, demum plano nudo nigro, thallo magis membranaceo, laciniis subtus fibrillosis, nec margine tantum ciliatis. Fibrillæ pro more in formis magis adnatis \& dissolutis magis obliterantur. Color quoque ad typum P. pulverulentæ in b. dilutior, (albido-canus; sed non e statu sicco aut udo mutatur,) qui in a. fuscescenti-glaucus. Geographica distributio hos limitites speciei confirmat; plurimisque speciebus commune est, versus patriæ suæ terminos tantum sterilescentes (indeque frequentius, ut hac via propagentur, fatiscentes) \& degeneratas occurrere.

75. PARMELIA stellaris, thallo subcartilagineo glaucescente nudo epruinoso, laciniis multifidis subtus albidis fibrillosis, apotheciis sessilibus, margine tumidulo subintegro, disco fusco-atro subpruinoso. Wallroth Flechtenk. 1.p.432. P. homochroa.

a. thallo stellari-expanso, fibrillis brevioribus. Mich. gen. 't. 43. $f$ 2. Lich. stellaris Linn. (inclusis proximis) et Auct. Hoffm. en. Lich. t. 13. $f .1,2$. F'. Dan. 95\%. L. ambiguus E/hrl. fide. spec. Parmel. stell. Ach. Imbric. Dec. - adultior lobis planis: L. aipolius. Ehrh. - Hoffim. en. t. 12. f. 2. Lobaria. Ejusd. Germ. Parm. Ach. Imbric. Dec. Lich. s. Parmelia anthelina. Ach.

Exs. Lich. Suec. n. 206. A. 207. Ehrh. Crypt. n. 197. 20\% Fl. Deutsch. n. 135. Molig. et Nestl. n. 163. Desmaz. n. 145.

b. hispida, laciniis adscendentibus, margine longius hispidis. Dill. musc. t. 20. $f_{0} 46$. v. tubuloso-inflatis. Mich. gen. t. 50. ord. 27. Lichen hispidus Auct. Wulf. in. Jacq. Coll. IV. t. 6. f. d. Fl. Dan. t. 1186. $f$. 1. Lobaria. Hoffm. Germ. Lich. tenellus. Scop. - Engl. Bot. t. 1351. Parmelia. Ach. meth. Borrera. Ach. syn. var. u. Physcia. Decand. Vide Mey. Flecht. ic. 
Exs. Lich. Suec. n. 206. B. transitus evidentiss. ad a. Moug. et Nestl.n. 450. Fl. Deutsch. n. 73 . c. laciniis adscendentibus squamulosis parce fibrillosis, apice pulverulentis. Mich. gen. t. 50. ord. 26. Lecan. tribracia. Ach. syn. p. 291, ex part. at apothecia lutea a P. parietina immixta. (Alia e Gallia est Parm. chrysophthalma).

Per omnem Europam, præcipue ad cortices arborum, copiose.

Thallo superne glabro, nec pruinoso, nec sorediifero, \& præcipue colore tam sicci, quam humidi glaucescente facillime dignoscitur; vidi tantum rarissime v. c. e Christiania in Norvegiæ maritimis lectæ cinereo-fuscescentem. Licet sæpe centro in crustam rugosam concrescat, immo totus crustaceus visus sit, nuinquam priorum more in centre leproso-granulosus evadit, nam lepra non nisi in apicibus adscendentibis erumpit \& hinc lacinir constanter lineares \& stellatæ magis, quam in reliquis, nişi adscendunt. Hæ formæ adscendentes (Borreræ Ach.) Lichenologorum crux fuerunt, \&, si earum natura jam non amplius dubia sit, adhuc in synonymis determinandis manent, nam perevidens est, plerosque Auctores ut unius speciei formas sæpius analogas diversarum confudisse v. c. $P$. stellaris, caesice, astroidlece, obscurce immo L. hispidus Wulf. $l$ c. $f . a-c$, meo sensu, a $P$. speciosa ortus. Uniús Michelii, ad lepræ diversam effusionem attendentis, synonyma prorsus pura sunt; quibus reliquorum Auctorum proxime accedant; saltim indigitabo. - Lichen quidam semipinnatus Leers, vulgo citatus, non exstat. Apothecia sequentis magis pruinosa \& juniora dilutiora, sed vetusta etiam nuda, atra; numquam margine squamuloso-foliacea. Athallina, ut optime Meyer, ad P. Hageni vulgo referuntur.

76. PARMELIA casia, thallo substuppeo cæsio aut cinereo-albicante, sorediis cæsiis adsperso, subtus pallido, laciniis subpinnatifidis ciliatofibrillosis, apotheciis sessilibus, margine tenui subinflexo integro, disco mox nudo atro. Ach. Lich. univ. p. 2 I 6.

a. laciniis stellatim expansis, brevius fibrillosis, sorediis regularibus. Dill. Musc. t. 24. f. 70. L.' Psora. Dicks. Lich. pulchellus. Wulf. in Jaeg. Coll. II. 
p. 199. t. 16. Lich. cæsius. Hoffm. en. Lich. $t$. 12. f. 1. Englo Bot. t. 1052. Psora. Hoffm. Pl. Lich, t. 8. f. 1. Lobaria. Ejusd. Germ. Imbric. Dec. - major, dealbata: Parmelia albinea. Ach. syn. p. 207. ipso teste. - angustior: Lob. dubia. Hoffm. Parmelia. Flörk.

Exs. Lich. Suec. n. 323. Moug. et Nestl. n. 44\%. Fl. Deutsch. n. 71, 72 .

b. tenella, laciniis adscendentibus longe hispidis. Mich. gen. t. 50. ord. 28. Vaill. par. t. 20. f. 5. Parmelia leptalea. Ach. meth. Physcia. Dec. Borrera tenella. $\beta$. Ach.

Exs. Lich. Suec. n. 298 (Lich. tenellus Suecorum pl.)

c. laciniis squamulosis, brevibus, obsolete fibrillosis. Lecan. tribracia. Ach. l. c. pr. p. Sommerf.

Per omnem Europam, præcipue ad saxa, tecta \& ligna fabrefacta.

A priori differt thalli indole \& figura, colore in vegeto subcæsio e. s. p., præcipue vero lepra in soredia hemisphærica cæsia e disco laciniarum erumpente, ut ob duos typos evidenter diversos non possit non distingui, licet infimæ degeneratæ utriusque formæ sæpe vix nisi in loco natali discerni possint. Hujus forma b., in quovis saxo circa Lund obvia, cum a. ita confluit, ut dimidium sane speciminum numerum ad neutram tute referas, sed in scopulis nostris marinis magis rigida, nigrescens, quasi adusta. - c. æque lucenter ab a. oritur ad parietes Smolandix. Denique ad saxa quoque legi thallo prosus crustaceo, vix effigurato.

77. PARMELIA obscura, thallo submembranaceo epruinoso læte viridi, sicco livido-fusco, subtus nigro-fibrilloso, apotheciis sessilibus integerrimis, disco primitus nudo nigro-fusco. - Ehrh. Lichen.

a. orbicularis, thallo adpresso, substellari. Lich. orbicularis. Neck. - Hoffm. en. Lich.t. 9. f.1. Placod. Plant. Lich. t.66.f.1. Lobaria. Ejusd. Germ. Lich. cycloselis dein Parmelia. Ach. - Engl. Bot. t. 1942 (2158, L. elaeinus, vix differt) Imbric. Decand. - P. adglutinata. Flörke (matri arcte adnata). - P. murina \& P. viridifusca. Schleich. Cat. variet. ex colore. 
Exs. Lich. Suec. n. 205. Sommerf. Norv.68. (ק. simill.) Moug. et Nestl. n. 543.

b. chloantha, thalli laciniis adscendentibus, subtus nudiusculis ciliatisve Mich. gen. t. 51. ord. 29. Dill. musc. $t$. 22. f. 47. P. chloantha. Ach. syn. p. 217. (media inter a \& b).

c. thallo squamuloso-pulverulento 1 . omnino crustaceo. Lichen, dein Parmel., demum Lecan. virella. Ach. Lecan. lepræformis. Flörk. Deutsch. n. 68. Lecan. nigricans. Fl. l. c. n. 91 .

Ad saxa, cortices \& ligna Europæ totius Iocis humidiusculis.

Cum P. ciliari \& pulverutenta (cum hac conjungitur ab Hagen) convenit colore humidæ viridi; sed in siccis magis mutabilis plus minus lividus aut fuscus. Margine integro, disco primitus nudo \&c. ab his reliquisque differt. Ceterum maxime mutabilis, thallo subtus atropannoso \& nudiusculo, laciniis dilatatis \& angustis, lepra nunc ad soredia cinereo-pallida planiuscula in laciniis, nunc pulveris instar e disco 1. margine laciniarum erumpente e. s. p. - occurrit quoque thallo mere crustoso \& obsoleto; in illo statu cum $P$. sophode ab incauto facillime confunditur; in hoc meliorem partem Lec. scrupulosae Ach. efficit, de qua videas obss. infra. Omnes hujus speciei formæ ab affinibus dignoscuntur voracite, qua Insecta eas commedunt.

B. $P$. ulothrix, thalli laciniis linearibus subciliatis, apotheciis subtus fibrillosis.

Dill. musc. t. 24. f. 72. Lich. ciliatus. Hoffm. en. Lich. t. 14. $f$. 1. Lobaria. Ejusd. Germ. Lich. ulothrix. Ach. Parmelia. Ejusd. Imbricar. Dec.

Exs. Lich. Suec. n. 139. Ehrh. Crypt. n. 177. Fl. Deutsch. n. 94. Mo:g. et Nestl. n. 448.

b. laciniis adscendentibus, longe ciliatis.

Ad cortices truncorum, præcipue Populi, locis siccioribus.

Singularis prioris est varietas; at speciei nomine minime digna. b., Parm. speciosae b. prorsus referens, \& status crustosus prioris forsan effecerunt ut Recentiores P. ciliarem, ulothricem \& sophodem in unam speciem conjungere voluerint.

E Flotowio etiam h. l.P. cas siella, melanion et elleinut Spreng. Neu. Entd. Il. 
78. PARMELIA eloeina, thallo membranaceo adpresso submonophyllo radioso-plicato umbrinoolivaceo, subtus nudiusculo, apotheciis elevatis integerrimis, disco nudo rufo-umbrino. Wahl. Lapp. p. 425. t. 28. f. 5. Lichen.

Parmel. elæina. Wahlenb. - Ach. Lich. syn. Lecan. Ach. Lich. univ.

Ad latera lapidum occulta ad alpem Rossmollen Qualöæ Fiımarkiæ occident. Wahlenberg!

A tribu parum deflectit ad sequentes, a quibus tamen \& hypothalli defectu \& apotheciorum margine genuino erecto integerrimo differt. Adsunt prioris specimina vix nisi colore constanter alio \& lepræ effusione (in hac non obvia) diversa. Nec ad Placodia referatur ob thallum vere foliaceum \& membranaceum.

Sunt e serie Glauca n. 69, 73,74,75, 76 - e Viridi-phea n. 70, 71, 72, 77, 78. Reliqua series in Europa desunt.

Sect. II. Thallo subfoliaceo, dein in crustam subgranulosam conglomeratam compacto, orto ex hypothallo fibrilloso, (raro obsoleto,) supro matricem effuso. Zeori. S. O. $V \cdot p r . p$.

Jam differcntiæ hujus sectionis thallinæ, idealiter intuenti, evidentes \& essentiales sunt. In præcedente primitus oritur thallus, cui dein l. saltim coætanee adnascitur hypothallus; in hac sectione supra matricem effusus est \& sæpe reperitur absque thallo evoluto, quod numquam in priori. - A sequente sectione thallo subcrustaceo plus minus effigurato luculenter differunt thallo primitus omnino foliaceæ structuræ, etsi plerumque squamulas parvas tantum profert. Omnibus insuper peculiare est, thallum vel centro vel totum per ætatem in compaginem crustosam abire \& hinc luculenter differunt a sic dictis Squamariis Placodiorum, in quibus thallus primitus crustosus, dein in squamulas effiguratus. Hæc morphoseos differentia magis essentialis est quam thalli crustacei aut squamulosi.

At quoad apothecia ipsa insigniter magisque recedunt plurimæ species, disci \& excipuli natura inter Biatoras \& Parmelias eximie ambiguæ. Cfr. Obs. sub Psoromate. Cum vero hæ differentiæ sæpe minus evidentes, servavi hoc loco sub Parmelia ob faciem \& usum 
consuetum, ob seriem tam cum prioribus, quam sequentibus, contiguam, præcipue vero qucd aliæe species, ceterum simillimæ, verissimam Parmelice (Imbricariae) structuram monstrant. - Porro in ouni sequente tribu occurrunt species apotheciis \& vere parmeliaceis \& biatorinas referentibus. Apothecia Amphilomatum pameliacea duplicis quoque generis: simplicia minuta, margine genuino tenui cincta, e thallo foliaceo orta, \& symphycarpea, triplo vulgo majora, margine thallode accessorio granulato, e thatlo granuloso-conglobato oriunda, quæ, licet jam primitus confluerint, ut non amplius discerni possint, e pluribus simplicibus certe coakita sunt.

Trib. III. AMPHILOMA (S. O. V.p. 243).. Apos thecia erumpentia, margine accessorio subcoronata. Discus ceraceus, crassiusculus, nudus. Thallus foliaceus, submonophyllus, rotundatus, centro demum crustaceo-compactus; hypothal. lo spongioso-pannoso impositus. (Synonyma sub Trib. 1. Panuaria. Delis. Dict. Class. XIII. p. 20).

Tres nobis tantum species \& quidem occidentali-maritimæ, plurimæ vero exoticæ ex America \& præcipue insulis oceanicis, nam geographicis rationibus cum Filicibus conveniunt. Priores ad seriem Glaucescentium, tertia ad Ochroleucarum, pertinent.

79. PARMELIA plumbea, thallo coriaceo-mem-

branaceo smbmonophyllo radiato-rugoso lividoplumbeo, ambitu crenato, hypothallo determinato e pallido coerulescente, apotheciis rufis, margine pallidiori integerrimo. Ach. Lich. $u$ niv. p. 466.

Mich. gen. t. 43. ord. 23. f. 1. (Dill. t. 24. f. 23 male) Lich. corulescens. Fiuds. L. plumbeus. Lightf. scot. t. 26. Imbric. Decand. Pannar. Delis.

Exs. Lich. Suec. n. 68.

b. Vetustior, thallo centro conglobato-crustoso, apotheciis symphycarpeis granuloso-marginatis, Pannaria myriocarpa. Detise.

Ad rupes \& truncos vetustos (optima in Fraxino) Europæ accidentalis, præcipue maritimæ, 
ab Italia \& Hispania Dufour! - ad Nordlandiam usque Wahlenberg!

Eximie orbicularis, sed plures subinde confluunt. Hypothallus determinatus \& integer a matre secedens, extra ambitum thalli prominens obtusus. Apothecia fere Biatoræ (aut potius Stictæ) ob excipulum coloratum, sed discus crassus primo inclusus; subtus observatur stratum gonimon. - b. vetustissima, nullo modo transitum ad sequentem offert. In hac \& sequente luculentissime vidi apoth. symplaycarpea a pluribus coalitis orta esse.

8o. PARMELIA rubiginosa, thallo membranaceo epruinoso livido-glauco, ambitu laciniato-multifido, hypothallo indelerminato tomentoso cœruleo-nigro, apotheciorum disco rufo-badio, margine thallode incurvo crenato. Ach. l. c. $p$. 467 .

Mich. gen. t. 43. f. 3. Lich. rubiginosus. Thunt. et Recent. L. affinis. Dicks. Crypt. IV. t. 12. $f .6$. Engl. Bot. t. 983. Parmel. Ach. meth. Imbricaria coerulesc. Decand. Pannaria. Delis.

Exs. Lich. Suec. n. 107.

b. conoplea, thalli centro in massam granulosam abeunte, apotheciis symphycarpeis immersis convexis granuloso-marginatis. Parm. conoplea. Ach. Imbricaria Dec. fr. 6. (2. P. pityrea). Pannaria. Delis.

Exs. Lich. Suec. n. 75.

Loco \& patria cum priori convenit, optima in Populo.

Rotundata aut effusa. Hypothallus indeterminatus, tenuior, arcte adnatus, haud integer a matre secedens. Apothecia jam primitus a thallo erumpentia crenulato margine cincta. A priori certe distincta!, licet affinis; utraque nobis frequenter obvia. Sed infimæ ejus proles a Parm. triptophyllace rite discerni nequeunt; at qux species ejusdem seriei non conjungendæ ex infimis prolibus? abit hujus b. in formam totam pulveraceo-granulosam pro Lecan. caronata facillime sumendam.

* 81. PARMELIA lanuginosa, thallo membranaceo pruinoso ochroleuco, ambitu lobato crenatoque, hypothallo tomentoso cœruleo-nigri- 
cante, apotheciorum disco rufofusco, margine thallode pulverulento. Ach. l. c. p. 465.

[Lich. membranaceus Dicks. Crypt. 2. t. 6.f. 1 .

b. thallo in centro l. ex maxima parte granuloso-pulverulento. Lich. lanug. Ach. Imbric. Dec.

Exs. Lich. Suec. 74. (sæpius a). Moug. n. 446. (b).

Ad rupes precipue versus mare occidentale; b. sterilis \& degener in cryptis \& ad truncos etiam Europæ mediæ.

- Specimina perfecta \& optima speciem extra dubium ponunt; prioribus proxima, at ex alia serie. Color ochroleucus, ut in $P$. caperata, facile in pallide sulphureum abit - Discus ceraceus, mollis, excipulo proprio nullo. - Ad formam b. in status leprosos \& byssinos solutam utique etiam pertinent Lepr. incana (Wahl. Suec. n. 1765), byssoidea, Conferva pulveria (Agardh Syst. Alg. sub Mycinemate) e. s. p.. at nemo cautus ejusmodi species, quibus nil determinatum, sed ferrago diversissimorum Lichenum solutorum subest, ad definitam speciem refert. Optime monuit Cel. Wallroth synonyma citata potissimum e Cladoniis thallo foliaceo soluto orta esse, in eo tantum errans quod his P. lanuginosam ipsam adnumeravit.

Tris. IV. PSOROMA (S. O. V. p. 243.) Apothecia adnata aut immersa, plerumque biformia ; nunc e thallo orta, margine thallode crenato; nunc ex hypothallo orta, margine proprio integerrimo. Discus ceraceus, primo clausus. Ex hypothallo communi discreto (raro obliterato) plurimce oriuntur squamulae discretce foliacece!, quce vero centro aut totae in crustam subgranulosam concrescunt. Psoræ sp. Hoffm. Lecan. \& Lecid. Ach.

Tribus thalli habitu \& apotheciorum facie facillima agnitu, ut etiam vegetationis historia maxime analoga; at apothecia simplicia \& symphycarpea, huic sectioni priva, in diversis non tantum speciebus, sed in eadem etiam mutantur, præcipue in subdivisione Glaucescentium, quorum metamorphosin qui non attendunt, species non possunt non \& male conjungere \& distinguere. Glaucescentes enim præcipue nunc apothecia Par- 
melix, nunc Biatorinis simillima proferunt. Gujus ratio est diversus eorum situs \& ortus. Qucando enim ex ipso thallo enascuntur, qui status omnino normalis dicendus est, margine thallode (vero in simplicibus, accessorio in symphycarpeis) instructa sunt! Quando autem apothecia hypothallus enititur, (quod etiam in sequentibus tribubus haud raro fit, unde tot species \& inter Lecanoras \& Lecideas simul recensentur), nullo margine thallode, ut per se facile patet, cingi possunt $v$. c. Lecidea triptoplyylla, Collema nigrum, C.velutinum, qux re ipsa nil nisi Parmelice triptophylloe status thallo plus minus suppresso, apotheciis ex hypothallo ortis. A similibus autem apotheciis Biatorinis sequentium tribuun recedunt margine plerumque proprio, qui oritur e strato proprio sub disco, (Ehypothecio duplici in Collemate, ex acuratiss. Eschweiler), in his \& priori tribu plerumque obvio, at sæpius tam parum evidenti, ut prapositum meum eas ab hoc ad Biatoras 1 . novum genus intermedium referendi in præsenti miserim. In ultimis inst:per speciebus, ceterum similibus, prorsus desideratur. In hac igitur tribu limitanda malui contra systematica principia, quam naturæ \& affinitatis leges peccare videri. - Ceterum harum hypothallus locis aquosis apothecia rarius profert magisque floccosus evadit, \& ex hoc statu, tam harum, quam aliarum Algarum Lichenosarum multæ exortæ sunt Algæ Aquaticæ, v. c. Conferva pannosa Web. \& Mohr \& Scytonema byssaideum Agardh S. A. a supra citata Parmelia triptophylla. - Species hujus tribus præcipue incolunt terram, muscos, saxa aut ligna humida, locis montanis \& subalpinis.

* Glaucescentes. Thallus livido-glaucescens (tantum hypothallo prædominante fuscus aut nigrescens); solutus in lepram incanam abit. Discus e rufo fuscus, strato albo impositus. Serie contigua cum Ámphil. * junctæ.

82. PARMELIA microphylla, thalli squamulis cartilagineis imbricatis crenatis livido-cinereis, dein in crustam contiguam compactis, hypothallo nigricante, apotheciis superficialibus, disco fusc-niggro, mox convexo marginem thallodem excludente. Stenhamm. Sched. Crit. 5. p. Io. Biat. 
Lichen leucophæus. Dicks. L. microphyllus. Swartz. - Westring in Vet. A.c. Handl. n. 1791. p. 301. Achar. l. c. 1795. t. 5. f. 3. Lecan. Ejusd. Lich. univ. exclus. $\gamma$. Lecid. Ejusd. syn. var. a. - Lich. escharoides. Engl. Bot. t. $124 \%$.

Exs. Lich. Suec. $n$. 158.

b. symphycarpea, apotheciis triplo latioribus, granuloso-marginatis.

Ad latera montium irrigua ad rupes ipsamque terram, precipue in Scandinavia \& Scotia! b. rara; speciosam e Norvegia attulit Blytt!

Thallus latas plagas occupat, demum plures lineas crassus, e livido-cinereo glaucescens (in b. recente pulchre cocruleo-glaucus); primitus constitutus e granulis confertis distinctis, quæ mox explicantur in squamulas crassiusculas e situ stipato adscendentes aut erectiusculas arcte imbricatas crenatas, at minime laciniato-dissectas, subtus albas, hypothallum crassum spongioso-leprosum ita plérumque obtegentes, ut vix ex hypothallo apothecia (eaque primitus immarginata) proferat. Per ætatem magis contiguus fit, rugosus \& inæquabilis; at corallinum numquam vidi. Apothecia e thalli superficie enata, prorsus facile genuinæ Parmelix, margine normaliter tenui crenulato, mox a disco turgido hemisphærico obliterato. Huic jure antiquitatis microphyllae nomen debetur.

83. PARMELIA triptophylla, thalli squamulis membranaceis li vido-fuscescentibus, primitus stellatim expansis dissectis, dein g!anuloso-corallinis, hypothallo coruleo-nigricante, apotheciis immixtis, disco planiusculo brunneo, margine erecto persistente.

a. \& b. coronata, apotheciis e thallo oriundis \& marginatis- I. simplicibus - I. symphycarpeis. Lichen granulosus. Dicks. Psora coronata. Hoffm. Pl. Lich. t. 56. f. 1. Verruc. Ejusd. Germ. Lichen leucoplixus. Fl. Dan. t. 955. $f .2$. Parmelia dein Lecan. brunnea $\beta$. Ach. Lich. brunneus. Engl. Bot. $t .1246$. Lecan. brunnea Botan. Gallice. Lecid. microphylla. B. Schaer.

Exs. Fl. Deutsch. n. 151. Lecan. coronata!

c. Schraderi Schaer., apotheciis ex hypothallo oriundis, planis margine thallode destitutis. Dill. Musc. 
t. 82. f. 2. Lichen microphyllus. Schrad. spic. 7. c. $t$. 1. f. 4. Engl. Bot. t. 2128. Psora. Hoffm. Collema. Decand. Lecid. Schaier. var. a. Lecid. triptophylla Ach. Lich. univ. - *hypothallo magis prædominante, nigrescens, squamulis mere corallinis. Stereocaul. corallinoides. Hoffm. Lecid. Flörke. in Berl. Mag: 1809. Lichen niger. Engl. Bot. t.1161. Lecidea, dein Collema. Ach. Lichen, dein Verrucaria. \&c. picinus. Ach.

Exs. Lich. Suec. n. 43. Moug. et Nesìl. n. 552. Schrad. Crypt. n. 184. Schaer. Helv. n. 159.

d. velutina, mere hypothallina, fibrillosa *saxatilis. Lichen, dein Collema velutinum. Ach. Parm. pannosa. Ach. meth. \& - prorsus sterilis: Conferva pannosa Web. et $M$. \& quæ inde pendent synonyma. **corticola. Lecid. triptophylla. v. velutina. Ach. Lich. un. Exs. Lich. Suec. n. 420. A. \& B.

Vulgatissima tribus per omnem Europam; ad terram, ad arborum radices, saxa granitica \& calcarea (præcipue $c^{*}$ ), ligna, muscos, cortices fere ubique.

Præcedenti \& valde similis \& affinis; at affinia non identica \& equidem lubentius distinguo simillima, in natura diversam evolutionis seriem servantia, quam dissimilima, sed ex eadem evolutionis serie facile confluentia. Ingenue fateor Lichenum formas, ut externa facie maxime differant, ita maxime mihi esse suspectas! Hanc \& precedentem per quinque lustra ad easdem rupes, numquam autem vere confluentes, amiciss. Stenhammar ipseque observavimus. In $P$. triptophylla hypothallus magis distinctus, cœrulescens, linea coerulescente thallum plerumque circumscribens; unde thallum sæpius excludit. Thallus, si rite evolutus, laciniatus, valde dissectus, primitus stellato-expansus ut Physcix, (qualis ad litora lacuum in Smolandia frequens), mox vero in massam granulosam subcorallinam transiormatus. Talis vero jam primitus oritur in c. ${ }^{*} ; \&$ in corticibus \&c. thallus etiam squamulosus, licet membranaceam indolem semper servet; at prior nec corallina evadit, nec arborea reperitur. Forma a. ex statu conglobato in lepram incanam facile deliquescit; nec mirum, cum in hac thallus tantum justam evolutionem attigerit. A pothecia hujus numquam elevata ut in priori ; simplicia P.rubiginosa juniora referunt; sym- 
phycarpea $P$. brunnece, quare in hoc statu vulgo junguntur. Discus planus, ut prioris firmior, margoque sive thallodes sive propius persistens. - Specierum, ceterum diversissimarum, sed simili hypothallo gaudentium, infimæ proles pro more ægre discernuntur, v. c. Parm. rubiginosa, badiae, Biat. uliginosce \&c., sed ex ejusmodi transitibus indirectis nullas conjungendas censeo.

\section{PARMELIA brunnea, thalli squamulis mem-} branaceis tenuissime dissectis livido-cinereis, mox in massam granulosam conglobatis, hypothallo nigro, apotheciis immersis, disco plano testaceo-rufo, margine incurvo persistente. $A c h$. meth. p. 186.

a. \& b. Pezizoides, apotheciis e thallo oriundis \& marginatis - simplicibus - 1. symphycarpeis. Lich. Pezizoides. Weber - Dicks. Crypt.1.t.2.f.4. Sturm. Deutsch. II. Heft. 3. Psora pezizoides \& brunnea Hoffm. Germ. Ps. nebulosa. Ejusd. Pl. Lich. t. 40. f. 1. Lich. brunneus. Swartz et Auct. Lecan. brunnea. a. Ach. Lich. univ. - Fl. Dan. t. 1718, f. 2. Leeid. microph. $\gamma$. Schaer. (Lich. multifl. Ehrh. ex spec. auth. E. Meyer).

Exs. Lich.Suec. n. 256. Schrad. Crypt.n. 155. Schaer. Helv. n. 160. Moug. et Nestl. n.639.

c. Biatoroides, apotheciis ex hypothallo oriundis, urceolatis, lacteo-flavescentibus.

Ad terram supra muscos, rupes irriguas, ligna putrida, Europæ totius.

Primus acutiss. Schaerer summam hujus cum priori observavit affinitatem; in his vero terris in analoga evolutionis serie constanter distincta manet. Margo constanter incurvus non accidentalis est; etiam in forma Biatoroidea margo proprius incurvus est, unde apothecia urceolata facie "Lecid. pineti" Ach. Hæc vero forma raro ab a. discreta occurrit, sed ad cortices ad terram prostratos hypothallus (in hac semper late effusus \& indeterminatus, ad terram vero cum ea contextus \& obsoletus) in medio profert apothecia formæ a. aut b., in ambitu vero deficiente thallo c., ut dubium non sit eas prorsus identicas esse. Discus hujus latior fit \& lætius coloratus, in his terris saltim vegetus primo flavicans mox testaceo-rufus, nec nisi mortificatus \& putrescens fusco- 
nigrescens. Stratum album, sub disco jin b. observandum, in c. abit in excipulum proprium. - Color thalli in brunneo-hepaticum in vetustis abit.

85. PARMELIA Hookeri, thalli squamulis imbricatis expansis incisis glaucescente-albis, demum granuloso-conglobatis, hypothallo fibrillo- so-nigro, a potheciis ad pressis, disco plano nigricante, margine erecto subpersistente.

Lichen Hookeri. Engl. Bot. t. 2283. Lecan. Hook. Scot. 2. p. 51. Lich. leucolepis. Wahl. Lapp. p. 420. Lecan. Ach. syn. p. 194. Lecan. mniarœa. Ib. p. 339. (et fere L. turfacea helvetica).

Ad muscos putrefactos, terram humosam, in subalpinis Lapponiæ Wahlenberg!, Scotia Houker!; in alpinis Helveticis Schleicher! v. c. in monte Grimsel Schaerer!, in Heiligenblut Carinthize Laurer!

Præcedentibus certe proxima, at sequenti etiam peraffinis; idem sub disco tumido at plano adest stratum album, ex quo formatum est excipulum proprium nigricans!, quando apothecia ex hypothallo, tum subglancopruinosa! ut in sequente, oriuntur. Margo sive thallodes sive proprius fere persistens, erectus. Monentc jam amic. Laurer Lec. leucolepidem \& P. mniarœeam Ach. conjungo, cum in hac thallus tenuior, magis lacero-squamosus, discus in fuscum vergat colorem, margo subinteger, h. e. ipsa cum priorum a. analoga sit; in illa thallus ma. gis granulato-conglobatus, discus ater, margo granulatocrenatus, ut in priorum b. Thalli colorem ut in ceteris etiam fuscescentem a Conferva incrustante deducit Wahlenberg; potius pro more ex hypothallo ortum habeo - Psora grisea Hoffm. Germ. Parm. dein Lecan. Ach., huc ab Achario relata, potius ad $P$. microphyllam pertinet, saltim nil distincti offert.

86. PARMELIA ostreata, thalli squamulis membranaceis reniformibus imbricatis crenatis glaucescentibus, subtus pulverulentis hypothallo obsoleto, apotheciis superficialibus, disco nigricante (glaucopruinoso), margine erecto persistente subintegerrimo. 
Psora ostreata. Hoffm. Germ. Lecidea. Schaer. Patell. Wallr. Flechtenk. I. p. 466. Lichen scalaris Ach. in Vet. Ac. Handl. 1795. t. 5. f. 1. Eng.l. Bot. t. 1501. Lecid. Ach. Lich. univ. - Cfr. Fries Sched. Crit. ad n. 229.

Exs. Lich. Suec. n. 155. 229. Fl. Deutsch. n. 82. In lignis vetustis putridis Pini, Quercus, Alni \&c. Europæe borealis \& montosæ. In Gothiæ silvis abunde fructificat.

Quin priorum congener, immo maxime affinis, sit, nequaquam in dubium vocabit, qui plenam ejus metamorphoseos seriem in natura persecutus est. Inter Biatoras vero s. Lecideas nulla vere affinis adest! Hypothalli vestigium utique vidimus, nec squamulæ hujus modo aggretatæ sine hypothallo oriri possunt. Squamulæ P.microphyllce haud absimiles, sed tenuiores subtus margineque pulverulentæ, e situ adscendentes 1 . decumbentes, haud raro priorum modo in crustam rugoso-verrucosam compactæ, immo prorsus in lepram æruginoso-glaucam dissolutæ. Apothecia etiam ut in prioribus: 1. e squamulis orta, excipulo thallode tenui genuino glanco subintegro, intus sub disco aterrimo nudo alba; $h$. e. vere Parmelix. (Lecid. scalaris v. myrmecina Ach. \& Wahl.) 2. Locis humidioribus idem discus protuberat magis convexus, nudus, rufus, dein fuscus margine pallidiori, quæ forma, cum specie sequente analoga, in Lich. Suec. $n$. 229 tradita est. 3. E crusta conglobata oriuntur apothecia symphycarpea, P. Hookeri similia, disco nigro, margine subgranulato. 4. Inter squamulas plerumque, ideoque typice ex hypothallo, oriuntur apothecia habitu Lecidex, ob excipulum nigrescens (licet non carbonaceum), tota glaucopruinosa, qualia etiam prioris analoga occurrunt \& hinc ab Achar. ad "Lecid. scalarem" relata sunt. Pendet vero differentia non parum e loco, cui vulgo innascitur P. scalaris, priorum sicciori; locis humidis enim apothecia priorum \& colore \& substantia similia. Ceterum, ut in serie glauca solemne est, color thalli passim in fuscescentem, subcervinum, abit.

** Olivaceo-fuscescentes. Thalli color primitus cervinus vel olivaceus. Stratum sub disco coloratum, fuscescens (in prioribus album).

- 87. PARMELIA muscorum, thalli squamulis rnembranaceis squarroso-explanatis dissectis fusco- 
castaneis, demum eroso-granululatis, subtus candidis, apotheciorum disco plano nudo carneorufo, margine primitus pallidiori integerrimo. Fries $V . A . H$. 1 $822 . p .276$. Biat.

Lichen muscorum. Osbeck. L. hypnorum. Liljebl. Ach. Prodr. Parmelia, Ejusd.meth. Lecan. Ejusd. Lich. univ. Lecan. muscorum. Ejusd. syn. p. 193. Pannaria. Delis. Lich. muscigenus. Waht. Parm. Ach. (scil. spec. Lapp., reliqua ad P. pulverulent.) Lich. carnosus. Dicks. Crypt. 2. t. 6. f. \%. Engl. Bot. t. 1684. Lecid. Sommerf. Lapp. p. 174. Lecid. Chauviniana. Dufour.

Exs. Lich. Suec. n. 44.

b. lepidota, thallo in massam granulosam subcompacto, apotheciis symphycarpeis (triplo majoribus \&c.). Sommerf. $l$. c.

In rupibus irriguis supra muscos (Trichostoma, Andreæas \&c.) Scandinaviæ totius vulgaris, Scotia! passim; ceterum rarior, ut in Ardemis, Vogesis Moug. in litt., Gallia occidentali Chauvin! \&c.

Est inter nobilissimas species, ob quarum distinctionem Acharius injuste carptus est; gravius vero ipsi errarunt, qui ad Biat. fuscoluteam, Parm. hypnorum, microphyllam \&c. retulerunt. Est quidem morphoseos lusu cum $P$. triptophylla prorsus analoga, sed ut e diversa serie ab eadem æque certe distincta, ac $P$. Acetabulum a $P$. tiliacea. Hypothallus subtomentosus niger raro observatur. At præcipue singularis est apotheciorum morphosis in forma a. Primitus e thallo erumpentium excipulum omnino proprium videtur; tam thallo, quam disco pallidius; sensim vidi in eo gonidia viridia demumque in vere thallodeum mutatum, margineque crenulatum. Qux morphosis ceterarum, Stictarum nonnullarum excepta, prorsus opposita est. In hoc statu, quem Wahl. Lapp.n.78\% describit, thallus quoque glauco-pruinośus, discus autem nigrofuscus, semper nudus. Temere de veritate hujus lusus raro obvii dubitavi, donec meis oculis in natura lustrare licuit.

88. PARMELIA amniocola, thalli squamulis membranaceis lacero-ramosis viridi-fuscis, hypothal- 
lo effuso nigro areolato-adpressis, apothec. disco mox convexo rufofusco, intus nigro, marginem thallodem integerrimum obliterante. - $A c h$. syn. p. 156 Lecan.

Supra muscos in Alpibus Helveticis. Schleicher! Schaerer!

Minime ad species crustaceas referri potest; squamule omnino affinium, hypothallo tantum magis adpresse; \& cum hic character ex unica forma petitus, forsan non constans. A priori, cui valde affinis, potissimum differt apotheciis minutis, minus elevatis, disco mox hemisphærico, demum nigricante, interiori strato ferme nigro. Márgine thallode evanido 1 . ad basin tantum persistente immarginata sunt; sed exstant alia ex hypothallo orta margine quasi proprio instructa.

89. PARMELIA paleacea, thalli squamulis membranaceis imbricatis flexuosis rotundato-incisis cervino-fuscis, apotheciis adpressis extus villosis, disco plano fusco-atro, margine thallode paleaceo-ciliato.

Lecan. ciliata. Herb. Ach. - at diversiss. a $\boldsymbol{P}$. ciliari n. $70 \&$ paleacex nomen potius meretur.

Supra muscos in Dania! Hornemann ex Achar. (Locus specialior mili haud innotuit.)

Speciem singularem \& Stictas illustrantem omittere nolui, licet specime:s mihi desideretur. Quoad squamularum irregulariter rotundato-incisarum crenatarum formam \& hypothallum vix conspicuum cum sequentibus, quoad colorem vero, magis essentialem, prioribus convenit. A pothecia valde singularia, extus thallo discoloria \& villosa, omnino ut in Stictis variis exoticis, (nec tantum vage fibrillosa, ut in Physciis quibusdam vo c. P. fibrosa, P. obscura. $\beta$.); margine cincta thallode crenulato-raciiato, mox paleaceo ciliato. Hinc excipulum $P$. muscicobo potius cum Stictarum decorticatum, quam Biatorarum, comparem. Discus nudus, $P$. muscicolce in statu parmeliaceo similis.

**** Citrince. Thallus luteus aut lete viridis. Discus tenuis subfulvus, strato gonimo impositus. ( $P$. aurea \& fulgens cfr. n. 116, 117). 
90. PARMELIA Hypnorum, thalli squamulis minutis imbricatis granulato-crenulatis luteolis (fuscescentibus), subtus pallidis, apotheciis sessilibus, disco membranaceo e fulvo fuscescente, margine thallode elevato granuloso.

Lichen Hypnorum ( $F$ l. Dan. $t$. 956. mala, decolor, ambigua) Engl. Bot. t. 740. Psora. Hoffm. pl. Dich. $t$. 65. f. 4-7. Lecan. Ach. syn. p. 193. Parmelia lepidora. Ach. meth. p. 185. Lecan. Lich. univ. Patellaria. Dec. Fr.

Exs. Lich. Suec. n. 162. Flörk. Deutsch. n. 150.

Supra muscos ipsamque terram in alpibus \& montibus editioribus. E plurimis Europæ regnis adest! insuper in Ostrogothia campestri legimus cum amic. Stenhaminar!

Thallus late \& indeterminate effusus, compositus e quamulis subimbricatis luteolis, per etatem cinereo-fuscescentibus, subtus nudis \& fere concoloribus. Apothecia omnino libera, verissimæ Parm. Imbricarix!, primo minuta urceolata, dein ad plures lineas dilatata, etiam extus præcipue versus marginem granulata, Discus membranaceus, politus, nudus, in optimo vigore fulvus, per ætatem badius \& fuscescens, immediate strato gonimo impositus, quare numquam excipulum thallodes excludere potest aut marginem proprium forraare. Hinc licet vetusta \& decolorata $P$. brunnece et muscorum similis sit, re ipsa ab illis magis differt quam ab ipsa Parmelia chrysophthalma, \&, nisi thallum consuluissem; hanc \& sequentem Imbricariis citrinis inseruissem.

91. PARMELIA Femsjonensis, thalli squamulis adscendentibus imbricatis crenatis viridissimis, - subtus candidis, apotheciis elevato-sessilibus, disco nembranaceo rubro, margine thallode crenato inflexo. Fries Stirp Fermsj.

Ad terram nudam fagetorum, etiam ad cortices muscosos Quércus ad Femsjö Smolandia, at raro fructifera.

Tam P. brinneam, quam $P$. crassam referens, ab illa apotheciorum stiuctura omnino præcedentis, ab hac squamulis prorsus membranaceis certe distinguitur. Thal- 
lus exacte Cladoniæ vo-c. Cl. gracilis, ut nil similius; sed ex hypothallo rigro enatus, semper foliaceo-squamulosus persistens, nec granulatus evadit, unde et apoth. excipulum semper læve. Discus læate testaceus aut ruber, nec fuscescens.

SEcT. III. Thallo crustaceo, ambitu lobato aut toto squamuloso effigurato. Hypothallus glaber, matrici adriatus, sape cum thallo confusus. Placodii, Psoræ \& Lobaria spec. Hoffm. Placodii \& Squamarix spec. Decand. Leeanora 'Ach. Lich. univ.

Crustacea substantia \& hypothallo glabro matrici adnato facile a priori dignoscitur; ad sectionem quartam, pluribus speciebus in statu imperfecto omnino crustaceouniformibus variis, ita accedit, ut tantum ad specimina perfecta tute determinetur. Vulgo subdividuntur huc pertinentes species in Placodia, thallo radioso-plicato seu ambitu tantum effigurato, \& Psoromata, thallo toto effigurato squamoso-imbricato; at hæ differentix, in multis prorsus fallaces, maxime affines semper longe separant v. c. Parm. Smithii a P. crassa, P. cartilagineam a $P$. saxicola, $P$.molybdinam a $P$. cervina, $\boldsymbol{P}$. auream a $P$. murorum, de quibus sæpe dubitetur, an non potius varietates sint. - Essentialem vero subdivisionis rationem offerunt apothecia, e quibus oriuntur duæ tribus, reliquarum sectionum eximie respondentes \& continuantes. - Felici casu, favore præcipue optimi Dufour, omnium specierum in Illustr. Decandollei Fl. Fr. descriptarum possideo, ut has cum Acharianis conjungere licuerit.

Trib. V. PLACODIUM. Apothecia scutellata, elevata. Discus immarginatus, nudus, saltim haud cresio-pruinosus. Thallus ut supra. Margo thallodes passim disci colorem induit. Exacte intermedia evolutionis series inter Imbricarias \& Patellarias, thalloque mutilato has referens.

* Glaucescentes. Color thalli e virescenti glaucus, albescens; lepra, si effusa, virescenti-alba. Apotheciorum discus plerumque ruber, opacus.

92. PARMELIA Dufourei, thallo crasso foliaceo- 
imbricato orbiculari lurido-glauco, laciniis contiguis sinuato-lobatis, subtus candidis, apotheciis superficialibus, disco rufo, marginem demum concolorem rquante.

Squamaria crassa. Dec. fr. sec. specim. visum. non Bot. Gallice. Lecan. rubina $\gamma$. liparia. Ach. Lich. univ. non methodi.

Ad terram in Gallia meridionali v. c. ad Bellucaire \&c. Dufour!

Speciosissima, thalli forma vera Imbricaria, sed structura \& indole crustacea Placodium, immo P. crassce ob hujus proteas formas peraffinis, at distinctissimam testatur Cel. Dufour, quo nemini lubentius fido. Orbes sistit amplos, lurido-glaucescentes, lacin iis a centro deductis, stellatim expansis, concretis, nudis, sinuato-lobatis, marginibus hinc inde $\&$ in ambitu adscendentibus, sed subtus semper candidis. Apothecia Stictce pulmohacece referunt, juniora clausa, dein concava, adulta plana, regularia, eumorpha, lævia, in omni ætate rufa, margine tenui integerrimo haud prominente; extus ob stratum corticale deficiens colorata, disco dilutiora sed intus tota candida \& a crusta formata.

Pro vera sua L. lip a ri u determinavit ACHARIUS, verum ista stirps in Syn. p. 190 tam mixta et hybrida e formis sequentis, n.112, 113 etc., ut ne ex herbario quidem diversa elementa exponi possint.

93. PARMELIA crassa, thallo crasso squamoso imbricato viridi-albescente, lobis irregularibus inciso-crenatis, apotheciis sessilibus, disco nudo subtestaceo-rufo, margine thallode tenui integro. Ach. meth. p. 183.

Dill. musc. t. 24. f. 74. Lich. crassus. Huds. Hoffm. en. Lich. t. 19. f. 1. Engl. Bot. t. 1893. Lecan. Ach.syn. Squamar. Chev. Lich. cæspitos. Vill Delph. - 3. t. 55. L. laqueatus. Wulf. in Jacq. Coll. III. p. 109. t. 5. $f .2$. Lobaria. Hoffm. Lecan. rubina. B. Ach. Lich. univ.

Exs. Lich, Suec. n. 289.

b. melaloma Ach. squamulis magis discretis margine nigris, apoth. obscurioribus. L. crassus. Schrad. Lob. crassiform. Hoffm. Parm. melal. Ach. meth. Squam. melanophthalma. Dec.

Supra terram in montibus calcareis ab An- 
glia ad Tauriam Stevens!, a Cadiz Dufour! ad Sueciarn, inque alpibus Carpathicis Wahlenb., Vallisiæe Schaerer! Carinthiæ Laurer! Pyrenæorum Montagne! \&c.

Thallus normaliter e squamis foliaceis, tartareo-crustaceis, irregulariter imbricatis compositus; variat vero squamis adscendentibus complicatis. Hypothallus niger. Apothecia pro ratione minora, nune pallide luteola, nunc rufofulva, nunc fusco-nigra; in genere tamen in testaceum vergunt colorem; margo rarissime excluditur, numquam vero in hac vidimus prioris excipulum coloratum.

94. PARMELIA gypsacea, thallo crasso crustaceo areolato pallescente, areolis demum concavis albomarginatis, ambitus radioso-lobatis, apotheciis depressis, disco primitus pruinato sordide pallido, margine thallode tumido.

Mich. gen. t. 51. f. 1. Lich. fragilis. Scop. (L. tartareus. Wulf. ex syn. et descr. Cfr. sequ. Psora cælata. Hoffm. Germ.? Lecid. Ach. L. gypsaceus. Smith. in Transact. Linn. Soc. 1. p. 81. t. 4. f. 2. Lich. dein Lecid. demum Lecan. Smithii Ach. (incompl., fere anceps). Squamaria. Dec.

In rupibus editioribus, præcipue gypsaceis, Hispaniæ usque ad Cadiz Dufour!, Pyrenæorum Montagne!, Galliæ meridionalis, Sabaudiæ Prevost!, Italix Ach.!, Tyrolis Schubert! (pro Ps. cælata) Vallisiæe Schleicher!, Helvetiæ in Pilato \&c. Schaerer!

Specimina undique allata faciem a priori, qualis apud nos nascitur, diversam monstrant \& potius illi \& sequenti affinem, evolutionis serie analogam, quam identicam speciem indicant. Est enim hactenus tantum ad specimina deformata vetustissima descripta; ex omnium ætatum serie verum esse Placodium centro areolato-verrucoso, ambitu squamoso-foliaceo, laciniis sinuato-lobatis, luculenter patet. Areolæ centrales primitus omnino adnatæ, verrucæformes, inter se contiguæ, vetustissimæ tantum elevato-marginatæ, sed margo in his numquam nigrescit ut in priori. Apothecia in junioribus in areolis detrusa, concava, margine thallode obtusissimo, sæpius bi- 
colori, cincta; in vetustis effiguratis areolis adpressa, explanata, subpeltata, passim rugosa. Disci color sordide pallido-luteus \& in olivaceum vergens. - Specimina hujus minora sub nomine Lecan. alphoplace ex Hispania \& Gallia sæpe accepi, at ab alpium borealium toto cœlo diversa.

95. PARMELIA Lagascae, thallo crasso crustaceo areolato-verrucoso pruinoso albescente, ambitu plicato lobato, subtus atro, apotheciis adnatis, disco pallide testaceo margine thallode tumidulo. Fries Sched. Crit. 9. p. 30.

Lich. calcareus. Lamark. Urceolaria Lamarkei. Dec. - Lecan. Lagascæ. Ach. Lich. univ. p.423. Lichen.' Wahl. Carp. p. 373. (Lich. tartareus, Wulf. in Jacq. Coll. IV. p. 241. t. 8. f. 2. huc citatus, e descriptione priori magis convenit).

Ad latera rupium subalpinarum, precipue calcarearum, in Hispania Lagasca!, Pyreneis Dufour!, Helvetia in Pilato, Grimsel \&c. Schaerer!, denique Carpathis Wahlenberg!

Thallus in hac nullo modo foliaceus aut squamosus, sed in placentas latas, 1-2 lin. crassas \& ultra, ex maxima parte ex areolis stipatis subrotundo-angulatis convexo-planis semper immarginatis (\& hinc L. tartareus Wulf. areolis albo-marginatis potius prior), vetustis rimoso-rugosis compositas radiatim effusus; tantum in ambitu breviter at pulchre plicato-lobatus. Hypothallus crassus, subspongiosus, ater. Apothecia areolis insident, e concavo-explanata; margine thallode evidente, persistente, integerrimo, rarissime demum decorticato. Hujus loci esse Psoram similarem Hoffm. (Parm. s. Lecan. $A c h$.) mihi asseveratum est, at descriptio haud sufficiens ad hanc recte determinandam. Nulli tamen magis adæquata.

96. PARMELIA Blyttii, thallo pulvinato-crustaceo verrucoso-gyroso nudo e glauco candicante, ambitu sublobato, apotheciis adnatis, disco plano nudo atro, margine thallode integerrimo.

In fissuris rupium, supra terram, in alpe Dovre Norvegiæ. Circa Kangsvold copiose Blytt. 
Valle linsignis, habitu $P$. Lagasca similis \& forsan proxima, sed thalli conformatione magis cum Lecidea Wahlenbergii convenit. Thallus admodum crassus, ut prioris, sed in pulvinulos subrotundos conglobatus, e lobis verrucoso-gy rosis reniformibus elongatisve in cruslam contiguam stipatis, in ambitu tantum leviter lobatis. Color pallide glancus, facile candicans (at in hoc statu non pruinosa fit), subtus fuscescens, at nullus adest hypothallus distinctus. Apothecia parum supra crustam elevata', disco tenui jam primitus plano nudo atro! (quo ab omuibus hujus tribus differt); margine thallode persistente, discum æquante.

97. PARMELIA lentigera, thallo crustaceo-foliaceo radioso contiguo viridi-albescente, ambitu lobato sinuato-laciniato subimbricato; subtus albo, apotheciis adnatis, disco testaceo, margine thallode tenui persistente. Ach. meth. p. $19^{2}$. Mich. gen. t. 51. f.3. Lich. lentigerus. Weber. Gött. t. 3. Hoffm. en. Lich. t. 9. f. 4. Fl. Dan.t.1185. f. 2. Engl. Bot. t. 871. Psora, Hoffm. Pl. Lich. t. 48. $f$. 1. Lecan. Ach. Lich. univ. Squamaria. Dec. fr. - Chev. par. t. 14. f. 2.

Exs. Lich. Suee. n. 288. Ehrh. Crypt. n.38. Moug. et Nestl. n. 68.

In terra montium calcareorum ab Anglia ad Dalmatiam!, ab Hispania (Cadiz Dufour!) ad Lapponian, passim.

Orbes minores, 1-2 unc. offert, confluendo raro latiores \& irregulares, superficie nudas. Lobornm margines passim elevati. Apothecia regularia, plana, demum convexa, fuscescentia.

Purm. gilva. Pers. in Wett. Ann.2.1. p. 16. P. lentige era proxima, sed subius Endocarpi miniati instar fulva, in ambitu palmata -- e monte Ceniseo -. milhi ignota; ex A. syn. p. 386. P. Lagasca.

98. PARMELIA incisa, thallo crustaceo adnato contiguo e cinereo-glauco albicante, ambitu foliaceo-lobato, apotheciis sessilibus, disco subtestaceo griseo-pruinoso, margine thallode persistente crenato.

Mich. gen. t. 51. f. 5. P. incisa. S. O. V. p. 284. 


\section{Ad saxa regionis mediterraneæ, inque Gallia} occidentali Prevost!

Invitus hanc, cum Michelii icone \& descriptione exacte congruam, a $\boldsymbol{P}$. saxicola d. distinguo; at thallus nullo modo lutescens sed e cinereo-viridi albescens, ut huic seriei competit; centrum ornnino contiguum, modo rimoso-inæquabile; ambitus vere foliaceus, sed adpressus obsolete lobatus. Albescens, etiam supra pruinosus evadit. Apoth. minuta, disco plano immarginato, primo pruinoso, dein nudo, fuscescente. Estne hæc Psora albescens Hoffm. ex Flörk. a P. galactina Ach. diversa?

99. PARMELIA gelida, thallo crustaceo adnato carneo-cinerascente, verruca centrali radiation rimosa fusca onusto, ambitu lobato, apotheciis adnatis, disco carneo-testaceo, margine thallode tumido integerrimo. Ach. meth. p. 188.

Lichen Hecle. Gunn. - Fl. Dan. t. 470. L. gelidus. Linn. Mant. - Engl. Bot. t. 699. Wahl. Lapp. p. 415. Lecanora. Ach. Lich. univ.

Exs. Lich. Suec. n. 361.

b. thallo lævigato irregulariter \& abrupte effuso carneo-pallido, apoth. minutis rufofuscis.

Ad saxa granitica regionum frigidarum Islandiæ, Scotiæ, Norvegiæ totius, in Sudetis, frequens in Smolandia occidentali. b. locis inundatis.

Nunc orbes sistit minores, regulares, radiosos, nunc in crustam latam subirregularem confluit, maxime insignis prole sua centrali semper in a. præsente. Sæpe insuper sorediis cinereo-virescentibus tecta. Apothecia normalia Parm. parella similia, dura, \& primitus pallidopruinosa, sed locis magis humidis prope terram turgescunt, carnoso-mollia, marginem obtegentia (simillima Biat. icmadophilce). b. est singularis status ab aqua superfusa ortus, verruca sæpius orbatus \& apotheciis sequentis, at ob colorem \&c. certe huc referendus. Ex hoc oritur Isidium, sequenti in Sched. Crit. ${ }_{2} n .162$. perperam adscriptum.

= Parm. erythrocarpia, hoc loco facile quærenda, seriei citrince inserenda est.

100. PARMELIA coarctata, thallo crustaceo are- olato-squamuloso e virente glauco-albicante, 
ambitu squarnulisque crenatis, apotheciis adnatis, disco molli rufo-fusco nigricante, margine thallode tenui coarctato evanescente. - Ach. meth. p. 362.

Exs. Lich. Suec. n. 362.

* Thallo genuino.

a. ornata, thallo effuso areolato-rimoso ambitu squamuloso lobato. Sommerf. Lapp. p. 92.

b. microphyllina, thailo minuto orbiculari contiguo, subtus libero albo, in ambitu crenulato-inciso. (Exs. l. c. B.)

c. trapelia, thalli squamulis adscendentibus imbricatis crenatis. Lecan. trapelia Ach. certissime mediam inter hanc \& d. sistit formam.

d. crusta granulata. (Lecan, retorrida. Chaubart. Lecid. argilliseda. Duf. etiam h. l.)

e. crusta effusa tenuissima contigua virescente. P. elacista. Ach. meth. t. $4 . f .4$.

th Thallo soluto, leproso, sæpe prorsus obliterato. (Ceterum vario modo ludens). Lichen coarctatus. Engl. Bot. t. 534. Lecid. cotaria. Ach. meth. Suppl. p. 11. Volvaria conchylioides Decand. V. coarctata Duf. ob similit. cum Thelotr. exanthem. Ach. Lecanora eoarctata. Lich. univ.

Ad saxa subirrigua, Europæ facile totius.- Optima a. b. c. in silvis montosis irriguis Scandinaviæ, Rutheniæ, Scotiæ ad saxa granitica; e. ad saxa aqua sæpius suffusa; ibidem reliquæe formæ, sed solæ fere per reliquam Europam, etiam ad saxa arenaria (crusta mutila) muros, tecta lateritia, terram argillaceam (Scaniæ! Galliæ!) \&c.

Est in agro Femsjonensi inter vulgatissimos Lichenes saxicolas, omnium maxime versiformis, in cujus unius studio plures hebdomas consumsi. Vix Lichenem sub pluribus peregrinis nominibus, vix plures heterogeneos, quam pro Parm. coarctata recepi. Inde explicantur diversissima de eadem judicia. At, optime monente Sommerfelt, cum nulla alia (semel probe intellecta) confundi potest; vix alii, quam Parm. gelidae, affinis, nam in abnormi statu utraque profert apothecia colore \& facie Biatorce icmadophiloe \& ipsam P. gelidam hujus apothecia proferentem vidimus. At thallo potius cum se- 
quente convenit. Thallus multarum more nunc Squamariam (c. præcipue ad saxorum majorum silvaticortum latera irrigua irregulariter effusa Parmelice microphylloe aut ostreatce faciem habet), nunc Pl:tcodium, nunc Patellariam exacte refert, semper vero crustaceo-tartareus, diffractus; recens pallide virens, siccus glaucus, adultior subtus ob hypothallum, raro vero distinctum, albus. Apothecia minuta, carnosa, mollia, végeta rufa, sicca fusco-nigra, nunc margine vero, nunc accessorio disco urceolato, nunc excipulo evanescente proprio tantum lam:næ instructa, den:que etiam prorsus immarginata, hemisphærica occurrunt - rarissime triplo majora, carneorosea.

** Olivaceofuscescentes. Thallus plus minus olivaceus aut fuscus, solutus lepram fusco-pallentem effundens. Discus fusco-niger, nudus. Cfr. Olivaceofuscescentes tribuum 1, 3, 7 .

ror. PARMELIA Schaereri, thallo crustaceo-peltato compacto areolato-diffracto e fusco glaucescente, subtus aterrimo, ambitu soluto lobata, apotheciis superficialibus, disco fusco-nigro, margine thallode persistente. (Dufour determin.) Endocarpon saxorum, deia Lecan. Schaereri. Chaill.! E. tephroides: $\beta$. Reich. Lich. exs.

Exs. Reichenbach.

In saxis Helvetiz prope Neuchatel Chaillet!, Galliæ ad Lozere alibique Dufour!, Germaniæ occiduntalis in Würtemberg Hochstetter!, Moraviæ Reichenb. l. c.

Habitus potissimum Endocarpi, \& substantia fere End. miniati, licet multoties crassior \& compactior. Thallus determinatus, subrotundus, $\frac{1}{2}-1$ unc. latus, 1-3 lin. crassus, valde durus, crustaceus, sed peltæ instar adultior a saxo solutus, subtus glaber aterrimus, supra vegetus fuscus nudus, siccus canescens, in areolas diffractus; intus sub strato gonimo candidus. Areolæ inter se contiguæ, angulosæ, immarginatæ, ambitus solutæ, sublobatæ. Apothecia pro ratione crustæ crassæ tenuia, minuta, omnino superficialia \& sessilia (tam in Helveticis, quam Gallicis speciminibus visa); margine thallode obtuso, integerrimo, superante discum planum, nigricantem, nudum aut casu pruinosum. Sub strato gonimo insuper 
frequentius observantur nucleoli, Endocarpi fructus referentes. - Adest analogia evidens cum prole centrali (concolori) Parm: gelidce. - Primus hujus speciei determinator est illustr. Dufour (P. Endocarpoidern proprie dicens) sed duabus speciebus : meritissime Schaerero dicatis, utriusque nomen supprimere ingratum videretur.

102. PARMELIA Montagnei, thallo crustaceocartilagineo rugoso-verrucoso olivaceo, ambitu radioso-plicato, apotheciis sessilibus, disco plano nudo fusco-nigro æquante marginem thallodem integerrimum.

Ad saxa in insulis Stoechadibus. Cel. Montage: ne primus detexil \& communicavit.

Species nobilissima, tribus typus olivaceus, medium locum tenens inter Parmel. olivaceam \& badiam, licet ejusmodi comparationes ex recepta videndi ratione paradoxæ videantur. Thallus crustoso-stuppeus, saxo adnatus, crassiusculus, suborbicularis, latitudinis indeterminatx, ex maxima parte rugoso-verrucosus, sed in ambitu plicato-radiatus \& lobatus, glaber, nudus, colorem servans olivaceum, siccum tantum magis fuscescentem. Apothecia sessilia, haud immersa, crassa, disco plano opaco ferme nigro, intus albo.

103. PARMELIA balanina, thallo stellato crustoso-adnato castaneo-fusco, laciniis planis concretis, ambitus radiatis liberis, apotheciis planis nudis atris intus fuscis, margine demum concolori.

In saxis Alpium Helveticarum; ut vidétur rarissima. Schleicher!

Primo obtutu Lecideam prorsus refert, ut ad hoc genus olim apotheciorum structura haud observata retulerim. Margo! vero horum nigrescens per thallodis metamorphosin oritur. Thallus quoque evidenter ad hanc viciniam trahit, licet vix alia adsit, cum qua comparetur. Thallus crustacex indolis, sed P.ccesice instar stellatus; laciniis contiguis, in centro plus minus concretis, in ambitu vero discretis multifidis apice dilatatis radians; ceterum arcte adglutinatus, glaberrimus. Color P. aquilæ, sed obscurior, subumbrinus, nitidulus, intus lute- - 
scens! Apothecia superficialia, sed adpressa, opaca, nigra, intus absque stratis discoloribus fusca! - A Lecan. balanina Ach., in Helvetia quidem non obvia, valde diversa est.

104. PARMELIA anea, thallo crustoso adnato contiguo, mox rimoso-areolato, pallide cervino subtus albo, ambitu subsquamuloso, apotheciis sessilibus fusco-atris intus albis, margine elevato subconcolori.

Lecid. ænea. Dufour, margine fere in proprium mutato.

Ad rupes subalpinos Sierræ Texeda in Hispania Cabrera!, inque Pyrenæis Dufour!

Habitus Parm. bacliae, sed thallus magis contiguus, determinatus, in ambitu squamuloso-effiguratus; substantia intus mollior quoque, spongiosa fere; intus tota ad basin alba. Apothecia in superficie sessilia, concava; disco in vivo rufescente-fusco, in sicco nigro, intus prorsus albo; margo elevatus, persistens, integerrimus, sed ut in aliis disco fere concolor, in humectato obscurior, ut præcipue specimina Dufoureana facile Lecideam, sensu Ach., dicas.

105. PARMELIA maritima, thallo crustoso adna-

to granulato-rugoso roseo-griseo nigrescente, ambitu brevissime radiante, apotheciis elevatis, disco turgido rufofusco, margine thahlode temui evanescente. Sommerf. in. Vet. Ac. Handl. 1823. $p$. I 6. Lecanora.

In lapidibus quartzosis litoralibus Nordlandiæ Saltensis. Sommerfelt!

"Crusta tenuis, margine obsolete effigurata, junior $\&$ occulte crescens roseo-grisea, senior fusco-nigrescens, ambitu dilutiore. Apothecia minora centralia rufofusca, margine tenui integerrimo crustæ concolori, dein subevanido. "S. Nimiam affinitatem cum sequente Auetor ipse notat, habitu tamen facile dignoscitur. In Suppl. Fl. Lapp. p. 97. cum Lecan. alpestri Ach. Syn. conjungitur, verum ista vexata species, quoad specimina archetypica, composita cst a Parm. subfusca (Lecan. alpestri Lich. luiviv.) \& $P$. circinata (Úrceol. ocellata $\beta$. ocellulata Lich. univ.). Hujus formis utique prope ac- 
cedit $P$. maritima, in qua vero nullum marginis disci vestigium detegere potui.

ro6. PARMELIA aipospila, thallo crustoso adnato papillato fusco cinerascente, in ambitu nigro sulcato-radiato, apotheciis in papillis elevatis subimmarginatis, disco turgido rufofusco. Wahl. in. 'Ach. meth. Suppl. p. 36.

Lichen aipospilus. W $\mathrm{W}$ ahl. Lapp. n. 764. t. 27. f. 2. In scopulorum maritimorum scrobiculis \& fissuris ad mare septentrionale; per totam Finmarkiam ubique copiose Wahlenberg!, Norvegia adjacentis passim Sommerfelt! Vidi quoque specimen ex Islandia ortum.

Species admodum singularis, in qua status Isidiomorphus, ut optime fructificans, normalis, videtur. Marginem thallodem ferme deficientem ex eo tamen vix deducam, cum in antecedentibus proximis etiam valde inconspicuus esse soleat, \& in $\boldsymbol{P}$. poliophoce ceterum eodem modo formata evidens adsit. $\mathrm{Ab}$ hac vero hypothallo nigro \& ambitu revera radiato tantum differt, ut has species potius analogas diversarum, quam affines ejusdem tribus dicam.

*** Ochroleucae. Color thalli flavovirescens, cartilaginea indole amissa pallide ochroleucus fit aut in lepram concolorem solvitur. Discus nudus, normaliter carneo-flavescens, at reliquarum subdivisionum magis versicolor, immo virescens \&c. Conferendx analogæ ochroleucæ subdivisiones, præcipue Imbricarioe \& Patellariae, cum quibus limitibus haud palpabilibus confluit.

107. PARMELIA straminea, thallo crustaceo plicato-radioso stramineo, laciniis convexis teretiusculis contiguis, apotheciis planis rubro-fuscis, margine thallode tumido. Wahl. in Ach. meth. Suppl. p. 47.

Lichen. Wahl. Lapp. p. 41\%.t. 28. f. 1. Lecanora, Ach. syn. p. 180. Fl. Dan. t. 2008. f. 1 .

In summis scopulis ventosis ad mare glaciale, Finmarkiæ Wahlenberg! (dein in Spitsbergen \& Grönlandia.) 
P. centrifuga adeo affinis, ut ejus filiam facile dicas, recedens ut $P$. elegans a $P$. parietina; a $P$. incurva longius distat. Thallus subimbricato-stellatus, at crassiusculus, crustaceus, centro persistens, subtus nudus pallens, laciniis teretiusculis arete adnatis ut ad Placodia omnino referenda sit. Discus crassiusculus, opacus, exsiccatus quidem nigrescens, sed ceterum a $P$. oreina ex hypothallo nigro oriunda adeo diversa, ut miremur eas ab Achario comparari potuisse.

108. PARMELIA carphinea, thallo crustaceo-ad- nato verrueoso straminec, laciniis ambitus linea(2. ribus convexis discretis radioso, apotheciorum - disco subimmerso turgido subrufo, marginem thallodem integerrimum demum obtegente.

- Ad rupes, soli infestos, juxta mare mediterraneum in regno Neapolitano Georgi!, Porqueyrolles insularum Stoechadum Montagne!

Colore, disco crassiusculo turgido, hypothallo obsoleto, fere et laciniarum forma prxeedenti accedit, sed re ipsa, præcipue ad specimina Cel. Montagne, sequenti proxima. Thallus irregulariter effusus, juvenilis contiguus stellatus, mox vero confluens, ex maxima parte in verricas solutus, tartareæ substantiæ, e stramineo in oehroleucum varjans, immo albo-pruinosus, at numquam viridi-flavescens. Apotheciorum disci semper minuti, nudi, ex ipsis verrucis erumpentes concaviusculi, dein margine thallode parum elevato cincti, demura turgidi marginem thallodem obtegentes aut proprio obscuriori (in prima æatate vero non præsente, ut in sequ. tribu) superantes. Disci color pro more varius; in Italicis spec. rufo-castaneus, in Gallicis fulvo-rufus.

109. PARMELIA saxicola, thallo cartilagineo crustaceo-adpresso areolato-squamoso virescentiochroleuco, ambitu e laciniis concretis planis radioso-lobato, apotheciis adpressis, disco e luteolo subtestaceo, margine thallode tenui, demum crenato. Ach. meth. p. I9) I.

Mich. gen. t. 51. f. 4. Lich. muralis. Schreb. Psora. Hoffm. Pl. Lich. t. 16. f. 1. Lobaria. Ejusd. Germ. Lichen ochroleucus. Wulf. in Jacq. Coll.II. p. 192. 
t. 13. f. 4. Placod. Decand. Lich. saxicola. Poll. Engl. Bot. t. 1995. Lecan. Ach.

Exs. Lich. Suec. n. 163. Moug. Nestl. n. 67.

b. diffracta, (ex hypothallo evidentiori) crusta obscurata, areolisque discretis nigromarginatis, apotheciis subrufis. Lichen dein Lecan. diffracta $A c h$.

c. versicolor, crusta e viridi dealbata, apotheciis rufofuscis. Lichen versicolor. Pers. Lobaria Hoffm. Cfr. Sched. Crit. 13. p. 1.

d. galactina thallo subobliterato albicante, apotheciis livido-carneis subpruinosis. (Psora albescens. Hoffm. e descr. optime convenit; h. l. negat Cel. Fl.) Lich., dein Parm., porro Lecan. galactina. Ach. Ad saxa totius Europæe communis; b. ad saxa
granitoidea, aquis sæe conspersa; c. ad saxa calcarea \& schistosa; d. precipue ad muros communis.

Normaliter ex hypothallo maculari nigro, ut tres proxime sequentes, oritur. Hic e loci diversitate in $b$. evidentior, in c. \& d. obsoletus, ad reliquarum locis similibus analogiam. Ceierum omnium evidentissimus \& directus transitus facile observatur; tantum de d. quibusdam dubia restare forsan videbuntur, cum habitus magis $P$. subfuscae angulosce. At tam ab a., etiam albo-pruinosa varia, quam c. Iuculenter ortam vidimus ; ipsamque jove pluvio viridem, nudam, P. saxicolce simillimam. Hac forma ad status omnino tartareo-leprosos hæc species deprimitur; simul occurrunt hujus apothecia omnino thallo orbata 1 . in aliis Lichenibus parasitica (Cfr. Lich. Suec. n. 392-394), quæ plurimi potius ad $P$. variam referant e falsa illa opinione, omnes $\mathrm{Li}$ chenes acrustaceos a speciebus thallo uniformi ortas esse; at cum thallum prorsus obliterari posse concedimus, nulla adest physiologica ratio, cur thallum effiguratum $\mathfrak{x}-$ que facile ac uniformem excludi denegemus. Utrumque passiva observatio demonstrat. Quibus vero in deliciis est ex transitibus indirectis species conjungere, ex ejusmodi apotheciis hanc cum $P$. varia conjungant, nam ex ejusmodi mutilatis formis cum alia subsimili specie confusis varia heterogenea jam copulata vidimus. - 'Porrò varix Parm. saxicolae oriuntur formæ e disci colore variabili. Harum præcipue notabilis disco apotheciorum olivaceo, tribus sequentibus etiam communis, ceterumque in ochroleucis Imbricariis v. c. $\boldsymbol{P}$. conspersa \& præci- 
pue Patellariis his respondentibus v. c. $P$.varia \& affin. obvius. (Prorsus autem diversus est hic lusus a Parm. ochroleucis hypothallo albo; apoth. disco crassiori rufofusco v. c. $P$. centrifuga, straminea, ventosa \&c.) Cavendum, ne ejusmodi coloris lusus tam thalli, quam apotheciorum, vel ut phænomenon singulare corisiderentur, vel ex eo exstructa theoria justo nimis extendantur. Denique notandum est $P$. saxicolam speciem esse quasi centralem, a qua proxime sequentes tres ( $P$. variam \&c. ut reticeam) primitus præfiscini ortæ videntur, at adeo evidentes adeoque tam characteribus quam geographica distributione constantes, præcipue si comparentur cum multis quisquiliis vulgo speciebus dictis, ut maluerim earum distinctione practicam Lichenum cognitionem sublevare, quam conjungendo pænes hodiernum genium Lichenologiæ me insinuare. Levius mihi videtur opus omnia affinia coacervare, quam singulorum vitam \& historiam explorare. At non is sum, qui alium proponendi modum impugnem, cum omnis sincera naturæ scrutatio ad eandem metam ducat.

I o. PARMELIA cartilaginea, thallo cartilagineo foliaceo-squamuloso, lobis imbricatis complicatisque stramineo-virentibus, subtus allis!, apotheciorum disco carneo-fulvo, margine crenato lobatoque. Ach. meth.

Lich. cartilagineus Westring. Ach. in Vet. Ac. Handl. 1795. t. 5. f. 4. Lecan. syn. p. 191. Squamaria. Decand.

Exs. Lich. Suec. n. 164. Sommerf. Norv. $16 \%$

Ad rupes maritimas; pracipue maris baltici copiose, sed etiam atlantici a Nordlandia Sommerfelt! ad Hispaniam, inque montibus Europa australis \& alpibus Pyrenceis Dufour! IVontagne!

Est quasi forma luxurians marina præcedentis, præcipue insignis squamulis thalli ab hypothallo prorsus solutis, unde subtus albæ sunt. Ceterum thallo albescente \& disco olivaceo-fuscescente (qualem eximiam e Pyrenæis misit Dufour) uti prior variat. In summis alpibus, v.c. Pyrenaeorum orientalium inter optimam $\boldsymbol{P}$. chrysoleucam \& oreinam, observante Montagne, occurrit hujus forma thallo fere crustaceo, sed verrucis bullatis inflatis subtus albis totaque facie huc facile referenda. Sunt 
itaque mnmenta has omnes efficientia haud adeo illustrata, ut mox conjungere debeamus.

I I r. PARMELIA chrrysoleuca, thallo cartilagineo subfoliaceo crenato-lobato viridi-stramineo, subtus nigro, apotheciis adpressis disco aureo-fulvo, margine thallode flexuoso tenui evanescente. Ach. meth. p. $1 \delta_{2}$.

Lecanora. A.$h$. Lich. univ. p. 411.

a. rubina, disco normaliter colorato. Lich. rubinus. Vill. delph.3.p. 977. Squamaria. Hoffm. Pl.'Lich. $t$. 32. $f$. 1. Lec. rubina. Ach. Lich. univ. var. $\alpha$. Lich. chrysoleucus. Smith. Transact. Linn. Soc. 1 . p. 83. $t$. 4. f. 5. - Squamaria peltata. Dec. $f r .2$. p. 377. status monophyllus. Lich. crassus. Fl. Dan. t. 1005.

Exs. Lich. Suec. n. 322.

b. opaca, disco morbose decolorato, pallide olivaceonigricante. Ach. l. c. Lecan. liparia. Schleich.'Cat. Ad rupes alpinas Norvegiæ, copiose in Dovre Sommerfelt! Blytt!; Germania in Carinthia, Laurer, Salisburgo, Tyrolia Schubert!; Helvetiæ Schaerer!; Gallix in Pyrenæis IMontagne!; Hispania Dufour!

Thallus admodum variabilis, nunc solutus monophyllus peltatus ut Umbilicaria, nunc squamuloso-imbricatus complicatusve, nunc matri omnino adpressus, areolatus, areolis nigro-marginatis aut hinc inde nigrofasciatus. Optime vero dignoscitur pagina inferiori, ob hypothallum adnatum, ex atro-viridi nigricante. Apothecia vulgo regularia, admodum saturate \& læte colorata; sed in summis alpium jugis maculæformia, adpressa, sublobata, demumque rugosa.

112. PARMELIA oreina, thallo crustaceo-adnato veriucoso stramineo-virescente pallido, ambitu radioso-lobato nigro-marginato, apotheciis depressis, disco turgido nigro, margine obtuso integerrimo.

Lecan. oreina. Ach. syn. p. 181. (male in Lich. univ, ut P. stramin. varietas). Lecid. marginata. Schleich.o! indeque Lecid. fimbriata. Schaer. spic, p. 126. 
Ad saxa \& rupes Alpium Norvegicarum Blyit! Helveticarum Schleicher! Pyrenæorum Montagne!

Est tandem priorum forma maxime crustacea, adnata, lævigata, sed pulchre radiata, radiis sæpius nigromarginatis; adestque forma cum P. saxicola b. analoga, pro L. diffracta a Schleichero missa. Discus areolis crustæ vulgo immersus, minutus, turgidus, omnino ater, nudus; passim magis protuberans Lecideam prorsus refert, sed interna structura alba Parmeliam facile demonstrat. Synonyma certa sunt, collatis archetypis Acharianis \& Schleicheri, aliena ubique pro Lec.oreina venduntur, etiam ab Achario ipso amiciss. Schaerero determinata.

**** Citrince. Thallus lutescens, passim decolorans, in lepram concolorem (aut expallentem) demum solutus. Apotheciorum discus aurantius aut fulvus, margine sæpe subconcolori, etiam in crusta decolorrata colorem servante. - Ab analogis Imbricariis ad Patellarias seriem contiguam efficiunt. (Vanitas differentix Parmeliarum \& Lecidearum sensu recepto in omni serie, precipue vero Citrinarum patet!)

113. PARMELIA elegans, thallo stellato-radioso adpresso aurantiaco, utrinque nudo, laciniis subdiscrelis linearibus contiguis flexuosis, apotheciis concoloribus integerrimis. Ach. meth. $p$. I39. (syn. corrig.)

Lich. cinnabarinus Bell. L. fulvus. Dicks. - uterque ex Ach. L. elegans. Link. - Wahl. Lapp. $n .775$. Lecan. Ach. syn. Placod. Decand.

In rupibus apricis ventosis alpinis, maritimis, ad fluviornm cataractas \&c. passim, præcipue Europæ borealis.

Forma hæc primaria $P$ parietince proxima apparet, ut $P$. stramin. $P$. centrifugae, eisdemque rationibus distincta. Thallus crustaceam induit indolem, subtus haud fibrillosus. Laciniæ subincisæ, planiusculæ - Ceterum ab illa charactere vix removeri potest alia forma minor, laciniis subteretibus (Dill. Musc. t. 24. $f .68$, in reliquis synonymis utraque vulgo commixta) etiam regionibus campestribus ad saxa formationis junioris, precipue in schisto, obvia, quæ ad P. murorum magis accedit. Hæc est vera Lecan. miniata e sententia Borreri!, 
Flörkei \&c. - Neutra in lepram soluta umquam visa est.

I 4 . PARMELIA murorum, thallo crustaceo adnato contiguo radioso-plicato ( $\alpha$. vitellino expallente pruiuoso) ambitu lobato, subtus albo, apotheciis sessilibus, margine thallode tenui integerrimo subpersistente, disco nudo saturatiori. Ach. meth. p. 195.

Dill. Musc. t. 18. $f$. 18. Lich. flayescens. Huds. L. candelar. Auct. var. Wulf. in Jacq. Coll. III. $t$. 6. $f$.1. Placod. Chev. par. -Lich. murorum. Hoffm. en. Lich. t. 9. f. 2. Engl. Bot.t. 215\%. Fl. Dan.t. 1946. Lecan. Ach. - Meyer. Flecht. p. 223. eximie! - Psora saxicola. Hoffm. Pl. Lich. t. 1\%. f. 3. Lobaria. Ej. Germ. Lec. cirrochroa. Ach. syn. p. 181. (media inter a \& f.) - Lich. tegularis. Ehrh. (ad præced. acced.)

Exs. Lich. Suec. n. 391. Fl. Deütsch. n. 69.

Ex hac forma vulgatissima, thallo mutilato \& dissoluto, oriuntur sequentes status atypici :

b. Lobulata, thallo subobliterato, Iobulato. Lecan. lobulata. (Flörk. pr. p.) Sommerf. Lapp.

c. steropea Ach. I. c., crusta contigua rimosa subglebulosa (sæpe expallida) haud effigurata - *apoth. 1 . concoloribus: Lecan. vitellina $\delta$. Ach. syn. vel ${ }^{* *}$ rufis, subconvexis. Patell. rufa. Pers. Lecid. Ach. syn. p. 333 .

d. crenulata, crusta granuloso-glebulosa sublobata, apotheciis symphycarpeis. Wahlenb. Lapp.!

e. incrustans, crusta verrucoso-conglobata pulverulenta. Patell. Dec. Lecan. Ach. (Engl. Bot. 1793.)

f. citrina, crusta prorsus in lepram soluta, apotheciis nunc simplicibus, nunc symphycarpeis (h. e. triplo majoribus, granuloso-marginatis, disco obscuriori). Crusta citrina: Verrucar. citrina. Hoffm. (non male distinguentis a $V$. flava s. Patell. citrella Pers. P. parietinæ analogo statu). Lich., Parm., Lecan. citrina $A c /$. Pat. candelaris. Dec. - denique omnino Chlorococcum: Chlor. murale, Grev. Crypt. Scot. t. 325. ad hoc potissimum referendum, ut Chl. vulgare I. c. t. 262 . ad Parm. parietinam.

Exs. Moug. et Nestl. n. 742. Desmaz. n. 142.

Hæc e saxis calcareis orta species in regioni- 
bus maritimis \& campestribus formatione recentiori substratis etiam in aliis saxis vagatur; frequentissima in muris, immo rarius ad ligna, rarissime ad cortices Europæ australis (v. c. Galliæ meridionalis Prevost!)

Hypothallus albus luculenter mihi visus est, rarius in a., evidentius in $f$. discernendus. Thallus semper crustaceus, adnatus, normaliter vitellinus, pallide pruinosus, at non raro prorsus dealbatus, apotheciis luteis \& rubris (color enim thalli, ut supra jam vidimus, in excipulo diutissime persistit), e sensu Achariano omnino Lecidea. Apothecia, nisi symphycarpea \& atypica, minuta, margine tenui integerrimo persistente simplici, quo æque ac hypothallo non nigro facile discernenda a $P$. aurantiaca in statu soluto P. murorum f. simillima. - Formæ allatis similes etiam ab sequentibus varr. oriuntur. Maxime inter illas recedit forma, ad c. ${ }^{\star *}$ referenda, in muris argillaceis Gallix a Clar. Prevost lecta, una cum maxime diti \& insigni copia plurimarum specierum eodem modo personatarum. Quin plurimæ hujus tribus species (at omnes non dicam) eadem ratione varient 1 , variare possint, nullum dubium est, licet formas h. $l$. tantum ut evidentissimum exemplum \& synonymorum gratia enumeraverimus.

$\beta$. miniata, thallo verrucoso, minus \& angustius radioso, nudo, miniato.

Psora miniata. Hoffm. Pl. Lzch. t. 60. f. 1. Lobaria. Ejusd. Germ. Parmel. s. Lecan. Ach. - \& crusta magis obliterata: Lich. obliteratus. Pers.

Ad saxa \& rupes sicciores, soli infestas.

Locis similibus a pallescit \& dealbatur; at meram tantum varietatem esse facile patet in rupibus soli infestis, sed rore marino irrigatis, ubi forma \& thallus nudus ut in $\beta$., color vero ut in $\alpha$, qux Lich. flavescens Sw. Lich. murorum $\beta$. Wahl. Suec.

$\gamma$. callopisma, thallo explanato eximie lobato intense luteo nudo, apotheciis subaurantiacis.

L. callopisma. Ach. L. mur. var. Flot. in Link. Jarhrb. Ad rupes subhumentes, rore saltim alpino (ut in Europa australi) aut marino (in Eur. boreal.) laetificatas. 
Hæc varietas re ipsa est status typicus speciei, quamquam vulgatissimam ut primariam admisimus. Transitun ad vulgarem jam innuit Lich. flavescens $S w$., quem etiam hujus statum forma var. $\beta$. facile diceres; evidentissimum vidi transitum tam in Pyrenaicis, quam Belgicis speciminibus.

d. chlorina, thallo pallido flavo-viridi nudo opaco, apotheciis majoribus convexis immarginatis pruinosis pallidis.

Lundæ in muris umbrosissimis.

$\mathbf{E}$ charactere sane sequentem crederes, at filia revera loci maxime umbrosi \& humidi - at singulare eam cum lætissima P. mur. $\alpha$. f. mixtam crescere.

E. lacteo-lutea, thallo orbiculari, levigato, obsolete effigurato, lacteo, apotheciis totis luteolis.

In calce candido Europæ australis - Gallix prope Agen. Dufour.!

Pauci forsan in hac Parmeliam, paucissimi P. murorum divinabunt (Achario Lecid. luteoalba!); "Lecid. Lalavei" enim, colore apotheciorum excepto, simillima; diversa, tamen certissime est. Crusta hujus non, ut subinde in $\alpha$, casu dealbata, sed jam primitus alba, tenuissima, quales status plurimi Lichenes in calce ex acido carbonico proferunt.

115. PARMELIA chlorophana, thallo crustaceo adnato areolato-verrucoso nudo ( $\alpha$. nitide sulphureo), ambitu radioso, subtus albo, apotheciis sessilibus, margine thallode turnido subevanescente, disco nudo pallido. Wahl. in Ach. Suppl. p. 44.

Lich. chlorophanus. Wahl. Lapp. p. 416. t. 28. f. 2. Lecan. Ach. Lich. univ. p. 436. Lich. electrinus. Ramond. Squamaria electrina. Dec. fr. 2. p. 374 . b. oxytona apothecior. disco rubro, margine crenato. (Symphycarpea?) Lecan. oxytona. Ach. l. c. Placod. Dec. fr. 6. p. 185.

Ad latera rupium granitoidearum \& quartzosarum per alpes altiores centrales Europæ fere totius: Lapponiæ Wahlenb.! Norvegiæ Blytt! Sudetorum Herb. Ach. Helvetia Schaerer! Sabau- 
diæ Bellardi! (Lich. flavus) Pyrenæorum Dufour! Montagne! - b. præcipue in Helvetia Schleicher! Vogesis Mougeot!

Faustum censeo huic speciei nitidissimæ angustiorem $\&$ diversam esse proventus regionem, sine qua forsan a priori, præcipue $\delta$. ægre dignosceretur. Nam quæ e thalli, laciniarum apotheciorumque forma petuntur differentiæ nimis variant, \& re ipsa et hujus apothecia normaliter scutellata, concava, semper vero prioris majora, margine obtuso, disco tantum protuberante evanescente cincta. Ceterum crusta magis cartilagiıea \& e longinquo colore lætissimo e viridi sulphureo dignoscitur. - Ob limites angustiores minus mutatur, vix ulla mihi cognita forma memoranda præter tersam, thallo effuso tenui lævigato rimuloso, ambitu hand effigurato, apotheciis imperfectis, e qua ferro oxydata oritur status ab "End. sinopico" non discernendus!

p. ochroleuca, crusta apotheciisque stramineoochroleucis. Dufozir.

In summis cacuminibus denudatis Pyrenæorum Dufour!, montis Canigou Montagne!

Præter colorem constantem ambitusque lacinias minus discretas planiores a priori nullo modo differt.

I 6. PARMELIA aurea, thallo crustaceo-squanuloso e viridi aureo, squamulis subrotundis imbricatis lobatis, subtus albis, apotheciis sessilibus disco aurantiaco, margine integerrimo persistente pallidiori. Schaer. spic. p. I18. Lecid. Exs. Schaer. Helv. n. 165.

- In fissuris rupium alpium calcarearum Helvetir; in montibus Schiebenfluh, Hogant, Stockhorn, Sanetsch, Gemmi. Sckaerer!

Lubens assentior Amicissimis Viris, Schaerero a Parmelia murorum distinguenti, Flotowio ad Parmelias referenti. Eandem apotheciorum morphosin, excipulum thallodes decorticans, in singula fere Parmelia, præcipue P. fulgente \& aurantiaca, observare licet. Sub disco crasso stratum gonimon. - An deperditus Lich. aurantius Pers. in Ust. Ann., Lich. sympageus Ach. e rupibus calcareis Hassiæ hujus loci sit, ut descriptio suadet, ipso loco inquirendum est. 
17. PARMELIA fulgens, thallo crustoso-foliaceo adpresso pallide flavo, lobis ambitus laciniatis flexuosis planis, apotheciis sessilibus, disco nudo fulvorubro, margine demum colorato flexuoso. Ach. meth. p. $19^{2 .}$

Lichen friabilis. Vill. Delph. 3. $t$. 55 . L. fulgens. Swartz. - Wahl. Suec. n. 1535. Lecan. Ach.syn. Placod. Dec. fr. 2. p. 378. L. citrinus. Ehrh. Hedw. St. Cr. 2. p. 60. t.20. f. c. Psora. Hoffm. Pl. Lich. t. 48. f. 2 .

Exs. Lich. Suec. $n$.

b. bracteata, crusta amorpha, granuloso-conglobata, apotheciis symphycarpeis. Psora bracteata. Hoffm. Germ. Lich. bracteatus. Ach. Prodr.

c. crusta leproso-pulverulenta, citrina, subiculo albo inspersa, apoth. abortivis punctiformibus.

Ad terram, priecipue petrarum calcarearum, in alpibus aut maxime campestribus (b), a Valencia \& Istria ad mare glaciale, passim. c. latissimas plagas camporum gypsaceorum Helvetiæ occupat. Schleicher!

Species distinctissima, 'P. lentigerce eximie analoga thallo subcoriaceo, contiguo, terræ arcte adpresso, e laciniis evidentibus concreto; ceterum intermedium locum inter hane \& priorem optime tuetur. Misit e Gallia amiciss. Prevost specimina, quæ quoad apothecia, ferrugineo-rufa \& flexuosa, a sequente vix discernenda. b. morphosi Psoromatibus valde accedit.

$\beta$. sordida, thallo mox expallente incano cinerascente, apoth. margine fulvo.

In Gallia meridionali, Vallisia Schaerer!

Forma thalli, ex qua Bot. Gallix, ceterum in vera affinitate plantarum dijudicanda facile principes, genera distinguunt, ne ad varietates quidem construendas valet.

118. PARMELIA erythrocarpia, thalle crustaceo adnato radioso pallido, mox granuloso pulverulento canescente (decoloratove), ambitu lobato, apotheciis innatis, disco nudo croceo-rubro, margine demum flexuoso discolori. cfr. Wallr.l.c. II. p. 120 ? 
(Patell. erythrocarpia. Pers. formæ cuidam quidem impositum, sed unicum congruum e synonymis nomen). Placod. versicolor. Dec. fr. 2. p. 380. Lecan. theicolyta. Ach. Lich. univ. p. 425. Placodium. Dec. fr. 6. p. 185 .

b. arenaria, thallo mutilato inæquabili granuloso solutove pallescente. Lichen arenarius. Pors. Patellaria. Hoffm. Pl. Lich. t. 58. f. 1. Parmelia. Mart. Erl. p. 219. Parmelia, dein Lecan. craspedia. Ach. Lich. univ. p. 391. «. Lecan. rubricosa. Ach. syz. p. 162.

* thallo (tam a., quam b.) grumoso cinereo-cæsio (etiam fusco \& nigricante). Lichen cæsiorufus. Sc/irad. Engl. Bot. t. 1040. Lecan. craspedia. P. Lich. univ. (male in Syn. ad Lecid. ccesioruf. $\beta$. citata). Lecan. helygea. Syn. Lic/..p. 155. (Variolar. coruleseens Pers. sterilis; sed æequo jure ad analogos status grumoso-corulescentes v. c. $P$. atrce, cerina, citari potest).

Ad saxa calcarea, colacea \&c., inque muris Europae pracipue occidentalis ; perfecte vero explicata (a.) vix nisi in australi in v. c. Hispania Dufour!, Gallia omni!; Germania occidentali ad Esslingen \&c. Hochstetter! b. præcipue ad saxa arenaria friabilia (unde pro more mutilata crusta), Germaniz, Auglize, Helvetia! \&c. 'c. cum utraque mixta.

Omnino certum mihi videtur: I:o hanc speciem veram esse Parmeliam (plurimi Recentiorum Lecideam s. Biatoram malunt); nam eadem exacte excipuli metamorphosis in præcedentibus, $P$. aurantiaca, cerina, ventosa \&c., affatim proxime cognatis, observatur; \& margo thallodes albidus aut lutescens, præcipue in crustis decoloratis, coloris normalis \& typici thalli indicium, ut in plurimis decoloratis speciebus vidimus. Sub laminæ superficie saturatius colorata observatur stratum dilutins, gonimo in perfectis impositum, nec excipulum proprium in ceierum simili Biat. ferruginea. Nec margo interior laminæ, excipulo vero thallode evanescente passim conspicuus, ab hoc genere removet; II:o Omnes allatas hujus speciei formas eandem efficere speciem, quum transitus evidens in plurimis, quæ coram habeo specimina Gallica; status casiorufus ab utraque evidenter oritur. Cel. 
Meyer formam primariam distinctam censere videtur, reliquis ad Biat. ferrugineam rejectis. III:o P. erythrocarpiam a B. ferruginea separandam esse non tantum ob varios characteres, sed etiam vegetationem \& geographicam distributionem diversam. Hos speciei limites quoque innuit Cel. Wallroth l. c., additis tantum synorymis nounultis mihi amphibolis visis. Sunt quidem hujus formæ mutilatæ $B$. ferruginea subsimiles, at major in vegetationis historia cum $P$.murali analogia, cujus quoque formis sxpe ita obviam venit, v. c. $P$. murali v. lacteo-lutece $P$. erythrocarpia v. Lallavei, ut haud perspicuo hypothallo nigro, certissima $P$. erythrocarpice differentia, utramque colore tantum apotheciorum (structura enim simillima est) oculi adsueti tute discernant. Thallus integer in hac specie rarissimus, nam \& a. centro plerumque granuloso-pulverulentus, ut hæc indoles utique in characterem ingredi possit, inter Lichenes licet atypica. "Byssus", sic dicta Lepraria casia, hanc aliorumque Lichenum crustas destruens \& decolorans, æque ac sic dicta Byssus antiquitatis, mihi nil nisi hypothallus simul solutus \& crustam inficiens. Vidimus enim hac omnes Lichenes hypothallo nigro destructos; nullosque Lichenes hypothallo aliter colorato infectos. Cum autem hypothallus niger jam primitus solvitur, oritur pura Byssus 1. Lepra antiquitatis, cujus origine sic, ut spero rite, explicata omnia dubia de ejus natura sublata sunt, simulque explicatum, quare ejusmodi fictitix plant $x$ ad nullam definitam referri possint. $-P$. cerincem in sequente sectione huic proximam habeo, sed $P$. erythrocarpia absolute saxicola est \& quoad geographicas rationes $P$. coarctatoe (eadem quoque gaudentis apotheciorum morphosi) opposita.

ß. Lallavei, thallo tartareo determinato lacteo, ambitu sublobato, apotheciis subimmersis vix marginatis rubris.

Iecidea Lallave. Clemente. Ens. Vid.p. 29\%. ex spec. Lallave! Ach. syn. ${ }^{*} p .45$.

b. hypothallo nigro prorsus obliterato, thallo soluto pulverulento. Patell. erythrocarpia. Pers. - Decand. fr. (exacte media inter a \& b.) Lecid. Ach.

Ad saxa calcarea Europæ australis.

Pulchra forma, ut tota in calcis potestate lactea. In statu optime explicato formam adhuc P. erythrocar- 
piæ normalem servat \& hypothallum nigrum; in b. vero non thallus tantum solutus, sed etiam hypothallus prorsus destructus. Margo apoth. plerumque nullus.

Color lamince in omnibus hujus formis etium sariat subferrugineus, rufus es locis irriguis rufofuseus, sed rubri quid semper admixtum habet, unde nomen ex eo sumtum optimum. Nomina tam dissona, quam L. Lainea, gangalea, papalea, helygca, ocrincta, theicolyta, aliis prasentibus synonymis, optime negliguntur. .-. Ex af. finitate hujus tribus; ex apoth. differentiis in sequentem potius quadrat.

Trib. VI. PSORA. Apothecia innata, primitus suburceolata. Discus fusco-nigrescens, margine laminæ intra thallodem (saltim in junioribns conspicuo) cinctus, (normaliter primitus ccesiopruinosus). Thallus et Synonyma ut supra.

Ad præcedentem tribum ut Physcia ad Imbricariam accedit, \& ut illa Imbricarias, hæc Physcias continuat. Ex suis principiis cum Urceolariis conjungere debuisset Acharius, qux deorsum hanc seriem continuant \& a quibus thallo imperfectius explicato haud rite discerni possunt.

* Glaucescentes. (P. cæsia crustacea \&c. vid. subPhyscia).

I 9. PARMELIA melanaspis, thallo crustaceo verrucoso cinereo-glauccscente, subtus nudo, ambitus laciniis linearibus multifidis stellato-imbricatis, apotheciorum disco turgescente fusconigro, margine thallode integerrimo. Wahl. in Ach. meth. p. 196.

a. thallo cinereo-albicante, apotheciis depressis marginatis cæsio-pruinosis. Lich. inflatus Schleich. Parm. alphoplaca. Wahl. in Ach. Meth. Suppl. p. 41. Lich. Wahl. Lapp. 421. Lecan. Ach. Lich. univ.p. 428. b. thallo cinereo-fuscescente, apotheciis protuberantibus subimmarginatis, subnudis. Lich. melanaspis. Wahl. Lapp. p. 421. Lecan. Ach. l. c. p. 427. In saxis subalpinis granitoideis Islandiæ, Norvegire totius, Sueciæ borealis; in alpibus Helvetiæ Schleicher! Schaerer! Carinthiæ Laurer! Salisburgi Hoppe! (pro Lec. circinala) \&c.

Ut P. Dufourei, Montagnei, straminea \& elegans ad Imbricarias, hæc ad Physcias accedit, sed thallo 
juniori licet substellato, vere crustoso, adnato, subtus nudo, apotheciis subinnatis, disco primitus luculenter a lamina marginato certe hujus tribus \& quidem sequentibus proxime connexa. - Specimina a. \& b. ab illustr. inventore accepta non parum inter se recedunt, sed omnia specimina exotica adeo intermedia ut ad neutrum stricte referenda. In genere Lec. alphoplaca Germanorum potius ad Lich. melanaspidem Wahl. referenda est:

Numquam inter ditissima spolia e Pyrenceis fuit ad nos missa; optimus D ufour ex Helvetia orta exemplaria tantum tradidit, quare in illis desiderari videtur. Alia stirps pro a. in Europa australi sumta ad priorem tribum omnino referenda est. Cfr. $n, 95$.

I 20. PARMELIA candicans, thallo crustaceo contiguo adnato glauco-candicante, ambitu laciniato-lobato, apotheciis adpressis, disco marginato pruinoso fusco-nigricante, margine thallode persistente.

Lich. candicans. Dicks. Crypt. 3. p. 15. t. 9. f. 5. ex spec. Auct. indeque Engl. Bot. t. 1778. Lecan. epigea. Ach. pr.p. excl. syn, Lecid. epigeæ - L. explicata. Chaub.

Ad saxa præcipue calcarea Angliæ!, Galliæ occidentalis Prevost!, meridionalis Dufour!

Thallus circulos format minores saxo arcte adglutinatos, contiguos, plus minus radiosos, mox albescentes \& obsolete pruinosos. Apothecia regularia, adpressa, nec immersa, disco plano, vegeto carneo-fusco, vetusto autem atrorufo \& exsiccato prorsus atro, margine laminæ supra thallodem eminente, persistente, intus prorsus e thallo formata; hinc vera Lecanora \& a Lecid. epigcea diversa, ut jam in S. O. V. p. 284 observavi \& amiciss. Schaerer (Spic. p. 119) confirmavit.

121. PARMELIA circinata, thallo crustaceo adnato demum areolato-verrucoso cinereo-plumbeo glaucescente, ambitu radioso-plicato, apotheciis innatis, disco subrnarginato fusco-nigro, marginem thallodem æquante. Ach. meth. p. I 89 . a. radiosa. Lichen radiosus. $H o f f m$. en. Lich. $t$. 4. f. 5. Ach. in Vet. Ac. Handl. 1794.t. 6.f. 5. Psora. Hoffm. Pl. Lich. t. 59. f. 1., t. 60. f.3. Lobaria. Ejusd. Germ. Lichen circinatus, Pers. - Engl. 
Bot. t. 1941. Parm. dein Lecan. Ach. syn. Lecan: myrrhina, Afzeliana, versicolor (excl. syn.) Fijusd. Syn. p. 185.

Exs. Lich. Sues. n. 394. Moug. et Nestl. n. 457.

b. variabilis, thallo orbiculari determinato subfibrilloso-radiante (sæpius umbrino), disco convexo cæsiosubpruinoso. Lich. variabilis. Pers. Parm. dein Lecan. Ach. - (Lec. psoralis Ejusd. status tenuissimus, apotheciis abortivis).

c. ocellulata, crusta effusa, indeterminata varioque modo mutilata, decolorataque. Urceol. ocellata. var. ocellulata. Ach. Lich. univ. (male sub Lecan. alpestri in Syn. quare nuperius \& Lec. alpestris dicta fuit). Lec. Agardhiana. Ach. syn. p. 152. - Lecan. pxpalea Syn. Lich. status maxime degeneratus \& amphibolus vix aptiori loco citandus.

Exs. Lich. Suec. n. 395.

E saxo calcareo oriunda in regionibus Europæ totius formationi recentiori substralis etiam in muris \& aliis saxis vagatur; sed in regionibus mere granitoideis, etiam maritimis, desideratur.

Thallus normaliter plumbeo-cinereus, sed in calce glauco-albescens, \& totus in calcis potestate pro more prorsus albus. Color umbrinus in $\mathbf{b}$. \& formis quilbusdam c. subsumtis, ut primus obtutus docet, oinnino peregrinus est, normali pro more in excipulo albido persistente. Licet ceterum thallus ita mutiletur, ut cum ipsius Parmelice cinerea \& calcarea formis confundatur, immo multorum Lec. dispersam \& Urceol. cinereorufescentem efficiat, a sedulo observatore, qui ex thallo atypico jam autonomas non esse videt, ad typum suum facile reducuntur. Apothecia in thallo crassiore omnino Urceolar. ex Achario, in tenuissimo vero Lecanorx s. Patellariæ, a quibus tum margine laminæ prominente nigro dignoscuntur. Pruina disci in minoribus evidentius observatur; majorum speciminum sæpius nudus, magis fuscus, immo rufescens. Denique ad prædium Xatardii in Pyrenæis orientalibus lectam possiden formam mere verrucosam habitu Porince Ach. Variis huc pertinentibus formis debitum locum significavit Meyer.

ק. myrrhina, thallo latiori rulescenti-cinereo (fusco-punctato,) ambitu radioso-lobato, apotheciis fuscoruifis, margine thallode flexuoso. 
Ad saxa duriora alpium Helvetiæ. Schleicher!

Vera \& constantior videtur varietas, eodem tamen modo ac prior varia, sepe Urceol. cinereorufescentem Auct. in statu mutilato offerens. - In spec, $P$. circinatoe ipsius prope Canigou Gallix lectis observo radios tinctura dilute luteolo-rubella (non ab oxido pendente) imbutos.

122. PARMELIA chalybcea, thallo crustaceo adnato levigato rimoso plumbeo-livido, ambitu determinato radiato-striato nigro-marginato, apoth. disco immerso submarginato e pallido nigro, margine thallode obsoleto.

b. thallo uniformi albescente, ambitu haud lobato. Urceol. n. sp. Dufour. in litt.

In rupibus Pyrenæorum. Dufour!, Montagne! etc.

Species pulchre distincta, saxo omnino adglutinata. Thallus subirregulariter effusus, haud radiosus, nudus, lævigatus, contiguus, leviter, ut videtur tantum siccitate, rimosus, intus virescens. Præcipue dignoscitur ambitu, licet in perfectis evidenter lobato, depresso, maculari, (minime laciniato), radiato-striato, nigrolimitato, fere ut in $P$. aipospila. Apotheciorum disci minuti, crustæ superficiei immersi, conferti, passim confluentes, sicci plani, opaci, nigri; humectati in vegetis vero turgidi, convexi, livido-pallentes, supra crustam prominentes. Margo thallodes tenuissimus, vix ullus. Color thalli humidi lividofusco-virens, siccus chalybæus aut cœrulescenti-griseus. Ceterum e variis præsentibus speciminibus variabilem esse patet, disco nudo \& cæsio-pruinoso; etiam crustæ figura, colore passim albescente e. $s$. p.

123. PARMELIA stannea, thallo crustaceo glaucescente, mox abeunte in squamulas confertas minutas imbricatas crenulatas albo-marginatas, apotheciorum disco nigricante pruinoso, margine thallode tumidulo a laminæe discreto.

In saxis graniticis in Norvegia v. c. in Ringerige prope Stensfjord. Blytt.

Parm.subfuscæ formis obiter adspecta, squamis nem- 
pe pro apotheciis habitis, similis, sed re ipsa $P$.cervince adeo analoga, ut, nisi facie prorsus differret, colorque, ex inventore plurimisque speciminibus omnino constans, aliam indicaret seriem, varietatem hujus forsan dixissem. Thallus primitus granuloso-verrucostis, effusus, indeterminatus, mox vero adolescens in squamas confertas, minutas, subimbricatas, rotundatas, sæpe cupulares, margine erecto, crenato, albo, ibique plerumque unim aut plura apothecia proferentes. Color glaucescens, non vero in album, vix in olivaceum vergens. Apothecia inter minora, regularia, concava, nigra, glauco-pruinosa, sed margo laminæ nudus niger. Margo thallodes simul evidens, persistens, tumidulus, integer aut leviter crenulatus.

** Olivaceo-fuscescentes, umbrinæ, cervinæ. (Lecan. balaninam Ach. vide sub Physcia).

124. PARMELIA molybdina, thallo crustaceo areolato-verrucoso radiato-plicato fusco-umbrino, subtus albo, laciniis ambitus linearibus, apotheciis innatis, disco urceolato fusco-nigricante marginato, margine thallode tumido. Wahl. Lapp. p. 418. t. 29. f. 1. Lich.

a. margine thallode laminæ obtegente. Parmelia molybdina. Wahl. in. Ach. meth. suppl. p. 42. Lecan. Ach. Lich. univ. p. 430.

b. ereutica, margine thallode a laminæ discreto. $A c h$. Suppl. l. c. p. 43. Lecan. Ach. syn. p. 186. Fl. Dan. t. 2008. $f .2$.

c. microcyclos, radiis planiusculis, apotheciis impréssis. Wahl. l. c.

d. viridescens, thallo vix effigurato obscure viridi. Wahl. ined.

In scopulis marinis (Americæ arcticæ, Grönlandix, dein) ad mare septentrionale Finmarkix copiosa Wahlenberg! Norvegix usque ad Christiania passim Blytt!

Thallus arcte adnatus, rádiatim expansus, primitus stellatus contiguus, dein in areolas verrucæformes, radiatim vero sæpius dispositas abiens, unde radioso-plicatus. Ceterum crassitie, radiiv convexis \& planioribus pro more variat. Color in prima infantia 1 . locis humidis olivaceo-viridis (d.), ut in hac serie solemne est, mox vero umbrinofuscus, (omnino errant, qui ex paucorum vulga- 
tiorum statibus ex hypothallo soluto decoloratis omnes ejusmodi cólores peregrinos judicant,) intus albus. Non potest non hujus esse tribus ob apothecia subimmersa, urceolata, laminamque marginatam, licet in hac sola specie discus nondum pruinosus visus sit. Hoc vero vento marino tribuendum videtur, cui exposita etiam apoth. maxime pruinosa v. c. $P$. ciliaris, aquilae, pulverulentce, nuda sunt. Ceterum inter omnes $P$. cervina proxime affinis est.

ß. $\boldsymbol{P}$. hysgina, squamulosa, substellata, disco immerso rubro immarginato. Ach. Lich. univ. p. 430. Lichen. Wahl. Lapp. p. 4. 9. t. 27. In saxo sicco ad Kaafjord Altensium Finmarkiæ. Wahlenberg!

Singularis, diminutus (2-3 lin. latus) prioris status, ut acutiss. inventor ipse indicat; prorsus analogos habemus $P$. cervince, badice \&c.; illi hac forma accedit species, sed manet distincta!

125. PARMELIA cervina, thallo areolato-squamaceo, squamis crustaceis subpeltatis repandis lobatisve e virescente livido-castaneis, subtus albis, apotheciis primitus immersis marginatis, demum protuberantibus, disco rufofusco. Sommerf. Lapp. p. 1 о6. Lecan.

a. glaucocarpa, thallo virescenti-fusco, apotheciis cæsio-pruinosis, margine tam thallode, quam laminx prominente. Lich. glaucocarpus, Wahlenb. in Vet. Ac. Handl. 1806. p. 143. t. 4. f. 4. Parm. dein Lecan. Ach.

b. squamulosa, thallo castaneo-cervino, apotheciis nudis, margine thallode tenui aut nullo. Lich. squamulosus. Schrad. - Engl. Bot. t. 2011. Parmel. Ach. meth. - Lich. cervinus. Pers. - Wahlenb. Lecan. Ach. syn. p. 188. - Urceol. castanea. Dec. fr. 2. p. 371. - Parm. peliscypha. Meth. Lich. suppl. - Lecan. halophæa, badia a. Ach. Lich.univ.

c. discreta, areolis plus minus discretis, apotheeciis plus minus imperfectis punctiformi-immersis. Gulor varius. Singularis status luteovirescens in rimis scopulorum occultis: Endocarp. smaragdulum Wahl.olim. - Ach. - Fl. Dan. t. 194\%.f. 2.'

Exs, Lich. Stuec. n. 392. (var. formæ). 
Ad saxa præcipue calcarea totius Europæ; in aliis macrior \& imperfecta, \& quidem tantum in regionibus vento maxime expositis, ut alpibus \& campis; in graniticis silvosis numquam vidi.

Mire variabilis, ut formæ allatæ plures complecti videantur, sed reliquæ his facile subsumuntur. Areolæ, licet subtus albæ, ex hypothallo nigro, in junioribus evidenti, oriuntur; nunc dispersæ, nunc aggregatæ, (tum sæpius angulato-repandæ, margine elevato albicanle;) nunc subimbricatæ, crenulato-lobatæ, semper crustaceæ indolis, colore in humectatis magis virescente. Lamina disci rufa, siccitate fuscescens, primitus areolis immersa, concava (\& abortiva tantum punctiformis;) dein emergens margine nunc simul thallode, nunc tantum laminæe ipsius cincta; nunc etiam convexa \& immarginata. In statu perfectissimo (a) tantum pruinosa. - Lecid. castaneola \& incusa Ach. syn. p. 52, 33 sec. specimina Schleicheri hujus quoque formæ sunt, nec dubito, quin etiarn primitiva specimina Acharii eadem fuerint, licet aliena deinceps substituta sint.

ק. percaena, areolis dealbatis, passim pulverulentis. Lecid. percæna. Ach.syn. p. 29. Cfr. Sommerf. Lapp. p. 162. Lecan. rubricosa. Ach. Lich. univ. p. 386. nec Synops. (Achario ipso monente).

In saxis calcareis, rarior.

Qui non noverint nullam Lichenum crustam albam vel pulverulentam normaliter existere, mirentur diversissimarum specierum afferri varietates albas \& pulverulentas'; sed tanta est carbonatis calcici vis, ut hoc modo fere, omnes species decoloret - demumque dissolvat.

$A b E n d . s m a r a g_{0} d u l o$, eodem tempore ab inventore, Sommerfeltio et me ad priorem Parmeliam relato, omnins diversum est End. sinopicum, quod ubi Meyer ad Parmelium priorem retuleril, ut affert Flotow in Regensb. B ot. Zeit. nee fugit. Putat in libro laudato idem ad End. Hedwigii pertinere. --. Sequens, End. Hedwigii potius referens, a presente diversissima est.

126. PARMELIA Endocarpea, thalli squamulis imbricato-complicatis verruceformibus olivaceofuscis, ambitus distinctiŝ sublobatis pallidis, apotheciorum immarginatorum disco immerso rufofusco.

Ad terram nudam montium Hispanire australis. Dufour! 
Species distinctissima, nisi status Parmeliaceus $E_{n-}$ docarpi pusilli Hedw., a quo tamen etiam thallo diversa. Thalli squamulæ densissime imbricatæ, in pulvinulos complicatæ, centro bullatæ; paucæ libere adscendentes, in ambitu vero magis discretæ, adpressæ, lobato-laciniatæ. Color humectatus viridi-olivaceus; siccus olivaceofuscus, in ambitu vero cervino-pallidus \& lutescens. Apothecia nullum supra thallum elevatum excipulum proferunt; disei plurimi, conferti, ipsis squamulis immersi, euncavi, nudi, humectati læte ruf,"sicci vero fusco-nigri; primo punctiformes, ostiola Endocarpi mentientes. Veram esse Parmeliam nullum dubium est; similia apothecia in subsequente tribu. Vegetatione diversissima, thallo tenuiori, fere Psoromæ, \& toto habitu a priori semper distincta manet. - Lecid. plicata Clement. - Ach. syn. p. 29 huic affinis est, ut pro ejusdem statu vetustissimo haberem, nisi nil ex hypothesi conjungere legis instar mihi propositum esset.

*** Ochroleuca.

127. PARMELIA nimbosa, thalli squamulis centro crustaceo-coalitis glaucopruinosis, ambitus squamuloso-lobatis luteo-virescentibus, apotheciis innatis, disco submarginato nigricante, margine thallode tumido integro.

Ad terram alpinm summarum Dovrensium Norvegiæ v. gr. in Drivdalen infra Kongsvold Blytt!

Species a ceteris remota; at inter priores \& sequentes medium locum optime tuetur; colore thalloque demum pruinoso etiam $P$. pulverulentam in memoriam revocans. Thallus terræ arcte adnatus, unde hypothallus parum evidens, primo obtutu uniformis apparet, sed revera e squamulis foliaceis concretus, in ambitu evidentibus; vidi quoque specimina tota squamulosa eaque semper nuda. Color vegeti \& humidi Lichenis luteo-virescens; siccus sordide s. fuscescenti-luteus, in medio dense glauco-pruinosus, qux vere pruina in humectato evaneseit, \& cum apotheciis prorumpentibus connexa videtur, nam in horum vicinia copiosissima est, in eorum margine accumulata; in sterilibus \& junioribus deest. Apothecia in crusta fere detrusa; margine thallode tumido, subintegro, parum supra crustam elevato; disco plano, 
fusco-atro, intus concolori, in ætate juniori margine tenui disci cincta.

**** Citrina.

128. PARMELIA Schleicheri, thallo crustaceo-areolato nudo flavo, areolis subeffiguratis, apotheciorum disco immerso plano atro, margine thallode tenuissimo. Ach. Lich. univ. p. 332. Urceolar.

Ad terram, in convallibus Helvetiæ Schleicher!, Gallix meridionalis Dufour!

Areolæ sublobatæ, dispersæ, plerumque in aliis Lichenum crustis insulares, læte flavæ, nudæ \& nitidæ. Apothecia in singula areola plura, mihi atra visa, ex Dec. fr. in fulvum vergentia, margine thallode primo nullo, dein tenuissimo prominulo cincta, Diversissima est a $\boldsymbol{P}$. chrysomelcena s. Lecan. Ach., cujus apothecia vere elevata, discus sanguineo-ater \&c.

SEct. IV. Thallo crustaceo, toto adnato, uniformi, ambitu similari aut ex hypothallo tantum fibrilloso-radiante. Hypothallus matrici adnatus, sape cum thallo confusus. Patellaria spec. Ho fij m. Decand. Lecanoræ, Urceolariæ \&c. Ach.

Hypothallus optimas præbet differentias, sed in speciminibus perfectis \& junioribus observandus. In hac sectione quoque plurimæ species priorum crusta obliterata, mutilata 1 . in lepram soluta (hæc enim numquam naturalis est) quæri possunt, at vix aliquem, status Lichenum normales perspicientem, fallere possunt. Querúntur vulgo hanc sectionem multis pravis premi speciebus, tales vero in natura non exstant, sed frequentissime mutilata \& imperfecta specimina, e quibus pravæ species ortæ sunt. Quasdam harum celebratiores \& frequentiores appendicis loco in usum tironum sub Trib. VII memorem, præcipue cum in isto statu non rite determinari possint. Querentur procul dubio plures, characteres non ita propositos esse, ut ex his quamvis obviam formam l. statum, etiam sterilem \& abortivum, determinare possint. At considerent velim etiam differentias plantarum perfectiorum, nunc e germinatione, nunc e vegetatione, nunc e flore, nunc e fructu sumendas esse, nec umquam 
simul in eodem individuo adesse. Non inter has petunt, ut characteres in omnem $x$ tatem, abnormitatem \& statum emortuum decorticatum quadrent, sed inter Lichenes volunt, ut non solum omnes abnormitates, licet ii ob majorem vivacitatem magis ex externis momentis mutari possint, sed etiam epidermide privata \& in lepram dissoluta comprehendantur. Eadem fere ratio est, ac si posceres, ut characteres phanerogamarum etiam caulibus entortuis, truncis in humum solutis e. s. p. convenirent. Hic est fons totius Lichenologiæ confusionis, quod nunc sing'llum obvium statum etiam maxime mutilum ut per se absolutum vegetabile consideraverint, nunc ex diversarum specierum statibus mutilatis diversissimas confuderint. - Hoc loco non possum non tironibus suadere, ne ejusmodi formas mutilatas quisquiliares nimis curent!, sed typicas primum sibi notissimas reddant, ex quarum studio dein reliquas facile dignoscere addiscant. Cui enim bono sit nomen ejusmodi mutilationum nosse, cum ex eis rihilo tamen minus ipsam stirpem non noverint? Bene quidem video, et a summis viris, receptum esse morem in speciebus \&c. exponendis ab infimis \& maxime imperfectis ad perfectiores adscendere, sed, me judice, male; nam Systema statum perfectum \& typicum potissimum respiciet. Sine temeritatis metu asseverare possum, neminem ipsum in earum studio ab infimis formis, ægre discernendis, ad summas adscendisse, sed via inversa, quam Linnæus in Systemate exponendo naturalissimam hinc bene vocat, descendisse; neminemque, qui ab infimis formis perfectiorum cognitionem sibi comparare velit, hanc umquam attingere. Conspirante hoc modo \& idealismo \& empirismo, in formis Lichenum exponendis non a statu gonimo aut leproso, sed a perfectissimo initium facimus.

Trib. VII. PATELLARIA. Apothecia regularia, scutellata, sessilia, margine thallode persistente. Lamina disci planiuscula, immarginata. Thallus crustaceus, adnatus hypothallo indeterminato, qui in paucis verniceus pallidus, in plerisque ater. Discus haud cæsio-pruinosus.

Nisi omnem historiæ auctoritatem \& naturæ convenientiam violare velis, alii generi aut tribui Patellarix nomen imponere haud licet. Cfr. Biatoras. T'hallum mere crustaceum brevitatis caussa crustam dicimus, 
quod, Achario licet gravissime objectum, æque facile concessum fingam ac pericarpium baccatum baccam dicere. - Omni loco sine discrimine innascuntur.

* Glaucescentes.

I 29. PARMELIA pallescens, crusta subtartarea rugoso-granulata glaucescente, hypothallo verniceo pallido, apotheciis tumidis, disco plano pallido innato-pruinoso, margine thallode erecto integerrimo persistente.

Lichen pallescens. Linn. Spec. et Fl. Suec. et Auct. Lich. albo-flavescens. Wulf. in Jacq. Coll. III. $p$. 111. $t$. 5. $f$. 1. Psora alabastrina. Hoffm. Germ. $p$. 164. Sequentis $\beta$. variet. Recent. - status crusta leprosa: Lich. Turneri. Engl. Bot. t. 857. Parm. dein Lecan. Achar. - tenuissimus, supra muscos: Lich. Upsaliensis. Linn. Engl. Bot. t. 1634. Dicks. Crypt. II. t. \%. f. 7. Patellaria. Hoffm. Pl. Lich.t. 21. f.2. - margine tenuiori: Lich. tumidulus. Pers. Exs. Lich. Suec. n. 103. - Upsaliensis : n. 286. Ehrh. Phytoph. n. 20.

Ad saxa, ligna, cortices, muscos ubique.

Crusta hujus ut omnium sequentium in Isidia \& Variolarias Ach. abit, tum plerumque sterilis, mag is sordida. Fertilem in illo statu pinxit Cel. Meyer (ic. titul.), at hoc non est Isidium Westringii Ach., cui inventor ipse scutellas urceolatas atras adscribit. Vide Westr. Färglafv. t. 4. Discus ex albido in pallide testaceum variat, inius concolor, strato medullari impositus. Investigari quidem possunt specimina degenerata, de quibus utrum ad hanc, an $P$. tartaream pertineant dubitari possit, sed non exinde, ut factum vidimus, conjungendæ. Vereor, ne multi formas ejusmodi sic dictas transitorias, quæ vero non directæ sunt, tamdiu inquirant, ut formarum primariarum cognitionem amittant. Probe tenendun: characterem, ut fingunt, non efficere speciem, (differentix duarum specierum erroneæ propositæ esse possunt, species tamen optimæ) sed, characterem tantum propositum esse, ut species dignoscatur. Characteres absolutos mens humana indicare non valet. Inde ortæ querelæ de specierum transitu. Licet harum constantiam, ut distinctarum naturæ idearum, non magis quam existentiam Dei mens humana demonstrare valeat, utramque tamen ut assumamus \& credamus necesse est. 
$\beta$. Parella, crusta amylaceo-tartarea lactea, disco demum rimoso verrucosove.

[Dill. musc. $t$. 18. f. 10. Lich. Parellus. Linn. Mant. Engl. Bot. t. 727. Fl. Dan. t. 1946. f.1. Patellaria. Hoffm. Pl. Lich. t. 12. f. 5. Parmel. dein Lecan. $A c \%$.

Exs. Lich. Suec, n. 13\%. Ehrh. Phyt. n. 100.

Ad muros, rupes ventosas juxta maris \& lacuum majorum litora.

Tam crustæ color \& substantia, quam præcipue apothecia (magis detrusa) degenerata testantur hanc formam non esse primariam, nec perinde esse, utrum hæc an prior pro typica habeatur. Hujus status sterilis sorediiferus, observante quoque Wallrothio, optimum Lichen. lacteum s. Variolariam lacteam efficit, sed sub ejusmodi nominibus diversa semper latent.

130. PARMELIA tartarea, crusta tartarea granulato-conglomerata glaucescente, hypothallo verniceo pallido, apoth. adnatis, disco plano ruguloso pallido testaceo, margine thallode inflexo integro. Ach. meth. p. 165.

Dill. musc. $t$. 18. $f .13$. Lich. tartareus. Linn. Engl. Bot. t. 156. Sv. Bot.t.77. Lecan. Ach. Lich. univ. p. 172. Patellaria. Decand. Verrucar. Hoffm. Lich. saxorum. Fl. Dan. $t$. 712. f. 1 .

Exs. Lich. Suec. n. 285 (saxatilis), n. 254. (arborea). Ehrh. Phyt. n. 50. Moug. et Nestl. n. 69.

b. crusta tenuissima levigata, excipulo colorato carneo. Ad saxa, terram, ligna \& cortices Europæ, præcipue frigilioris copiose. b. lignis subinnata.

Crusta plerumque admodum crassa, nodulosa, sed ad cortices tenuior \& in b. cum hypothallo confusa tenuissima sorediifera, unde profert apothecia exacte Lecidex Ach. Hujus status isidioideus est, observante Wahlenbergio, Isidium gonatodes Ach. meth.; totus leprosus vulgo ad Lepr. farinosam refertur (misit acutiss. Dufour specim. cum apotheciis, cui inscriptum: Lepraria farinosa in $\mathbf{P}$ tartaream transiens) - sterilis sorediifer Lich. lacteus Ehrh.! \&c., nucleis simul præsentibus: Variolaria conglobata Ach. syn. p.132. Sæpe quoque in discos in ipsis sorediis explicantur nuclei, tum ad Lecan.'Tur- 
neri ab Ach. relati. - Lichen normalis, sed disco elapso, excipulo tantum persistente est Lich. pallidus. Pers. $\beta$. frigida, hypothallo cum thallo confuso, crusta vernicea, demum granulata, apotheciis minoribus carneolis. Ach. l. c.

Lich. frigidus. Linn. - Swartz. meth. musc. t. 2. f. 4. Engl. Bot. t. 1879. Fl. Dan. t. 1348. Ach. in Vet. Ac. Handl. 1794. t. 5. f. 2. Lecan. tartar. $\beta$.

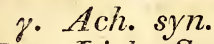

Exs. Lich. Suec. n. 255.

Ad terram, muscos, Cornicularias, fruticulos incrustans, in alpestribus \& maxime campestribus v. c. Ölandiæ; in silvaticis paludes profundas incolit.

E matrice diversissimas induit formas, fruticulosam, spinulosam \&c. - Utique prioris statu, Upsaliensi dicto, insignior est.

I3 . PARMELIA rubra, crusta subeartilaginea demum granulata glaucescente, hypothallo verniceo pallido, apotheciis adnatis disco concavo rubro, margine thallode elevato inflexo crenulato. Ach. meth. p. 170.

Lich. Ulmi. Swartz. Engl. Bot.t. 2218. Lich. Dufresnii. Bell. Lich., Patellaria, dein Verruc. rubra. Hoffm. Pl. Lich. t. 17. f. 2. Lecan. Ach. Lich. univ. p. 389. Fl. Dan. t. 1351: f. 1.

Exs. Lich. Suec. n. 47. Moug. Nestt. n. 459.

b. crusta tenuissima (subhypothallina), lamina sola erumpente (excipulo thallode destituta) concava rufofusca, nigricante. Lecid. carneola. Ach. pr. p.

Ad truncos arborum, ad muscos, Europæ totius; b. ad truncos, stillicidio subirriguos.

"Maxime affinis $P$. tartarece, quasi inter hanc \& subfuscam media. Apothecia madida carneo-rubella, dissecta tria produnt strata, quorum supremum aurantiacum, pruina superficiali alba, quæ colorem in carneum seu rubrum transmutat, medium virenti-pellucidum, \& infimum, cui crusta intus viridis substrata est." Sommerf. Lopp. p. 91. Discus facile elabitur, sed a Gyalecta cuipulari admodum differt. Crusta leprosa partem Lepr. albce efficit. b. huc optime traxit Flotow. 
13. PARMELIA carneolutea, crusta sibcartilaginea lievigata glaucescente, cum hypothallo verniceo confusa, apotheciis innato-erumpentibus, disco plano pallescente, margine thallode tenui inflexo crenulato evanescente. Turn. in Transact. Linn. Soc. IX. t. 12. f. 2.

Lichen carneoluteus. Engl. Bot. t. 2010. Lecanora. Ach. syn. p. 171. Sommerf. Lapp. p. 85.

Ad cortices arborum levigatos Angliæ Turner! Gallix occidentalis Guepin!, Sueciæ occidentalis, Norvegix, Lapponiæ Sommerfelt!

Crusta admodum tenuis. Discus demum convexus,' in spec. anglicis magis lutescens; in scandinavicis carneus siccitate fuscescens. Excipulum tantum ab ipsis apotheciis prorumpentibus formatum est, discum quasi involucrans. Facilis distinctu, sed an genuina species adhuc dubitetur.

$=P$. coarctata, heic facile quærenda, vid. n. 100.

133. PARMELIA oculata, crusta cartilagineo-tartarea rugosa inæquabili papillosa glaucescente, hypothallo verniceo pallido, apotheciis sessilibus concavis, disco subfusco, margine elevato integerrimo thallo albidiori.

Lichen epibryon. Wahl. Lapp. p. 408. Lecan. obsoleta. Sommerf. Lapp. p. 94? spec. non vidi. Transitus ad b: Lichen obtusatus. Flor. Dan. $t$. 1126. $f$. 1. Stereocaul. dein Dufourea. Ach.

b. thallo in Isidium mutato, apotheciis e badio nigris. Lich. oculatus. Dicks. Crypt. 2. t. 6. f. 2. Engl. Bot. t. 1833. Isidium. Ach. Lich. univ. p. 576. Lecan. Ach. syn. p. 148. Lich. dactyliferus. $W$ ahl. Lapp. p. 414 .

Ad terram supra muscos putridos; a. locis siccis; b. uliginosis in alpestribus maritimis Scotiæ Dickson! Norvegix totius Ahnfelt! Blytt! usque ad Nordlandiam Sommerf.! \& Finmarkiam Wahlenberg!

Transitum utriusque formæ specimina e Norvegia edocuerunt. Affinis quídem sequenti protec speciei, at 
thallus aliter constitutus, licet cartilagineus, magis ad $P$. tortaream accedit, quo forsan explicatur, hujus thallum adeo frequenter in Isidium abire, ut hic status normalis videatur; sequens in Isidium haud vidimus mutatum. Apotheciorum margo magis elevatus, unde concaviuscula ipsa fiunt, integerrimus, crusta albidior. Disci color normaliter fuscus, sed pro more locis humidioribus emollitus humidus badius, immo ruber fit, sed in sicco hxc forma co magis contrahitur \& nigrescit, omnino ut Parm. coarctatce. - Facile huc quoque cum Rev. Sommerfelt referas $I$ sid. dactylinum Ach., verum specimina Broomyc. rosei a me missa pro illo \& hujus varietaté ipse agnovit.

134. PARMELIA subfusca, crusla carilaginea primitus contigua lævigata, dein rimosa granulataque glaucescente, hypothallo maculari, apotheciis aduatis, disco plano-convexo sublusco, intus albido, margine thallo concolori erecto subintegro.

Dill. musc. t. 18. f. 16. (Cfr. Turn. in Transact. Linn. Soc. VI1. p. 111.) Lich. subfuscus. Linn. Wahl. Suec. p. 804.

Ad cortices, ligna, muscos \& saxa varia totius Europa; species longe frequentissima, protea. Multum, at irritum, deposui laborem, ut innumeras ex hac ortas species limitarem; ornnes ita reticulatim connexæ \& a se invicem ortæ, ut non possim non conjunctim tractare, sepositis, licet varietatibus insignioribus, ut, qui specierum reductionem dolent, easdem ut distinctas considerare possint. Disci structura, in statu incorrupio, omnibus eadem, sed color ab incarnato-albido per rubrum \& rufum in fuscum \& nigrum mutatur, excluso tantum omni luteo. Idem quoque thalli habitus, nisi tenuitatem majorem minoremve respicias vel abriormes status v. c. crustam totam pulverulentam. Hæc ad cortices haud raro obvia l. sterilis lactea, 1. discis diminutis corruptis nucleiformibus, qualis Lich. 1. Lepraria argena; discis prasentibus Lecan. verrucosa Ach. Lich. univ. Thelotrema Tairolarioid. $\beta$. Ach. syn., ut optime Cel.Meyer, (Cfr. Lich. Suec. n. 192) cum aliis analogis statibus dicta fuit. Ad ligna cariosa obviam venit crusta viridicineraseente, immo viridi, leprosa, apotheciis perfectis; 
talis forma ab Achar. ad Lecan. effusam relata est \& ab accur. Wallroth pro Lecan. Turneri habita videtur, quando hanc ad Lec. silbfuscain pertinere suspicatur. - Circa Lund in saxis adest forma fallacissima crusta sulphuirea leproso-tartarea, apothec. immersis, $P$. ventosa facie; at color evidenter adventitius. Variæ insuper occurrunt formæ Variolarioideæ (Isidiophoræ mihi tamen ignotæ) quales etiam quædam supra memoratæ, nune stejiles, nunc in ipsis sorediis fertiles. Harum præcipue memoranda Patellaria pulicaris Pers. s. Lecanora Ach. syn. p. 386 (Gfr. Lich. Suec, n. 250) crusta ligno carioso fere innata, lævigata, sorediis albis efflorescens, discis in sorediis nidulantibus, subgelatinosis turgidis, e pallide fusco atris, evidenter, morbose degeneratis. (Tanta est hujus cum Lecan.bryontha Ách., quæ etiam Lecan. epibryon. $\beta$. Lich. univ., Lecan. turfacea $\beta$. Syn. Lich., analogia, ut eandem separatim non tractem, licet disci indole, cum Porinis degeneratis ètiam conspirante, valde recedens sit, nam multiplici experientia edoctus șum, ea, qux maxime recedunt, haud normalia esse. Lecan.bryonthae Ach. disci in propriis verrucis nidulantes gelatinoso-turgidi, ex olivaceo nigrescentes, demum rugosi, normalis Lecanorx Ach. non sunt, sed ad typum Lecan. pulicaris deformati, at forsan non tantum a Liecan. subfusca, sed ab Urceolariis Ach. etiam originem ducunt). Sed habemus insuper insignem copiam formarum apotheciis abortivis: Patellaria (Verruc. Fl. Germ.) detrita Hoffm. Pl. Lich. t. 64. f. 1-4, Parm. dein Lecan. detrita Ach. re ipsa nil nisi hujus status apotheciis mechanice detritis, ut nomen omen. Adest vero alia forma apotheciis vere Arthonioideis, Arth. radiatam Ach. referentibus, maculæformi-immersis, subramoso-radiatis, alia apotheciis in soros fuscos, facile spiloma fuscatum Ach., solutis. Exstant quoque alix degenerationes, Urceolariam, Porinam, Pyrenulam, Lecideam sensu Acharii referentes, qux unice ex usu addisci possunt. - Varietates primarix, disco \& crusta incolumi, sub sequentibus comprehendi possunt.

a. P. discolor, crusta ut supra, apotheciis regularibus, disco crassiusculo semper nudo (rubro, rufo, fusco, nigro), margine integro aut per ætatem rugoso.

a. Disco planiusculo, margine thallode immutato per- 
sistente. Ad ligna, cortices \& saxa: Lich. subfuscus. Auct. - Hoffm. en. Lich. t. 5. f. 3. Engl. Bot. t. 2109. Patellaria. Ejusd. Pi. Lich. t. 5. f.3. Verrucar. Ejusd. Germ. c. varr. Parmelia dein Lecan. Ach. cum varr. - Parm, glaucorufa. Mart. Lecan. sarcopis v. marina. Sommerf. Lapp.: Ad muscos, cæspites graminum emortuos: Lichen $\mathrm{Hyp-}$ norum. Wulf. in Jacqu. Coll. IV.t. $\% f .4$. Patellaria. Dec.fr. Parmel. dein Lecan. epibryon. Ach. Exs. Lich. Suec. n. 250. Moug. et Nestl. n. 120.

b. Disco turgido, subhemisphærico, marginem persistentem thallodem immutatum superante. In cortice: Lecan. steatina. Lich. univ. p. 677. In saxis: Lichen punctatus. Engl. Bot. t. 450 sec. spec. certum. Lecan. gangalea. Ach. syn. p. 152. Lecan. alpestris Ach. Lich. univers. certissime; in syn. cum P. circinata commixta.

c. crusta tenuissima (mere hypothallina), apotheciis concaviusculis, margine persistente colorato! (Huc quoque formæ Lecid. erythrophaece Fl. spectare videntur.)

d. apotheciis minutis, disco hemisphærico, margine pallidiori subevanido. Lecan. Hageni. $\beta$. Ach. - Sommerf. - Lecid. cyrtella. Ach. meth. Lichen. Engl. Bot. t. 2155. (deinceps cum aliis Lecan. \& I ecidea anomala, sub Lecid. luteola, carneola \&c. \&c.)

Exs. Lich. Suec. n. 195. Fl. Deutsch. n. 162. Sommerf. Norv. n. 62.

Ubique; c. præcipue ad sæpes ligneas; d. ad ramulos tenuiores.

Hanc formam a truncis crassioribus (ubi a.) ad ramulos tenuiores (d.) sequens evidentem \& directam transitus videas seriem. Synonyma infimarum quisquiliarium formarum vix umquam definite determinari possunt, cum v. c. in Lichenophylacio Acharii ubique fere, ubi de his agitur, analogi status diversarum specierum commixti sint. Sic optimus vir etiam $P$. subfuscee status ad d. accedentes pro Lecan. metabolica, pharcidia \&c. determinavit, sed, ex specim. inventorum, aliorsum pertinent. At sæpe ne e speciminibus quidem, tantum in loco, eorun, origo explorari potest. Hoc de multis aliis formis censeo justo prorsus omissis. In his conterminis optimum videtur omnia minus evidentia indeterminata relinquere. Ad hanc varietatem primariain ceterum 
quoque referendæ variæ exoticæ species v. c. Parmel. tumidula Spreng. Mant. Hal. I. p. 57 \&c.

$\beta$. $P$. distans, crusta tenui, apotheciis orbiculatis, márgine elevato crenulato, disco tenuiori pallido, primitus pruinoso, mox nudo. Ach. syn.

Patell. populicola. Decand. Lecan. distans. Ach. Lich. univ. p. 397. Parm. Mart. Erl. p. 218.

Exs. Lich. Suec.

Ad cortices varios, apprime Populi.

Crusta in ambitu passim zonata.

$\gamma . P$. albella, crusta tenui lactea, apotheciis orbiculatis tumidis pallidis albido-pruinosis, margine integerrimo subevanescente.

a. major, disco planiusculo, margine subconcolori. Lich. glabratus Dicks. e spec. certo. Lecid. alabastrina. a. Ach. syn. p. 46. omnino. Lecid. argena, Flörl. in Berl. Mag. 1807. p. 13.

b. minor, disco convexo, margine thallo concolore. Lich. albellus. Pers. - Eng.l. Bot. t. 2157. Lecanora albella. $A c h$.

Exs. Lich. Su. n. 249. - b. Flörk.n. 88. Sommerf.64. Ad cortices arborum, præcipue locis nemorosis; a. optima in truncis Fagi. b. in ramulis tenuioribus.

Præcipue a. insignis est, at in eodem thallo cum $\alpha$. sensim transeuntem vidi. Inter hujus $b$. \& d. nulli limites; me lustrantem Herb. Ach. ratio, ob quam varia specimina ad hanc vel illam transtulit, plane fugit. Talia specimina exacte media sistunt Lich. pallescens. Wulf. in Jacq. Coll. IIT. p. 112. t. 5. f. 3. a. a. Lich. pallidus. Schreb. Hoffm. - Analoga est hujus a. cum P. glaucoma v. subcarnea.

$\delta$. $P$. angulosa, apotheciis congestis anguloso-difformibus, disco livido-fusco glauco-pruinoso, margine thallode subpersistente flexuoso.

Lich. angulosus. Ach. Prodr. p. 54. - Parmel. dein Lecanora Fjusd. Patell. Decand. fr.

Exs. Lich. Suec. n. 284.

Ad truncos arborum, præcipue in campestribus regionibus. 
Tam cum $\alpha$, quam $\gamma$. luculenter confluit, sed facilius commutatur cum formis saxicolis dealbatis $P$. saxicolae d., immo Parm. glaucoma. Utramque harum absolute saxicolam inveni.

ع. P. coeruleata, apotheciis congestis variis, disco subgloboso fusco-nigro pallescenti-pruinosis.

Ad truncos arborum.

Hujus alia exstat forma major, apotheciis repandis nullo modo ab $\alpha$. separanda, quamvis notis datis recedat. - Alia insuper minor, eisdem quidem gaudens differentiis, sed habitu tám dissimilis, ut lubens distinguerem. Ab hac non separare possum $P$. glaucoma $\beta$. ceruleata Ach. syn. p. 166, nam vera $P$. glaucoma numquam nisi in saxis a me reperta est. Sub nomine fecan. atroocarpae Duby huic proximam formam e Gallia quoque misit Prevost aliique. (Eidem optimo viro varias debeo $P$. subfusca formas muris argillaceis innatas \& more solito personatas, quas ut omnes similes status magis accidentales sigillatim notare nimis longum foret).

$\eta$. P. lainea, crusta lævigata areolata glauco-albi-

. da, pallida (aut flavo-virescente), apotheciis minutis fusco-nigris. Sched. Crit. 9. p. 7 .

Lecan. lainea. Ach: syn. p. 147. Lec. gangalea Ib. ad a. accedit.

Exs, Lich. Suec. n. 371 .

In saxis aqua suffusis, pracipue in scopulis marinis, ab undis sæpe tritis, frequenter.

Aliæ hujus formæ a $P$. subfusca $\alpha$. luculenter oriuntur, ut nonnisi crusta tersa dignoscantur; aliæ eísdem locis prorsus immixtæ colore pallido, immo flavovirescente, recedunt, quasi a $P$. atrosulphurec orta fuissent. Apothecia semper adpressa, subinnata, nigra, aut humectata fuscescentia.

$O$ bs. Gratissirnum sane mihi foret, si detegerentur notce essentiales et limites stabiles, quibus adeo proteam stirpem in plures distribuere possemus. At vegetationis historia in omnibus allatis scarietatibus prorsus eadem, ut levem spem mihi superesse fatear. Potius milhi persuasum est, sequentem (et forsan atias) ejus esse filiam, quum autem prosens jam nimia formarum mole prenitur, eundem tamen ob vegctutionem alienam, limites evidentes et distributionem geogruph. propriane separare utile duxi. At etsi maxime protea sit, sedulo attendendum ne infima proles diversissime originis ad presentem trahantur. Nam ii ipsi, qui externo babilui discique colori fidentes, nostram angustissimis 
limitibus sumunt, vulgo etiam ex eisdem rationibus aliena simul addere solent. -- De P. exigua vide sub P. sophode.

135. PARMELIA frustulosa, thallo glebuloso-granulato, granulis primitus discretis, demum effiguratis sublobatis pallescentibus, hypothallo nigro, apotheciis sessilibus, disco subfusco, intus fuscescente, margine tenui subcrenulato. Ach. meth. p. 159 .

a. argopholis, granulis subsquamaceis, imbricatis. Lich. frustulosus. Dicks. Crypt. 3. t. 8.f. 11. Lecan. Ach. syn. Lich. argopholis. Wahl. Lecan. Ach. Lich. univ. p. 346. Cfr. S. O. V. p. 243.

b. insulata, areolis discretis, sublobatis crenatisve. $\mathbf{L}$. insulatus. Ramond. Squamaria. Dec. fr. $2 . p .375$. Parmel. Ludwigii. Spreng. Mant. Hal. I. p. $5 \%$. Lecan. Ach. syn. p. 188. Lecan. hydrophila. Sommerf. Lapp. p. 91.

c. thiodes, granulis glebulosis in crustam subtartaream coacervatis sublutescentibus. Lecan. Wallrothii s. thiod. Spreng. Neu. Ent. I. p.224. (Lecan. oreinæ var. Ach. in litt. ad Schaerer).

In regionibus montanis, pracipue vero alpinis, ad rupes \& saxa irrigua, totius Europæ.

Inter præcedentem \& sequentem media, a quibus dignoscitur: Thallo insigniori, granulis jam primitus ex hypothallo (si conspicuus est) nigro effuso discretis oriundis, demum sublobatis coacervatisque; apotheciorum juniorum margine acuto coarctato crenulato, discoque intus nec albo, nec atro. Locis similibus occurrunt formæ tersæ, diminutæ $P$. subfuscee \& atræ, quæ hanc insigniorem distinguere suadent. Color, qui normaliter glaucopallescens, in b. jam passim flavicat, in c. sæpissime, sed fatiscentes omnes formæ in lepram albam solvuntur, ut certe hujus seriei. Discus semper nudus; variat concavus \& convexus; locis humidioribus ruber, siccioribus nigresscens. Vidi in a. etiam laminam solam in thallo crasso emersam; absque excipuló thallode, concavam, marginatam, quæ in L. subfusca non observatur. - Formæ c., nec $P$. atrosulphurea, proxime accedit Lec.thiodes Sprengel, at simul $P$. subfuscae ita affinis, ut qui ad illam transferret vix erraret.

ı36. PARMELIA atra, crusta cartilaginea mox 
granuloso-verrucosa glaucescente, hypothallo nigro, apotheciis sessilibus, disco polito aterrimo, intus nigro, margine thallode persistente integro. Ach. meth. p. 154.

Dill. musc. t. 18. $f$. 15. A. Lich. ater. Huds. Hoffm. En. t. 4. f. 4. Engl. Bot. t. 949. Westr. Fägl. $t$. 15. L. cinereus. Wulf. in Jacq. Coll.IV. p. 183. t. 14. f. 5. b. L. tephromelas. Ehrh. Patell. Dec. fr. Verruc. atra. Hoffm. Germ. Lecan. Ach. Lich. univ. pr. parte.

Exs. Lich. Suec. n. 370, 203. Ehrh. Crypt. n. 313. Moug. et Nestl. n. 458. Fl. Deutsch. n. 133, 134.

* grumosa, crusta subpulverulenta, ex hypothallo soluto coerulescente. Lich. coerulescens \& grumosus. Pers. Patell. l. Verruc. grumosa. Hoffm. - Pl. Lich. t. 51. $f .1,2$. Parmel. Ach. meth. Urceol. Segestria. Flörk. in Berl. Mag. 1807. 1. p. 18.

Ad saxa \& rupes, etiam cortices arborum, Europæ totius.

Crusta ad cortices tenuior, lævigata, passim lutescens. Discus in omni ætate \& statu, etiam humectatus, aterrimus ab omnibus affinibus distinguit. Margo junior integerrimus, per ætatem tantum flexuosus \& inæqualis. * Est status degener, cum P. erythrocarpia * cæsiorufa, $P$. cerina * cyanolepra \&c. analogus. Alium statum dealbatum, sorediiferum, sistit Lecan. leucopis Ach. syn. p. 150.

$\beta$. confragosa, quoad omnes partes triplo minor. P. confragosa. Ach. meth. Suppl. p. 33. Ad saxa, sæpe irrigua.

Varietas satis insignis \& constans, at nullas essentiales differentias offerens. - Subinde margo thallodes excluditur, 'qui status pro more facile pro Lecidea sensu Acharii sumitur, at a Lecid. ambigua Ach. diversa est. Potius quædam hujus specimina ad sequentem referam. Lich. mastrucatus. Wahl. Lapp.p. 413 Lecan. Ach.syn. p. 148, inter hanc, n. $141 \beta . \&$ n. 144. ambigua, ex ipso sincerrimo inventore, in cujus Lichenophylacio tantum vidi, nimis imperfecte cognita, ut rite determinetur. 137. PARMELIA cinerea, crusta subtartarea areolato-rimosa glauco-cinerea, hypothallo nigro, 
apotheciis innatis, disco nudo nigrescente, intus pallido, margine thallode subelevato obtuso nigro: Sched. Crit. 13. p. 2.

Lichen cinereus. Linn. \& Auct. boreal. - Engl. Bot. t. 1751. Wahl. Lapp. p. 412. Westring Färglafv. t. 18. Urceol. cinerea. Ach. - Schaer. spic. p. 70. Verrucaria ocellata Hoffm. Pl. Zich.t.20. f. 2. Urceol. ocellata. Flörke in Berl. Mag. 1809. p. 315 ; 1810. p. 115. Urceol. tessulata. Dec. fr. Lecan. multipuncta. Ach. Lich. univ. Parmelia. Ach. meth. Urceol. microcelis. Ach. syn. p. 145. Urceol. gibliosa. Ach. certe. potiss. h. 1.; exstat enim forma apotheciis abnormiter erumpentibus margine crenulato cinctis.

Exs. Lich. Suec. n. 366. Fl. Deutsch.n.13. Schaer. Helv. n. 125, 126. (128. crusta ochracea).

b. Urceolaria fimbriata. Ach. meth. $p$. 145 .

Ad saxa precipue granitica Europæe totius (numquam ad ligna aut cortices a me visa); sed versus septentrionem frequentia accrescit, ut omnium Lichenum saxicolarum copiosissima.

Hypothallus niger, a thallo vero plerumque obtectus, in libere vero natis individuis ambitum zona plumbeo-nigricante cingit \& in quartzo fimbriata. Thallus ex acido carbonico etiam dealbatus, ex hypothallo predominante cinereo-nigricans, (var. atrocinerea Schaer. I. c.), ex hydrate ferrico ochraceo-rubra. Lich. diamartus Wahl. - Engl. Bot. 1776. Urceol. diamarta. Ach.); e Pyrenæis a Dufoureo habeo formam puldhre carneorubellam, h. e. e mente Cel. Meyeri oxido mangani tinctam. - Lamina concava \& plana, in his terris absolute nuda \& immarginata, vulgo nigrescens, at jove pluvio \& hieme sæpe rufofuscescens, immo æneo-virens ad rupium latera irrigua. Apothecia optime evoluta prioris speciei simillima, immo omnino superficiei innata maculæformia, quæ Lec. pantosticta a. Ach., ex. p. (species maxime hybrida, ut ex herbario patet) sed vulgo magis detrusa (Urceolariæ Ach.); passim quoque abortiva, verruczeformia, margine subconcolori, medio depressa (Sagedia zonata, depressa Ach. Lich. univ. p. 327, 329). Hujus status in Isidium mutatus certe est: Isid. lavigatum Ach. Lich. univ. p. 577. Pyrenula thelepho- 
ra $\alpha$. Ach. syn. p. 128. - Locis magis humidis, v. c. ad saxa amnium, crusta magis glebuloso-granulata, granulis verrucæformibus nigropunctatis, qualis ipsissima $P_{0-}$ rina chionaea Lich, univ. p. 311. Thelotrema. Ach. meth. t. 8. f. 3. Crusta sterilis sorediifera Variol. - v. coniza. Ach. sub $V$. aspergilla \& lactea. Tota soluta leprosa Leprarice segestrice (potissimum a Lecid. contigua ortæ) adscripta fuit. Porro Lichen illimatus Wahl. - Lecan. Ach. syn, ipse Inventor, certarum nec novarum specierum studiosus, ut oblivioni tradatur, suasit. Imperfecte enim cognita est, $\boldsymbol{P}$. cinerea simillima, nisi ob locum natalem cum $P$. maritima comparanda.

$\beta$. aquatica, crusta spongioso-tartarea glebulosa grisea, lamina urceolata immersa, margine thallode haud prominente.

In saxis sape inundatis amnium \&c.

Areolæ sæpe discretæ \& ex aqua adscendentes Porinam chionceam evidenter efficiunt. Adhuc magis ab aqua fere perenni emollita fit Lichen. mazarinus Wahl. Urceolaria Ach. syn., cujus discus simul dissolutus est, adeoque prorsus atypica. Ad saxorum cavernas in montibus habemus quoque formam spongiosam, sed crusta fere lobulato-inflata, apothecia normalia.

$\gamma \cdot P$. protuberans, crusta verrucoso-nodulosa albo-pallescente, apotheciis verruca elevatis, margine thallode flexuoso.

Lich. protuberans. Wahl. Lapp.p.412. Urceol. Ach. Urceol. gibbosa. Ejusd. ex p.

In cryptis rupium.

Forma, ut bene explicata, prominéns, sed ejus ortum a vulgari in monte Omberg observavimus evidentem.

ס. $P$. alpina, hypothallo denudato, crustæe areolis planis lævigatis rimosis cinereo-pallidis, apoth. disco immerso nudo rufo (sicco nigro).

Lecan. alpina. Sommerf. Lapp. p. 91.

Ad saxa in alpium jugis ventosis.

Valde insignis, sed ut hæc multi alii Lichenes, v*c. Lecid. atrovirens, locis ventosis quoad crustæ figuram mutantur. Habitu crustæ omnino convenit cum Urceol. cinereo-rufescente Schaer: exs. it. 130. 
\&. P. cinereo-rufa, hypothallo denudato, areolis verrucæformibus, disco nudo rufescente, margine thallode elevato.

Lich. cinereorufus. Wahl. Lapp. $p$. 407. Urceol. cinereorufescens. Ach. syn. p. 141.

Ad snxa quartzosa, ventis exposita.

Vera "Urceol. cinereo-rufescens" certissime P. ci nerex varietas, ægre limitanda, nam discus rufus in $\alpha_{0}$ etiam occurrit \& specc. originalia crusta ab hypothallo inquinata \& obscurata, disco in exsiccatis nigro, Urceol. cinerece v. atrocinerece Schaer., ut ovum ovo, simillima sunt.

5. P. laevata, hypothallo cum thallo in crustam tenuissimam levigatam glaucoluridam (flavovirentemque) confuso, disco nigricante.

Lecan. graphica. Ach. Lich. univ: p. 3448. Jreeol. cinerea $\delta$. Ach. syn. apoth. perfectis - apotheciis mutilatis, qualia sæpius sunt: Sagedia laevata, zonata, protuberans a. Gyalecta athalea. Ach. Lich. univ.

Exs. Lich. Suec. $n .36 \%$.

Ad saxa prope terram, locis humentibus.

Hujus originem ab $\alpha$., a qua recedit circiter ut $P$. subfusca lainea a suo typo, quisque facile observare potest; in rupibus irriguis insuper adeo luculenter abit in sequentes, ut de earum unione nullum dubium supersit. Simile specimen bis missum altera vice pro Sagedia lavata, altera pro Urceol. Acharii cyrtaspi determinavit Acharius.

$\eta$. P. rhodopis, hypothallo obliterato, crusta subpulveracea roseo-albida, apothec. disco roseo (fusco, nigricante). Sommerf. Lapp. p. 89.

Ad saxa calcarea, stillicidio irrigua.

Conferantur, quæ de hac maxime recedente forma, acutissime disseruit Rever. Sommerfelt, qui ejus transitum tam in Sagediam depressam seu var. a. mutilam, quam in sequentem observavit ejusque originem ex iis momentis deducit, quæ locis similibus omnes Lichenes analogo modo personant. Urceol. hypoleuca Ach. hujus aut certe affinis analogus status.

$\vartheta$. P. lacustris, hypothallo obliterato, crusta læ- 
vigata rimosa alba (1. ex hydrate ferrico testacea, ochraceo-rubra), apothecior. disco rubello (fusco, nigro).

Lich. lacustris. Wither. Lecanora rubelliana, cyrtaspis, Urceolaria Acharii, Gyalecta epulotica. Ach. Lich. univ. et Syn. Lich. Lich. Acharii. Prodr. Lich. cum ic. in titulo. Engl. Bot. t. 108\%. Fl. Dan. $t$. 2009. $f_{\text {. }} 2$.

Exs. Lich. Suec. n. 368.

Ad saxa hieme inundata ad lacuum litora in Europa saltim boreali copiose.

Formam esse atypicam primo obtutu perito' patet. Diversissima licet a $P$. cinerea $\alpha$. videatur, ejus origine ab illa nil certius, sive empirice persequaris utriusque transitum, sive ad momenta peregrina eam deformantia \& decolorantia theoretice attendas. Similibus locis ab aqua tersi crustam lævigatam, dealbatam (aqua simul ferro imbuta, testaceam, ferrugineam \&c.) fere omnes Lichenes acquirunt \& si hanc a $\boldsymbol{P}$. cinerea separare vellem, saltim viginti alios eadem ratione ortos status diversarum specierum distinguerem; ejusmodi enim status v. c. in agro Femsjonensi, in quo huic speciei eo tutius studui, quum subsimiles v. c. $P$. calcarea ibi prorsus exsulent, frequentissimi sunt \& juxta omnium lacuum litora peculiarem occupant zonam. Ex sola, fatali in Lichenologia, ad externam faciem attentione non dignosci possunt v. c. P. cinerea v. lacustris \& Lecidea atroalbav. lavata, sed ex apotheciorum structura facile dignoscuntur, ubi etiam earum thalli in unum quasi coaluerunt.

Synonyma et formas nimias priori a me tributas non esse ex annorum longa observatione et singulari hujus et affinium per menses studio milii plene persuasum est. Latent forsan alia etiamnum forma peregrinis sub nominibus, sed stirps ipsa nostro scnsu undique bene limitata mihi visa est. Quceritur forsan, quomodo hypothallum nigrum esse in thallo oxidato divinetur; at respondeo primo ad statum normalem in systemate esse attendendum; secundo me numquam alios, sed et fere omnes hypothallo nigro oere oxydatos reperisse. A quibus vero rationibus singularis illa lex pendeat, me sane fugit.

$$
\text { Olivaceo - aut viridi - fuscescentes. }
$$

38. PARMELIA poliophaca, crusta rimosa-papillato-ramulosa cinereo-fuscescente, hypothallo fibrilloso albo, apotheciis podicellatis, disco pla- 
no brunneo, margine thallode persistente subcrenato. Wahlenb. in Ach. meth. suppl. p. 38. Lichen defraudans. Olafs It. 1sl. app. p. 17. Isidium. Ach. Prodr. Lich. poliophæus Wahl. Lapp. p. 410. $t$. 27. f. 3. Lecan. Ach. Lich. zuniv. p. 398. b. spodophrea, obscurior, hypothallo obsoleto. Lich., Parmel., Lecan. spodophxa. $l l . c c$.

Ad scopulos marinos, ventis maxime expositos, intra circulum arcticum copiose.

Species maxime insignis, ab omnibus in serie fusca Patellariarum hypothallo fibrilloso albo byssino radiante diversissima. Tota statura $P$. aipospilae (n. 106), cum qua seriem fuscam a Placodiis ad Patellarias continuat; num in Systematica dispositione locum commutent? At ambitus in hac non evidenter radians. - Avide hujus quoque crusta a larvis insectorum comeditur, quæ singulari ratione species seriei fuscescentis præcipue appetunt.

Parmelice hujus seriei rariores sunt, regionibus definitis magis priva indeque inter se magis differentes, quam prooris.

139. PARMELIA torquata, crusta tartarea contigua levigata pallide murina, hypothallo atro, apotheciis superficialibus, disco opaco fusco-atro, margine persistente incurvo subcolorato. Syst. Orb. Veg. I. p. 284 .

Lecan. Schaereri. Ach. sec. spec. Schcerer (non n. 101). In summis alpibus Helveticis. Schaerer! Schleicher! Prevost!

Vix alii, quam Biatorce rivulosce affinis. Crusta late effusa, contigua aut senio indeterminate rimosa, lavigata, pallide murina, intus alba, hypothallum obtegens, qui tantum in ambitu 1 . lineolis decussantibus dignoscitur. Apothecia solitaria l. conglomerata, fere libera, excipulo thallode, nunc concolori, nunc \& sæpius colorato fusco, margine semper integerrimo incurvo albicante, quo normalis color indicari mihi videtur; intus tota candida sunt. Discus planus, durus, opacus, nudus aut obsolete pruinosus, marginem in adultis æquans.

140. PARMELIA badia, crusta cartilaginea rimoso-areolata subsquamulosa olivaceo-badia, hypothallo atro, apotheciis adpressis, disco nudo 
polito fusco-atro, margine thallode persistente integro. Sched. Crit. 3. p. 5.

Lich. badius. Ehrh. - Pers. Patellaria s. Verrucaria. Hoffm. - Plant. Lich. t. 5. f. 2. Lich. fuscatus. Schrad. Parmel. Ach. meth. p. 189. Lecan. badia. Syn. Lich. p. 154. (Patell. nitens. Pers. Lecan. Ach. syn. p. 335 status dissolutus).

Exs. Lich. Suec. n. 369. A.

b. picea, crusta picea, lamina immersa concava immarginata concolori. Lich. piceus. Dicks. Crypt. Brit. t. 12. f. 5. Lecid. picina. Ach. meth. Ad saxa granitica Europa totius.

A $P$. cervina, cum qua frequenter confusa, abunde diversa lamina disci semper immarginata, nuda, subcornea, haud versicolori e statu sicco \& humido, nec non thallo adnato, vere crustaceo, licet areolæ etiam in.hac dispersæ \& adpresso-squamulosæ occurrant. Ceterum formas monstrosas degeneratas habet plurimas, apotheciis male explicatis, subimmersis, punctiformibus, quales sunt: Sagedia rufescens Ach. ad saxa cotacea frequeus; Endocarp. smaragdulum Schaer. Exs. n. 117 forsan et Engl. Bot. t. 1512; idemque ferro oxydatum est verissimum End. sinopicum Wahlenb. - Ach. syn. p. 98. Engl. Bot. t. 1776. Schaer. Exs. n. 116. Lich. Suec. n. 393. His accedit forma externa facie Porinam pertusam colore excepto prorsus referens. - In aliis formis diminutis discus protruditur rufescens, omnino convexus \& immarginatus, quarum uni verbotenus quadrat Lecid.pulvinata Schaer. spic. p. 123. (Specimina ab amiciss. Viro missa sub itinere corrosa, ut quid certi haud statuam). Deniquetstatns mere hypothallinus apothecia profert minuta rufescentia prorsus immarginata, qui utique pro Lecidea anthracina haberi posset, at illa non est species definita, sed e diversissimis formis hypothallinis aut hypothallo soluto inquinatis (ut et ipsa P. badia) composita.

$\beta$. P. milvina, minor, crusta subgranulata, apotheciis atris.

Lichen. Wahl. Lapp.p. 410. Parm. dein Lecan. Ach. Ad saxa, juxta aquas \&c.

A præcedente recedit ut $P$. atra $\beta$. a suo typo, \& ad $P$. sophodem accedit statura, verum crusta ut in omnibus P. badiæ formis colorem humectata servat. Occurrit etiam crusta mutila, obliterata, quare Lich. simplex, 
crusta deficiente! distinctus, ad hanc etiam relatus fuit, quasi tales species ad singulam acrustaceam referri non possent. E specimine Daviesii! tamen certe comperi adesse excipulum carbonaceun, adeogrue ex hoc genere saltim excludendus est.

$\gamma$. $P$. atriseda, hypothallo denudato, areolis verrucæformibus sparsis in apothecia urceolata abeuntibus, disco rufo. - Exs. l. c. $B$.

Ad saxa in umbrosis \&c.

Cum P. cinerea $\varepsilon$. comparanda. Ex hac oritur forma hypothallina, supra memorata.

8. commolita, crusta granulata cinerea, apotheciorum minutorum excipulo discoque badiis.

Ad saxa friabilia: in Weisenstein montium Piniferorum. Laurer!

Crusta granulata, ut in $\beta$, at macrior; licet cinerea, nativo prioris seriei glauco colore destituitur. Ob colorem ei normalem in excipulo pro more remanentem et ex hac habemus veram Lecideam Achariano sensu.

Ír. PARMELIA sophodes, crusta tartarea verrucoso-granulata e lete viridi fuscescente, hypothallo nigro, apotheciis adnatis, disco opaco impolito fuscoatro, margine thallode ruguloso crenatove. Ach. meth. p. 155.

Lichen sophodes, pyrinus. Ach. Prodr. Engl. Bot. t. 1791. Lecan. soph., colobina. Ach. Lich. univ. p. 357, 358. Lee. sophodes et mortosa. Ach. syn. "p. 153,151 .

Exs. Lich. Suec. n. 252.

b. turfacea major, hypothallo obsoleto, crusta griseoopaca, margine apothec. albo-pruinoso. Lich. turfac. Wahlenb. Lapp. p. 408. Lecan. Ach. syn. p. 156. pr. p.

c. exigua, minor, hypothallo obsoleto, crusta fuscocinerascente, margine apoth. albicante evanidoque. Lich, exiguus. Ach. in Vetensk. Acad. Handl. 1795. t. 5. f. 6. Engl. Bot. 1849. Parmel. Meth. Lecan. periclea. $\beta$. Ach. syn. p. 151. - * crusta prorsus disparente l. soluta, cinereo-albicante: Lecan. pharcidia \& metabolica: Ach. syn. p. 147, 153. sec. 
spec. inventorum, Acharius et aliena huc retulit v.

c. P. subfuscae formas.

Exs. Lich. Suec. n. 100.

Optima (a.) ad cortices lævigatos, præcipue in arborum coronis, ad saxa humida \&c. b. ad terram turfosam supra muscos putridos. c. ad ligna \& cortices scruposos. Per omnem Europam.

Species minuta, at in statu vegeto optime distincta colore thalli humectati saturate \& læte viridi, sicci mox fusco; apotheciorum in illd fusco, in hoc nigrescente, opaco \& impolito. Thallus, licet tenuis, revera tartareæ indolis, facile in lepram solvitur. Hypothallus pro more in saxis \& corticibus lævibus tantum observatur distinctus; ad terram \& ligna cariosa cum matrice pro more confunditur marginemque thallodem apotheciorum in his albopruinosum evadere communis fere est lex. c. * esse formam in sole destructam dealbatam luculenter vidimus; at non omnia sub his nominibus vendita hujus loci sunt. - Infimæ proles $P$. obscurce (n. 77.) crusta haud evoluta aut leproso-soluta cum hac facile commutantur, at si ad utriusque status primarii diversam evolutionem attendes, distinctas esse nou dubium videbis. ค. P. melanochlora, apotheciis majoribus constanter atris. Sommerf. Lapp. p. $9 S$.

Ad saxa inferalpina Nordlandiz.

Hæc tantum forsan ab $\alpha$. differt, quantum $P$. frustulosa a $P$. subfusca, at donec melius innotuerit subjungendam censeo.

I 42. PARMELIA? Bokii, crusta tartarea areolato-verrucosa fuscescente, hypothallo nigro apotheciis verrucaformibus, disco protruso jextus intusque aterrimo, primo papillato, dein gyroso plicato, margine thallode integerrimo persistente. Syst. Orb. Veg. p. 285.

Lecanora Bokii (an Bookii, \& specimina Bockii inscripta erant.) Rodig. bert!

Ad rupes in Saxonia metallifera. Misit Schu-

"In magnis rebus rara fides" vulgo dicitur, certe in Lichenologia omne nimis insigne jure meritoque suspectum, adeoque ct hujus apothecia, quæ si normalia (talia 
in omnibus visis tamen inveni \& semper in natura occurrere mihi asseveratum est), peculiare efficerent genus. Grusta late expansa, verrucis inæqualibus fuscescentibus, humectatis colorem servantibus, passim in soredia grisea fatiscentibus, adspersa. Verrucæ majores, ut in P.badia $\gamma$, abeunt in apothecia, disco primitus ut ostiolo Porinæ nigro protruso, dein magis dilatato scutelliformi papillato, demumque plano rimoso \& gyroso-plicato, quasi discus Umbilicarice intra marginem genuinum persistentem thallodem. Hic discus non tantum ut $P$. atrce, qui fungosus, extus intusque ater est, sed etian subcarbonaceus, non tamen ut Lecidearum discretum stratum carbonaceum offert, sed omnino similaris integerque elabens foveolam seu excipulum denudatum, omnino Parmeliarum more, reliquens.

I 43. PARMELIA nephraea, cruste areolis granulato-verrucosis umbrino-fuscis, hypothallo nigro, apotheciis immixtis, disco fuligineo-rufescente intus albo, margine thallode elevato crenulato persistente. - Sommerf. Lapp. p. 103. Lecan. In rupibus \& saxis graniticis Sueciæ \& Norvegiæ rarius. In schisto aluminis prope Christiania. Blytt!

Habitus Lecidece atroalba fuscae hanc speciem primo obtutu distinguit. Ceterum valde variabilis est, ut specimina tam in Hallandia a me lecta, quam Nordlandica Sommerfeltii \& e variis Norvegiæ australioris locis a Blytt allata testantur. Hypothallus ater, evidens, nisi totus Lichen e ferro ochraceo-ferrugineus, qualia specimina quoque dedit Blytt. Areolæ verrucæformes, convexæ, rotundatæ, minutæ, nunc dispersæ, nunc confertæ, normaliter ut puto cervinæ, ne dicam cinereæ, sed ob hypothallum prædominantem sæpius umbrinæ \& nigrescentes. Apothecia ex areolis transformatis orta, in diversis individuis magnitudine varia; in omnibus margo per ætatem valde flexuosus \& crenatus evadit. Discus nudus in majoribus rufofuscus, humectatus magis rufescens, intus totus albus.

144. PARMELIA atrocinerea, crusta areolato-granulata subfusca, hypothallo nigro, apotheciis sessilibus, disco nigro-fusco turgescente margi- 
nem thallodem tenuem integerrimum excludente.

Lichen atrocinereus. Dicks. Crypt. Brit.p. 14. t. 9. $f_{.}$2. Engl. Bot. t. 2096. Lecan. atra $\beta, \delta, \varepsilon . A c h$. Lich. unis. p. 345. Lecan, anomala. d. cooperta. $l$. c. p. 382 . Lecan. atra. $\gamma$. \& Lecan. cooperta. Ach. syn. p. 146, 339 .

Ad saxa granitica in montosis Scandinavix, Scotiæ! Germanix! Galliæ!, at non ubique. Etiam in saxis cotaceis in regno. Würtembergico. Hochstetter!

Species insignis, Biatoris affinis. Crusta plerumque late expansa, hypothallo evidenti, areolis verrucosis nunc discretis \& dispersis, nunc conglomerato-coacervatis, cinereofuscis, humectatis non virescentibus, ut in P. sophode, sed fuscescenti-obscurioribus, immo fusco-nigricantibus. Apothecia semper minuta, disco nudo, sicco atro, sed humectato insigniter turgido fusco, immo rubelio, intus albo, marginem thallodem tenuem integerrimum sensim excludente.

* PARMELIA granatina, crusta tartarea rimoso-diffracla granulosa fusco-rufescente, apotheciis planis demum convexiusculis adnatis minutis coccineo-rubellis nitentibus, margine tenui integerrimo albido. Sommerf. Lapp. p. 90.

E saxis, tam Nordlandiz, quam vallis Valders Norvegiæ australioris dedit amic. Sommerfelt!

Nimis insignis \& a normali Lichenum habitu recedens; simillima infimis prolibus P. badice (nam in ejusmodi statu omnes species apothecia intensius colorata offerunt, ut facillime conspicitur in Parm. cerina in P. luteoalbam transeunte), sed ab illa differt margine thatlode albido, qui, thalli naturalis coloris vulgo certissimus testis, cum colore superficiali thalli ("videtur quasi alba fuisset \& rubro tincta esset") dubium me de ipsa naturali serie reddidit. Conjecturæ campum evitans meam suspicionem supprimam.

145. PARMELIA castaneola, crusta cartilaginea areolato-verrucosa fuscescenti-eæsia, hypothallo 
nigro, apotheciorum disco areolis urceolato-immerso mox hemisphærico atrosanguineo marginem thallodem obliterante. Dufour in litt.

Ad saxa \& rupes juxta litora maris mediterranei v. c. ad Monspelium. Dufour!

Species cum Parmel. erythrocarpia \& Biat. ferruginea facilis commutatu, at omnino diversa. Areolæ verrucosæ, primitus discretæ, dein hypothallum plus minus obtegentes, fuscescentes aut cinereo-cæsiæ, at hic color omnino typicus est \& genuinus in hac specie. Excipulum adest mere thallodes, nullo modo proprium, at mox exclusum a lamina lentiformi prorsus immarginata turgida atro-sanguinea, etiam in statu juniori, \& hunc colorem sicca servante, intus tota pallidiori albida usque ad crustam. Discus colore \& substantia cum P. ventosæ comparari potest.

*** Ochroleuca.

I 46. PARMELIA ventosa, crusta tartarea areolato-verrucosa flavo-pallescente, hypothallo albo, apotheciis adpressis difformibus, disco nudo brunneo-rubro, margine thallode integerrimo pallente. Ach. meth. p. 166.

Dill. musc. t. 18. f. 14. Lich. ventosus. Linn. - F'l. Dan. $t$. 472. Westring Färglafv. t. 6. Verrucar. Hoffm. Pl. Lich. t. 2. f. 1. Patellar. Decand. Lecanora. Ach. Lich. lepadolemma. Ehrh. - Engl.Bot. t. 906. Lich. scopulorum. Fl. Dan. t. 712. $f .2$. Lich. cruentus. Weber. Verrucar. Hoffm. Lichen flavescens. Wulf. in Jacq. Coll. II. t. 9. f. 1.

Exs. Lich. Suec.n.161. Ehrh. Phyt.30. Moug.n. 256. In saxis apricis, ventis expositis, montium \& alpium Europie totius ad Carpathos \& Pyrenæos; in Scandinavia quoque ericetorum campestrium.

Thallus crassus, areolis demum rugoso-plicatis, subinde decolor flavocinerascens \& expallens. Apothecia intus alba, mere a crusta formata, sed margo, discum planum æquans, aut albescens aut disco subconcolor, omnino ut in Parmel. erythrocarpia. Variat insuper discus radiato-stellatus, omnes Leuco grammatis characteres com- 
prehendens. Parum variat, ob locum definitum, vix quidem pulveracea.

147. PARMELIA hoematomma, crusla tartareogranulosa (sæpius leprosa) ochroleuca, hypothallo fibrilloso albo, apotheciis innatis, disco nudo e coccineo sanguineo,' margine crenato evanido. Ach. meth. suppl. p. 35.

a. coccinea. Lich. hæmatomma. E/hr/. - Engl. Bot. t. 486. Lecid. demum Lecanora. Ach. Patellaria \& Verruc. Hoffm. Pl. Lich. t. 11. f. 1. Lich . coccineus. Pers. Patell. s. Verruc. frondosa. Fioffm. Pl. Lich. t. 49. f. 1. Lecan. Turneri. (Ach. pr.p.) Fl. Dan. t. 1718. f. 1 .

Exs. Lich. Suec. n. 201. Flörk. n. 46. Moug.n. 638. b. porphyria, crusta magis dealbata, apotheciis obscurioribus. Ach. l. c. - Lich. porphyrius Pers. Patell. s. Verrucar. Hoffm. - Pl. Lich. t. 51. f. 1. Lich. Vahlii. Fl. Dan. t. 1185. $f .1$. Lecid. saxetana \& callosyne. Ach. syn. p. 44.

c. leiphcemia, crusta granulosa pallente, hypothallo byssino-fimbriato. Lecid. dein Lecan. Stonei. Ach. Lepraria leiphæmia Ach. optima, sed ut omnia ejusmodi nomina collectiva.

Exs. Lich. Suec. n. 200. Desmaz. n. 295.

Ad rupes plerumque absconditas, ad cortices Quercus, Fagi \&c. Europæ præcipue borealis. In Helvetia longe rarissima. Schaerer.

Crusta normalis utique granuloso-tartarea, at raro obvia ob locum in rupium cryptis, ubi plurimi Lichenes pulveracei evadunt. Hypothallus fibrillosus in hac sæpe valde insignis est. Apothecia per ætatem vel saturatiora vel decolorata sordide luteola, margine pulveraceo cincta, ubi crusta soluta. Synonymis a me olim huc relatis optime addidit Cel. Meyer Lecid.callosynen, quam etiam huc pertinere monuit amiciss. Stenhammar. At Lecan. alpina Ach. ob hypothallum nigrum, \&c. tam ex ipsius, quam Schleicheri speciminibus ad P.aurantiacam certo pertinet.

I48. PARMEL'A elatina, crusta cartilaginea demum granulata leprosaque pallide ochroleuca, hypothallo verniceo albo, apotheciis sessilibus, 
disco ruguloso rufo-brunneo, margine thallode demum colorato.

Lecan. elatina. Ach. Lich. univ.p. 38\%. Lec. lutescens. Syn. Lich. p. 168. exclus. syn. Lec. Laureriana. Flörke in litt. sec. Laurer.

Ad cortices Pini Abietis in montosis Suecire, Norvegiæ Blytt! Germaniæ Laurer! Silesiæ Herb. Ach.

Inter præcedentes \& sequentes intermedia, sed optime distincta. Thallus cum hypothallo plerumque confusus, late \& indeterminate effusus, cartilagineus, e quo erumpunt soredia et granula totam. crustam leprosam reddentia. Apothecia e thallo oriunda, sessilia, colore \& substantia $P$. ventosa, ejusque more marginis thallodis integerrimi color mutatur, disco concolor aut dilutior. Discus ob crassitiem insignem mox explanatur, dein convexus, marginem obliterans, ruguloso-impolitus, at nullo modo more sequentis tribus cæsio-pruinosus. Ab omni statu $P$. varice facilis distinctu, $P$. rubra quodammodo analoga. - Lepr. cinereo-sulphuream Syn. p. 330 Acharius crustam sterilem leprosam dixit; ceterum ut $L$. leiphoemia l. c, frimitus prioris status, ad totam seriem ochroleucam forsan extenditur.

149. PARMELIA conferta, crusta cartilaginea rimoso-areolata flavo-pallescente, cum hypothallo verniceo confuso, apotheciis subinnatis, disco impolito lutoso-fuscescente, marginem thallodem tenuem crenulatum mox occultante. Duby - ex Prev. in litt.

Ad terram lutoso-argillaceam in Italia, inque muris Galliæ.

Crusta late \& indeterminate effusa, primitus contigua cartilaginea, mox areolato-diffracta, glabra pallescens. Sorediiferam aut deliquescentem non vidi. Apothecia admodum conferta innata, dein more analogæ $P$. carneolutece protrusa, margine thallode tenui crenulato, qui vero mox obtegitur a disco inæquabili subpruinoso turgescente hemisphærico pallide lutoso fuscescente semper opaco, intus hyalino pallido. Ad P. variam $\beta$. accedit, at conjungere non ausus sum. - Integra morphoseos series vix cogaita est; forsan huic proximus aut idem $\mathrm{Li}$ - 
chen argillaceus Bellardi, Lecid. Ach.syn. - Cfr. Obs. ad $P$. cerinam.

150. PARMELIA varia, crusta cartilaginea areolato-verrucosa flavovirescente, deliquescente ochroleuca, hypothallo glabro maculari, apotheciis sessilibus, disco polito lutescenti-carneo decoloreve margineque erecto integro tenuibus. Sched. Crit. 9. p. 28.

a. apotheciis scutellatis plano-concavis, margine thallo concolori persistente (ad ligna spurie crenulato, I. thallo deliquescente pulverulento). Lichen varius E/hrh. - Engl. Bot. t. 1666. Patell. s. Verrucar. Hoffm. - Plant. Lich. t. 23. f. 4. (sine crusta): Parmelia dein Lecan. Achar.- Fl. Dan. t.1347. f: 1. - disco carneo-rubro: Lichen sarcopis. W ahlenb. Lecan. Ach. syn. - disco olivaceo: Patell. olivacca. Pers. Lecan. Ach. svn. 336 ex ipso. - crusta leproso-dcliquescente: Verruc. lutescens. Hoffm.Germ.p. 195. quoad spec. scutellifera. Lich. orostheus Engl. Bot. t. 1549. Patellaria lutescens. Dec. fr. 2. p. 354. Parmelia. Flörke in Rerl. Mag, non Lecan. Ach. Lecan. expallens $\alpha . \beta$., Lecan. strobilina $\omega_{0} \beta$., L. symmicta $\beta$. Ach. syn. p. 171, 340. - crusta innata sorediifera, apotheciis inter a \& $\mathbf{b}$ variis: Parmelìa sulphureo-nigricans Flörk. l. c. p. 19\%. Lecan. apochroea seu symmicta $\gamma$. Ach. syn. p.162,340. Parm. cerina. $\delta$. ravida. Ach. meth. (Adest porro sub Lecan. effusa Syn. \&c.)

Exs. Lich. Suec. n. 46. Ehrh. Crypt. n. 68. Moug. et Nestl. n. 840. leprosa: Lich. Suec. n. 104.

b. symmicta, apotheciorum disco subhemisphærico marginem pallidiorem integerrimum subobtegente (lutealo, carneo, fusco, sæpe in eadem crusta:) Lecan. anomala. $\eta$. ochrostoma \& variæ varr. Ach. Lich. univ. Lecid. \& Lecan. symmicla $\%$. Ach. syn. p. 36, 340. Lecan. alabastrina. $\beta$. Syn. p. 46. excl. syn. - Verrucaria maculiformis. Hoff $m$.

Exs. Lich. Suec. n. 45. Sommerf. Norv. n. 65.

c. spepincola, apotheciis semiimmersis convexis immarginatis (helvolis, olivaceis, nigrisque) Lecid. sæpincola \& crusta soluta: L. aitema $A c h, s y n . p .35,24$. Ad saxa, cortices, muscos, \& præcipue ligna 
emortua. b. magis in pineto-montanis. c. in campestribus \& maritimis.

Paucarum specierum formæ luculentius confluunt quam præsentis; intimus omnium nexus jam patet e diver'sis modis, quibus Acharius nunc a se invicem distinxit, nunc conjunxit, ut mirandum ante me neminem hanc speciem in genuino ambitu proposuisse. Sed exstant quæ'dam proles infimæ acrustacex carneo $-\&$ rubrofuscæ (quas a formis Lecid. pellucidoe Fl. discernere non valeo), quæ non nisi in loco natali a similibus Parm. subfuscae, Biatorce vernalis \&c. dignoscuntur. Est enim presens species summe analoga cum $P$. subfusca ( $\& P$. sophode inter Viridi-fuscas), at optime distincta, præcipue colore omnium partium alio; thalli vegeti flavovirescens (locis soli magis expositis in pallide sulphureum abiens, humidis vero, ut hujus seriei mos est, dealbatus, at non glaucus); lepræ solutæ ochroleucus, quæ ad ligna determinate erumpens : Lepra expallens. Pers. (Lich. Suec. n. 62), ad cortices superficialis, effusa: Lepraria sulphutea Ach. syn. p. 330. Disci color normaliter sordide flavidus, locis vero magis. a rore \& pluviis irriguis in carneum abil, \& corruptus, $\boldsymbol{P}$. saxicoloe more, olivaceo-nigrescit, analogia $P$. subfusca pulicaris. Color pure rufofuscus, P. subfuscæ normalis, ab hac æque peregrinus, ac lutescens a P. subfusca. Apotheciorum margo normaliter integerrimus est, per ætatem tantum flexuosus, sed ut in $P$. sophode aliisque hypothallo cum lignis cariosis confuso marginem spurie crenulatum assumit. Lich. Suec. 46. B. male ad $P$. sophodem relata fuit. - Sequentes status a loco orti. evidentius discrepantes ut varietates notandi:

ß. P. chondrotypa, crusta tenui lævigata areolato-diffracta, disco primitus albido-pruinoso, mox nudo turgescente luteo-fuscescente.Ach.syn.p. 67 . Ad cortices Betulæ.

Rara forma, cum $\boldsymbol{P}$. fusca b. analoga; evidenter tamen in vulgarem abit. Margo ut in corticola P. varia integerrimus.

$\gamma$. P. leptacina, crusta granuloso-conglomerata stramineo-pallescente, apotheciorum disco (concolori) subolivaceo obsolete irrorato-pruinoso. Lecan. leptacina. Sommerf. Lapp. p. 96. 
In terra, muscis summarum alpium. Norvegix copiose Sommerfelt! Blytt!

Species omnino distincta apparet, sed transitum vidi evidentem in saxis irriguis, ubi $\delta$. in hypothallo Lecid. atrovirentis, in floccos soluto byssaceos, nascitur. Nec desunt analogi status P. subfuscoe, sophodis. Discus, qui in statu normali pallidus, crustæ fere concolor, sæpissime in olivaceum mutatur atque Lecan. bryonthce analogus sit.

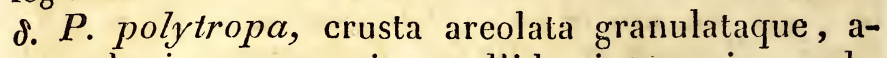
potheciorum margine pallido integerrimo subflexuoso. - Fl. Dan. t. I $472 . f .2$.

Lich. polytropus. E/hrh. - Engl. Bot. t. 1264. Patellaria s. Verrucaria. Hoffm. - Pl. Lich. t. 58. f. 2 . Lecidea Ach. meth. L. Ehrh. $\beta$. Ach. syn. p. 47. Lich. atrovirens Wulf: in Jacq. Coll. II. t. 14.f.2. Lecan. varia. «. Ach. Lich. Liniv. p. 380. - apotheciis morbose olivaceis: Lich. intricatus. Schrad. Parmel. dein Lecan. Ach. - Syn. p. 154. Lecan. mutabilis. Sommerf. Lapp. p.82 ut ovum ovo specim. Schraderi simillima - crusta deliquescente, decolorataque: Lecidea leucinata. Ach. Lich. univ. p. 190. L. ālabastrina $\delta$. Syn. Lich. p. 47 - crusta dealbata: Parmelia anomala. Ach. meth. Suppl. p. 39. Lecan. livida, L. varia ', L. anomala 2. Lich. univ. omnes sub L. livida Syn. p. 170. Lec. leucococca. Sommerf. Lapp. p. 83.

Exs. Lich. Suec. n. 372. Mo g. et Nestl. n. 748. disco olivaceo. Lich. Suec. n. 101.

Ad saxa granitica ubique copiose.

Var. $\alpha$. rarius quoque in saxo occurrit; reliquas omues formas graniticolas sub hac varietate comprehendimus, cum, licet inter se sæpe dissimiles, evidenter a se invicem oriantur, margineque pallidiori \& flexuoso inter se conveniant. Jam Holfmann (Pl. Lich. III. p. 11) de intimo nexu Lich. intricati, polytropi \& varii loquitur; solus acutissimus Wahlenberg hanc varietatem ad typum summ retulit (Lich. varius $\beta$. Fl. Lapp. p. 403). Crusta variat areolata, granulati $\&$ omnino deficiens, vulgo flavovirescens, sed, ut seriei solemne est, etiam locis humidis dealbata. Ab amiciss. Blytt accepi specimina crusta leprosa alba, quæ nisi apotheciis Lecid. Ehrhartianæ ipsissimæ onusta fuisseut, quisque ad $P$. haematom- 
mam retulisset. Disci color pallide lutescens, carneus, raro fuscescens, at frequenter olivaceus. Talia individua a $P$. saxicola d, caute separanda, præcipue disco semper nudo, qui in $P$. saxicola $d$. pruinosus.

$\varepsilon$. coniotropa, crusta tenuissima leprosa albicante, apotheciis convexis flavescente-olivaceis.

In saxis calcareis ölandiæe.

Nisi apothecia prioris habitum adhuc servarent, originem hujus eque ac aliarum carbonatis calcici filiarum non facile divinares. (Exacte in hanc var. quadrat $\mathrm{Li}_{i-}$ chen viridiflavescens Wulf. in Jacq. Coll. 3. p. 101. t. 2. f. 1. Lecid. Ach. Lich. univ, p. 211. Parmel.ochrochlora Ach. meth. p. 180, quæ certe typica species non est, at specimine haud viso non citavi).

ל. parasitica, apotheciis in crusta Cliostomi corrugati parasitantibus, pallide flavicantibus, flexuosis.

Lich. Ehrhartianus. Ach. Prodr. t. 2.f.1. Engl. Bot. t. 1136. Lecid. Ach. syn. p. 47. $\alpha$.

Exs. Lich. Suec. n. 253.

Ad cortices quercinos, parietes ligneos.

A priori $\delta$. removeri non posse optime monet Sommerfelt, utriusque enim apothecia simillima sunt. At Lich. Ehrhartianum tantum sistere $P$. variae apothecia in Cliostomi crusta parasitica, ut non sine teneritatis metu l. c. enunciavi, paulo post a IWallrothio, meæ observationis nescio, \& Flotowio ita confirmatum est, ut res extra omnem dissertationis aleam posita sit. Hoc ut aliis locis mihi objici video, me similes aliorum Lichenum status ut varietates non distinguere, \& in genere varietates haud ubique ad eandem legem distribuere; at certe tamen temere non egi; e multa enim Lichenum in natura consuetudine bene novi, quæ sint formæ singulæ speciei maxime frequentes tironibusque præcipue prominentes \& has, præcipue longa simul synonymorum serie celebratas, proponere volui. Omnes enim enumerare tædet! \& præcipue e theoretica intuitione indolis speciei deficientes formas supplere.

15i. PARMELIA ocrinceta, crusta cartilagineotartarea areolata straminea, areolis turgidis gyroso-plicatis hypothallum nigrum obtegentibus, 
apotheciis liberis, disco subcarneo, margine thallode tenui incurvo flexuoso.

Lecan. pallide-flava. Schleich. Cat. - non Fće. (Lecan. ocrinæta $A c h$. syn. p. 162, certissime ad specimen atypicum \& decoloratum descripta, hujus aut præcedentis statum exhibet.)

Exs. Schleich. Pl. venal.

Ad saxa alpina; optima in Helvetia Schleicher!; minus evoluta \& evidens in Nordlandia Sommerfelt!

Ut $P$. frustulosa a $P$. subfusca, hæc a $P$. varia distat, at in utriusque differentiarum ratione longe discrepant, \& P.ocrinceta potius ad præcedentem ut $P$. chrysoleuca ad $P$. saxicolam accedit. Crusta adnata, in perfectis speciminibus longe crassior \& insignior quam in $P$. ventosa \& omni affini specie, composita ex areolis confertis maxime turgidis plicatis gyroso-conglomeratis, in superficie nudis, pulchre straminea, sed pro more expallens. Apothecia superficialia; disco tenui amplo læte carneo aut ochraceo-carneo, opaco, concavo, primitus obsolete pruinoso (variat vero in eodem individuo frequenter olivaceo-nigrescens); excipulo thallode subtus libero, margine prominente, incurvo, passim crenato, adulto maxime flexuoso \& lobato. De forma ininori cfr. Sommerf. Lapp. p. 83. Hanc maxime insignem stirpem, etiam geographico respectu diversam, non potui non lubentius separare, quam multas prioris formas quisquiliares.

152. PARMELIA atrosulphurea, crusta tartarea glebuloso-coacervata pallide sulphurea, apotheciis adpressis, disco polito e viridi atro convexo, marginem thallodem tenuem integerrimum obtegente. Wahl. Lapp. p. 41 . Lichen.

Lecan. atrosulphurea. Ach. syn. p. 149. Sommerf. Lapp.p. 99.

Ad scopulos \& rupes maris septentrionalis a Maasöa Finmarkix Wahlenberg!, per Nordlandiam Sommerfelt! \& Norvegiam ad Hallandiam mediam.

Ob colorem crustæ nativum e virescenti pallide-sulphureum, deliquescentis ochroleucum, als analogis speciebus primæ seriei, speciatim $P$. atra, in quibus color 
subinde ochraceo-lutescens evidenter adventitius est, diversam habeo \& ad Ochroleucam seriem refero. Confirmatur hic locus a disci colore virente, a prima serie alieno, tam interno, quam in vegeto (humido) Lichene externo; h. e. color disci, qui in præcedentibus abnormis est, in statu morboso tantum obvius, in hac in statu incorrupto normalis est. Qua ratione differt a prioribus, ut $P$. oreina a suis affinibus. Thallus prioris sat similis, at minus evolutus, juxta aquæ salinæ terminum tersus \& lævigatus, quales status Lecan. thallinam Ach. prorsus referunt, simulque ad Parm. subfuscam v. laineam ita accedunt, ut, monente amiciss. Sommerfelt, equidem olim commiscuerim.

153. PARMELIA Chaubardii, crusta ........ deliquescente leprosa pallida, apotheciis areolis flavovirescentibus immersis, disco sordide luteo, margine thallode persistente radiato-crenulato tunido.

Ad saxa calcarea Europx australis. In Gallia. A. Le Prevost.

Forma typica hujus speciei, cujus status solito more in calce personatus mihi tantum innotuit, sedulo inquirenda; videtur enim species admodum insignis, Parm. cinerece analoga, nec cum ulla mihi nota conjungenda, nisi "Thelotrem. exanthemat." Ach. adhuc inferior sit status. Crusta, ut in calcis potestate solet, tenuissima, subleprosa, pallescens; veram vero observo in verrucis granulosis in excipulum thallodes (prorsus ut in P. badia $\gamma$. ) abeuntibus, pallide flavo-virescentibus. Apothecia tumida, disco crasso, polito, concaviusculo, sordide luteo, immerso verrucis, e quibus formatur margo radiatim dehiscens, crenulatus (forsan abnormis, ut Lecan. Hageni suadet), dein magis orbicularis \& integer, semper obtusus $\&$ persistens.

**** Citrince. Disco flavo-Iuteo aut ferrugineo-rubro. Cfr. Placodia analogae seriei, quorum status mutilati hic facile quæruntur.

154. PARMELIA epanora, crusta glebuloso-tartarea verrucosa virescenti-citrina, hypothallo fibrilloso albo, apotheciis sessilibus, disco sor- 


\section{dide luteo, margine tumido subincurvo persi-} stente. Ach. meth. p. I79.

Lecanora. Ach. Lich. univ. p. 377. Syn. p. 161.

Ad rupes schistosas, micaceas in Scandinavia, rarior.

Suæ sectionis maxime spectabilis. Hypothallus in rimis, v. c. in schisto, more omnino Biatorae byssoidis radicatur. Crustæ conformatione ad sequentem accedit(ejusque typicam indolem confirmat), sed granula multiplo majora, hinc inde enitentia soredia lete citrina, unde crusta quoque pulverulenta evadit. Ex hoc lepræ colore seriei citrinæ certa species. Apothecia ex areolis granulosis enata, sessilia, per ætatem adpressa, ampla, (1-2 lin. lata) plana, margine tumido, elevato, subincurvo, primo integro, per ætatem crenulato flexuosove. Discus pallide flavus (carneum non vidi) mox sordidus, strato gonimo viridi impositus. - E principiis Meyeri forsan ad $\boldsymbol{P}$. chlorophanam ob colorem similem referres, at extra hujus regionem tantum occurrit, multisque acutis notis differt. - E Christiania Norvegix, ubi copiosa, misit eximius Lichenum observator Blytt formam mechanice ex hydrate ferroso pro parte tinctam, qualem etiam $P$. chlorop/hanam e Pyrenæis vidi, at chemice oxydatæ nec hæ, nec aliæ præter species hypothallo nigro occurrunt.

155. PARMELIA vitellina, crusta tartarea granuloso-coacervata flavovitellina, hypothallo maculari albo, apotheciis sessilibus, disco luteo fuscescente, margine simplici tenui erecto integerrimo demum concolori. Ach. meth. p. $17^{6}$. Mich.t.53.f.3. Lichen candelarius. Linn.! nec Auct. Lichen vitellinus. Ehrh. - Engl. Bot. t. 1792. Fl. Dan. t. 1347. f. 2. Patellaria s. Verrucaria. Hoffm. - Pl. Lich. t. 26. f. 1; 27. f. 2. Lecan. Ach.syn. p. 174. $a . \rho$. $\gamma$. (at vix Patell. aurella Hoffm.) ad terram decolor: Lecid. epixantha. Ach.syn.p. 48. Exs. Lich. Suer. n. 160. Ehrh. Crypt. n.155. Sommerf. n. 66. Moug. et Nestl. n. 741.

b. holocarpa, apotheciis ochraceoluteis, opacis, ex hypothallo oriundis, margine proprio. Lich. holocarpus. Ehrh. Verruc. obliterat, var. Hoffm. Germ. Lecid. Luteoalba B. Ach. syn. p. 49. Lecid. aurantiac. $\beta$. Flörk. 
Exs. Ehrh. Crypt. n. 284. Fl. Deutsch. n. 186. Ad rupes, saxa ventosa, ubi optima, ligna $\&$ cortices Europæ totius, etiam ad terram, præcipue in alpibus.

Formam adeo insignem, evidentem \& bene cognitam ad varietates rejicere nolui, quamquam hujus \& reliquarum špecierum omnium e serie citrina deliquescentes \& imperfecti status non nisi attentius lustratæ discernuntur. Qualis hæc crusta crassissima, contigua, tartarea, fere $P$. ventos $\propto$ !, ad rupes Sueciæ lacustres nascitur, eam cum $P$. parietina jungere impossibile videtur. Mihi hoc modo hanc, P. murorum \& subsequentes in statu perfectissimo, in quo luculentissime differunt, primo sedulo observanti indeque ad status infimos persequenti successisse puto diversa elementa secernere, e quibus adeo distinctæ species conjunctæ fuerunt. Sic verum est, omnes a Meyero conjunctas cum Lecidea luteoalba Ach. syn. confluere, attamen non inter se confluunt; nam Lecid. luteoalba composita est ex analogis statibus harum omnium specierum, ab attento observatore facile discernendis. - Occurrit quoque utique $P$. parietina subcrustosa, tam leproso-deliquescens, quam foliis haud explicatis; alia vero est thalli in his structura; numquam ex hypothallo oritur. Si vero locis lævigatis, etiam saxis, $P$. vitellina \& aurantiaca observantur, videbimus earum primordia ex hypothallo in illa albo, in hac nigro erumpere. In his omnibus quoque diversissima apothecia. Cfr. $P$. aurantiacam. - Ceterum $P$. vitellinae crusta meo sensu non atypica est; sed tartareogranulosa, qualem genuinam in multis Lichenibus agnoscimus, passim squamuloso-lobata, sed ejus foliola semper crassa \& crustacea, nec membranacea, ut squamulæ vel tenuissimæ $P$. parietince. - Ex omnibus vero speciebus, me judice diversis, quas sub $P$. parietina cumulavit Cel. Meyer, hæc eidem proxime accedit, \& qualis ad parietes ligneos cum $\boldsymbol{P}$. parietinae infimis prolibus intertexta nascitur, easdem non esse separandas, antequam Cel. Meyeri librum videram, sæpe in mentem meam venit, at individua utriusque perfecta per totam morphosin \& metamorphosin sequens, transitum hunc apparentem tantum inveni. - Apothecia hujus speciei minuta, conferta, regularia, disco luteo, mox fuscescente, sæpius leviter pruinoso; excipulum etiam in a. nunc prorsus Lecidex Ach.!, nunc Lecanoræ. Lecid. epixantha est 
hujus status cum Patellaria incrustante Dec. a P. murorum \& Lich. chloroleuco Engl. Bot. a P. cerina ortis analogus. In alpibus Norvegicis ad terram crustæ granula insigniora \& lobata, minime vero foliacea! In b. omnia granula in apothecia plerumque abeunt, qux, formarum hypothallinarum more, margine thallode destituta sunt. Hæc ab omni Lecid. luteoalba a P. parieti$n a$, quam pingit Meyer 1 . c., a $P$. murorum (Lecid. luteoalba $\delta$. Ach.), P. aurantiaca (Lecid. aurantiaca Ach.), $\boldsymbol{P}$. cerina (Lecid. luteoalba $\gamma$. Ach.), $P$. ferruginea \&c. orta, haud difficile est distinguere. - Præsens species e descriptione, loco primario, synonymis \& præcipue usu (hæc enim materia tinctoria pollet, qua caret $P$. parietina) evidenter est Lich: candelarius Linn., quem in statibus P.parietince, murorum \& chrysophthalmoe, (ad hanc enim pertinent specim. Mühlenber giana ad Lobariam candelarem ab Hoffmanno Fl. Germ. $p .159$ relata) omnes quæsivere Auctores. Conferenti quoque hujus \& Byssi candelaris Linn. (Dill. t. 1. $f .4$. Leprariæ flavæ Ach. - Turn. et Borr. Lich. Brit. p. 9. Lich. flavi Engl. Bot. t. 1350. Fl. Dan. t. 899. f. 2,Exs. Suec. n. 61. a qua non nisi hypothallo persistente differt Lepra citrina Schaer. exs. n. 3.) communes fontes Linnæanos patet, Linnæum has stirpes re ipsa diversas non censuisse, licet utrumque statum seorsim notare utile duxerit. Si ad definitam speciem referas, quod vero inter Leprarias sine exceptione fieri nequit, potissimum ad $P$. vitellinam trahas; color lætius flavus cum lepra prioris in analogo statu citrina bene conspirat, sed etiam in omnino viridem locis irriguis abire vidi.

Exstat forsan in Europa australi P. vitellina analoga stirps, thallo artilagineo, apoth. rufo-fulvis (P a t. $r$ ufa Pers., in prosente sub P. muror um allata), sed haud rite jam nota. --. Status mutilatos et deliquescentes P. parietina et mur or um videas sub n. 6\%, 114.

I56. PARMELIA ochracea, crusta tartarea contigua lævigata ochracea cum hypothallo brevissime fibrilloso-radiante confusa, apotheciis sessilibus aureis, disco plano, margine integerrimo subcolorato. Schaer. Naturw. Anzeig. 1818. p. I 1 . sub Lecid.

Ad saxa-\& rupes alpinas calcareas Europæ ausiralis, in Gallia Dufour! Helvetia Schaerer! Crusta \& color in hac specie normales, ut non pos- 
sim non cum acutiss. Schaerer ab omni $P$. murorum distinguere, at considerata apoth. morphosi in omnibus corcoloribus erit e genere Parmeliæ. Hypothallus cum crusta coalitus, in optimis vero speciminibus in ambitu sub lente fibrilloso-radians pallidior conspicuus. Crusta tenuis, determinata, sed irregulariter effusa, lævigata, (normaliter forsan aurea, sed expallendo) ochracea, intus alba. Disci structura Parmeliarum affinium, at margo disco plerumque concolor. - Magis in carbonatis calcici potestate crusta tenuior, expallens, apothecia magis convexa, cèntro tantum depressa, qualia specimina Acharius Dufoureo pro Lecid. rupestri $\beta$. prrithroma determinavit (spec. Suecana hujus varietatis, licet simillima, alius originis sunt), sed a communi Lecid. rupestri diversissima monuit acutiss. Dufour, qui $\boldsymbol{P}$. ochracea varietatem insignem sub nomine lecid. ochroleproe misit. Cfr. $P$. aurantiacam $\gamma$.

I57. PARMELIA cinnabarrina, crusta subcartilaginea rimoso-areolata aurantio-miniata, obtegente hypothallum nigrum, apotheciis immersis, disco immarginato aurantio-rubro, margine thallode integro persistente.

Lecan. Ach. Lich. univ. p. 402.

Specimen ad saxa granitica juxta mare mediterraneurn lectun communicavit Aspegren.

Crusta cartilaginea, glabra, subnitida, areolis discretis, sed stipatis, in ambitu subradiantibus, hypothallum ita obtegentibus, ut tantum e lineis nigris thallum decussantibus aut circumscribentibus appareat. Color in Europæa vix cinnabarinus, ceterum cum Americana prorsus convenit. Lamina disci in ipsis areolis immersa, ut in Urceolariis Acharii, sed prorsus immarginata. Analogia adest évidens cum $P$. castaneola. Duf.; colore vero magis ad $P$. murorum $\beta$. accedit.

I58. PARMELIA aurantiaca $\alpha$, crusta cartilaginea inæquabili subgranulata lutescente, innata hypothallo nigro, apotheciis sessilibus, disco marginato aurantiaco, margine thallode tenui crenulato evanescente. Fingerh. Effl. p. 78 . Lichen aurantiacus. Lightf. \& Auct. optimus, quare hoc nomen aptissimum servet, sub quo semper a- 
pud nos notissima fuit; Ehrh. \&c. ad status vagos mutilos affinium pertinet. Ach. Prodr.p. 44. Wahl. Suec. - Biatora. Fries Vet. Ac. Handl. 1822. p. 275. Lecidea. Ach. syn. p. 50. (crusta dealbata) Lich. fulvus. Schreb. L. salicinus. Schrad, - Engl. Bot. t. 1305. Patellar. s, Verruc. Hoffm. - Plant. Lich: t. 61. f. 3-9. Parmel. dein Lecan. Ach. - crusta papillosa, apothec. imperfectis: Lich. flavo-rubescens. With. ex Ach. Parmel. microthelia. Ach. meth.

Exs, Lich. Suec. n. 41.

b. crusta viridi-lutea. Wulf. in Jacq. Coll. II.t.14. f. 5, a. a. (ab Auctore nullibi allata) Patell. dein Verruc. flavovirescens. Hoffm. - Pl. Lich. t. 20. $f$. 1. Parmel. s. Lecan. erythrella. Achar. Lecan. inalpina. Ach. syn. p. 178 (crusta dealbata) - Transitus ad $\gamma$, crusta tenui, disco rufescente: Lich. flavoviresc. Wulf. l. c. p. 230. t. 13. f. 4. b. Verrucar. viridi-rufa. Hoffm. Germ.

Exs. Lich. Suec. n. 156.

Per omnem Europam a. ad cortices \& ligna, præcipue Fraxini, Populi. b. ad saxa, sæpius formationis junioris.

Post iterum iterumque repetitum examen maxime scrupulosum in hac specie limitanda non possum non a sententia Cel. Meyeri, eandem prolem Parm. parietinoe statuentis, prorsus discedere, at, ut videtur contra Eundem, Lecan. inalpinam, Lecid. rupestrem Ach. \&c. ut anomalos status l. loci filias addere: - Ab omnibus $P$. parietince prolibus diminutis in statu typico evidenter discrepat hypothallo insigni nigro, e quo thallus, etiam typice crustaceus, primitus innatus, granulosus erumpit, apotheciis margine duplici, utroque a P. parietinæ simplici diverso, disco intus albido nec strato gonimo immediate imposito. Nec cum alia præcedentium confundi potest, licet specimina saxicola in lepram $P$. murorum $f$. simillimam deliquescentia viderimus, ut cum hac potius ex mente Flotowii conjungenda. At quorsam non ducit hoc transituum indirectorum studium? - Quod ad Cel. Meyeri iconem attiuet, observem me in hac nec certo detegere Parm. aurantiacam nec cerinam, sed status tantum mutilos, ut videtur, ad $P$. parietinam ipsam referendas. In $P$. salicina 1 . c. nec hypothalli, nec crusta vestigium perspicitur; margo albidus, simplex ex icoue eandein ab hac varietate primaria prorsus excludere 
videtur. Locis nimis irriguis hujus thallus albicat (unde Lecid. aurantiaca Ach. in cortice, L. inalpina in saxis), Parm. parietina virescit. - Specimina corticola \& saxicola nil differre jam optime monuerunt Decandolle \& Sommerfelt; crusta in utraque passim leprosa, in saxo citrina, in cortice ochracea (qux saltim dignosci nequit a Lepr. ochracea Turn. \& Borr. Lich. Brit. ined. p. s.) A potheciorum discus variat ruber \& fuscescens. ק. P. flavofusca, crusta parca granulata flava, apotheciis convexis fuscescentibus.

Ad saxa arenaria.

Est forma in cote pro more mutila, hypothallo fere obliterato. Quoad descriptiouem \& specim. visum non differt: Lichen flavofuscus Schrad. spic. p. 86. Verrucar. Hoffn. Germ. Lecid. Ach. Syn, p. 37.

$\gamma$. $P$. calva, hypothallo obliterato, crusta tenuissima albicante, apotheciis convexis a thallo haud marginatis luteis aut rufis.

Lich. calvus Dicks. Crypt. Brit. 2. t. 6. f. 4 ex spec. ipsius, adeoque Engl. Bot. t. 948. Lich. rupestris. Vulgo. Patell. Dec. fr. 2. p. 360. (qui in evidenti transitu ad $\alpha$. describit) Lecid. Ach. syn. p. 39 . Cfr. infra!

Exs. Lich. Suec. n. 400. (Fl. Deutsch.n.5. non vidi.) Ad saxa calcarea; in durioribus apotheciis superficialibus, in mollioribus immersis.

Lichen. 1. Lecideam rupestrem auctorum haud genuinam \& typicam efficere speciem primus adspectus docet, sed plurimarum more, præcipue L.albocoerulescentis p. immersce, in calce personatam. Sed ejusmodi specierum more, v. c. simillimæ Lecid. luteoalba, \& Verrucariae obliteratae Hoffm., non ex unico deducuntur fonte onnes formæ L. rupestri adscriptx. Jam apud primum determinatorem Scopoli ex heterogeneis analogis conflatus, magisque synonymis \& formis a sequentibus additis. Tales inter alias habemus ortas a Parmelia varia, (cum qua ex omni parte saltim convenit Lich. viridiflavescens Wulf.,) a $P$. ochracea, (quales Acharius ipse pro Lecid. rupestris var. agnovit,) a $\boldsymbol{P}$. ferruginea, (a qua saltim ex icone non discernere valeo, in loco vero determinandam, Verrucariam rufescentem $\mathrm{Hoffm}$. Pl. Lich. t. 1\% f. 1.) - At multum laboris nimis scru- 
pulosi in ejusmodi speciebus determinandis deposuimus, cum determinatores ipsi facile alteram pro altera sumserint. Melior vero Lecid. rupestris pars hujus loci est; certe omnis Lecidea rupestris Ach. Suecica, jam a Walilenbergio cum Lecan. erythrella Ach. juncta. Equidem in monte Omberg transitus vidi adeo evidenles, ut nullum dubium supersit; Decandolle $l$. c. transitus quoque in descriptione indicat. - Ejusdem categoriæ est $L_{e-}$ cid. irrubata Ach. - Terreant prisca nos vestigia, ne in posterum ab ita degeneratis formis species fingamus; hodierna, ne ex eisdem transitum ad diversissimas species videamus. Rite cognitis formis primariis species ad infimas proles in natura persequi valemus \& etian inter has oculorum acie diversa elementa discernere.

Proxime affines sunt Parmelia russula (Lecid. $A \mathrm{ch}$. Syn. p. 40, a qua L. rubina 1. c. longe distat) \& P.dominingensis 1. c. p. 386.

159. PARMELIA cerina, crusta primitus contigua dein granulata cinerea, hypothallum cœerulescenti-nigrum obtegente, apotheciis sessilibus, disco immarginato subcerino, margine tenui æquali opaco integro. Ach. meth. p. 175 .

a. margine discolori. Lich. cerinus. Hedw. Stirp. Crypt. t. 21. f. B. Engl. Bot. t. 627 Patellaria s. Verrucaria cerina. cum. var. Hoffm. - Pl. Lichenos. $t$. 33. f. 1. Lecanora. Ach. syn. p. 173. Patell. cerina B. cyanolepra. Dec. fr. 2. p. 360 . perfectissimus status.

Exs. Lich. Suec. n. 102. Ehrh. Crypt.n. 216. Moug. et Nestl. n. 460. a. et b. Desmaz. n. 293. Lecan. cyanolepra.

b. gilva Ach. 1. c., apotheciis minoribus, margine disco pallidiori aut concolori. Lich. luteo-albus Turn. in Transact. Linn. Soc. VII. $t$. 8. f. 3. hanc sistit, transitumque ad a. monstrat; specimina ipsius propius ad c. accedunt. - Patell. aurantiaca. Dec. fr. 2. p. 35s. Fl. Dan. 955. 1.

c. pyracea Ach. I. c. hypothallo crustaque obliteratis, apotheciis aurantiis aut lote vitellinis, margine proprio evanescente. Lichen aurant.l Ehrh. et German. - Hoffin. En. Lich. t. 4. f.7. Verruc. Ejusd. Germ. Patell. Ulmicola Dec. l. c. Lecid, luteoalba 
$\alpha, \gamma$. Ach. syn. p. 49. Gyalecta Persoonianá. l. c. p. 10. certe!

Exs. Lich. Suec. n. 196. Flörk. Deutsch. n. 185.

* cyanolepra, crusta tartareo-leprosa, ex hypothallo soluto coerulescente. (Apothecia prorsus a.).

Ad saxa, terram, cortices arborum; ad ligna plerumque acrustacea.

Status hujus Lichenis primarius \& rite evolutus, quem ad saxa crusta ultra lineam crassa vidi, tam a præcedentibus, quam ab omni P.parietina thallo obliterato evidenter diversus est. Ejus vero transitus directus in b. \& c. luculentissimus est, tam in speciminibus terrigenis \& corticolis, quam præcipue in lignatilibus, ubi ómnes hujus formæ acrustaceæ esse solent. Sæpius in eadem grege \& crusta observantur. Licet hujus proles reliquarum similes, in has non abeunt. c. nunc hypothallo nigro insidet, nunc aliorum Lichenum crustis parasitica, ut $P$. varia $\zeta$, cum qua in hac serie analoga est, sæpius autem cortici dealbato, quem non confundas cum vero hypothallo $P$. vitellince. In his mutilatis formis discus saturatius coloratus, vitellino-aurantius, immo ruber; in a. luteus, cerinus, olivaceus, margine per ætatem sæpe nigrescente cinctus.

ß. stillicidiorum, crusta granulata cinereo-albicante, apotheciorum disco Iuteo-virescente, margine subpulverulento.

Lichen stillicidiorum. Fl. Dan. t. 1063. f. 2. - * disco olivaceo subpruinoso, crusta leprosa alba: Lich: chloroleucus. Fingl. Bot. t. 1373. Lecanora. Ach. syn. p. 160. Spreng. pug. 2. p. 96.

Ad terram locis humidis supra muscos; * eisdem locis \& ad saxa calcarea.

Ad vulgarem accedit ut $P$. varia $\gamma_{.}, P$. sophodes b. \&c. ad suos typos. * est status magis dissolutus, disco morboso (unde pulverulentus), ad Patell. obliteratam Dec. fr. accedens, at hæc ad $P$. murorum e. incrustantem disco eadem ratione decolorato \& pruinoso referenda est.

$\boldsymbol{\gamma} \cdot \boldsymbol{P}$. harmatites, apotheciorum margine tumidulo subincurvo, disco ferrugineo-rubro. Chaub. in St. Amans Fl. Agen. p. 492. 


\section{Ad cortices Galliæ occidentalis inter P. ceri-} nam frequens Chaubard! Le Prevost! \&c:

Inter hanc \& sequentem prorsus intermedia, nisi peculiarem speciem malles; ad illam tamen certe referenda ob hypothallum cocrulescenti-nigrum, thallum prorsus similem nec non apotheciorum habitum; color vero sequentis, margo thallodes subincurvus, passim crenatus, subinde e lamina bicolor vel a lamina discedens, ut in Parm. erythrocarpia.

16o. PARMELIA (Biatora) ferruginea, crusta subcartilaginea, primitus contigua, demum verrucosa albida, hypothallo nigro predoninante cinerascente, apotheciorum excipulo proprio colorato margine subcrispo cingente discum opacum luteo-ferrugineum. Fries Vet. Ac. Handl. 1822. p. 274 .

Lichen ferrugineus. Huds. - Engl. Bot. t. 1650. Patellar. dein Verrucar. Hoffim. - Plant...Lich. $t$. 35. f. 1. Dec. fr. 2. p. 358. Lecid. Sommerf. Lapp. p. 168. Lich. crenularius. With. arr. 4.t.31. f. 5. Lichen cinereo-fuscus. Web. Spic. p. 188. Pa-. tellaria Hoffm. Pl. Lich. t. 12. f. 1. Lecidea. Ach. syn. p. 43. (Dill. t. 18. f. 4 non h. l., sed a Dillenio cum $P$. subfusca commixta sec. Turn. in Linn. Transact. VII. p. 111.)

Exs. Lich. Suec. $n .227$.

Ad cortices arborum frequens, e quibus in museos rarius descendit; etiam ad saxa, at vix a $\gamma$. tum discernenda.

Species optime a natura distincta, nec a characteribus tantum pendens, nam hi in variis formis ita mutilantur \& personantur, ut a $P$. aurantiaca, cerina \&c. limites vix indices, at in easdem nihilo tamen magis transit. Præcipue singularis est excipulo proprio Biatoroe (ne dicam Lecidex, sed colorato), at ob apothecia primitus clausa summamque cum prioribus affinitatem non potui non in loc genere collocare, etiam'si Systematicis displiceret. At vidimus insuper formas, ad hanc speciem absolute referendas, in quibus idem excipulum non tantum margine thallode accessorio cingitur, sed etiam in quibus in verum thallodes mutatum fuit. Ha- 
bemus etiam hujus formæ primariæ (a.) specimina in $\mathbf{F a -}$ go lecta, excipulo crispatissimo luteo cum crusta lutea! concolori, qualem etiam Hoffmainn in $\alpha$ \& Decandolle in $\gamma$ notant. (Facile hunc coloresn esse typicum, non normalem, crederem.) Frusta conaberis hæc specimina ad $P$. aurantiacam referre; ab hac quam luculentissime differunt. - Hypothallus hujus speciei ater est \& solutus in Leprariam atram s. Byssum antiquitatis (nec in Leprariam ccesiam Ach. Syn. p. 332, qux a P. erythrocarpia \& $P$. casia oritur) crustam decolorat; at in corticibus nunc plane excluditur, túm crusta albida aut lutescens, nunc \& sæpius e lineis nigris crustam limitantibus tantum dignoscitur. Ad saxa evidentior est, sed sxpe et hoc loco more Parm. cinerece v. loevatoe cum thallo tenuissimo contiguo in crustam lurido-glaucescenteim \& albicantem confusa. Apothecia colore maxime variant, aurantiaca, fulva, crocea, sanguinea, atrosanguinea; locis nimis humidis fuscus \& olivaceus! at ferrugineus evidenter prædominatur. In his omnibus margo in perfectissimis exemplaribus elevatus, coloratus, snbnitidus, flexuosus, persistens; tantum locis humidioribus, ubi discus mollior fit \& turgidus, passim excluditur. Sed exstant quoque individua minora margine omnino æquabili, lævi \& minus nitido. - Denique ad truncos muscosos Sorbi vidimus hanc speciem a cortice in muscos descendere, \& his bryogenis exemplaribus nil similius esse potest, quam Lichen Jungermannice Fl. Dan. t. 1063. f. 1., jam olim ab Achario cum P. ferruginea conjunctus, nec alio modo discrepans ac Parm. cerina $\beta$. a suo typo. Et ut meam præfiscini dicam sententiam, quam tamen licet e natura desumtam ulteriori examini subjectam velim: Lichen fuscoluteus Dicks. Crypt. Brit. 2. p. 18. t. 6. f. 2. Engl. Bot. t. 1007. Patell. Hoffm. Pl. Lich. t. 65. f. 1. Parmelia Ach. meth. Lecidea fuscolutea a Flörke. Fl. Dan. $t$. 1541, nil nisi P. ferrugineæ status e loco humidiori mutatus, disco pro more similium morboso inæquabili pruinoso, quod analogia Patellarioe incrustantis et obliterata Dec., Lecidece epixanthoe Ach., Lichenis chloroleuci Engl. Bot. \&c. exactissime eadem ratione a suis typis (P. murorum, vitellina, cerina) recedentium evidentia sua maxime urget. At non omnes formas ob locum consimilem, discum analogo modo mutantes, ad Lecid. fusco-luteam relatas huc traham; de var. $\gamma$. Acharii!, vero Lich. sanguineoatro Wulf., sal- 
tim constat eandem esse analogum statum Biatoræ vernalis. Nil fallácius quam locus natalis inter Parmelias (alia ratio inter Verrucarias \&c.), \& præcipue omnes muscicolæ suspectæ. Si hæc nostra sententia confirmetur, ne temere rejiciatur enixe rogo, Lichen Jungermannice, ut olim apud Acharium, hujus $\beta$. efficiat.

p. arrmiospila, apotheciis margine thallode accessorio instructis, proprio opaco. Sommerf: Lapp. $p .168$.

Lich. ammiospilus. Wahl. Lapp. p. 40\%. Lecidea. Ach. syn. p. 44 .

Ad ligna vetusta putrida.

Rite hanc in Lich. univ. p. 203 pro prioris varietate proposuit Acharius, \& dolemus sane humanisssimum Virum nimis sæpe ad aliorum monita a sua sententia discessisse. Est tantum forma ligniaria inter corticolas \& saxicolas media; at simul Parmel. cerinæ iisdem locis obvix tam similis, ut nisi margo excipuli proprii, sæpius flexuosi quoque, promineret, ægre dignosceres.

$\boldsymbol{\gamma}$. festiva, crusta cinerascente, apotheciis margine thallode destitutis, margine proprio æquabili, demum evanescente. Sched. Crit. 13. p. 8.

Fl. Dan. t. 825. f.2.: 472.2. Lichen, Lecidea crsiorufa.Ach. excl. syn. - $\beta$. festiva Syn. Lich. p. 44. exclus. syn. ad $P$. erythrocarpiam referendis. Patell. lamprocheila. Dec. $f r$. 2. p. $35 \%$. (sec. numerosa spec. authentica, quibus vero unum alterumve $P$. aurantiacx immixtum). - A Chlorococco inquinata: Lecid. viridi-rufa Ach. syn. p. 44. - Ab hypothallo soluto corrupta: Lichen fuscatus Lamarck. (e Gallia habeo) Lecid. obscura. Ach. meth. Lecid. fuscata. Ejusd. Syn. p. 34 .

Exs. Lich. Suec. n. 373.

Ad saxa granitica Europæ, præcipue borealis, copiose.

Ne levissimum quidem ab hac ad $P$. erythrocarpi$a m^{*}$ transitum detegere potui. Crusta variat ut in a. tenuissima \& areolato-verrucosa, pallida \& cinerea, cum hypothallo soluta nigrescens, at numquam cæsia, ut apud Acharium dicitur. Nec apotheciorum color minus mutatur quam in a, sed minora sunt, margine æquabili minus nitido, sæpe prorsus evanido. Ejusmodi apothecia 
crusta lsimul obliterata pro Lecid. rupestri facillime sumuntur.

8. aractina, crusta verrucosa (ex hypothallo dominante nigricante), apotheciis immersis, margine thallode persistente, proprio obsoleto. Sched. Crit. l. c. nec syn.

Lecan. caucasica. Ach. Lich. univ. p. 406. P. aractina. Syst. Orb. Veg. p. 284.

Ad scopulos marinos in Hallandia.

Est tandem prioris status maxime degeneratus, in Urceolariam sensu Acharii, sed ejus a $\gamma$. originem vidi luculentissimam. Discus e luteo-rufo plerumque mox fuscus.

Ad infimas hujus seriei proles quoque pertinet Lich. atroflav us Engl. Bot. t. 2009, Le gid. a tro fla o a Turn. in Transact. Linn. S. IX. t. 11. f. 2. L. Turneriana Syn. Lich. p.49, non autonomam sistens stirpem. Exemplar a me visum L. aurant. formas referebat.

\section{Appendix: Thallo obliterato aut nullo.}

Normaliter nulla Parmelia thallo caret. Occurrunt vero plurima specimina, in quibus vel per ætatem evanuit, vel jam primitus apothecia sine crusta orta sunt, præcipue ad ligna fabrefacta $\&$ ad aliarum specierum thallos parasitica. In saxis in regionibus montanis raro crusta deficit, sæpissime autem in regionibus campestribus ad saxa junioris formationis. Lichenum enim saxicolarum, ut ad Protophytarum seriem (cfr. Syst. Myc. I. p. xx) pertinentium, optimum solum sunt saxa primæva; in saxo cotaceo, calce juniori e. s. p. semper fere degenerata occurrunt. Idem de phytophilis valet (absolute vero phytophili pauci Lichenes sunt, ad Hysterophyta accedentes v. c. Calicii, Opegraphæ, Verrucarix spec., plurima genera tropica, Sphæriis peraffinia); optimi in cortice incolumi ; in ligno vero, muscis putridis, cæspitibus graminum emortuis \&c. obvii sæpissime ad formas derivatas pertinent. Ex his momentis non parum labefactatur hodierna Lichenum generatio æquivoca, quæ licet a Clarissimis Viris assumatur, pro tributo, et ab his ævi genio soluto, a me habetur. At de hac theoria non plura a me alferenda sunt; fatear, me illam non intelligere eamque mentis potius, quam oculorum, acie esse observatam censere. - De his formis athallinis de cetero observandum est, easdem non, ut vulgo fingitur, tantum a thallo crustaceo ortas esse, sed sæpe etiam e thallo ef- 
figurato \& vere foliaceo, numquam vero e thallo normaliter primitus adscendente aut erecto, indeque numquam inter Usneas, Evernias, Ramalinas, Roccellas, Cetrarias. Sed etiam in generibus thallo horizontali numquam observantur nisi in speciebus apothecia cum thallo coætanea proferentibus; genera \& species apotheciis serotinis numquam thallum primitus excludunt v. c. Peltigera, Sticta variæque Parmeliæ, sæpius steriles obviæ. Parmeliæ autem apotheciis coætaneis, etiam e tribu Imbricariarum, v. c. $P$. olivacea, $P$. parietina \&c. thallum sæpe excludunt, quas ne in sectione quarta quæras, cavendum est. E colore vero excipuli seriem saltim determinare valemus! Hoc in serie Citrina eo magis memorabile est, cum thallus in hac sæpe decolor indeque etiam excipulum thallodes, at acrustacei typicum colorem excipulo luteo sæpius monstrent v. c. formæ acrustaceæ Parm. erythrocarpo, cerino, ferruginece, varietatum P. murorum. Hæ proles porro specierum ejusdem seriei tam similes evadunt, ut, licet ex usu dignosci, vix characteribus limitari possint; id quod vera ratio est etiam inter perfectiores plantas, nam nec Muscorum species e sola theca, nec phanerogamarum e capsula tantum acutis limitibus circumscribere valemus. Ex ista vero approximatione infimarum prolium pendet recentior totius fere Citrinæ seriei in unam speciem coacervatio, nam longe inferior ratio est "Gyalectam Persoonianam," "Lecideam rupestrem" \&c., quas ut distinctas servarunt, a Parmelia parietina excludendi, quam reliquas omnes conjungendi. E Zoologia novimus primordia diversissimorum animalium discerni non posse, quis vero ex illis hæc conjungat? Deo \& naturæ tantum omnia identica sunt, philosophi ad hanc identitatem amplectendam tendunt; nobis vero naturæ scrutatoribus omnia diversam evolutionis seriem servantia diversa sint \& maneant. - Ut in Mycologia plurimorum generum omnes species tantum inter synonyma specierum aliorum generum a me relatas esse, dubia \& mirationem movit; fingo etiam multis paradoxum videri, formas inter se simillimas, v. c. sub Lecidea luteoalba, rupestri, anthracina \&c. comprehensas, ut Leprarias, Isidia \&c. taceam, inter diversas species a me distribui, \& cum dissimilibus conjungi; at nonne diversorum Papilionum larvæ $\&$ imagines inter se magis similes sunt, quam ejusdem speciei larva \& imago. Hre comparatio inter Lichenes 
quidem magis clandicat; probat autem, quod demonstrandum erat, nos numquam ex unius status externa facie, sed ex tota evolutionis serie species dijudicare debere.

Ne hæc excursio nimis extendatur, hoc loco tantum cito formas ut species descriptas (plurimas addere facillimum foret) easque e variis ita conflatas, ut ad definitam speciem referri non possint:

*. "Lecanora scrupulosa" ramorum incola, crusta nulla aut irregulater conglobata, apotheciis stipatis planiusculis, disco nudo diversicolori, margine integerrimo. Ach. syn. p. 160.

Ut supra jam notavimus ad lacuum litora, v. c. Smolandiæ, regionem aquæ periodicæ occupari a copia $\mathrm{Li}-$ chenum ad typum Urceolariæ Acharii personatorum, sic etiam in regionibus campestribus, v. c. in planitie Lundensi, in corona Salicum obtruncatarum observatur congeries scutellarum minutarum disco nigro, fusco, carneo, cerino crusta aut nulla, aut conglobata (nec ex hypothallo vero evoluta), quæ ex Acharii recentiore determinatione, exclusis nempe formis evidentius ad Lecanoram subfuscam pertinentibus, ejusdem Lecan. sirupulosam efficit. Etsi hæc species ut Parmelia per se nihil vel potius fere omne est, omni attentione digna, ut evidentissimum testimonium loci vis in Lichenes mutandos, ut exemplum diversissimarum specierum transitus apparentis in prolibus infimis. Orta nempe est hæc congeries e miscela diminutorum scutellarum Parmel. obscura, $P$. parietina, cerina, subfusca, sophodis \&c., quæ ita inter se concrescunt, ut sæpe non dicas, ab hac an ab illa ortæ sint. Cfr. Lich. Suec. exs. n. 320.

\. "Verrucaria dispersa" calcicola, aut muralis, crusta nulla aut leprosa, apotheciis sparsis, disco versicolori, margine crenulato. Hoffm. Germ. p. 189. Lich. dispersus Pers. Parm. Ach. melh. Lecan, galactina $\beta$. Ach. Lich. univ. Lecan. dispersa. Fl. exs. n. 45.

Vidimus jam sæpius supra, quomodo omnes Lichenum crustæ in calce juniori, ex acido carbonico, deliquescant in lepram tandemque dispareant. Tales formas variarum crusta "subnulla," (quod per crustam sæpius deficientem, nec "parum nullam," ridicula non inquirentes, vertimus) complectitur Lec. dispersa. Margo crenulatus est atypicus, cum hypothallo \& crusta soluta connexus, ut in P. varia, sophode \&c. vidimus. 
Ejus mater in diversis regionibus diversa est; vidimus sane in his regionibus etiam a $P$. saxicola \& varia ortam, immo a $P$. cervina $\beta$ \& calcarea, sæpius ve-ro $P$. subfuscam \&c. refert.

\. "Verrucaria abietina," corticola aut saxicola, crusta nulla aut leprosa, apotheciis confertis disco opaco nigro, margine albo subpulverulento. Hoffm. Germ. p. 193. Lecan. exigua. Recent. - Plerumque status fatiscens \& carbonisatus Parm. sophodis, sed etiam a L. subfusca orta vidimus specimina.

7. "Lichen carulescens," lapilli - 1. lignicola, crusta suboliterata haud leprosa, apotheciis confertis, disco fusco-nigro cæsio-pruinoso, margine persistente. Hag. Lich. t. 1. f. 5. Lich., Parm. \& Lecan. Hageni. Ach. - Magna hujus speciei pars est tantum P. subfusca mutilata, optima vero a Parm. cæsia, obscura \& stellari observante acutissimo Meyer, qui ad spuriam infimarum prolium specificam dignitatem dijudicandam me audaciorem reddidit.

5. Lecan. anomala, apotheciis subimmarginatis nudis carneolis luteisve Ach. Lich. univ. p. 381. jam supra decomposita est $\&$ inter proles Parmel. subfuscæ \& variæ citata. Complectitur simul Biatoram mixtam, quam cfr.

7. Lichen aurantiacus crusta obliterata, apotheciis sparsis luteo-aurantiis - Wulf. in Jacq. Coll. III. t. 6. f. 2. b. æque ac Ehrh. \& Lich. luteoalbus Turner e formis infimis $P$. parietinæ, murorum, vitellinæ, cerinæ \&c. conflati, sub suis speciebus citati sunt.

At his exemplis satis superque. Superflum videtur ob:orvatu me non afferendum esse, quasi has ut autonomas distinxissem; ne vero ex his sumatur pratextus, ut ex Leprariis et Isidiis $=0$ appendicis instar a me olm memoratis, argumentandi, me veram harum stirpium naturam non perspexisse, expressis verbis annotatum volui.

Triв. VIII. URCEOLARIA. Apothecia crustce innata, vel verrucis protuberantibus immersa. Lamina urceólata aut protuberans verrucæformis, nigrescens, normaliter casio-pruinosa, marginata. Thallus crustaceus adnatus hypothallo scepe fibrilloso radiante aut cum thallo confuso albido:

Seriem a præcedente tribu efficiunt evidenter diversam, at e variis differentiis acutum quendam characte- 
rem Systemati artificiali satisfacientem, exceptionem non admittentem, proponere difficile est. Maxime essentialis est margo laminæ (sæpius in ambitu liberæ) conspicuns, qui vix nisi in $\boldsymbol{P}$. aurantiaca prioris tribus observatur $\&$ in illa est excipuli proprii rudimentum; ceterum disco læte colorato, nudo \&c. facile distincta. Discus enim Urceolariarum semper plus minus nigrescens est, sæpiusque cæsio-pruinosus, cum in priori tribu discus normaliter nudus aut pruina tenuissima albida vix discernibili obtectus, nisi in formis e loco udo corruptis degeneratisve. Hypothallus, unius speciei excepto, in Urceolariis albus, locis liberis sæpe in ambitu fibrilloso-radians. Apotheciorum forma urceolata minus constans est, vidimus in $P$. sordida discum \& thallo immersum \& protuberantem verrucæformem, sed thallo utique magis innatus est, licet thallo in verrucas effigurato aut protruso scutellæ formam apothecia induant. Sic et multis veris Patellariis, disco immarginato \& nudo, apothecia imperfectiora urceolato-immersa v. c. $\boldsymbol{P}$. cinerece, hinc et Lecanoris \& Urceolariis adscriptæ. - Disci pruina tantum locis humidioribus in Urceolariis desideratur, quibus locis oriuntur Placodia \& Patellariæ pruinosæ $\mathrm{v}$, $\mathrm{c}_{\text {。 }}$ P. incrustans \& obliterata Dec. a murorum, P. chloroleuca a $P$. cerina \&c. - Omnes Urceolariæ e serie Glauca, \& alii colores accidentales aberrationes.

* Apotheciis scutellaformibus, margine thallode genuino, disco plano immerso demum subprotuberante. Lecanoræ. Ach.

16. PARMELIA repanda, crusta amylaceo-compacta laevigata determinata glauco-candicante, hypothallo fibrilloso albo, apotheciis tuberculoso-elevatis, disco cæsio-pruinoso, intus nigro, margine thallode elevato obtuso persistente.

Ad rupes calcareas Gallix meridionalis ad. Massiliam Le Prevost!, precipue loco Montredon dicto copiose Dufour!; in Pyrenæis orientalibus Montagne!

Admodum spectabilis, ambitu determinato repando ad Psoras accedens, sed habitus sequentis, a qua disco intus aterrimo \&c. abunde diversa. Thallus mere crustaceus, in optimo vigore fibrillis albis fimbriatus, primitus contiguus \& lævigatus, demum vero rimoso-areolatus \& in॰ 
xquabilis, valde crassus (lineam \& ultra) \& compactus, sed amylaceus, quod a calce, cui innascitur, pendet, sed ceterum omnino typicus, (non pulverulentus) \& sub epidermide contigua evidenti strato gonimo ornatus. Apothecia valde protrusa, primo verruceformia in thallo $\mathfrak{x}-$ quabili, mox poro pertusa, adulta scutellæformia superficialia, subinde ut in sequente. multilocularia. Excipulum e verruca thalli formatum, tumidum, elevatum, persistens, demum valde flexuosum \& lobatum marginem laminæ obtegens. Lamina crassa plana, demum convexa, extus intusque otra, sed e pruina (raro evanescente) cæsia, elabens foveolam albam relinquens.

- 162. PARMELIA sordida, crusta tartarea contigua rimoso-areolata, ( $\alpha$ glauca, albicante), hypothallo albo, apotheciis innatis, disco carneopallido pruinoso, demum convexo nigricante, margine thallode demisso integerrimo evanescente. Wallr. Flecht. I. p. 485.

a. glaucoma, apotheciis versicoloribus. Dill. musc. $t$. 18. $f .12$ (sterilis sub n. 8.) Lich. rupicola. Linn., sed anceps. L. rimosus Retz. e F'l. Dan. t. 4 fis.f. 3. L. sordidus. Pers. L. albido-c’sins. Schrad. L. varianis. Davies in Transact. Linn. Soc. II.t.28. f.2, 3. Patella:. s. Verrucaria glaucoma. Hoffm. - Pl. Lich. t. 52, 53. Parmelia s. Lecan. Ach. Lichen. Engl. Bot. 215\%. - * ambitu distinctius radiante, apotheciis minutis, subglobosis: Lich. glaucescens. Swartz. Lichen, Parmelia, Lecanora Swartzii. Ach. -Vet. Ac. Fiandl. 1796. t. 6. f. 2. Prodr. t. 1. f. 2. Sv. Bot.t.552. - crusta substerili sorediifera deailbata: Lich. lacleus. Wulf. in Jacq. Coll. III. p. 16it. t. 4. Variolaria oreina. Ach. meth. Suppl. p. 6. \&\&. - ${ }^{* * *}$ crusta in Isidium mutata: Lich. corallinus. Linn. - Wulf. l. c. II.t.13. Westring Färglafv. t. 10. Stereoc. corallin. \& madreporxforme. $H o f f m$. Isidium corallinum. Ach. \& Variolaria cor. pr. p. (Lecid. papillosa Lich.univ. p.171. \& Lecanora micraspis Sommerf. Lapp.p. 102 quoad crustam).

Exs. Lich. Sulec. n. 263. Flörk. Deutsch. n. 44. Aloug. et Nestl n. 547. - * Lich. Suec. 12.397. Flörl. l. c. n. 32. - ** Lich. Suec. n.364. ${ }^{* \star *} 16$. n. 419 . 
b. subcarnea, apotheciis subcarneis persistentibus. Lich., Lecid. \& Lecan. subcarnea. Ach. - Vet. Ac. Handl. 1796. t. 6. f. 4. * Crusta radiante, apotheciis subglobosis.

Exs. Lich. Suec. n. 159. A. * l. c. B.

Ad saxa \& rupes, préecipue graniticas, in Europa australi magis montana \& alpina; versus septentrionem uberrima magis campestris, sed alpes fugiens, ut in Lapponia non nisi degener obvia ; in genere $* 2 \%$ in Suecia frequentiores. b. Locis magis absconditis, ad rupium latera eisdem regionibus ac a. usque dd Pyrenæos!

In formis junioribus libere natis crusta fibrillis adnatis hypothalli pulchre radians. Apothecia re ipsa s:epius crustæ immersa, ut in Urceolariis, sed discus valde protuberat, induratus, nec humectatus mollior fit, ut in $P$. rugosa, colorque niger in individuis vetustis omnino superficialis (nec lamina tota intus nigra ut in priori). Margo proprius laminæ passim evidens, sæpe obliteratus, præcipue ipsa protuberante. Non potest tribu tames a sequentibus proxime cognatis distingui. Omniuim huc relatarum formarum transitus directus evidentissimus est, nec rorallina, in Suecia saltim, a Porina pertusa ortum ducit. - Vix ab a * distinguere possumus Lecan. Sommerfellianam a Flörk. in Sommerf. Lapp. 1. 84., at $\beta$. l. c. simul habitum infimarum prolium P. saxicolce præ se fert.

ק. P. sulpkurea, crusla livido-sulphurea, apotheciis ocius protuberantibus nigricantibus. Clemente. - Ach. svn. p. 166.

Lich. sulphureus. Hoffm. en. Lich. t. 4. f. 1. Engl. Bot. t. 1186. Verrncaria. Tíffm Pl. Lich. t. 11. f. 3. Parmelia, Lecan., Lecid. Ach. - Syn. Lich. p. 37. * minor, ambitu evidentius radiato: Lecan. unicolor. Sommerf. Lapp. p. 85., qui Ipse cum Lecan. subcainea jam junxit, estque fere eadem ac Lich. lutescens. Pers. in Ust. Ann. Bot. 7. Lecid. ochroida. Aill. meth., Lecan. subcarnea $\beta$. Lich. univ., quæ hujus status cum b. subcarnea var. $\alpha$ analogus.

Cum pracedente, sed locis editioribus magisque perflatis; in Europa australi praecipue sum- 
ma alpium juga occupat, in Lapponia vero campestris fit.

Tota vegetationis \& morphoseos historia prioris, nec nisi colore differt, hinc pro vera varietate sumenda, cum status intermedii non desint \& fatiscens in lepram albam diffluat (Lecid. sulph. leucogaea Ach. I. c.). Vulgo autem apothecia in hac magis protuberantia, nigricantia, immarginata facie Lecideæ. At hac ratione nulli exstant limites.

* PARMELIA orosthea, crusta tartarea rimosoareolata obscure ochracea, deliquescente ochroleuca, hypothallo fibrilloso albo, apotheciis adpressis, disco luteolo pallide-marginato, dein protuberante livido-fusco subpruinoso, margine thallode evanescente.

Lichen sulphureus. Quibusdam. Lich., Lecid., Lecan. orosthea. Ach. est status deliquescens.

Exs. Lich. Suec. n. 165.

Ad rupium latera, præcipue Europæ borealis.

Lichenem, quotidie fere mihi obvium, nec tamen affinitate, nec autonomia certum esse fatear. Proximum esse priori, ejusque filiam, cui subjunxit Wallroth, et mihi maxime probabile videtur', at passim majorem cum P.varia, ne dicam Biat. lucida vidi nexum; ceterum fatiscens in lepram ochroleucam abit, apothecia juniora marginem pallidum quasi proprium sæpe offerunt, plerumque nuda \& luteola (raro nigra) e.s.p. Vidi in iisdem maxime absconditis rupibus $P$. sulphuream omnino diversam. Hinc hoc modo ut suspectam notavi ; sed ista forma Flotowii a Ramalina pollinaria prorsus excludenda.

163. PARMELIA Cenisia, crusta granulis primitus discretis subglebulosis glaucescentibus, hypothallo albo, apotheciis sessilibus, disco submarginato luteolo lividoque, demum convexo fusco nigricante cinereo-pruinoso, margine thallode persistente demum crenulato. Ach. syn. p. I63. Lecan.

Exs. Sommerf. Norv. n. 63. Lecan. subfusca. $\beta$. In montanis \& alpinis regionibus Europæ 
fere totius; sed rarior, ad saxa \& rupes. In Norvegia passim.

Parmelice sordidae quidem affinis, sed licet ad illam, $P$. frustulosce instar ad $P$. subfuscam, accedat, $P$. cenisice differentia adhuc insignior videtur. Hypothallum album etiam fibrillosum vidi, at ob crustam haud contiguam facile obliteratur. Ob hypothallum affinium more subdeterminatum crusta etiam spithamam lata orbicularis, granulis minutis nunc sparsis nunc coacervato-conglóbatis. Apothecia, præcipue juniora, magis elevata \& in ambitu libera, conferta, vetusta ampla \& irregularia. Discus primo concavus, suburceolatus, mox planus, vetustus convexus; in media ætate præcipue pruinosus cum margine proprio nudo conspicuo. Color disci variat, junior normaliter videtur luteolus aut lividus, vetustior fuscus \& nigrescens, passim quoque versicolor, centro obscurior, in ambitu dilutior; etiam e pruina olivaceofuscum vidi. Margo thallodes primo integer, demum flexusus \& crenulatus, persistens, sed observante Sommerf. Lapp. p. 93. occurrit varietas minor apotheciis confertissimis, margine proprio thallodem suboccludente. Aliam dedit Blytt formam, in qua excipulum thallodes abortivum plures minores scutellas profert. A P. subfusca laminæ versicoloris margine proprio, pruina genuina \&c. omnino diversam habeo. Synonymon Acharianum certum est.

Ureeolaria scabra Pers. in Act. Wett. 2. 1. p. 10, quæ collatis speciminibus Lecanora rhagadiosa. $A c h$. Syn. p.164., evidenter status monstrosus indeque a me omittitur. Est quoque e monte Cenisio orta; habitus præcedentium.

164. PARMELIA helicopis, crusta rimuloso-areolata livido-cinerea, ex hypothallo albo albo-limitata, apotheciis adnatis, disco marginato nudo livido-nigricante, margine thallode libero obsoleto. Wahl. Toapp. p. 414. Lichen.

Lecidea. Ach. meth. Suppl. p. 9. Lecan. Lich. univ. p. 156.

Ad saxa litoralia aqua marina interdum irrigata Finmarkiæe ad Altenfjord passim Wahlenberg!, Hallandiæ rarissime. 
Ex hac regione est species insignis, ob defectum pruinæ (uti solent analogæ in irrignis \& maritimis) quoad veram affinitatem difficilius coguoscenda. Crusta inæequabilis, humida livida, sicca cinerea, sed per ælatem valde obscura, intus alba. A pothecia proximorum molliora, humectata livida; sicca nigra \& contracta margine laminæ evidente, Lecidinis simillima, sed deest excipulum carbonaceum.

165. PARMELIA rugosa $a$, crusta tartarea ex areolis rugosis verucosa glaucescente, hypohallo albo, apothecis immersis, disco marginato glauco-pruinoso, humectato fusco, margine thatlode persistente demisso. Ach. Lich. univ. p. 36o. Lecan.

Ad saxa "in alpibus" Helvetiæ, Schleicher!

Vix alia evidentius jungit species hujus tribus inter Lecanoras \& Urceolarias dispersas. Habitus priorin ob apothecia plana scutelliformia, sed crustæ omnino immersa margineque thallode demisso, demun flexuoso cincta. Hypothallun radiantem et in hac vidi, non vero fibrillosum. Discus jom primitus sub densa pruina niger, sed humectatus mollis, livido-fusens, intus albus, margine vero nudo nigricante. His notis \& thallo perfecte evoluto videtur species bene disinincla.

Occurrit ceferum crusta mutilata, disperso-irregulari, apotheciis minoribus, qualem $1^{\text {no }}$ verissima Lecan. paepalea Ach. Syn. p. 165 a Schleichero inventore habeo; alia vero citatæ speciei specimina ad $P$. circinatam referenda sunt. Denique et Eich. Luberculosus Eugl. Bot. t. 1733. Lecan. Ach. Syn. p. 165. accedit, at specim. anglico cum icone haud exacte congruo citare nolui. P. P. Iundensis, crusta tartarea contigua, dein rimoso-areolata inequabili glatucescente, hypothallo albo, apotheciis immerso-adnatis, disco marginato cessio-pruinoso, humido coeruleo, margine thallode persistente demisso.

Exs. Lich. Suec. n. 321 .

Circa Lund Scanize frequens ad saxa, ligna putrida \& terram.

Transitum hujus in præcedentem observare quidem non licuit, at in novis speciebus admittendis difficilis sum 
\& ex utriusque perfecta diagnosi, quam difficiles distinctu re ipsa sint, patet. Inter illam \& sequentes quasi media est. Pruina disci densa \& persistens, laminæ inarginem tenuem nudum tamen plerumque relinquit in vegetis conspicuum. Lamina ipsa intus prioris magis nigrescit, inde pendet forsan color ejus in lichene humido cæsio-cœruleus. Crusta quam prioris minus effigurata, ceterum convenire videtur.

166. PARMELIA impolita, crusta tarlarea contigua rimosa glaucescente (sape sorediifera rufescente), hypothallo araneoso alho, apotheciis subinnatis, disco plano-convexo ex hyalino subfusco glauco-pruinoso, demum nudo intusque atro, margitie utroque subevanido. Fries Syst. Orb. Veg. I. p. 244.

Liclien impolitus. Ach. Prodr. p. 56. Lecan. glaucoma. a. Lich. univ. ex spec. deterin. - probe nempe ab omnibus similibus formis Lecan. subfusce distincta. Parmelia velata. W allr., dein Phlyctis velata. Ejusd. Flechtenk. p. 52\%. et sq. Reliqua syn. infra in obs. Patell. detrita Decand.

b. disco plano convexo, margine thallode nullo. Lecidea biformis. Fl. Deutsch. n. 122.

* apotheciis dilatatis maculæformibus fuscis pruinosis abortivis: Lichen impolitus. Eírh. - Engl. Bot.t. 981. Verrucar. Hoffin. Parmelia. Ach. meth.p.160. Fl. Dan. t. 1950. f. 1. Lichen pruinatus Pers. secundum Act. syn. p. \%. Arthonia pruinosa.

** crusta sterili, detrita subaurea, sorediis fusco - I. rufo-cinereis adspersa: Spiloma decolorans. T'urn.et Borr. Lich. Brit. p. 39. Engl. Bot. t. 2098. Lepraria dorcochroa. Flörk. olim.

Exs. Lich. Suec. n. 202 (* cum trans. ad b.), 183 ${ }^{(*)}$. Fl. Deutsch. n. 122. A. (b.) B. $\left(^{(*)}\right.$ n. 61. $\left(^{*}\right)$ Flotow. variæ formæ.

In truncis arborum frondosarum, præcipue Quercus, regionum campestrium per omnem Europam omnes formæ promiscue \& copiosissime; sed in pineto-montanis ne obsoletissimum quidem hujus formarum vidimus vestigium.

Lichen valde abnormis, inter varias: hujus tribus se- 
ctiones ambigens, nam apoth. perfecta minuta, nunc scutellæformia, nunc verrucis elevatis, nunc ipsi crustæ immersa s. adnata; sed hanc sedem optime tueri videtur ut inter præcedentem et sequentem speciem media, utrique maxime accedens. Dignoscitur ab his hypothallo araneoso, crustæ sæpe sorediiferæ natura, apotheciis difformibus, margine utroque quasi accessorio, disco intus colorato, denique vegetationis historia, a Wallrothio optime exposita, quem conferas. Ceterum admodum difficitis ob proteam indolem tam in ampla synonymorum \& formarum grege determinatu; limites nimis \& perstringere \& dilatare ubique periclitamur, sed allatæ formæ cum plurimis aliis omnes ita promiscue $\&$ in se invicem, ut apparet, transeuntes in omnibus Scanix quercetis (nullius vestigium in Smoland. occidentali) nascuntur, ut, donec meliora edoctus fuerim, non possim non modo a me olim proposito conjunctas servare. - Arth. pruinosc cum Opegrapha Lyncea ab Achario comparatur \& a Meyero conjungitur, nec denegemus plures diversas hujus, ut plurimarum specierum abnormium, esse matres (simillimas ab Opegr. Lyncea ortas, sed carbonacei quid servantes, e Gallia occid. vidimus-Arthonia lyncea Ach.), at nostram semper in $P$. impolitce consortio, extra omne Opegr. lynceæ, nascentem cum illa jungere eo minus dubitavimus, cum amiciss. Ljungstedt directos attulerit transitus. Ne fingamus omnes Arthonias ex Opegraphis ortas, optimas quoque e Lecideis \& Lecanoris habemus, quarum $P$. subfuscee Arthoniæ pruinosa simillima est, tantum nuda. - Inter omnes species nulla enim est, a cujus infimis statibus $P$. impolita difficilius dignoscitur, quam $P$. subfuscee, licet ipsæ species in statu genuino valde diversæ. Ob nimiam authenticorum speciminum copiam visam, quæ nunc hanc runc illam sistunt, tute detérminare non ausus sum multos abnormes illos status, qui sub, composito (et ex Licheni periısi L. \&c. formis) Thelotremate Variolarioide Syn. Lich. p. 117. comprehenduntur, quales Lich. argenus \& agelceus Ach.Prodr. Engl. Bot. t. 1923, 1730 Eecidea argena et Urceol. agelcea Ach. meth. I,ecan. verrucosa Lich. univ. Variolaria agixa \& argena Lich. Brit. Urceolar. leprosa, \&c. Pers., licet majorem partem cum Cel. Wallrothio huc lubens referam. - Denique sub nominibus Verrucarice byssacee, Lecidece dryince \&c. etiam hæc species passim venditur. Ad proximas vero pertinere videtur Arth. pruinosa. $\beta$. lobata Flörk. 
** Apotheciis verrucis thallodibus elevatis subdiscretis deliscentibus immersis, suburceolatis. Tanta est harum affinitas cum Porinis $A c h$. s. Pertusariis Decand., ut utrarumque adsit forma alia ad hoc, alia ad illud genus facile referenda. Limites generum inter Lichenes nullos posuit natura.

167. PARMELIA casioalba, crusta cartilagineotartarea rugoso-plicata lobulataque glaucescente, lamina planiuscula immarginata immersa ex hyalino subfusca glauco-pruinosa, margine thallode lacero-rupto tenui irregulari. - Le Prerost in litt. sub Urceol.

Ad saxa formationis junioris, terram argillaceam \& parietes lutosos Germaniæ! Helvetiæ Schleicher! Gallix occidentalis Prevost!

Habitus sic diclæ "Variolariæ communis." Crusta primo cartilaginea, rimosa, lævigata ; per ætatem subtartarea, crassior rugosa, areolato-verrucosa, conglobata \& in squamulas lobatas abiens, e glauco albicans. Lamina c crusta cjusque verrucis lacero-dehiscentibus erumpens, prorsus immersa, e concavo plana, tenuis, margine proprio destituta, sed thallo lacero irregulari cincta, primo hyalina, densissimo nec dispergibili pulvere lacteo obtecta, demum vero magis denudata cæsio-nigrescens. A Parm. rugosa subsimili diversa tam crusta, quam lamina immarginata. Summa vero cum præcedente affinitas. Arthoniam pruinosam $\beta$. lobatam Flörke Deutsch. n. 22. videre non contigit; descriptio accedit. Cum Lichene pertuso Linn. majorem suspicor affinitatem, quam e descriptione concluderes; sunt enim etiam huic formæ disciferæ pruinosæ \&c.

168. PARMELIA nodulosa, crusta tartarea subareolata pulveraceo-conspersa glauco-albicante, hypothallo albo, lamina verrucis subeffiguratis immersa planiuscula nuda fusco-nigricante, marginem tenuissimum demum protrudente. (Dufour determ.)

Ad terram glareosam in Hispania. Lagasca, Dufour!

Crusta semper tartarea, junior \& sterilis contigua, 
inæquabilis, areolis tantum fertilibus protuberantibus, magis dicretis \& subeffiguratis, ad Parm. Schleirheri re ipsa accedentibus; in omni statu, quod admodum singulare, denso obtecta pulvere albido, qui a statu leproso aliarum specierum probe distinguendus est. Lamina in apicibus areolarum dehiscentium regulariter \& omnino immersa; junior concaviuscula tantum, rufofusca, margine tam proprio, quam thallode destituta; dein plana atra opaca, margine tenuissimo thallo concolori cincta. Sub nomine Urceol. Lagasca misit Illustr. Dufour, sed ob aliam Parmeliam homonymam nomen mutare mihi permisi.

I69. PARMELIA verrucosa, crusta carlilaginea verrucosa nuda glauco-albicante (sepe pulveracea), hypothallo albo, lamina verrucis immersa concava nigrescente subpruinosa, margine proprio cum thallode convexo connato.

a. Urceolaria. Normalis: Urceolaria mutabilis. Ach. Lich. univ. p. 33.5. Schaer. spic. p. $7 \%$ Urceolaria verrucosa $\beta$. l. c. p. 340 , quæ prorsus eadem. Crusta magis dealbata: Urc. verrucos. l. c. p. 339. Eadem apotheciis corruptis: Urceol panyrga. $A c h$. meth. p. 146. t. 4. f. 2. Lichen. Wahl. Lapp. p. 408. Crusta deliquescente farinosa aibissima: Urceol. verrucosa. Schaer. spic. p. $7 \%$.

Exs. Schaer. Helv. n. 134. - farinosa : l. c. n. 133. b. Pertusaria, verrucis clausis, disco ostioli instar nigri prominente. Meyer Flecht. p. 214. Thelotrema mammosum. Pers. in Act. Wett. 2. Lichen glomeratus. Schleich. Porina glomerata. Ach. Lich. univ. p. 310. Pertusaria. Schaer. spic. p. 66. Endocarp. globulare. Sommerf. Lapp. p. 136.

Exs. Schaer. Helv. n. 120.

Ad ligna, corices arborum \& ad terram supra muscos putridos Gallize Dufour!, Helvelize Schleicher! Germaniæe Laurer! alpium Norvegice (sub omuibus formis) Blytt! Lapponia Wahlenberg! Sormerfell! Cir. Obs. infra.

Species multis rationibus valde insignis, utique omnium vulgatiorum more maxime variabilis, sed nomen verrucosce præferendum. - Crusta \& verrucæ potissimum Pertusariæ; glaucæ, plumber, in muscis præcipue 
dealbatæ, sed etiam sæpe insigniter lutescentes, præcipue in b.; dissolutx albissimx. Verrucæ in ligniariis exemplaribus magis depressæ, in muscicolis subglobosæ. Sed hæ omnes formæ luculenter eandem efficiunt speciem. Lamina ex urceolato explanata, pruinosa aut nuda, passim morbosa turgicia quasi dissoluta, margine instructa pioprio, cum margine verrucarum connato, nota speciei primaria, e quibus oritur in perfectissimis margo bicolor. - b. cum Lich. pertuso Linn. genere omnino, convenire videtur, sed alium eam modo statum P. verrucosce efficere cum Cel. Nleyer mihi plene persuasum est; cujus analoga exempla in plurimis tan Patellariis, quam Urceolariis, vidimus. Cf $r$. Pertusariam. - Urcenl. verrucosam \& mutabilem eandem efficere speciem, præcipue e speciminibus Dufoureanis authenticis "nullum dubium mihi superest. Et corticolam et ligniariam prorsus confluentes e Norvegia dedit amiciss. Blytt. U.mutabilem ad $P$. cineream certe ex errore retulit G. $F \cdot W$. Meyer; specimina sub priori nomine Göttingæ collecta \& ab E. Meyer liberalitate, qua pollet, donata omnino ad $P$. scruposam lisgnicolam pertinent. - Urceol. panyrga, jam indicante acutissimo Wahlenberg, est Lichen corruptus \& atypicus; licet variis Parmeliis in alpibus deformatis accedat, ex ipsius laudati viri speciminibus ad Parm. verrucosam (etiam in Lapponia obviam) potissimum referam. Ad hanc vel illas quoque pertinet $L e-$ can. roscida Sommerf. Lapp. p. 97. (Specimen a me non visum). Tandem de Patellaria muscorum Hoffm. - PI. Lich. t. 21. f. 1. restant controversix solvendx; b. m. Acharius cum Schaerero plurimisque ad $P$. scruposam b.; nisi antem Cel. Flörke, ut videtur, specimine \& Laurer Flörkeana, ni fallor, optima auctoritate ad P.verrucosam referunt. Holfmannum, Lich. suum muscorım nune cum Parmelia scruposa conjungentem, nunc ab eadem distinguentem, utramque commiscuisse facile fingam; sed icon \& descriptio I. c., quantum video, a $\boldsymbol{P}$. scruposa $\beta$. sumta est. - Est denique hre species geographico respectu aberrans; in Europa australi loca convallium calidiora vel montes alpesque calce \& gypso fundatas incolit; in Scandinavia extra regiones alpestres, et quidem potissimum formationis primævæ, non lecta est. - b. constantius ubique alpina.

70. PARMELIA calcarea, crusta subcartilaginea areolato-verrucosa glaucescente (sæpe farinosa 
alba), lamina areolis inmersa e concavo plana nigrescente cæsio-pruinosa, margine proprio a thallode plano primo rugoso-crenato mox soluto. Mich. gen. t. 54. f. \% Lichen calcareus Linn. et Auct. pl. (præcipue ad formas farinosas). Urceolaria calcarea Ach. syn. p. 144. Schaer. spic. p. 73. Lich. rupicola. Hoffm. en. Lich. t. 6. f. 3. Verrucaria contorta \& tessulata. Hoffm. Germ. - Pl. Lich. t. 22. f. 1-4. Urceol. contorta. Flörk. in Berl. Mag. 1810. p. 121. (ubi optima hujus speciei expositio, cum plurim. formis). Lich. Hoffmanni. Ach. - Engl. Bot. t. 1940. Urceolar. Lich. univ. p. 333. Lich. cinereus. Engl. Bot. t. 820. Fl. Dan, t. 1432. f. 1. Urceol. tessulata. Ach. meth. p. 142. Urceolaria ocellata \&. Lich. univ. p. 332. excl. syn., in Syn. Lich. p. 139 sub Urc. pelobotrya. Lecan. cæcula. Ach. syn. p. 164, ut rite Meyer; alii perperam cum Lecan. varibili conjungunt. Urceol. compuncta Schleich.minime Ach., quæ genere diversa. * areolis in tubercula elongata crassa cylindrica productis: Isidium melanochlorum Dec. fr. 2. Isidium stalactiticum. Ach. syn. p. 282.

Exs. Lich. Suec. n. 396-397. Fl. Deutsch. n. 30. Schaer. n. 131.

b. verrucis ciausis, Porinam Ach. prorsus referentibus. Porina plana. Dufour!

In saxis calcareis orta, sed in regionibus formatione juniori substratis etiam in aliis saxis vagatur, normalis in calce primavo \& duriori ut marmore; oxydata \& farinosa in calce juniori \& molliori. " \& b. in Europa australi!

Crusta e matricis indole mire mutatur, unde plurimæ oriuntur formæ, quæ in herbariis sic forsan optime disponuntur: a) crusta verrucosa, contigua. b) crustæ areolis discretis. c) crusta lævigata, contigua, imperfecta, cum $P$. cinerea lcevata analoga. Isidium ab hac ortum indole a reliquis abunde differt et ex ipsis areolis caulescentibus \& productis oritur, ut evidenter in spec. Montagnei video. Sequuntur formæ crusta tartarea cinerea \& albicante, demum farinoso-pulverulentæ agmen claudunt. Apotheciorum peculiaris habitus, a disco margineque proprio solutis contortus; sæpe plura in singula 
verruca \& per ætatem confluentia. In formis farinosis apothecia raro rite evoluta. b. valde insignis, omnino analoga, cum prioris b.

p. glaucopis, disco rufescente. Flörke. l.c. Ad saxa calcarea.

Crusta mutabilis est, subtartarea. Est quoque et hæc Urceol. cinereorufescens dicta, ut plurimarum specierum varr. disco rufescente. Cfr. Flotow in Flora Ratisb. 1828.

171. PARMELIA pelobotrya, crusta tartarea areolato-verrucosa griseo-pallescente, lamina areolis immersa planiuscula atra, demum in ambitu marginato-libera cinerascente. Wahl. Lapp. p. 4r3. Lichen.

Urceolaria. Wahl. in Ach. meth. Suppl.p.31. Lich. univ. p. 333. Lecan. Sommerf. Lapp. p. 31.

Ad rupes irriguas, præcipue micaceas \& schistosas, rarius Finnarkiæ Wahlenberg!, Nordlandiæ Sommerfelt! Norvegiæ australis passim Blytt!, inque Suecia montanis minus evidens.

Propter discum areolis immersum ad hanc subdivisionem relata, ceterum $P$. scruposce certe proxima $\&$, si omnem perfectionem scientiæ in speciebus affinibus conjungendis quæramus, cum hac conjungi potest. Locis irriguis, quæ præcipue incolit, crusta spongiosa; locis vero siccioribus fere cartilaginea tuberculisque pallide rufescentibus Lecidece panoolae instar variegata est. $\mathrm{Hy}-$ pothallum rite discernere non licuit, suspicor album, etsi crustam intus ad basin atram vidimus, nam hoc a loco irriguo derivari potest ( $\&$ forsan ex illo etiam ortus

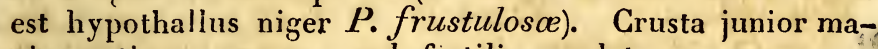
gis contigua, rugosa; sed fertilis areolato-verrucosa; areolis gibbosis, confertis, passim effiguratis, nec pulverulentis, nec fatiscentibus (quantum hactenus innotuit). Color peculiaris in udis livido-griseus, in siccis pallescens, sed semper quid pallide rufescentis admixtum offerens. Lamina areolis irregulariter, sed plane immersa, quare margine thallode obtusissimo rotundato cincta apparet, at verus margo non est, nam nunc plures in eadem areola, (quibus confluentibus oritur discus multilocularis,) nunc ad latus areolæ posita est, margine quasi dimidiato. La- 
mina per xtatem in ambitu libera, marginata, cinerascens, qua etiam affinitas sequentium indicatur.

*** Apothecia crustce subcequabili prorsus immersa, emergentia et passim margine thallode elevato coronata.

172. PARMELIA ocellata, crusta tartarea verrucoso-plicata glauco-candicante, hypothallo albo, apotheciis difformibus, disco inmerso plano nigro-crsio, intus albo, margine thallode tumido demum elevato \& a laminæ concolori inflexo discreto.

- Mich. gen. t. 52. ord. 34. Lich. ocellatus. Vill. Delph. III. p. 988, t. 55. Urceolaria. Dec. fr. 2. p. 372. Lich. vallesiacus. Schleich. Lecan. Villarsii. Ach. Lich. univ. p. 338.

Ad saxa \& terram montinm Europa australis v. c. Italix! Vallisiæ Schleicher! Galliæ mepidionalis frequens Prevost! Pyrenæorum Hoffman Bang!, Hispanire usque ad Cadiz Dufour!

Recentiores speciosissimum hunc Lichenem, forsan cum P. scruposa v. gypsacea commutantes, pro hujus varietate sumunt; equidem, suadentibus autoptis, non possum non distinguere; in Europa boreali nil ad $P$. ocellatam accedens observatur. Grusta (ad P. Lagascee \& Blyttii accedens) latissime eifusa, crassa, contigua, areolato-plicata, subgyrrosa, sæpe valde undulata, in ambitu præcipue ad terram obsolete lobata. Apothecia ut prioris verrucoso-elevata Patellarize, sed lamina immersa, demumque secedit margo interior inflexus thallodi tumido flexuoso concolor, quare duplici margine thallode instructa apparet. - Variat in statu atypico crusta al* Jissima \& pulverulenta, ut sequens, pro cujus formis in hoc statu etian sumta videtur, at typi evidenter differunt.

- 173. PARMELIA scruposa, crusta tartarea rugoso-granalata glancocinerascente, hypothallo albo, apotheciis immersis, margine disci urceolati casio-nigri cinereo-nigricante connivente a thallode crenato primitus obtecto. Sominerf. Lapp. p. 1 оo. Lecan. 
Dill. musc. t. 18. $f$. 15. Lichen scruposus Linn. Ho.fm. en. Lich. t. 6. f. 1. Engl. Bot. t. 266. (ad $\beta$. accedens). Patellaria s. Verrucaria Hoffin. Pl. Lich. t. 11.f.2. Urceolar. Ach. - Schaer. spic. p. 75. Lich. pertusus. Wulf. in Jacq. Coll. II. $t$. 13. f. 3. - * crusta dealbata, tartareo-pulveracea. Urceol. gypsarea. Ach. syn. p. 142 - apotheciis abortivis: Lecidea talcophila: Ach. Lich. univ. p. 183. - crusta in Isidium mutata: Lichen, Isidium Westringii. Ach. - Westring Färglafv.t.4. ("scutellæ passim nigræ") Variolaria. Wahlenb.

Exs. Lich. Suec. n. 398, 122 Isidium. Moug. et Nestl. n. 169. Schaer. n.132. (plumbea) Sommerf. Norv. 61. * dealbata.

Ad saxa granitica, arenaria \&c., in terra, frequens; raro ad ligna \& cortices; Europæ totius. Crusta e loco diverso quoad crassitiem \& colorem varie mutatur; formam pulveraceam, albam ab hac luculenter oriri vidi, quæ a præcedente, etiam pulveracea visa, sine dubio differt. Præcipua hujus speciei differentia posita est in lamina juniori connivente, mox urceolato-aperta, margine proprio integerrimo pallido, dein vero nigrescente. Color disci cæsio-niger a pruina tenui oritur. Hypothallum equidem vidi album, numquain nigricantem Parm. cinerece, quare tam Lichenem fibrosum Engl. Bot. t. 1732, quam Urceol. fimbriatam Ach. ad P. cineream refero. Uic. gibbosam ex optima parte ad eandem spectare omnino certum est. Formas hujus habemus plures notabiles; aliam ad rupes irriguas lectam tersam, colore \& facie ad $P$. pelobotryam accedentem; aliam ad terram argiliaceam, crusta tenui lævigata, lamina immersa planiuscula, margine utroque obsoleto, quæ vero var. plumbea Ach. multisque formis mediis cum vulgari jungitur e. s. p. Cel. Flotow memorat varietatem disco cinereo-rufo. Regensb. Bot. Zeit. 1828. p. 722, ex quo Auct. etiam Spiloma umbrinum Flotow 1. c. 1825. p. 322 \& Lecid. leprosa Schaer. huc referantur. Sepono celebratiores:

ß. bryophila, crusta rugosa, apotheciis minoribus, lamina energente urceolata, ore contracto, margine thallode subevanescente. Ach.meth.p. 148. ifich. gen. t. 52. ord. 33. I/all. helv. t. 47. f. 6. Liches excavatus Rell. L. impressus Swarts. L. mu- 
scorum. Scop. etc. Urceol. bryophila. Ach. Lich. univ. p. 341. Fl. Dan. t. 1351. f. 2. Cfr. Schaer. Sommerf. $l$. c.

Exs. Lich. Suec. n. 282. Ehr. Crypt. n: 236. (Lichen bryophilus) Moug. et Nestl.n.170. Desmaz.n.239. Ad terram supra muscos, quos destruit.

Crusta hujus, certe varietatis, in ambitu sæpe foliacea apparet, quod vero e thallo Cladoniarum incrustato pendere optime monuit Sommerf. Lamina sape tota cmersa \& omni margine thallode destituta. At etiam in a., qualia specimina ad Gisors Gallix a Passy lecta sunt, margo laminæ omnino nudus passim conspicitur.

$\boldsymbol{\gamma}$. diacapsis, crusta rimosa inæquabili alba, margine laminæ libero incrassato, thallode discreto aut nullo. Schaer. $l$. c.

Lichen diacapsis. Engl. Bot. t. 1954. Urceol. Ac/. syn. p. 142. Gyalecta cretacea. l. c. p. 10.

Ad saxa, pixcipue calcarea, \& muros Angliæ! \& Europæe australis!

Transitum hujus directum in var. $\alpha$ ipse haud observavi, at pulveraceo-dissoluta simillima fit, quare optimorum Virorum auctoritate subjungo. Specimina anglica ad præcedentem speciem referre nequeo.

74. PARMELIA striata, crusta areolato-diffracta inæquabili glauco-cinerascente, hypolhallo nigricante, lamina nigra subpruinosa mox emersa in ambitu libera striata albicante, margine thallode nullo.

Urceolar. striata. Duby Bot. Gall. ex Prev. in lilt. Ad saxa silacea Galliæ occidentalis circa Rothomagum. A. Le Prevost!

Sola est Urceolariæ species, in qua hypothallum lnrido-nigrum, nec albidun, certo observavimus. Crusta crassiuscula, contigua, rimosa, glauco-cinerea ; in varietate quadam luteo-pallescens, magis nodulosa. Excipulum thallodes nullum; lamina perexigua in superficie areolarum lævi immersa, mox emersa, in ambitu omnino libera, striata \& albicans, primo connivens, demum magis aperta, nuda, nigra.

Formæ crusta farinoso-amylacea $P$. calcarece, in quibus verrucæ evanescunt, lamina crustæ lievigatæ im- 
mersa, cum priori non confundendx. Hoc loco facile quæruntur; videas sub n. 170.

175. PARMELIA lepadina, crusta cretacea substupposa lævigata cæsio-grisea, hypothallo albo, lamina crustæ immersa plana nuda atra immarginata.

b. lamina crustæ glebulosæ adnata, superficialis. Lecid. lepadina. Sommerf. Lapp. p. 145.

In alpium saxis Norvegia occidentali-meridionalis v. c. ad V. Moland Ahnfelt!; b. in Heckeltind Skjerstadiensium in summis alpium cacuminibus. Sommerfelt!

Habitus hujus Parmeliæ maxime inconsuetus est \& ab omnibus alienus; a. Endocarpon \& b. Lecideam referunt. Crusta admodum variabilis est, tenuior semper sterilis; fertilis crassa, turgida, nuda, lævigata, sive contigua (numquam late effusa) sive in glebulas discretas conglobata; hæ glebulæ in b. præcipue insignes, valde turgidx, obtuse conicæ. Color cresio-griseus aut lividus, intus sub strato viridi albissimus. Substantia admodum compacta, cretacea, substupposa. Apothecia primo Endocarporum ostiola referunt, dein in laminam planam foveolis thalli immersam dilatata, absque omni excipulo \& thallode \& proprio. Discus opacus, ater, nudus, immarginatus, sed in ambitu subsolutus. In b. lamina prorsus superficialis, intus albida.

Lichen Gagei Engl. Bot. t. 2580, crusta rimoso-diffracta fuscescenti-alba, lamina immersa minuta nigra - mihi ignotus est \& ob locum: ad rupes inundatas, valde suspectus. Facile ex icone conjecturam injicere; mihi vero consultissimum videtur 0 mnes conjecturas, quibus Lichenologia jam abundat, supprimere \& nil nisi ad specimina certa determinare. Præcipue sunt conjunctiones specierum ex habitus \& characterum approximationibus, tota morphoseos serie non perspecta, caute evitandæ; nam errores e speciebus nimis multiplicatis facile tolluntur; difficillime autem conjunctiones e præmaturis præcipue theoreticis judiciis.

\section{D I R I NA.}

Lecanoræ spec. Ach. Lich, univ. t. \%.f. 5. Diriná. S. O. $V \cdot$. p. 244. 


\section{CHAR. Apothecia primo tuberculiformia clau-} sa, demum centro dehiscentia scutellata, horizontalia, a thallo marginata. Discus tenuis, strato cartilagineo-corneo atro impositus. Thallus horizontalis crustaceus, adnatus, cartilagineus.

Habitus Porinæ l. Parmeliæ Urceolariæ potissimum. Incolit regiones calidiores; una alterave tantum species Europæ maxime australis cives. Forsan cum Phlycti Wallroth, mihi non quoad characteres cognita, conjungendum \& latius extendendum. Discus pruinoso-velatus. Cetera omnino Parmeliæ.

I76. DIRINA Ceratonice, crusta cartilaginea rugosa glauco-albicante, apotheciis sessilibus, disco cinereo-pruinoso, margine thallode tumido persistente. Ach. Lich. univ. p. 36r. Lecan.

Ad cortices Ceratoniæ Siliquæ, Juniperi phœniceæ \&c. Hispania Acharius! Galliæ meridionalis Dufour!

Crusta indeterminata, tenuis, hypophlæa, adultior rugoso-plicata. Apothecia admodum conferta, e mutua pressione angulata, quasi truncata, Lamina immarginata cinereo-fuscescens, stratum atrum plane obtegens. Aliam subsimilem in herbariis vidi ex Europ. australi speciem crusta determinata rudiori, superficiali, fere lobata, apotheciis magis liberis, margine demum flexuosolobato $(D$. repandla), cujus vero specimen nunc non adest indeque omittitur.

obs. Species Z $\mathrm{Z}$ or re, subgeneris disco strato proprio ceraceo imposito a Parmeliis, apotheciis excipulo thallode primitus elausn etc. a Biatoris diversi, habitu cum Parmeliis ita conveniunt, ut easdem, donec hoc subgenus asutius limitutum fuerit, inter Purmelias inseruerim.

\section{G Y A L E C T A.}

Urceolariæ spec. Acl. meth. Gyalecta \& Lecidea $A c h$. syn. Gyalecta. Schaer. spic. p. 79. Fries S. O. V. 1. p. 246.

CHAR. Apothecia urceolata, excipulo ex hypothallo formato primo clauso, dein varie dehiscente, limbo elevato discreto discum cingente. Discus primitus nuclei instar inclusus, gelatinosus, 
dein apertus, explanatus, induratus. Thallus ho. rizontalis, crustaceus, subtartareus.

Est cum præcedente Lichenis, sensu Wahlenbergii, subgenere, qualia omnia antecedentia considerata velim, aberratio Parmeliæ, at tam insignis \& recedens, ut seorsim proponere debuerim. Habitus exacte Biatoræ, ob excipulum quoad externam faciem proprium \& a thallo heterogeneum, at re ipsa a thallo primario formatum, primo clausum, dein dehiscens, ut accedente disci indole diversa a Biatoris non possit non distingui. Est re ipsa typice Parmelia e statione humidiori aut calce mutata, testantibus variis degenerationibus Parmeliarum, præcipue $P$. cinerece v. lacustris, at in his limbus desideratur. Ceterum limites ut plurimorum infimorum generum, differentia thallina haud suffultorum, fluctuant, licet species habitu conveniant, nec apte præcedentibus immisceantur. Cum homonymo Achariano genere vix nisi nomine \& prima specie convenit.

177. GYALECTA cupularis, apotheciis radiatodehiscentibus cupulari-apertis, limbo orbiculari elevato tumido pallido, disco testaceo-pallescente. Schaer. spic. $p$. 79 .

Lich. cupularis. Hedw. Stirp. Crypt. II. p. 58. $t$. 20. f. R. et Auct. plur. Wahl. Suec. p. 801. Verrucar. Hoffm. Germ. - Lecid. Ach. meth. - Lich. marmoreus Scop. - Hoffm. en. t. 6. f. 4. With. arr. IV. t. 31. f. 3-6. Engl. Bot. t. 736. Parmel. dein Lecid. Ach. Lich. fuscorubens. Wulf. in Jacqu. Coll. 1II. p.112. t. 2. f. 2. Peziza jenensis. Batsch El. Fung. C. I. p. 219. t. 28. f. 153. Lecid. foveolar. d. Sommerf. Lapp. p. 173.

Exs. Lich. Suec. n. 401. Schaer. Helv. n. 135.

Per omnem Europam, præcipue ad saxa calcarea \& arenaria, in his regionibus frequenter in muscos descendens; regiones vero formationis mere graniticæ prorsus fugiens.

Crusta primitiva (hypothallina) continua luteolo-rubella, demum vero leprosa albocinerascens aut, ut locis indicatis solet, obliterata. Apothecia in hac varietate primaria superficialia, cornea, flavo-rubella 1 . incarnatoalbida, extus subpulverulenta, primo sphærica clausa, dein poro aperta, limbo radiato-rugoso, qui vero magis 
explanatus lævior fit. Discus facile elabens, ut in subsimili Lecan. rubra, sed excipulum in hac longe magis essentiale, utpote numquam deficiens. Rev. Sommerfelt speciem optime illustravit \& sequentes varietates esse demonstravit.

ק. G. foveolaris, crusta crassiori, apotheciis urceolatis immersis flavis. Sommerf. $l$. $c$.

Urceol. foveol. Ach. meth. p. 149. Lichen. Wahl. Lapp. p. 405. Gyalecta Wahlenberg. Ach.syn.p.9. Ad terrain muscosam, turfosam, immo stercoratam in alpinis.

$\mathrm{Ob}$ solum pinguius magis luxuriat, quoad omnes partes mollior \& subgelatinosa. Var. $\beta$. Ach. l. c. sec. specimina Schleicheri etiam h. l. est, apotheciis passim decoloratis, sæpe Stictidi radiata simillimis; alia ab Ach. determinata vidi ad Biat. rosellam spectantia.

$\gamma$. G.lutea, crusta tenuissima, apotheciis demum explanatis ambitu tenui pallidiori. Sommerf. l.c. Lich. luteus. Dicks. Crypt. Brit. I. p. 11. t. 2. f. 6 . (Engl. Bot. t. 1266). Lecid, melizea Ach. syn. p. 47. ex Sommerf.

In muscis \& ramentis cum priori.

Priori $\beta$. proxima, sed ob crustam tenuiorem apothecia magis explanantur, nec immersa sunt. Specim. Dicksonianum in Herb. Swartz. hujus omnino loci videtur; quod vero in Ach. herb. vidi, Biat. vernali. v. luteolae (cum qua olim jungendam censui) magis affine, at confirmante descriptione Dicksonii, a quo species pendet, ad hanc $G$. cupularis var. omnia ista synonyma referenda credidi.

78. GYALECTA geoica, apotheciis immersis urceolatis, limbo orbiculari elevato integro discoque albido hyalinis Ach. syn. p. 9 .

Lichen geoicus. Wahlenb. in Vet. Ac. Handl. 1806. p. 142. t. 4. f. 6. Urceol. Ach. meth. p. 149.

Ad terram supra petras calcareas Gottlandiæ. Wahlenberg!

Priori valde affinis, at transitúm non ohservavi. Apothecia puncto vix majora, poro integro dehiscentia, omni colore flavorubello destituta (nec tantum ut prioris 
speciei abortiva decolorata), nam etiam crusta primitiva hyalina videtur.

179. GYALECTA odora, apotheciis immersis urceolatis, limbo orbiculari demisso tenui integerrimo albido, disco lutescente. Schaer. spic. p. 8 o.

Gyalecta suaveolens. $S . O . V \cdot p \cdot 285$.

Exs. Schaer. Helv. n. 136.

Ad saxa granitica irrigua Helvetiæ in monte Grimsel Schcierer! Saxoniæ metalliferæ Schubert!

"Thallus crustaceus, tartareus, tenuissime rimosoareolatus, eifusus, ex roseo sordide rubescens; recens Jolithi odorem spargit. Apothecia minuta, singula crustæ areolis immersa ; juniora punctiformia, adulta latiora, disco carneo-rubescente, linbo recto, pallidiori, rarius supra crustam elevato." Color crustæ primarius videtur albidus, odor adventitius, at cum prioribus tamen non conjungam, nec cum Urceol. suaveolente 1. c. p. 70. Exs. n. 124, quæ evidenter analogus status Parmeliæ, forsan ipsa $P$. cinerea $\eta$.

180. GYALECTA Prevostii, apotheciis immersis subrotundis lirellæformibusque , limbo repando integerrimo albido, disco roseo-incarnato.

Exs. Moug. et Nestl. n. 848 .

Ad rupes calcareas Gallixe satis frequens; primus circa Rothomagum distinxit accuratiss. Lichenum observator $A$. Le Prevost!

Crusta primaria incarnato-albida, vulgo autem cum calce turgescente coalita confusaque, cinerascens, non pulveracea. A pothecia foveolis saxi profunde immersa, minuta, valde difformia, (subrotunda, angulata l. lireltæformia). Discus primo gelatinosus, carneo-pallidus, demum etiam nigrescens, canaliculatus, libero cinctus limbo albido. Quin pulchelli hujus Lichenis singularis habitus e loco in calce juniori magna ex parte pendeat, nullum dubium est, sed a Parmel. cinerea $\eta$. limbo aliisque notis bene diversus videtur.

181. GYALEC'TA ? exanthematica, apotheciis subimmersis conniventibus, limbo supero a centro 
versus anbitum radiatim fisso', disco nucleiformi luteo.

Lichen volvatus. Vill. Delph. III. $t$. 55. Lich. exanthemat. Smith. Transact. Linn. Soc. I. p. 81.t.4. f. 1. Engl. Bot. t. 1184. Urceolar. dein Thelotrema Ach. Volvaria Decand. Lichen clausus. Holfm. en. Lich. Verrucaria. Ejusd. Germ. Thelotrema Schaer. spic. p. 68 .

Exs. Flörk. Deutsch. n. 105. Moug. et Nestl.n.846. Schaer. Helv. n. 122.

Ad saxa calcarea Europæ fere omnis, excepta Scandinavia.

Crusta primaria etiam in hac specie contigua \& lutescens videtur, sed ex antecedentium lege ob locum natalem mox leprosa albido-cinerascens aut disparens. Apothecia plus minus immersa, primo clausa, excipulo subdimidiato (supero tantum), dein a centro radiatim fisso, tandem decidua. Nucleus in perfectis disciformia, luteus, marcescendo collapsus elabensque foveolam albam in saxo relinquens. - Lichen valde atypicus, a Thelotremate (ceterum vix nisi Urceolaria personata) abunde diversus, quem in natura satis observare non licuit. Tanta vero cum hac tribu affinitas (Cfr. n. 153) \& cum hac serie analogia, ut hoc loco inserere debuerim.

\section{Trib. II. L E C I D I N $\mathbb{E}$.}

CHAR. Apothecia libera, orbiculata, mox convexa, cephaloidea, subimmarginata. Discus semper apertus, æquabilis, excipulo proprio impositus.

Quamquam limites hujus tribus a præcedente in infimis utriusque formis ita obliterantur, ut multæ in bivio positæ videantur, utramque ex integro contemplanti facile patet, diversam eam a præcedenti efficere evolutionis seriem, non oppositam, sed parallelam. Sic v. c. licet Stereocaulon Usneæ, Cladonia Everniis, Ramalinis \&c., Bceomyces Peltigeræ, Biatora Parmeliis, externa facie similiores videantur, re ipsa cum citatis tantum aanaloga sunt, inter se vero maxime affinia. Ex hac propioris \& remotioris, quæ sæpe cum externa facie magis convenit, affinitatis lege, quam per omnem naturam observatam volui, pendet, quod in naturali dispositione $\mathrm{Sy}$ - 
stema constructum adaptato prætulimus (vide Syst. Orb. Veg. p. 9. Syst. Myc. I. p. XIV \&c.) Nemo igitur miretur post Parmeliam \& Gyalectam non sequi simillimam Biatoram, sed Stereocaulon, Cladoniam \&c.; nam in singula serie, per se ut integra considerata, eandem dispositionis legem secuti sumus, unde oritur dispositio parallela, nec adaptata. Ex eisdem rationibus, quas ad primam attulimus, etiam hæc tribus, utpote contiguam evolutionis seriem sistens, ut genus superius (Lecidea. Syst. Orb. Veg. p. 247) considerari potest \& quidem ex principio v. c. in Mycologia stabilito debet., At licet ipse dispositionibus thallinis parum faveam non possum non thallo majorem vim inter Lichenes tribuens pleraque genera thalli habitu simul non suffulta vacillantia esse agnoscere. Videntur quidem genera hujus tribus inter se magis discreta quam Parmeliacea, sed pendet hoc e formis paucioribus, quare plura membra intermedia deesse videntur, \& characteres primarii non minus thallini sunt quam Parmelix. Optime monuit Eschweiler podetia variorum Stereocaulorum haúd majore jure dici podetia quam Usnex; conferas e. g. Stereocaulon laccatum \& Usneam melaxantham. Tantum abest, ut Stereocaulon, Cladonia \&c. altioris sint dignitatis firmioriumve fundamentorum quam Usnea, Ramallina \&c., ut potius longe facilius cum Biatora confluant, quam genera citata cum Parmelia; nam horum nullæ extant formæ, quæ cum Parmelia confundi possunt, cum plurimæ Stereocauli \& Cladonix apotheciis atypice in thallo horizontali, sessilibus nullo modo a Biatoris separari queant. Exstant porro directi transitus; v. c. inter Stereocaulon \& Lecideam prorsus intermedia est Lecidea vesicularis, inter Cladoniam \& Biatoram Biatora Cladonia. Sic natura contigua' est, quamquam circa certos typos formæ magis colliguntur, unde sectiones oriuntur. Sectiones inde plurimas nec absolute naturales (h. e. ut abscissa \& stricte limitata naturæ membra, qualia vero nonnulla insularum instar oceani exstare videntur) nec mere artificiales censemus, \& perinde sæpe videtur, utrum has sectiones tribus an genera, subgenera \&c. dicamus. Meam potius admirationem movet certitudo absoluta, qua nonnulli de his rebus judicium fuerunt, cum ex usu \& consuetudine ex maxima parte pendeant. Et cum Cladonia, StereocauJon \&c. sint naturales sectiones ut genera vulgo consideratæ, non invenio rationes sufficientes, mutationis molestias compensantes, ab hoc usu discedendi, At omnia 
Parmeliacea genera conjungere \& hrc distinguere certe. erroneurn est. Wallrothius sub Patellariae nomine conjungere in, animo habere videtur, ut apparet per antiphrasin, cum ab his forma patellata præcipue aliena. In Lecideis optimis ob insignem duritiem apothecia patellata tantum persistunt. - Sub Baomycete Wahlenberg tria prioria genera jam in Fl. Lapp. conjunxerat, Booomycetem \& Cladoniam in Methodo Acharius; in Lichenologia universali Cladonias sub Cenomyce distinctas describit.

\section{STEREOCAULON.}

Coralloidis spec. Dill. - Hoffm. - Stereocauli spec. Ach. Stereocaulon. Decand. - Eschweil. - Fries Syst. Orb. Veg. - Meyer.

CHAR. Aputhecia discreta, libere enata, primo turbinata marginata, demum cephaloidea immarginata solida. Discus semper apertus, excipulo proprio impositus, ascis perfectis linearibus. Thallus verticalis caulescens, solidus, intus filamentosus (podetia), "horizontalem squamuloso. granulosum suffulciens (\& in quibusdam speciebus $e$ thallo horizontali granuloso adnato surgens).

Stereocaula naturalissimam cum Usneis analogam efficiunt sectionem, quare specierum limitatio difficillima. Possent quidem omnes pro unica primitiva specie haberi, sed considerata tota evolutionis serie præcipue vulgatiorum specierum omnes conjungere temerarium mihi visum est. Inter se tantum differunt, quantum Peltidex Ach., licet ob proteam indolem ægrius limitentur. Meis observationibus ad omnes determinahdas haud sufficientibus ab amiciss. Laurer, qui annos complures』 generi huic, monographice a se tractando, felicissime operam dedit, rogavi specierum Europæarum dianomen, quam quoque liberalissime communicatam stricte me secutam esse gratissima mente agnosco.

Præter apothecia vera cephaloidea, in omníbus normaliter rufofusca, observantur quoque cephalodia fungosa immarginata rugósa nigricantia ut in Parmelia ceis (Vid, Flörl. Deutsch. Lich. 4. p. 14.), quæ 
apothecia abortiva censeo. Cum his non confundendi pulvinuli tomentosi, simul passim obvii, ab indumento podetiorum orti.

* 'Thallo foliaceo-squamuloso aut fibrilloso. Laurer. 182. STEREOCAULON tomentosum, podetiis laxis teretibus ramosissimis, tomento spongioso albicante densissimo obtectis, squamulis subrotundis inciso-crenatis cinereo-cresiis, apotheciis minutis lateralibus, demum globosis. Sched. Crit. 3. p. 20.

Stereoc. tomentosum. Laurer. Monogr. ined. Wahl. Suec. p. 855. St. paschale, Sommerf. Lapp.p. 125. (Reliqua synon. hybrida.)

Exs. Lich. Suec. n. 90. Fl. Deutsch. n. 199. $A$.

Ad terram præcipue ericetorum, sed etiam supra saxa, Europæ magis montosæ \& borealis copiose.

Optime dignoscitur defectu thalli horizontalis ad basin podetiorum; podetiis basi liberis (unde specimina hujus saxicola saxo tomento tantum laxe inhærentia ab omnibus sequentibus facillime dignoscuntur) \& solitariis (nec cæspites ut subsequentium e pluribus discretis podetiis aggregatis oriuntur), densissime tomentosis, unde reliquorum crassiora fiunt, laxis, ramis adultis recurvis; thalli squamulis optime evolutis, confertis \&c. nec non minutie, forma \& situ constante apotheciorum. - Coralloides paschale Hoffm. Pl. Lich. p. 23. t. 5. f. 1. huic proxime accedit, at nec icon accurata, nec a reliquis rite distinctum est.

183. STEREOCAULON corallinum, podetiis laxis compressiusculis ramosissimis glabris, squamulis fibrillosis subdigitato-ramosis cinereo-cæsiis, apotheciis sparsis conglomeratisve, mox globosis. - Laurer. Monogr. ined.

Lichen paschal. Fl. D. t. 151. Stereocaulon paschale fibrillosum Ach. Stereoc. corallinum. Schreb. spic. p. 113. Fries Sched. Crit. 4. p. 24 (coralloides). Stereocaulon dactylophyllum. Flörk. Stereocaul. Rösleri. Hochstett.

Exs. Lich. Suec. n. 118. Fl. Deutsch. n. 78. Moug. et Nestl n. 73. Funk. Crypt. Gew. 
Saxis innatum in regionibus pineto-nontanis frequens ; etiam in subalpinis v. c. Helvetice $S c h a e$ rer! inque ramis Pinuum in silva nigra regni Würtembergici speciosissimum Hochstetter!

Ab infimo statu, lineam haud attingente, per totam evolutionis seriem pulcherrimam haric speciem secutus sum \& a reliquis eximie diversam inveni. Thallus ad basin semper \& jam primitus nullus. Podetia plurima in densum cæspitem (primitus digitato-divergentem) basi conjuncta \& saxo, Umbilicariæ instar, innata. Podetia adulta ramosissima, laxa, basi glaberrima subtestacea, ceterum pallida tenuissime tomentosa. Squamulæ thalli in podetiis sparsa ramos referunt in ramulos corallinoideos abeuntes, qux ob majorem fragilitatem \& ramificationem hanc Sphærophoro coralloidi simillimam reddunt. Varietatem hujus pumilam conglomeratam, quales occurrunt specierum plurimarum, e Norvegix alpibus attulit Ahnfelt.

184. STEREOCAULON paschale, podetiis laxis compressiusculis ramosissimis glabriusculis, squamulis phylloideo-granulosis crenatis conglomeratis glaucis, apotheciis subterminalibus dilatatis planis. - Laur. Monogr. ined.

Lichen paschalis. Linn. (circa Upsaliam frequens \& optime evolutum). Stereocaul. paschale. Ach. pr. p. Wahl. Suec. p.854. a. Exs. Ehrrh. Crypt.n.118. b. minus, conglomeratum. Sched. crit. 3. p. 98. Exs. Lich. Suec. n. 89. Fl. Deutsch, n. 199. B. c. subcrustosum, ramuloso-inæquabile, apotheciis maximis.

Saxis adnascitur præcipue in regionibus Sueciæ montanis frequens, rarissime in cortice Pini; exteris rarius videtur.

Ceteris magis variabile \& forsan nonnullorum sequentium mater. Oritur e thallo crustaceo saxo adnato evanescente, unde plurima podetia vulgo densissime stipata (nec cæspitoso-juncta ut in priori) sæpe latas plagas saxormm occupant. Podetia juniora \& superne tomento tenuissimo vestita, adultiora vero glabra, plus minus irreguiariter ramosa, dense incrustata. Squamulæ primæ speciei crassiores, subrotundæ, crenulatæ, glaucæ nec cæ- 
six. Apothecia plerumque ampla, solitaria l. glomerata. c. primo obtutu $P$. subfuscam terrestrem refert.

85. STEREOCAULON condensatum, podetiis erectis teretibus subdivisis, tomento tenui alboincarnato vestitis, squamulis subrotundis teretiusculis confluentibusque glaucis, apotheciis terminalibus dilatatis planis subpeltatis. Laur. Monogr. ined.

Hoffm. Germ. p. 130. Stereocaulon condyloideum, \& pileatum Ach. Bæom., Stereoc. paschale. $\beta$. Wahl. Lapp. et Suec. St. meissnerianum. Flörk. ex Laurer.

Exs. Lich. Suec. n. 88. Fl. Deutsch. n. 38. Ad saxa \& terram glareosam passim. Præcedenti peraffine, at facillime dignoscitur. Thallus horizontalis ad basin in hoc persistit. Podetia inter se discreta, sed in thallo aggregata, simplicissima I. parum divisa, omnino erecta, teretia $l$. obsolete angulata, per xtatem quoque glabra, plurima fertilia, ipsa ramive apothecio subsolitario valde dilatato planiusculo, in ambitu demum reflexo, termináta. - Specim. authentica St. Cereolini Ach. meth. t. 7. f.1., (a quo vero Stereoc. vulcani Bory ex spec. authent. ab amic. Fée misso abunde differt \&, inventore ipso indicante, St.ramuloso proximum est) nil nisi hujus status macrior, sterilescens \& deliquescens, unde superficies pulverulenta.

** Thallo verrucaeformi rotundato aut angulato. Laurer.

186. STEREOCAULON incrustatum, podetiis erectis teretibus ramosis, tomento spongioso densissimo vestitis, granulis verruceformibus coacervatis glaucis, apotheciis terminalibus dilatatis subpeltatis. Flork. D. Lich. 4. p. 12. Fl. Dan. $t$. 1721. Laurer $l$. c.

Exs. Flörk. l. c. n. 7\%. Funk. Crypt. n. 624.

Ad terram in pinetis campestribus, formatione juniori substratis Galliæ, Germanix, Gotlandiæ.

Ánalogum cum Stereocaulo tomentoso, at basi adnatum notisque allatis facile distinctum. 
187. STEREOCAULON alpinum, podetiis laxis teretibus ramosis, tomento spongioso tenui vestitis, granulis verruceformibus immarginatis glauco-albicantibus, apotheciis sparsis dilatatis convexis. Laur. IMonogr. ined.

Scheuchz. It. alp. II. t. 19. Petiv. Gazophyl. II. n. 158. Mich. gen. t. 33. f. 7. Stereocaul. spec. nov. Ahnfelt in Vet. Acad. Arsb. 1826.

b. botryosum, Laur. podetiis erectiusculis inferne glabris, granulis in ramulis densissime conglomeratis. St. botryosum. Ach.

In summis alpibus Europæ fere totius.

In statu normali ad elatiores \& valde cæspititias pertinet; b. est forma solito more conglomerata. Basis in vetustis nigrescit. Granula confertissima, subrotunda \& angulata, numquam sequentis more peltata \& marginata. * STEREOC. vesuvianum, podetiis erectis subangulatis ramosis, tomento spongioso tenuissime vestitis, granulis subglobosis crassis conglomeratis fusco-punctatis, demum planiusculis flavente-marginatis. Pers. in Act. Wett. 2. $t$. Io. $f$. 5 .

Lich. saxatil. Mich. $t$. 53. $f .6$.

Ad saxa Italia, præcipue in Vesuvio!

Dubium \& hactenus sterile lectum prioris var. ex Achario, sequentis ex Laurero. Cum hoc quoque metamorphosi granulorum prorsus convenit.

- I88. STEREOCAULON denudatum, podetiis laxis teretibus ramosis glabris, granulis subrotundis cinerascentibus, dein planiusculis crenato-lobatis olivaceis albo-marginatis, apotheciis lateralibus minutis planiusculis. Flörk. l.c.p. 13. Moris. Hist. 11. t. 7. ser. 3. f. 12. Dill. Musc. t. 17. $f$. 33. Ster. denudatum. Sommerf. Lapp. p. 126. Laurer Monogr. ined.

Exs. Fl. Deutsch. n. 79. Moug. et Nestl. n. 466.

Ad rupes in præruptis montium subalpinorum Europæ totius.

Ster. paschale valde analogum est, offertque statum 
podetiis simplicioribus dense incrustatum huic in statu sterili valde similem, sed hujus thallus primitus granulosus peculiari modo applanatur in squamulas spurias subpodicellatas quasi peltatas albomarginatas a squamulis St. paschalis prorsus diversas. Ceterum habitu facile dignoscitur. Tres notat amiciss. Laurer status: a. tenue, podetiis gracilioribus, ramosioribus, granulis subrotundis glomeratis subpodicellatis. b. validum, a Dillenio pictum, podetiis crassioribus, parum angulatis, granulis majoribus scutiformibus aggregatis. c. digitatum, podetiis simplicioribus, superne digitatim ramosis, granulis tam rotundatis quam scutiformibus. Hoc Morisonii icon exhibet. Offert simul statum cum "St. cereolo" Ach. analogum \& confusum ex Laurer.

189. STEREOCAULON nanum, podetiis erectis gracillimis fastigiato-ramosis, inferne denudatis nigricantibus, superne tenuissime pulverulentis, granulis verrucxformibus minutis pallide virentibus floccosis, "apotheciis lateralibus convexis." Ach. syn. p. 285.

Mich. gen. t. 53. f. 8. Hall. helv. n. 2026. Lich. quisquiliaris. Leers. Stereocaul. Hoffm. Lich. dein Stereoc. nanum. Ach. - Laur. Monogr. ined.

Exs. Lich. Suec. n. 59. Moug. et Nestl. n. 647.

In fissuris rupium Europæ totius, præcipue occidentali-maritimz. Copiosissime in Hallandia.

Tam a precedentibus granulis floccosis, quam a" $\mathrm{Ce}$ nomyce delicate" Ach. podetiorum solidorum structura, omnibusque speciebus, ad quas relatum fuit, plane diversum, licet valde atypicum appareat. Vulgo enim floccoso-pulverulentum occurrit (in hoc statu cum Stereoc. cereolo Ach., Stereocaul. pileati aberratione, analogum) colore plerumque ochroleuco, sed pulchre æruginoso \&c. variante. At e Norvegix alpibus attulit optimus $A h n-$ felt specimina magis integra, cinereo-pallescentia, thallo eximie granuloso, ut habitus omnino prioris, modo longe tenuior, quare non potui non sub hoc genere servare; structura thalli a Cladoniarum prorsus recedit.

\section{C L A D O IA.}

Coralloidis spec. Dill. Cladonia. Hoffm. - Schrad. Schaerer (qui apothec. normalem indolem primus 
indicavit) - Fries Syst. Orb. Veg. - Meyer. Flörk. Mon. Cladonia, Scyphophorus \& Helopodium. Decand. Capitularia Flörk. olim. Martius. Patellariæ Steliophoræ. Wallr. Monogr.

CHAR. Apothecia discreta, libere enata, primitus scyphuliformia, mox inflata cephaloidea immarginata intus inania. 1)iscus apertus, mox protuberans reflexus excipulum proprium, cui impositus, abscondens, ascis obliteratis. Thallus horizontalis squamuloso-foliaceus aut crustaceus, a quo surgit verticalis caulescens (podetia), cartilagineus, fistulosus.

I. Genus Everniæ \&c. analogon in hac serie, eximie naturale, inter omnia maxime proteum. Hinc in nullo alio genere tantum dissentitur, quid sit species, quid varietas, quasi in hac dijudicanda lite amabilis disciplinæ unicus finis positus esset. Evidentissimum exemplum offerunt nuperrime hujus generis monographix a Cell. Viris Flörke \& Wallroth editæ, quas ducibus summa experientia \& ingenii acumine conscriptas esse nemo est qui non videat. Accedit nostra, secundum principia in Sched. Crit. 8. p. 16-20 elaborata, ab utraque, in proponendi modo magis a Wallrothiana, in principiis a Flörk eana, recedens, l. potius viam mediam tenens. Qualem his monographiis non visis elaboraram, meam cemmunico, postquam denuo cum his in natura comparavi. - $S_{i}$ quid in Cladoniis determinandis progrediemur, non sufficit formas similes conjungere, dissimiles distinguere, sed morphoseos indoles plene est exploranda \& physiologiæ trutina ponderanda. At ea est Lichenum indoles, ut si vel leviter indulgeamus ingenio, omnes differentiæ tam generum quam specierum facile tollantur. Dignoscuntur tantum cijusvis sectionis \& speciei typo normali, sed singuli typi aberrationum limites facilius perspiciuntur, quam indicantur. Præcipue cavendum ne ex apparentibus approximationibus speciminum atypicorum diversa confundamus. Sic inter innumera exempla utique adest forma sterilis -Clad. botrytis, quæ ab omnibus ad Cl.uncialem rejecta videtur, \& thallo privata vix ab eadem discerni potest; earum vero origo abunde diversa est. Ad transitus demonstrandos seligi possunt specimina omnium Cladoniarum, Biatora- 
rum e. s. p. tam sibi invicem ut apparet appropinquantia, uf, qui singulam in natura haud persecutus sit, omnia confluere paratus sit jurare. - Ratione supra indicata inventas formas primarias \& typicas distinguimus, singulares, mere fallentes, aberrationes, utpote quæ formis primariis non stabilitis controversiarum cumulum tantum superstruant, consulto reponentes. Per quinque licet lustra intensissimum huic generi dicaverim laborem, non is equidem sum, qui fingam mea judicia magis pollere 1. recepta fore, quam omnium antecessorum, licet et his ipsis quam mihi non magis persuasum sit de suorum practico usu, sed spero me vere affinia recollegisse \& formas prominentes tantum protulisse, quas quisque deinceps species, subspecies, varietates ad suum genium facile dicat. Studio ductus auctoritatem vetustatis \& stabiliti, quousque fieri posset, servandi, numquam nisi summa urgente necessitate ab hac discessi \& in rebus problematicis malui cum Patribus errare, quam forsan cum recentioribus vera dicere. Quo peritiores magisque natura: nexum perspicientes fuerint observatores, eo liberalius concedent, in his rebus dijudicandis multum semper subjectivi adhiberi. Aequo jure ac Cel. Wallroth, inģenio scatens, omnes Cladonias ad tres species reduxit, mihi videntur, ut a Scopolio, Hudsonio \&c. factum, in unam conjungi posse. Equidem vero qui a naturæ adytis extra indubiam experientiam resignandis religor, id tantum affirmare adspiro, nil a me conjunctum umquam salva natura veritate distingui posse.

II. Sectiones a podetiorum forma hactenus receptas haud persistere posse, jam 1. c. demonstrare conatus sum \& Cel. Wallroth, ut solet, plene nuperrime deduxit. Nec majoris ponderis est nova subdivisio, scyphis e centro proliferis, a Cel. Meyero indicata; licet hanc notam, in nostris inconstantem, in exoticis v. c. Clad. perfoliata Fl. (apotheciis veris a me visa) stabilem agnoscam. Summas differentias in thallo crustaceo \& foliaceo \& apotheciorum colore positas esse adhuc urgeo, licet meas rationes Gel. Wallrothio non satisfecisse videam. At ipsius optimi viri species, nostræ fere sectiones, re ipsa apotheciorum colore potissimum nituntur, Clad. papillariam non ad Patell. coccineam suam, sed $P$. foliaceain ex suis principiis referre debuit. Apotheciorum color cum totius stirpis habitu \& lepræ colore ita conjunctus est, ut etiam sterilium apotheciorum colorem sine te- 
meritate præsagire liceat. Observandum modo, duplicem esse apotheciorum vulgo colorem, alium laminæ superficialem, alium excipuli latentem, utrumque tamen constantem. Sic color superficialis Cocciferarum coccineus est, latens vero luteolus, qui cum illo locis udis evanescente 1. quasi eloto prodeat, omnium hujus sectionis specierum habemus formam ochrocarpiam. Exinde acutiss. Wallroth Cladonias cocciferas \& ochroleucas conjunxis'se videtur. - Ex apotheciorum colore oritur quadruplex Cladoniarum series, Parmeliarum omnino respondens. Obtemperans rationibus sub Parmeliis allatis, quibus accedit diversa morphosis podetiorum, sectionem thallo crustaceo distinctam seposui, licet ceterum perevidens sit singulam illius speciem antecedentis sectionis series continuare \& claudere.

Sect. I. Thallus horizontalis squamuloso-foliaceus, passim evanescens. Podetia e squamulis orta, sæpeque tecta.

Morphosis \& metamorphosis thalli. E granulis primordialibus oriuntur squamulæ aggregatæ, primitus rotundatæ. Locis nimis udis sub hac forma primaria pronascuntur in frondes subrotundas, concaviusculas, integras, quæ, ut primus observavi, certe verum Endocarp. viride Ach. syn. p. 100 (Lich. Suec. n. 37) efficiunt. (Alii dein ad Peltig. saccatam retulerunt; analogon forsan, quod vero apud nos non obvium nec a me visum). Normaliter autem uno latere extenduntur, varie lobatæ \& incisæ evadunt, supra glabræ virescentes; subtus albæ, normaliter nudæ, locis udis 1 . cariosis variant pulverulentæ, quem characterem itaque certæ speciei adscribere nolui, cum omnino inconstantem viderim (vidi v. c. $\mathrm{Cl}$. Cornucopioidis, deformis squamulas subtus pulverulentas, $\mathrm{Cl}$. digitatoe subtus nudas). Ulterior squamularum evolutio non parum e loci diversitate pendet. Vulgo minutæ, imbricatæ, crenulatæ; ad latera umbrosa fossarum glareosarum evadunt tenellæ, adscendentes, tenuiter incisæ, sæpe apice recurvæ \& in pulverem fatiscentes, ad typum "Lichenis tenelli" inter Physcias, quæ forma leptophyllince dicendx; at in irriguis, in stillicidiis rupium similibusque locis nascuntur formæ macrophyllina, squamulis insignioribus, elongatis, erectiusculis , nudis, qualis Cenomyce cervicornis Ach. tam a Cl. pyxidata, quam præcipue a Cl. gracili v. verticillata orta. Simi- 
les habemus plurimarum specierum; in Clad. alcicorni, turgida \&c. normales apparent, illam tamen sæpissime legi microphyllinam. Cum formis macrophyllinis non confundendæ platyphyllinoe, squamulis valde dilatatis expansis parum incisis, quarum frequentissimum exemplum offert Clad. digitata, sæpe vero etiam microphyllina, (unde Flörkei in Acharium de hujus thallo observatio pendet); at in reliquis analogi status minime desiderantur. Denique in maxime apricis, præcipue calcareis, vidimus formas pachyphyllinas squamulis crassioribus, subnitentibus, in medio sæe crustaceis. Talis Clad. pyxidatce status est Cen. pocillum. Ach. Porro notandum est thallum ad basin in plerisque, præcipue inter muscos nascentibus, prorsus obliterari. Tandemque in cryptis locisque perumbrosis irriguis, ut ad latera muscosa saxorum majorum sylvaticorum, thallus foliaceus prorsus deliquescit \& in lepram byssaceam, qualem in evidenti transitu per Lich. Suec. Exs. distribuemus, solvitur. In hoc statu e lævi varietate cum aliorum Lichenum analogis promiscue dicitur Lepraria byssoidea, latebrarum, aruginosa \&c., Conferva pulveria \&c. Cladonia nulla "thallo nullo" describi potest.

Morphosis podetiorum. Thallus verticalis s. Podetia, licet in generico charactere etiam ut pars fructificationis recipiantur, non sunt organum adeo necessarium, ut non passim prorsus excludatur. Tales status, Biatoras referentes, habemus plurimos omnium serierum. Hujus exempla sint Lich. Suec. n. 231. A., Lichen rubiformis Engl. Bot. t. 2112 (at minime Lecid. rubiformis Wahlenb.!) \&c.; proxime accedunt Cladonioe varix epiphyllae, podetiis abortivis, quæ omnes pro statibus abnormibus \& degeneratis habendæ sunt. Vera podetia in hac sectione e pagina superiori squamularum prorumpunt (atypica sunt e squamulis ipsis transformatis orta) $\&$, licet in adultioribus terræ infixa appareant, tantum thalli abortu epigæa facta sunt. - In omnibus, typice saltim, podetia primitus glabra sunt; haud raro obviam veniunt specimina 1 . ex parte l. tota glabra specierum vulgo pulverulentarum. Podetia pulverulenta \& glabra, sensu recepto, species non distinguere, plurimis exemplis in Sched. Crit. 1. c. demonstravi. In eximia Cladoniarum monographia Cel. Flörke, qui huic momento debitam attentionem primus dicavit, Clad. pleurotam pro statu pulverulento Clad. cocciferce habet; nec aliter differunt 
Cl. chlorophaea Fl. a Clad. neglecta Fl., Cladon. pityrea Fl. a $\mathrm{Cl}$. degenerante e. s. p. Habemus analogos status variarum v. c. Clad. gracilis \& s bulatoe, quorum illius videtur Clad. Rei Schaer. spic. p. 34., at non Clad. glauca Fl. Clad. p. 140. At in ipsa epidermide podetiorum ejusque diversa deliquescendi ratione differentiæ satis certæ latere videntur. In aliis enim v.c. Clad. cornucopioide, pyxidata, gracili \&c., epidermis primitus cartilaginea, lævigata, dein verrucosa, verrucis nunc in squamulas thallinas, nunc in furfurem grossiusculum abeuntibus. In aliis autem epidermis potius membranacea, mox \& sæpe sub ipsa evolutione in pulverem subtilissimum subvelutinum fatiscens, in omni ætate lævis, qualis in Clad. deformi, carneola, fimbriata, cenotea \&c. Hæc differentia cum plurimis in podetiorum metamorphosi conjuncta est, unde magis essentialis evadit, quam primo obtutu apparet. Podetia epidermide membranacea $a b$ apice deorsum determinate fatiscunt; inferior pars sæpe glabra persistit, nec umquam verrucosa fit: podetia epidermide cartilaginea magis indeterminate in granula \& furfurem solvuntur. Servo specimina Clad. gracilis per intervalla glabra \& furfuracea. Evidentior observatur epidermidis diversæ vis squamulas diverso modo formandi. Verrucæ ex epidermide cartilaginea diffracta ortæ facile in squamulas excrescunt, \&, quod in plerisque admodum notabile, ab apice, incipientes a margine scyphi, deorsum squamulas explicant, unde ex his formantur formæ insignes vel margine scyphi folioloso vel symphycarpex, apotheciis squamulis cinctis. (Cfr. Clad. cornucopioides, gracilis, alcicornis, crispata \&c.). At pulvis specierum epidermide membranacea numquam in squamulas abit; in his squamulæ thalli tantum $a b a-$ si non fatiscente in podetia adscendlunt. Hinc in Sched. Crit. I. c. squamas in his pro prole thalli s. thallo polyphyllino; in illis pro epidermidis metamorphosi, nam cum podetiis decorticatis conjuncta sunt, habui. Accedit porro podetia cartilaginea, quantum hactenus observavi, in siccis numquam in furfurem fatiscere, sed tantum in uliginosis, ad latera saxorum irrigua e. s. p.; at contraria est ratio specierum epidermide membranacea, quæ in siccis maxime deliquescunt, in uliginosis autem, magis persistunt. - At ipsa podetiorum forma multas magisque fallentes subit mutationes. Normalis est forma $p y$ xidata aut infundibuliformis, a qua reliqux omnes, li- 
cet typica in quibusdam speciebus recedentibus rarior sit, degenerationes tantum. Hinc apud me in singula serie agmen ducunt species optime scyphiferæ scyphis amplis cyathiformibus, podetiis perraro ramosis \& sterilibus, quarum formæ symphycarpeæ aut abortivæ tantum scyphum excludunt. Quo magis podetia elongantur, eo minores evadunt scyphi, eo frequentiores formæ cornutæ \& steriles. Typice quoque podetia hujus sectionis simplicia sunt; omnis ramificatio pro prolificatione haberi posset. In formis optime scyphiferis omnes proles aut in podetia abeunt scyphifera aut saltim symphycarpea; sed hæc scyphos imperfectiores proferentia proles plerumque cornutas \& steriles enituntu̧r. Egrediuntur proles (in nostris promiscue) vel e disco l. sæpius e margine scyphorum; quæ ad latera podetiorum rarissime observantur, omnes abnormes 1., ut in Clad. fimbriata, e scypho abortivo pendent. Inter scyphos veros, epiphragmate clausos, \& apertos s. infundibula, nondum adeo directos vidi transitus, ut hanc differentiam ut non primariam omittam. Occurrunt quidem illi epiphragmate pertuso \& podetiis dehiscentibus, at hoc evidenter accidentale est. Tandem ut status podetiorum prorsus degener \& morbosus certe consideranda sunt pocletia cariosa, lateraliter rimose dehiscentia, quales status fere omnium specierum habemus. In speciebus reducendis vel difficillimum in his terris facile convincam "Clad. cariosam" a Clad. degenerante, pyxidata e. s. p. ortam esse. Reliquæ omnes species clavatæ (Fielopodia) atypicæ sunt, \& ab apotheciis symphycarpeis potissimum pendent.

Metamorphosis Apotheciorum. Tantum apothecia in charactere indicata normalia sunt $\&$ in omni specie obvia. Omnes differentiæ petitæ ab apotheciis extensis, peltaformibus, maximis, demum pertuso-perviis e. s. p. \& ad species distinguendas adhibitæ abnormes certæ sunt. Omnia ab apotheciis pluribus primitus coalitis orta sunt, quare sub communi nomine symphycarpea a me comprehenduntur. Horum magna est vis ad ipsius podetii faciem mutandam. Quando apothecia jam primitus in podetiorum apice confluunt, nullus scyphus explicatur, unde e speciebus podetiis obconicis oriuntur formæ vulgo symphycarpea dictæ, apothecio demum pervio; a podetiis vero elongatis formæ sic dictæ fibulaformes. Sæpius autem prolificationes e scyphis perfectis symphycarpeæ evadunt ut in "Cladonia extensa" Hoffm., cujus 
apothecia magna cum margine extenso certissime nil nisi prolificatio ex apothecio symphycarpeo suppressa, nec aliter differt hæc forma a s. d. Helopodiis, quam podetio primario in his symphycarpeo, cum in "Cl. extensa" (\& tales exstant omnium specierum) prolificatio demum symphycarpea. Inter formas fruticulosas \& ascyphas apothecia symphycarpea prorsus desiderantur. Ex his omnibus in morphosi \& metamorphosi explicatis lusibus varietates distinguere inutile censeo. Innumeris illis formis, proprio nomine designatis, e podetiis sterilibus \& fertilibus, simplicibus \& proliferis, junioribus \& adultioribus \&c. \&c. tempus \& charta tantum perdi mihi videntur.

Ser. I. Glaucescentes. Apothecia rufa, unicoloria. Podetia cum thallo, normaliter insigni, viridi-glauca, sed colorem incusum flavidum exsiccatione proecipue prodeuntem foventia, basi carie flavida. Patell. foliacea. Wallr. p. 162. ex max. parte.

Series maxime insignis præcipue apotheciorum colore tam superficiali, quam latente rufo; per ætatem obscuriori, unde numquam pallescunt; porro thallo submacrophyllino, ceterum tantum in proximis sequentis seriei ut abnormi obvio; epidermide numquam quantum innotuit deliquescente h. e. pulveracea aut granulosa. Ceterum hæc series magis australis est, potissimum $A$ fricana; nam inde plures habemus formas \& in Africe desertis, una cum simili Parmelia e vicinia. P. crassce ex obs. illustriss. Ehrenbergii, præcipuum Antilopis offert pabulum, ut species seriei Fuscæ (Cl. rangiferina) Cervo Tarando in Lapponia.

190. CLADONIA endiviafolia, thallo foliaceo subtus efibrilloso, podetiisque lævibus turbinatis glaucis, scyphis concavis irregularibus incisis, apotheciis rufis.

Mich. gen. t. 42. $f .3$ (quam Dill. a sequente diversam monet) Lich., Bæomyc., Cenomyce endiviæfol. Ach. (e Michelio recepta). Lichen convolutus. Lamarck. Scyphophorus. Dec. ex spec., syn. sequentis. Clad. alcicornis. $\beta$. Fl. Clad. p. 25. Patell foliacea - - f. convoluta. Wallr. l. c. p. 165. 


\section{In campis vastis sterilibus arenosis (Africæ} \&) Europæe meridionalis versus mare mediterraneum ut Hispaniæ! Galliæ! Italiæ, Vallisiæ!

Limitibus geographicis definitis \& habitu proprio facile dignoscitur; ne levissimum quidem in his terris sequentis ad hanc transitum vidimus. Quod ad illos attinet, facillimum est dictu sequentis esse statum australem, sed in eisdem terris et sequentem sine transitu nasci testantur autoptæ. Thallus adultus omnium Cladoniarum maximus, coriaceus!, obscurus, repetito sinuato-pinnatifidus, subtus fibrillis semper destitutus, qualis casu tantum in formis microphyllinis sequentis, nec in rite explicatis, evadit. Podetia e disco laciniarum assurgentia, brevia, scyphifera turbinata, scyphis irregularibus, sæpe palmatofissis, vix umquam proliferis aut foliosis; variant ceterum symphycarpea cylindrica (Scrphoph. endiviaefol. Chev. par. t. 13. f. 1.), apotheciisque in thallo sessilibus. Huc e syn. Decand. potissimum trahi debet $P a-$ tell. foliacea a. Wallr., sed tales formas epiphyllas singulæ speciei fere vidimus, etiam $\mathrm{Cl}$. alcicornis \& parecha, \& quidem hujus in eodem thallo cum podetiis, ut non possimus probare hanc methodum singulas has mutilationes diversæ originis sub eadem varietate conjungere. In his non magis veras varietates, quam v. c. Botrychio Lunaria capsulas in fronde sæpe gerente \&c. video. Ad formam symphycarpeam, supra memoratam, porro trahi posset $P$. folicac. $b$. Wallr. exclus. tamen syn. Acharii, ad Cl. pyxidatæ analogum statum certe referendo, de quo vero eadem observatio valet.

191. CLADONIA alcicornis, thallo subfoliaceo, margine pilis nigris fibrilloso, podetiisque lævibus turbinato-cylindricis glaucis, scyphis concavo-planis regularibus crenulatis, apotheciis rufis. Sched. Crit. 7. n. 210.

Vaill. par. t. 21. f. 3. Mich. gen. t. 42. f. 1,2. (P. P. auctæ) Dill. Musc. t. 14. f. 12. A.D. Lich.alcicornis. Lightf. et Auct. plur. Bæomyces. Ach. meth. Wahl. Suec. n. 1649. Cenomyc. Ach. syn. Capitul. dein Clad. Flörke. - Clad. Mon. p.23. $\alpha$. Lich. foliac. Huds. - Schreb. Clad. Hoffm. Lich. endivixfol. Dicks. et Varior. Englo-Bot. $t$. 2361. Cenomyc. damæcornis. Lich. univ. p. 530. C. 
Vaillantii Dicf. rev. Cen. Patell. foliacea - - e., g. Wallroth. l. c.

Exs. Lich. Suec. n, 210. Fl. Deutsch. n. 58.

b. microphyllina. thallo squamuloso. Wall. l.c. var. d. neglecta.

Ad terram sterilem sabulosam Europæ australis \& medir; in Suecia tantum in calidissimis provinciis litoralibus, ut in vastissimis arenis Scaniæ orientalis, \& supra petram calcaream ölandiæ, Gottlandireque. b. macrior cum vulgari, etiain in Hallandia maritima.

Post formam primariam turbinato-scyphiferam in quavis serie sequitur gracilior, podetiis magis cylindricis, $\&$ hac ratione præsens ad priorem accedit ut C. gracilis ad C. pyxidatam. Etiam hujus thallus insignis plerumque est, sed prioris omni respectu tenuior \& angustior, lætior, subtus ad margines fasciculato-fibrillosus, qui pili tantum in macris, solo sterili natis, deficiunt, quibus vero prior omnino caret. Podetia, ut dixi, graciliora, longiora, vulgo e margine laciniarum enata; scyphi explanati, margine regulariter crenulato foliosoque. Ceterum valde mutatur ad typum exacle vulgatioris $\mathrm{Cl}$. gracilis, prolibus nunc centralibus, nunc marginalibus e. s. p., ut cum formis Cl. gracilis sæpe in herbariis commutetur. Mich. l.c. f. P. P. hujus sistere specimina aucta rite jam notavit Dillenius; vulgo ad formas Cl. gracilis verticillatas referuntur. - Sic Clad. phyllophora Hoffm., licet Vaill. male citet, omnino est Clad. degenerans. Clad. cornucopioides Hoffm., excl. syn. Mich., itidem aliena \& e diversis formis mutilatis composita. Suadentibus porro ipsis nominibus Lich. sterilis Gonan $\&$ L. ambiguus Vill., ex hac licet regione, oblivioni tradendi, si synonymia aliud sit ac nominum coacervatio.

Ex Europa australi porro vidimus specimina $\mathrm{Cl}$. degenerantem referentia, sed evidenter hujus seriei, quæ vero, plenius in natura haud observatis \& præcipue limitibus geographicis ignotis, distinguere nolui. Omnino respondent Dill. Milsc. l. c. f. B., ex qua Clad. alcic. cladomorpham confecit Acharius; hujus formis accedunt quoque formæ australiores Clad. furcatoe nivea Ach. Conferatur Clad. flabellum. Duf. Rev. n. 27.

-192. CLADONIA turgida, thallo foliaceo subtus 
efibrilloso podetiisque lævibus fruticulosis ramosis glaucis, scyphiferis obconico-cylindricis, scyphis spuriis immarginatis dentato-radiatis, apotheciis carneo-rufescentibus. Hoffm. Germ. 2 . p. 124.

Lich. turgidus. Ehrh. spec. ex herb. misit E. Meyer. Bæomyces. Wahl. Suec. n. 1641. Clad. Dufour Fl. Mon. p. 115. (excl. syn. Schaer.) Lich. parechus. Ach. in Vet. Acad. Handl. 1801. t. 4. f.2. Bæomyc., dein Cenomyce. Ejusd. - Fl. Dan. t. 1356.f. 2. Sommerf. Lapp. p.132. cum forma cornuta, subulata. Scyphophorus diffusus. Dec. fr. 2.p. 338. Lich. Candelabr. Bory. Patell. foliacea. k. turgida. IV allr. l. c.

Exs. Lich. Suec. n. 147. Ehrh. Crypt. 297. Sommerf. $n .73$.

Ad terram sterilem, subirriguam, totius Scandinavie montoso-silvaticæ satis frequens, semper extra prioris consortium; in reliqua Europa per regiones montanas \& alpestres rarius.

Quotcumque conjungere placeat Cladonias, hanc ab omnibus distinctam servem, affinitate $C$. Papillarice proximam. Re ipsa haud scyphifera est, sed ramosa, \& sic dicti scyphi sunt tantum axillæ inter ramos verticillatos 'excavatæ, hinc podetia juniora simplicia (contra omnem Scyphiferarum legem) \& macriora parcius ramosa subulata, scyphifera vero turgida \& scyphi necessario radiato-proliferi; ut etiam proles, quam diu non ramificantur, semper subulatx. Scyphi immarginati, primo \& normaliter clausi, sed ob podetia turgido-distenta passim lacerantur. Apothecia, ut in Fuscis fruticulosis, juniora magis in carneum vergunt. Nec minus thallus insignis est, suberectus, laciniis subpinnatifidis, at podetia ipsa numquam foliacea evadere possunt. Ulterius inquirendum, anne thallus primitivus Cl. turgidæ crustaceus sit, \& folia potius pro podetiis dehiscentibus explanatis habenda. Reperiuntur revera etiam hujus specimina thallo prorsus destituta; alia dealbata, cum " $\mathrm{Cl}$. amaurocraea" Fl. facile commutata \& ab Ach. pro $\mathrm{Cl}$. parecha v. cetrarioide determinata. At ab omni $\mathrm{Cl}$. unciali, ceterum analoga, vere diversa, ut quoque ingenuus Schaerer, visis nostris speciminibus, mox observavit. 
Ser. II. Fusca. Apothecia jam primitus fusca, excipulo dilutiori. Podetia virescenti-fusca, deliquescendo cinerascentia; passim, at semper atypice, dealbata, putrescentia basi nigrescunt. Patell. fusca. Wallr. mon. - ex max. parte.

Optime dignoscitur colore superficiali apotheciorum sordide \& opace fusco, plus minus tamen obscuro, quo evanido apothecia pallide fuscescunt, at numquam in luteolum vergunt. Thallus squamulosus, in duabus primis macrophyllinus varius, in quarta \& quinta vero platyphyllinus sæpe obvius. - Hæc series præ celeris Europcea, quare omnes species ubiquitariæ nec ut reliquarum serierum magis definitis locis, speciebus \& formis ditissima est. Infimæ proles, epiphyllæ \& symphycarpeæ, diversarum specierum difficile e definitionibus dispescuntur, minime vero omnes in peculiares species aut varietates conjungendæ, quales $P$. fusca a. c. \&c. Wallr.

* Scyphiferce. Podetia normaliter simplicia, (tantum prolifero-ramosa,) scypho diaphragmate clauso terminata. Abnormia subulata, ascypha, 1. ramosa, axillis clausis. Clad. pyxidata. Hoffm.

* podetiis cartilagineo-corticatis, glabris aut deliquescendo verrucosis furfuraceisve.

193. CLADONIA pyxidata, thallo squamuloso, podetiis cartilagineo-corticatis mox verrucosis furfuraceisve viridi-cinerascentibus, scyphiferis turbinatis, scyphis cyathiformibus dilatatis, apotheciis fuscis. - Sched. Crit. 8. p. 21.

Tournf. Inst. R. H. t. 325. D. Vaill. par. t. 21. f. $7,11-\& 9$ furfuracea. Mich. gen. ord. VIII. t. 41. f. 1, 2. Dill. Musc. t. 14. f. 6. A. - C., I. M. f. 9. A. Lich. pyxidatus Linn. et Auct. Engl. Bot. t. 1393. Sv. Bot. t. 498. f. 1, 2. Westring. Färglaf. t. 17. Wahl. Suec. n. 1646. Cl. simplex, prolifera, tuberculosa, marginalis. Hoffm. Lich. radiatus Fl. Dan. t. 1188. $f$. 3. Bromyces, dein Cen. pyxidata \& Pocillum. Ach. - Duf. Rev. Capitularia \& Cen. neglecta. Flörke. [Cen. chlorophæa. Fl. in Somm. Lapp. p.130. Clad. neglecta, C. pyxidata $\zeta$. chlorophaa \&c. Fl. Clad. p. 49, 70. Patell. fusca. h. pyxidata. Wallr. pr. $p$. 
Exs. Lich. Suec. n. 235. Fl. Deutsch. n. 16, 200. Schner. Helv. n. 53-55.

Ad terram canporum \& silvarum Europæ tolius vulgaiissima.

Forina primaria hujus speciei pyxidata facile dignoscitur, sed superficies variat verrucosa, granuloso-furiuracea \& squamosa. In hujus speciminibus glabris (Clad. neglecta Fl.) \& furfuraceis (Cl. chlorophcea FI.) transitus apud nos evidentissimus, \& utramque quoque jain conjunxerunt Dillenius, Acharius, qui speciem in Lich. zuniv. bene limitaverat, ipsius $\gamma$. etiam huc pertinet, \& Schaerer. In siccis locis humilior, simplicior, glabro-verrucosa (ultimum extremum sistit Dill. Musc. t. 14. f. 11. Clad. exilis Hoffm.); quo humidiori loco vero nascitur, v. c. in ericetis udis, eo magis solvuntur granula in furfurem, podetia elongantur \& prolifero-ramosa evadunt. (Dill. I. c. f. 6. I. M.) Prolificationes plerumque marginales, sed sxpe etiam centrales ex epiphragmate, at ex his optime perspicitur Clad. gracilem verticillatam $\mathrm{ab}$ hac distinctam efficere speciem. Ceterum tanta cum Clad. cornucopioide \& carneola analogia ut has non nisi omnium partium colore primitivo alieno a priori distinguere valeamus. Ut vulgatissima offert evidentissimum exemplum omnium fere aberrationum monstrosarum supra sub metamorphosi thalli, podetiorum \& apotheciorum allatarum. Inter has, synonymorum gratia, ne omines repetamus, præcipue notandæ: specimina scyphifera thallo macrophyllino ad Cen. cervicornem a multis referuntur; vera autem Achariana est analogus status $\mathrm{Cl}$. gracilis. Ad latera rupium irrigua cum analoga Clad. cornucopioidis forma communis est, sed platyphyllina desideratur. Cen.pocillum Ach. est forma irsignis pachyphyllina. - Apothecia podetiis exclusis $\mathbf{s} x-$ pe epiphylla, simplicia l. conglomerata; in thallo micrcphyllino Lichenem, Bacomyc. l. Cenomycen epiphyllum Ach. $p$. $p$. efficiunt; in thallo macrophyllino, similibus locis ac forma normalis macrophyllina obvio, Cen. coralloideam Ach. Lich. univ., optime in Syn. C. pyxidatæ subjunctam. - At apothecia primitus symphycarpea hanc speciem præcipue monstrosam reddunt, ut non sine longa experientia intelligi possit istas formas a Cl.pyxidata ortas esse, de qua re vero nullum nobis dubium supersit, non tantum ex analogia Clad. cornucopioidis Lich. Suec. 1. 231. B. \& Clad. incrassatce Fl., sed ex 
directo a me sæpius observato transitu. $\mathrm{Ob}$ apothecia symphycarpea, scyphi evolutionem ut in omnibus vidimus supprimentia, podetia cylindrica evadunt. Нæc limitibus haud palpabilibus variant brevissima \& prælonga; ut formæ primariæ verrucosa, granulosa \& squamosa; ut omnes formæ symphycarpeæ, quasi vis expansiva scyphis obliteratis impedita ipsa podetia finderet, facile cariosa evadunt, quo in statu certe Clad. cariosa (C. cariosa ipsa Ach absolute est analogus status Clad. degenerantis) adnumerata sunt, ut Cl. cariosam $\beta$. Fl. Monogr. p. 15 huc referre non dubitemus, præcipue cum Lich. Suec. exs. n. 81. huc referat, quæ hujus formæ ultimum extremum exhibet!! - Synonyma harum formarum symphycarpearum plurima cum analogis Vaill. par. $t .21$. $f$. 10. referentium v. c. Cl. gracilis, formis communia sunt: v. c. Dill. Musc. t. 14.f. 2. Lichen agariciformis. Wulf. in Jacq. Coll. IV. t. 7. f. 3. Lichen symphycarpeus Ehrh. \& Auct. Tubercularia fusca Hoffm. en. Lich. t. 8. f. 4. Claclonia fiusca Ejusd. Germ. Baeomyces caspititius Pers. Baeomyces et Cenomyce Ach. Capitularia et Cladonia. Flörk e Cen. Hoffmanni. Duf. Rev., quas, in natura licet facile discernendas, dispescere nolui, cum Auctores ipsi haud distinxerint formas a diversa matre ortas. - Denique ad hanc speciem quoque pertinent specimina cornuta sterilia, habitu \& ramificatione irregulari, ubi non ut vulgo simplicia sunt, prorsus cum Cl. carneola $\gamma$ analoga, quæ si a $C l$. chlorophoea Fl. oriuntur furfuracea sunt; a formis vero elongatis symphycarpeis producta squamosa decorticata, qualia in Lich Suec. n. 81 quoque tradidi. Tales refert Mich. gen. t. 40. D. Hac ratione Clad. pyxidatam ad ultimas aberrationes persequens, non possum non a $C l$. gracili \& fimbriata distinguere; analogæ harum formæ semper specificam differentiam magis confirmarunt, quam labefecerunt, etiam ubi hæ formæ sibi invicem obviam venire videntur, nam speciei essentiam non in characteribus, sed in speciei vita \& moribus ponimus \& his rationibus v. c. Clad. pyxidata \& fimbriata prorsus oppositæ sunt. Cfr. Clad. fimbriatam.

194. CLADONIA gracilis, thallo squamuloso, podetiis cartilagineo-corticatis cylindricis politis fusco-virescentibus (dealbatisve), scyphis clausis planiusculis, apotheciis fuscescentibus. 
a. verticillata, podetiis brevioribus, omnibus scyphiferis, scyphis dilatatis planis (plerumque e centro proliferis). Vaill. par. t. 21. $f .5$. Dill. Musc. t. 14. f. 6. D. - H. f. 9. B. Lich. pyxidalus $\beta$. Linn. Suec. n. 1111. Clad. dilatata \& verticillata. Hoffm. Bxomyces turbinatus v. verticillatus. Ach. metín. Cen. allotrepa v. verticill. Lich. univ. Capitul. verticill. Flörk. in Web. et Mohr Beytr. 2. p. 283. Bæomyces $W$ ahl. Cenomyc. Ach. Sym. Cladonia. Schaer. spic. p. 31. Fl. Clad. p. 26. Wallr. 1. c. p. 12s. Patell. fusca. 1. B. ${ }^{\star \star *}$ n. \%. a. - status macrophyllinus. Lichen cervicornis. Ach. in Vet. Ac. Handl. 1801. t. 4. f. 3. Bæomyc. \& Cenomyc. Aich. - Syn. p. 251.

Exs. Lich. Su. 234. Schaer. n. 62,63. Moug. n. 749. b. hybricla, podetiis longioribus validioribus, plurimis scyphiferis, scyphis dilatatis (margine plerumque proliferis). Schaer. spic. p. 32. - Mich. gen. Ord. VIII. t. 41. $f .5,6$ ex habitu. Lich. \& Bæomyc. turbinatus. Ach. Cenom yce allotropa $\alpha$. \& $\beta$. Lich. univ. Cen. gracilis Ach. syn. Capitul., dein Cladon. gracilis Flörk. hanc \& c. complectuntur. - macrophyllina. Lich. cervicornis. Engl. Bot. t. $254 \%$.

Exs. Schaer. Helv. n. 65, 66. Sommerf. Lapp. n. 75. Funk. $n$ i78. (cum sequente in Lich. Suec., Moug.)

c. elongata, podetiis elongatis, gracilibus, plurimis subulatis furcatisve, scyphis angustatis concaviusculis. Scheuchz. It. alp. t. 3. f. 3. Mich. gen. ord. VII. t. 41. f. 3, 5. Dill. musc. t. 14. f.13. A.-D. Lich. gracilis. Linn. - Engl. Bot. t. 1284. L. elongatus. Jacqu. misc. II. t. 11. f. 1. Clad. gracilis \& elongata. Hoffm. Bæomyces gr. \& el. Ach. meth. Cenomyce ecmocyna. Ach. Lich. univ. p. 549. Lich. radiatus Fl. Dan. t. 1356. f. 1. Patell. fusca, 1. B. d. Wallr. l. c.

Exs. Lich. Suec. n. 55. Fl. Deutsch. n.113. Schaer. n. 64. Moug. Nestl. n. 649. Funk. n. 478.

* amaurocraea, podetiis dealbatis, plurimis subulatis, apicibus nigricantibus. Dill. l. c. $f . E$. Capitul. s. Cl. amaurocræa. Fl. ex opt. parte. C. oxyceras $A c h$. excl. varr. \& var. formis. Cfr. Wall. $l$. c.

Exs. Schaer. Helv. n. 70.

Per omnem Europam vulgatissime; a. præcipue in terra sterili aprica sicca; b. locis magis 
humidis. c. precipue inter muscos $\&$ in alpinis evidenter abit in *.

Omnium harum formarum transitus directi evidentissimi, physiologice facile explicati; tantum de * observandum est sub istis nominibus simul comprehendi formas similes aliarum specierum, analoga ratione mutatarum. Habitu angustato, polito, scyphis planiusculis angustatisve facile dignoscitur. Basis putrescens nigrescit, sed non albo-guttata fit. Non nisi rarissime vidi hujus specimina per intervalla furfuracea \& glabra, sed omnes formæ squamis frequenter obteguntur, excepța *, quæ tamen etiam squamulosa visa est. Aberrationes singulares $\&$ mutilatas easdem profert ac prior. Boeomycess. Cen. strepsilis Ach. est hujus forma leptophyllina apotheciis epiphyllis aut podetiis imperfectis. Cen. leptophylla Ach. \&, ipso teste, Lich. leptophyllus Engl. Bot. t. 1782 est pulcher status gracilior symphycarpeus in ericetis sterilibus passim obvius. Alii validiores symphycarpei \& cariosi sub Cen.symphycarpa \&c. comprehenduntur. De his inter hanc \& præcedentem simul obviis formis, quarum synonyma cum hac communia, videas C. pyxidatam. Ubi inter muscos altiores nascitur, thallus ad basin evanescit \& obliteratur, omnino ut in omni respectu maxime analoga Cl. subulata, cujus evolutionis series prorsus eadem est, mutatis a differentia primitiva pendentibus. Ab ejus formis angustissimus Cl. gracilis subulata \& furcata ramulis longis strictis \&c. dignoscenda.

Lich. vermicularem Swartz. Engl. Bot. t. 2024. Cladoniam. Dec. fr. - Fl. Mon. p. 175, podetiis alutaceopapyraceis, subulatis, imperforatis, dealbatis, semper sterilibus, tam ob podetiorum indolem evidenter morbosam, quam sterilitatem perpetuam, nullo modo speciem esse normalem et genuinam certissimum est. Plene assentior acutiss. Wallrothio, ne efficere quidem varietatem; sed tantum esse prolem degeneratam in uliginosis alpium ortam. Specimina, quæ laudatus vir in conventu Botanicorum Berolini 1828 demonstrabat, ejus ortum a $\mathrm{Cl}$. gracili satis superque probarunt. In uliginosis vero Snolandix ipsius Clad. uncialis similem formam vidimus, \& ex alpibus Norvegicis specimina ex parte inferiori veram $C l$. cornutam, cum qua jam conjungebat Dillenius, sistentia. Nolui itaque nec omnia synonyma ad definit.m speciem referre, nec ex his analogis, quasi confluentibus, formis tranșitum videre ad formas in statu genui- 
no luculenter diversas. Duplex notatus est $C l$. vermicularis status: a. gracilior, simpliciuscula, prostrata. $L i$ chen subuliformis Ehrh. Crypt. n.30. Cladonia Hoffm. Pl. Lich. t. 29. f. 1-3. Schaer. exs. Helv. n. 86. Cenomyce Ach. - \& b. ventricosa, subramosa, erectiuscula. Dill. musc. t. 15. f. 14. E. Lich. tauricus Wulf. in Jacq. Coll. II. t. 12, f. 2. Clacionia. Hoffm. Plant. Lich. t. 34. f. 2. Funk. Grypt. Ficht. n. 72. - Utramque ut speciem Pycnotheliæ distinxit iterum Dufour. Rev. Pycnoth.

195. CLADONIA degenerans, thallo squamuloso, podetiis cartilagineo-corticatis gracilibus prolifero-ramosis viridi-pallescentibus, basi nigricantibus alboguttatis, scyphis irregularibus cristato-laceris, apotheciis fuscis. - Flörk. Clad. $p$. 41.

Dill. musc. t. 15. f. 20. Clad. cristata. Hoffm. excl. syn. Capitul. degenerans. Flörk. in Web. et Mohr. Beytr. 11. $p$. 308. Baomyces Wahlenb. Cenomyce. Fl. Lich. Deutsch. Cenomyc. gonorega. Ach. syn. p. 258. excl. forma 1. - podetiis granulato-furfuraceis: Capitularia, dein Clad. pityrea Flörk. l.c. Cenomyce. Ach. syn. p. 254. $\alpha$. - podetiis squamosis: Bæomyces trachynus \& anomæus. Ach. meth. Engl. Bot. t. 1867. Lich. phyllophorus. Ehrh. exs. n. 28\%. Cladon. Hoffm.

Exs. Lich. Suec. n. 54. Fl. Deutsch. n.110,111, 194. - furfuracea. Lich. Su. n. 236. haud optima Fl. Deutsch. $n .193$.

b. scyphis in ramos fastigiatos digitatim divisis (qui scyphi abortivi semper indicium) - Hujus status vetustior cariosus est: Lich. cariosus (verus) Ach. in Vet. Ac. Handl.1801.t.4.f. 4. Bromyc., dein Cenomyc. Ach. Cladon. Flörk. Clad. var. a tantum. (nec Dill. t. 15. f. 15. B.) Exs. Lich. l. c. n. 149.

Ad terram in pinetis \& ericetis Europæ, præcipue borealis copiosissime.

Filiam esse præcedentis facile concedere possumus, at nihilo minus distinguimus, cum ipsa typica sit, cum semper peculiarem \& definitam evolutionis seriem sub innumeris formas servet, cum maxime eximiam vegetationis Lichenosæ partem in his terris efficiat. Cl. Flör- 
keance proximam habet Dillenius, estque eidem ac Clad. botryti perfecte analoga, forma scyphifera vulgatiore quam in illis. - b., cum harum statu vulgatiori magis congruum, meram esse varietatem luce meridiana clarius vidimus, immo ex hac primum didici omnes formas Helopodium dictas \& cariosas esse degeneratas. Forma hujus speciei furfuracea a simili $C l$. pyxidatce \& decorticatce caute discernenda. Colore ad Glaucescentiún seriem accedit, sed basis insigniter nigrescens \& alboguttata, quod in alia affini non vidi. Statura porro ita convenit cum analoga forma Glaucescentium, ut Dill.musc. t. 14. $f \cdot 12 . B$. omnino ex illa huc referatur, at cum numquam invenerim acutissimum Dillenium species diversarum serierum commutasse, indicia auctoris sequenda videntur. At inter proximas suæ seriei eximic eminet scyphis jam primitus cristatis, digitato-divisis (optime convenit $C l$. cristata Hoffm., at syn. exclud., sub quo nomine acceptam vidimus), prolificationibus copiosis, foliosis, sæpe peculiari modo cristato-ramulosis ascyphis.

** podetiis apice saltim membranaceo-corticatis, in pulverem subtilem fatiscentibus. Scyphi siepe deficiunt. Podetia cylindrica aut ventricosa.

196. CLADONIA fimbriata, thallo squamiloso, podeliis cylindricis epiciermide tota membranacea in pulverem subtilem glauco-candicantem fatiscente, scyphis cupulæformibus margine erecto, apotheciis fuscis.

Lichen fimbriatus. Linn. Suec. n. 1112. eximie! et Auct. Engl. Bot t. 1438. Cenomyc. Ach. syn. p. 254. Sommerf. Lapp. p. 130. Bæomyces. Wahl. Stiec. 1647. Cl. pyxidat. v. Iongipes \&c. Flörk. Berl. Mag. 1808. p. 145 ex p. Clad. Ejusd. Mon.p. 51.

a. podetiis brevibus, omnibus scyphiferis, scyphis subdentatis, apotheciis simplicibus. Dill. Musc. t. 14. f. 8. Lich. fimbriatus a. Linn. l. c. Clad. fimbriata Hoffm.

Exs. Fl. Deutsch. 55. Schaer. Helv. n. 58. spec. minus!

b. tubaeformis, podetiis elongatis, plurimis scyphiferis, scyphis subintegerrimis, apotheciis symphycarpeis. Vaill. par. t. 21. f. 6. Mich. gen. t. 4 1. ord. VIII. $f$. 4. Lich. fimbriatus R. Linn. l.c.! - sta- 
tus primitivus symphycarpeus: Clad. s. Cen. fibula. Auct.

Exs. Lich.Suec. n. 86. Fl. Deutsch.n.52,54. Schaer. Helv. n. 57, 58 (spec. elong.) 60 - omnes ad c. proxime accedunt.

c. radiata, podetiis elongatis subulatis aut scyphis subulato-proliferis, sæpe obliteratis, radiato-fimbriatis Lich. - - acetabulis fimbriatis. Tournf. I.R.H. unde pendet nomen Linnæanum. Mich.t.41. ord. VII. f. 4. Dill. Musc. t. 15. f. 16. A. - G. in genuino ambitu, numquam ulterius subdividendo! Lich. fim-

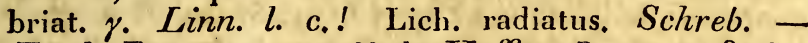
Engl. Bot. t. 1835. Clad. Hoffm. Bæomyc. \& Cenornyc. Ach. meth. et Lich. univ. Clad. cornuta. Duf. Rev.

Exs. Lich. Suec. l. c. Flörk. n. 50, 53, 56. Schaer. $56,61,51$.

Ad terram \& ligna putrida Europæ totius frequentissime.

$\mathrm{Ut} C l$. deformis ad $C$. cornucopioidem hæc exacte se ad $C l$. pyxidatum refert, nec magis quam Clad. cornucopioides pleurota ad $\mathrm{Cl}$. deformem, $\mathrm{Cl}$. pyxidata chlorophaea ad hanc transitum elicit, quamquam eodem exacte modo sub oppositis rationibus sibi invicem obviam venire videntur. Admiranda mihi videtur Linnæi sagacitas in hac specie limitanda; primo quidem ipsam c. tantum comprehendebat, mox vero perspexit a $\&$ b. esse formas primarias easdemque exacte ac nos distinxit formas. Cum prolificatio \&c. apud me formas non distinguat, tantum individua, sub a. complector omnes status scypho pyxidato, sive simplex sit, sive scyphifero-prolifer. Sub b. apotheciis symphycarpeis, sive podetium primitivum symphycarpeum (Cl. fibula Hoffm.) sive proles scyphi primarii symphycarpeæ. Eadem ratione ad c. refero individua vel primitus cornuta (L.cornutus Auct.; male pro Linnæano L. cornuto habitus!) vel e scypho primario cornuto-prolifera; nam his rationibus in natura præcipue promiscue occurrunt. - In multis hujus historia Clad. pyxidatoe plene opposita; at adsunt singulares deformationes, quibus ducibus omnes conjungi possunt v. c. Cl. fimbriata \& alcicornis e var. pyxidatæ $\varepsilon . F l$. $l$. c. p. 69 , quam a me non visam tamen potius ad $C l$. pyxidatum referam, cum in hac sola pili fasciculati nigricantes mihi subinde obvii. Primo 
thallus dilutior. $C l$. fimbriatce sub eistem momentis, ac Cl. pyxidatæ obseurior macrophyllinus (Cl. pyxid. d'. Fl. 1. c.), platyphyllinus evadit; at macrophyllinus in CI. fimbriata \& platyphyllinus in Cl. pyxidata a me non visus est. Podetia elongata in $\mathrm{Cl}$. fimbriata normalia sunt, abbreviata in $\mathrm{Cl}$. pyxidata, ita vero ut Cl.pyxidatæ locis siccissimis brevissima (Cen. pocillum) in humidis elongentur (Clad. chlorophaea FI.); at Clad. fimbriatce locis siccis maxime elongantur, in humidis abbreviantur. Semper servant in hac formam magis cylindricam, graciliorem, nec sensim in scyphum dilatantur \& deorsum æqualiter attenuantur ut in $\mathrm{Cl}$. pyxidata. Ita epidermis in Clad. fimbriata membranacea, qualis utique sæpe basi persistit, locis siccis in pulverem albicantem subtilissimum optime solvitur; $C l$. pyxidata eisdem locis semper glaberrima, verrucosa, e margine scyphi deorsum squamosa, cum in Clad. fimbriata squame a basi adscendunt. At locis humidis, epidermis $C l$. fimbriatce, ob podetia minus extensa!, grossius pulverulenta virescenticinerea pulverulenta, cum Cl.pyxidatæ verruca ibidem ob podetia magis extensa! in furfurem solvuntur \& sic $C l$. fimbriata obviam veniunt. Ita etiam in scypho formando, prolificatione, apotheciis \&c. oppositus nisus observatur, quo ha species circa duos typos evidenter diversos colliguntur, quibus tantum consideratis hæ ut in aliis generibus intricatissimis certo dignoscuntur, licet theoretica explicatione haud difficile tollantur. Practico Lichenologo hoc modo eas distinguere (ut species, subspecies, varietates \&c. per me plantas ipsas magis quam denominationes respicientem perinde sit) utile duco, cum in adeo intricato genere paucis at essentialibus punctis acquiescendum sit, ut technica respicienti necessarium, cum $C l$. pyxidata materia tinctoria polleat, qua $\mathrm{C}$. fimbriata, etiam epidermide haud soluta, caret. Celerum accidentales abnormitates ex affinium analogia optime digroscuntur.

Obs. Lichen pyxidatus teres, acetabulis minoribus repandis Tournef. et Vaill., utique ex hac regione, at difficilis determinatu. Duie istius exstant icones, utraque ad Vaillantii specimina delineata, nempe Mich.gen.t.41. ord. VII. f. 1. \& Dill. musc. t. 15. f. 15. A. inter se primo obtutu diversæ. Hæc vulgo ad $C l$. fimbriat. $b$. symphycarpeam, illa ad Cl. deformem (at apoth. non coccinea) vulgo referuntur, neutrius tamen habitum be- 
ne exprimunt. Si fontis testimonia componere vellemus, utraque referenda esset ad Cl.cornutam, cujus saltim utrique iconi similia specimina servo.

197. CLADONIA cornuta, thallo squamuloso, podetiis cylindricis subventricosis, epidermide inferne persistente cartilaginea, superne membranacea mox pulveraceo-deliquescente, scyphis angustatis planiusculis, margine incurvo subintegro, apotheciis fuscis. - Sched.Crit.4.p. 23. Lichen. Linn. Lapp. n. 434., teste Sommerf. Lapp. p. 131., ex quo Lichen cornutus. Linn.! certissime et Alct., qui definitum quoddam, nec meram congeriem formarum cornutarum ascypharum (contra verba Linnæi) sub hoc nomine intellexerunt. Ehrh. sec. spec. E. Meyer. Ach. Prodr.! et omnium Suecorum. Bæomyces Ach. meth. et Wahl. Suec. $n$. 1648. plene hujus loci. Cenomyc. Ach. Lich. univ. paululum vagans, sed ex optima parte hæc.

a. excelsa, podetiis præelongis, supra medium glabris, scyphis, si adsunt, perfectis. Syn. ut supra; cfr. quoque observ. anteced. - Cen. Clavarioides. Duf. Rev. Cen. n. 8. Cen. coniocræa. v. excelsa. $F l . D$. L. Clad. coniocræa. Fl. Monogr. p. 84 .

Exs. Lich. Suec. n. 116. Fl. Deutsch. n. 139. b. clavulus, podetiis brevibus, infra medium pulverulentis, scyphis imperfectis aut nullis. Dill. Musc. $t$. 15. f. 14. A. - C. Clad. cornuta. Hoffm. Pl. Lich. t. 25. $f$. 1. nam apoth. fusca; exclusa in descript. var. podetiis alboflavescentibus $\&$ tuberculis coccineis. In Europa, saltim boreali copiosissime; a. ad terram, præcipue silvarum deustarum; b. ad ad truncos.

Ut prior ad $\mathrm{Cl}$. pyxidatam, vel ut $\mathrm{Cl}$. digitata ad $C l$. bellidifloram, hæc ad gracilem accédit. Sunt tamen varia in hujus historia singularia. Contra omnem præcedentium analogiam podetia elongata optime scyphifera \& ex maxima parte glabra sunt, humiliora magis Cladonioidea, sensu Acharii, magisque pulveraceo-deliquescentia, quæ vero perident a loco formæ a. sicciori, formx b. magis carioso. Has eandem sistere (speciem, subspeciem \&c.) omnino certissimum est. Mox dignoscitur podetiis inferne Clacl. gracilis, quibus adhuc infe- 
gra simillima sunt, superne $C l$. fimbriatce similibus, simulque nisu in formas ventricosas, sæpe cornu instar curvatas abeundi. Essentialis vero differentia posita est in forma scyphorum, qui sæpius podetiis angustiores sunt. Statura robusta, præcipue in $a_{.}$, \& tam elatæ formæ omnium aliarum specierum non, ut hujus, simplices persistunt, ut nomen cornutce aptius excogitari non potuerit. Hunc esse Linnæanum cornutum certi sumus, nec exinde rejiciendum, quod aliæ formæ ab aliis cum hoc dein confusæ, nam quæ nomina Linnæana hac ratione persisterent. Ingenue fatear, mihi haud placere morem omnes fere species pyxidatas Linn. apotheciis fuscis ad Cl. fimbriatam referendi, reliquasque reque vulgares sub novis nominibus, minus expressivis, distinguendi. Dill. $f$. $B$. l. c., ut apotheciis carens, etiam formas alias refert, sed cum hujus exstet forma simillima, nullam video rationem hanc excludendi, præcipue cum non fingam Dillenium oculatissimum speciem e serie Cocciferarum confundere potuisse. Sit probis auctoribus, qui non sortito species contrahunt \& distinguunt, auctoritas! E Norvegia vidimus formam dealbatam in Dill. f. E. 1. c. quadrantem. Cfr. Obs. sub Cl. gracili.

O b s. Cen. coniocrcea $\alpha$. Fl. Deutsch. Lich. 1. c. $\mathrm{n}$. 138. in recentiori Monographia generis p. 75 ab hac specie sub nomine $C l$. ochrochlorae distinguitur, \& simul specimina in Exs. 1. c. tradita pro nimis imperfectis ad speciem dijudicandam declarantur, quare et meum judicium supprimam. Ceterum de hac judicia mire variant; alii pro $C l$. fimbriato basi haud raro glabræ, Sommerfelt pro $\mathrm{Cl}$. cornuta, Wallroth pro Cl. carneolae decolorato statu habent; Wallrothii sententia nomine quoque suffulcitur. Specimina aliunde accepta varia hæc judicia confirmant, immo inter hæc vidi quoque sequentis, admodum affinis, a Dillenio conjunctæ, statum typicum.

198. CLADONIA decorticata, thallo squamuloso, podetiis cylindricis epidermide submembranacea in squamulas furfuraceas secedente pulverulentis, scyphis angustatis obsoletisque, apotheciis fuscis. Fl. Clad. $p$. 10.

a. scyphifera., podetiis simplicibus scyphiferis, cfr. obs. antec.

b. symphycarpea, podetiis subsimplicibus, apotheciis 
symphycarpeis. Dill. Musc. t. 14. f. F. Cen. decorticata. Flörk. Deutsch. Lich. - Sommerf. Lapp. p. 132. Clad. Fl. l. c. Cen. pityrea. c. Ach. syn.

Exs. Fl. Deutsch. n. 75.

c. ramosa, subulata, sterilis. (Cl. subuliformis. Duf. non vidi - ambigua) Cl. pityrea. $b$. Ach. aut hæc aut C. pyxidatæ analogus status, certe non C. subulata.

In silvis Europæ, præcipue ad terram, rarius. Species ob multiplicem analogiam diu neglecta. A Clad. macilenta \& Flörkeana notis seriei certo diversa. A Cl. squamosa axillis semper clausis \& in statu scyphifero epiphragmate clansis. A Cl. fimbriata scyphorum forma, epidermide ipsa in squamulas soluta \&c. A C. cornuta epidemide similari, demum decorticata squamulosa \&c. A C. pyxidata decorticata symphycarpea 1. cornuta, cui simillimæ b. c., \& C. degeneranie podetiis pulverulentis. Podetia plene decorticata lignosa evadunt \& nigricantia, ut in simili statu C. Flörkęanoe \&c. Scyphorum morphosis ut in Cl. macilenta. - Dill. $t .15$. f. 15. $f$. B. non est vera Cen. cariosa A., sed simillima statui carioso $\mathrm{Cl}$. pyxidatae (Cl. decorticata Lich. Suec. n. 80), at hæc squainoso-decorticata numquam "pulverulenta simul est, qualem suam petit Dillenius, ut huc referrem, si umquam tam valida vidissem specimina.

*t PERVIE. Podetia semper scypho diaphragmate clauso destituta, sed axillæ apicesque in formis simplicioribus turgescentibus infundibuliformi-dilatatæ; in gracilescentibus ramosissimis simpliciter pertusæ.

Exstant tantum in hac serie, alia ratio vero Glaucescentium, duæ rite limitabiles sectiones e podetiorum forma, nempe vere Scyphiferarum \& Perviarum. Omnes fruticulosæ ab utraque harum ortæ sunt \& quidem ab omni specie, etiam a Clad. pyxidata, scyphi abortu oriuntur. Ambæectiones in statu primario satis similes, differunt tantum scyphis in Scyphiferis diaphragmate clausis - \& scyphis apertis, diaphragmate destitutis, unde infundibula dicuntur, in Perviis. Hac primaria differentia neglecta parum admodum differt $C$ l. brachiata a Clad. fimbriata, Cl. crispata a Clad. gracili, C. squamosa a $\mathrm{Cl}$. decorticata. In reliquis differunt minus evidenter, ut thalli squamulis in Scyphiferis magis inte- 
gris, in Perviis magis dissectis basi mox evanidis sed sursum frequentioribus, podetiis illarum simplicibus aut irregulariter prolifero-ramosis, harum normaliter dichotomis; apotheciis Perviarum primo carneo-fuscis dilutioribus, per ætatem vero nigro-fuscis. Nil evidentius, est visu, quam status infundibuliformis in magis fruticulosum transitus, nam limites prorsus deficiunt. Sic egregius Flörke Clad.crispatoe directum in Clad. subulatam transitum jam demonstravit, qualem etiam vidi inter Clad.cenoteam \& formam fruticulosam, quam pro $\mathrm{Cl}$. glauca Flörk. habeo, analogamque Clad.squamosa. - Hæ formæ fruticulosæ a similibus Cladoniarum Scyphiferarum dignoscuntur podetiis magis \& definite ramosis dichotomis, axillis perviis, saltim apicum fertilium subdigitatarum, ut thallum \& reliquas supra notatas differentias minus evidentes reticeam. In Scyphiferis degenerantibus podetia haud vere fruticulosa, sed fasciculato aut irregulariter ramosa, axillis semper clausis, quæ insuper sæpissime sterilia \& deformia. - Exstare vero specimina tam imperfecta \& semper sterilia (fertilia enim facile dignoscuntur) Clad. subulatoe, ut ea descriptione a C. gracili vix distinguere possis, omnino fatendum est; at exinde non cogimur hæc ut transitus considerare, nam quot Gramineas, Cyperaceas \&c. sine fructificatione stricte definire valemus. - Series sequentes apud nos similes formas non proferunt, sed ex Asia \& America adsunt.

199. CLADONIA brachiata, thallo squamuloso dissecto, podetiis dichotomo-brachiatis membranaceo-corticatis mox subtiliter glauco-pruinosis, axillis apicibusque fertilibus perviis, apotheciis sessilibus e pallido fuscis. Fries Stirp. F'ems.

a. cenotea, turgida, axillis apicibusque infundibuliformibus. Cen. uncinata. Hoffm.? ni forte Cl, uncialis, saltim verba: "radiatim uncinata" \& syn. ad hanc pertinent. Bromyc. cenoteus. Ach. meth. t.7. f. 7. Cen. Syn. Lich. p. 271. Clad, Schaer. spic. p. 35. Fl. Mon. p. 123. Cenom. gonorega. a. Lich. univ. p. 551 .

Exs. Lich. Suec. n. 55. Flörk. n. 177. Schaer. n.71. b. furcellata, gracilis, fruticulosa, ramis subulatis, axillis perforatis. Clad. furcellata. Hoffim. excl. syn. Cl. dilatata Duf. 1817!, ex qua orta videtur Cl. a- 
xillaris. Duf. rew. Cen. n. 14. Clad. glauca. Flörk. monogr. p. 140 .

Ad terrain, precipue vero truncos putridos v. c. Pini, Europæ fere totius, præcipue borealis. b. sapius terrestris.

Epidermide membranacea, læte viridi, in statu infantili aut basi, ubi vulgo persistit, observanda, sæpius vero in pulverem glaucum aut cinereo-cæsium soluta, unde podetia tenuis substantiæ mollia, facillime dignoscitur. $\mathrm{Nec}$ levissimun transitum in aliam speciem vidimus, licet podetia deorsum quoque squamosa evadant. Specimina simplicissima (juniora) prorsus tubulosa, apice aperta; infundibulorum margines in hac specie incurvi sunt, in sequente vero patentes, \& in subsequente erecti. Color crsius in thallo podetiisque sæpe incusus non accidentalis videtur, cum redeat in colore latente apotheciorum. Nomen cenotece, unicum a me mutatum nomen, sub Cenomyce prorsus ineptum, sub Cladonia vix melius, rejeci, consentiente ipso Achario. - Sic etiam sequentis nomen Linnæanum unicum est Linnæanum inter Lichenes, quod omitti posse credidi.

200. CLADONIA furcata, thallo squamuloso subdissecto, podetiis dichotomo-fruticulosis cartilagineo-corticatis politis fusco-virescentibus (dealbatisve), axillis apicibusque fertilibus perviis, apotheciis podicellatis e pallido fuscis. Sommerf. Lapp. p. 134 . Cenomyc.

Clad. fruticulosa. Schaer, spic. p. 39. Cl. subulata. Stirp. Fems. Clad. furcata \& pungens Fl. Clad. p. 141-160.

a. crispata, turgida, axillis apicibusque infundibuliformibus. Clad. ceranoides. Hoffm. Germ. p. 116. e specimine! Bromyc. turbinatus v. crispatus. Ach. Cen. allotropa crispata. Lich. univ. Bæomyc. crispatus. Wahl. Cenomyc. Ach. syn. p. 272. Cl. furcata. $\varepsilon$. crispata $F l$. $l$. c. Patell. fusca II. - B. e. $\alpha$. a. Wallr. 1. c.

Exs. Lich. Suec. n. 56.

b. cristata, podetiis turgidulis, ramulorum lateralium ad axillas oblique dilatatas in cristas fimbriatas abortu simplicibus, apicibus cristato-ramulosis. Valde insignis, clavis Cen. portentosae Duf, vide infra. (Ac- 
cedit ad Dill. t. 16. $f$. 23., quæ C. verticillaris Raddi in Act. Soc. Ital. Sc. XVIII. t. 3. f.4, e Brasilia, \& (Cl. Dilleniana Fl. Clad.p.138, e Dillenio, at non eadem).

c. racemosa, podetiis turgescentibus ramosis axillisque rimose hiantibus, ramis fertilibus (\& passim cum toto podetio) explanatis - ramis recurvis: Mich. $t$. 40. ord. 7. f. 5, 6. Dill. musc. t. 16. f. 25. Lich. spinosus. Neck. Clad. Hoffm. Bæomyc. racem. Wahl. Cenom. Ach. - ramis erectis: Mich. gen. t. 40.f. 3, 4. Lich. racemos. Schrad. Clad. Hoffm.

Exs. Lich. Suec. n. 58. Schaer. Helv. n. 80.

d. subulata, podetiis tenuioribus xqualibus, axillis simpliciter subpertusis, apicibus fertilium fissis - elatior ramosissima, ramulis divergentibus (Lich. subulatus. Linn. Bæomyc. Wahl.) ramis recurvis: Vaill. par. t. 7. f. 7. Dill. t. 16. f. 27. D. Cl. f. recurva. Hoffm. - gracilior, ramoșissima, erectior: Dill. l. c. f. $2 \%$ A. - C. Lich. furcatus. Sclureb. Clad. Hoffm. Cenomyc. Ach. - (gracillima, parce ramosa, erecta, substerilis vix pertusa, hinc inter hanc \& Cl. gracilem vaga: Clad., Bæomyc., Cenomyc. subulata. Auct.)

Exs. Lich. Suec. n. 11\%. Fl. Deutsch. n. 196, 197 (18 inter d. \& * prorsus media) Schaer. $n .81$.

* pungens, tenella, fruticulosa, fragilis, pallens, sæpe dealbata. Dill. musc. $t .16 . f .30 . C$. D. Clad. rangiformis. Hoffm. Cen. Flörke olim. Bæomyc. pungens. Ach. meth. a. $\beta$. G. furcata v. pung. \& nivea. Lich. univ. C. rangiferina v. pungens. Syn. (male!) Clad. frutic. $\varepsilon$. Schaer. $l$. c. Clad. pungens $\alpha .-\gamma$. Fl. Clad. p. 156-159. - Wallr. p. 144. - Cl. foliolosa. Duf. Rev.

Exs. Lich. Suec. n.318. Fl. Deutsch.158, 159. Moug. n. 754 .

Per omnem Europam copiosissime sub innumeris formis, ita vero ut a. b. magis boreales sint (a. in Suecia multis locis frequentissima) \& pungens optima nivea vix nisi in Europa austiali obviam veniat.

Formæ allatæ seriem contiguam, nullo modo divellendam sistunt; adsunt plurimæ intermediæ ad neutram tute referendx. Est in hac sectione, ut maxime analoga 
Clad. gracilis in priori, superficie polita, lævigata facile distincta; non nisi rarissime superficiem hinc inde furfuraceam vidi. Ceterum frequentissime squamulis adnatis adspersa, sed epidermis tum haud decorticata ut in sequente. * est status in sole adustus morbosus, apud nos parum admodum notabilis. Ceterum ad hanc quoque refero Cen. spadiceam, chloroticam \& C. hamatam Duf. Rev. Analoga est $C l$. Cetrarioides Schwein.! sub Cenomyc. inter cocciferas, sed variis rationibus longe insignior; $\mathrm{Cl}$. bullacea inter ochroleucas.

-2ot. CLADONIA squamosa, thallo squamulosodissecto, podetiis ramosis lacunosis mox decorticatis, granulis squamaceis exasperatis, axillis perviis denticulatis, apotheciis cymosis fuscis. Hoffm. Germ. 2. p. 125.

a. ventricosa, podetiis ventricosis, axillis apicibusque dilatatis infundibuliformibus. Mich. gen. t. 42. ord. $I X$. Cladonia sq. * denticollis (apoth. simpl.) \& irregularis (apoth. symphycarp.) Hoffm. l. c. Lich. ventricosus Huds. sub pyxid. Ach. Prodr. Cladonia Schrad. Schaer. spic. p. 36. Lich. cæspitos. Lam. Cen. Duf. Rev. Bromyc. sparassus Ach. meth. Cen. gonorega $\beta$, allotropa 9. Lich. univ. Lich. sparassus. Engl. Bot. t. 2362. Cenomyce. Ach. syn. Bæomyces squamos. Wahlenb. Cenomyce Flörk, dein Clad. Ejusd. Monogr. p. 129.

b. attenuata, Hoffm. 1. c., podetiis angustatis attenuatis, axillis perviis, apicibus subulatis. Dill. musc. $t$. 16. $f .22 . ~ H$. (reliqua syn. ut supra.) - var. $\beta . F l$. inter $a$ et 6 . media. Clad. pityrea v. acuminata. Quibusd.

Exs. a. \& b. Lich. Suec n. 5\%. Fl. Deutsch. n. 112. Schaer. Helv. n. 72-74. Moug.et Nestl n. 645.

* lactect, podetiis dealbatis. (a. b.) Fl. l. c. $\gamma$.

*t delicata, pusilla, podetiis simpliciusculis symphycarpeis 1. apotheciis epiphyllis. Ceterum sæpe in eodem thallo cum a. \& b. Lich. parasiticus. Hoffm. en. Lich. t. 8. f. 5. Lich. delicatus. Ehrh.-Engl. Bot. t. 2052. Clad. squamosa c. (symphycarpea) \& Cl. parasitica (apoth. epiphyllis) Hoffm. l. c. et p. 127. Bæomyces quercinus. Pers. B. \& Cenomyce delicata. Ach. Helopodium. Decand. Clad. Fl. Mon. p. 7. Cl. parasitica Schaer. p. 37. 
Exs. Lich. Suec.n.51. Ehrh. Crypt. n. 247. Fl. Deutsch.

n. 36. Schaer. n. 75. Moug. et Nestl. n. 753.

Ad terram, saxa, inter muscos \& ad ligna putrida; $*$ præcipue ad ligna durissima quercina vel etiam locis suffocatis. : Per omnem Europam silvaticam abunde.

Cuique observatori, Cladonias fere omnes per xtatem squamaceas evadere videnti, primo intuitu in mentem venit sæpius enunciata sententia, hanc speciem tantum priorum esse statum vetustissimum. Est tamen huic peculiaris evolutionis series priorum specierum analoga; jain primitus granuloso-exasperata, quales priores numquam; \& squamulis thallinis luxuriantibus insuper ornata squamosissima evadit. Thallus valde dissectus, sæpe omnino furfuraceo-conglobatus \& corallinus, ad morphosin Parm. triptophyllæ, in quo statu pro Stereoc. nano a multis habetur. Ad hos status mutilatos præcipue referenda Patell. fusca 1. A. B, b-e, sed includuntur priorum analogi status. $\mathbf{E}$ deseriptione ad has quoque facile referres Cen. ccespiticiam \&c. at specimina, quatenus terrestria, truncicola huc referenda, $\mathrm{Cl}$. pyxidatoe analogum statum monstrant. - Analoga est Clad. pulchella, Schwein.! sub Cenomyce, inter Cocciferas.

Ser. III. Ochroleucae. Apothecia carneo-livida, supra fundum lutescentem. Podetia ochroleuca, carie basi fusco-ccerulescentia. Patell.coccinea. II. Wallr. IMon. p. 186.

Series cum Fuscis hactenus prorsus confusa, quam in Stirp. agr. Fems. primus ut distinctam proposui. Wallrothius acutissimus dein cum Cocciferis conjunxit; est tamen ab utraque diversa; a Fuscarum colore tam thalli, quam apotheciorum præcipue latente flavido, qui in prioris seriei sect. *** apotheciis junioribus sæpius pallide fuscis, prorsus desideratur; cum hac tamen magis contigua est, quam cum cocciferarum. Ab his certe differunt podetiis basi numquam fulvescentibus, colore apotheciorum superficiali constante. Copiosius \& terrestris præcipue in Europa orientali occurrit hre potissimum Asiatica series; ex hujus orbis partis desertis montanis adest species nova maxime insignis, forsan ibidem non minoris ponderis, quam C. rangiferina in Lapponicis. Etiam ad Cl. turgidam, seriei Glaucescentium, accedit id- 
eoque inter omnes media. Ut Europa, Africa \& America inter se discretæ, sic et Cládoniarum Fuscarum, Glaucesccntium \& Cocciferarum series limitibus difinitis distant; Asia vero cum reliquis orbis partibus fere contigua est, sic \& series Ochroleuca. Ignoscatur exemplum, plerisque forsan nimis heterogeneum.

202. CLADONIA carneola, thallo squamuloso, - podetiis membranaceo-corticatis mox -subtiliter pulverulentis ochroleucis, basi demum fuscocorulescentibus, scyphiferis turbinatis, apotheciis carneolis fuscescentibus. Fries Stirp. Fems. a. podetiis turbinatis, omnibus scyphiferis simplicibus aut proliferis. Lichen pyxidatus - - oris carneis. Rupp. Jen. p. 383. - Mich. gen. t. 41.f. 7. ex habitu optima. L. scyphigerus - - tuberculis subcarneis. Hall, Helv.n.1919. Cenonym. carneola. Fries Sched. Crit. 4. p. 23. inclusis sequ. varietatibus \& specim. cornutis, quod contra Sommerf. observandum. C. carneopallida. Sommerf. Lapp. p. 123. Cfr. Obs. infra, Patell. coccinea. II. є. carneola. Wallr. l. c. p. 189. Cen. pleurota. Nonnullis.

Exs. Lich. Suec. n. 115.

b. podetiis elongato-turbinatis, prolificationibus radiatis subulatis. Dill. musc. $t$. $15 . f .17$ precipue B., C. optime conveniunt, $\&$ apoth. subfusca ab ipso dicuntur, quæ Cl. ventricosa Hoffm. C. coccinea II. d. coniocræa. Wallr. l. c. p. 188. p. p. saltim, exclusis vero Cl. polydactyla Fl. ob apoth. coccinea \& $\boldsymbol{C}$. coniocrcea Ejusd. ex spec. a me visis.

c. cyanipes, podetiis longissimis cylindricis cornutis simplicibus aut scyphis in ramulos subdivaricatos sterilescentes obliteratis. Sommerfelt l. c. - C. carneola specimina cornuta Fr. Sched. l. c. Patell. coccinea II. c. fallax Wallr. l. c.p.117 saltim a.alpestris; non vero Cl. coniocræa $\beta$. excelsa $\mathrm{Fl}$.

Ad terram præcipue in silvis adustis Europæ orientali-borealis (Sueciæ, Rutheniæ, Borussiæ) copiose; per reliquæ Europæ montana ad ligna putrida rarius.

Hæc a me primo recentiorum distincta species ad maxime insignes, nec raras, pertinet; hactenus sub Cen. pleurota cum Cocciferis, sub Cen. fimbriata, cujus ex- 
stat status apotheciis carneo-pallido-fuscis, sed absque hypothecio luteolo \&c., sub quo nutu determinatoris ejus var, carneopallidam potius citarem, licet et hanc complectatur, cum Fuscis commutata; est tamen ab utraque serie optime distincta. Podetiorum basis carie numquati fulvescit, ut Cocciferarum, sed per ætatem fusco-cocrulescit. Apotheciorum \& podetiorum color omnino constańs est. Ceterum ad maxime mutabiles species pertinet, eandem ac Clad. fimbriata evolutionis seriem sequens. Hac \& epidermide $m n x$ in pulverem snbtilissimum fatiscente a reliquis suæ seriei facillime dignoscitur. Ex errore quodam monet optimus Sommerfelt, me hanc cum Cl.polydactyla s. macilenta commutasse. Nescio, utrum casu in cæspitibus amicissimo viro missis hæc immixta fuerit (easdem vero a me non conjunctas fuisse definitio evincit), an Auctor hujus b. pro C. polydactyla, ut habet Wallroth, habuerit. - Hujus ceterum synonyma variis locis delitescere omnino certum est. Varietatis a. habitum optime icon citata Michelii refert, sed cum nec color nec superficies indicentur, numquam absolute determinari potest. Etiam Dill.t. 14. f. 6. B. hanc, etiam in Grönlandia obviam, forsan exprimit e. s. p. Cl.ventricosaHoffm., ex allata Dill. icone pendens, optime sane cum hujus b. convenit.

203. CLADONIA straminea, thallo squamuloso, podetiis cylindricis cartilagineis pallidis mox squamuloso-decorticatis, basi fuscescentibus, scyphis cupulaformibus, apotheciis carneolis lutescentibus. Sommerf. Lapp. p. 228. Cenom.

In Europe orientali-borealis muscosis sterilibus, supra saxa, rara. (Forte in Siberia frequentior).

Species minus nota, hactenus tantum sub unica forma, at evidenter hujus seriei, nec cum præcedente nec sequente conjungenda. Epidermis podetiorum cartilaginea est, mox ut in C. squamosa \& decorticata in squamulas tota abiens. Podetia ipsa, ut in $C$. gracili, cylindrica, omnia, quatenus hactenus innotuit, in scyphos cupulæformes, rarissime proliferos, abeuntia. - Clad. straminea Fl. Clad., e descr. \& syn. primario Cen. Flörkeanae excluso, ad priorem potius spectat. 204. CLADONIA Botrytis, thallo squamuloso, po- 
detiis cylindricis cartilagineo-corticatis verruculosis ochroleucis, in ramos subfastigiatos subdivisis, apotheciis carneolis pallidisve. Hoffm. Germ. 2. p. 128.

Lich. Botrytes. Hag. Hist. Lich. p. 121. t. 2. f. 9 . Wulf. in Jacq. Collect. IV. p. 237. t. 4.f. 3 . Bæomyces, dein Cenomyce. Ach. Cladon. F'. monogr. p. 18. Bxomyces abietinus. Pers. Patell. coccinea II. b. Wallr. l. c. p. 186 .

Exs. Lich. Suec. n. 80 .

Ad terram! \& truncos putridos in pinetomontanis Europæ orientalis copiose; per reliquam rarior \& magis sporadica ad truncos.

Optime monet Inventor, Hagen, hanc speciem ad Scyphiferas, nec Fruticulosas, esse referendam, quod Clad. Flörkeana \& reliqux analogæ suadent; nam a me scyphifera, licet rarissime, lecta est, scyphis planis peltatis subangulatis e margine fertili subextenso. Thallus evidenter squamulosus, qui hujus formas steriles ab omni Clad. unciali distinguit. Podetia semper gracilia, mox rugoso-granulata, immo furfuracea, numquam tamen subtiliter pulverulenta, carie basi fuscescentia, nec fulvescentia. Nisi scyphifera, qualia rarissima, in ramulos divisa subfastigiatos, ut mos est scyphis abortivis. : Occurrunt vero omnino simplicia, symphycarpea. A pothecia pro more livido-carnea, colore interno luteo, præcipue ad truncos cito decolorata \& expallentia. Hoc modo distinctissima apparet, sed accedunt etiam podetia substerilia dichotomo-ramosiora, immo ramosissima, facie prorsus uncialis. Forte hrc ad Clad. coccineam II h. hybridam Wallr. referenda sunt, quatenus Europæa, nam ipsam Cen. peltastam Ach. ex Europa non vidimus, licet a priori haud admodum distet.

Ser. IV. Cocciferce. A pothecia coccinea. Podetia substramineo-viridia in statu vegeto, putrescendo aut carie basi fulvescentia. Patellaria coccinea I Wallr. monogr. exclus. Clad. papillaria.

Analogæ cum serie citrina Parmeliarum. Apothecia in herbariis diutius servata rubiginoso-atra; colore coccineo superficiali evanido luteola evadunt; unde omnis 
speciei forma oritur ochrocarpia, non separanda. Species omnes tam affines ut in unam (Scyphophortes cocciferus Fl. Fr. 2.p. 339) conjunxerit Cel. Decandolle; plures adhuc addit Wallroth. At plurimæ insigniores adsunt in America, optima hujus seriei patria. Huic sensui latiori Cocciferce nomen, jam apud Linnæum collectivum, servandum est; ne ex his duabus diversis ideis eodem nomine designatis confusio oriatur. Speciei, vulgo cocciferæ dictæ, eo minus hoc nomen tribuiere debui, cum Lich. cocciferus a. L. evidenter sit Clad. macilenita aliudque exstet nomen Linnæanum ad istam plene pertinens \& ad analogiam $C l$. pyxidatoe designandam pæue necessarium.

* Podetiis cartilagineo-corticatis, numquam subtiliter pulverulentis. Cfr. supra.

205. CLADONIA Cornucopioides, thallo squamuloso, podetiis cartilagineo-corticatis, scyphiferis elongato-turbinatis, scyphis cyathiformibus dilatatis, apotheciis coccineis. Sched.Crit.3.p. I. Vaill. par. t. 21. f. 4. Mich. gen. t. 41. f. 3. Dill. musc. $t$. 14. $f$. \% Lichen Cornucopioides. Linn. Suec. $n .1101$. Clad. coccinea \& extensa. Hoffm. Lich. cocciferus. Auct. - Engl. Bot. t. 2051. Bxomyc. dein Cenomyce. Ach. Cladon. Schaer. spic. p. 24. Flörk. Clad. p. 89. Patell. coccinea h. Cornucop. Wallroth. monogr. $p .177$.

Exs. glabra: Lich. Suec. n. 83. Fl. Deutsch. n. 35. Schaer. Helv. n. 51. Moug. et Nestl.n.752. Ehrh. Crypt. $n$. 168. - pulverulento-furfuracea: Lich. Suec, n. 84. Schaer. $n$. 50 .

Per omnem Europam in terra sterili camporum \& silvarum. Locis humidiusculis varie degenerat.

Podetiis brevibus, deorsum, attenuatis, primo glabris, dein verrucosis vel etiam locis humidis pallido-furfuraceis, numquam vero subtiliter flavo-pulverulentis, optime distinguitur. Ab Achario in Lich. univ. optime limitata fuit. - Forma normalis, scyphis æqualibus denticulatis, apotheciis minutis discretis, nunc e margine, sæpius e centro (Capitularia asotea FI. in Berl. Mag. 1808. p. 223.) prolifera. Frequentior forma scyp̋his margine extensis, apotheciis amplis sive prolifero-symphy- 
carpea (Capit. extensa 1. c.); rarissima vero podetiis primariis symphycarpeis ascyphis (Clad. incrassata Fl. Clad. p. 21.), quæ demum etiam rimoso-cariosa vel ramulosa. Locis udis præcipue epidermis deliquescit: Cap. pleurota. 1. c. ex payte. De infimis prolibus vide Lich. Suec. exs. n. 236 \& A. astelides. Wallr. l. c. 170. Ex his non magis formæ nominibus designandæ creandæ, quam ex Abiete fruticosa, pendula \&c.

206. CLADONIA bellidiflora, thallo squamuloso, podetiis cartilagineo-corticatis elongatis ventricoso-cylindricis glabris, mox squamuloso-exasperatis, scyphis angustissimis, apotheciis coccineis. Schaer. spic. p. $2 \mathbf{\text { I. }}$

Lich. bellidifl. Ach. in Vet. Ac. Handl. 1801. $p$. 218. t. 4. f. 1. Engl. Bot. t. 1894. Bæomyces, dein Cenomyce. Ach. Capitular. Flörk. in Berl. Mag. $l$. c. p. 224. Clad. Fl. Clad. p. 95. Cenomyc. coccocephala Ach. Lich. univ. Patell. coccinea. g. polyceph. Wallr. mon. p. 174.

Exs. Lich. Suec. XII. Schaer. Helv. n. 39. elc., at minus insignes.

Ad terram sterilem alpestrem Europæ, nec non in paludosis muscosis in pineto-montanis Scotiæ \& Scandinaviæ.

Podetiis longioribus, cylindricis aut sursum attenuatis, sæpe ventricosis \& apice subulatis, scyphorumque minutorum forma a priori facile dignoscitur. Epidermis tenuior est, mox peculiari modo rimoso-exasperata, dein squamis dense imbricata, at non decorticata. Basis insigniter fulvescit. - Forma typica scyphis regularibus denticulatis, apotheciis simplicibus, plerumque eleganter conglomeratis, ut passim scyphi discum obtegant, in uliginosis montanis Sueciæ copiosissima est. In alpibus magis occurrunt formæ symphycarpeæ \& cornutæ. - $V$ aill. par. t. 21. $f \cdot 10$, ob habitum valde diversum, huc non referam, cum insuper nec apothecia coccinea dicantur, nec credere fas sit hanc speciem Parisiis nasci; est status degener symphycarpeus, exacte referens similem $C l$. pyxidatce, \& si apoth. coccinea fuissent potius ad priarem retulissem. Ex hac icone pendet $C l$. polycephala. Hoffm. - Toto colo differt huc citata $C l$. sulphurina Mich. sub Scyphoph., (cujus adsunt specimina tam au- 
thentica Canadensia, quam e Carolina, ubi teste Cel. Schweiniz vulgaris) quæ non tantum numquam squamosa evadit, sed et thallo foliaceo carere videtur, infundibula nec veros scyphos habet \& tota indole $C l$. uncialis gaudet.

207. CLADONIA Florkeana, thallo squamuloso, podetiis cylindricis gracilibus cartilagineis, demum squamoso-decorticatis basi nigricantibus, scyphis in ramos subdigitatos fastigiatos abenutibus, apotheciis coccineis. Fr.Stirp.Fems.

Dill. musc. t. 15. f. 19. C. optime. Lich. digitatus. Fl. Dan. t. 1188. f. 2. Engl. Bot. t. 2439. Cenomyc. Flörkeana. Sched. Crit. 3. p. 18. Sommerf. Lapp. p. 128. Clad. Fl. Monogr. p. 99. Patell. coccinea. 1. B. *. ०. ** d. \& **. e. Flörkeăna.Wallr.l. c. p. 173 (at non c. incrassata).

Exs. Lich. Suec. n. 82.

b. conglomerata. (Forte Dufourei, sed spec. non vidi). Ad terrant apricam sterilem ericetorum \& silvarum deustarum, etiam truncos, frequens in Suecia occidentali.

Dillenius, cujus dispositio quoad analogiam peracuta est, proxime ad ixacte analogan $\mathrm{Cl}$. degenerantem collocavit, cui omni respectu analoga, ita vero ut illius forma digitata, in Cen. cariosam abiens, in hac fere normalis facta sit, \& a præcedente differt ut Clad. degenerans a $\mathrm{Cl}$. gracili; at facilius quam duæ ultimæ dignoscitur, cum hactenus tantum extra regionem $\mathrm{Cl}$. bellidiflorce reperta sit. Huic vero esse proximam, nee Cl. macilentae (analogæ sequentis subdivisionis), optime observavit Flörke, qui primus differentiam observavit. Raro profert scyphum planum integrum, disco sæpe apotheciis pulchre conglomeratis obtecto, podetia vero in ramos digitatos fertiles (Helopodium Ach., cujus nulla certe species genuina) abeuntia sæpissime ascypha; sed occurrunt etiam ramosa, substerilia. Epidermis cartilaginea, primo lævigata, per ætatem granula in subsquamosa tota solvitur, squamis granulisque omnino innatis! Tales status vetustissimi omnino nigricantibus lignosis decorticatis podetiis valde insignes sunt. Ceterum in hac serie abnormis est colore podetiorum etiam corticatorum per ætatem cinereo \& fusco, basique nigrescente! Нæc 
species primitiva est $\mathrm{Cl}$. digitata, ex qua hoc nomen, huic aptissimum, ortum est.

* podetiorum epidermide membranacea, laevi, ab apice mox (sæpe primitus) in pulverem subtilem fatiscente.

208. CLADONIA deformis, thallo squamuloso, podetiis cylindricis nembranaceo-corticatis mox superne sulphureo-pulverwlentis, scyphis cupulæformibus, margine erecto crenato-dentato, apotheciis coccineis. Hoffman Germ. 2. p. I 20. Mich. gen. t. 41. ord. VIII. f. 8. ex habitu. Linn. Lapp. t. 11. f. 5. Dill. musc. t. 15. $f$. $A$. Lich. deformis. Linn. et Auct. - Engl. Bot. t. 1349. Bxomyces, dein Cenomyce. Ach. Clad. Schaer. spic. p. 23. Capitul. crenulata Flörk. Clad. Ejusd. Clad. p. 105. P. coccinea. 1. B. m. 23. Wallr. p. 184.

Exs. Lich. Suec. n. 148. Schaer. Helv. n. 47-49.

Ad terram sterilem macram Europa borealis, ubique copiosa \& insignis; in Europa australiori alpestris est.

Reliquis elatior \& crassior, semper cylindrica aut ventricosa, licet scyphi adulti ampli, dilatati cupulæformes, nec podetia sensim in scyphum incrassata ut in $\mathrm{Cl}$. cornucopioide. Hoc vero non unice a podetiis elongatis pendere, forma pumila monstrosa podetiis abbreviatis, quæ ex ipso IIl. Flörkeo partem Capitul.pleurota Ejusd. efficit, testatur. Tam ex hac forma, quam especiminibus prorsus glabris, epidermide a $\mathrm{Cl}$. cornucopioidis diversissima, concludo Clad. deformem, eam esse statum pulverulentum $\mathrm{Cl}$. cornucopioidis declarando, non plene esse explicatam. Vulgo autem saltim superior podetiorum pars eximie sulphureo-pulverulenta, numquam squamuJosa, sed in inferiori podetiorum glabra parte tantum thallus adscendit. Aberrationes ut reliquis communes nominibus notare superfluum duco; quales apothecia epiphylla, simplicia \& symphycarpea; podetia cornuta \& sterilia (simplicia tamen, nisi monstrosa, semper vidi, \& proles plerumque symphycarpeæ); cornuta demum solito more fissa; talem statum hujus cariosum sistit Cen. pulvincita Lich. univ. p. 538. Speciosa \& frequens est hujus forma ochrocarpia. (Proxime accedit forma speciosissima sub $\mathrm{Cl}$. portentosa Duf. infra memorata). 
209. CLADONIA digitata, thallo squamuloso, podetiis cylindricis membranaceo-corticatis mox superne ochroleuco-pulverulentis, scyphis angustatis margine incurvo integro, aut prolifero dimidiato-palmatis, apotheciis coccineis. Hoffm. Germ. p. 124.

Dill. musc. t. 15. f. 19. A. R. mala \& omnino amphibola. Lichen digitatus Linn. Suec. n.1114. Clad. Schaer, spic. p. 22. Fl. Clad. p. 102. Bæomyc., Cenomyce. Ach. Capitul. Fl. Berl. Mag. 1808. p. 261. Lich. cornutus. Engl. Bot. t. 1836 sec. specim. Cen. apophysis. Duf. Patellaria coccinea 1. B. oo m. Il. Wallr. l. c. - Monstrum: Dill. Musc. t. 15. $f .18 . B$.

Exs. Lich. Suec. n. 85. Fl. Deutsch.n. 176. Schaer. Helv. n. 43-46. Moug. et Nestl. n. 751.

Ad terram turfosam, supra muscos putridos \& ligna cariosa silvarum, Europæ totius.

Præcedenti affinis, (in Lich. univ. cum eadem ab Achario conjuncta \& ex Wallroth. status campestris ejusdem formæ), sed tenuior, multo magis irregularis, in eisdem regionibus ac prior optime evoluta. Ipsa hic polymorphiæ historia, scyphorum indoles, qui numquam dilatati \& crenulati, sed vel nodosi integerrimi margine incurvi, vel e prolibus plus minus evoluti dentati $\&$ adultiores obliquo-palmati, diaphragmate glabro \&c. facile dignoscitur. Podetia admodum versiformia, non raro ramosa, alia subulata, alia cornuta; locis udis pulvis pro more virescit. E centro scyphorum et hanc proliferam. vidi. Duplex præcipue forma distingui posset: thallo platyphyllino, scyphis plerumque integris \& th. microphyllino, squamulis subtus sæe nudis, scyphis plerumque dimidiatis palmato-ramosis.

2г. CLADONIA macilenta, thallo squamuloso, podetiis cylindricis sursum membranaceo-eorticatis, mox incano-pulverulentis, scyphis tubæformibus evanidisque, margine erecto, apotheciis coccineis. Hoffin. Germ. 2. p. 126.

a. filiformis, podetiis gracillimis, scypho angustissimo integerrimo aut sæpius apothecio symphycarpeo obliterato. Dill. musc. t. 14. f. 10. Lich. coccife- 
rus. $\alpha$. Linn. Suec. n. 1109. ('integerrimus, stipite cylindrico"). L. macilentus. Ehrh. Schrad. \&c. Capitul. Fl. Berl. Mag.l.c.p. 214. Bæomyc. Wahl. Lapp. et Suec. Lichen filiformis. Relh. - Engl. Bot. t. 2028. Clad. Schaer. spic. p. 19. Lich. tubiformis. Lightf. Clad. Hoffm. germ. p, 122. (Bæomyces scolecinus. Ach. meth. p. 324. t. \%. f.2. ex ipso, \& quatenus apothecia decolorata!) Bæomyc. 1. Cenomyce bacillaris. Ach. Cladonia polydactyla. $F l$. Clad. p. 108. Patell. coccinea 1. B. $\odot \odot *$ o. k. $\alpha_{\text {. }}$ a. b. \&c. Wallr. p. 179. 180. Status singulares: Lich. monocarpus Thunb. Bæomyc. s. Cenom. Ach. Cen. carcata Ach. Lich. univ.

Exs. Lich. Suec. n. 52. Ehrh. Crypt.n. 267. Schrad. n. 194. Schaer. n. 34, 35. Funk. n. 477.

b. polydactyla, podetiis gracilibus, scyphis latioribus cristato-radiatis, radiis numerosissimis \& proliferis. Cen. polydactyla. $\alpha$. Fl. Deutsch. X. p. 13. (Dill. musc. $t$. 15. $f$. 17. $A$. habitum exprimit.)

Exs. Fl. Deutsch. n. 195.

* scyphis omnino obliteratis in ramos fastigiatos. Cl. polydactyla $\gamma$. corymbiformis. Fl. Clced. p. 114 .

c. clavata, podetiis ventricosis apice subulatis ramosisve substerilibus. Clad. cornuta. Hoffm. var. apoth. coccineis, at non PI. Lich., cui apoth. fusca. Cen. pseudocornuta. Delis. sec. spec. - Wallr. 1.c. p. 179. i.

Exs. Schaer. Helv. n. 33.

d. decorticata, apotheciis semper symphycarpeis.

Ad terram, rupes \& truncos putridos Europæ totius vulgaris; b. $\&$ d. autem raræ.

Nisi rationem stricte habes ad characteres hujus seriei, ut apothecia coccinea \& podetia carie basi fulvescentia, qui constantissimi \& primarii sunt, nullo modo ab analogis formis analogarum specierum seriei Ochroleuca \& Fusca discerni potest; præcipue difficile est dispescere synonyma inter Clad. macilentam b. \& $\mathrm{Cl}$. carneolam b., inter $C$. macilentam c. \& $C$ cornutam \& C. fimbriatam, cujus statui decorticato Cl. macilenta singulo ceterum verbo convenit. - Inter Cocciferas eminet habitu macilento, epidermide sursum membranacea mox l. primitus in pulverem subtilem incanum fatiscente, scyphorum forma eorumque margine nec crenulato nec incurvo 1. prolifero dimidiato, diaphragmate 
semper pulverulento \&c. Basis in hac epidermide subcartilaginea gaudet, in prioribus prorsus desiderata. Forma primaria a., optime a Dillenio expressa, (Mich. gen. t. 42. ord. 10. $f .1,2$ minime hujus loci est) scyphos habet parvos subregulares, integros (nisi podicellos apotheciorum pro radiis habeas), subinde scyphifero-proliferos. Sed ob summam scyphorum angustiem sæpius symphycarpea evadit. In b., sæpius elatiori, scyphi cristato-radiati, prolibusque subcornutis ornati; apothecia in hac raro perfecta. Non sine summa attentione a prioris (scyphis haud dimidiatis, colore \&c.) formis dignoscitur. c. est monstrum atypicum. Alios magis accidentales lusus, v. c. apothecia epiphylla \&c., omitto.

Cladonia acicularis Ach. syn. p. 275. sub Cenom. ex exemplaribus originalibus a b. m. Sivartzio missis ad priorem minime trahi potest; thallus omnino sequentium, fere Clad. Papillaria, podetia glabra nuda verruculosa et apoth. fere sequentis generis, ut valde diversa sit. Novo orbi priva est, ubi hujus seriei optima Patria; plures ex illo (ut $n .199,200,201$ anulogas), habemus eximie diversas thallo fruticuloso ramosissimo etc. Ibidem sub Zona torrida etiam interna sub. stantia in sanguineum incenditur (Cl. sanguinea Mart. Bras.), id quod inter Parmelias ejusdem regionis simul observatur.

Sect. II. Thallo horizontali crustaceo-granuloso, granulis in podetia abeuntibus. Podetia uniformia, fruticulosa, ascypha, definite ramosa. Pycnothele. Ach.

Multæ suadent rationes species hujus sectionis, quarum plurimæ vero exoticæ, inter prioris series esse dispescendas singulamque seriem ad formas crustaceas esse deducendam, id quod speciebus exoticis simul tractandis necesse fit. At propter morphosin longe aliam \& simpliciorem hoc loco seposui. Omnibus thallus horizontalis primitus crustaceus, nullo modo foliaceus, quare etiam podetia numquam squamulis foliaceis adspersa, ut in omnibus præcedentibus, excepta huic sectioni variis rationibus proxima Cl. turgida. Hic thallus crustaceus optime conspicitur in Clad. Papillaria aliisque speciebus exoticis, ortis neinpe e serie Glaucescentium \& affin., (cujus thallus insignior hac ratione etiam in crustaceis prodit, v. c. nobili Cl. retipora Fries Sched. Grit. p. 21, cujus thallus pertusus nullo modo cum carioso nostratium comparandus est, sed omnino normalis, ut pertusus in Laminaria Agaro \& affin.). Eundem vero etiam in reliquis adesse, primitus nempe, præecipue in $\mathrm{Cl}$. unciali iteratis vicibus vidi. Prima attendebam in terra, cæspite 
gramineo orbata, maculam crustaceam, spem Biatoræ, secundo vero anno Gl. papillariæ faciem præbentem, tertio demum $C l$. uncialem agnovi. Præcipua differentia inter crustas $\mathrm{Cl}$. uncialis \& Cladonioe papillaria posita est in granulis illius omnibus in podetia abeuntibus, quum multa in hac abortiva persistunt. Desunt in hac sectione non tantum apothecia epiphylla, ut per se patet, sed etiam podetia symphycarpea. Hæc vix nisi superficie \& colore, nec non ramificatione plus minus evoluta, mutantur. Per ætatem verruculosa evadunt, numquam pulverulenta, sed prima præcipue species (Cl. rangif.) nitore cartilagineo amisso quasi velutina. - Species e serie Cocciferarum, ut Physciæ \& aliæ tribus e citrina serie, patriam Americam non deserunt. Nascitur in America boreali species (Cladonia leporina) Cl. rangiferince simillima, sed colore thalli flavoviridi basi cariosa fulvescente \& apotheciis coccineis distinctissima.

211. CLADONIA rangiferina, crusta evanida, podetiis fruticulosis trichotome ramosissimis, axillis subperforatis, apicibus sterilibus nutantibus, fertilibus erectis cymosis, apotheciis fuscis. Hoffm. Germ. p. I 4 .

a. Mich. gen. t. 40. f. 1. Dill. musc. t. 16. f. 29. Lich. rangif. Linn. et Auct. Engl. Bot. t.173. Fl. Dan. t. 180, 539. Sv. Bot. t. 47. Bæomyc. s. Cenomyce. Ach. Clad. Schaer. spic. p." 3\%. Fl. Clad.p. 160-170. Patell. fusca. I. holophyllina v. rangif. Wallr. p. 145.

Exs. Lich. Suec. n. 238. Schaer. n. 76, 7\%. Moug. Nestl. 72.

b. silvatica, dealbata. Dill. musc. t. 16. $f .30 . A . B$. Cen. silvatica. $F l$. Deutsch. n. 76. Bæomyc. rangif v. pungens. Wahl. Patell. fusca II. schizophyllina' v. silvatica. Wallr. l. c. p. 160.

Exs. Lich. Suec. n. 239. Filörk. l. c. Schaer. n. 78. * alpestris, major, ramis ramulisque in thyrsum densissimum implexis. Dill. l. c. f. 29. $\boldsymbol{E}$. $\boldsymbol{F}$.

Exs. Lich. Suec. n. 240.

Ad terram \& inter muscos Europæ totius; in boreali vero maximam partem vegetationis constituit, omnium Lichenum copiosissima.

Color in statu typico lecvigato \& glabrato (raro!) 
cinereo-viridi-pallidus; vulgo autem superficie quasi velutina cinereus aut fuscescens; putrescens, ut decet seriem fuscam, basi nigrescens, albo-guttatus; b. vero albicans \& siccata in stramineum vergens. Ceterum notissima, valde mutabilis. Cen. portentosa Duf. Rev. n. 29 est status maxime inflatus, axillis infundibuliformibus, ramulis lateralibus abbreviatis. - Ut hæc seriem fere contiguam cum Cladonia pyxidata efficit, sic et reliqux series in ambitu integro species prorsus analogas offerunt; ut sæpe species detegendas divinarim, quas deinceps accepi; at nimis a practica vita \& usu se divellit Lichenologia, si singulam seriem tantum ut speciem considerat. Similis in evolutione analogia omnes plantarum saltim Homonemearum sectiones percurrit; nec est temerarius "calculus physico-mathematicus," ut quidam naturæ harmoniam metuentes fingunt.

212. CLADONIA uncialis, crusta papillosa evanida, podetiis fruticulosis dichotomis lavigatis stramineis, axillis subperforatis, apicis sterilibus erectis nigrescentibus, fertilibus digitatoradiatis, apotheciis carneolis.

Lich. uncialis. Linn. et Auct. - Engl. Bot. t. 174. Bæomyces. Wahl. Suec.p. 846. Cenomyc. Ach. syn. p. 279 Clad. stellata. Schaer. - Fl. Clad. p. 171. Patell. coccinea II. f. W'allr. p. 190.

a. elatior, magis turgida, sursum incrassata, axillis hiantibus. Mich. gen. t. 40. $f .2$. Dill. musc. $t .16$. f. 21. Cl. biuncialis. Hoffm. Bæomyc. s. Cenomyc. adunca. Ach. Cl. ceranoides. Decand.

Exs. Lich. Suec. n. 87. Flörk. De.tsch. n. 156.

b. humilior, angustior, subattenuata, axillis passim integris, (vulgo sterilis). Dill. musc. t. 16. f. 22. "(at formas, potissimum steriles $\mathrm{Cl}$. botrytzs, commiscuit thallum squamulosum dicens). Lich. uncialis. Plurim. Clad. Hoffm. Bæomyc. s. Cenomyc. Ach. meth. et Lich. univ. - Gen. oxyceras Ach. syn. pr. p. v.c. var. obtusata \&c.

Exs. Lich. Suec. n. 25\%.Flörk. l. c. n. 155. Schaer. Helv. 82,83 status degener, obtusatus, quales plures.

c. turgescens, mollis, turgido-incrassata, ramis subtruncatis, fastigiatis. Schaer. l. c. d. excl. syn.

Exs. Schaer. Helv. n. 84 .

Ad terram \& inter muscos Europa totius 
communis; in uliginosis varie degenerans, cujus ultimurn extremum c. in alpibus.

$\mathrm{Jt}$ prior seriem prioris sectionis Fuscam, hæc $O$ chroleucam continuat, \& a Cl. Botryti sterili, thallo tamen foliaceo, axillis semper clausis \&c. distincta, caute distinguenda. Ceterum Clad. turgidce analoga, formaque a. podetiis obconico-cylindricis, quæ ut fertilis omnino primaria, ejus statum normalem, b. vero ejus formam corniculatam referunt, sed thallo mere crustaceo evanido, axillis clausis scyphos imitantibus, cum axillæ $\mathrm{Cl}$. uncialis dilatate infundibnliformes, omnino recedit. Denique a formis dealbatis Clad. fuscarum insuper probe distinguenda.

Cl. vermicularis Auct. Pycnothelia, Duf., quam priaris quxdam forma in uliginosis nata refert aut omnino efficit, videatur sub $\mathrm{Cl}$. gracilis Obs.

213. CLADONIA Papillaria, crusta papillosa persistente, podetiis clavatis simplicibus ramosissimisve glaucis, ramis fastigiatis apice indivisis obtusis, axillis imperforatis, apotheciis rufis. Hoffrn. Germ. 2. p. 117 . c. var. molariformi. Dill. musc. $t$. 16. $f$. 28. Lich. papillaria. Ehrh. Engl. Bot. t. 907. Bæomyc. \& Cenomyce Ach. Sommerf. Lapp. p. 133. Cladon. Dec. Fr. 6. p. 180. Pycnothel. Diff. Lichen madreporiformis. Wulf. in Jacq. Coll. 1II. p. 105. t. 3. f. 2. Lich. madreporoides. Rutstr. diss. Patell. coccivea. 1. B. *. $\odot$. *. *. b. $\alpha . \beta$. \& **. c. $\alpha . \beta$. Wallr. l. c.

Exs. Lich. Suec.n. 233. Sommerf. Aorv.n. 74. Moug. et Nestl. n. 259. Ehrh. Phyt. n. 160.

Ad terram sterilem glareosam Europæ præcipue medize \& borealis; optime evoluta in maritimis occidentalibus.

Vulgo legitur podetiis brevissimis vesicularibus subconicis papilla rufo-fusca, ex apothecio abortivo, terminatis, at hæc forma omnino atypica est. Perfecta enim $\frac{1}{2}-1$ uncialia sunt, ramosissima, ramis stipatis, pulchre fastigiatis, axillis semper clausis, unde et apices indivisi, licet apothecia sæe conglomerata. At hæc minime forman diversam sistunt, cum in eodem thallo vulgo obvia. Est itaque cum certe proxime affini C.turgida distinetissima species; seriei Glaucescentium terminus, ut 
Cl. acicularis Cocciferarum, Cl. ptilota Schwein. Fuscarum, cum quibus analoga est.

Cladonia a potheciis ferme nigris propriam seriem, Austras li a potissimum hospitam, unde eximiam seriem dedit Cel. Greville, sistere videntur, Glaucarum tamen proximum, ob nexum vegetationis Africance et Nove Hollandia. Hac ad Europam, vix hemispharium boreale, non attingit, sed in Americam meridionalem vagatur.

\section{B E O Y CES.}

Coralloidis spec. Dill. Bæomycetis sp. Pers. Ach. Bæomyces Fries Syst. O. V. p. 249. Patellariæ spec. Meyer. (Nescio vero cui Licheni hoc nomen minus conveniret.)

CHAR. Apothecia primitus globosa, immarginata, velata!; adulta inania intus araneosa, basi stipitem arcte ambientia. Lamina peripherica, undique ascigera. Thallus crustaceus, uniformis, protrudens stipites fertiles, strato corticali destitutos.

Genus distinctissimum, licet unica nobis adsit species, inter Cladonias \& Biatoras medium, at ab utraque optime distinctum. Biatoræ stipitatæ habitu conveniunt, sed apothecii structura valde diversa. Analogum, quoad apothecia, est Peltigeræ genus; inter Fungos Mitrula \& Onygena, jam a Dillenio (t. 14. f. 5.) comparata. Stipites hujus cum Fungorum prorsus conveniunt, nec podetia dicenda.

2 14. BEOMYCES roseus, crusta verrucosa glauca, stipitibus brevibus cylindricis, apotheciis subglobosis carneis. Pers. - Ach. Lich. univ. p. 572 .

Fungi incarnati coloris \&c. Menz. Pug. t. 6. Mich. gen. t. 59. infer. Dill. musc. t. 14. $f$. 1. Lich. Bxomyces. Ehrh. - Hoffm. en. Lich. t. 8.f.3. Engl. Bot. t. 374. Lich. ericetor. (Linn. pr.p.) Scop. - Fl. Dan. t. 1003. f. 2. - * crusta densius papillosa, apoth. abortivis: Isidium dactylinum. Ach. syn p. 282 ex ipso.

Exs. Lich. Suec. n. 145. * 230. Ehrh. Phyt. n. 89. Schaer. Helv. 31. Moug. Nestl. n. 91. Desmaz. n. 390. Fl. Deutsch. n. 97. 
In terra sterili ericetorum Europæ totius; *locis uliginosis, subalpinis.

Cum alio Lichene europæo confundi nequit, sed $B$. fungoides parum admodum differt. - Biatora byssoides quoad stipites convenit, sed apothecia longe diversa.

\section{B I A T OR A.}

Lichenoidis spec. Dill. Psoræ \& Verrucariæ sp. Hoffm. Lecidex \& Lecan. spec. Ach. \& Auct. pl. Biatora. Fries in Dian. Lich. 1817. Vet. Ac. Handl. 1822. p. 263. Syst. Orb. Veg. I. p. 250. Eschweil. Syst. f. 19. Mann. Lich. Boh. - Wahl. Suec. p. 796 sub Lich. Sommerf. Norv. p. 79 sub Lecid. Patellariæ spec. Mever. Accedunt Bæomycetis spec. Auct.

CHAR. Apothecia libere enata, primitus ab excipulo thallode in proprium mutato ceraceo mar ginata, dein hemisphærica aut globosa subimmarginata solida cephaloidea. Discus semper apertus; primo punctiformi-impressus, dein dilatatus turgescensque, narginem excipuli pallidiorem obtegens; strato siepius pallidiori, numquam carbonaceo, impositus. Thallus horizontalis, ex hypothallo oriundus, subcrustaceus, effiguratus aut uniformis. Podetia nulla, in paucis apothecia stipitata. Margo numquam primitus niger.

I. Est in hac tribu genus centrale, ut Parmelia nimis analoga in priori, undecumque radios ad proxima emittens, indeque simul limitatu difficillimum, quamquam Lichenologiam idealiter intuenti maxime necessarium appareat. Præcedentibus tribus in serie naturali proximum, at, licet duo saltim priora status proferant abnormes Biatoras mentientes, in statu normali sine negotio dignoscuntur. De horum autonomia \& limitibus, etiamsi unam alteramve Biatoram ad illa referre malis, vix ulla orietur dissentio, tantum de eorum dignitate, quatenus ut genera, subgenera, aut quidquid dicas sectiones superiores naturales, considerentur, de qua re verbum vix perdam. Nec de differentia Lecidearum dubitamus, nam inter duo tam vasta genera exstare species transitum pandentes haud mirum. Alia vero est ratio Parmeliarum; certe cum his conjunxissem, nisi duo 
exstarent typi evidenter diversi \& harum differentia sublata omnia genera Parmeliacea \& Lecidina collaberentur. Tam diu \& a tot diversæ rationis observatoribus limites stricti inter Lichenum genera, quibus tamen carere non possimus, frustra quæsiti, ut eos inter omnia fere deficere tandem ingenue agnoscamus. Character vero, inquit Linné, non est, ut genus fiat, sed ut genus noscatur.

II. Ut, quantum fieri possit, Parmelice \& Biatorce differentia eluceat, pauca de utriusque statu normali afferenda sunt. Primo notandum est nec Parmeliam nec Biatoram, nec ullum omnino Lichenem disco hymenino, normaliter exsistere disco vere immarginato. Sunt horum apothecia immarginata vel status abortivi, v. gi. Arthonice, quales plurimos habemus Parmeliæ, Biatoræ, Lecidex, immo Cladonix \&c.; vel alia ratione degenerati. Normale fere est inter Biatoras, Cladonias \&c. marginem a disco turgescente excludi, sed in haud exiguo numero specierum omnium a me visarum \& immarginatarum descriptarum in statu primitivo \& normali marginem vidi. In Parmeliis discus vulgo planus persistit, margine evidenti thallode cinctus, non vero desunt species marginem (thallodem) per atatem excludentes ut $P$. hoernatomma, atrocinerea, sordicla, de quarum vero genere statu primario observato nullum dubium oritur. Magis fallaces sunt aliæ abnormitates apotheciis et junioribus immarginatis, quales similes proferunt \& Parmelix \& Biatoræ, at in neutris respiciendx ut abnormes \& atypicæ. Sic ubi thallus deficit vel nimis macer est, Parmeliæ marginem thallodem excludunt vel tam tenuem protrudunt, ut pro Biatoris facile habeas. v. c. Lecidectm. symmictam, cyrtellam, luteoalbain Ach., quæ vero ab, origine observatæ \& oculis adsuetis facile a Biatoris dignoscuntur. Præ, ceteris fallaces sunt, quarum, v. c. $\boldsymbol{P}$. coarctatce \& rubrce, apothecia excipulo thallode excluso concava \& marginata persistunt, at attentius adspecta facile distinguuntur margine similari \& concolori, h. e. ipsius tantum laminæ est. Sic etiam facile explicatur excipulum in quibusdam Parmeliaceis thallo discolor, licet thallodes sit, e crusta decolorata v. c. in serie Citrina, Parmelia badia $\delta$ e. s. p.; ab excipulo decorticato v. c. in variis Stictis, forma Parm. ventosce \&c. Adsunt vero certiores differentiæ, licet minus primo obtutu, evidentes, quam quæ ab excipuli colore petuntur. Apothecia Parmelice primitus thallo innata \& clausa, disco 
connivente incluso; Biatora jam primitus plus minus discreta \& aperta, disco in umbilico excipuli impressó semper nudo. Margo Biatorarum semper a disco discretus est, Parmeliarum vero similem proferentium cum lamina contigurus, h: e. ab eadem formatus. Sub eisdem momentis apothecia tam horum generum, quam Lecideæ varie mutantur, v. c. in aquosis Lecidearum excipulum carbonaceum \& atrum persistit; Parmeliarum discus in humidis magis emollitur, ater color abit in rufofuscum \& in genere his locis lotior fit. In Biatoris humectatis etiam excipulum dilutius fit; at in natura humoris copia lætior disci color in fusco-nigricantem aut lividum vulgo abit; discus vero normaliter mollis est \& turgescit, unde forma scutellata inter Parmelias typica, cum inter Biatoras cephaloidea. Duplici ratione harum apothecia jam primis immarginata fiunt, vel disco mox turgescente, ut excipulum obtegat; vel excipulo discum prorsus excludente, qualis vero status rarissimus est. Analytice examinatus uterque a Parmeliarum similibus mox dignoscitur.

III. Consideratis sic Parmelix \& Biatoræ ideis, in superioribus generibus utriusque seriei evidentius adhuc expressis, non potui non hæc genera servare, cum nihilo tamen minus eadem ipsa, ut centrum Lichenum constituentia, unde simul intimus nexus pendet, omnium vastissima sint. Nec tolluntur in examinando difficultates, a formis quibusdam mutilatis potissimum orta, si ut ejusdem generis tribus proponuntur, at evolutionis series \& specierum affinium in utraque tribu turbatur. $\mathrm{Pa}-$ rallelismo dispositionis in omni genere analogarum, qui quasi Systematis anima, eas ex parte sublatas esse spero. Sic si tiro inter Biatoras frustra quæsierit mutilatos status Parmeliarum, v. c. Lecid. cyrtellam, symmictam, luteoalbam Ach., mox transeat ad definite respondentes Parmelias. In genere vero difficultates non tantæ sunt, quantas quis facile concluderet ex ingenuitate, qua indicavi, contra morem easdem, ut Systema politum appareat, reticendi \& sic tironem in compito sine indice relinquendi. Hæc porro ratio est, cur maxime inter se affines species n. 79-89, in hoc scilicet opusculo, sub Parmelia reliquerim, licet re ipsa sectionem mediam (Zeorce, cum aliis) efficiant. Omnes, ipsamque $P$. triptophyllam, habeo apotheciis e thallo incolumi (nec conglobato) enatis scutelliformibus, margine thallode genuino, primitus clau- 
so. Possunt quidem explicatione tolli harum notæ, sed v. c. $P$. brunneam vix in hoc genere quxerat tiro, amans plantam primum invenire, dein explicationem videre, nec versa vice. Permulta ejusdem indolis sunt, e quibus singularibus me errasse judicetur; nolim autem iguorantix speciali tribuatur l. me rem integram non perpendisse fingatur. Ceterum non dubitanus species alia ratione inter hæc genera distribui posse; præcipue Parm. (Biatora) ferruginea ad hoc genus, Biatora (Parm.) icmadophila ad Parmelix secundum characteres potius referantur.

IV. Quare a primo generis determinatore impositum nomen rejiciatur non video, multo minus qua ratione Patellaria Hoffmanni dicatur. Genus sub hoc nomine, quantum novi, nullum determinavit \& definivit Hoffmann; in unico ipsius Systematico opere, Fl. Germ., prorsus deest. Sub Patellarice nomine varias quidem Lecanoras Ach. in Pl. Lich. pingendas curavit, sed quoad jdeam hoc genus nil cum nostro commune habet. Sensu Hoffmanni Verrucaria dicendum foret, si liceret nomina stabilita mutare. Forma patellata ab hoc genere mazis aliena, quam a proximis, Ehrhartque, qui primus Patellariæ nomen excogitavit, Parm. pallescenti tribuit. Hinc nec aptum, nec æquum, neque justum videtur Biatoræ nomen rejicere. Plene improbandus est mos ob limites dilatatos 1 . constrictos generum nomina mutandi; num Asia toties nomen mutabit, quoties Geographi ejus limites varient?

Ex affinitate huc pertinent Parmelix 79-89, quæ etiam statum Biatorinum proferunt.

Sect. I. Thallo crustaceo, effigurato!, squamoso, s. in ambitu lobato. Psoræe spec. Hoffm. Decand.

Thalli indole crustacea, subtartarea, facile dignoscuntur a sectione II. Parmeliarum, quarum status Biatorini hic forte quærentur; prorsus enim analoga est præsens sectio cum tertia Parmeliarum sectione, quæ conferenda, nam licet in statu normali recedant apotheciis primo clausis \& excipulo thallode, exstant status mutati \& mutilati hoc loco facile quærendi v. c. $P$. coarctata. Series ochroleuca \& citrina in Europa deficiunt, nisi huc referas Parm. n. 116-118, quæ tamen e characteribus pimariis \& affinitate cum reliquis Parmeliis intime cohærent. - Species hujus sectionis optimæ, sed rariores, soló privo, præcipue calcareo \& alpino, obviæ. 


\section{* Apothecia sessilia.}

Glaucescentes. Hypothallus albus. Thallus glaucescens. Cfr. Parm. n. 92-100.

2 5 . BIATORA testacea, thallo squamuloso viridi glaucescente, squamis subimbricatis undulato-lobatis subtus ambituque albis, apotheciis sessilibus nudis mox convexis ex aurantio cinnamorneis, intus albis.

Mich. gen. t. 51. ord. $X X X$. f. 2. Psora testacea. Hoffm. Germ. - Plant. Lich. t. 22. f. 5, 6. Lich., Lecan. \& Lecidea. Ach. - Schaer. spic. p. 116. Lich. saxifragus. Smith Transact. Linn. Soc. II. $p$. 82. t. 4. f. 4. Lecan. baldensis. Spreng.

Ad saxa \& fissuras, tenui terra tectas, montium calcaneorum Europæ australis, ut Italiæ!, Gallize australis Prevost! Pyrenæorum Montagne! Hispania Dufour! Helvelize Schaerer! Germanize australis Laurer!

Squamæ subfoliacex, sed tartareæ indolis, primo totæ adpressæ, dein ambitu solutæ \& sinuoso-undulatæ, subtus albæ (ex Smithio radiculosæ), supra virescenticinereæ, siccitate albentes, ut seriei glaucæ sit, suadente analogia eximia Parm. crassa, qux tanta est, ut cum illa conjungere velit Amic. Wallroth; apotheciis magis P. Dufourei huic accedit, quxiam pro Lecan. baldensi habita fuisse videtur. Apothecia juniora aurantiaca, margine pallidiori flexuoso, adılta subglobosa, immarginata, cinnamomea 1. rufa. - Mich. syn. etiam, ob locum ad parietes, sub $P$. ambigua allatum, potius hanc exprimit. Ex Achario sit Lecid. castaneola Syn. Lich. p. 52 (Cfr. supra p. 128.)

216. BIATORA albilabra, thallo squamuloso cinerascente, squamis aggregatis subrotundis subtus ambituque submarginato candidis, apotheciis sessilibus planis nigricantibus glauco-pruinosis, intus albis. - Dufour.

Ad terram in regno Valentino. Dufour!

Thallus late \& irregulariter effusus, tartareus, constans ex areolis aggregatis subrotundo-angulatis adpressis; mox squamaceis, subtus \& in ambitu elevato sub- 
pulverulentis candidis. Color paginæ superioris e sorde peregrina sæe squalidus, immo in olivaceum vergens; at hic omnino peregrinus \& etiam antecedentem simili ratione inquinatam vidimus. Apothecia colore a prioris prorsus recedunt, areolis enim immixta sunt.

2 I 7. BIATORA glebulosa, thallo squamuloso albido-glauco, squamis crustaceis imbricatis rotundatis crenatis, apotheciis sessilibus nudis rufofuscis, margine tenui pallidiore evanescente hemisphæricis.

Lecid. testacea. Vinch. Lich. glebulosus. Engl. Bot.t. 1955. Lecid. pholidiota Ach. syn. p. 53 . Ad rupes quartzosas Anglix, Gallix.

Quoad specimen, ad speciem vero dijudicandam haud sufficiens, a $B$. teslacea, cum qua iterum conjungenda ex Cel. Schaerer, distincta videtur, nec B. testaceam veram in Anglia lectam novimus. Differt squamulis minoribus, vix foliaceis, potius glebulosis, albicantibus \& apotheciorum colore per xtatem nigro intus fuscescente.

** Fuscescentes. Hypothallus niger. Thallus luridofuscus, olivaceus, in prima specie in incarnatum simul vergens. Cfr. Parm. 101-106.

218. BIATORA decipiens, thalli squamis discretis peltæformibus angulatis incarnato-lateritiis (passim fuscescentibus), subtus anbituque albis, apotheciis marginalibus adnatis subimmarginatis nigricantibus, intus albis.

Lich. decipiens. Ehrh. - Hedw. Stivp. Crypt. II. p. 7. t. 1. B. Engl. Bot. t. 870. Psora. Hoffm. Pl. Lich. t.43. f.1-3. Lecid. Ach. meth. et Syn. Schaer. spic. p. 115. Lecanora. Ach. Lich. univ. p. 409 . Lich. Elvelloides. Wulf. in Jacq. Coll. 1II.p.108. t. 3. $f$. 3. Lich. Pezizoides. Swartz in Nov. Act. Ups. IV. p. 247. Lich. incarnatus. Thunb. Pr. Fl. Cap. Lichen dispermus \&, pantospermus. Villars. L. gypsophilus. Schrad. spic. Lich, peltiphyllus. Bell. Exs. Lich.Su.n. - Moug.Nestl.n.58. Schaer.n.164.

Ad terram per omnem Europam, precipue in alpibus; sed etiam in planitiebus, formatione calcarea juniori substratis (ut ölandiæ \& Gott- 
landiæ, numquam vero apud nos saltim supra marmor 1. calcem primitivam); in Europa australiori etiam in arena (quali?) nasci dicitur.

Hypothallus spongiosus, indeterminatus, ater. Squamulæ juniores concavæ Pezizulam disco lateritio, excipulo albo referunt, dein explanatæ \& mutua pressione angulatæ; subinde plures concrescunt, apothecio applananato facie Solorinæ. Variat thallo dealbato, subpruinoso. Apothecia juniora utique marginata, e fusco nigricantia, sed margo fugacissimus est; observavit amiciss. Schaerer etiam vetusta apothecia albo-marginata. Cum nulla alia confundi potest.

2r9. BIATORA tabacina, thalli squamis areolæformibus adnatis subrotundis lobatisque ferrugineo-fuscis, apotheciis immixtis convexo-planis submarginalis nigricantibus, intus albis. Dec. Fr. 2. p. 367 . Psora.

Ad rupes schistosas in Pyrenæis Ramond! alibique in montosis Galliæ meridionalis Dufour! Hic verus Lich. tabacinus Ramond.! colorem quidem habet sequentium, cum quibus conjunctus fuit, sed vegetatio potius prioris, \&, quantum ex observatione Schaereri spic. p. 121. perspicio, ab hoc pro genuino Lich. paradoxo Ehrh. Psora. Hoffm. Germ. p. 163, cujus descriptio bene convenit, habetur. Hypothallus fere idem ater. Areolæ squamaceæ, discretæ, nunc sparsæ, nunc imbricatæ, terræ adpressæ, turgidæ, plerumque convexæ, minores rotundæ, majores in ambitu lobatæ, humectatæ fulvorufæ, siccæ ferrugineo-fuscæ. Apothecia majuscula, libera, juniora planiuscula margine tenui flexuoso, adulta convexa, nigra, subimmarginata, inter areolas sita. Ob fructum deficientem haud determinda Ps. denticulata Chev. par. t. 14. f. 1. habitum exprimit.

220. BIATORA lurida, thallo squamoso imbricato viridi-fuscescente brunneo, squamis orbiculatis lævibus sinuato-lobatis, apotheciis adnatis planis marginatis atrorufis, demum convexis nigris, intus albis. Stenh. Sched. Crit. p. 9 .

Lichen luridus. Swartz in N. Act. Ups. IV. p.247. Ach. in Vet. Ac. Handl. 1795. p. 247. t. 5. f. 2 . 
Engl. Bot. t. 1329. Lecid. Ach. Lich, univ. p. 213. Schaer. spic. p. 108. Psora. Dec. fr. 2. p. 370. fide speciminis hæc, nec sequens. Lichen squamatus. Dicks. Psora. Hoffm. Germ. p. 161.

Exs. Lich. Suec. n. 137. Schaer.n.15\%.Moug. Nestl. n. 643 .

Ad terram in fissuris rupium calcarearum, etiam calce primitiva constitutarum, raro ad muros, per omnem Europam. Ad finitima loca in his regionibus passim descendit, sed mere graniticas prorsus fugit.

Cæspites format suborbiculares, palmares \& ultra, dense complicatos \& imbricatos. Collema ramulosum nigrum, ex Hoffmanno, interspersum est hypothallus. Squamæ crassæ, arcte adnatæ, margine liberæ, læves, opacæ, humidæ viridi-fuscæ, siccitate cervino-brunneæ. Apothecia in lamina 1. ad basin squamarum sita initio concaviuscula, obtuse marginata, demum disco elevato convexa. Adsunt porro abortiva punctiformia, quo habitus Endocarpi. At Mich. gen. t. 54. f. 4. \& Dill. $t .30$. $f$. 134. ob fructificationem Endocarpi huc certo non referam. Idem de Lichene (anonymo) Leers herb. n. 950 valet. - Ex autopta Schaerer hic sit Lich.squamulosus Schrad. Crypt. n. 153., sed plurima alia sub hoc nomine visa specimina fuere $P$. cervina.

22.. BIATORA globifera, thallo squamoso imbricato virescente-castaneo nitidulo, squamis reniformibus rugosis lobatis, apotheciis elevatis globosis subimmarginatis e rufo nigricantibus, intus albidis.

Lich. Iuridus. Fl. Dan. $t$. 1064. f. 2. Lecid. globifera. Ach. Lich. univ. p. 213. Syn. p. 51. Sommerf. Lapp. p. 175 Schaer. spic. p. 109.

Exs. Sommerf. Norv. n. 53. Schaer Helv. n. 158. b. apotheciis conglomeratis. Bæom yces rubiformis. Ach. meth. Lecid. Wahl. Suec.n. 1715. Ach. syn. p. 52.

In alpibus calcareis \& micaceis, sxpe in inferalpina proxima descendens, ad plerasque al. pes Eurojie centrales; per totam fere Norvegiam copiosa.

Est e pulcherrimis, præcedenti peraffinis. Squamæ 
adhuc crassiores, "maxime cartilagineæ, rigide adseendentes" Wahl. (quo ab omni Cladonia epiphylla, v. c. Lich. rubifcrmi E. B., distinctissima, ut apothecia taceam), subreniformes, serius lobatæ, a basi rugosæ, nitidæ, unde habitus Iætior, minus luridus, in ferrugineum vergens. Apothecia laminæ aut margini squamularum inserta, magis elevata, jam juniora subglobosa \& in hac ætate tantum margine obsoleto instructa.

* L. pulvinata Schaer. l. a. p. 123. inter n. 225 et 226 inseratur, si quidem ab infimis prolibus $P$. b a di a diversa. Vide n.140. Exemplaria, quce vidi, haud satis evidentia fuerunt.

222. BIATORA atrorufa, thallo crustaceo adnato, primitus contiguo dein areolato cinereo-fusco, subtus nigro, in ambitu foliaceo lobato, apotheciis applanato-adnatis rufofuscis, intus albidis.

Lichen atrorufus. Dicks. Crypt. 4. t. 12. f. 4. Engl. Bot. t. 1102. Lecid. atrorufa. Ach. Lich. univ. p. 200. Wahl. Lapp. n. 918. Schaer. spic. p. 123. Lich. demissus. Rutstr. diss. $p$. 8. quoad spec. in loco a me collecta. Lecidea. Ach. l. c. p. 216.

Exs. Lich. Suec. n. 228. Schaer. Helv. p. 171. Ad terram summarum alpium Europæ fere totius; sed etiam copiose in maritimis boreali-occidentalibus Scotiæ, Hallandiæ Smolandiæque \& per totam Norvegiam occidentalem Ahnfelt!; denique ipsissima lecta ad ligna putrida in Trondhiem a Blytt!

Distinctissima, cum nulla alia in statu perfecto facile commutanda, tam thalli, quam apotheciorum applanatorum forma insignis. Caveas, ne hypothalli nigri stratum, cui impositus est discus, pro strato carbonaceo Lecidearum habeas! Exstant quoque fallaces aberrationes; altera crustæ areolis lobisque magis squarrosis, altera crusta macra verrucosa, e quibus (hac cum Lec. phoeocarpa Fl. conjuncta) quidam transitus, sunt vero hi omnino indirecti, hinc ad B. luridam \& illinc ad uliginosam videre voluerunt.

223. BIATORA olivacea, thallo crustaceo adnato, primitus contiguo, mox verrucoso viridiolivaceo, ambitu subfoliaceo adpresso, subtus 
albo, apotheciis sessilibus plano-convexis rufofuscis intus albidis. Dufour sub Lecid.

Ad saxa calcarea Gallize meridionalis v. c. ad Monspelium. Dufour! Aliique. Syst. Orb. Veg. I. p. 285 .

Thallus late effusus, determinatus, in ambitu effiguratus plicato-radiosus subfoliaceus, sed præcedentis more arcte adglutinatus, per ætatem minute rimoso-verrucosus. Color in humido saturate viridis, in sicco olivaceus, intus albus. Hypothallus quoque albus videtur, licet nullus distinctus in adultis conspiciatur. Apothecia superficiali-adnata, nec applanata, minuta, sparsa, mollia, rufofusca; primo plana, margine tenui pallidiori ; adulta convexa immarginata. Species valde distincta, quales detegere \& determinare Dufoureo fere soli contigit.

** Apothecia stipitata, margine demum revoluto.

Hypothallus albus, crustaque glaucescens in nostris. A sequentibus nullo modo genere separari potest hæc sectio, nam solo stipite differt, quem levioris esse momenti e Parmeliis, Caliciis, Pezizis (genere maxime analogo) facile patet. Ceterum cum sequentibus \& serie naturali \& characteribus confluit; sæpe enim videre licet $B$. byssoidem apotheciis sessilibu, subinde B. icmadophilam stipitatis, quas genere non distinguendas esse monuerunt Ill. Decandolle \& Dufour. Quod ad externam faciem attinet non in hac tantam video cum $B a-$ omycete convenientiam, nec hæc genera efficit. Mnium punctatum v. c. genere distinguitur a Cinclidio, licet huic similius quam multis Mniis.

224. BIATORA Cladonia, thallo squamoso viridiglaucescente, squamis foliaceis adscendentibus imbricatis incisis, subtus albis, apotheciis stipitatis pileiformibus carneis. Syst. Orb. Veg. I. p. 285.

Mich. gen. t. 42. X. f.1,2. a Dillenio ad B.byssoidem relata, hujus saltim habitum optime exprimit. Ob stipitem solidum \&c. minime est Cl. macilenta ut voluere Recentiores.

Ad terram glareosam juxta pedes montium \& lacuum litora, precipue inter Ericas, raro v. c. Smolandire occidentalis. 
A Cladoniis descendisse videtur. Sunt nempe præsens* \& Bceom. imbricalus Hook., qui hujus generis \& valde affinis etiam in Antillis obvius, quoad thallum Cladoniis simillimæ, ut olim in animo fuerit experientiæ præripere \& pro harum statu abnormi declarare, verum apothecia denuo scrupulose examinata prorsus ab his abhorrent \& cum B. byssoidis ita ex omni parte, colore dilutiori \& subpersistente excepto, congrua, ut non possit non hujus esse generis. A B. byssoide luculenter differt thallo foliaceo-squamoso, cum in hac tantum granulosus, passim effiguratus cum evidenti hypothallo. Interea hujus sectionis tres maxime affines species luculenter evincunt, quam levis sit differentia a thallo foliaceo, crustaceo-effigurato (Placodii) \& crustaceo.

225. BIATORA placophylla, thallo subcrustaceo - orbiculari corrugato glauco-albicante, ambitu foliaceo lobato, subtus candido, apotheciis stipitatis pileiformibus e rufo fuscis.

Bromyces placophyllus. Ach. meth. p. 325. t. \%.f.4. Lich. univ. p. 574. Wahl. Lapp.n.851. Suec.n.1660.

In terra arenosa macra ad devias silvarum Lapponiæ rarius Wahlenberg!, in subalpinis Norvegir australioris v. c. in Goustafjeld copiosius Blytt!

Inter præcedentem \& sequentem exacte media, præcipue ad hujus optime evolutam formam in ambitu squamulosam accedens; at facile dignoscitur thallo primitus $P$. lentigerce instar monophyllo in ambitu lobato, in adultioribus plicato, quasi e lobis squamosis imbricatis connato, ambitu vero semper determinato foliaceo-lobato. 226. BIATORA Byssoides, thallo crustaceo effuso granuloso virescenti-glauco, ambitu squamuloso, hypothallo fibrilloso albo, apotheciis substipitatis pileiformibus e carneo fuscis.

Lich. Byssoides. Linn. - Engl. Bot. t. 373. Leers Herb. p. 255. Lich. fungiformis. Scop. - Weber - Hoffm. en. t. 8. $f .2$. Bæomyces rupestris. $A c h$. Lich. univ. p. 573. B. rufus. Wahlenb. - Ach. Syn. 280. B. Byssoides. Schaer. spic. p. 17.

a. crustæ granulis subsquamaceis crenulatis (deliquescentibusque) ex æruginoso glaucis. Dill. Musc. to 
14. $f$. 2. Lich. rufus. Huds. Bæomyc. carneus. $F l$. Deutsch. VIII. p. 16.

Exs. Lich. Suec. 146. Fl. Deutsch. n. 160. Schaer. Helv. n. 32. Demaz. n. 389. Moug. Nestl. n. 70. b. rupestris, crusta tenui lévigata subcontigua pulveraceave albicante, apotheciis minoribus. Lich. peltifer. Wulf. in Jacq. Coll. 11I. p. 104. t. 3. f. 1 . Bæomyces rupestris. Pers.

c. lignatilis, crusta rugosa cinereoglaucescente, apotheciis subsessilibus fusco-nigris. B. lignorum. Pers.

* apoth. abortivis nigris, Lec. tuberculosa. Sommerf. Ad terram glareosam \& argillaceam, etiam ad rupes, precipue schistosas, Europæ totius. $b$. ad rupes graniticas irriguas. c. ad ligna putrida, cespites graminum emortuos in campis.

In rupibus schistosis inter fissuras hypothallus radicularum fibrillosarum instar sæpe longe descendit. Thallus omnino crustaceus, tantum in ambitu foliolis minutis squamosus, sed in perfectissimis individuis etiam thalli granula squamacea crenulata ; in b. \& c. magis tartareus \& uniformis. Podetia plus minus elongata, subcompressa, pallida; subinde vero granulis thalli tota obducta \& quasi corticata usque ad laminam, ut facile Parmeliam quoque diceres; hæc vero secundaria, nec primaria. Apothecia margine demum revoluta, solitaria 1. conglomerata. - Byssus incana Linn. Suec. n. 1188 est hujus status crusta deliquescente leprosa; talem eximiam formam dedit Flotow Exs. n. 5. B.

Sect. II. Thallo crustaceo effuso uniformi. Verrucariæ spec. Hoffm. Patellarie. Decand.

Differentiæ specierum non nisi ex statu normali \& tota historia proponi possunt, nec singularibus formis adaptari.

* Glaucescentes. Hypothallus albus. Crusta e viridi cinereoglauca aut alba. Apotheciorum color sxpius valde mutabilis, primitivus subincarnatus, numquam intense luteus aut aurantius! Cfr. Parmel. 129-137, quarum status mutili heic facile quaeruniur.

227. BIATORA (Parmelia) icmadophila, crusta tartarea granulata viridi-glaucescente, hypothal- 
lum album obtegente, apotheciis incarnatis, excipulo cupulari subvestito, margine tenui evanido. Fries Vet. Ac. Handl. 1822. p. 273.

Lich. ericetorum. Linn. Suec. n. 1068 e loco, non vero synon. Lich. icmadophila. Ehrh. - Linn. Suppl. - Hoffm. en. Lich. t. 8. f. 1. Wahl. Suec.p.799. Lecid. Ach. syn. p. 45. Lich. xuginosus. Scop. Hagen. Lich. t. 1. f. 4. Fl. Dan. t. 472. f. 4 . Jacq. Austr. t. 275. Engl. Bot. t. 372. Lich. Elvelloides. Web. Bxomyces ærugin. \& Elvelloides. Dec. Fr. 2. p. 343.

Exs. Lich. Suec.n.6\%. Ehrh. Phyt.n. 40. Moug.n.173. Locis humidis supra terram, ligna putrida \& muscos, pracipue Sphagnum, in paludosis \& silvaticis Europæe totius.

Speciosa, tristissimas paludes exhilarans. Crusta, ut in omni specie, variat leproso-deliquescens. Apothecia ampla, mollia, carnosa, incarnata, 1. in alpibus etiam rosea, non fuscescentia, at passim livida, in quo statu in Lec. Wallrothii Flk. Spr. Neu. Entd. II. p. 96 (mihi ignotam) abire Flotowio videntur. - Ex affinitate huc relata, e charactere vero potius Parmelia; apothecia extus vulgo a crusta vestita $\&$ juniora obruta, quasi clausa. 228. BIATORA pachycarpa, crusta tartarea (subleprosa) glaucescente, hypothallum album obtegente, apotheciorum disco rufofusco, excipulo cupulari, margine obtuso persistente. Dufour sub Lecid.

Ad terram \& truncos putridos, præcipue Castanex, in Hispania, Gallia passim Dufour! Prevost! Mougeot!

Statura prioris; sed crusta frequentissime deliquescens, leprosa, quare uti similes pro Lepraria s. Lecidea incana v. c. in Chev. Fl. Par. habita. Certissime vero ab antecedente dignoscitur apotheciis firmioribus, tumidis, adpressis; extus nudis; margine tumido persistente pallido; disco, qui semper nudus, fertili rufofusco, sterili vero pallido.

229. BIATORA rosella, crusta cum hypothallo confuso vernicea granulifera glaucescente, a- 
potheciis planiusculis pruinatis incarnatis, excipulo cupulari, margine obtuso. Fries l.c.p. 272. Lichen albo-incarnatus. Wulf. in Jacq. Coll. III. $p$. 106. t. 2. f. 3. Lichen rosellus. Pers. - Schrad. - Fl. Dan. t. 1243. f. 2. Lecidea. Ach. meth. p. 5\%. Verrucaria. Hoffm. Germ. 2.p.176. Patellaria. Dec. Fr. 2. p. 355. Lecid. alabastrina. $\gamma$. Ach. Lich. univ. $p .190$.

Exs. Lich. Suec. n. 198.

Ad cortices arborum, præcipue Fagi \& hujus limitibus definite circumscripta, ut postquam cum ista arbore in Suecia evanuit cum Fago inopinato in Omberg, Bohman, redeat.

Latas plagas obducit crusta parum conspicua, cui innata granula. Apothecia magnitudine fere præcedentium; discus semper incarnatus persistit, tenuiter pruinosus (sequentis semper nudus), planiusculus; margo albidus, fere Lecanoræ facie, at semper optima Biatora, excipulo numquam clauso, disco jam primitus punctiformi superficiali. Sequenti, quæ tanta formarum copia premitur, affinis, at nullum transitum inveni, ceterumque limịtibus geographicis \& vegetation is historia admodum insignis. Caveas ne commutes, cum Leran. subfuscae $v$. albella a., ad quam referam Lepram farinosam Hoffm. En. Lich. t. 1. f. 1. Verrucar. Fl. Germ., licet descriptio et $B$. rosellæ conveniat.

23o. BIATORA vernalis $\alpha$, hypothallo membranaceo-verniceo albicante, dein granula minuta glaucescentia proferente, apotheciis turgidis nudis decolorantibus, excipulo cupulari, margine obtuso subevanido. Sched. Crit. 8. p. I3.

Dill. musc. $t$. 18. $f$. 4. Lich. vernalis. Linn. et Auct. Engl. Bot. t. 845, 1863.

- a. luteola, apotheciis majoribus convexis opacis. - Apotheciis rubellis: Lich. rubellus. Ehrh. Verrucaria. Hoffm. Patellar. Dec. Fr. 2. - luteolis fuscescentibusque: Lich. vernalis. Hoffm. en. t.5. f. 1 . Verrucaria. Ejusd. Germ. Lich. luteolus. Schrad. Lecid. Ach. syn. p. 41. a. - crusta magis pulvere viridi obruta : Lich. anceps. Rutstr. diss. p. \%. Le-

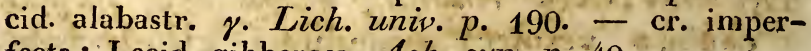
fecta : Lecid. gibberosa. Ach. syn. p. 40. 
Exs. Lich. Suec. n. 197. Ehrh. Cr, 136. Moug. 641: b. conglomerata, apotheciis minoribus subglobosis nitidulis (color varius, ex albo vulgo mox in helvoloferrugineum abit). Lich. sphæroides. Dicks. Crypt. I. t. 2. f. 2. Verruc conglomerata. Hoffm. Germ. p. 174. Lecid. vernalis. Ach. syn. p. 36. - crusta deliquescente: Lecid. incana. Sommerf. Lapp.p.164. Patell. sphæroidea. Dec. Fr. 2.

Exs. Lich. Suec. n. 224. Moug. Nestl. n. 845.

c. sphoeroides, apotheciis terruioribus, demum vero convexis, ex albido variis fuscescentibus. Lecid. alab. $\beta$. Ach. cum Parm. varia confusa. Lecid. sphæroides. Sommerf. Lapp. p. 164. Lecid. luteola. $\delta . \varepsilon$. Lich. univ. Lecid. erysibe. Ach. meth.

Exs. Lich. Suec. n. 225.

d. pineti, apotheciis exiguis albidis, disco minuto ex albido carneo-luteolo elabente urceolatis. Peziza diluta. Pers. syn. p. 668. Peziza virens. Albert. et Schwein. Consp. p. 338. t. 10. f. 10 . Pers. myc. Eur. I. p. 311. Lich. pineti. Schrad. Lecid. Ach. Biatora Fries $V$. A. Handl. 1822. p. 271.

Exs. Lich. Suec. n. 226.

* inundata, hypothallo albo fibrilloso-radiante, crusta granulosa viridi, apotheciis subimmarginatis luteolis, rufis aut fuscescentibus. Fr. l. c. p. 270 .

Per onnen Europam copiosissime, raro ad saxa \& ligna; ubique a. ad cortices; b. suprà muscos; c. ad bases truncorum, ligna putrida; d. in jpsa terra, præcipue arida acerosa pinetorum. locis inundatis tam ad saxa quam ligna \& cortices.

Tot protei Lichenis notandæ videntur formæ primariæ \& evidentiores, quæ exacte analogæ redeunt in sequente varietate, diversa apotheciorum colore tam externo quam interno jam primitus saturatiori; apothecia oinnium sub $\alpha$. comprehensarum, licet per ætatem sæpe intense colorata, locisque udis fusca \& nigricantia, primitus lactea pallida sunt. Formæ, quas distinximus, valde insignes, ut primo obtutu totidem species videantur, at serie contigua \& directa ita confluunt, ut nulla ratione distingui possint; e loco quoque facile explicantur. Omnibus crusta e viridi glaucescente albicans, primaria tenuis membranacea, per statem granulifera, gra- 
nulis minutis, nunc sparsis, nunc conglomeratis tecta, at numquam primitus tartarea areolata, areolis sublobatis. Apothecia e primario lacteo colore mox abeunt in luteolum aut rubellum, in b. insigniter helvolum, demumque fuscescentem; locis vero cariosis \& udis citius fusca evadunt. - Accedunt plurimæ degeneratæ formæ, externa facie magis recedentes, sed eo ipso minus typicæ \& memorabiles, quarum rationes typicum Lichenum statum perspicientes facile vident. - Crusta sic minus evoluta tantum sistit vernicem tenuissimam viridem, at jam apothecia diminuta immarginata proferentem, qualis ex Flotow Lecid. aneo-fusca Flörk.; cfr. quoque Lich. Suec. n. 245. B. Hre magis explicatur in crustam varie deformem virescentem (Lecid. erysibe Ach. meth.); sed et melius explicata hujus speciei formæ a Chlorococco sæpissime dense obruuntur \& leproso-farinaceæ evadunt. Ad latera lignorum carie pæne consumtorum crusta ipsa in lepram granuloso-farinaceam æruginoso-viridem deliquescit, apothecia ex albo mox fusco-nigra (sæpe, ut in aliis accidit, scabrida), quxe optimam Lecid. viridescentem Ach. (Lichen. Auct.) sistunt, licet sub hoc nomine etiam analogi status $B$. decolorantis ab Achario, Decandolleo \&c., a Reich. \& Schub. Lich. exs, n. 101 Parmelice coarctatce e. s. p. recipiantur. Communis est lex omnium formarum atypicarum, eas utpote erronea idea fundatas numquam ad definitam speciem pertinere, unde tot inutiles apud Auctores contentiones. Eadem est ratio Lecidece incanoe Ach., etiam pro parte v.c. Sommerf. Lapp. p. 164 huc referendæ, quæ est crusta loco sicciori leproso-deliquescens; Lecanorce effusce, subquo nomine in Herb. Ach. adest \& in Engl. Bot. t. 1863 (Lichen effusus) pingitur. Cfr. quoque Gyalectam cupularem $\gamma_{0}$ - Apothecia certissime etiam scabrida aut disco punctulata evadunt, \& omnino huc pertinent formæ ad Lecid. fuscoluteam $\beta$. leucorrhaeam Fl. referendie. - Felici casu omnes proximæe bene limitatæ, ut ab his facili negotio dignoscatur $B$. vernalis; sed nisi ad status primarios attenderis facile credideris eatn confluere cum infimis prolibus Parm. subfusca, variae \& ferruginea, quamvis earum differentia nullo prematur dubio, nisi ex transitibus indirectis speeies dijudicentur. - Tandem duæ haud notatæ at admodum illustrantes anomalix addendx. 1) prasina, cujus crusta est primitus ipsissima Palmella botryoides, apothecia disco prorsus 
excluso sphærica tota lactea, qux loci abseonditi maximi udi filia, \& 2) obruta, crusta crassa viridi-fuscella, apotheciis immersis quasi urceolatis.

$\beta$. B. sanguineo-atra, apolheciis primitus carneo-sanguineis margine pallidiore, dein nigris. a. (ut sub $\alpha_{\text {. }}$ ) Lich. muscorum. Auct. ut Weber \&c., sed hoc nomen collectivum est, \& ab ipsis inventoribus diversis externa facie similibus statibus imponitur. Verrucaria. Hoffm. Germ. ("scutellis e dilute fusco-nigris"). Lichen sanguineo-ater. Wulf. in Jacq. Coll. 1II. p. 114. Lecid. Ach. Lich. univ. Lecid. fusco-lutea. $\gamma_{\text {. Ach. syn. p. } 43 \text { certissime, nec }}$ differt Flörkei, nisi disco punctato. - Patellaria sinapisperma. Dec. fr. 2. p. 349.

b. (ut sub a.) Lecid. hypnophila. Ach. Lich. univ.p. 199. Lecid. sphæroides b. obscurata. Sommerf. Lapp. p. 165.

c. (ut sub $\alpha$.) Lecidea tenagea. Ach. syn. p. $2 \%$.

* lacustris (ut sub a.) F'ries ibidem.

Exs. Lich. Suec. n. 223. Moug. Nestl. n. 548.

Singula forma eisdem sub momentis ac analoga varietatis primariæ; præamat vero terram argillaceam, in qua jam legit Wulfen, nullusque Lichen vulgatior in aggeribus argillaceis Scaniæ. Exstat quidem quædam differentia primitiva inter $\alpha \& \beta$, sed vegetationis historia exacte eadem, vetustiores sæe vix dignosci possunt, \& formas eximie connectentes jam in junioribus individuis, licet rarius, vidimus. Vulgo apotheciis denigratis, ob fatalem illam ad externam faciem attentionem, cum Lichenes tantum ex historia sua cognoscantur, cum Lecidea sabuletorum, (ne dicam cum Lecidea parasema, ex quorumdam sensu omnes patellas nigras complectente!) confunditur, at crusta diversissima est $\&$ in $B$. vernali $\beta$. juniori marga disco pallidior, in Lecid. sabuletorum semper \& primitus aterrimus, etiam quando discus coloratus! Ceterum variat omnino ut $\alpha$; addendum tantum, discum lævigatum \& punctatum esse accidentalem lusum; hujus statum crusta orbatum esse Lecid. dolosam Ac.h. (non Wahl.) in Lich. Suec. $n$. 217! ; crustam membranaceo-gelatinosam viridem proferre apothecia Arthonioidea, a Mosigie pro Arth. lurida habita; ad qux potius quam analogum statum B. decolorantis pertinet Lecidea gelatinosa 
Flörke - Ach. syn. p. 88. Moug. \& Nestl. exs. n. 843. Lecid. Pezizoidea Ach. syn. p. 28. (cfr. Lich. Suec. 1. c. B.) insignis est apotheciis elevatis, substipitatis, ex urceolato explanatis, quibus notis ad B. campestrem \& carneolam accedit; at ceterum vix distingui potest. Eandem esse Lecid. muscicolam Sommerf. Lapp. Ip. 159. Norv. exs. n. 45 tam specimina, quam litteræ amicissimi auctoris testantur, licet descriptio l. c. data quoad colorem B.uliginosam a., sirnilia apothecia offerentem, suadere videatur.

Preter jan enumeratas formas saria mihi misse sunt, habitus cantillum differentes, at notas evidentes non offerentes. Harum duce memoranda, apoth. immarginatis magis diaphanis aberrantes, qua forte singularem in Europa australi ex D uf our! Brebisson! alisque obviam varietatem sistunt. Sunt L. fos sa $r$ u $m$ Duf., thallo gelatinoso levi viridi-griseo, in terra u dla ping $u i$, et L. "r lobo sa Clem. Ens. Vid. p. 297, qua L. mi crobola Syn. L. p. 48, thallo pulverulento griseo, qua ad arbores obvia magis normulis est. - P e $z i z a R e$ sin a Syst. M. 2. p. 148. in his terris frequentissima, thallo familia $\epsilon$ tiam ad ligna levigata prorsus destituta, sed sepe stipitata $j a m$ p $r_{\imath}$ mitus et persistenter lutea, qualis nulla hujus seriei Biatoru, et affinium Pezizarum indolem monstrans, omnino removenda; abunde insuper differt tam a Sph. Resin (e, ud quam retulit Sommerfelt, quam a L. c a rneola, pro qua fide Mosigii divulguvit Flotow. Ultima harum ad Mosigiana exemplaria quidem determinata est, sed illa, quie vidi, maxime aliena sunt. Eadem ratione scepisszme orta est synonymorum perturbatio ad exemplaria inventorum distributa ab iis, qua determinatori miserint, prorsus diversa. Non omnes erronea denominationes, sub quibus diversa venduntur, Achurio tribuende.

23r. BIATORA carneola, crusta cum hypothallo confusa cartilagineo-inembranacea glaucescente, demum granulato-pulverulenta, apotheciis sessilibus concavis nudis e carneo-rubro fuscis, excipulo cupulari, margine elevato pallidiori tandem evanescente. Fries l. c. p. 267 .

Lich. tricolor. With. arr. 4.p.20. Lich. corneus Engl. Bot. t. 965. fide Auctorum. Lecid. Ach. meth.p. 56. Lecid. carneola. Lich. univ. p. 194. Syn. p. 42. pr. p. excl. saltim hybrida $\beta$. (Lecid. spadicea. $S y n$. $p$. 34 vix differt.)

Ad cortices arborum, rarius, ut videtur præcipue Europæe occidentalis.

$\mathrm{Ob}$ colores facile cum B. mixta commutatur, at certe dignoscitur apotheciis magis liberis, superficialibus, disco juniori concavo nudo in lividum colorem haud vergente, excipulo (licet a thallode mutato evidenter ortum 
sit) integram cupulam offerente. Per ætatem apothecia vero explanantur, immo convexa evadunt, marginemque sensim disci colorem assumentem excludunt. Distinctam \& rariorem sub hoc nomine vago speciem forma inter B. vernalem \& campestrem mediam, colore \& affinitate B. pachycarpce propinquam intelligimus, sed adsunt simul formæ excipulo thallode destitutx Parmelice tartarece! (cfr. P. tart. b.), rubroe \& subfuscae huc relatæ, facile distinguendx crusta mutila apotheciisque atypicis, proventu in locis singularibus absque definita vegetationis historia.

232. BIATORA campestris, crusta tenuissime granuloso-deliquescente virescenti-pallida, hypothallo membranaceo inspersa, apotheciis testaceis, excipulo cupulari substipitato, margine sublacero pruinato. Fries l. c. p. 275.

Peziza Mougeotii. Pers. myc. Eur. t. 12. f. 5, 6, 7 . Exs. Lich. Suec. n. 222.

Locis campestribus ericetosis Suecia supra graminum cæspites emortuos, muscos \& Peltigeras præcipue, quas necat; etiam in Vogesorum sumrnis jugis Mougeot!

Pezizis valde affinis, at crustæ semper innascitur Lichenosæ, quamquam valde tenui, per ætatem tamen leprosæ, e viridi cinereæ 1 . albicanti. Vegetatio admodum subitanea, per paucos menses latissime diffusa. Apothecia minima fere generis, nunc sessilia, nunc in stipitem pro ratione crassum constricta, primo clausa, mox rupta, margine quasi velato albido-pruinoso, persistenter testacea, disco saturatiori. Est itaque species a proximis saltim distinctissima, aberrans, at alio loco haud aptius inserenda.

233. BIATORA cuprea, crusta tartarea rimosogranulata lactea, cum hypothallo confusa, apotheciis sessilibus mox hemisphæricis subferrugineis, excipulo cupulari subimmarginato. Sommerf. Lapp. p. 165. Lecid.

In terra glareosa alpium Lapponicarum, Nordlandiæ Sommerfelt! Norvegiæ in Gousta, Dovre \&c. Blytt! passim copiose. 
Apothecia faciem habent $B$. vernalis; at margo in junioribus tantum conspicuus parum admodum discretus, nec prominens, disco fere concolor, \& color ipsorum extus intusque ochraceo-rufus, siccitate rufo-fuscus; humectatorum dilutior, subpellucidus. Crustæ autem conformatione ad $B$. decolorantem magis accedit; est enim, hypothallo cum thallo confuso, tartarea, late effusa, granulis sublobatis contiguis composita.

234. BIATORA cinnabarina, crusta cum hypothallo confusa cartilaginea inæquabili glaucoalbicante, apotheciis adpressis cinnabarrinis nudis, excipuli margine demisso subconcolori evanido convexis immarginatis.

Lecid. cinnabarina. Sommerf. in Vet. Ac. Handl. 1823. Lapp. p. 170. Fl. Dan. t. 2009. f. 1. Lecid. coccinea. Schaer. spic. mscr.

Ad cortices arborum Juniperi, Abielis, Betulæ (Americæ arcticæ, v. c. Grönlandice; dein) in silvaticis Nordlandix Sommerfelı! rarius; in alpinis Norvegiæ meridionalioris, haud infra 1000 pedes supra mare Blytt!; Helvetiæ rarissime Schaerer!

Colore apotheciorum puro \& persistenter cinnabarino aut coccineo, opaco tamen, facillime dignoscitur ; nec ullo modo cum formis immarginatis Parm. hamatomma comparanda est. In individuis junioribus, ab ipso Sommerfeltio missis, discus planiusculus, \& excipuli margo, licet parum promineat, evidens \& paulo dilutior, nitidulus. Crusta per ætatem rugoso-verrucosa, sorediffera granulisque pulverulentis adspersa. - Exstat quidem sequentis forma crusta tenui leprosa lactea, apotheciis etiam exsiccatis miniato-carneis persistentibus, quæ tamen certe diversa est.

235. BIATORA decolorans, crusta tartarea cum hypothallo confusa areolato-granulosa glaucescente, apotheciis adpressis, disco nudo e miniato \& carneo-livido fusco nigroque, excipuli margine tenui elevato pallidiori evanido convexo-difformibus. Fries l. c. p. 268. 
Lecid. decolorans. Flörk. Berl. Mag. 1809. p. 192. Ach. syn. p. 37.

a. apotheciis regularibus, planiusculis, marginatis. Lich. granulosus. Ekhrh. Verruc. s. Patell. granulosa \& decolorans f offm. - Plant. Lich. t. 30. f. 3, 39.f. 2. Lecid. Ach. meth. Lecan. granulosa \& minutula. Ach. Lich. univ. p. 384. Lich. quadricolor. Dicks. Crypt. 3. t. 9. f. 3. Engl. Bot. t. 1185. - crusta tenuiori primitus leproso-deliquescente: Parm. incolorata. Fl. l. c. p. 200. Lecan. Ach. syn. p. 160. Patell. Mougeotiana. Dec. fr. 6. p. 181.

Exs. Lich. Suec. n. 220. Ehrh. exs. n. 145. Fl. Deutsch. n. 142. Moug. et Nestl. n. 551.

b. apotheciis subconfluentibus convexis deformibus rugosisque subimmarginatis fusco-nigricantibus. Lich. escharoides. E/hrh. - Dicks. ex spec. - Engl.Bot. t. 1247. Verruc. Hoffm. Germ. p. 194. Lecid. esch. \& desertorum. Lich. univ. p. 167, 168.

Exs. Lich. Suec. l. c. Ehrh. n. 313.

c. apotheciis regularibus, convexis, levibus scabridisve, iminarginatis fusco-nigris, intus albidis, (crusta mox leprosa, sordide viridescente). Lich., Lec., Patell.viridescens Auct. v. c. Ach. ex p., Dec. Fr. (etiam Moug. Nestl. n. 550 h. l. videtur). Biatora. Fr. l. c. Lecid. fungicola. Ach. syn. p. 35. - crusta sterili, pulchris sorediis viridibus ornata: Lich. viridulus. $\mathrm{Hoffm}$. en. Lich. $t$. 2. $f$. 6 . (huic saltim optime convenit)Variolaria. Ach. meth. p. 15.

Per omnem Europam copiosissime, numquam tamen saxis innata; a. præcipue ad terram humosam, turfosam; b. ad sabulosam \& firmiorem; c. ad ligna putrida.

Uti omnes vulgatissimæ species admodum mutabilis. Crusta, quæ in statu normali areolato-verrucosa, immo lobulata, facile leprosa deliquescit, idque in c. præcipue sub ipsa evolutione. Ejus color tantum inter seriei glaucescentis limites continetur, occurrit enim e viridi-glauca, dealbata; passim quoque obscure cinerea, saturate viridis, præcipue locis humidis. Licet crusta formæ degeneratæ ad $B$. vernalem satis accedat, ejus constructio evidenter alia; cavendumque ne hujus varietas argillicola pro Parm. coarctata habeatur. In hac præcipue optime perspicitur, marginem proprium tantum a thallode 
mutato ortum esse; junior enim crustæ similis \& pro Parmeliæ facile habendus; adultior magis coloratus, subflexuosus, qualis vero adhuc evidentius in $\beta$. Discus ut reliquarum variat scabridus, ab archetypo vero Lec. $A r-$ thonioides Ach. diversa est.

$\beta$. B. flexuosa, apotheciis primitus atris, margine tenui livido persistente, demum flexuosissimo. Fries Sched. Crit. 8. p. 11.

Exs. Lich. Suec. n. 221.

Ad ligna Quercus, Pini \&c. copiose.

Hanc insignem \& omnino constantem, ad Lec. sabuletorum vulgo relatam, formam priori subjungendam esse 1. c. observavimus, nain hujus granula, licet magis rugoso-plicata viridi-cæsia, prioris modo in lepram fatiscunt \& historia ceterum eadem. Apothecia semper plana persistunt; margo junior evidenler disco, pallidios, cum in Lec. sabuletorum jam primitus aterrimus carbonaceus persistens etiam ubi discus expallescit. A $B$. decolorante $\alpha$. eadem ratione recedit ac $B$. sanguineoatra a $B$. vernali.

236. BIATORA mixta, crusta cartilaginea cum * hypcthalio confusa rugoso-verrucosa glaucescenti-lactea, apotheciis adnatis, excipulo annulari, diseo-primitus plano pruinoso carneo lividove, dein turgido fusco nigroque marginem obtusum excludente. Fries \%. c. p. $26 \%$.

Lich. mixtus. Herb. Vet. Suec. Lecidea. Sommerf. Lapp. p. 15s. Flotow. Exs. - Lich. corneus. With. Lich. ferruginosus. Turn. sec. spec. Lich. Griffithii. Engl. Bot. t. 1735. Lecid. hamadryas. Ach. Lich. univ. p. 672. cum plurimis heterogeneis sub L. anomala. Syn. Lich. p. 38. cfr. Fl. Deutsch. Lich. 9. $p .1$.

Exs. Lich. Suec. n. 40. Fl. Deutsch. n. 161. Ad cortices arborum v. c. Quercus, Tilize, Abietis, Betulæ \&c. Europæ saltim occidentalis copiose; rarior ad ligna putrida pinea.

Est quidem eximia hujus analogia cum præcedente in mutatione formæ \& coloris apotheciorum; sed species certo \& eximie diversa. Crusta variat tenuissima (immo ad ligna prorsus obliterata) \& leproso-deliquescens, 
normalis autem \& perfecta rugoso-verrucosa, sxpe crassiuscula, sed in granula discreta, multo min ıs lobulata, numquam abit. Excipulum annulare, seu infra laminam strato thallodi albo impositam deficiens, primo margine regulari obtuso nitidulo semper nudo \& evidenter pallidiori (passim subferrugineo) cingens discum planiusculum pruinosum incarnatum (numquam vero miniatum), carneo-fuscurn, lividum, nigricantem; disco vero turgescente margo flexuosus fit demumque prorsus excluditur \& apothecia valde difformia, confluendo tuberculosa, sæpius livido-nigra. Substantia apotheciorum prioris crassior \& firmior. Talia apothecia tota nigra ad Lec. parasemam vulgo referuntur.

* BIATORA - crusta tenuissima leprosa alba evanescente, apotheciis corneis adnatis tumidis carneo-fuscis undique glauco-pruinosis, humidis incarnatis, excipuli annularis margine incurvo persistente.

Ad saxa calcarea Suecia, rarius.

Quoad apothecia, ad maxima generis numeranda, valde insignis est, at crusta solito more in calce muti lata \& personata pro genuina specie inserere non ausim. A pothecia adnata, superficialia, crassa, tumida, sicca $u n-$ dique glauco-pruinosa \& carneo-fusca, humectata vero amone incarnata, \& pruina inconspicua; intús sub lamina tota alba \& a crusta quasi formata. Margo elevatus, incurvus, persistens. Discus planus, lævis, pruina superficiali adspersa. An Patell. carnea Dec. fr. 2. p. 356, quæ fere unica Decandolleana species, cujus specimen autheniicum non vidi, alius hujus, quoad crustam saltim perfectior, status? Diversissima a Lecid. percana Ach., quæ $P$. cervince status. Tam parum de origine Lichenum personatorum ex externa facie concludere licet.

237. BIATORA anomala, crusta cum hypothallo albo confusa demum granulosa albo-cinerascente, apotheciis mox hemisphærico-globosis nudis e hyalino-livido obscuratis, margine tenuissimo mox evanescente. Fries l. c. p.. 266. cfr. syn. b. Lec. commutata. Ach. Syn. p. 149.

Ad cortices, ligna \&c., sed parum notabilis. Exclusis formis diminutis Parmelice subfuscae \&c., 
sub Lecidea anomala Syn. Lich. p. 38 comprehensis, restat hæc utique ambigua species, at cum alia haud tute conjungenda, crusta genuina, apotheciis magnitudine mire variis. Habitus potissimum Lecidece enteroleucce \& sicce L. parasema, sed hypothallus numquam niger, excipuli margo tenuissimus, pallidus, sæpe antem jam primitus evanescens. Apothecia humectata pellucida, subhyalino-livida, sicca carneo-fusca \& nigra, - Ceterum nomen omen, quare huic ipso suadente in litt. Achario nomen servavi; apud me expressis verbis, ut tacite apud Acharium, sit collectivum formarum simillimarum tam parum evolutarum, ut rite distingui non possint v. c. Lecid. pellucida Fl. Exs. n. 102 (crusta fere nulla), L. populina Schleich., Lec. cinerea Schaer. spic. p. 156, (L. Lenticularis Ach. syn. p. 28 saxicola), e. s. p. Lecid. erythrophcea Fl. saxicola etiam quoad crustam mutila est (vera adest in typo species) \& magis ad $P$. coarctatam colore apotheciorum accedit; at omnia hac ob specimina imperfecta (crusta plerisque nulla!) determinare non potui; sed ad interim ut inquirenda post B. anomalam in Lichenophylacio servo.

238, BIATORA denigrata, crusta granulata e sa- turate viridi glauca, ab hypothallo evanido discreta, apotheciis immixtis convexis subimmarginatis e fusco nigris, intus albidis. Fries l. c. p. 265.

Exs. Lich. Suec. n. 98.

Ad parietes vetustos ligneos Scandinayiz silvaticæ copiose; fere eadem ad muscos alibique.

Invitus recipio species minutas, sæpissime tantum status mutilatos; at hæc proventus copia multisque notis adeo insignis, ut omittere non debuerim. Proxima videtur Biat. uliginosce granulorum forma \& præcipue, colore humidæ \& vegetæ crustæ læte viridi, sed hic siccitate numquam fuscescens sed glaucus 1. albus - nec hypothalli nigri vestigium umquam vidimus. Granula plerumque discreta \& licet minuta squamacea passim evadunt. A pothecia humectata tota mollia, fusca intus albida l. fuscescentia ; in junioribus excipuli annularis margo pallidior, parum discretus \& mox obliteratus, tantum conspicitur. Hinc a Lecid. sabuletorum quoque omnino diversa, nec umquam in eadem regione legi. Crusta subinde deliquescens, quem statum Lec. synotheam 
Syn. Lich. p. 26 denominat Acharius; quod nomen perspecta identitate ideo in Exs. recepi; postquam vidi ex ipsius \& aliorum ab Achario determinatis, v. c. Dufoureo Biat. vernalis, speciminibus id nomen mere collectivum esse formarum variarum degeneratarum iterum neglexi. Ceterum hujus loci quoque Lecidea euphorea Sommerf. Lapp. p. 156 \& form $x$ ab aliis Lecidece punctatoe \&c. e superficiali inspectione adscriptx.

** Fuscescentes. Præter habitum seriei in colore crustæ fuscescente expressum, a prioribus certissime dignoscuntur hypothallo nigricante. Apothecia subfusca, sicca nigricantia. Cfr. Parmel. $n$. 138-143.

239. BIATORA erysibe, crusta tartareo-spongiosa virescente-olivacea, hypothallum nigricantem obliterante, apotheciis luteo-fuscis, intus albis, excipuli annularis margine tenui. Fries $l$. c. p. 265 .

Lecid. luteola v. erysibe. Ach. ex spec. det. primaria vero est $B$. vernalis var.

Ad muros \& rudera Sueciæ, Galliæ Prevost! Crusta late \& indeterminate effusa, crassa, spongioso-tartarea, subcontigua, sed, præcipue exsiccatione, ob laxum contextum in lepram virescenti-olivaceam facile deliquescit. Apothecia majuscula, carnosa, humida mollia, in statu pulveraceo margine thallode accessorio quoque cincta, hinc ut B. icmadophila valde Parineliacea apparet. Ob locum parum suspecta, nescio vero cum qua potius, quam sequente \& B. uliginosa, abunde tamen diversis, comparem.

240. BIATORA rivulosa, crusta tartarea murina expallente, hypothalluin fusco-nigrum obtegente, apotheciis e crusta oriundis carneo-fuscis nigricantibus, intus albidis, excipuli annularis margine tenui. Fries l. c.

a. saxicola, crusta humida rufescente, sicca cinerascente. Lecidea rivulosa. Ach. meth. p. 38. Syn.p. 28. Lich. rivulosus. Engl. Bot. t. 1737. Lecan. falsaria \& griseo-atra. Ach. Lich. univ. p. 349, 350. (Ad spec. a Mosigio Achario missum \& ab Hoffmanno determinatum Verruc. seu Patell. griseo-atra. Hoffm. Germ. - Pl. Lich. t. 60. f. 2. nec admo- 
dum convenit, nec obstat!) Lecid. ambigua. b. griseoatra. Ach. syn. p. 15. - ipse misit, \& minime fert.

Exs. Lich. Suec. n. 404.

b. corticola, crusta humida magis virescente, sicca fuscescente. Lecid. Lightfothii, Ach. syn. p. 34. absolute. Lecidea rivulosa. Hepp. - crusta dissoluta leprosa virescente: Lec. sophodes. Botanicor. Gallice! L. Lightfothii, Schaer. spic. p. 132.

Exs. Lich: Suec. n. 39.

Ad saxa \& rupes graniticas; nec non cortices arborum v. c. Fagi, Betulæ, Alni, Ceratoniæe in Hispania, \&c. per omnem Europam occidentali-maritimam copiosissime; de cetero magis sporadica in montanis.

Species optime distincta, perquam variabilis, qua nullus Lichen arboreus simul ac saxatilis in agro Femsionensi vulgatior. Optime dignoscitur hypothallo umbrino-nigro, crustam sæpius decussante, crusta tartarea submurina, locis apricis in griseum vergente, magis irriguis locis leprosa virescente, apotheciis junioribus \& humidis carnosis, carneis aut carneofuscis, siccis nigricantibus, margine per xtatem flexuoso pallidiori; intus totis albis \& a crusta formatis, ut sensu Cel. Wahlenbergii omnino Parmelia margine mutato, nec Lecidea. Apothecia vulgo majuscula, sed omne magnum semel parvum fuit $\&$ in hoc statu etiam hujus apothecia persistunt, crusta tum mutilata e. s. p., in quo statu Lecid. ly gea dicta fuit. Cfr. cet. de formis Ach. Lich. univ. I. c. Flotow in Fl. Ratisb. 1828. p. 673. (at v. conglomerata vix eadem species ac Schleicheri).

ק. B. Kochiana, crusta subareolata fuscescentecinerea, apotheciis detrusis nigricantibus, disco tenuissime pruinoso.

Lecid. Kochiana Hepp. Wü̈rtzb. p. 61. Schaer.spic. p. 131. Lecid. morosa. Duf. ex spec. L. contigua.

a. Flotow l. c., at nec forma primaria speciei, nec

Verruc. contigua. Hoffm.; melius convenit allata V. griseoatra.

Exs. Schaer. Helv. n. 181. Moug. et Nestl. n. 545. Ad saxa in alpibus Europæe totius, speciosa in Pyrenæis! 
Est sine dubio præcedentis forma in saxis alpinis vel magis continentalis, plurimis formis mediis (v. c. Lecid. cyathoide Ach. meth. p. 51) cum a conjuncta; faciem mutatam, crustam lævigatam, apothecia minus libere evoluta præcipue in summis perflatis alpium jugis acquirit; magis absconditis locis areolæ turgidæ plicatæ.

* BIATORA fuscescens, crusta, areolis minutis discretis albicantibus ex hypothallo nigrescente emergentibus, fuscescente, apotheciis fuscis, intus albicantibus, excipuli annularis margine tenui evanescente. Sommerf. Lapp. p. 16 I. Exs. Sommerf. Norv. n. 44. Lecidea.

In epidermide juniori Betulæ Europæ septentrionalis.

Facillime dignoscitur maculis tenuissimis unguicularibus fuscis, sed accuratius inspectis granulis albidis adspersis, in libro nitellino tantum obviis; ob ipsam vero singularitem hujus loci, quo nullæ species 'rite explicatæe occurrere solent (Cfr. p. 175 N) mihi atypicus status est \& re ipsa omnes acutæ differentiæ a priori deficiunt. A sequente similiori differt apotheciis a crusta oriundis \& hypothallo fuscescente.

24r. BIATOR̈A panceola, crusta areolato-verrucosa fusco-cinerascente, hypothallo nigro innata, apotheciis ex hypothallo oriundis e rufo lividove fusco-nigris, excipuli annularis margine obtuso regulari. Fries l. c. p. 269.

Lecid. panœola. Ach. Lich. univ. p. 201. Syn. p.33, quoad spec. fertilia.

b. Lecid. pelidna Lich. univ. p. 158. Schaer. spic.p. 130. Lecid. -lygæa. b. Ach. syn. p. 34.

Ad rupes \& saxa Scandinaviæ, Germaniæ, Helvetiæ Schaerer! Galliæ Prevost!

A $B$. rivulosa nostra sane distincta est hypothallo aterrimo, crusta magis cartilaginea, semper areolato-granulosa nec umquam contigua, granulis nunc sparsis, nunc confertis e colore primario fuscescente cinerascentibus, immo albicantibus, apotheciis numquam e crusta oriundis ut vel tenuissima granulosa prioris specimina, margine obtuso integerrimo equabili (nec umquam flexuoso) 
subpersistente; discus per ætatem hemisphæricus. - b. habitu aliquantulum differt, color magis fuscescens, margo sæpe flexuosus, at certæ notæ desunt. - Mihi e contrario sæpe a formis Trecid. atroalba v. fuscatae difficilis distinctu visa fuit, quando apothecia rufa aut livida normaliter intus alba, margine pallidiori \&c. per atatem nigricant. Singularis sane est nexus inter Lec. atroalbam \& Biatoram panceolam \& sine dubio ad eandem referuntur formæ ad $B$. panoeolam potius spectantes. 242. BIATORA plicata, crusta tartarea contigua dein verrucosa fusco-cinerascente, hypothallum obtegente, apotheciis immersis e fusco nigricantibus, margine tenui mox evanido hemispharicis plicato-rugosis. Clement. Ens. Vid. p. 296. Lecid.

Ad terram in Hispania. Lallave!

Jam notavimus quandam habitus \& proveniendi modi convenientiam $P$. Endocarpea, at cum eadem conjungere temerarium foret; potius videtur $B$. decoloranti: analoga in hac serie; a sequentibus differt crusta primitus contigua, nec virescente. Apothecia normalia detrusa, plana, $B$. decolorantis instar mox confluentia difformia, turgida, rugosa, immarginata ; sed color B.uliginosa. 243. BIATORA miscella, crusta tartareo-granulosa diffracto-rimosa e cervino glaucescente, hypothallum obtegente, apotheciis adnatis, disco nigricante intus basi albido, excipuli cupularis margine obsoleto. Sommerf. Lapp. p. 158.

In terra turfosa ex muscis putrefactis orta in rimis rupium marilimarum Nordlandiæ. Sommerfelt!

Est quidem B. uliginosce affinis, attamen tam crustæ habitu, quam differentiis apotheciorum recedens. Crusta (in perfectis saltem) crassa, cohærens, firmior, humectata cervina, sicca glaucescens. Apothecia pro ratione crustæ valde exigua, parum difformia, juniora subconcava margine haud prominerte, mox convexa immarginata ftusco-nigricantia, discus quasi strato albo ab excipulo discretus. Ceterum mihi non satis nota. - Multa quidem sub $L$. miscellce nomine in herb. Ach. servantur, non tamen adest hæc. 
244. BIATORA uliginosa, crusta granulata e sálurate viridi fuscescente, hypothallo fuligineonigro, apotheciis e rufo-fusco nigricantibus, intus unicoloribus, excipuli cupularis margine tenui evanescente. Fries Sched. Crit. 8. p. 10.

a. botryosa, crusta tartareo-granulosa solida (nec gelatinosa), apotheciis elevatis evidentius marginatis. $l$. c. B. botryosa. $V . A . H .1812 . p$. 268. Lecid. hypopta. Ach. meth. p. 61. L. luteola. $\gamma$. Ach. syn. p. 41. excl. Verr. fusco-rubell. Hoffm. huic rite varietas L. luteolæ (saxatilis pro Lecid. coniopside, $\&$ deliquescens pro $L$. viridescenti facile sumeretur). Exs. Lich. Suec. n. 219.

b. humosa, crusta areolato-granulosa subgelatinosa, apotheciis immixtis obsolete aut non marginatis. Lich. uliginosus Schrad. - Engl. Bot. t. 1466. Verruc. Hoffm. cum var. humosimili. Lecidea. Ach. - Syn. p. 25. Patell. Decand. Lecid. terricola. Ach. Lich. univ. p. 679. Lecid. microphylla Schaer. spic. $p$. 112. - Nec quoad varia spec. visa distinguere valeo $L$. phococarpam Fl. v. g. $\gamma$. montanam. Sommerf. Lapp. p. 159. Status fere junior granulis minimis, saturate viridibus: Lec. icmalea. Ach. Lich. univ. p. 201. ex spec. ipsius invent. $S_{w a r t z}$ Cfr. infra. - Apotheciis scabridis: Spiloma humosum. Lich. univ. p. 139.

Exs. Lich. Suec. n. 218. Schaer. n. 162, 163. Moug. Nestl. n. 747. Schrad. Cr.n.163. (Ehrh.n.135 et d.)

c. fuliginea, crusta cum hypothallo confusa leprosogranulosa fusco-nigrescens. Lecid. fuliginea. Ach. syn. p. 35. Biat. Fr. l. c.p. 264. - Gollema nigrum Auct. \& reliqua syn. sub $P$. triptophylla $c .{ }^{*}$ allata etiam huc pertinent, \& quidem e recentiori Auctoris limitatione omnino C. nigruin Ach., analogum statum P. triptophyllæ Lec. psotinam in mscr. dicenti. Hinc explicatur Schaer. Obs. 3. l. c.p. 115. Exs. Lich. Suec. n. 97.

d. coenosa, crusta mere hypothallina, fuscoatra - vel leproso-deliquescens: Lich. humosus. Ehrh. (qui vero ex spec. E. Meyeri et b. complectitur). Verrucaria. Hoffm. Germ. p. 191. Lecid. uliginosa $\beta$. Ach. syn. p. 26 - vel contigua gelatinosa : Lecid. terrigena. Lich. univ. p. 181. Collema cænosum. 16. p. 629. Syn. p. 309 . 
Per omnem Europam vulgatissima; a. locis siccioribus, ad ligna indurata quercina, saxa; b. præcipue ad terram humosam; c. locis magis udis tam ad saxa crassior, quam ad ligna cariosa tenuior; d. tandem in ipso luto paludum.

Hujus speciei evolutionis seriem \& hac ratione convenientium $B$. vernalis, Parm. triptophylloe \&c. differentiam omnino claras mihi esse fingo; a priori vero vix nisi crustæ indole apotheciisque intus unicoloribus fuscescentibus differt. Illa seu B. vernalis est e serie glaucescentium, quare crusta non nisi inquinata a peregrinis fuscescit, hypothallus numquam niger; ceterum evolutionis series eadem, quaare analogi status frequenter commutantur. Sic e descriptione ad $B$. uliginosam a., quæ prorsus similia apothecia profert, facile referres Lec. $P e-$ zizoideam Ach. \& I. muscicolam Sommerf., sed primus adspectus speciminum authenticorum eas ad seriem Glancescentium retulit. Etiam hujus apothecia proferunt discum ruguloso-scabridum pro Lecid. fuscolutece primaria differentia habitum, at Cel. Meyer Flecht. $p$. 47 ad hanc referens $\beta$ (potius Lec. fuliginece, quam I. uliginosa Ach.) non formam hujus speciei respexit, sed illam formam $B$. vernalis, quæ est in exacte eodem evolutionis statu ac Biat. uliginos. c. \& sæpe Lecid. icmalea dicitur. Gaudeo mihi successisse acutissimi viri sententiam hoc modo cum nostra conciliare. Probe quoque perspicio rationes, quibus ductus egregius Schaerer hanc cum Parmel. triptophylla conjunxit. Sunt nempe utriusque status mutilati, hypothallo prædominante, adeo similes, ut, licet mox oculis, vix characteribus distinguas. Sed ex his rationibus cum $B$. uliginosa potius conjungeres Parm. badiam, Biator. Iy gacam, Lecidea atroalbam, Verrucariam umbrinam et facile dicam omnes crustaceos hypothallo nigro, cum hi difficilius sub eodem evolutionis momento distinguantur quam Parm. triptophyllae, in qua hypothalli coerulescentis vestigium in ambitu saltim persistere solet. Ex multis mihi missis \& in herbariis obviis formis vidi Auctores haud ipsos rite novisse, quid pro $C$. nigro habuerint, unde superflua contentio de definitione synonymorum. Equidem vellem, ut generum, specierum \&c. characteres non ut harum criteria consideremus, sed ut malum quoddam, necessarium ad species, genera \&c. ignota determinanda. 
Nam quo plenius \& acutius characteres proponimus, eo magis non raro a natura aberramus. Studemus ut specierum historiam \& formas, characterum non quidem ignari, sed nec servi, typicum \& aberrationum leges in protea natura quærentes, noscamus. - Forma hujus speciei typica est a., crusta \& apotheciis optime evolutis, deposito omni gelatinoso. Quando hanc olim pro specie describebam, veram B. uliginosam, pro Lecidea habitam, non examinaveram. Hoc facto identitatem mox perspexi. Quo dein humidiori loco oritur eo magis crusta imperfecta, subgelatinosa, donec in aquosis tantum restat hypothallus. Nam thallus, ut characterem Lichenum s. Algarum aërearum offerens, optime in aëre explicatur; hypothallus vero, typice Alga aquatica, in humidis \& totus in aquæ potestate multas enititur proles pro Phyceis autonomis habitis, cujus rei mox infra sub Lecidea videbimus exempla.

Attulit insuper ACHARIUS L. umbrinam Syn. L. p. 35, quas quoad omnes partes ita degenerata, ut ad exemplaria in Herbar. ipsius saltim non definienda. Quid sit et ucutiss. Flotowium, Mosigii vestigia prementem, fugit.

L. anthracin a Ibid. p. 43 itidem e formis variarum stirpium haud rite evolutis pendet adeoque ad definitam non referenda. Primi-tiva saxatilis in formas clementares $P$. ba di a, ferrugine a, Biatora uliginosa, vernalis inquinate ete, omnino quadrat; exemplaria arborea, ab ipso determinatore agnita, omnino B. vernalis Cfr. Exs. L. S P. n. 24.5. C.

*** Ochroleucae. Color apotheciorum pallide flavidus aut rufonigrescens, thalli virescenti-flavus, deliquescentis ochroleucus. Hypothallus, ultimæ subcitrinæ'speciei excepto, niger. Cfr. Parm. 146-152.

245. BIATORA viridi-atra, crustæe areolis cartilagineis granulosis dein confluentibus e pallido flavovirescentibus, ex hypothallo determinato atro oriundis, apotheciis innatis tenuiter marginatis e rufofusco atris, intus albidis. Stenhamm. Sched. Crit. XIV.

Lich. atrovirens. Linn. Suec. n. 1062.?

Exs. Lich. Suec. n. 403.

In jugis graniticis montanis ad saxa Sueciæ; in Ostrogothia frequens \& copiosa Stenhammar! Colore insignis hic Lichen Parmeliam variam $\delta$. mox in memoriam revocat, at 're ipsa B. panoeoloe \& Lecid. atroalboe proximus. Faciem vero potissimum Le- 
cid. geographicae præ se fert, at tam colore thalli semper pallido virescente, quam apotheciorum eorumque structura abunde differt. Hypothallus insignis, determinatus, aterrimus, demum vero a crusta obtectus. Crustæ areolæ primitus sphæricæ, minutæ, inter se discretæ, sed hypothallo innatæ, mox varie concrescentes, turgidæ, rugosæ, ex apotheciis abortivis nigro-punctatæ; semper solidæ, firmæ, nec umquam deliquescentes visæ. Quædam areolæ discretæ lobulato-effiguratæ, ad typum Parm. frustulosa b. Apothecia ex areolis enata margine thallode spurio sæpe coronantur, a qquo discedit proprius tenuis disco primitus pallidior, demum vero $\&$ præcipue diutius exsiccatus una cum disco rufofusco plano aut convexo nigrescit vel evanescit \& in hoc statu facillime pro Lecidea habetur. - Nomen viridi-atri ad hanc speciem ut aptissimum \& ob insignem similitudinem cum Lecid. vulgo atrovirente dicta relatum fuit; \& sane Lich. atrovirens $L$. in hanc speciem longe melius quam in $L$. gengraphicam, quam bis a Linnæo descriptam vix fingas, quadrat, præcipue cum $B$. viridiatra insignem vegetationis Lichenosæ partem in variis Sueciæ mediæ provinciis efficit. - Etiam nulli alii Licheni melins convenit Lichen viridi-ater Wulf. in Jacq. Coll. II. p. 186, quem a Lecidea armeniaca diversum esse optime monuit Cel. Flörke, sed Lecid. geographica v. viridiatra Fl. a nostra omnino differt $\&$ ab illa suam speciem diversissimam esse Wulfenius ipse monet. Nolui vero hunc Lichenem citare, ne nomen ex isto, sat ambiguo, pendere videatur. Quantum iconem Lich. verruculosi Engl. Bot. t. 2517, ante plurimos annos præsente specie nondum distincta visam, in memoriam revocare valeo, habitum bene exprimit; Cel. Meyer fide authentici spec. ad $\boldsymbol{L}$. atroalbam refert. Color tamen, ni fallor, flavovirescens iconis, quantum expertus sum, extra $L$. atroalbae variationis terminum positus est.

246. BIATORA exigua, crusta granulis primitivis innatis confluentibus lævigata cartilaginea ochroleuca, lineolis hypothalli nigri decussata, apotheciis submarginatis e pallide luteolo fuscis. Chaubard Fl. Ag. p. 478. Lecid.

Lecidea varians. Ach. syn. p. 38 e Gallia; nec Americana nisi varietatis lege diversa. 
In cortice arborum circa Agen Gallix. Chaubard!

Species admodum exigua, $\boldsymbol{B}$. anomaloe analoga, at eximie diversa \& potius cum formis diminutis $P$. varice comparanda. Hypothallus niger admodum evidens, licet macularis tantum, pluribus individuis confluentibus crustam nigro-rivulosam reddens. Huic innata sunt granula admodum conferta \& minuta, quæ cum numquam liberentur, in crustam tenuem lævigatam concrescunt. Apothecia quoque exigua, excipuli annularis margine parum prominulo at satis persistente, unde apothecia multa concaviuscula inter alia convexa manent. Cfr. quoque $\mathrm{Le}$ cid. anomala $\gamma$. flavicans Ach. syn. p. 39 margine ferrugineo tantum diversa.

247. BIATORA quernea, crusta deliquescente granuloso-farinosa fuscescenti-ochroleuca, hypothallo nigro, apotheciis immersis convexis brunneis, mox immarginatis. Fries l. c. p. 268.

Lich. querneus. Dicks. Crypt. Brit. 1. p. 9. t. 2. f. 3. Engl. Bot. t. 485. Verrucaria. Hoffm. Fl. Germ. p. 195. Lecid. Ach. Lich. univ. p. 202.

Exs. Lich. Suec. n. 199. Fl. Deutsch. n. 123.

Ad truncos vetustos apprime quercinos; raro Fagi, Juniperi, Sueciæ meridionalis, Daniæ, Angliæ Dickson! Germaniæ Laurer! Galliæ Prevost!

Species hæc vix crusta typica integra lecta est; in hoc statu ad $P$. variam proxime accedere suspicor; color fuscescens immixtus ab hypothallo oritur. Apotheciorum color insignis.

248. BIATORA lucida, crusta granulata virescenti-flava, deliquescente ochroleuca, hypothallo albo, apotheciis convexis luteolis, mox immarginatis.

Lich. lucidus. Ach. - Engl. Bot. t. 1550. Lecidea Ach. syn. p. 48. Lich. s. Lecan. citrina Suecis vulgo. Wahl. Suec. n. 1489. - * tota pulverulenta, sterilis. Pulveraria alboflava. Fl. Berl. 180\%.p.10. Lepr. Flörkeana. Ach. Lich. univ. p. 663.

Exs. Lich. Sliec. n. 42. 
Ad saxa \& ligna putrida, præcipue in montanis Europæ borealis haud raro; " etiam in campestribus, v. c. Lundæ, ad parietes ligneos late regnat.

Species distinctissima, colore puro \& persistente insignis. Crusta normalis eximie granulata; leprosa est modo status deliquescens. Apothecia minuta, numquam pruinosa, jam primitus aperta, marginemque pallidiorem sæpe excludentia.

Hoc loco facile quæratur $P$. orosthea p. $180, \mathrm{cu}-$ jus vero excipulum, ubi adest, thallodes immutatum. Lecid. leptomerea Sommerf. Lapp. p. 161 ex spec. hactenus inventis atypicis ab eadem vix discerni potest.

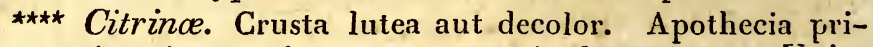
mitus intense lutea aut aurantio-ferruginea. Unius speciei excepto, hypothallus niger.

248. b. BIATORA ochracea. Vide Parmel. n. 56. 248. c. BIATORA aurantiaca. Fries Vet. Ac. Handl. 1822. p. 275. - Vide Parmelia n. $15 \%$. 248. d. BIATORA ferruginea. Fr. 1. c. p. 274 .

- Vide Parmelia n. I6o.

Quoad ideam suam omnino hujus generis sunt, æque ac analogæ Parm. fulgens, aurea \& erythrocarpia prioris sectionis; verum hæ cum $P$. elegante, chlorophana \& murorum, illæ cum Parm. vitellina, P. cinnabarina \& cerina ita connexæ, ut infimæ proles vix verbis distinguantur simulque margine thallode licet accessorio, etiam in $B$. aurantiaca, (numquam a B. ferruginea genere removenda) ita fallaces ut conjunctim tractare debuerim. Ob intimum ceterum nexum \& fere identitatem coloris apotheciorum \& thalli in hac serie, singulæ demum historia perspecta, veram excipuli naturam determinare vales v. c. $\boldsymbol{P}$. vitellince, $\boldsymbol{P}$. elegantis; in multis thallus decoloratur, sed excipulum thalli veram indolem servat v. c. in Parm. murorum, quale pro proprio necesse primo obtutu habeatur. Alio itaque modo, quam proposito, tiro in hoc bivio se expedire uon potest, quamvis dein ipsarum specierum historiam pernoscens verum \& typicum locum facile perspiciet. Hic reticulatus nexus in characteribus acquiescentibus est ingratus, iis vero, qui totam familiam missis systematicis differentiis ut integram velut arborem, seriebus ramorum instar in spe- 
ciosam coronam collectis, intueri valent, summæ sunt dilicix. Omnes hæ convergentes evolutionis series in libro quodam explanari \& connecti non possunt, nec in verborum angustie describi, sed in dispositione adumbrare studui. Felicem me prædicarem, si quis eandem mente animoque complecteretur, qualis pænes me in integrum fusilis vivit. Non e theoretico calculo deducta, sed maxime passiva naturæ contemplatione obtrusa.

\section{L E C I D E A.}

Synonyma videas sub Biatora. Lecidea. Fries $V$ et. Ac. Hiandl. 1822. p. 253. Syst. Orb. Veg. p. 252. Eschw. Syst. f. 18. Patellarix species (strato carbonaceo sub disco destitutæ) \& Lecidea, excl. Umbilicar., (disco strato carbonaceo imposito). Meyer. Trachylia Fr. l. c. (disco scabrido, atypico).

CHAR. Apothecia subdiscreta, primitus ab excipulo omuino proprio carbonaceo aterrimo marginata, dein scutelliformia aut hemisphærica, solida. Discus semper apertus, primo punctiformiimpressus, sæepius corneus \& strato carbonaceo impositus. Thallus horizontalis, ex hypothallo oriundus, subcrustaceus, effiguratus aut uniformis. Apothecia jam primitus aterrima, raro discus coloratus.

I. Genus Lecidex a Stereocaulo, Cladonia \& Baomycete tantum recedit, ut ad eandem seriem vix referres, nisi existeret omnino medium Biatoræ, quod jam hac ratione, præcipue cum omnino diversam seriem sistat, recipere necesse videatur. Transitus inter Lecideas \& Biatoras magis apparentes, quam veræ sunt, pendentes a Biatoris vetustis denigratis Lecideæ faciem præbentibus, at de nullius speciei, in statu normali \& primario observatæ, loco dubius fui. Si exinde conjungamus, etiam Parmeliam \& Pertusariam, Parmeliam \& Endocarpon, Lecideam \& Galicium \& facile plurima. Re ipsa difficilius Lecideas quoque est a Parmeliis deformatis distinguere; \& Biatora cum Parmelia, vel Biatora cum Lecideis conjuncta omnia hæc tria genera conjungere necesse erit; nam duplex inter Parmelias indicata est series, quarum altera (Imbricariæ, Placodia, Patellariæ) ad Biatoras, altera (Physcix, Psoræ, Urceolariæ) ad Lecideas ten- 
dit. Hujus rationis attentione multæ formæ mutilæ tantum dignoscuntur; multaque necessaria esse patet, quæ e singularibus observata erronea videntur; quid, quod multa ex illa ad genera reformanda in posterum deduci possunt.

- II. Primaria differentia Lecidex a Biatora posita est in excipulo vere proprio, jam primitus aterrimo et carbonaceo, quod in Biatora a thallode mutato (Cfr. Fries Vet. Ac. Handl. 1822.p.263) ortum est, unde margo junior semper pallidus nec carbonaceus; licet dein in his, ut in variis Parmeliis v. c. $P$. balanina, anea, cerina \&c, per ætatem nigrescat. Sed inter inferiores plantas semper ad statum primitivum attendendum. Excipulum Lecidearum etiam in ipsa crusta nidulans aterrimum est. Hic character e colore plerisque forsan minus notabilis videatur; est tamen summi ponderis non tantum inter Lichenes, sed etiam in Fungis; ex eo pendet Phacidiacearum \& Elvellacearum differentia, harum excipulum, Biatorarum instar, semper disco pallidius, illarum atrum cum disco pallidiori. De cetero Lecidex a Biatoris differunt apotheciis normaliter scutelliformibus s. patellatis, (ut his potius Patellariæ nomen, quam Biatoris tribuatur), a thallo minus discretis, disco vulgo corneo atro (sed in quibusdam humectatus mollior \& coloratior evadit; margo vero semper ater persistit); \& ob ejus evolutionem primitivam infra stratum corticale primitus sæpius pruinoso, omnino ut in analogis Parmeliis. - Servavi hoc loco genus eodem sensu, quo primitus 1. c. proposui, utpote habitui \& practicæ Lichenum cognitioni optime inserviente. Recentiores ad species disco strato carbonaceo imposito tantum restrinxerunt, \&, licet hi limites magis Systematici videantur, in natura facile evanescunt \& simillima removerıt.

III. Specierum limitatio ob habitum generis naturalissimi conformem \& infinitarum formarum copiam ipsarum Cladoniarum difficilior 'est. Species thallo effigurato, bene explicatæ, facile dignoscuntur, sed in statu mutilo ad crustaceas potius referas. Attamen etiam in hoc statu glebuloso sine negotio agnoscuntur. Specierum limitatio in altera sectione plene de novo construenda fuit, quum hactenus receptæ sint fundatæ notis atypicis - v. c. crusta leprosa, pulveracea, arnylacea \&c., quæ omnibus in statu typico subcartilaginea, coloribus prorsus peregrinis v. c. candido, ochraceo, ferruginoso e. s. 
p. - vel omnino accidentalibus, v. c. apotheciis amplis, quasi ulla adulta nascerentur, scabridis \& immarginatis, quæ omnia degenerata, pruinosis; plurima primitus pruinosa sunt, per ætatem l. solo mutato nuda, ut exinde nulla differentia, sed probe observanda apothecia primitus nuda, quæ diversam originem indicaut. Nullam speciem "crusta nulla," rectius deperdita \& detersa dicendum, genuinam esse vix est quod moneam; in hoc statu sunt apothecia sola quasi consonantes sine vocalibus non legenda, indeque cum hebraica Parmeliarum serie (p. 173-176) analoga. - Notas primarias offerunt: hypothallus, licet per ætatem facile obliteratus, necesse observandus; crustæ normalis evolutio, in granula I. areolas prirnitus contiguas, et color glaucescens, fuscus, ochroleucus, citrinus (reliqui atypici, leviores modificationes vix limitabiles), præcipue vero excipuli integri 1 . annularis h. e. basi deficientis structura \& margo acutus \& obtusus; disc.s primitus nudus aut pruinosus. Discus in nonnullis humectatus substantia molli, coloratus, intus simul albus eximiam in quibusdam differentiam offert. In apotheciis atris excipulo cupulari minoris ponderis videtur stratum sic dictum discolor sub disco, nam in eadem specie (v. c. minuta apothecia L. contiguce intus tota atra, adultiora intus stratum lividum, vetusta album monstrant) admodum variat. Ceterum, ut observat Cel. Meyer, non est stratum discretum, sed disci basis, optica ratione sic dictum fuit, ut dicimus solem oriri \&c. - In hodierno speciei notionis dissensu aliis nimias (ipse quondam ad longe inferiorem numerum reduxeram), aliis perpaucas recepisse videar species; h.l. post diligentissimum in natura studium non quid absolute species sit dicam, sed id præcipue cavere volui, ne ullam reducerem forman, cujus mutationis physiologica aut chemica ratio non plane evidens erat - nullamque reciperem definita vegetationis historia non gaudentem, characteribus palpabilibus vel a tirone limitabilem \& habitu proprio sine negotio recognoscendam; nam id mihi pessimum videtur cum nemo præter Auctorem, nec forsan hic, species discernere valet. Vix credam tamen e descriptis quasdam insigniores periisse, licet non pauca mihi missa mutila specimina indeterminata reliquerim; nam ignorantix potius quam experientixe est singulum qualecumque specimen denominare. Ad species distinguendas non sufficit quorsum pertineant ignorare sed 
statum esse typicum \& veras differentias nosse. Nam quæ clare \& distincte non novimus, re ipsa ignoramus. Præcipue suadendum tironi velit paucas species sibi notissimas reddere, nec multas dubias amplecti, quæ omnia confundunt. Ipse expertus sum quam difficilis sit labor e multarum s. d. specierum cognitione ad certiorum redire. Sect. I. Thallo crustaceo, in ambitu effigurato aut toto rugoso-plicato. Psoræ spec. Hoffm. Decand.

Thallus adhuc magis crustaceus, hinc crusta dictus, quam in analogis sectionibus Parmeliæ \& Biatoræ. Ut Biatoræ analoga sectio a Placodiis, hæc a Psoris descendisse videtur. In genere Parmelia magis hinc Biatoram, illinc Lecideam tangit, quam Lecidea Biatoram. - Species hujus sectionis plurima valde-inter se diversæ, omnes terrestres vel rupestres, unica tantum simul arborea, plerumque alpince, nec nisi degeneratce in planities descendunt. - Non tantum margo semper \& primitus aterrimus est, primaria mihi Lecideæ a Biatoris differentia, sed in omnibus etiam discus; hirc, serie contigua, ad Biatoras non retuli species strato carbonaceo sub disco minus completo l. omnino deficiente. Inter Lec. vesicularem \& candidam hoc respectu essentialem differentiam non vidi, ab illius excipulo libero \& hujus magis innato non pendentem. Hypothallus, ubi evidentior, niger.

* Glaucescentes. Color e glauco candicans. Cfr. Psoras n. 119-123; thallo foliaceo recedunt Psoræ 82-86; ultimæ vero duæ proferunt apothecia his similia.

249. LECIDEA canescens, crusta orbiculari rugoso-plicata glauco-albicante, in ambitu lobata, apotheciis centralibus planoconvexis tenuiter marginatis nudis. Ach. Lich. univ. p. 2 I6. Dill. t. 18. f. 17. A. Lich. canescens. Dicks. Crypt. 1. p. 10.t.2.f. 5. Engl. Bot. t. 582 . Psora Hoffm. Placodium. Decand. L. incanus, Relh.\$

Exs. Fl. Deutsch. n. 124.

Ad muros, rárissime ad cortices. Fertilis in Anglia, Hispania \& Gallia maxime occidentali; dein sterilis per reliquam Galliam \& Germaniam usque ad Gryphiam!; non vero mare balticum transcendit aut Helvetiam intrat. 
Forma vulgo Placodii dicta a sequentibus scriei recedit; tantum ad $L$. epigceam hac ratione accedit. Superficies nuda, aut sæepius in superficie deliquescens, sordide alba. Hypothallus non distinctus. A pothecia sæpius scabrosa. - Sola species haud absolute saxatilis aut terrestris.

250. LECIDEA mamillaris, crusta areolato-verrucosa turgida subgyrosa nuda glauco-albicante, in ambitu lobata, apotheciis inter areolas oriundis tenuiter marginatis nudis. Dufour! in litt. Lich. mamillaris. Gouan! Lich. tumidulus Smith in Linn. Transact. I. p. 82. t. 4. f. 3 .

In rupibus earumque fissuris Galliæ meridionalis Prevost!, circa Monspelium Dufour!

Admodum spectabilis. Crustæ configuratio fere Lecid. Wahlenbergii, sed color maxime recedit. Hypothallus obsoletus. Areolæ magnæ, turgidæ, nunc Endocarpi facie omnino discretæ uniformes, nunc \& normaliter aggregatæ, subconfluentes gyrosæ, e glauco candicantes, eburnex, nudæ persistentes, rimuloso-rugulosæ; ambitus lobatæ. Apothecia constanter inter areolas enata vidi, nam ubi areolis insidere videntur, plures confluxerunt \& harum rimis insident, conferta, sæpe conglomerata \& confluentia, nuda, extus \& intus atra, margine tenui cincta, demum vero convexa $\&$ immarginata, strato carbonaceo distincto.

25 r. LECIDEA candida, crusta rugoso-plicata candicante, mox albofarinosa, in ambitu lobata, hypothallo atro, apotheciis adpressis obtuse marginatis glaucopruinosis, intus albis. $A c h$. Lich. univ. p. 2 г 2.

Lich. candidus Weber - Engl. Bot. t. 1138. Patellar. Hoffm. Pl. Lich. II. t. 33. f. 2. Sturm. Deutsch. 4. Psora. Decand. Lecid. Schaer. spic. p. 120. Wahl. Stuec. $n .171 \%$.

'Exs. Ehrh. Cr. n. 49. Schaer. n. 167. Moug. n.642.

b. crusta nuda, apoth. minoribus innatis. Lec. pennina. Schaer. l. c. e descr.

c. crusta vix effigurata, gleboso-verrucosa. Lecid. lutosa. Ach. syn. p. 33 ad spec. Schleich. \& Ach. descr., ipsius specimina valde imperfecta. 


\section{Ad terram, supra muscos, præcipue supra ru-} pes calcareas Europæ australioris \& mediæ copiose; denique in alpibus prope mare septentrionale.

A præcedente eximie differt, præcipue si hujus status nudus b., qui mihi omnino typicus videtur, attenditur. Hypothallus crassus, spongiosus, ater. Areolæ turgidulæ, multo minus quam præcedentis, in crustam rugoso-plicatam \& ambitu lobatam concrescentes. Apothecia intra areolas enata quidem videntur, sed re ipsa e latere areolarum, quare hujus substantiam primitus, secum elevant \& margine thallode instructa videntur (facies sæpe Parm. Psoræ) \& pruina consperguntur; intus alba sunt, sed excipulo cupulari integro, at non uti $\mathcal{L}$. vesicularis libero recepta. Margo per ætatem sæe flexuosus.

252. LECIDEA cinereo-virens, crusta areolatosquamosa, squamulis reniformibus lævibus obscure cinereo-virentibus nudis subtus margineque albidis, apotheciis marginatis cesio-pruinosis, intus albis. Schaer. spic. p. $\mathbf{1 0 9 .}$

Ad saxa ad arcem Tourbillon Schaerer, ad terram Galliæ Mougeot, in regno Valentino Hispania Dufour!

"Squamulæ exiguæ, reniformes, crenatæ, aut lobatæ, imbricatim sibi incumbunt serius in pulvinulos coacervantur irregulares, adeo sæe coarctatos, ut crustam areolato-pulvinatam referant. Apothecia squamulis fere majora \& insidentia, plana, margine in junioribus crasso, in adultioribus tenui \& flexuoso, donec turgida eum amittunt." Specimen originale non vidi, quare Schaereri descr. mutuavi; huic vero omnino respondent specimina Hispanica ab opt. Dufour pro Lecid.albilabra no sp. missa, si a squamis magis sparsis subtus etiam albopulverulentis variis apotheciisque inter areolas ortis discessero. 253. LECIDEA vesicularis, crusta bullato-plicata subcaulescente e virescenti glauca, basi radiculosa, apotheciis liberis peltatis obtuse marginatis, primitus pruinosis, intus albis. Ach. Lich. univ. p. $2 \mathrm{I} 2$.

Hall. helv. t. $4 \%, f .3$. Lich. sedifolius. Scop. Patell. 
\& Psora vesicularis. Hoffm. - Pl. Lich. t. 32. f. 3. Lich. Ach.Prodr. Lich. cơruleo-nigricans. Lightf. - Engl. Bot. t. 1139. Lecid. Schaer. spic. p. 120. Exs. Schaer. n.168. Moug. Nestl.n.172. Funk.n.319. a. opuntioides, glebulis stipitatis nudis, basi fulvis. L. opuntioides. Villars. Psora. Decand.

b. paradoxa, maxime caulescens, suffruticulosa, nuda, rubiginoso-rufa. Lecid. paradoxa Ach. Lich. univ. p. 214.

c. rugoso-plicata, imbricata, glaucopruinosa. Verrucaria grisea. Willd. Bot. Mag. 4. t. 2.f. 4. Lich. candidus. Fl. Dan. t. 1064. f. 1. Lecid. vesicularis Vulgo. Psora. Decand.

d. glebosa, macra, granulatc-verrucosa, cinereo-cæsia, pruinosa. Lecid. glebosa Ach. syn. p. 32. Lecid. vesicularis. Wahl. Suec. n. 1718.

Ad terram, præcipue calcaream, in alpestribus \& montanis Europæ totius a. \& c. promiscue; b. in Europa australi, speciosissima in Pyrenæis Dufour!; d. etiam in planitiebus v. c. Gottlandia.

Species admodum paradoxa, mire varia, re ipsa cum Stereocaulo, cujus species crustaceæ variant, \& Biatora, cum qua interna apotheciorum structura convenit, at excipulum omnino proprium nec thallodes mutatum, jam primitus aterrimum, discus corneus; affinitate quoque cum proximis ita conjunctum, ut sæpe ægre dignoscantur infimi status hujus, Lecidece candidae \& epigcece, in evolutis distinctissimarum. - Formæ allatx inter se omnino confluunt, licet inter b. \& d. primo obtutu vix ulla similitudo. In rite explicatis crusta constat e lobis stipitiformibus in cæspitem stipatis apice in squamas bullatas sublobatas turgescentibus, deorsum attenuatis, fibrillis hypothalli (nullo modo in subiculum atrum spongiosum Lec. candidae expansi) radicatis, rubiginoso-fulvis, qui color in b. totum cxspitem eximie tingit. Thalli color nativus est griseo aut fuligineo-virescens, sed in formis minus explicatis a farina alba aut grisea obtegitur. A pothecia omnino libera, excipulo cupulari integro; disco plano, adultiori convexo marginem supprimente, nudo, aterrimo; intus sub lamina substupposa, alba.

254. LECIDEA conglomerata, crusta rugoso-plicata, in pulvinulos glebosos conglomerata, glau- 
cescente, basi radiculosa, apotheciis liberis obtuse marginatis nudis, intus albis. Schäer. spic. p. $\mathrm{I} 2 \mathrm{I}$.

Lecid. conglomerata. Ach. Lich. univ. p. 201. Syn. p. 33.

Exs. Schaer. Helv. n. 169.

Ad saxa tenui terra tecta in montibus Helvetiæ Schleicher!, ut in Grimsel \& Susten, etiam in vallem Gasten descendens Schaerer!, Norvegiæ Blytt!

"Priori similis, sed omnibus partibus minor. Grusta stipitibus formatur utroque fine ramosis sursum inflatis, deorsum fibrillosis, quam in priori brevioribus \& tenuioribus, arctius congestis," (nєc pruinosis vel basi rufis). "Superficies a ramulis congestis pulvinata, pulvinulis rugoso-plicatis \& glebosis; color albus (1. glaucus) cum nitore. Apothecia subtus plerumque libera, frequentissima, sæpissime coacervata, minuta, marginata, absque ulla pruina atra" Schaerer 1. c., qui hanc multasque alias species quoad veram affinitatem, sine qua omnis descriptio irrita, primus determinavit, \& hic quoque refert Lich, aromaticum Engl. Bot. t. 1777, Lecid. Turn. in Transact. Linn. Soc. IX. p. 140. t. 11. f. 1., qux tamen ut ipsa Lec. conglomerata cum Lec. sabuletorum frequenter confusa fuit.

* Fuscescentes. Thallus (numquam pruinosus) cervinus, rufescens aut fuscus. Cfr. Psoræ 124-126.

255. LECIDEA squalida, crusta rugoso-plicata squamacea conglobata cervino-fuscescente, hypothallo obliterato, apotheciis adnatis e plano convexis intus albis. Ach. Lich. univ. p. 169. Lich. squalidus. Schleich. Lecid. Schaer. spic.p.122. Lecid. norvegica. Sommerf. Lapp. p. 175.

Exs. Schaer. Helv. n. 170.

Ad terram supra montes, præcipue alpinos Nordlandia Sommerfelt! Norvegiæ Blytt! Sueciæ, Helvetiæ Schleicher!, Schaerer! Vogesorum Mougeot, Gallix meridionalis Dufour!

Prioribus, observante Gel. Schaerer, proxima, at crusta non e lobis erectis stipitiformibus radiculosis, sed e 
squamulis diminutis depressis fragilibus in crustam subgranulosam congestis. Color in fuscum semper vergit, sed intensitate variát, plus minus cervinus, rufescens, lividus; in junioribus humectatus virescit. Apothecia minuta, juniora plana, marginata, dein convexa immarginata, passim corulescenti-atra, intus alba.

256. LECIDEA badia, crusta plicata noduloso conglomerata subsquamulosa olivaceo-fuscescen te, hypothallo obsoleto, apotheciis adnatis ele vato-marginatis nudis, intus atris. Fries $\mathbf{S y s t}$ Orb. $\mathrm{Veg} \cdot \mathrm{p} .287$.

Exs. Flotow Lich. Sil.

b. crusta cinereorufa. Lecid. cinereorufa. Schaer. spic. p.122.; ex Auctore quidem non habeo, sed, ut Schærero, mihi pro Lec. badioatra missa fuit a.

In saxis graniticis \& cotaceis montium Germanix, Helvetix.

Color intra badii limites variat; ut $P$. cervince nunc in olivaceum, nunc in cinerascentem vergit. Crusta rugoso-plicata, forma varia, sæpius sistens pulvinulos diffractos irregulares; re ipsa e squamulis conglomeratis orta. Apothecia superficiei adnata, sparsa, plana, semper nuda, extus intusque atra, at stratum carbonaceum discretum non observatur.

257. LECIDEA opaca, crusta orbiculari gibbosoareolata (ex olivaceo?) picea, ambitu radiosoplicato, hypothallo confuso, apotheciis adnatis tenuiter marginatis nudis, intus atris. - Dufour in litt.

In rupibus alpinis Galliæ. Dufour!

Color maxime recedens est, Parm. molybdinam quasi repetens, in statu vegetiori forsan ex olivaceo umbrinus; intus olivaceo-pallidus. Etiam forma ad P. molybdinam accedit; in centro areolata, areolis confertis gibbis solidis; in ambitu vero Placodii Dec. instar radioso-plicata. A pothecia adplanato-adnata, at superficialia, planiuscula, opaca, aterrima, margine elevato tenui integerrimo. $0-$ mnia specimina a me visa minuta fuerunt.

*** Ochroleuca. Color e viridi aut sordido flavescens, in nostra specie mox farinoso-albescens. Cfr. 
Psoram n. 127, mire analogam, maxime vero diversam.

258. LECIDEA epigaea, crusta rugoso-plicata, in ambitu laciniato-lobata, flavo-virescente, mox deliquescendo farinosa candicante, apotheciis prorumpentibus tenuiter marginatis intus atris. Schaer. spic. $p$. 118.

Lich melanocarpus, dein epigæus Pers. - Psora. Hoffm. Germ. 2. p. 164. Parm. s. Lecan. Ach, syn. p. 179. quoad nomen, sed Parm. candicantem (n. $120)$ in mente habuit \& descripsit. Placodium Chev. par.

b. apotheciis globosis immarginatis. Huc spectat, quod possideo specimen originale Lichenis epigcei, a Persoonio Swartzio olim missum. Lecid. sphærica. Schoer. spic. p. 119.

Ad terram sterilem, apricam, Galliæ, Germaniæ, Helvetiæ calidioris.

Normale est in hac specie crustam deliquescere \& albo-farinosam evadere, ut non nisi in statu infantili adhuc tuberculoso integram strato corticali sordide flavovirescente tectam, quod in nullo Lichene typico deficit, conspicere liceat, ut egregie exposuit Cel. Meyer Flecht. p. 5\&. (Hac ratione analoga est cum Cladoniis subtiliter pulverulentis; sed in $P$. nimbosa excipulum thallodes tantum deliquescens crustam integram persistentem pulvere simili conspergit, indeque deliquescentia centrifuga, quæ in L. epigaca centripeta). Crusta optime explicata rosulæ instar expansa, terræ adnata, centro rugoso-plicata, ambitu in lobos latos subconeavos divisa, sed variat irregulariter squamosa; \& adhuc imperfectior glebosoverrucosa, ægre ab analogis statibus mutilatis $L$. candidae \& vesicularis discernenda, quare amic. Laurer Lec. glebosam non sine jure huc retulit, at tam hæc, quam nimis analoga $L$. lutosa, quam ob colorem lutescentem dictum (qualem vero equidem non observo) huc potius traheres, margine obtuso, interna disci structura \&c. recedunt. Ceterum, cum utraque certe non autonoma sit, de hac re non disputandum; ipse inventor se quas formas speciatim indicare voluerit Acharius nescire ingenue fassus est. - At ex his formis transitum, quem dico direetum, ad Lecid. atroalbam Schærer cum Cel. Flotowio non video, tantum indirectum \& apparentem. A- 
pothecia primitus e crusta prorumpunt, hinc marginem thallodem spurium \& pruinam disco inspersam primo accipiunt; omnes formæ immarginatis apotheciis, minoribus simul semper, mihi atypicæ sunt.

*** Citrince. Thallus intense luteus. Cfr. Psoram n.128. 259. LECIDEA Wahlenbergii, crusta gyroso-plicata in ambitu lobata e viridi lutea, hypothallo atro, apotheciis inter areolas oriundis obsolete marginatis nudis intus atris. Ach. meth. $p$. 81. t. 2. f. 3 .

Lich. pulchellus Schrad. L. Davallii. Smith. Psora galbula. Dec. fr. 2. p. 368. Lec. Wahlenb. Lick. univ. p. 211. Wahl. Suec. n. 1716. Schar. spic. p. 118.

Exs. Schoer. Lich. Helv. n. 166.

Ad latera rupium subhumectata eorumque terram in alpibus Lapponiæ Wahlenberg!, Norvegia omnis Ahnfelt! Blytt! Sudetorum Ludwig! Helvetiæe, Schleicher!' Pyrenæorum Dufour!

Admodum speciosa, palmaribus usque pulchre gyrosis circulis rupes ornans. Color, ut $P$. chlorophance; viridi intense luteus. Apothecia juniora plana, utique evidenter \& obtuse marginata, dein magis tumida confluentia, immarginata.

260. LECIDEA flavovirescens, crusta determinata areolato-glebulosa plicata, in ambitu lobata, e virescente lutea, apotheciis adnatis tenuiter marginatis intus atris.

Lichen flavovirescens. Dicks. Crypt. Brit. 3. p. 13. $t$. 8. $f$. 9. ex icone; nam ipsius specimina b. m. Swartzio data sistunt Lec. citrinellam, unde et Lichen citrinellus. Engl. Bot. t. 1877. - Trachylia flavovirescens. Fries Vet. Ac. Handl. 1822. p. 252. Lecidea scabrosa. Ach. meth. p. 180 ex ipso. Lec. citrin. ß. Syn. p. 25. Cfr. Deutschl. Lich. 5. p. 5 . Ad saxa \& terram in regionibus alpinis \& montanis nec umquam in planities descendens.

Præcedenti longe minor, magis lobulata, hypothallo obsoleto, apotheciorum situ \& margine certe diversa. In aliis Lichenum crustis v. c. Biat.byssoidis, Parm. Schlei- 
cheri instar, parasitica, crusta vix effigurata, sed semper areolato-adpressa, determinata, subcinerascens, ambitu a matrice spurie foliaceo. In superficie passim deliquescit, præcipue locis udis, farinosa. Apothecia subaggregata, marginem tenuem mox excludentia convexa fiunt \& facile scabrosa; hic vero status, ut in reliquis, degener est. Cfr. Lecid. citrinellam, cum qua ab omnibus fere Auctoribus utriusque statu leproso pro normali sumto ita confusa, ut diversa elementa vix disceŕni possint.

O bs. Dua istce tribus, in quas sequentes resolvendae sunt, etiam inter priores persequi poteris, ut omissa thalli figura inter utramque distribuenda sint. Forma minus evolute sub sequentibus tribubus for san qucerentur, ut n. 251, 252, 259 sub Areolatis, n. 253, 254, 260 sub Granulosis.

Sect. II. Thallo crustaceo effuso uniformi. Verrucariæ spec. Hoffm. Patellarix. Decand.

Semper quidem, sed præcipue in hac sectione, Lichenum status naturales \& colores nativi probe memoria tenendi sunt, ut etiam faciei externæ nullum pretium ad species distinguendas. - Cum præcipue in hujus sectionis tribu prima, licet a ceteris crustaceis non alienas, hybriditates (sensu improprio hoc loco me uti verbo nemine corrigente facile video) sæpe observaverim, ut v. c. in eodem hypothallo, immo areola, adfuerint Lecid. atroalba \& geographica, Lecidea geographica \& Parmelia cinerea, Parm. pallescens \& P. subfusca e. s. p., simplicem, at neglectam, earum rationem paucis notabo. Ubi duo Lichenes hypothallo ejusdem aut peraffinis structuræ juxta se invicem oriuntur, sub explicatione confluunt \& concrescunt \& utriusque speciei areolas apotheciaque proferunt. Plurima vidimus hujus hybriditatis non tantum evidentissima exempla, sed etiam indicatam earum originem demonstrantia. Quantum perspicio, multi inopinato observati transitus, v. c. inter Lecid. atroalbam \& geographicam, ex hac ratione tantum pendent. Loca subirrigua, ubi hypothallus laxior, similium evolutioni præcipue favent. - Ubi hypothalli vero inter se magis heterogenei sibi invicem obviam veniunt, alter alterum repellit; nigri linea atra limitantur; albi vero sæpius jugum elevatum marginale protrudunt. At etiam hypothalli ejusdem speciei locis siccis non assimilantur, quare omnes sic dictas hybriditates locis irriguis tantum vidimus. In rupibus irriguis, transituum indirectorum fonte inexhausto, tantam vidimus miscelam mutilatarum for- 
marum Lecidece atroalbae, geographica, fusco-atroe, Parmelice cinerece, varice \&c. \&c. , ut species non existere quisque minus attentus facile dixisset.

Trib. AREOLAT'ARUM. Hypothallus niger. Crusta innata,' primitus aut rimose areolata.

Grusta oritur ex hypothallo heterogeneo ; persistente \& evidentiori, ubi crustæ areolæ discretæ; obtecto obliteratoque, ubi crusta primitus contigua vel areolæe confluunt, ut vix nisi linea atra marginali dignoscatur. Quo humidioribus locis, ut etiam in puro quartzo crustæ evolutioni parum favente, specimina ejusdem speciei nascuntur, eo magis dominatur hypothallus; quo siccioribus, ut precipue ad latera abscondita rupium videre licet, eo magis supprimitur. - Varii vero sunt ejusmodi status hypothallini, - vel regulares, substellatim expansi, subfibrillosi, radiantes (Rhizocarpon Decand.), facie prorsus Byssocladii, qualis v. c. status Lecideoe atroalbae est Lichen astroideus Fl. Dan. t. 1352. f. 2. Parmelia astroidea Ach. syn. p. 207 - vel confusi cum crusta, quales v. c. status variarum specierum seriei fuscescentis Lecid. coracina dicuntur. Si hypothallum in rnpibus irriguis locisque similibus attentius observaveris, facile videbis $a b$ ejus metamorphosi ortos esse pulvinulos atros floccosos in variis Lichenum crustis memoratos, qui quoque in Phycologia, plurimorum statuum Lichenum elementarium more, redeunt sub Conferva ebenea, nigra \&c. s. inter Chroolepi \& Scytonematis genera. Expositio horum typici nexus cum $R a-$ codio rupestri aliisque Byssaceis ad harum historiam, utpote a præsente scopo nimis aliena, differenda est. Quando vero hypothallus prorsus supprimitur, crusta vel per senium depertita vel in degenerationes tendente, vix nisi habitu \& historia a sequente tribu dignoscuntur. Sic primum nominandx formae oxydatae, quæ omnes hujus loci supt, nam sequentis tribus species oxidum, etiam sub hydratis forma, repellunt \& inter species hujus oxidatas mixtæ nativum colorem servant. Strato corticali destructo hujus species amylaceæ \& tartareo-compactæ evadunt, sequentis magis leprosæ, qua ratione vero, ut etiam crustæ indole primitiva, $L$. parasema cum affinibus ad sequentem tribum accedit. Pendet hoc a crusta hujus tribus magis innata in areolas abeunte, cum sequentis in granula normaliter liberatur. Deficiente vero crusta apothecia magis scutellata, levia, margo sxpius 
persistens, in majoribus flexuosus, hujus tribus saltim indicia sunt, cum sequentis apothecia citius \& sæpius turgescunt, marginem excludunt, scabrosa \& rugosa evadunt. Denique loco quoque differunt; Granulosce plurimænulli definito solo adscriptæe esse solent, sed in saxis, ligno, cortice, terra promiscue vagantur; Areolatce genuince absolute saxicolæ sunt; tantum aberrans $L$. parasema cum suis proximis arborea.

* Genuince. Absolute saxicolæe.

1. In areolis rotundis 1 , angulatis equidem characterem primitivum non video, cum primitus omnium areolas rotundas invenerim, \& forma earum angulata e pluribus confluentibus 1 . e crusta contigua rimose diffracta oriatur. Etiam caute adhibendus est situs apotheciornm in hypothallo 1 . in crusta, nam licet alteruter in plerisque speciebus normalis videatur, omnium specierum ex hypothallo vulgo apothecia proferentium etiam apothecia ex ipsis areolis enata, \& quidem tum a thallo sæpius spurie marginata, ut jam Meyer observavit, vidimus.

2. Dubius fere hæsitavi utrum multa synonyma inter has citarem, an negligerem, cum ex herbariis \& speciminibuș, exceptis Schcereri \& Sommerfeltii, e Flörkeanis pauca vidi, clarum fit, raro definitam speciem, sed sæpius analogos status diversarum specierum respici. Sie formæ ferro tinctæ promiscue Lecid. silacea \& Öderi dicuntur præcipue apud Veteres; formæ amylaceæ lacteæ cum majoribus Lecidea ámylacea, cum minoribus apotheciis L. petrcea; formæ crusta cum hypothallo in crustam cinerascenti-nigram confusa Lecidea coracina; formæ crusta detrita, apotheciis amplis Lecidea platycarpa 1. omnino deperdita Lich. simplex Dav. Patellaria nuda Pers., Lecid. privigna, steriza; formæ normales apotheciis amplis pruinosis Lecid. albocorulescens; apotheciis minutis nudis Lecid. iapicida e. s. p. Ejusmodi ab externa facie sumtæ differentiæ Lichenum historiam pernoscere studenti non satisfaciunt; tantum contento singulam formam, cujuscumque originis sit, nomine quodam salutare. Attamen collatis archetypis cum descriptionibus, quibus potissimum adscribenda sunt, non sine certitudine quadam indigitare potui. Similes fere omnes vulgatiores enituntur; quarum nondum observatæ sunt, in potestate saltim existere fas est credere. Analogia specierum diversarum serierum perevidens est. 
- Glaucescentes. Crusta nativa glauca cinereo-albescens (aut decolorata), hypothallum nigrolimitantem aut evanescentem obtegente, apotheciis e crusta oriundis. Ubiquitarice, per regiones planitierum, procipue silvaticas, et inferalpinas late regnant. 26r. LECIDEA albocorulescens, crusta primitus contigua e coeruleo albescente, hypothallum nigrum obtegente, apotheciis e crusta oriundis, excipulo annulari tenuiter marginato, disco ceraceo primitus coérulescenti-pruinoso humectato rufesce:ite, intus albo. Fries Sched.Crit. 13.

p. $9-\mathrm{r} /$.

Lich. albocorulescens Wulf. in Jacq. Collect. II. p. 184. t.15. f.1. certissime \& optime! Patell. Hoffm. Pl. Lich. t. 14. f. 2. \& Verruc. Germ. p. 189 pr. p. Lecid. albocoerulescens Ach. pr. p. - $\beta$. Lich. univ. p. 188. - apotheciis obsolete pruinosis: Lecid. cxsia. Ach. syn.p. 17. (potius ad 262.) \& L. lapicida $\delta$. cyanea (minutis) \&c. Ib. p. 14. - apotheciis vetustis atris, crusta subevanida: Lecid. lithophila $A c h$ : syn. p. 14 certissime bæc! (at recedit Lecid. polycarpa. Flörk. in Sommerf. Lapp. p. 149.) -omnino acrustacea: Lecid. privigna. Clement. ex spec. Lallave. Crusta varia ratione e ferro oxydata: $\mathrm{Li}$ chen pruinatus. Dicks. Crypt. Brit. 3. t. 9. f. 4. ad specim. ipsius a me visum. Engl. Bot. t. 2244. Lecid. pruinosa Ach. meth. Lecid. daphoena $\beta$. Lich. univ. p. 166 (Cfr. Syn. p. 22, 337) $\alpha$. in ipsiusherb. diversa. Lecid. silacea. Botanic. Gallice. Lecid. discoides. Chev. par. p..566. (Fl. Dan. t. 1431. f.1. habitum disci non male exprimit, at e speciminibus ad subsequentem pertinet).

Exs. Lich. Suec. n. 374; 375 oxydat.; ut vix Schaer. n. 188.

Ad saxa, præsertim granitica \& micacea, Europa totius; in pineto-montanis copiosissime.

Hæc \& duæ proximæ habitu \& metamorphoseos serie sub infinitis formis exacte conveniunt, sed evidentissimis notis atque constantissimis differunt. Bene novi ad sequentes jam frequentius "tranşferri $L$. albocoerulescentis nomen, sed et hanc primitivam esse, huicque hoc nomen optime convenire, tam ob crnstam e coerulescente 
albicantem, quam ex apotheciis e pruina albida coerulescentibus. Cfr. Sched. Crit. l. c. - Hypothallus e lineolis nigris juniorem præcipue Lichenem limitantibus \& decussantibus distinguitur, crusta crassiore, amylacea aut demum deperdita omnino evanescit. Crusta insignis est utpote, etiam normalis, haud cartilaginea \& colore primitivo in crsium vergente, dein cinerascenti-albida aut lactea; locis humidis dissoluta passim quoque virescit ( $L$. - - v. erysibe Flotow); primo contigua lævigata, dein amylacea 1 . rimosa, inæquabilis \&c. (nec ad aliam jam citari potest Lec. pustulata Ach. syn. p. 18 ad duo apoth., quæ nunc dissecare non licet, descripta). Saxum corrodit, magis quam alia species, ut huic debeatur L. lapicidae nomen. Apothecia crustæ adpressa formam planiusculam \& marginem tenuem servant, juniora minuta regularia, adulta angulosa margine flexuosa; discus reliquarum mollior strato thallodi impositus; intus albus demum farinosus; in superficie tantum coloratus, humidus \& vegetus subsanguineus, siccus ater, sed e pruina tenui albida coerulescens; specimina vetustissima exsoleta, crusta simul deperdita, nuda \& humectata quoque atra persistunt. - Variis locis insuper in herb. redit: sub Lecid. pantosticta $\alpha$, L. confluente \&c.; exstat quoque status ad $L$. amylaceam facile referendus.

p. L. immersa, crusta mutilata tenuissima evanidaque albicante, apotheciis minutis sæpius saxo immersis.

Lich, immersus Web. potius Verrucaria. Engl. Bot. t. 193. Lecid. immersa. Flörk in Berl. Mag.1809. p. 308. Ach. syn. p. 27. Patell. Dec. Fr. 2. Verruc. atrosanguinea. Hoffm. Germ. 2. p. 192. sub Lecid. parasema. Lich. calcivorus. W Wahl. Suec. p. 808 - ferro oxydata pallide ochracea. Lecid. delibuta. Ach. syn. p. 31. - ex oxido Manganii, teste Meyer, roseo-purpurea: Lich. marmoreus Wilf. in Jacq. Coll. II. p. 174. t. 13. f. 1. Verruc. purpurascens. Hoffm. Pl. Lich. t. 15. f. 1. Urceol. \& Lecid. Wulfenii $A c h$.

Exs. Fl. Deutsch. n. 23.

Ad saxa calcarea Europæ totius; etiam prorsus acrustacea ad muros. .

Inter innumeras prioris formas hæc sola ut varietas notari meretur, ipsa admodum varia, multisque formis 
(v. c. Lecid. casia Chev. Par. p. 567, Lec. goniophila Flotow) cum priori confluens. Est nempe pracedentis status in carbonatis calcici potestate, ut Lecidea rupestris $A$. Verr. Schraderi $A$. earumque more variat apetheciis nunc immersis, nunc emersis, immo, optime monente Wahlenbergio, monstrosis subclavatis. Talis status ad specimina certa est Lichen clavus Ramond s. Patell. Dec. Fr. 2. p. 548. Plurima veterum synonyma hujus \& Verr. rupestris adeo confusa ut discerni nequeant. - Lecid. Wulfenii hujus esse varietatem, ut monuit jam Clemente, nullum mihi dubium est; ex oxido Manganii pendere declarantem Cel. Meyer lubenter sequor. 26. LECIDEA spilota, crusta primitus contigua glaucescente, hypothallum nigrum obtegente, apotheciis e crusta oriundis, excipulo annulari valide marginato, intus sub disco corneo primitus glauco-pruinoso albis fuscisve. Fries $S_{y s t}$. Orb. Veg. p. 286.

Lecid. pantosticta. $\gamma$. spilota. Ach. syn. p. 13. apoth. amplis. Lecid. lapicida. $\beta$. l. c. p. 14. (apoth. minut. L. albococrulescens. Ach. ex ic. - Flor. Dan. t. 1432. $f$. 2. ex Sommerf., analysis desiderata, habitus se-

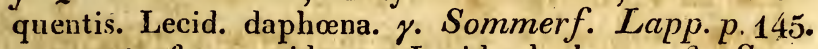
- crusta ferro oxidata: Lecid. daphoena. $\beta$. Sommerf. I. c. - crusta amylacea lactea. Lecid. amylacea vera \& descripta in Syn. Lich. p. 16.? Ceterum non ita definita fuit, ut ipsius spec. \& Lich. anylac. Vet. Ac. Handl. 1794. t. 6. f. 6. huc tute se ferantur. E descr. L. cæsia. Syn. p. 17.!

Exs. Lich. Suec. n. 406.

Ad saxa granitica in regionibus magis montanis campestribus; ubi vero nascitur, sæpe copiosissima v. c. Ostrogothiæ Stenhammar! Nordlandia Sommerfelt!

Inter præcedentem \& sequentem medium exacte tenet locum, sæpe cum utraque confusa, at luculenter diversa. A Lecidea albocoerulescente excipulo, annulari quidem, sed firmiori, unde et margo validior fit, disco in ormni ætate \& statu corneo \& aterrimo persistente, intus solido nec demum farinaceo, ut etiam crusta normali magis cartilaginea, in cæsium haud vergente, \& per ætatem magis areolata. A L.contigua dignoscitur excipulo an- 
nulari, basi deficiente, disco strato carbonaceo hand recepto, unde apothecia intus albida, margine tenuiori, apotheciis adpressis. Specimina perfectissima crusta insignia sunt rimoso-areolata, areolis demum plicatis, apotheciis semi-immersis, margine demum fere crispato-flexuoso, etiam inflexo, difformibus, suboblongis \& c. Ad easdern prorsus leges ac vicinæ eisdem modis mutatur. At tam in hac quam in priori discus perfecte prolifer visus est, in sequente vero tantum papillatus, papilla in marginem duplicatum abeunte. Notandum porro $\mathcal{L}$. spilotam in agro Femsjonensi, ubi priori \& sequente nulla Lecidea vulgatior, prorsus exsulare; has vero in iis Ostrogothiæ plagis, in quibus L. spilota luxuriat, admodum rarescére. Ab exteris terris rarius recepi; sub $L$. cyanea nomine e Vogesis e. s. p. Inter Schaereri species nullam huc referendam invenio, nisi forsan $L$. casio-pruinosa Spic. p. 136, e descriptione ambitu sublobato tantum discrepante.

Utrum $L$. albocerules:ens Schaer. Exs. n. 185 habitu L.confluentis, que a L. spilot a strato aterrimo sub lumina etc. omninn differt, msdiam inter priorem et sequentem sistat speciem, an ob crustce primitiva descr. ad sequentem refererida sit, quum a nostra margine tenui demisso, apotheciis primitus intus albis, discrepet, haud affrmabo. At ab ipso cillaiam $L$, hydrop hil am nostram ad sequentem pertinere ex autopsia testor:

263. LECIDEA contigua, crusta primitus contigua glauca albicante, hypothallum nigrum obtegente, apotheciis e crusta oriundis, disco corneo primitus glaucopruinoso, excijulo crasso carbonaceo discreto recepto. Fries Siked. Crit. I3. $p .14-16$.

a. disciformis, excipulo cupulari persistente discoque tumido cingente discum planiusculum. Lecid. flavicunda Sommerf. Lapp. p. 146. * apotheciis amplis, subrepandis. Lecid. albocórulescens Ach. syn. ex maxima parte. Patell. crenata. Dec. fr. 2. - Lec. speirea. Ach. syn. p. 31. Lich. Engl. Bot. t. 1864. (jam in transitu ad $\varepsilon \&$ sequentem b.) crusta amylacea - Lich. s. Lec. Dilleniana. Ach. Prod. t. 1. f. 1. Syn. p. 30. crusta Bysso rosea intertexta Lec. flavicunda \& L. flavoczerulescens. Ach. syn. $p$. 22, 23. Fl. Dan. t. 1431.f. 2. e minera ferri tinctæ. ** apotheciis minoribus regularibus. Lecid. margaritacea. $\alpha$. Ach. syn. p. 31. Lecid. epipolia. Sommerf. Lapp. p. 147. (Hoffm. Pl. Lich. t. 14. f. 2 . 
a. b. ex icone, at hujus spec. authent. non vidi) A potheciis nudis pro L. lapicida \& L. carphina passim venditur. - Lecid. petræa Auct. ex parte (Cfr. obs. infra) \& Patell. cretacea. Dec. crusta dealbata, amylacea. - Lich. silaceus. Hoffm. Pl. Lich. t. 19. f. 2. (Verruc. Ejud. Germ., ut Lich. Öderi Web. miscela) crusta ferro oxydata. *** apotheciis minimis. Lich. Suec. exs., quæ amiciss. Schaerero in litt. teste Lec. pusilla. Turn. et Borr. \& Lecid. petræa $\beta$. Schaer. spic. p. 13\%, cautissime vero separanda a similibus formis Lec. atroalbæ. ***t apotheciis detrusis, haud rite evolutis, aliis abortivis punctiformibus. Verruc. s. Patell. multipunctata. Hoffm. - Pl. Lich. t. 63. f.1-3. Biatora turgida. Ach. Lich. univ. p. 273. Lec. albocœrulesc. $\beta$. Flörk. (at a sua excludit \& ad L. calcaream, quæ præsens, refert Schaerer. - Pyrenula marmorata. Schleich: Cat. crusta primitiva tenuissima oleosa nigro-punctata, quæ sterilis passim soredia alba profert, quæ pro $V_{a-}$ riol. aspergilla Ach. sat ceterum vaga cum acutiss. Meyer facile habeam - vel omnino leprosa grisea, late apud nos rupes operiens: Byssus saxatilis. Linn.! Lêpr. Segestria. Ach. meth: p. 8 .

Exs. Lich. Suec. n. 376, 37\%, 410 forma speirea, 411. Dilleniana-apotheciorum morphoseos seriem exhibentes. Moug. Nestl. n. 463. sp. sinistrum.

b. convexa, excipulo, a disco turgiào convexo, quasi reflexo sub disco hemisphærico, margine obliterato. Dill. muso. $t$. 18. $f$. 8 . Lecid. confluens regionum campestrism. Ach. \& Suec. ex max. parte. - Lecid. amylacea. Botanicor. Gallice et plurim., ipsius. quoque Acharii. crusta amylacea.

Exs. Lich. Suec. n. 378. - Schaer. n. 184. subamylacea.

Ad saxa granitica Europre totius copiosissima; a. præcipue in silvis, b. in magis ventosis. Status amylacei pracipue in rupium cryptis, oxydati in ferro-montanis.

Maxime licet protea sit, notis evidentibus \& certissimis distincta. Ut crusta habitum satis diversum taceam, discus crassus corneus aterrimus immutabilis, primitus pruinosus, ob stratum suum inferius (sit venia verbo) corneo-hyalinum dilutius, $I_{\text {. }}$ in varietatibus quibus- 
dam album, evidentius distinctus a strato carbonaceo crasșissimo, cui impositus est, quam in alia specie. Ex hoc strato carbonaceo sub disco excipulum integrum fit, plano-cupulare \& margo obtusissimus, sed disco magis turgido margo fere supprimitur \& excipulum nuclei instar hemisphærici includitur. Hac ratione est evidentissima Lecideæ species. Addendum quoque discum in hac sæpe papilla, demum in marginem duplicatum abeunte, ornari. Hæ notæ in omni forma persistunt; observes tantum omnes simul obviam venire disco denudato, stratumque a disco minus distinctum esse in individuis minimis. - Cum nulla itaque alia suæ seriei confundi potest; facile vero fornı degeneratæ cum itidem atypis $L e$ cid. atroalba, fuscoatra \&c., ai formæ primarix tam evidentes, ut de differentia dubium vix oriatur. Hypothallus ut in Lecid. immersa. - Difficile est libellum de hac specie non scribere; omnia, quæ de illa per lustra annotavi, repetere tædet, cum quisque in natura ipse optime persequetur. De perfecta identitate omnium citatarum formarum ne levissimum quidem superest dubium. Crustam a primitiva macula tenuissima cartilaginea, oleosa quasi, abire in crassam tartaream rimoso-areolatam, areolis passim quoque discretis, in eodem latissima individuo ad saxa majora silvatica facile est observatu. Crustam tartaream cinerascenti-albidam in amylaceam lacteam ad rupium latera mutari adhuc evidentius est. In hoc statu apothecia vulgo margine thallode spurio coronantur. Formæ ad dimidium l. ex integra oxydatæ vulgatæ sunt, etiam tam hujus quam præcedentis disco tantum ferruginoso-pruinoso. Lec. Dillenianam a Bysso peregrina pendere patet ab eadem Bysso, ejusdemque odoris, rupes late extra hunc Lichenein obtegente. (Lecid. basaltigence Fl. specimen nimis parvum vidi, ut citem, at ratio eadem est; analogum statum habemus Lecidece atroalba, Biatorae rivulosa'\&c.) Formæ crusta nulla nullius momenti. Adsunt multi æque memorabiles status, sed pariter accidentales, ut earum enumeratione molem hujus speciei augere nolim, nam omnes tam promiscue nascuntur \& facile confluunt ut varietates non dicam; sequentes distinximus, cum aut per se insignes aut definitorum locorum filix sint \& proprium vegetationis Lichenosæ characterem indicant.

ק. L. platycarpa, crusta lævigata tenui demum disparente, hypothallo obsoleto, strato disci inferiori albo. 
Quoad apotheciorum vero figuram variat prorsus ut a. Status apotheciis maximis planis marginatis: Lecid. platycarpa. Ach. syn. p. 17. Lich. univ. p.173. t. 2. f. 6. Schaer. spic. p. 136. Patell. macrocarpa. Dec. fr. 2. p. 347, ut quoque Cel. Dufour in schedula addita observavit. - Crusta nulla : Lecid. steriza Auct. at similes omnium fere specierum.

Ad saxa precipue arenaria \& similia magis friabilia, ubi crusta vulgo disparet; in schisto habitu s.' d. L. petraece.

Huic utique primaria quædam differentia inesse videtur, at historia ceterum prorsus eadem, \& sæpius unice disci inferiori colore discerni potest, quare tantum pro vera varietate habeo. Vidimus quoque directos transitus \& differentia a loco explicari possunt. Ex specimine Hookeriano hujus statum ferro oxidatum exhibet $L_{i c h}$. silaceus Engl. Bot. t. 1118.

$\gamma$. L. nobilis, crusta crassa areolata, areolis amplis subdiscretis angulatis cæsiis albicantibus, apotheciis convexis cœeruleo-nigris.

Lecid. nobilis. Sommerf. Lapp. p. 149? e descriptione - hujus unius Auctoris speciei, semel modo ab ipso visæ, specimen mihi deest.

Ad rupes stillicidio irriguas. In Kalaberget ad Femsjö unico loco.

Eminentissima, areolis fere $L$. mamillaris, sed versus ambitum minoribus uniformibus, intus substupposis. Nostra vero certe a loco indicato pendet \& jam exsiccata humidi Lichenis speciosam faciem \& colorem amittit. Ex aqua quieta madefactæ areolæ plurimarum specierum tument; ab aqua vero fluente suffusæ 1 . undis tersæ lævigantur.

d. L. hydrophila, crusta tenui lævigata lactea, apotheciis tumidis convexis immarginatis nudis, collabescendo subrugosis. Fries 1. c. p. 256 .

Exs. Lich. Suec. n. 379.

Ad saxa sepius inundata lacuum \& amnium Smolandia alibique copiosissima.

Ob locum \& proventus copiam præcipue notabilis, nam var. $\alpha$. similes formas ad rupes madidas quoque enititur. Vulgo cum Parm. cinerea v. lacustri, cum qua 
ex omni parte analoga, ita hybrido-confluens, ut non crustæ, tantum apothecia discerni possint. Ut citatæ Parmeliæ ad aquas martiales color crustæ abit in testaceum, ochraceum \&c., qui etiam apotheciis suffusus est. Cfr. Exs. l. c. Apothecia ex aqua hausta lavissima, nitida \& revera emollita, ut exsiccata sæpe collabescant \& corrugentur; humectata vero vix reviviscunt. - In hujus vicinia quoque observatur crusta sterilis verrucoso-granulosa, quæ ad $L$. contiguam referenda, ut Porince chionoea Ach. ad $P$. cineream.

\&. L. calcarea, crusta contigua farinoso-amylacea candida, ambitu determinato, apotheciis in crusta detrusis obvelatisque.

Lich. calcareus. Weis. Patell. s. Verrucaria. Hoffm. - Pl. Lich. t. 56.f.2. Parmelia. Fl. in Berl. Mag. 1810. p. 126. Lecid. Schaer. spic. p. 138. propter locum in calce; nam junguntur etiam formæ amylaceæ var. $\alpha$. Lich. cretaceus $\mathbb{E} / \mathrm{hrh}$. (in Lich. univ. sub Lec. margaritacea, in Syn. sub L. speirea). Sagedia candidissima. Syn. Lich. p. 135 speciosissima forma, (at et Urceol. scruposa. $\gamma$. sic dicta) Lecid. lithyrga. Syn. Lich. p. 25. status incoinpletus, amphibolus.

Exs. Lich. Suec. n. 412.

In saxis calcareis præcipue Europæe australioris \& mediz; Gottlandix tamen etram copiose. Marklin!

Varietas in calce orta, sæpe admodum spectabilis, præcipue ille status perfectissimus crusta crassa, rugosoplicata, verrucosaque, in ambitu lobata, apotheciis protuberantibus deformibus, quem pro Saged. candidissima in Lich. univ. descripsit Acharius. At minus evoluti s $x$ pe ad $\alpha$. in statu amylaceo tantopere accedunt, ut ægre discernas, nisi rationem habeas substantix \& loci natalis.

๖. L. coesia, crusta leprosa effusa cresio-cinerea, passim granulata verrucoso-conglobata dispersa subplumbea, apotheciis sessilibus, strato disci inferiori tenui albo.

Leprar. cæsia. Ach. Lich. univ. p. 66\% spec. Dufoureana in Obs. memorata; Persooniana ad Parm. erythrocarpiam pertinent. Lecid. Duf. in litt. 
In saxis calcareis cinereis Galliæ meridionalis Dufour! Delphinatus Miribel!

In hac nil fere habitus speciei genuini restare facile conceditur, at omnes characteres essentiales $P$. contiguam \& evidenter atypicam formam suadent, ut me haud graviter errasse, eam h. l. citando, fingam. $\mathrm{Hy}$ pothalli nigri vestigium non desideratur. Crusta magis integra verrucosa 1. conglobata humectata cæsio-plumbea, sicca cinereo-cæsia glauco-pruinosa; sæpius vero pulyeris instar leprosi rupes late operit, \& quidem in hoc statu a simili statu varietatis $\alpha$ tam leviter recedit, ut fere eandem diceres. In utroque fructificat. Apotheciorum minutorum excipulum admodum crassum, primo cupulare, dein plano-convexum, margine obtuso evanido. Discus primitus pruinosus, dein nudus linea alba $a b$ excipulo discretus.

Exstat quoque hujus protece stirpis forma palde tenuis, rotundata, dealbata, habitu $L$. p e $t r a a^{2}$; inhabitat vero rupes aridas umbrosas extra omne L. petriere sodalitium. - E schistosis Gallice adsunt exemplaria sar, b. referentia, at lamina nuda rufa persistit, adleoque melius inquirenda. - Plures ista varietates, que Hoffm. Germ.p.184. 2. 36 . afferuntur, agre absolute determinantur ex figuris in Pl. L. datis, externum habitum tantum referentibus. At neutram harum Biat. $r i$ v ulosam, ad quam e. g. L. petraa trahi non potuit, exprimere mihi perevidens. Multorum exemplarium fide, et quidem Flörkeanorum Sommerfeltio determinatorum, ad sequentes refero. Patellaria pantherina et P. 'tigrina Pl. L. t. 57 non male exprimunt ha. bitum formarum prioris, at in sede ab Hoffmanno allata tantum determinanda sunt. P.tigrina ad L. petraam vulgo trahitur, at sub hujus nomine varice prasentis forme etiam inteltiguntur. A thalli indole, nullo apto prasente synonymo, nomen, etiam hujus formis tributum, figere solui.

264. LECIDEA variegata, crusta mox areolata glaucescente, hypothallo nigro innato-lævigata, apotheciis e crusta oriundis depressis, intus nigris, margine persistente primitus coarctato, discoque pruinoso. Fries Sysi. Orb. Veg.I.p. 287 . Lecidea lapicida $\zeta$ radians. Ach. Lich. univ. p. 160. Syn. p. 14. Wahl. Lapp. n. 903. - Lecid. melanophxa. Fries $V$. A. H.1822.p.259. colore fulvo. Exs. Lich. Suec. n. 387.

In scopulis graniticis marinis. (Americze horealis) Scandinavia totius a Finmarkia ad Hallandiam copiose \& sine dubio alibi. 
Qualis hæc ad scopulos marinos nascitur perevidens est, cum alia haud conjungenda, licet ad variet. subcontiguam Lec. fuscoatræ accedat. Hypothallus late \& determinate effusus, insignis, subfimbriatus. Crusta primitus contigua, sed interrupta, ut per intervalla hypothallus niger sæpe promineat nudus, subcartilaginea, glaucescens, mox fissa in areolas minutas semper adeo depressas ut cum hypothallo æquabiles sint. Crusta intus sæpe aurantiaca, qualis etiam recens trita apparet. Apothecia re ipsa e crusta oriuntur, etiam ubi inter areolas sedere videntur basi crustæ. recepta sunt. Discus ex urceolato-explanatus, primitus \& sæpe persistenter, glauco-pruinosus demum dilatatus numquam convexus, per ætatem subinde pIicato-rugosus; intus ater strato carbonaceo haud discreto aut determinato receptus. Margo primo tenuis coarctatus, dein obtusiusculus firmior persistens.

Huic habitu \& characteribus accedunt variæ aliis locis obviæ formæ, quas vero in specierum limitatione nil magis metuens quam heterogenea confundere, potius post Lecideam variegatam, quam sub eadem afferre velim. Harum proxime ad L. variegatam accedit Lec. petrcec Wahl. Lapp. p. 476 - Lich. Suec. exs. n. 407 - ab ipso acutiss. Auctore cum priori, cui sjmillima, in Flora Suecica juncta, sed semper discreta nascens, quare transitus directos observare non licuit, locis licet analogis obvia. Præsens enim in alpibus ventosis 1 . etiam ad rupes juxta lacus Suecix majores passim copiosa cst. Differt crusta minus definita, magis cinerea, vere glauca non visa est, margine juniori quidem coarctato albo, sed discus haud vere pruinosus, \& nescio quid in habitu peregrini. Jam Cel. Wahlenberg nexum cum Parm. cinerea observavit \& conferuntur hujus abortus, v. c. Sagedia depressa, margine thallode, ut in variis Parmeliis fit, nigricante affinitas adhuc evidentior. Singularis ille character: "crusta intus præcipue sub receptaculis rubicunda" tam ad priorem, quam ad $P$. cinererim, cujus formæ in borealibus? eo gaudent charactere, spectat. Cfi. Lecan. Acharii Sommerf. Lapp. p. 88. - Cum his intime quoque connexa est vera Lecid. ambigua Ach. syn. p. 14., diversa tantum crusta intus non rubente, apotheciis demum applanatis, immarginatis, quam æque ac quædam specim. Lec. pantostictce, apotheciis latiolibus tantum diversa, ad $\boldsymbol{P}$. cineream referre hesitem. Au- 
getur difficultas e variis formis fulvo-ferrugineo tinctis. Lec. melanophacam a L. variegata oriri luculenter vidimus, sed etiam similem agre discernendam a $L$. geographica, quam conferas. Nec in saxo, cui Lec. melanophcea adnascitur, adest ferrum, nec ipsa ab aqua martiali suffusa est; color igitur fulvus cum interno crustæ connexus videtur. Cum istum internum crustæ colorem ut characteristicum in Lich. petrceo Prodr. Lich. mernoret Acharius, talem statum potissimum respici vero simile videtur. Etiam in recentioribus Auctoris citati scriptis" sub Lec. petroea occurrit; est v. c. L. petræa c. Syn. Lich. p. 15. - Ut meam profiscini dicam sententiam, L. petrcea Wahl. \& L. ambigua Ach. sunt varietas e ventis terso-lævigata $L$. atroalba, $L$. atroalbav. ambigua dicenda - \& ad L.variegatam, ut perfectior minus tersus status, areolis turgidis, pertinet $L$. contiguc Sommerf.! Engl. Bot. t. 821 \&c. - In hac discus intus albo-cinerascens, adeoque evidentius discretus a strato fusco-nigro, quo haud vere carbonaceo 1 . determinato, margine firmiore \& persistente \&c. a $L$. Juscoatra differt.

Lecidea lactea Flörk in Schaer spic. p. 127. Fxs. 176, huic amicissimo Viro videtur eadem ac nostra Lec. variegata'; Liec. lactece autem specimina a me visa a Liec. atroculba ægre dignoscere valeo. Cfr. Flotow in Reg. Bot. Zeit. 1828. p. 692 (unde vero Lecan. s. Biat. intricatoe Ach. syn. huc veniat non facile intelligitur). Disci pruina accidentalis apparet \& in meis speciminibus deficit.

265. LECIDEA polycarpa, crusta rimoso-areolata glauco-cinerascente, hypothallum nigrum obtegente, apotheciis crustæ adpressis, intus albidis, excipuli annularis margine tenui, disco aterrimo semper nudo. Flörk. Sommerf. Lapp.p. i 49. L. Dicksonii. $\gamma$. Lich. univ. p. 6\%0. oxyd.

Exs. Lich, Suec. ined.

In saxis hinc inde rarius.

Habitus quidem Lec. immersæe, at omnino distincta, magis vero $L$. spilotce affinis, a qua differt præter crustæ habitum diversum apotheciorum situ, forma, absoluto, ut in sequentibus, pruinæ defectu, margine tenuiori, disco maxime opaco. Sunt nempe hæe maxime characteristica \& Lecidece confluentis Schaer. adeo analoga ut, nisi stratum carbonaceum sub disco defuisset, cum 
hac conjungere tentassem. Sunt semper inter minora affinium, magnitudine parum varia, crustæ superficiei adpressa, numquam inter areolas in formis areolatis collocata, admodum vulgo conferta, sæpe quasi inter se,contigua (unde nulla magis, quam hæc \& $L$. confluens, ex apotheciis contigua diceretur), e mutua pressione valde. angulata, passim confluentia. Margo obtusus, sed tenuis \& demissus, persistens, per se numquam flexuosus ut in præcedentibus, tantum e situ apotheciorum angulatus, niger quidem, sed ob discum aterrimum dilutior apparens, cinerascenti-niger, quo primo obtutu dignosci solet. Discus semper planus persistens, numquam glauco-pruinosus, potius ob colorem semper aterrimum, normaliter maxime opacum, tritum nitidulum atro-pruinosum dicas. Sub disco in junioribus 1 . crusta amylacea observatur stratum crustæ album, verum in optime evolutis adest stratum fuscum, id quod etiam sæpe adest in Lecidece spilota, thejode Sommerf. quod ad excipulum non refero, cum magis indeterminatum sit nec definite cum margine cohæreat, \& licet $L$. contigua stratum carbonaceum subinde referat, ab eodem in omni retate \& statu præsente vere diversum est. - Ceterum observandum est me tam sub L. spilotoe disco, quam L. albocoerulescentis, observasse tenuissimam lineam sub strato thallode ductam, qua excipulum quasi contiguum fit, at me ad micrologicas rationes tironi parum evidentes hoc loco attendere non debuisse. Quoad crustam, tartareæ vulgo indolis, sed etiam pulverulentæ, disparentis \&c., variat ut affines.

Videtur sub Lecid. lapicidae, contigua \&c. nominibus latuisse - Lecid. petroea Wahl. (vide supra) ad hanc quoque accedit, immo L. confluens. $\mathbf{E}$ calce habemus specimina priori apotheciis satis similibus, sed crusta mutila non rite definienda.

266. LECIDEA lapicida, crusta mox areolatoverrucosa e glauco cinereo-alba, apotheciis in strato crustæ corticali oriundis sessilibus, intus corneis cinerascenti-nigris, excipuli confluentis margine tenui, disco æquabili primitus nudo.

Lecidea lapicida. Ach. syn. p. 13 ex minore parte, nempe ex mente Auct. Lecid. cinerco-atra. Lich. $u$ niv. p. 167 \& L. lapic. $\beta$ monticola Syn. p. 14. etiam huc referri posset, quoad apoth. vero" subinde 
coerulescentia" potius L. spilota. Non obstat L. spuria. Schaer. spic. p. 127 at specimen non vidi. Status e ferro oxydatus: Lecid. silacea. Wahl. Lapp. p. 474. Ach. syn. p. 22. Fries in Vet. Ac. Handl. 1822. $p .258$.

Exs. Lich. Suer. n.408. - Vix differt: Schaer.n.191. Ad saxa \& rupes graniticas montanas, præcipue in septentrionalibus.

Species rarior, quantum video, a præcedentibus certo diversa, $L$. spilotoe subsimilis. Notæ essentiales definitæ: Apothecia superficialia, in arenlis sessilia 1. adpressa, sed in strato corticali enata, indeque absolute epruinosa, per ætatem margine tenui valde flexuoso angulata vel etiam margine evanido confluentia \& difformia, opaca aterrima; intus unicoloria cinereo-atra, ut discus cum excipulo integro confluere videatur. Hypothallus parum evidens. Crusta sæpius arcolato-verrucosa, sed cum in Suecia meridionali non occurrat, ad infimas prolés persequi non licuit. Cum re ipsa sæpius lapidem rodere videatur, huic nomen maxime vagum Lec. lapicidae, sub quo apud nos passim venit, adscribere volui. Tam ex herbario Auctoris, quam adhuc plenius e multis centuriis speciminum ab ipso quotannis mihi determinatis fingo me ipsius ideam suarum specierum ita accepisse, ut noverim quorsus etiam formas a se non visas retulisset. Lecid. lapicida, Ach. mente, complectetur omnes formas crusta plus minus rimosa albido-cinerascente, apotheciis adpressis minoribus nudis; marginem tenuem \& internam structuram haud adeo stricte sumsit; hinc $\alpha$. Syn. Lich. ad Lecid. fuscoatram $\beta$., L. sabuletorum, L. lapicidam nostram \&c. pertinet; $\not 3$. potissimum ad L. spilotam, $\delta$. ad $L$. albocorulescentem, $\varepsilon$ ad $L$. variegatam; nec prorsus exclusis $L$. atroalba \& $L$. contigua. - Eadem est ratio L. pantostictce, complectentis apothecia majora crustæ adpressa non aut tenuiter marginata, disco-strato carbonaceo haud recepto (misit tamen Schleicher sub hoc nomine L. confluentem Web.) adeoque status Parm. cinereae, potissimum vero $\alpha$ certe Lec. albocoerulescentis. $\gamma$. L. spilotce, $\delta$. L. flexuosa. E descriptione $\beta$. potissimum Parm. cervina, at sit L. badioatra.

267. LECIDEA amphibia, crustæ areolis verrucosis cinerascentibus, hypothalluni obliterantibus, apotheciis areolis immersis plano-convexis 
excipulo immarginato plano suffulciente discum primitus nudum. Fries Vet. Ac. Handl. 1822. p. 263.

Exs. Lich. Suec. n. 362.

In saxis graniticis per dimidium fere annum inundatis ad lacus silvaticos Sueciæ passim copiose.

Expositis jam speciebus primariis transimus ad quasdam insignes quidem habitu \& vegetatione propria, at a loco speciali magis forsan pendentes. Notæ hujus primariæ sunt: Apothecia verrucis semper innata, primo margine thallode cincta, (hoc quidem in multis aliis, ut in re ipsa affini $L$. atroalba obviam venit, at in præsente constans est), sed proprio semper destituta, e plano convexa, opaca, atra, numquam centro papillata; disci basis lividior imposita est excipulo s. strato carbonaceo plano semper immarginato. Crusta areolato-verrucosa, cæsiocinerascens, ut hac ratione etiam sequenti seriei peraffinis. - Ceterum loco definito insignis, adhuc magis tenacitate qua oxidum ferricum repellit, nam sola inter plurimas oxidatas nascens nativum colorem semper servat \& ne dealbata quidem fit, ut crustæ glaucescentes loco simili evadunt. - Apothecia sæpius concentrice disposita, habitus Lecanoræ. Ach.

* LECIDEA nitidula, crusta e glauco albicante,deliquescente amylaceo-tartarea, hypothallum nigrum obtegente, apotheciis ex hypothallo oriundis, excipuli cupularis discreti margine subtenui, disco æquabili primitus nudo. Fries l. c. p. 255. var. deliquescens.

Lecidea petræa v. crustulata. Flotow in Bot. Zeit. 1828. p. 692. optime.

a, crustæ areolis granulosis subglobosis, apotheciis immixtis. Lecid. lapicidoe, e mente Acharii, vulgo adnumerata, a me olim L. atroalboe, \& hæc potissimum Verruc. atroalba. Hoffm. Germ. 2. p. 182.

b. crustæ areolis applanatis subcontiguis. Lecid. parasema saxicola. Ach. et Auct. Lecid. atypea Ach. syn. p. 14.

c. crusta subamylaceo-deliquescente tenui contigua, apotheciis per crustain emergentibus minoribus. Ver- 
rucar. punctata. Hoffm. Germ. p. 192 \& V. punctata \& limitata, quatenus saxicolæ. Lecid. parasema e. crustulata. Ach. syn. p. 18. Lecid. petrææ var. Nonnullis.

id. crusta cum hypothallo confusa fuscescenti-lurida. Lec. holomelæna. Flörk. ex Flotow.

Exs. Lich. Suec. - Flotow.

Ad saxa; a. \& b. ad granitica in pinetomontanis; c. \& d. magis in campestribus in saxis ad terram dispersis, sæpius schistosis \& formationis recentioris, passim copiose.

Hanc sine numero attuli, non quum mihi ignotam J. per totam evolutionis seriem non cognitam fingam, sed cum varia ratione considerari possit. Re ipsa enim omnibus notis evidentioribus cum Lecidea parasema convenit, ut nisi locum natalem morphosinque arborearum aliam, de qua plura sub harum subdivisione, pro differentia in hac tribu habeas, ab illa non distingui possit, nam aliæ, quæ afferuntur, notæ integra formarum serie considerata evanescunt. - Inter saxicolas tanta quoque est affinitas cum Lecid. atroalba, utraque profert formas adeo correspondentes, ut has inter se potius, quasi ex uno fonte ortas, conjungeres. Hinc mihi, ut Flotowio l. c., $L$. atroalbae varietas. Adsunt tamen quædam essentiales differentiæ totam formarum utriusque seriem percurrentes; nempe Lec. nitidulae crusta normalis 'e viridi-glauco albescens, hypothallum tenuiorem vulgo magis obtegens; excipulum evidentius carbonaceum ob basin disci discolorem quasi discretum, margine præcipue in formis evolutis evidenter tenuiori; discus $x-$ quabilis; color quoque apotheciorum in statu normali nitidulus. Variat disco convexo, marginem, in hac specie numquam flexuosum, obtegente. Quoad disci internum colorem abit in duas varietates, alteram strato disci inferiori candido, quæ evidentissima, alter am eodem cinereo-livido. Illa a statione sicciori, hæc ab humidiore pendere mihi visa est. - Plures exstant formæ, bene observante Flotowio, ferroso-oxidatæ, primo intuitu facile a similibus Lec. atroalbae discernendæ. - Quisque suo utatur judicio utrum cum L. parasema, an L. atroalba, immo omnes tres, conjungere mallet; mihi sufficit singularum historiam, quantum fieri potuit, nosse \& formas ad naturæ nutum discernere. 
* Fuscescentes. Crustæ color varie fuscus aut brunneus, sed decolor passim fumosus \& albicans. Apothecia ex hypothallo normaliter oriunda vel areolis confluentibus in crusta detrusa. A regionibus montanis, ubi dominantur, in alpes adscendunt.

Characteribus evidentissimis a priori serie differunt formæ normales, quibus addendum hypothallum harum non tantum magis denudatum ob areolas primitus subdiscretas, sed et per se crassiorem esse, \& facilius in formas dendriticas abire. Sunt vero variæ formæ imperfectæ \& amylaceo-tartareæ decolores non sine difficultate dignoscendæ, hinc species serie adaptata, nec constructa, dispositæ sunt. Hac ratione series quoque geographico respectu maxime simul contigna, incipiens a maxime campestri Lec. albocoerulescente \& Glaucescentibus, per magis montanas Fuscescentes, quarum ultimæ vere alpinæ, adscendit ad Ochroleucas summarum alpium vulgo incolas. Ut status primitivi hypothallini fere omnium specierum, potissimum vero vulgatissimæ $L$. atroal$b a$, considerandæ - hypothallo nunc dendritico Verruc. \& Psora dendritica Hoffm. - Pl. Lich. t. 19. f.4. Lichen dendriticus. Dicks. Crypt. t. 12. f. 1. Engl. Bot. t. 1734. Lecid. Ach. meth. Lecan. fusco-atra $\beta$ Ach. Lich. univ. p. 359. Rhizocarpon asteriscus. Dec. fr. 2. p. 183. Lich. astroideus. Fl. Dan. t. 1352. f. 2. Parmelia. Ach. syn. p. 20\% - \& nunc magis æquabili: Lich. atratus. Engl. Bot. t. 2335. \& demum hypothallo cum thallo in crustam cinerascenti-nigram rimosam confuso, quales status communi nomine Lecid. \& Parm. coracinae Ach. syn. p. 11. Verrucar. Hoffm. Germ. p. 183. Sturm. Germ. c. ic. orti a Lec. atroalba \& fusco-atra, sed Lec. coracina Sommerf. \& Schaer. Exs. n. 182, ipso teste, a Lec. Morione e. s. p. Omnes has incompletas \& degeneratas formas æque ac acrustaceas \&c., a nulla alienas, sub singula annotare superfluum duco, cum optime ex observationibus in locis natalibus dignoscantur.

268. LECIDEA atroalba, crusta subareolata opaca fusca decoloratave, apotheciis ex hypothallo atro oriundis, intus atris, excipulo confluente, margine obtusissimo, disco primitus nudo, demum subpapillato. Ach. syn. p. I I.

In varietate primaria areolæ primitus discretæ verrucæformes, sæpe in hypothallo sparsæ. Lich. atroalbus. 
Linn. et Auct. Wulf. in Jacq. Collect. II. t. 14. f. 1. Engl. Bot. t. 2336. Lecid. Wahl. Suec. n. 1693. Sched. Crit.13.p. 17. Fl. Dan. t. 1850. f. 2. Verruc. fuscoatra. Hoffm. Pl. Lich. t. 54. f.1. Fl. Germ. $p$. 181. cum subjuncta V. cinereo-atra. $l$. $c$. p. 182. Rhizocarpon Confervoides. Dec. Fr. 2. p. 366. Lecid. Schaer. spic. p. 128. - crusta ferro ox ydata: Lich. Öderi. Swartz. - Engl. Bot.t.1117. Ach. - Wahl. Suec. p. 684. Fries Vet. Ac. Handl. 1822. p. 258. Lich. cæsius. Dicks. sec. spec. ex ipsius manu, at non descr. Lecid. Dicks. $\beta$. Ach. Lich. univ.

Exs. Lreh. Suec. n. 40\%, 382. B. C. magis fuscata \& æquabilis, 384 s. d.L. Oderi. - Schaer. Helv.n. 178. Ad saxa præcipue granitica \& micacea a planitiebus in alpes sub iunumeris formis frequensissima; optima in silvis montanis.

Color crustæ ab atro per varias modificationes, exclusis vero viridi-glaucescente, ochroleuco \& citrino, in griseo-albicantem mutatur, ut nomen Linnæanum optime indicat; normalis \& frequentissimus vero est fuscus, plus minus in umbrinum, violaceum, rufescentem $\mathrm{l}$. griseum vergens. Hinc in Germaria vulgo pro Lecid. subfusca habetur; Linnæana vero \& reliquorum Auct. species abunde diversa est. Ceterum areolarum magnitudine, copia \& forma tantopere variat, ut quotcumque optaveris facile separes formas. In hac primaria optimos quidem thallus offert characteres ad hanc speciem a reliquis discernendam, verum in sequentibus varietatibus tot variisque modis mutatur, ut notæ essentiales in apotheciis suam semper faciem servantibus sint quærendæ; observandum tantum colorem semper esse opacum \& stratum crustæ corticale non vere cartilagineum, ut in subsequentibus in statu primario exinde nitentibus. Apothecia ex hypothallo normaliter oriunda semper minuta, quasi constricta, opaca; excipulum cupulare, sed basis ejus l. tenuissima l. omnino evanescens; margo parum discretus, obtusus; discus primitus nudus, per ætatem subumbonatus, rotundatus, numquam applanato-dilatatus, at in formis a $L$. fusco-atra ortis, absque basi discolori, niger. Horum habitu facile ad matrem suam referuntur etiam formæ quoad crustam maxime personatæ, v. c. L. Öderi \& L. petrcea, quarum transitum in $L$. atroalbam sæpe sxpissimeque cum 
Cel. Flotowio vidi evidentissimum. Attamen locis singularibus apothecia quoque mutantur; ubi crusta magis unita \& contigua, per hanc prorumpunt, \& subinde ipsis areolis cinguntur, ut in structura proximis L. geographica \& amphibia, at originem normalem ex hypothallo et in hoc statu indicatur apotheciis valde depressis, nec ut in analogis statibus $L$. contiguce elevatis. Ubi apathecia particulis crustæ insident 1 . locis magis irriguis convexa immarginata fiunt, intus albicant ob stratum carbonaceum distinctum sub disco deficiens. Vidimus quoque raro discum juniorem rufescenti-fuscum, sed siccum nigrum. At magis fallaces sunt formæ e crusta leproso-deliquescente ortæ, quarum plurimas colore diversas, omnes vero ad saxa locis humidis prope terram ortas habemus. Harum primo memoranda L. petraec v. chloromela Flotow, crusta leprosa viridi, passim in griseum aut cinereum abeunte. His in regionibus præcipue obviam venit in pinetis ad lapillos juxta margines viarum, sæpe in consortio cum Lecid. Oderi leprosa, quæ nonnisi colore peregrino differt. De hujus identitate cum $L$. Óderi areolato-verrucosa nemo dubitavit; certum est formam chloromelam alia ratione a $L$. atroalba ipsa non diversam esse. Alia dein occurrit forma crusta leprosa griseo-fusca (quæ Lichen fiuscoater Wulf. in Jacqu. Coll. II. $t_{\text {. }}$ 14. f. 3. Lich. scytropus $A c h$. Prödr.), in qua præcipue apothecia intus infra laminam albicantia visa sunt, sed etiam hujus origo a vulgari $L$. atroalba evidens. Etiam hypothallini status in crustam leprosam nigricantem dissolvi possunt. Licet \& hi status \& supra notati hypothallini non rari sint, ex his omnibus varietates fingere nolui, cum eos atypicos esse mox pateat eorumque origo evidenter accidentalis. Ultimum quidem de sequentibus allatis varietatibus ex parte quoque dici potest, attamen habitu typico magis fallaces sunt, ceterumque proventus copia \& definita vegetationis historia insigniores. De $L$. lactea Fl. vide supra p. 305.

$\beta$. concreta, areolis planiusculis in crustam rimoso-areolatam congestis. Wahl. Lapp. p. 471. Exs. Schaer. Helv. n. 177. Cfr. Lich. Suec. $40 \%$.

Eisdem ac vulgaris locis, at magis ventosis, subalpinis.

Color plerumque fuscescens, sed variat ceterum ut a. - forma albescens a $L$. variegata caute distiuguen- 
da. Ob areolarum formam situmque subcontiguum hypothallus magis obtegitur \& apothecia e crusta, at perperam, enata crederes. Est forma quidem localis, at satis insignis. Lec. coracina hujus speciei ab hac forma oritur, etiam, ut videtur, L. ambiguc Ach. Cfr. p. 305. $\gamma$. murina, crusta cum hypothallo in maculam tenuem levigatam murinam confusa.

Lecid. murina. Ach. Lich. univ. p. 171. Syn. p. 16. Ad saxa, locis subirriguis.

E descriptione in Lich. univ. data \& archetypis Iuculenter patet hanc ad Verr. rupestrers non referendam esse. Apothecia perfecte L. atroalbce, crusta vero in eodem evolutionis statu ac Parm. lacustris v.loevata. Ex Ostrogothia præcipue evidentem misit Petren.

d. lavala, hypothallo obsoleto, crusta tartarea contigua subrimosa alba (aut testacea). Sched. Crit. 13. $p .18$.

Exs. Lich. Suec. n. 383.

Ad litora lacuum Smolandiæ, inque saxis rivuloruin \& paludum copiosissime.

Mixta vulgo crescit cum Lec. contigua v. hydrophila \& Parm. cinerea v. lacustri \& cum eisdem ita concrescens, ut sæpe cujus speciei sit crusta non facile dicas, at apothecia sine discrimine mox distinguunt. Crusta ex hydrate ferroso tincta variat ochracea, testacea \&c. - Lecid. carphina Ach. Lich. univ. p. 15\%, probe distincta a similibus formis Lec. contiguce, inter hanc, $\varepsilon$. $\& \beta$. media est; hujus omnino speciei status.

E. subconcentrica, crusta tartareo-amylacea rimosa alba, apotheciis in crusta impressis \& margine thallode accessorio subcoronatis, sæpe concentricis. Flotow 'l. c.

Verrucar. petræa. Hoffm. Pl. Lich. t. 50. f. 1, 2. Lecid. petræa. $\alpha$. Ach. syn. p. 15. Schaer. spic. p. 137. Patell. Decand. Lich. concentricus. Davies in Transact. Linn. Soc. II. p. 284. Engl. Bot.t. 246. Exs. Schaer. Helv. n. 183. Moug. et Nestl. n. 744. Reichenb. et Schub. n. 148. ex Schaerero.

Ad saxa formationis recentioris \& ad lapillos silaceos aliosque in regionibus formatione juniori fundatis dispersos. 
Equidem cum eximiis viris Flotow \& Stenhammar originem hujus varietatis a Lec. atroalba sæpissime directa via persecutus sum, id quod ex apotheciis simillimis confirmatur; at caveas, ne omne in herbariis sub hoc nomine servatum huc referas; similes elim formæ a $L$. contigua, $L$, nitidula, immo a $L$. fuscoatra, oriuntur. Varietates: b. callistea Ach., ex ab ipso determinato specimine est $L$. contigua, c.nordlandica L. ambigua A. Lichen petraeus Wulf. in Jacq. Coll. III. p. 116. t. 6. f. 2. ex hac grege quidem est, at presenti varietati parum convenit. (Hoffmannum suum a Wulfenio habuisse, ab ipso indicatum non invenio.) Fingo Lec. petraeam Wahl. Suec. n.1704 ad L. contiguam v. calcaream potius pertinere e. s. $\mathrm{p}$.

Sub mixba Lec. lygáa $A c h$. s y n. p. 34. alibique insuper redit. 269. LECIDEA lugubris, crusta areolata opaca subfusca, hypothallum nigrum obtegente, apotheciis e strato corticali oriundis, excipuli margine obtuso, disco primitus nudo æquabili intus cinereo-albo. Sommerf. Lapp. p. 143. Ad saxa \& rupes Norvegiæ. Sornmerfelt! Blytt!

Crustæ natura \& colore opaco lugubri violaceo- aut rufescenti-fusco 1. cinereo-griseo prorsus cum priori convenit (Sommerfelt speciosissimam descripsit formam), at apothecia magis Lec. lapicicloe nostræ, ad quam se fere habet ut Lecid. atroalba ad L. nitidulam, \& si oxidata reperietur, difficile forsan erit distinguere. Crusta areolata, in perfectissimis conglobata areolato-lobata; adsunt vero simul specimina areolis sparsis magis applanatis, in quibus etiam apothecia non inter, sed supra areolas nascuntur, quales status non cum ocellatis prioris formis commutandi sunt. Apothecia primitus nuda, strato corticali areolarum innata, margine quasi ab illo deusto formato!, dein elevata, sessilia, in ambitu libera, demum magis dilatata (etiam flexuosa) quam in $L$. atroalba. Margo obtusus, prominens, persistens. Discus planus, opacus, numquam papillatus, intus albidus 1 . cinerascens, impositus strato fuscescenti, non carbonaceo. Est itaque multis rationibus insignis, \& a typo hujus seriei recedens. 270. LECIDEA pancola, crusta areolis verrucosis griseis \& tuberculis rufescentibus variegata, 
apotheciis ex hypothallo atro oriundis, excipuli cupularis margine obtuso, disco primitus pruinoso æquabili, intus albo.

Lecid. panoola. Ach. syn. p. 38. quoad spec. sterilia, Schaer. spic. p. 130. - L. Dicksoni. Lich.univ. p. 165. ferro oxidata.

Exs. Lich. Stiec. n. 380. Sommerf. Norv. n. 51.

In saxis graniticis \& micaceis in pineto-montanis v. c. Smolandix copiose fertilis, in aliis regionibus plerumque sterilis.

Crusta Lecidea atroalbae proxima videtur, apothecia vero prorsus Lecid. contiguoe. Hypothallus riger, in ambitu saltim evidens, plerumque areolis verrucosis plane obtectus; hæ primitus fusco-rufescentes, mox vero grisex, facile in soredia virescenti-cinerea fatiscentes. Hac ratione saltim convenit sat ambigua $L$. atrofulva Sommerf.! - Areolis immixta sunt tubercula e crusta formata rufescentia, scabrosa, qux ab apotheciis veris probe distinguenda. A pothecia areolis passim circumsepta, at ex hypothallo revera oriunda, $L$. atroalba multo majora evadunt, disco semper plano æquabili aterrimo cæsio-pruinoso, intus, unde excipulum evidens carbonaceum, albo aut cinereo. Margo obtusus, persistens. - His in terris adeo frequens \& constans, ut non potuerim non seorsim proponere. Analogia adest quoque cum Parm. gelida. B. L. obscurata, areolis tenuioribus applanatis subcontiguis fuscescentibus. Schaer. spic. p. 138 . Exs. Schaer. Helv. n. 180.

Ad saxa granitica, micacea \&c. in alpibus.

Certe est præcedentis varietas alpina, recedens ut prioris $\beta$. a $L$. atroalba ipsa, habitu ad $L$. atroalbam v. nurinam simul accedens; locisque similibus subirriguis Lec. panoeolam in hanc abire vidi. Apothecia prorsus eadem, nam pruina in a. non constans est, nec tantum in hac sed etiam L. atroalba \& L.badio-atra discus subinde rufescenti-fusconiger reperitur, at numquam in tribus subsequentibus. Etiam in hujus crusta verrucas prioris rufescentes conspicere licet. Natura \& crustæ \& apotheciorum a sequente utique differt. Ob crustam magis contiguam apothecia ex areolis orta esse videntur. 271. LECIDEA badioatra, crusta areolis applanatis pulposo-tartareis opacis badiis, apotheciis 
ex hypothallo atro oriundis, excipuli cupularis margine tenui, disco plano primitus nudo, intus albo. Schaer. 'spic. p. I 29.

Lecid. incusa, Ach. herb. et mscr. (an vero Synops. p. 33. potius fuerit Parm. cervina, quam sub hoc nomine misit Schleicher, ut descriptio suadet, dubitetur). Fries Syst. Orb. Veg. p. 286. Lecid. badioatra. Flörk. - L. puntosticta. ß̧. Ach. Lich. univ. Exs. Schaer. Helv. n. 129.

Ad saxa, precipue granitica, in alpibus Helveticis, Carinthiæe Laurer! Norvegiæ Blytt!

Media quasi inter Lecid.atroalbam \&. fusco-atram. Dignoscitur ab, illa crustæ areolis opacis quidem, sed magis subpulposis, applanatis, etiam si sparsæ sint (non ni$s i$ in varietatibus concretis L. atroalbse applanantur), $s x-$ pe in crustam rimoso-areolatam congestis, hypothallo minus evidenti, præcipue vero apotheciis majoribus, inter areolas pressis sæpe difformibus, excipulo cupnlari evidenti ob discum planum intus albicantem. A L. fuscoatra differt areolis opacis evidentissimeque tota apotheciorum forma, margine tenui $\&$ interdum parum prominente, disco primitus nudo. Areolæ badix, variant quoque rufofuscæ ad ambitum pallidiores. Discus passim papillatus. Pro vera $V$. fuscoatra Hoffm. misit Laurer. 272. LECIDEA fuscoatra $\alpha$, crustæ areolis cartilagineis applanatis olivaceo-fuscescentibus fuscisve nitidis decoloratisve, apotheciis ex hypothallo nigro oriundis adpressis, excipuli integri plani margine tenui, disco primitus pruinoso, demum tumente. Sched. Crit. i3. p. I9. Lich. fuscoater Linn. et Auctorum, at non Germanorum. Lecidea fiscoatra. Wahl. Lapp. p. 473. Suec. p. 863. Ach. syn. p. 22. (status areolis discretis \& Lecid. fumosa. b. Ib. areolis concretis) Lecan. Ach. Lich. univ. p. 359. Patellaria s. Verrucaria fumosa. Hoffm. - Pl. Lich. t. 49. f. 2. Lecid. Flörk. Berl. Mag. 1809. p. 312. Schaer. spic. p. 134. Lecid. cechumena. Ach. meth. p. 42. - areolis magis convexis. Lichen athrocarpus. Ach. Prodr. - Eingl. Bot. t. 1929. Lecid. Ach. meth. p. 41. Exs. Lich. Suec. 385, 405 (status areolis discretis). Fl. Deutsch. n. 3. Moug. et Nestl. n. 461. 
Ad saxa granitica \& micacea Europæ totius, præcipue in pineto-montanis copiosissima \& fere semper normalis.

Est inter vulgatissimas species facillima in statu normali distinctu crustæ semper areolatæ, maculas plerumque determinatas offerentis, habitu ad Parm. badiam accedente, areolis hypothallo plus minus applanatis, eximie cartilagireis, lævigatis, nitidis, angulatis, in ambitu passim elevatis, immo incisis, marginatis albidis. Colore castaneo, olivaceo-fusco \& fuliginoso variat. At in statu exoleto nitorem \& cartilagineam indolem amittit, varietatumque color expallescit; hinc essentiales differentix in apotheciis quærendæ, diversis ab omni $\boldsymbol{L}$. contigua, cum qua strato eximio carbonaceo sub disco convenit. Apothecia ad majora affinium pertinent, inter vel in ipsis areolis depressa, plana, per ætatem vero tument, magis elevata \& convexa, marginem semper tenuem subacutum per xtatem flexuosum reprimentia, sæpe valde congesta \& e pluribus minoribus quasi fasciculata, ut Verruc. fasciculatam Hoffm. Germ. p.190, pro certo quidem non determinandam, huic vero ab Auctore proxime collocatam, huc non male retulisse videatur Acharius. Discus pro ratione tenuis, subnitens, primitus vero cinereopruinosus, dein nudus, intus cinerascens aut lividus, strato distincto crasso planiusculo carbonaceo impositus. Specimen $L$. daphoence $\alpha$. in Herb. Ach. hujus ferro oxydatæ faciem habet; e descriptione vero potius ad $L$. atrobrunneam aut $L$. armeniacam forsan referenda.

p. tessulata, crusta areolis confertis gibbis, hypothallum obtegentibus pallescentibus, apotheciis immixtis subconvexis, intus albidioribus.

Exs. Fl. Deutsch. n. 64. Lecid. tessulata.

Ad saxa arenaria aliaque formationis recentioris.

Cum archetypo Flörkeano 1. c. satis convenit Lec. fuscoatrae status, in Scania v. c. in schistosis ad Löddeström obvius; qui certissime prioris status campestris ad saxa laxiora natus. Differt tantum colore pallescente, vix "albo" dicendo \& quoad interiorem disci colorem ut Lecid. platycarpa a $L$. contigua, nam areolarum forma $\&$ apotheciorum situs in $\alpha$. similes passim occurrunt. $\gamma$. subcontigua, crustre areolis stipatis subconti- 
guis cinerascenti-fuscis, apotheciis ex hypothallo oriundis depressis convexis. Fl.Dan. 1350. f. 2 . Cfr. sq. b.

Ad saxa precipue formationis recentioris.

Fallacissima est, crustæ indole subtartarea simul, immo passim amylacea, sed originem a vulgari vidimus evidentem.

A Lecid.variegata præcipue caute distinguenda est. Exstat enim insuper forma grisea e multorum sententia vera Verruc. contigua s. Lecid. contigua; speciatim L. lapicida Flotowii, ipso teste a L.fumosa orta, huc referenda est.

* LECIDEA confluens, crusta rimoso-areolata opaca cinerascenti-fumosa, hypothallum nigrum obtegente, apotheciis e crusta oriundis adpressis subcontiguis, excipuli carbonacei margine demisso obtusiusculo, disco semper nudo aterrimo, intus cinerascente. Schaer. spic. p. 144.

a. crusta cartilaginea, areolato-rimosa, fumoso-cinerea albidaque. Lecid. fumosa $A c h . m e t h . p .41$ h. I.

b. crusta tartarea crassiori magis contigna rimulosa fumosa fuscescente. - ? Lich. confluers. We eb. spic. p. 180. $t$. 2. Engl. Bot. t. 1964. Verrucar. Hoffm. Pl. Lich. t. 19. f. 1. Patell. Dec. fr. Lecid. confluens Auct. (ex p. tantum Acharii!) - fide Schaereri l. c. Fl. Dan. t. 1431. 2. oxidata.

Exs. Schaer. Helv. n. 187. Moug. Nestl. n. 463. Ad saxa varia, vix autem calcarea, in regionibus montanis \& b. in alpibus.

Summa cum præcedente affinitas, præcipue si hujus statum primitivum epidermide adhuc cartilaginea \& præcedentem in statu expallente comparaveris. Cel. Meyer pro ejus statu alpino habet. Exstare vero differentiam primitivam urget Schaerer, e recepta Meyeri sententia in Schaereri abit Flotow; mihi haud satis contigit has in natura sequi. Differt crustæ areolis vix discretis, semper opacis, apotheciis e crusta evidenter oriundis minoribus, semper planis, marginatis, jam primitus nudis, disco aterrimo opaco, unde margo (obtusior demissus persistens) dilutior apparet. Cfr. ceter. Lecid. polycarpam, quæ exacte similia, profert apothecia, sed defectu strati carbonacei sub disco differt, nec apothecia adeo frequenter 
confluentia, qux hújus speciei insignem præbent characterem, nam in hoc statu ipsa etiam plana \& margines persistunt, unde apothecia multilocularia.

273 . LECIDEA atrobrunnea, thalli areolis cartilagineis squamulosis rufo-cupreis nitidis, apotheciis ex hypothallo atro areolisve oriundis, excipuli annularis margine subtenui, disco primitus nudo æquabili. Schaer. spic. p. 134 . Rhizocarpon atrobrunneum. Dec. fr. 2. p.367. Lecid. Dufour! Lecid. cechumena. Ach. pr. p. at mox cum priori confudit. Schaer. Naturw. Anzeig. Aug. 1818. p. 10. Lich. cechumenus. Engl. Bot. t. 1830? ex Schaerer.

Exs. Flotow. Siles.

Ad saxa granitica \& micacea montium \& alpium Europæ præcipue mediæ $\&$ australis, ut in Pyrenæis Dufour! Montagne!, Helvetiæ Schleicher!, Sudetis Mosig!, in convalles raro descendens \&c. In Scandinavia non vidimus.

Specimina e diversis regionibus admodum similia, habitu præcedentis, sed adhuc magis speciosa; ab illa excipulo prorsus annulari, quare lamina strato thallode albo recepta, luculenter differt. Hypothallus, ubi insignior, intus albus, ut in duabus sequentibus. Areolæ squamulas referunt, mox turgidx, læves, brunneæ ad ambitum sæpe pallentes. Apothecia plana, dein tumida, margine potius tenui, quam crasso, demum flexuoso. Quando areolæ totum hypothallum obtegunt, illis insident apothecia magis congesta.

274. LECIDEA Morio, crustæ areolis verrucosis nitidis flavo-cupreis, ambitus radiantibus, apotheciis ex hypothallo crasso determinato atro oriundis, margine tenui, disco primitus nudo intus atro. Schaer. spic. p. 133 .

Rhizocarpon Morio. Dec. fr. 2. p.366. Lecid. Dufour!

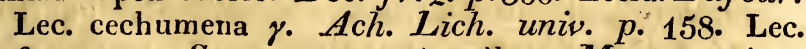
fumosa. c. Syn. p. 13. - * pallens. Montagne!

Exs. Flotow Sil.

Ad saxa granitica aliaque formationis primitivæ in summis alpibus Europæ facile totius. 
In statn normali \& integro pulcherrima. Hypothallas insignior, quam in ulla forsan alia, vere crustaceus, in ambitu determinatus \& sublobatus. Areolæ discretæ, ex magna parte hypothallo immersæ, sæpe nigro-marginatæ, nitidæ; in centro verrucosæ, versus ambitum in perfectis pulchre plicato-radiosæ; peculiari flavido aut armeniaco in eupreum vergente colore. Apothecia semper minuta, depressa, areolas haud superantia, semper nuda, plana, intus unicoloria, quare stratum sub disco non discretum discernitur; per ætatem gyroso-plicata. - Ut loco ad summas alpes constricto, sic colore ad sequentem seriem accedit; vidimusque sequentis specimina diminuta valde similia, at quoad apotheciorum structuram $L$. atrobrunnea magis ad $L$. armeniacam accedit. Analogæ sunt $L$. variegata \& "fimbriata." Schaer.

ק. L. coracina, crusta ex hypothallo predominante cinerascenti-nigra. Schaer. $l$. c.

Lec. coracina. Auct. ex p. Sommerf: Lapp. p. 142. Exs. Schaer. Helv. n. 182. ipso teste.

E rupibus alpinis ad subalpinas etiam descendit.

Quamvis præcedentes similes status atypicos, non separatos, proferant, hujus unius distinximus, cum \& per se insignior sit ceterarumque celebratior \& sæpe extra prioris regionem occurrat. Caute vere determinanda, ne priorum status immisceantur; ab omni coracina a $L$. atroalba orta dignoscitur margine tenuissimo.

*** Ochroleucce. Color pallide flavovirens, subarmeniacus 1. ochroleuco-pallescens. Apothecia e crusta oriunda. Summarum alpium juga inhabitant.

Præter differentiam hanc primitivam hujus species analogis præcedentium serierum ita respondent, ut differentias vix detegas. Hypothallus a crusta plerumque prorsus obtegitur \& in quibusdam rarius tantum conspicuus est.

275 . LECIDEA armeniaca, crustre areolis primitus discretis ochroleuco-armeniacis hypothallum nigrum subobtegentibus, apotheciis ex areolis oriundis adpressis maculæeformibus subimmarginatis, sub disco primilus nudo albis. Fries Syst. Orb. Veg. I. p. 286.

Rhizocarpon armeniacum. $D \in \epsilon . f r .2 . p .366$. Lecidea: 
Dufour. - Schaer. spic. p. 126. Flotow. in Bot. Zeit. 1828. p. 698. Lecid. viridi-atra. Ach. syn. p. 21. Lecid. spectabilis Flörke.

Exs. Schaer. Helv. n. 174.

Ad saxa granitica \& micacea summarum alpium Europæ totius, exceptis ne quidem Britannicis, at in septentrione admodum rarescens; in Gousta aliisque Norvegia australioris alpibus tamen insignis. Blytt!

Maxime spectabilis \& admodum varia, tam statura quan crusta colore, non male a Flotowio cum Parmelice ventosae comparato, in diversis regionibus diverso, in genere pro more hujus seriei versus meridiem intensiori, versus septentrionem pallescente. Vulgo colore druparum Pruni armeniacae gaudet, e viridi sordide ochroleuco, siccitate vero sæpe obscurior fit, testaceus \& rufescens. - Rupinulam misit optimus Dufour in qua ab infimo statu evolutionis seriem sequi licuit. In infimo statu ad Leczd. coracinam Auct. referenda esset; areolis primum discretis prodeuntibus Lec. Morionem refert, optime evoluta habitum offert proprium, areolis sparsis aut confertis in hypothallo determinato crasso, passim in ambitu effigurato, intus albo. Sæe autem hypothallus tenuior \& ab areolis plane obtectus; in aliis in hypothallo immersæ sunt areolæ eumque vix superant; immo vidimus hujus statum pro Lecidea daphoena habendum. Areolæ inæquales, per ætatem plicato-rugosæ, versus ambitum haud effiguratæ. Apothecia areolis innata, maxima fere generis, semper nuda, juniora tenuiora maculæformia plana, adultiora confluentia, turgida, vulgo prorsus immarginata, at e Pyrenæis itidem marginata, magis regularia vidimus. Discus intus similaris ater, absque stratis distinctis, quare a substantia thalli alba receptus videtur.

p. L. nigrita, areolis obscurioribus nitidis atromaculatis, apotheciis paulo minoribus. Schaer. l. $c$.

Exs. Schaer. Helv. n. 175.

Cum $\alpha_{0}$ in Pyrenæis Montagne! Vogesis Mougeot! Helvetia Shaerer!

$\gamma$ : $L$. melaleuca, areolis magis superficialibus spar$\mathrm{s}$ is pallescente-ochroleucis. Sommerf. Lapp.p. 148. 
In summis alpibus Nordlandiæ. Sommerfelt!

Insignis hypothallo crasso coerulescenti-nigro, intus stuppeo albo (eundem tamen et in a. vidimus), per lata intervalla nudo \& colore areolarum magis discretarum pallescente, at certissime hujus speciei varietas.

276 . LECIDEA aglaea, crusta areolato-verrucosa ochroleuco-pallescente, hypothallum nigrum obtegente, apotheciis areolis innatis subimmarginatis, disco primitus nudo convexo, intus cinerascente, strato tenui carbonaceo recepto. Summerf. Lapp. p. 144.

In alpibus maritimis Nordlandia vo c. ad Bodöe Sommerfelt!

Re ipsa præcedenti valde affinis, præcipue diversa disco intus cinerascente, sed stratum carbonaceum discretum non conspicitur, ceterum eadem apotheciorum forma, situs, structura. In junioribus margo tenuissimus conspicitur. $\mathrm{Ob}$ areolas confertas, turgidas, primo læves, demum prioris modo plicato-rugosas hypothallus magis obtegitur. Color fere prioris $\gamma_{\text {. }}$, pallescenti-nitidus. Structura apotheciorum præcipue comparanda est cum I.variegata, nam stratum carbonaceum haud adeo evidens ac in L. contigua $\beta$. \& fuscoatræe varr. sed longe politior est \& pulchrior. Non est Lecid. ochrochlora. Ach. syn. p. 23. s. L. confluens. $\delta$. Lich. univ.

Nominata stirps ex errore orta, nempe ad exemplaria L.nitidula mutilata, thallo fere deperdito et quisquiliis inquinâto, ut ex herbario ipsius determinatoris perspexi. In Synopsi, e P. albozona. ri a Fl. Fr., eidem tribuitur erusta flavoviridis, sed genuina P. albozon a ri a est stirps e L. paraseme grege ad librum arborum obvia. Plurima quoque a D ufour, Mont a gne etc. possideo s. d. P. a lbozon a ri a specimina in saxis nata, sed omnia thallo fere deperdito, apoth in suxo sessilibus, qualia prior eniti nequit, ad L. contig u am b. referendia. Est itaque prorsus delenda, P. albozonaria etiam cum $L$. a $\boldsymbol{t} \boldsymbol{r}$ a conferatur.

277. LECIDEA marginala, crusta rimoso-areolaLa flavicante-ochroleuca, hypothallum nigrum obtegente, apotheciis e crusta oriundis liberis, intus albis, excipuli annularis margine obtuso, disco primitus nudo. Schaer. spic. p. 146.

Lecid. pantosticta. 8. viridana. Lich. univ. p. 154. Lec. flexuosa, Fries Syst. Orb. Veg. I. p. 286. 
Exs. Schaer. Helv. n. 189.

Ad saxa granitica summarum Alpium Helvetia Schaerer! Sudetorum Mosig herb. Ach.

Hypothallus niger, evidens, præcipue ad ambitum crustæ, quæ maculas efficit minores, primitus contiguas, dein areolato-rimosas crassiusculas, in superficie verruculoso-inæquabiles, haud vero plicato-rugosas ut in præcedentibus. Color e pallide sulphureo in albidum abit. Apothecia ad Lec. spilotoe proxime accedunt, at magis elevato-superficialia \& nuda. Margo validus \& flexuosus, in tumentibus vero evanescens, ut nomen nostrum fere servandum, nisi nomina exsiccatorum auctoritate classica, étiam si recentiora, præferenda viderentur. Re ipsa adest analogia inter quattuor istas species, quas sub totidem varietatibus Lec. pantostictæ proprie intelligit Achajius, nempe $\alpha$. Lec. albocoerulescens, $\beta$. L. badioatra, $\gamma \cdot$ L. spilota. $\delta . L$. marginata; sub hac in Syn. addita forma vaga \& quisquiliaris Lec. lapicida $\vartheta$. illuta Lich. univ, p. 160 excludenda est.

= Lecid. fímbriata Schleich. in hac regione quoque facile quæritur, sed areolas habet discretas nigrofimbriatas versus ambitum radiato-effiguratas totumque habitum Parm. oreince, it ab eadem distinguere non ausim. Est hrc Lec. fimbriata. Schaer. spic. p. 126.

278. LECIDEA glacialis, crusta contigua rimulosa ochroleuca, hypothallum nigrum obtegente, apotheciis e crusta oriundis innatis intus albis, excipuli annularis margine demisso subcoronato, disco cæsio pruinoso. Schaer. spic. p. 147.

Ad saxa granitica in alpibus summis Helveticis Schleicher!, Pyrenaicis Dufour!

"Crusta crassiuscula, æquabilis, rimulis tenuissimis in areolas divisa, atra linea limitata, colore pallide armeniaco. Apothecia satis magna, frequentissima, ab initio puncta in una areola plura, crustr impressa, concava, mox superficie sua eminent plana, margine proprio a thatlo coronato, tandem libero \& flexuoso, serius tumescunt \& confluunt. Color eorum ater, pruina cæsia suffusus, intus sub lamina tenuissima alba sunt. Habitus Lecanoroe glaucomae" Schaer. 1. c., a qua hypothallo nigro diversa est, sed an ab eadem tribu separari debeat in medio relinquimus. Tanta est speciminis Schleicheri con- 
venientia cum speciminibus Lec. elatce Schaer. spic. p. 137 ab ipso, ut hanc statum esse L. glacialis amylaceum ad alpes calcareas facile credam. Et Parmelice sordidce exstat forma crusta amylacea, apotheciis nigricantibus nudis pro $L$. amylacea facile habenda!

279. LECIDEA biformis, crusta contigua rimulosa virescenti-flavida, hypothallum obliterante, apotheciis crustæ adnatis nudis planis marginatis, demum convexis immarginatis, intus albis linea tenuissima nigra a crusta discretis. Dec. Fr. 2. p. 353. Patellaria.

Lec. atrosulphurea. Sommerf. ex specim. - Lecid. alpina. Schaer. spic. p. 147. ex descript., ad unicum specimen facta, in formam primitivam omnino quadrante.

In rupibus alpinis Pyrenæorum! Norvegiæ! an et Helvetix? rarior.

Hypothallum in hac specie non vidi, at e crustæ habitu ad tribum Areolatarum pertinet. Crusta tartarea, nec cartilaginea, normalis tamen, effusa, contigua, passim rimulosa, indeterminata, haud admodum crassa, ochroleuca aut flavovirens. Apothecia e crusta oriunda, primo adpressa, plana, margine obtuso \& demisso, intus fere nigra, adulta vero turgida, semiglobosa, albida, ex habitu e crusta quasi formata, sed sub disco intus pallido ducta est linea tenuissima nigra hunc a crusta distinguens. 280. LECIDE $\Lambda$ protrusa, crusta primitus contigua mox rimoso-areolata sulphureo-pallescente, hypothallum obliterante, apotheciis e crusta prorumpentibus subglobosis intus nigris, excipuli cupularis margine obtuso primitus coarctato, disco nudo, demum subplicato.

In rupibus alpinis Helvetix. Schleicher!

Apothecia ad Lecid. atroalbce proxime accedunt, sed adhuc magis quam hujus varietatis petroea primitus coarctata globulosa, fere clausa!, nec umquam thallo coronantur, sed e crusta protruduntur libera. Crusta effusa eximie cartilaginea, primitus contigua, mox rimose areolata, inæquabilis, sulphureo-pallescens, nunc late confluens, nunc in pulvinulos minutos inæquales conglomerata, intus basi subfloccosa alba (forte ex hypothalli su- 
perficie nigra destructa, nam simile vidimus in L.armeniaca \&c.) Apothecia pusilla, e crusta crassiori prorumpentia, mox cupulari-aperta \& persistentia, margine obtuso persistente, disco nudo, passim inæquabili \& plicato-gyroso; intus unicoloria nigra.

Pro hujus statu amylaceo dealbato haberem Lecid. petroeam d. globulatam Ach. Lich. univ. p. 156, nisi nimis diversa specimina sub hoc nomine venderentur.

Lecid. petræam Ach. Lich. univ. p. 155., respectis magis Auctoris speciei idea, descriptione \& locis natalibus, quam synonymis \& speciminibus passim denominatis \& determinatis, sequenti modo optime resolvendam fingo: Var. $\alpha_{0}=$ Lec. atroalba; $\beta$. = Lec. contigua; $\gamma_{.}=L_{0}$ pancola $\beta . ; \delta .=$ Lec. protrusa; $\varepsilon$. in cote $=$ Lecid. nitidula $;$ in saxis alpinis = Lecid. ambiguae status, qui Lec. petrxa Wahl. Fl. Lapp. Vide sub n.264. Ad lapillos prope terram, aqua pluviali sape suffusos, obviam venit forma pusilla Pa rm. vari a apoth. nigris, deformatis, rugosis (Le cid. sordid a. Chev. p. 564.) cum L. fi mb r i a ta P. oreina analogia, forsan h. l. querenda. Cfr. quoque Parm. n. 137.

${ }_{* * \star \star}$ Citrinoe. Crusta nativa lutea, passim vero decolor. Ab alpibus, ubi optime luxuriant, vulgatissima species etiam in planities descendit.

Series citrina in cinerascentem colorem facile vulgo abit \& hinc ad Glaucescentium revertitur, - sæpe inter has, ut inter fuscas \& ochroleucas, major videtur affinitas. Etiam hujus seriei species formam coracinam enituntur, eamque magis denigratam quam priorum.

281. LECIDEA superficialis, crustæ areolis confertis luteis, hypothallum nigrum obtegentibus, apotheciis in crusta sessilibus excipuli annularis margine obtuso, sub disco nudo albis. Schaer. spic. p. 125.

In saxis micaceis montis St. Bernhard.

"Hypothallus tenuissimus, ater, areolis distinguitur in crustam rimoso-areolatam congestis Iuteis, quarum superficiei apothecia insident mediæ magnitudinis, orbiculata, plana, margine crassiusculo prominente, subtus ad ambitum fere libera, atra, sub lamina satis crassa alba, subiculo carbonaceo nullo (discreto saltim) instructa." Schaerer. Specimen tantum incompletum vidi. Vegetatio hujus \& proximarum iu natura plenius observanda.

282. LECIDEA theiodes, crusta rimoso-areolata 
sulphurea, hypothallum nigrum obtegente, 'apotheciis innatis, excipuli annularis margine tenui, disco primitus cæsio pruinoso intus cinereo, strato fusco recepto. Sommerf.Lapp.p. I 45.

In saxis inferalpinis Nordlandia. Sommerfelt!

Ad typum L. spilotoe quoque formata, sed stratum sub disco fuscum, nunc tenue, nunc crassius, in illa accidentale, in hac constans videtur. Areolæ rugoso-granulatæ, quasi e pluribus granulis connatis conflatæ, sulphureæ, sed opacæ. Apothecia majuscula, depressa, margine persistente, demum flexuoso-crispato, disco plano e pruina tenui cærulescenti-nigro.

283. LECIDEA alpestris, crustæ areolis flavis demum pallescentibus pruinosis, apotheciis ex hypothallo nigro oriundis, margine obtuso, disco nudo intus cinerascente, strato crașso carbonaceo recepto.! micacea.

In alpibus Scandinavia ad saxa granitico-

Quoad apothecia a sequente differt, ut Lecid. contigua, cum cujus apotheciis præsentis prorsus analoga videntur, licet pruinosa non viderim, a Lecid. atroalba; illa sequentis duplo l. triplo ipsisque areolis multo majora, easque longe superantia, neutiquam inter areolas depressa, juniora plana, margine elevato crasso cincta; dein vero turgida, hemisphærica, immarginata ; discus intus cinerascens, excipulo crasso carbonaceo primo plano-cupulari, dein hemisphærico receptus. Areolæ multæ in hypothallo innatæ persistunt, cinerascentes, unde hic crassus \& rimoso-inæquabilis, rite evolutæ simplices, sparsæ, subrotundæ, convexæ, læves, ob pruinam in adultis tegentem pallido-, detritæ vero læte flavæ. Videtur sub $L$. atroviridi var. alpicola latuisse, sed tam ab illa in Schaer. exs. $n .173$ quam a forma expallescente conglomerata sequentis locis udis obvia perquam diversa.

De hac aliisque minus copiose observatis observandum easdem versiformes esse; ad typum vulgatiorum magis mutari. Differentiam potissimum indicant apothecia.

284. LECIDEA geographica, crustæ areolis subconfluentibus nitide luteis, apotheciis ex hypo- 
thallo atro oriundis intus nigricantibus, excipuli cupularis confluentis margine tenui, disco nudo. Schaer. spic. $p$. 124 .

Rhizocarpon Dec. Fr. 2. Lec. atrovirens. Ach.

a. atrovirens, areolis verrucæformibus in hypothallo perspicuo sæpius sparsis, apotheciis immixtis l. * in areolis immersis. Lich. atrovirens. Auct. -Wulf. in Jacqu. Coll. II. p. 186. t. 14. f. 2. Verrucar. Hoffim. Pl. Lich. t. 17. f. 4 .

Exs. Lich. Suec, n. 386. Moug.n.640.- * Flörk. 63. b. contigıla, areolis applanatis in crustam subcontiguam rimosam confluentibus, apotheciis detrusis. Dill. musc. t. 18. $f .5$. L. geographicus. Linn. et Auct. Verruc. Hoffm. l. c. t. 53. f. 6, 54. f. 2 .

Exs. Flörk. n. 62. Schaer. n. 172. Moug. l. c. b.

c. alpicola, areolis applanatis, e pluribus" coalitis majoribus, subrugosis, hypothallum interrupte obtegentibus, apotheciis innatis. Schaer. l. c.

Exs. Schaer. Helv. n. 173.

d. pulverulenta, areolis discretis albopulverulentis.

e. conglomerata, crusta leproso-granulata conglobata pallescente. L. atrovirens. $\beta$. alpicola. Wahlenb. Ad saxa granitica \& micacea Europæ totius, copiose. b.) pracipue in ventosis campestribus \& scopulis marinis; c. in alpibus; $d$. in saxis calcareis; e. ad rupes udas.

Color lætior \& nitidior quam in præcedentibus, e virescenti sæpe in intense luteum abit. Quoad crustæ figuram variat ut analoga $L$. atroalba, nec magis hujus varietates a se invicem discrepant quam formæ allatæ $L$. geographicce. Apothecia crustam vix umquam superant sive discreta inter areolas, tum plerumque angulosa, sive in areolis,' plerumque confluentibus, immersa. Vulgo plana sunt, numquam centro papillato, intus tota nigricantia, at passim discum intus lividiorem quoque discernere licet. $\mathrm{Ab}$ his vero maxime aberrant apothecia var. viridi-atrae Flörk., quæ magis protuberant sphærica, hypothallo quoque obsoleto magis, quam quidem in $L$. $a$ troalba frequenter parasiticam vidi, at non vere transeuntem. Analoga Lecid. atroalba etiam similem profert formam. - Admodum illustrans in Lecidearum historia est hujus var. urceolata Schaer. crusta levigata, apotheciis urceolatis, ore contracto pallidiori, immo mar- 
gine thallode instructa. Detexit ille in alpibus Helveticis; nos in Hallandix maritimis legimus. Est in hoc statu prorsus analoga cum Lecid. ambigua Ach. (Lec.petrae Wahl. Lapp.), quam exinde ad Lecid. atroalbam referam! Porro Lecid. variegata similem enititur statum, quæ omnes tres in statu ferro oxydato adeo similes, ut tantum in locis natalibus discerni possint, quare Lec.melanophoea Fr. \& Urceolaria Öderi Schaer. exs. n. 123. Spic. p. 69. (exclus. vero omnibus synonymis) pro omnium harum collectivo haberi debet. Pro illa \& Lec.variegatam \& L. geographicam distribui; Schaereri L. atroalbam \& geographicam potius complectitur. Nomen servavimus, duce Schaerero, antiquissimum Dillenï; recentius atrovirentis L. minus certum est.

L. atra, tartarea, tenuis, rugosa, inaquabilis, pollide citrino-cinerea, apoth. planis nudis marginatis, demun turgidis immarginatis Clem. Ens. Vid.p. 296 L. melambola Syn. L. p. 23 ex fidis exemplaribus mihi haud nota, et ob matrem, saxa arenaria, valde dubia. Similem ipse semel singulari situ (quod idem fere ac numquam) legi ad saxa friabilia, at crusta keprosi, minime stutum nativum aut genuinum sistens.

** Corticoliè. Cfr. p. 294.

Quatenus hæc differentia primitiva \& absoluta sit in medio lubentissime relinquo, at ad formas rite \& definite distinguendas in presenti necessaria est, nisi conjungerem sensu recepto diversissima v. c. Lecid.atroalbam \& L.parasemam. Confirmare videntur analogæ Verrucariæ $\&$ omnes præcedentis sectionis species tam bene evolutæ ut confusioni non sint subjectæ, nam priscorum tentamen cum Lecid. albocoerulescente, Lecid. fuscoatra \&c. etiam formas arboreas conjungendi omnes jam deseruimus. At licet acutæ differentiæ in quovis statu palpabiles deesse videantur, vegetationis historia longe alia. Primo discus numquam, nisi e sporidiis obscuris, pruinosus. Porro crustæ evolutio alia, hypophlocades vulgo, \& deliquescendo tota abit in lepram laxam, nec priorum crustam amylaceam. Quod hypothallus in formas dendriticas non abeat, a matricis indole pendet, at in his semper coætaneus est cum crusta, nec ut priorum præcox, quare vulgo in corticolis obscurior, numquam solus obvius. Denique crustæ color variat cinereus \& e viridi flavus (an hic typicus, ut soredia passim lutea $=$ Spiloma xanthostigma Ach. ex Laurer, quxstio est a nostro scopo nimis aliena), ex quo facile concludetur, hanc differentiam in procedentibus incertam esse, at neglectis formis 
spurie tinctis diversa vegetatio \& geographica specierum dispositio contrarium suaserunt. Alia esset ratio, si plene evidens \& perspicua esset diversorum colorum caussa, ut coloris ferruginosi \& candidi; at in præsenti parum prodest ex theoretico principio Lec. geographicam pro forma luteo coloratæ L. atroalbae habere e. s. p. Quamvis pellicientes ejusmodi explicationes sint, major est resignatio ab eis desistere \& magis laboriosam passivam nature scrutationem sequi. Minime improbo alteram viam, ipse ut indicem sub observationibus summi ponderis censeo, at maxime caveat tiro, ne in illam ingrediatur, priusquam omnes formas in natura rite observaverit, ne in perenni confusione versetur. Est in scientiis, ubi vivunt, esotericum quoddam, quod non quovis tempore, tantum successiva evolutione exotericum \& catholicum fieri potest. - Non Achariurn fugit colorem ferruginosum \&c. (peregrinum esse primus monuit Smith. Transact. L. Soc. II. p. 11.) ab oxido ferri pendere, omnesque mechanice tinctas ad suas species reduxit; at non definite sibi fixerat, utrum species naturæ ideæ, an a chemismo pendeant - \& qui hoc adhuc crédunt, illas distinguere debent.

285. LECIDEA premnea, crusta glaucescente, deliquescendo leprosa, hypothallum obliterante, apotheciis elevatis, excipuli cupularis nitidi margine obtuso, disco corneo obsolete atropruinoso, intus albo. Ach. Lich. univ. p. ${ }_{7} 3,67$.

L. premnea. Fries Vet. Ac. Handl. 1822.p. 260. Patell. leucoplaca. Dec. Fr. 2. p. 347. Lecid. :Chev. par. p. 572.

Exs. Lich. Suec. n. 26.

Ad cortices arborum Europæ occidentalis passim, optima in Fraxino.

Quoad apothecia $L$. contiguam refert (cum $L$. platycarpa conjuncta fuit), sed crusta corticolarum \& disco numquam glauco-pruinoso, sed passim adeo atro-pruinoso, ut Calicium referat, differt. Potius cum L. parasema comparanda, a qua distat ut $L$. contigua a nitidula; dignoscitur apotheciis magis elevatis \& liberis crassioribus, strato carbonaceo magis discreto margine tumido \& nitido, disco ob pruinam, vulgo innatam quasi, admodum opaco. Numquam in hanc abire eam vidi $\&$ semper 
plagas a prima infantia distinctas occupat. Rarissime lineis nigris circumscribitur.

286. LECIDEA parasema, crusta subleprosa glaucescente, ab hypothallo nigro sublimitata, apotheciis sessilibus, excipuli cupularis margine tenui, disco corneo nudo aterrimo.

Dill. musc. t. 18. $f$. 3. Lich. sanguinarius Auct. Vet. - Hoffm. en. Lich. t. 5. f. 3-5. Wulf. in Jacq. Coll. III. t. 5. f. 3.b. Lich. limitatus. Scopol. - Verruc. punctata. Hoffm. Germ. 2. p. 192. cum var. limitata \& guttata ex parte. Lich. parasemus Ach. Prodr. - Lecid. parasema \& tersa. Ach.syn.p.17, 27. Wahl. Suec. n. 1686. Patell. Dec. Fr. Lecid. punctata. Flörk. in Schrad. Journ. IV. I. p. 34. corticola. Lecid. Lightfootii. Engl. Bot. t.1451. sec. spec.

Exs. Lich. Suec. n. 215, 216. A-C. Schaer. Helv. n. 197-199. Flörk. n. 81. (Moug. et Nestl. n.841. acrustacea).

b. apotheciis convexis, subimmarginatis. Lich. Suec. l. c. $I$.

* flavida, crusta lutea. Patell. albozonaria. Dec. Fr. 2. $p$. 348. vera, ex qua color crustæ descriptus est; saxicola acrustacea, secundum multa, quæ vidi, specimina. Plene h. l. Lecid. ochrochlora. Chev. par. p. 571 .

** areolata Duf. hypothallo insigniori nigro, crusta areolata, apotheciis ex hypothallo oriundis.

Per omnem Europam vulgatissima, rarescens vero in maritimis occidentalibus, ubi sequens vulgo substituitur, optima ad cortices, degener ad ligna \&c.

Species licet notissima \& vulgatissima, caute inquirenda, nam nullum vidi Lichenem tot peregrinis formis conspurcatum; fingere videntur Auctores hujus loci esse omnia apothecia nigra acrustacea l. crusta tenui in cortice 1. ligno obvia, nulla ratione habita status primitivi \& normalis. Hinc forsan equidem justo angustius limitavi, at melius est decadem formarum negligere, quam unam peregrinam addere. Præcipue commutantur B. vernalis denigrata (Lecid. dolosa Ach.), Lec. sabuletorum (Patell. glomerulosa Decand. observante Meyer, at cum L. para- 
sema b. etiam rugosa obviam veniat, var. rugulosam Ach. h. I. relinquere possumus), Biat. anomala (Schaer. Helv. n. 200?), ut proximas taceam. Crusta in arboribus e tenerrima arborum pellicula lepram continente primo membranacea apparet, adultior verrucoso-areolata, ad ligna sæpius leprosa. Apothecia opaca, extus intus nigra, nec humectata decolorantia, magnitudine admodum variant, a puncti ad 2 lineas, ut punctatce nomen parum conveniat, etiam cum fons fuerit confusionis formarum punctiformium diversissimi originis. Discus minutorum apotheciorum intus unicolor niger apparet, adultiorum basis lividi-cinerea, \& in varietate ad priorem accedente omnino alba. - Ad ligna desideratur hypothallus. Forte Lecid. nitidula hujus forma saxicola, quam cfr. ** habitum L. atroalba omnino præ se fert. Patell. myriocarpa Dec. Fr. 2. p. 346, in cavis arboribus obvia, ut e loco patet, status degener, potissimum ad $L$. milliariam spectat. Similes habemus plurimos, sed $\boldsymbol{L}$. punctata $\zeta$ Schaer. e speciminibus nostris alienæ originis est.

Crusta hujus et L. sanguinaria, ut ctiam Parmel. palleseentis, steriles et leproso-diffluentes Lepraria m alba m sistunt. Ubi simul adsunt apoth. vera L. parasema, optimam sistunt $L$. a lb a m Flörk. - Ach. syn. p. 24.j sope vero etiam in alienis crustis parasitantur.

287. LECIDEA enteroleuca, crusta primitus contigua glaucescente, deliquescendo leprosa, hypothallo nigro sublimitata, apotheciis adnatis, excipuli annularis margine tenui, disco subceraceo intus albido. Fries l. c. p. $26 \mathrm{r}$.

Lich. punctatus. Scopol. Verrucar. cyanescens \& punctata. Hoffm. pr. p. Lichen parasemus. Engl. Bot. t. 1450 ex spec. viso. Lecid. enteroleuca Ach.syn.p. 19. ipso affirmante. Schaer. spic. p. 155. Lecid. eleochroma. Sommerf. Lapp. p. 150. L. hyalina. Mart. Erl. p. 248 ex spec. Laureri. L. parasema $\alpha$. livida. Ches. par. p. 570.

Exs. Lich. Suec. n. 27. Sommerf. n. 46. Flotow. n. 98, 99. Moug. et Nestl. n. 746. Desmaz n. 240. - inclus. formis sequent.

* olivacea, crusta flavovirescente aut flavida, apotheciis sæpe difformibus rugosis subæruginoso-atris. Verruc. olivacea. $H o f f m$. l. c. L. paras. $\beta$. Ach. Lich. univ. - Wahl. Lapp. - L. elæochroma Syn. Lich. 
p. 18. - vulgo vero et analogus prioris status huc relatus.

Eisdem cum priori locis, \& quidem illa vulgatior per regiones campestres \& maritimas, rarescit in regionibus pineto-montanis.

Præcedenti simillima, at notis gravibus diversa. Sub disco molliori magis turgescente, sæpe subtiliter pruinoso, intus albo aut sordido, nullum adest stratum carbonaceum sed thallodes album, unde excipulum annulare fit, at non raro simul conspicere licet lineam nigram profunde sub strato thallode ductam, ut in $L$. spilota ipsaqué $L_{\text {. }}$ albocœrulescente, cum qua analoga \& ab Hoffmanno simul jungitur. Disci indole ad Biatoras prope accedit; madefactus turgescens, locis humidis excipulum quoque excludens, sæpe hyalinus, rufescens, cœrulescens; in * $x-$ ruginosus, passim maxime deformatus \& rugosus, quare pro stato atypico habeo, sæpe vix a Parm. varia formis ex externa facie discernendo. (Discum præcedentis semper corneum \& aterrimum observavimus). Crusta deliquescens in lepram magis sordidam abit; in hoc statu variis sub nominibus, Lec. pulveracea \&c. accepimus. In lignis crusta vix limitata, sed vidimus hydrate ferroso tinctam - L. lapponica. Herb. Ach. - Caute separanda a formis L. sabuletorum, cui Lec. dolosa Wahl. magis affinis est.

L. as ser cu lor $u$ m primitiva Ach. syn. p. 26 est P. Lecideola S. M. - Scl. Suce. exs. $13 \%$.

Ut melius perspiciatur diversa apotheciorum structura \& specierum diversarum serierum hac ratione analogia, ex his saxicolarum dispositionem addere lubet.

\section{A. Disco primitus subpruinoso.}

1. Discus ceraceus, intus absque stratis discoloribus albus, excipulo annulari tenui \&c. Lich. univ. t. 2. f. 1 .

1. L. albocœrul.

II. Discus corneus, strato thallodi albo aut fusco impositus, excipulo annulari valido \&c. Lich. univ. t. 2. f. 3 .

1. L. spilota. 2. L. badioatra $\frac{4}{4}$ 3. L. margin. 4. L. theiod. III. Discus corneus, strato carbonaceo impositus, excipuli margine tenui subcontiguo.

1. L. varieg. 2. L. fuscoatra. 3. L. aglæa.

IV. Discus corneus, impositus strato carbonaceo in 
excipulum abtuse marginatum abeunte. Lich. univ. t. 2 . f. 5 .

1. L. contigua. 2. L. panceola. 3. L. biformis *. 4. alpestr. B. Disco primitus nudo.

V. Apoth. e strato corticali oriundis, excipulo haud discreto, intus ad stratum thallodes similaribus atris. Lich. univ. t. 2. f. 2. Cfr. I.

1. L. lapicid. 2. L. atrobrunn. 3. L. armen. 4. L. superfic. VI. Apoth. e strato cortical. oriundis, excipulo annulari, disco intus albo. Gfr. II.

1. L. polycarp. 2. L. lugubr. (3. L. fimbriata. Schaer.) VII. Excipulo cupulari, margine obtuso. Cfr. IV.

1. L. nitidul. 2. L. atroalb, 3. L. protrus. (4. viridiat. Fl.) VIII. Excipulo cupulari, margine tenui. Gfi. III.

1. L. amphibia. 2. L. Morio. (3. L. ocellat. Fl.) 4. geograph. Vulgo apotheciorum structura ita convenit, simulque thalli habitus, ut facile inducaris singulam sectionem pro unica specie habere; sic II. Lecid. spilotam Ach. tota efficit; V. Acharius in mscr. sub $L$. viridiatra, cui et adnumeravit L. silaceam, complectitur; VII. Lec. petroea Flotow.; credo vero easdem differre ut Cladovias analogas, nam in natura magis ad species proximas suæ seriei, quam ad analogas appropinquantur, ut v. c. Lecid. panoeola evidentissime testatur. Recedit quidem ex charactere una alterave species, * notata, sed habitus veram analogiam satis indicat. Intra parenthesin addidi species quasdam Auctorum a me non receptas, ut alienæ forsan originis, at notioni ideali sui loci bene respondentes. - Restant duæ species a me non visæ, \& ob colorem candidum, ab omni ortum, quoad seriem dubiæ, nempe $L$. areolata Schaer. spic. p. 127, quæ ex sect. I. 1. V, L. Brunneri Schaer. 1. c. p. 136. e sect. III. I. VIII. - Lecid. albocoerulescens Schaer. exs. n. 185. (cfr. p. 298), videtur e sect. III, quo probato hoc nomen ad Glaucescentes pruinosas omnis sectionis relatum fuisse patet; Wulfenii enim e disco rubello picto, excipulo annulari dicto \&c. evidentissime est $L$. albocoerulescens nostra; Acharius re ipsa, ut descriptio in Lich, univ. testatur, L. spilotam in mente habuit; Hoffmann cum vera Wulfenii evidenter confudit Lec. contiguam: "ætate \& intus nigrescunt scutellæ;" sed $L$. contiguce intus jam primitus aterrimæ nec L. albocœrulescentis, quam per scutellas juniores intus non nigricantes intellexit, umquam per ætatem nigrescunt. - Eadem fere ratio est 
nominum vulgatiorum fere omnium; at cum novis nominibus nil tædiosius, scrupulose perpendi, cui nomina divulgata vel ex primitiva idea vel ex naturæ convenientia tribuenda sint, \& si quid in speciebus ipsis limitandis præstiterim, omni qua par est observantia rogo, velint futuri emendatores non omnem auctoritatem in illis figendis mihi denegare, memores ov Galeni: Tum primum homines res ipsas neglexerunt, quum nimio studio nomina quærere inciperent.

Trib. GRANULOSARUM. Hypothallus albus, subleprosus. Crusta magis libera, rite evoluta granulosa; deliquescens leprosa.

Crusta cum hypothallo, sæpe homogeneo, fere confluens, effusa, indeterminata, tartarea, potius quam cartilaginea, subgranulosa; quando areolæ prioris tribus turgescunt, ut granula referant, hypothallus niger semper evidens est; deliquescens laxe leprosa, nimis macra hypothallo cum thallo confuso membranacea, haud nigrescens. Oxidum ferrosum repellunt. Apothecia subcornea, facile convexa, immarginata, scabrosa. His Biatoris proxime accedunt, cum Areolatce magis cum Parmeliis conveniunt. Loco indefinitæ, vulgatiores promiscue ad terram, ligna, cortices, immo saxa occurrunt.

* Glaucescentes. Color nativus glaucus in album vulgo abit.

288. LECIDEA ileiformis, crusta turgida in juga elevata intestiniformia flexuosa effigurata glauco-candicante; hypothallo albo, apotheciis superficialibus nudis mox convexis, excipulo annulari, intus albis.

Ad terram nudam summarum alpium Norvegicarum. In Dovre. Blytt!

Species maxime spectabilis \& paradoxa, structura apotheciorum sequentibus affinis, at crusta ob omnium Lichenum, recedens, ut atypicam facile fingam. Non aliorum more effusa est, sed in juga valde elongata, flexuosa, turgida, crassa (semicylindrica), intestiniformia, passim anastorrosantia, producta, quasi Lecid. Wahlenbergii crusta gyrosa explicata. Specimina minora quoque gyrosa, sed ex unico jugo contorto (fere ut Perichcence contortoe peridium) constant. Superficies rugosa inæqua- 
bilis, nuda, glauco-candicans; absque hypothallo nigro! A pothecia majuscula, e thallo irregulariter orta, juniora plana, excipulo carbonaceo annulari obsolete niarginata, mox vero convexa, sed sæe confluentia \& conglomerata; discus strato thallode albo receptus. - Aërem alpinum ad hanc enitendam multum contulisse non dubium videtur, at cum alia comparare non valeo.

289. LECIDEA sanguinaria, granulis in crustam tartaream confluentibus glaucescentibus, hypothallo albo, apotheciis superficialibns nudis mox convexis, margine annulari, disco strato sanguineo! recepto. Ach. Lich. univ. p. i 70.t.2. J.4. Lich. sanguinarius. Linn. et Auct. Engl. Bot. t. 155 . - Verrucaria Hoffm. Pl. Lich. t. 41. $f$. 1. Lecid. Fl. Dan. t. 1473. f. 2. (facile etiam f. 1.) Schaer. spic. p. 150.

Exs. Lich. Suec. n. 92. Schrad.n. 165. Moug.n.842. Ad cortices arborum, ligna putrida, terram \& saxa. Hrec, qua nulla vulgatior in pineto-montanis septentrionalibus, in Europa australi \& Helvetia quoque alpina mire rarescit.

Charactere essentiali ab omnibus differt; stratum sanguineum in perfectissimis per totam crustam infra gonimon effusum est. Crusta perfecta Parm. tartarece similis, evidenter, granulosa, vere tartarea, quo saxicola ab amylaceis priorum formis abunde differt, sed variat etiam tenuis, lævigata, immo sterilis leprosa!; colore, serei more, e glauco viridi, cinereo, albo. Apothecia normalia marginata rarissima sunt, horum margo semper aterrimus, deest quando discus in rubrofulvum vergit, qualia specimina in abiegnis irriguis a me lecta sunt!! Hinc meo sensu vera Lecidea; lineam atram sub strato thallode sanguineo ductam in Engl. Bot. 1. c. pictam non vidimus, sed simillimam subinde in Lec. enteroleuca, spilota, albocorulescente.

p. alpina, crusta submembranacea lævigata grisea, a potheciis congestis.

Ad terram in alpibus Norvegiæ meridionalis copiosissime. Blytt!

Primo obtutu Lec. sabuletorum concretam omnino fingas, at interna apotheciorum structura mox distinguit. 


\section{LECIDEA papillata, granulis in crustam} tartaream coniluentibus glauco-candicantibus, hypothallo albo, apotheciis superficialibus nudis mox convexis, disco strato atro subcarbonaceo recepto. Sommerf, Lapp. p. 154 .

Ad muscos \&c. rupium inferalpinarum Saltdalen Nordlandiæe rarius. Sommerfelt!

Grustæ \& apotheciorum habitu præcedenti similis, at strato atro sub disco facillime dignoscitur. Apothecia insuper minora, margine tenui evidentiori instructa, superficie demum inæquabili. Crusta magis candicat, passim ramuloso-papillosa. - Præsentibus licet speciminibus archetypis haud detegrre valeo notas palpabiles, quibus inter hanc \& sequentes mediam. L. geophilam, crusta tenui submenbranacea inæquabili alba, apotheciis planis marginatis, margine tenui, dein corvexis immarginatis, intus nigris - Fl. in Sommerf. Lapp. p. 157 ab utraque distinguatur; habitus prioris $\beta .$, ei analogus status.

= Hoc loco forsan quxrentur status mutili Lecicl. epigoea, vesicularis \& candidce, scilicet L. lutosa \& glebosa Ach., quas videas sub sectione prima. - Lich. intermedius Schrad. spic. p. 89 sequenti vulgo adscriptus his potius accedit; nam sequentem nos saltim numquam glebulosam terrestrem vidimus, nec affinitatem cum B. decipiente \& L. epigaea, ab Auct. indicatam, invenimus. Specimen visum tamen sequens.

29. LECIDEA alboatra, crusta areolato-verrucosa glauco-candicante, sæe tartareo-farinosa, hypothallo albo, apotheciis innato-protuberantibus primitus coronatis cesio-pruinosis, intus carbonaceis atris, margine tenui evanido. - Schaer. spic. p. 140.

a. L. corticola. L. alboater. Hoffin. et Auct. Verrucar. Hoffm. Pl. Lich. t. 15. f. 2. Lich. corticola. Ach. Vet. Ac. Handl. 1795.t. 5: f. 6. - Engl. Bot. t. 1892. Lecid. Ach. syn. p. 32. Fl. Dan. t. 1350. $f$. 2. Patellaria. Decand. * crusta deliquescente. Lich. amylaceus. Ehrh. - Verr. atroalba v. amyl. $H o f f m$. L. cortieola. b. farinosa. Ach. Exs. Lich. Suec. n. 153. Ehrh.n. 176. Schrad.n. 161. 
- Ehrh. n. 303. Fl. Deutsch. n. 41. Moug. Nestl. 844. $g$.

b. trabinella, apoth. confluentibus immarginatis.

Exs. Moug. l. c. b. Reichenb. $n$. 80. (79 est a, $81 \mathrm{a}^{\star}$ ) ex Schaer.

c. saxicola. Lichen niveo-ater. Dicks, Crypt. IV. $p$. 21. t. 12. $f$. 1. L. epipolius. Ach. - Engl. Bot.t. 1137. Lecid. Ach. syn. p. 32. Patellaria. Decand. Lecid. margaritacea Flotow. - Sommerf. Lapp.p. 148. (at non $\alpha$ Ach.) * crusta deliquescente: Lecid. margaritac. b. Ach. syn. p. 31 .

Exs. Lich. Su.n.413, * 414. Sommerf. 50. Desm. 241: Per omnem Europam in regionibus magis campestribus ad cortices, ligna fabrefacta, muros $\&$ saxa calcarea \& arenaria copiose; at numquam per regiones montanas mere graniticas legi.

Hypothallus prorsus albus, unde crusta numquam nigro-limitata, sed passim $P$. sordidce instar ad saxa radians. Crusta magis contigua $\&$ æquabilis, quam in reliquis hujus tribus, sæpius amylacea \& candida, sed in statu typico omnino cartilaginea est. Apothecia minuta, per æetatem supra crustam plus minus elevata, a crusta præcipue in amylaceis coronata, intus tota carbonacea, atra, at stratum carbonaceum discretum haud invenio. Pruina disci evidens, sed per ætatem, præcipue crusta non amylacea, etiam evanescit, \& discus scabrosus fit. - A Lec. parasema, passim confusa, facile dignoscitur; non sine difficultate a $L$. contigua v. calcarece formis, attamen certe diversa est. Lecid. margaritacea a cum var. conspurcata. Ach. luculenter ad L. contiguam pertinet; itidem Lich. conspurcatus Engl. Bot. t. 964, si quidem vera specimina vidi.

CPriori persimilis est L. turgidula, crusta lavigata albida, apoth. semper immarginatis primitus pruinosis, intus atris. $S$ ched Crit. I. p. 10. Ex s. Su. n. 25. - Ad Pinus in silvis nostris montanis frequens, etium majoribus apoth. ad ligna putrida (L. den udat us. Sclrad.) obvia - ut plane diversa; ceterum tam parum insignis, et potius omittan.

292. LECIDEA dolosa, crusta subverrucosa virescenti-glauca, sæpius leprosa alba, apotheciis depressis, excipuli cupularis margine tenuissimo, disco (punctato-scabrido) subnudo aterrimo, intus cinereo-nigricante. Wahl. Lapp.p. 470. 
Lich. abietinus. Ehrh. Verrucaria. Hoffm. Germ. p. 193. Lecan. Schaer. - vix differunt ab hujus statu leproso. Lich., Parmel. \& Lecan. periclea. Ach. - Syn. p. 150. a et b Lecid. dolosa l. c. p. 19 quoad locum \& syn. Wahlenb. Lecid. pinicola. Sommerf. Lapp. p. 153.

Exs. Lich. Suec. n. 66. Ehrh. Crypt.n. 166.

Ad cortices arborum præcipue Pini \& Abietis; optima in silvis montanis; forma campestres, ad arbores frondosas, huic accedentes magis difficiles sunt.

Species omni respectu dolosa, at nolui cum alia temere conjungere. Quo jure de synonymo optimo Wahlenbergii dubitetur, ut rejiciatur, non video, cum nullam inventor in meis, equidem in inventoris differentiam invenire possumus. - In statu normali Lecid. parasemam potissimum refert, at numquam nigro-limitata, apotheciorum structura \& præcipue vegetationis historia longe alia. Vulgo enim legitur crusta leprosa alba, normali statu pro L. parasema forsan præterviso, l. e Bysso rubente intertexta varie rufescente, \& in hoc statu, more L. corticolce, $\boldsymbol{L}$. contiguoe $\varepsilon$, apoth. margine thallode accessorio semper fere coronantur, unde additis apotheciis depressis vulgo pro Lecanora Ach., \& quidem sæpe pro L. soploode, sumitur. At ab omni Lecanora Patellaria differt nostra excipulo proprio, quod sub strato fulciente discum ut linea nigra conspicitur, margine proprio (licet a disco turgido demum obtecto) \& disco aterrimo; etiam in optimis conspicitur discus inferne discolor cinereus, a Parmeliis peregrinus. - Re ipsa medium tenet locum inter Lec. sabuletorum cum affinibus $\&$ L. alboatram. Ad hanc accedit crustæ indole, apotheciorum situ, margine accessorio thallode, disco adeo frequenter punctato-scabrido, ut fere normale fiat, \& rarius simul pruinoso; sed pruina in hac fugacissima est $\&$ in humectato evanescit; maxime vero differt strato sub disco non carbonaceo. Ad sequentes accedit apotheciorum structura, at habitu prorsus differt.

Ut L. turgidula sub L. alboatra, sub L. do losa notanda diminuta et parum itidem evidens $L . g l o b u$ losa, erusta tenuissima lipvigata albida (granuls subadspersa Sehaer. spic. p. 156), apoth. elevatis planis marginatis nudis, subinde globulósis rugosis, extus intusque atris, margine tenui mox evanido - Fl. Deut $s \in h . n$. 181. - ad. Abietes passim obvia. Cum non quare divinamus, sed qua nosimus áfferonda sint, meam sententiam de utraque differo. 
Fuscescentes. Color e viridi cervinus, sæpius autem e fusco cinereus, immo albescens. Hypothallus subleprosus albidus, subinde fuscescens, at $a b$ Areolatarum prorsus diversus.

293. LECIDEA sabuletorum, crusta cartilaginea primitus contigua, mox rimoso-areolata granulata sublobataque cinerascente fuscave, hypothallo confuso, apotheciis e crusta oriundis corneis, disco nudo, margine annulari evanescente. Lich. sabuletorum Schreb. - sec. specimen e loco. Cfr. \&. Lecid. sabuletorum Flörke et Auct. ex parte. Per ornnem Europam, exceptis forsan regionibus pineto-montanis formationis primitivæ, ad saxa, terram, lign \& cortices.

Habitus hujus speciei tantopere mutatur, ut primariæ ejus formæ seorsim describendx, præcipue \& interno \& externo apotheciorum colore mutabili insignis; ille ex atro per fuscum \& cinereum in omnino album mutatur; hic passim fuscus \& rufescens, \& in hoc statu Biatoram potius diceres; margo tamen, nisi prorsus deficeret, niger persistit. Eadem lege quoque internus color in Biat. vernali, decolorante (cui re ipsa affinis), Lecid. enteroleuca \&c. mutatur, de quarum formarum indentitate non dubitatur. Ne igitur terreat me hanc speciem latissimo sumere sensu; qui sic malent, varjetates infra allatas pro totidem speciebus habeant, sed in crustæ rite explicatæ habitu tanta convenientia, totque transitus haud limitabiles, ut conjunctim non potuerim non tractare, probe distincta huc vulgo adnumerata $L$. milliaria. Sed etiam cum aliis diversissimis speciebus frequenter confunditur, præcipue cum citatarum Biatorarum varietatibus. Nomen parum aptum, confusionis perennis fons, meliús abolendum, æque ac adhuc infaustius $L$. muscorum.

a. alpestris, apotheciis hemisphæricis subimmarginatis nigris, sub disco basi lividiori strato corneo nigro instructis.

Lichen muscorum. Wulf. in Jacq. Coll. IV.t. $\%$ f. 1. Fl.'Dan. $t$. 1003. $f .1$. Lecid. sabuletorum $\beta$. Sommerf. Lapp. p. 155. \&c. Lecid. miscella Ach. syn. p.21. primitiva; in herbario valde diversa complectitur. 


\section{Ad terram \& muscos in alpestribus copiose.}

Crusta hujus varietatis, ceterum valde mutabilis, plerumque bene efformata, areolata, areolis turgidis demum rimoso-rugulosis, 1. squamaceo-effigurata, squamis crustaceis imbricatis concrescentibus; supra muscos vero magis æquabilis, passim admodum tenuis. Apothecia constanter nigra, raro marginata, apotheciis subconglomeratis. Specimina fida $L$. miscellae toto habitu conveniunt cum L. cumulatoe Sommerf., recedentis apotheciis minimis stipatissimis planis tenuiter marginatis intus albidis, quæ hac ratione ad $\zeta$, in qua simillima vidi apothecia, accedit. Acute de $L$. cumulata suspicatur inventor ( $F l$. Lapp. p. 157), eandem ex apotheciorum prolificatione ortam esse. Hic status in terra uda summarum alpium Nordlandiæ copiosa est.

ק. campestris, apotheciis applanatis concaviusculis submarginatis atris, intus nigricantibus.

Lecid. aromatica. Ach. syn. p. 19. e descr. \& spec.

Suecan. Lecid. sabuletor. $\alpha$. l. c. p. 20. potissimum quoque hujus loci.

Exs. Desmaz. Cr.

Ad terram sabulosam \& argillaceam in inferalpinis campestribus, non ubique.

Crusta satis bene evoluta, quasi squamaceo-concreta. $\gamma$. coniops, apotheciis liberis elevato-marginatis atris, intus fuscis, margine tenui persistente.

L. coniops. Ach. meth. Suppl. p. 8. e descriptione exactissime, at nostra numquam nigrolimitata. An huc L. coniops Wahl.?

Ad saxa, præcipue formationis recentioris, locis humidis prope terram.

Grusta cartilaginea, areolato-rugosa, quasi e granulis concretis, granulatoque-lobulata. Apothecia externa facie L. parasemoe prorsus referunt, sed intus eximie fusca, passim quasi nucleum fuscum includentia. Pulchram in foveis calcareis Ostrogothix legit Stenhammar!, quem eandem in Exs. Suec. divulgaturum esse speramus.

8. euphorea, apotheciis adnatis nigris submarginatis, intus cinerascentibus, margine subevanemescente. Flörke. 
Patell. glomerulosa. Dec. Fr. 2. n. 93\%. Lecid. enteroleuca. Chev. par. p. 571. sub Lecid. parasema. \&. rugulosa. Ach. Lich, univ.p. 176. L. Tiliæ. Schleich. Exs. Lich. Suec. n. 154.

Ad ligna putrida \& cortices arborum in regionibus campestribus.

Crusta eximie cartilaginea, areolato-verrucosa, non squainaceo-effigurata. Discus intus passim quoque fuscescit \& albicat. - Variat crusta lutescente.

8. pilularis, apotheciis plano-convexis, demum imynarginatis subglobosis, humectatis mollioribus subfuscis, intus fuscis albidisque.

Lich. pilularis. Davies in Transact. Linn. Soc. $p$. 283. $t$. 28. $f$. 1. Lecid. artyta, L. confluens $\beta$., L. coniops $\beta$. Ach. Lich. univ. p. 170, 171, 174. Lecid. leptoderma. Duby Bot. Gall. - e specim. Prevost. crusta macra lutescente.

E loco Schreberi misit Sihubert!, similibusque locis, ad parietes argillaceos, e Gallia Prevost!; ceterum ad saxa recentioris formationis passim.

Biatoris admodum propinqua. Crusta maxime diversa granuloso-squamacea, subcontigua, immo prorsus deperdita, ut in L. pilulari Davies (qui sui apothecia in fuscum vergentia quoque tribuit) frequenti in Scania campestri.

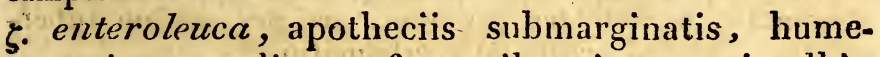
ctatis sæpe disco rufescentibus, intus totis albis. Lecid. enteroleuca. Flotow in Link. Jahrb. I. 3. $p$. 106. Sommerf. Lapp. p. 150. - crusta imperfecta, squalida: Lecid. stigmatea. Ach. Lich. univ. p. 161. ex spec. ips. (eandem pro L. Lygaea a Schleichero habeo. Cfr. Schaer. spic. p. 146.) Lec. lapicida $\vartheta$. illuta Lich. univ. p. 160.

Exs. Flotow n. 105, 106. (104 arborea).

Ad saxa formationis recentioris in regionibus præcipue campestribus.

Apothecia intus tota alba, absque omnibus stratis discoloribus; ut hanc cum precedente $\varepsilon$. separes, si lubeat; geographicis vero rationbus \& vegetationis historia cum hac specie prorsus convenit. Crusta rimosoareolata, in perfectis eximie granulosa, var. $\gamma$. sæpe simillima. Specimina a Flotowio divulgata in eodem evo- 
lutionis statu sunt ac L.coniopis $\beta$. a Schaerero. - Sed huic accedunt plurimæ formæ crusta mutila, terso-lævigatæ crusta cinerea fuscaque $\&$, ut in maxime campestribus fieri amat, e variis glebosis adflatis particulis inquinata. Margo niger in humectatis (sed eo deficiente totum apothecium), discoque elapso ut cupula annularis persistit, unde mihi Lecidea.

Ex prasenti regione restant varia ut nova mihi missa, que transeo. $V$. eapitellatam Hoffm. Ger m. p. 194 h. l. esse mihi narratum est. 294. LECIDEA arctica, crustæe granulis cartilagineis, primitus discretis papillæformibus persistentibus fuscescente-cinereis, apotheciis immixtis subimmarginatis cesio-pruinosis, intus corneis cinerascentibus. Sommerf. Lapp.p. i 56. Lecid. sabuletor. $\beta$. Wahl. Lapp. p. 470 . L. cesioatra. Schaer. spic. p. 151. - L. sphæralis. Fries. Vet. Ac. Handl. 1822.

Exs. Sommerf. Norv. n. 49.

Supra Andreæas, Jungermannias, radices emortuas \&c. in Europa arctica copiose, nec non in summis alpibus Silesiæ, Helvetia.

Forma insignis, constans, nullo modo mutabilis, nisi granulis subinde deficientibus (unde $L_{\text {. }}$ sphoeralis). Granula minuta, sphærica, primitus discreta, sed aggregata coacervataque. Apothecia minuta, subglobosa, haud conglomerata, persistenter pruinosa, sed per senium tuberculata. "Margo oculis mox subducitur."

295. LECIDEA milliaria, crustæ granulis primi-

tus discretis fuscis e cinereoque albidis, siepe leproso-deliquescentibus, apotheciis liberis inter granula oriundis globosis subimmarginatis nudis, intus nigricantibus, excipulo cupulari. Fries Vet. Ac. Handl. 1822. p. 255.

a. terrestris. Lecid, sabuletorum. Flörke pr. p. ex spec. originali. - $\beta$. Ach. syn. p. 20, sec. ipsius determ. Patell. Decand. ad spec. - Lecid. rudeta. Ach. syn. p. 338. - crusta deliquescente: Lecid. Limosa. Ach. syn. p. 26.

Exs. Lich. Suec. n. 243.

b. saxatilis. Lec. sabuletorum. v. viridans. Flotow in Reg. Bot. Zeil. 1828. p. 697 . 
c. ligniaria. Lich. dubius. Engl. Bot. t. - Verruc. pilularis. Hoffm. Lecid. ligniaria. Ach. syn. p. 26. \& herb. (vix primitiva, ipsi in Schedul. ined. ad Biat. uliginosam). Patell. myriocarpa. Dec. Fr. 2. p. 346 ad spec. nostra.

Exs. Lich. Suec. n. 29. - 212. B.

* hypothallina, cinerea, apotheciis stipatissimis.

** hypothallina, fusco-nigra. Lich. Su. 212. $A$.

Ad terram, saxa, ligna, rarissime ad cortices locis humidis in regionibus pineto-montanis passim copiose; at numquam $L$. sabuletorum in eadem regione vidi. * in alpibus. $*$ locis limosis $\&$ ad ligna cariosa.

Cum $L$. sabuletorum vulgo jungitur, at mihi facile distincta videtur hypothallo alio, granulis primitus \& inter se \& ab hypothallo discretis, passim leprosis; apotheciis globularibus subimmarginatis, non e crusta, sed inter granula libere enatis, excipulo cupulari integro, nec e margine deorsum incurvo tantum formato l. basi deficiente ut in Lec. sabuletorum; disco, nisi ater, hyalino; in hoc statu apotheciorum tenuem marginem tantum conspicere licet. - At præcipue memorabilis est vegationis historia. In agro Femsionensi, ubi vulgatissima, ne unicum quidem ad $L$. sabuletorum accedens specimen per quinque lustra detegere mihi contigit. Crustæ morphosis Lec. citrinella, \& sane in statu primitivo viridi sæpe non facile dignoscuntur; ut illa in lepram citrinam, hæc in albido-cineream laxam facile deliquescit, quod in neutra priorum observavimus. Hæc granula numquam areolas referunt, multo minus inter se contigua sunt, nec in squamas abeunt, sed sæpe corallino-caulescentes ramulosæ, cujus ne indicium quidem in $L$. sabulet. observavimus. Apothecia Lecid. sabuletorum basin saltim crustaceam habent, hujus vero apothecia omnino libera, quare frequenter prorsus acrustacea oriuntur, sparsa l. conferta globularia, qua forma ab omni Lecid. parasema, cui vulgo adnumerantur, recedunt. Discus induratus in hac marginem semper obtegit, per ætatem rugulosus \& tuberculatus fit; numquam dilatatur 1 . applanatur; intus sæpius niger est, at hoc respectu varians. Præcipue memorabilis est hypothallus ejusque morphosis. Sub intensis pluviis hunc ut gelatinam tremellosam hyalinam, passim effiguratam, sæpe conspeximus, supra quam apothe- 
cia quasi natant; exsiccatus vero maculam fuscam tantum sistit. Tam ad ligna, quam ad teriam sub hac forma sæpe vidimus evidentissime in $L$. milliariam ipsam abeuntem; specimina in Lich. Suec. n. 212. B. tradita sunt partes ejusdem individui ac $A$. - $A b$ omni simili statu B. uliginosae differunt apoth. jam primitus atris. - Ex hoc hypothallo ad terram inter granula surgunt flocci, passim pulvinati nigri, in quo statu Lecid. rudeta descripta est. L. arctica peraffinis est, $L$. sabuletorum meo sensu longius distat.

Trachylia ligniaria Fries $V$. A. H. l. a. adhus mahi dubia est, a pracedente vero diversa.

296. LECIDEA myrmecina, crusta granulis discretis cartilagineis e viridi cervinis, apotheciis immixtis applanatis nudis demum rugoso-plicatis, intus atris, margine tenui. Fries $V$ et. Ac. Handl. I $822 . p .257$.

Lecid. Friesii. Ach. in Liljebl. Sv. Fl.

Exs. Lich. Suec. n. 28.

Ad truncos vetustos Pini, Alni, Quercus \&c. Sueciæ meridionalis.

Species eximie diversa, male ad"Lecid. scalarem ק." Ach., quæ diversissima, relata, potius optime monente Wahlenbergio Lecid. sabuletorum affinis. Granula omnino discreta e ligno erumpunt, rotundata, gibba, e viridicervina, nitida, dein concrescentia \& effigurata, at semper compacta, nec foliacea. Apothecia tenuia, inter granula e ligno quoque enascuntur, semper opaca, aterrima \& nuda, intusque similaria apparent, juniora planiuscula æequalia, dein centro umbonata, mox margine duplicato, demimque convexula corrugato-crispata. Hypothallus videtur idem ac in Ochroleucis, sed minus evidens.

*** Ochroleuca. Color granularum pallescens, subochroleucus. Hypothallus ut in Caliciis byssinoaraneosus canescens ligno innatus.

297. LECIDEA elabens, crustæe granulis discretis cartilagineis pallescenti-albis nudis, apotheciis immixtis, excipulo carbonaceo cupulari, disco nudo demum rugoso-plicato, margine obsoleto. Fries l. c. p. 256 . 
Ad ligna indurata putrida Pini, Suecize meridionalis, rarissime.

Ex hypothallo fibrilloso-canescente, telæ instar ligno innato, oriuntur granula discreta, cartilaginea, primo globosa, dein applanato-difformia pallescenti-alba. Apothecia inter granula libere propullulantia, ab diseum tumidum, sæpe rugoso-plicatum, fere immarginata, sed disco elabente restat excipulum integrum cupulare marginatum carbonaceum. Minime cum Cliostomo corrugato confundenda, sed priori forsan nimis affinis.

298. LECIDEA xanthococca, crustæ granulis discretis flavescentibus nudis, apotheciis immixtis nudis concavis, intus atris, margine tenui elevato. Sommerf. Lapp. p. 154.

In ligno ramisve decorticatis Pini in Saltdalen Nordlandie, rarius. Sommerfelt!

Et hæc duabus præcedentibus evidenter cognata est hypothallo, granulis discretis e ligno erumpentibus \&c., ut non mirarer, si cui in mentem veniret, considerata simul matrice simili, omnes tres conjungere. Hæc ceteris multoties minor est, fere rainima generis, sed maculas determinatas subpollicares in ligno efficit. Apothecia nudo oculo puncta nigra tantum sistunt, areolis immixta aut rarius adhærentia, sed sub lente eximie regularia, eumorpha, lævia.

299. LECIDEA farinosa, crustæ granulis discretis areolato-applanatis lutescentibus, mox albido-farinosis, apotheciis areolis adpressis subimmarginatis nudis, intus atris. Stenham. sched. crit. $V . p$. I.

Exs. Lich. Suec. n. 123.

Ad trabes pineas redium silvaticarum in $\mathrm{O}$ strogothia. Stenhammar!

Hypothallus est ille Calicioideus, tenuissime byssinus, canescens, ut re ipsa Cal. tigillari affinis videatur areolis adhuc lutescentibus, at harum stratum corticale, more Lec. epigceae proxime analogæ, mox in farinam albidam superficialem solvitur, unde facies Lichenis exoleta. Apothecia minuta, areolis more Cal. tigillaris immersa, margine ægre perspicuo, disco per ætatem sca- 
broso-punctato, intus similari. Non cum L. dolosa confundenda.

$=$ Occurrunt specimina casu, ut videtur, lutescentia Lec. sabuletorum, vide n. 293, a prioribus probe distinguenda.

**** Citrinae. Crusta lutea aut citrina. (Calicium $t i$ gillare, disco integro.)

* L. argillacea, crusta tenui obscure lutea, apotheciis subaggregatis nigris intus ex rubro fulvis. Ach. meth. p. $5 \mathrm{r}$.

Lich. argillaceus. Bell. App. Ped.

Ad terram argillaceam Italiæ.

A me non visa; forte $L$. sanguinariae in hac serie analoga. - Hujus seriei porro est Lecid. pallidonigra Ach. syn. p. 23, Capensis, quam in Museo Thúnbergiano vidi, \& plures exoticæ.

300. LECIDEA citrinella, crustæ granulis rotundis confertis virescenti-flavis, in lepram citrinam deliquescentibus, apotheciis immixtis, excipuli cupularis margine obtuso, disco depresso nudo, demum papillato. Fries l. c. p. 257 . Lich. citrinellus. Ach. in Vet. Ac. Handl. 1795.t.5. f. 5. Lecid. Ach. meth. p. 47. a. Syn. p. 25. Lich. scabrosus. Engl. Bot. t. 1878.

Exs. Lich. Suec. n. 214. Fl. Deutsch. n. 83. Ad terram glareosam sterilem, margines fossarum, in regionibus inferalpinis, immo maxime campestribus ut Scanize, Berolini \&c.

Absolutam hujus differentiam a Lec. flavovirescente urgente fide dignissimo Schaerer iterum has in natura contuli \& statum utriusque normalem adeo diversum reperi, confirmante geographica distributione diversa, at cum illa conjungere non ausus sim, licet utriusque status deliquescens, rarior tamen ex $L$. flavovirescente obvius, transitus indirectos utique offerat. Crusta hujus in statu normali $L$. milliarice, cui valde affinis apparet, similis, e granulis liberis, sed confertis, magis virentibus composita, quæ tota facillime in lepram citrinam collabuntur; omnino diverso e areolis adpressis lobatis effiguratisque 1 . flavovirescentis. Apothecia inter granula oriuntur, juniora subglobosa, dein depressa obtuse mar- 
ginata, sæpeque papilla centrali elevata notata; discus versus excipulum livido-nigrescens.

Genus inter Lecidinas \& Graphideas medium:

\section{UMBILIGARIA.}

Lichenoidis spec. Dill. Lich. umbilicati. Linn. ex maxima parte. Umbilicaria. Hoffm. - Schrad. Decand. - Schaerer. - Fries S. O.V. Gyrophora. Ach. Gyromium. Wahl. Lecid.spec. Meyer.Gyrophora \& Umbilicar. Chev.

CHAR. Apothecia libera, superficialia, excipulo proprio carbonaceo primitus clauso (h. e. perithecio), dein plus minus aperto, forma varia. Discus corneus, ascigerus, adultus rimosus aut sæepissime gyroso-plicatus margine incurvo cinctus. Thallus horizontalis, cartilagineus, foliaceus, submonophyllus, puncto centrali adfixus. Apothecia semper atra, serotina.

1. Secundum principia Linnæana:"genus dabit characterem, nec character genus" - "character est ut genus noscatur, non ut genus fiat" \&c.; multaque ab ipso viro, v. c. Leguminosas monadelphas ad Diadelphiam referente, tradita exempla, non potui non hoc genus integrum servare, nec inter Lecideas, Umbilicarias sensu strictiori, \& Opegraphas, ut apotheciorum forma suadet, dispescere; nam affinitas est primarium, character secundarium. Præstantia characterum carpologicorum non ex eo pendet, quod carpologici sunt; sed ex ipsorum constantia vulgo majori, at ubi hi aperte inconstantes vilipendendi, "Character characterem non antecellit nisi constantia" Link. - $\mathrm{Si}$ podetiis in charactere Cladoniarnm \&c. utimur, parum interest ea pedunculos dicere. Pendent quoque omnes istæ differentiæ inter Umbilicarias tantum ab externa apotheciorum forma, nec ullis magis essentialibus ab earum origine \& natura suffulciuntur; his rationibus inter se prorsus convemiunt \& tam a Lecidea, quam ab Opegrapha differunt. Sunt nempe Lecidece apothecia primitus aperta, margine erecto; Umbilicarice primitus clausa, dein aperta margine incurvo; Lecidese apothecia normaliter in stratu medullari enituntur, excipulo ab omnino propria substantia formato; Umbilicariæ 
in, ne dicam supra stratum corticale formantur, excipulo e thallo deusto fere orto, nam quando podicellata sunt, podicellus e substantia thalli omnino formatus est, $\mathrm{cf}$. Schaer. Exs. n. 145 (númquam iu Caliciis aut Lecideis) \& subinde margo thallodes persistit; vide Schaer. Exs. n. 154, saltim in meo exemplari. Hac ratione, additis apotheciis primitus clausis, non desunt rationes hoc genus quoque comparandi cum Parmeliis, inter quas etiam thalli statura proximæ formæ margoque denigratus occurrunt. - Potius quam hoc genus inter plura dispescerem, cum Cel. Meyero integrum ad Lecideas ut aberrationem apotheciis luxiriantibus referrem, at tum etiam Opegr.phas cum Lecideis conjungerem. Cfr. Opegrapham. Apothecia hujus generis gyroso-plicata, si atypic: inter Lichenes esse concessero, in hoc genere non possum non pro normalibus habere; nam meo sensu id quod in plerisque semper constans est, abuorme dici non potest. Et cum Umbilicarix sectionem bene discretam efficiunt, easdem proponere ut peculiare genus practicæ Lichenologiæ finibus optime convenit. Est quoddam in scientis, ut artibus, studium putidius correcti, justo magis ad regulas stricti \& ad preceptum genium accomodati, quo genuina veritas \& nativa pulchritudo in horum favorem perditur. Character s. litera occidit, spiritus vivificat. Nos methodo carpologicæ faventes fastidiose nimis sæpe despicimus in thallinam, nescii quæ solidiora fundamenta dispositionis, teste hodierna Cruciferarum reformatione, utramque forsan magis conciliantia, datura sit dies futura. Percurrenti mihi veterem Botanices literaturam sententiam eorum, qui de aliorum divergentibus apodictice \& aspere judicarunt, sæpius a posteritate explosam fuisse sensumque naturalis minus, quam abstracti reflexionem, seduxisse visum est. Principium, quod alterum seculum ut summum \& irrefutabile laudavit, alterum illius præcipuum fuisse errorem invenit. Exstant sane tot approximationes ad Umbilicarias inter Stictas v. c. Delisea Fee! \& Parmelias v. c. Umbilicatas, nobis exoticas, collatas cum $U$. atropr:inosa, ut non prorsus impossibile sit posteros inventuros esse Umbilicarias medium inter hæc genera in serie naturæ tenere evolutionis locum \& a Sticta differre, ut Lecidea a Biatora, cui Sticta aperte accedit. At exinde thallista non poscant ut carpologici in eorum partem transeamus, priusquam hæc. methodus solidiori talo, quam thalli forma, defe- 
ctu strati corticalis \&c., niti possit. Nam definitum vago, etiam perfectioris evolutionis semina continente, præferendum est. Quis est Auctor, qui non ulterius perspiciat, vel plura divinet, quam exposita, non satis claris \& evidentibus, vel pro ratione operis non aptis, suppressis?

II. In Umbilicariis Europæis triplex præcipue observatur apotheciorum genus:

a. Lecidene, apotheciis patellæformibus marginatis, facie Lecidex, disco æquabili aut Lecidearum more tantum papillato. Huc Umb. atropruinosa, in qua tamen discus vetustus rimosus (numquam in Lecideis obvius) \& $U$. pustulata, cujus vero possidemus specimina Europæa concentrice plicata \& Americana qui$\operatorname{dem} U$. deustae simillima.

b. Gyrophoroe, apotheciis orbiculatis marginatis, disco plicato, plicis in lirellas demum solutis. Huc plurimæ nostræ.

c. Opegrapha, apotheciis maculæformibus, primitus jam margine communi destitutis \& abeuntibus in lirellas ramosas, radiatim excurrentes, in tuberculum hemisphæricum stipatissimas. Vidimus similia inter Opegraphas, at Glonii generis inter fungos potissimum respondent. Hic præcipue Americanus typus, evidentissimus in $U$. Mühlenbergï, tantum in Europæa Umb. polyrrhizos observatur.

Aliæ exoticæ species aliis rationibus aberrant, at omnes circa idem generis centrum rotant. - Glomerulos illos flocculoso-fruticulosos in quibusdam speciebus obvios pro apotheciis abortivis habet Cel. Meyer, nec, ut videtur, male, licet majorem similitudinem cum Parmelice glomeruliferce offerant. Exstat insuper tantum typica cognatio inter hos glomerulos \& vera apothecia, nam hæc ipsa in illos excrescere sane nequeunt. Cfr. Schaer. spic. p. 107. Obs. 2.

III. Species Umbilicarix omnes non tantum absolute saxicolæ, verum etiam graniticolæ, saxa recentioris formationis saltim fugientes. (Arborea Gyrophora Clementei Ach. syn. p. $66=$ Theleph. carnea Schrad s. quercina Pers.). Incolunt præcipue regiones septentrionales, in America arctica vere luxuriant, in Europx borealis planitiebus silvosis copiosæ, in australiori vix nisi in alpibus. Hinc valde diversa oritur ratio specierum. In Europa boreali species optime segregantur utpote discretæe nascentes, altera extra alteram diversas vulgo occu- 
pantes plagas; in cacuminibus vero alpium Helveticarum fere omnes inter angustos limites stipantur indeque difficilius singularum specierum formæ discernuntur. Aliæ ad perfectam evolutionem non attingunt, v. c. U.polyrrhizos, quare accuratiss. Schaerer, cui solidior hujus generis notitia præcipue debetur, cum $U$. depressa ut emortuam formam conjunxerat, donec specimina perfecta \& fertilia septentrionalia comparaverat. At \& typice $U$. polyrrhizos, ut epruinosa \&c., magis normalis est, \& per omnem Sueciam vulgatissima extra omne $U$. vellece consortium, ut si conjungerentur, quod vero a nullo Lichenologo Sueco probatum puto, $U$. polyrrhizos saltim esset primaria. Magis adhuc singularis est $U$.depressa Schaer.; omnium hujus a Schaerero allatarum formarum nullum vestigium in septentrione, tantum analogæ $U$. vellea, apotheciis haud depressis \&c. diversæ, ut nisi hodiernus genius omnia similia jungi juberet, illam pro propria specie, a Scandinavia exsule, facile haberes; recedunt ut Stachys germanica, lusitanica reliquæque affines, quæ analogo modo in diversis terris variant, sed in singula peculiares notas \& faciem impressam habent. Pari modo U.cylindrica \& proboscidea apud nos longe aliter se habent, quam apud Exteros. - De hoc genere præcipue consúlendi Schaerer in Ser. Mus. I. et Spic. - Stenhammar in Sched. Crit. $V, X$ - cum hoc genus quoad definitiones specierum \& synonymorum ceteris jam melius cognitum obiter tantum tractarim.

* 3or. UMBILICARIA pustulata, thallo coriaceo papuloso viridi-cinerascente, subtus reticulatolacunoso fuscescente, apotheciis adpressis obtuse marginatis patellatis subsimplicibus, Hoffm. Germ. II. $p$. i I I.

Vaill. par. t. 20. f. 9. Mich. gen.t. 47. Dill. musc. t. 30. f. 131. Lich. pustuI. Linn. et Auct. $-F l$. Dan. t. 597. f. 2. Eingl.'Bot. t. 1283 . Sv. Bot. t. 65. Westr. Farglaf: t.13. Umbil. Hoffm. Pl. Lich. t. 28. f. 1, 2.; 29. f. 4 . Schaer. mus. I. $p$. 113. Lecid. Ach. meth. p. 85. Gyroph. Lich. univ. Gyromium. Wahl.

Exs. Lich. Suec. n. 125. Schaer. Helv.n.156. Moug. et Nestl. n. 60. Funck Cr. n. 96. E/hrl. Cr. 79.

In regione subalpina Europae australis, in 
montanis medice planitierumque præcipue juxta aquas in boreali, ut Scandinavia inferiori, copiose; versus septentrionem rarescens, in Lapponia prorsus deficiens.

Maxima nostratium, spithamam usque attingens, at vulgo minor, papulis inflatis facile distincta. Junior integra concava, adultior lobata \& uno latere producta; subcoriacea, ad saxa vero irrigua legimus formam membranaceam $U$. polyphyllam c. prorsus referentem. Recens utique virens, sicca proprie fuliginosa, sed e pruina adspersa cinerascens. Apothecia passim papillata, raro concentrice plicata; in America bor. etiam lirellifera. 302. UMBILICARIA atropruinosa, thallo coriaceo epapuloso e nigro fuligineo, subtus lævi atropruinoso, apotheciis elevatis marginatis patellatis simplicibus. Schaer. in Ser. mus.p. ıo. t. I $2-14$.

Gyroph. Ejusd. Naturwiss. Anz. Lecid. Spic. l. c. a. anthracina, thallo supra æquabili. Lich. anthracinus. Wulf. in Jacq. misc. 2.t. 9. f. 4. - Num Auctores reliqui hanc cum subsequente jungentes veram ante oculos habuerint, satis incertum.

Exs. Schaer. Fielv. n. 154.

b. tessulata, thallo supra tenuiter rimoso-areolato aut punctato verrucoso, ad umbilicum rugoso. Umbilicaria leiocarpa \& flocculosa. Decand. Fr. 2. p. 410, 412. Gyroph. tessulata. Ach. syn. p. 64.

Exs. Schaer. Helv. n. 155.

c. reliculata, thallo supra reticulato-rugoso. Gyroph. glabra 1 . heteroidea. $\delta$. corrugata. Ach.

In alpibus Europæ australioris, Pyrenæis, Delphinatus Montagne! Dufour! Helvetiæ Schleicher!

Species perquam distincta. Thallus tenuis, monophyllus aut varie lobatus, normaliter lævis, sed sæpe rimoso-tessulatus aut corrugatus varians, numquam vero papulosus, superne ater, pruina coerulescenti adspersus, in b. vero cinerascens; subtus lævis, fibrillis destitutus, tantum sub apotheciis foveolis notatus. - Apothecia enim semper elevata, plerumque pedicellata, opaca; disco raro tumente, numquam gyroso-plicato, senescente rimis 
tenuissimis exarato, quo, a Lecideis omnino peregrino, major mihi indicari videtur affinitas cum Umbilicariis, v. c. U. Mühlenbergii, quamquam lirellæ ipsæ, in aliis dehiscentes, non evolutæ sunt. "Lamina senio confecta stratum conspicitur thalloideum album sæpius denuo proliferum, novam apotheciorum vel singulorum vel plurium prolem enixa." Schaer. Adest reipsa affinitas cum Sticta Delisea Fée \& Parmelizs umbilicatis.

* 3o3. UMBILICARIA polyphylla, thallo coriaceo-cartilagineo lævi corrugatuque olivaceo-æneo, subtus glabro aterrimo, apotheciis sessilibus, primo patellatis marginatis, demum convexis concentrice plicatis. Hoffm. Germ. 2. p. 109 .

Dill. musc. t. 30. f. 129. Lich. polypb. Linn. et Auct. Engl. Bot. t. 1282. Umb. Hoffm. Pl. Lich. t. 59. f. 2. Gyromium. Wahlenb. Suec. n. 1668. Lich. glaber. Ach. Vet. Ac. Handl. 1794. t. 2. f.5. Gyroph. Meth. p. 101. Umbilic. Decand.

Exs. Lich. Suec. 278. Flörk. n. 67. Moug. n. 342.

b. thallo crassiori demum rugoso, evidentius sultus atropruinoso. Gyroph. anthracina. Ach.meth.p.102! (Suecica).

c. deusta, thallo tenuiori furfuraceo-flocculoso subtus sublacunoso. Lich. deustus. Linn. certissime. Engl. Bot. t. 2483. Gyrophora. Ach. syn. p. 66. Gyromium. Wahl. Lich. flocculosus. Wulf. in Jacq. Coll. III. t. 1. f. 2. Umbilic. Hoffm. Pl.; Lich. III. $t .68$.

Exs. Lich. Suec. n. 279. Flörk. n. 86.

In montanis \& alpinis Europæ australis, ubique in Europa boreali. b. ibidem locis montosis magis \& perflatis; c., status degener, locis aqua sulfusis.

Hujus frondes reliquarum minores, formæ variæ, magis aggregatæ \& cæspititiæ sunt, ut nomen Linnæanum optime mereatur, licet et hæc primitus monophylla sit. Pagina inferior plus minus evidenter atropruinosa ceterumque habitu \& variationis typo ita cum priori connexa, ut passim apud nos reperiantur specimina ad illam ex habitu referenda, quare veteres sæpe commutarunt. At geographica distributione, confirmantibus apotheciis, 
ab eadem diversissima est; nec magis liceat nobis Suecis ex talibus sterilibus speciminibus præcedentem huc trahere, quam Helvetis $U$. polyrrhizon ad $U$. velleam. Species enim in vera sua patria dijudicandæ sunt. Umb. deusta Auct, optime monentibus Schradero \& Schaerero, prioris status locis irriguis extenuatus \& dissolutus certe est ; prorsus analogos habemus plurimarum, nec desunt rationes suspicionis sequentis sub hoc nomine etiam vendi. Margo in c. magis angulatus est, at discus tamen concentrice plicatus.

3o4. UMBILICARIA hyperborea, thalla coriaceomembranaceo, adulto rugoso-papuloso olivaceofusco, subtus sublacunoso glabro, apotheciis adpressis primo patellato-lirellosis demum pardlele plicatis. Hoffm. Germ. p. I r o. Linn. Lapp. n. 453. Lich. hyperb. Ach. in Vet. Ac. Handl. 1794. p. 89. t. 2. f. 2. Umbil. Schrad.Hoffm. Pl. Lich. t. 71. f. 1-5. Sturm. Deutsch. Fl. II. 7. Gyrophora. Ach. Lich. univ. p. 225. Flörk. Berl. Mag. 1810. p. 66. Fl. Dan. t. 1744. Gyromium Wahl. Suec. n. 1670. Umb. papillos. Dec. Fr. 2. p. 411. Umb. ænea. ß. Schaer. spic. p.91. Exs. Lich. Su. n. 126. Schrad. n. 117. Funk. n.99. Per regiones alpestres ventosas Europæ facile totius; in Scandinavia in regiones inferalpinas descendit quousque Peltigera arctica, non vero ut illa ad regiones sylvaticas, sed potius ad campestri-maritimas tendit.

Priori major, in ambitu erosa, quod non nisi in prioris c. observatur. Apothecia valde irregularia, sed vulgo patellæ jam primariæ lirellas Opegrapharum referunt. - Infantilis lævis quidem, at mox papulosa; qualis prior numquam, sed sub eisdem momentis ac hæc obvia incrassatur \& corrugatur. Læves \& corrugatæ plurimæ species, non vero læves \& papulosæ variare solent. Potest pro prioris filia forsan haberi, at non mera est forma alpestris 1. senilis, nam exstat utique quædam differentia primitiva, sub analoga evolutione constans, quod e diversa distributione geographica \& diversa vegetationis historia in Suecia, ubi melior explicata forsan quam in alia terra, patescere videtur. Nam in sua regione angustiori priorem non excludit, sed in magis recedentem for- 
mam mutat e. s. p. Ubi vero hæ omnes formæ intra angustos limites stipantur, eos discernere difficile fore video, si prior ut campestris re ipsa in summis alpibus obviam venit.

*彞 3o5. UMBILICARIA erosa, thallo cribrosoreticulato mox ruguloso olivaceo-fusco, in ambitu eroso-laciniato, subtus exasperato papilloso cinerascente, apotheciis adpressis patellatis marginatis, dein gyrosis irregularibus. $\mathrm{Hoffm}$. l. c. p.' I I I.

Dill. musc. t. 30. f. 118. Lich. erosus. Weber, - Ach. in Vet. Ac. Handl. 1794. t. 2. f.1. Umb. Schrad. - Hoffm. Pl. Lich. t. 70. Sturm. l. c. 7. Schaer. spic. p. 93. Gyroph. Ach. - Engl. Bot. t. 2066. Fl. Berl. Mag. 1810. p. 62. Gyromium. Wahl. Suec. $n$. 1671. Lich. torrefactus. Lightf. Umbil. Schrad. spic. p. 104.

Exs. Lich. Su. 127. Ehrh. Cr. 306 (Lich. corros.) Schrad. n. 118. Schaer. n. 153. Moug. n. 250. Funck. n. 98.

Per regiones montanas \& maritimas Scandinaviæ usque ad Hallandiam copiose; in reliqua Europa tantum alpestris \& in australi summa juga occupat.

Thailus priorum \& $U$. probossidece casu cribrosopertusus fit (uon U. cylindricæ \& reliquarum); in hac vero normale est ob frondem ipsam cribroso-reticulatam. Primo æquabilis, mox rimoso-rugosa, numquam papulosa. Ceterum paginæ inferioris fere tophacea natura ob papillas exiguas, passim in fibrillas rigidas productas, distinctissima est. Discus primo subrimatus, mox plicatus, plicis variis sublongitudinalibus.

3o6. UMBILICARIA proboscidea $\alpha$, thallo submembranaceo contiguo reticulato-rugoso olivaceo-fuligineo, subtus sparsim fibrilloso nudove pallido, ad umbilicum nigro, apotheciis subelevatis e patellato subglobosis gyrosissimis. Decand. Stenh. Sched. Crit. V.p. 3.

Lich. proboscideus. Linn. Fl. Dan. t. 471. f. 3. Gyroph.-Ach. syn, p. 64. Engl. Bot. t. 2484. Gyro- 
mium. Wahl. Suec. n. 1672. Lich. deustus Quibusd. minime Linn., quidquid servetur in Herb. Linn. Lich. exasperatus Gunn. Lich. pullus. Wulf. in Jacq. misc. II. t. 9. f. 3 (forma ad priorem accedens) Lich. mesenterif. Ehrh.! - Rutstr. Diss. p. 15. Umb. mesenterica \& corrugata. Schrad. - Hoffm. Pl. Lich. t. 43. f. 4-7. Gyroph. Jacquini. Ach. meth. p. 104. Gyroph. s. Umbil. polymorpha $\beta$. Schaer.

Exs. Lich. Su. n. 129. Ehrh. Cr. 89. plane! Flörk. n. 7. Schrad. n. 119. Schaer. n. 148. Moug. n. 249. Funck. n. 100.

b. G. tornata, thallo indurato complicato magis plicato-rugoso, subtus obsolete fibrilloso. Ach. Lich.univ. p. 222. t. 2. f. 13.

c. G. arctica, thallo incrassato rugoso, elevato-punctato subtus glabro. Wahl. Lapp. - Dill. musc. t. 30. f. 119. G. arctica. Ash. meth. p. 106.t.2.f.6. Locis ventosis Scandinaviæ fero totius formatione primitiva fundate, non tantum prioris fida socia in maritimis, sed etiam in silvaticis planitierum (v. c. Femsjö), b. c. in alpestribus induratæ; per reliquam Europam tantum in editioribus montanis \& alpibus.

Si cum sequente $U$. cylindrica conjungetur, saltim ex ejus historia in Suecia primaria esse debet; sed haec tantopere differt, ut Lichenologi nostri omnes de earum unione possint dubitare, videntes quidem characteres utrique adscriptos obliterari, ipsas vero stirpes facillime dignosci. Alia videtur ratio per reliquæ Europx alpes, ubi in angustiem reducuntur, cum ex indole Suecanæ terræ hic objecta, quasi microscopio aucta, magis segregantur. Regiones nostras inferiores silvaticas 1. scopulos marinos lustranti mox obviam venit $U$. proboscidea, ibidemque magis ad $U$. erosam quam ullam $U$. cylindricam sæpe accedens; versus regiones alpestres magis induratur, corrugatur, subtus eximie glabrescit \& obfuscatur; in hac regione primum obviam venit $U . c y-$ lindrica livida, lævigata, subtus maxime crinita \&c., qua demum in summis alpibus, ubi evanuit $U$. proboscidea, formam subverrucosam, subtus nudam enititur. Inest utique evolutionis seriei insignis analogia, sed, ut videtur, etiam primitiva differentia. Fingere quidem possumus $U$. cylindricam levigatam e superficie pruino- 
so-deliquescente ortam esse, unde vero patet hanc subtus glabrescente $U$. proboscidea maxime crinitam evadere e. s. p.? - Thallus plerumque monophyllus, eximie umbilicatus, exasperatus, subtus absque papillis, fibrillis brevibus raris sparsis, haud marginalibus. Apothecia sessilia, magis gyrosa.

$\beta$ UMBILICARIA cylindrica, thallo subcoriaceo læviusculo livido cinereo-pruinoso, margine nigro-fibrilloso nudove, subtus ochroleuco-pállido, apotheciis pedicellatis demum concentrice circinatis. Wahl. Suec. $n,{ }_{1} 6_{7} 3$. Gyromium. Dill. musc. t. 29. $f_{.}$116. Hall. helv. $t$ : $47 . f_{\text {. }} 4$. Lich. cylindricus. Linn. - Fl. Dan. t. 471. f. 1 , 2. Gyroph. cylindrica. Ach. - Syn. p. 65. Eng $l_{\text {. }}$ Bot. t. 522. ex Corrig. in indice. Gyromium cylindric. Wahl. Lapp. n. 927. - Lich. proboscid. Hedw. S't. Cr. 2. t. 1. f. A. Wulf. in Jacq. Misc. II. t. 9. $f .{ }_{2}$. L. crinitus. Lightef. Umbilic. Hoffm. Pl. Lich. t. 44. f. 1-9. Umb. polymorpha. Fl. BerL. Mag. 1810. p. 65. Schaer. spic. p. 86.

Exs. Lich. Suec. n. 315. Schaer. n. 143-147. Ehrh. Cr. n. 19. Schrad. n. 120.

b. rigida, ambitu subnudo. Hoffm. Germ. p. 112. Lich. mesenteriformis, Wulf. in Jacq. Misc. II. $t$. 9. f. 5. Gyroph. mesarea. Ach. meth. p. 106.

c. punctato-verrucosa. Schaer.

In alpibus tolius Europæe, nec in Scandinavia a montibus altioribus descendit. b. c. in asperrimis jugis.

Transitum directum ad præcedentem in Suecia non vidimus, sed ut Lichenologis reliqux Europæ in media via obviam eamus, ut veram speciem haud proposuimus. Differt a priori colore paginæ superioris e pruina lividocinerascente, inferioris præsertim versus umbilicum pallido, substantia rigidiori, apotheciis pedicellatis magis circinatis. Pagina superior, quæ in priori definite, in hac non nisi casu corrugatur. Fibrillx, quæ in priori in pagina inferiori sparsx, tenues; in hac marginales tantum, rigidx, sxpe admodum insignes \& ramosæ, passim in denticulos reductæ. Deficiunt quidem in utraque locis frigidioribus fibrillæ (scilicet $U$. probosciden in regione optime crinitæ $U$. cylindrzcae), at numquam in pagina 
inferiori sparsæ in $U$. cylindrica, 1. marginales in $U$. proboscidea. Hæc forma rigida Hoffn., licet Umb. proboscidea proxima videatur, ab eadem loco natali longius distat; male ad priorem transtulit Acharius ex charactere, sed ea speciernm \& formarum limitatio, quæ e characteribus \& speciminibus siccis comparatur, nimis facili pretio emitur.

307. UMBILICARIA vellea $a$, thallo eoriaceo lævi glaucocinerascente, subtus subhirsuto, apotheciis superficialibus primo papillatis dein patellaformibus, disco papilloso coneentriceque plicato demúm verrucoso, margine tumido.

Diil. musc. t. 82. f. 5. Lich. velleus. Einn. Ach. in Vet. Ac. Handl. 1794. t. 3. f. 3. Gyrophora Ash. syn. p. 6s. Gyromium. W Walil. Suec. n. 1674.

b. sijalochroa. Ach. I. c. subtus atrovillosæ.

Exs. Lich. Suec. n: 130.

In (regionibus arclicis Americæ,)alpibus Scandinavia, nec non in martimis, v. e. in Roslagiæ extimis scopulis copiosissime.

In statu perfectissimo maxima generis, valde coriacea \& vellerea, recens viridi-glauca, nuda; sicca cinerascens sæpeque (præcipue in $\beta . \gamma$. evidenti) pruina glauca adspersa. Apothecia semper superficialia, ne adpressa quidem, sed elevata potius, primo eximie Lecidina, margine crasse elevato persistente. Hane eisdem locis \& sub eisdcm momentis ac $U$. polyrrhizon legenti, licet singula diversas plagas occuparet, affinitatem sane inter has non divinare licuerit. Transitum in sequentes nee eximius. observator Sten/lammar nec ipse detegere potuinus, sed habitu saltim conveniunt.

B. $U$. depress thallo coriaceo rigido, apotheciis thallo impressis planis gyroso-plieatis, margine crasso.

Gyrophora s. Umbilicaria depressa. Schiaer. - Ser. mus. I. p. 93. t. 10, 11. Spic. p. 81. Varias hujus formas sistunt: Lichen velleiformis. Bellardi..- sec. spec. originale a Prevost communicatum. Arthonia, Peltigera. s. Gyroph. Ach. Gyrophora crustulosa. Ach. syn. p. 68. Umb. saccata. Dee. Fr. 2. p. 408.

Exs. Schaer. Helv. n. 137-142. 
In alpibus Europæ australioris copiose. Hanc in Scandinavia non vidimus.

Est quoddam in habitu, thallo magis constricto rigidiori \& præcipue apotheciis depressis, thalloque impressis, a nostra $\alpha$. peregrinum, ut peculiarem saltim omnino efficiat varietatem, thallo subtus tam pallido-, quam nigro-hirsato, I. tantum papilloso ludentem ut reliquæ hujus speciei varietates.

r. U. hirsuta, thallo membranaceo pulverulento e viridi cinereo, apotheciis adpresis superficialibus mox patelleformilous, dein convexis subglobosis gyroso-plicatis, margine semper tenui. Stenh. l. c. p. 4 .

Dill. musc. t. 30. f. 117. Lich. hirsutus. Ach. in Vet. Ac. Handl. 1794. $t$. 3. $f$. 1. (subtus cinereofuscns) L. polyrrhizus. l. c. t. 2.f. 3, 4. (subtus niger), Gyroph. hirsuta. Ach. syn. p. 69.

Exs. Lich. $S$ ec. 131.277. spadochroa. E/hrh. Cr. n.317.

* murina, thallo subtus tantum punctato scabro. Vaill. par. t. 21.f. 14. Lich. griscus. Ach. l. c. t. 2.f.3. Lich. muriuus. Ach. Pradr. Sv. Bot. t. - - - Gyroph. murina. Ach. syn. p. 69. Engl. Bot. t. 2486. Umb. grisea. Holfm. U. murina Dec.

Exs. Lich. Suec. n. 132.

Locis apricis ventosis, campestribus l. alpestribus passim, semper vero ab a. discreta \& facile distinguenda. Stenhammar!

Cfr. Stenh. in Sched. Crit. de hac maxime varia specie. Nec $\alpha$. nec $\gamma$. apud nos xneo-fusca. Var. hirsuta non tantum ut priores variat subtus pallido- \& nigro-hirsuta, vel ut $\beta$. simul papillosa tantum, sed etiam subtus glabra (b. papyrea. Ach. I. c.) - Umb. cirrhosa. foffm. Pl. Lich. t. 2. f. 3, 4 sterilis, haud rite definienda. - Lich. s. Vimb. spadochroc Auct. ut status subtus nigrescens ad omnes tres priorum promiscue citanda.

308. UMBILICARIA polyrrhizos, thallo coriaceo lævi nudo æneo-fusco, subtus atra fibrillosopannoso, apotheciis primitus lirellæformilus mox compositis gyrosissimis absque margine communi. - Stenh. Sched. Crit. V.p. 3. 
Lichenoid. pullum - inf. nigrum Dill. musc. $t .30$. $f$. 130. Lich. Linn. Suec. n. 1108 certissime. Gyromium. Wahl. Suec. n. 1675. Umbill. vellea. Hoffm. Pl. Lich. t. 26. f. 3. Lich. pellitus. Ach. l. c. t. 3. f. 2. Engl. Bot. t. 931. Gyrophora. Ach. syn. p. 6\%. Flörk. in Berl. Mag. 1810.p.66. Umbil. Decand. Fr. ex syn.

Exs. Lich. Suec. n. 129. Ehrh. Phytoph. 80. "Scalpodora."

Per Sueciam omnem inferalpinam \& in silvaticis \& in maritimis, vulgo extra omne prioris, longe angustioribus limitibus circumscriptæ, consortium; in Britannia montana; per reliquam Europarn, ut videlur, magis sporadica.

Nulla species in Suecia nec vulgatior, nec quoad thallum magis typica, nec evidentioribus characteribus diversa. Vegela semper nitida, viridi-ænea, sicca fusca semperque nuda; tantum emortua et putrida supra livido-cinerascens, qualia vero specimina rarissima. Quæ cum contrarie se habeant in U. depressa a. F. Schaereri, huc trahi vix delet. Subtus. semper dense atropannosa est, unde polyrrhizos nomen optime meretur. Apothecia nitida, depressa, \& lirellosa, in tuberculum semper immarginatum tenuissime gyrosum stipata. Hujus speciei abolitio sine dubio Lichenologos theoreticos multum vexabit. Proximæ species Americanæ sunt.

\section{Trib. III. GRAPIIDEÆ.}

CHAR. Apothecia difformia, plerumque oblonga aut lirellæformi-extensa. Discus primo connivens aut velatus, oblongus, subcanaliculatus. In statu normali excipulo l. proprio l. thallode marginata.

Est hæc tribus quasi deformatio duarum præcedentium, intimo nexu cum utraque conjuncta earumque differentias vilipendens. Parmeliæ enim, v. c. $P$. vento$s a, \&$ Biatora in statu atypico, deformant apothecia omnino ad typum Leucogrammatis Meyer, Ustalioe; Lecideæ comprimuntur \& elongantur, ut Opegraphas referant. Nec dubium videtur in tropicis Leucogrammata, liberius explicata ad typum Parmelix, ut Opegraphæa- 
pud nos ad Lecidex, revergere. Lecanactis inter has tres tribus omnino ambigit. Attamen ob habitum consimilem omnium normalium Graphidearum, vix ullus dubitat easdem ut peculiarem sectionem considerare. - Potissimum tropicas inhabitant regiones, in quibus in plurima luculenter diversa genera (observantibus primis Eschweiler \& Fée) abeunt. Versus septentrionem admodum rarescunt. Restant quidem in Europa australi generum tropicorum vestigia, sed adeo obsoleta, ut exoticis non cognitis hæc a centrali Opegraphoe genere distinguenda vix separarentur. - $\mathbf{E}$ corticolis Lapponiam ipsam tantum intrat status ille deformatus "Arthonia radiata" dictus, in Nordlandia primum obviam venit $O$. rimalis. Illa per reliquam Sueeiam explicatur simul in $O$. atram, hæc certe in O.variam, acceditque O. scripta. Reliqua omnes extimas provincias litorales tantum attingunt. Summi ponderis est hæc geographica distributio tam ad species distinguendas, v. c. infinitæ $O$. herpeticœe formæ eisdem limitibus circumscriptæ sunt, quam præcipue ad formas abortivas determinandas. Abeunt nempe plurimæ species versus terminum suum borealem (cum Gr. dendritica Ach. tantum australior sit, non pro forma Arthonioidea borealis O. scriptæ sumenda est) vel etiam in vera sua patria ad cortices tenellos levigatos nascentes, in maculas magis dilatatas, confluentes immarginatas, qux Arthoniæ genus cum similibus formis Parmeliæ, Lecideæ, Verrucariæ efficiunt. Defectu omnis excipuli marginantis ut atypicæ dignoscuntur. - Saxicolæe æqualiter magis distributæ videntur. - In australioribus terris perfectius simul explicantur, lepra nempe per stratum corticale, cum epidermide matris confluens, line inde erumpit \& stroma quoddam spurium apotheciis subministrat, unde genera Glyphis, Sarcographa Fúe, Medusula Eschw., $A-$ sterisca Meyer. Quatenus hæc differentia ad has distinguendas sufficiat, nulla specie genuina (Opegraphas harum charactere gaudentes vidi) in natura persecuta, mea dubia supprimo. Utique ha differentix evidentes v. c. in Glyph. labyrinthica Ach., sed Gl. tricosa etiam sine illo pulvinulo occurrit; \& in omnibus formis Europxis mihi cognitis hæc momenta 1 . prorsus accidentalia $\mathrm{l}$. tam parum evidentia, ut in Flora Europæa hæc genera inserere non debuerim. Cfr. Opegr. scriptam, O. herpeticam, Medusulam \&c. Id tantum observem, differentias horum generum, facile dicerem abnormium, multorum- 
que inter Lichenes innatos similium, nulla vegetationis primitiva suffultorum, licet eorum character in Systematicum usum evidentius proponi possit, e majori naturæ licentia in infinis formis re ipsa magis esse \& variabiles \& accidentales, quam. v. c. Usneæ \& Parmeliæ, Cladoniæ, Unbilicarix \& Lecideæ, quamvis harum apothecia normalem Lichenum typum exprimentia inter se similiora. Has insuper separat differentia thallina primitiva, illas tantum secundaria, a morphosi perfectiori pendens; nam s. d. stroma non potest non pro thalli mera prole haberi.

\section{OPEGRAPHA.}

Opegrapha. Humboldt. - Pers. - Schrad. - Ach. meth. - Decand. - Schaerer - Fries - Dufour. - Opegrapha \& Graphidis spec. Ach. Lich. univ. - Opegrapha, Graphis, Scaphis Eschw. Syst. Graphidis \&c. spec. Meyer. (Plures Arthonix \& Spilomatis spec. Ach. abortivi).

CHAR. Apothecia varia, sublirellæeformia, rima longitudinali aperta, excipulo proprio carbonaceo (perithecio) libero marginata. Discus canaliculatus, primitus excipuli margine inflexo-connivente clausus, dein apertus induratus, corneus. Thallus crustcaceus.

I. E formis aberrantibus æque facile conjungeres Opegraphas cum Lecideis ac Umbilicarias, l. illas pro Lecidearum degeneratione haberes, præcipue cum inter Opegraphas \& Lecideas deest primaria quædam in vegetatione differentia, quain occulte consulendam jubet Linnæus, prorsus negligendam tantum Linnæo strictiores Linnæani. Ad Umbilicarias transire videntur Lecideæ quædam disco demum papillato plicatoque, ad Opegraphas disco demum elongato \& difformi. Ad Lecideas revergere videntur Umbilicariæ disco subæquabili, Opegraphæ disco rotundato. Hæe omnia vero accidentalia sunt, \& ex isto argumentandi genere plene deducto nulla fere Lichenum genera persisterent. Tam Opegrctphce quam Umbilicarice a Lecideis recedunt excipuli margine incurvo, undc discus primo clausus. Servavi per omnem orbem literatuin jam receptissimum Opegraphæ nomen, cum sub isto omnes species jam descriptoe et cognitce sint, \& vix succedat Graphidis Adans., omnino vagum nulliseque 
speciebus definitis subscriptis obsoletum ubique receptum reddere. Ad genium Linnæanum speciebus quibusdam exoticis, Graphidi adscriptis ab Achario, potius servandum videtur.

II. Species hujus generis maxime proteæ sunt; ex apotheciorum forma, divisione vix ullæ differentiæ petendæ sunt. Crusta adhuc magis incerta, si tartaream paucaruin saxicolarum excepero; ad corticolas discernendas vix adhibere potui. Quomodo res se habeat cum harum chrysogonidio \& chlorogonidio ex acutissimis $W$ allrothii observationibus, practicæ Lichenologiæ minus interest. Corticolarum crusta mihi, ut indicat cel. Meyer, semper normaliter leprosa e viridi albicans visa est, sed ob epidermidem arboris cum strato corticali confluentem l. ejus vices gerentem typicum Lichenum cartilagineum habitum præ se ferunt. Omnes reliquæ crustæ differentiæ (coloris, structuræ \&c.) vel a Piycomatre (Syst. Orb. Veg. I. p. 200, 201) vel a Bysso intertexta pendere mihi visæ sunt. At hic situs lepræ, ut ajunt, hypophlœodes, momentum mihi videtur minoris ponderis \& a Lichenum facultate substratum assimilandi 1 . substituendi pendere; nam in multis ejusmodi speciebus, etiam Opegraphis, v. c. $O$. varia terrigena, strati corticalis structuram simillimam inveni, sive epidermis matricis ejus vicibus fungatur, sive proprio instructe sint. Cfr. Eschweil. in Mart. Lich. Brasil. \& obs. ad O. scriptam. Quoad locinn natalem nempe maxime variabiles sunt Opegrapha, normaliter corticolæ, quales absolute oinnes apotheciis erumpentibus, sed species apotheciis superficialibus etiam saxicolae, præcipue vero in saxis formationis recentioris obviæ, variant - at quarum crusta vere tartarea, absolute saxicolæ sunt. Omnes ad ligna denudata, terram conglomeratam, argillam \&c. obviæ, quantum equidem experiri potui, aberrationes sunt lociles. - Ceterum hoc genus potius exponendum a Lichenologis Europoe australis, unde variæ mihi missæ sunt formæ, nec differentias evidentes offerentes, nec transitus directos monstrantes, quas omisi. Primi Dufour \& Schrcerer, quibus completam quoque ipsorum specierum collectionem debeo, species veras hujus generis determinarunt. * Apotheciis superficialibus, margine thallode de-
stitutis.

109. OPEGRAPHA petroea, crusta cartilagineotartarea areolato-verrucosa glaucescente, apo- 
theciis sessili-adpressis obtusis, excipuli integri margine incrassato persistente, disco lincari primitus nudo. Ach. syn. p. 72 .

Ad rupes \& saxa granitica Scotiæ Hooker! Smolandiæ ad Femsjö rarius.

Sprcies distinctissima, præcipue crusta pro ratione crassa cartilagineo-tartarea, pulchre rimoso-areolata aut verrucosa, alba aut cinerascente. Apothecia crustæ ad dimidium immersa, sed absque omni margire thallode, tumida, nitidula, utrinque obtusissima; margine proprio elevato crasso connivente, nec per ætatem distante, unde discus semper angustistimus linearis æquabilis. Ceterum forma \& magnitudine varia, subrotunda (rima tamen semper transversalis), elliptica, elongata \& flexuosa, sæpe triradiata \&c. - Hujus status ad saxa ferruginosa ferro tinctus videtur $O$. tesserata Dec. Fr. 2. p. 313.

310. OPEGRAPHA cerebrina, crusta subtartarea contigua indeterminata, leprosa alba, apotheciis superficialibus subrotundis, excipuli integri margine tumido persistente inflexo subtriquetris, disco dilatato deınum papillato. Dec. Fr. 2. p. 312.

Lecid. plocina. Ach. syn.p.16. Lecid. cerebrina. Schaer. spic. p. 136. Opegr. variæ variet. Meyer. Flecht.

In rupibus calcareis alpinis Pyrenæorum Dufour! Helvetia! in saxis Anglix I'urner! Omberg Sveciz.

Habitu \& historia tantum ab O. varia discrepat, nt distinguere non dubitern, at ob apothecia iuniora clausi, rimose dehiscentia, marginem incurvum, formamque demum triquetrain \& stellato-radiatam non possum genere movere. Crusta lineolis nigris numquam circumscribitur. - Ceterum diversarum regionum specimina habitu inter se admodum recedunt. In Pyrenaicis primariis, cum quibus Suecica quoque satis conveniunt, crusta admodum tenuis, tartarea potius quarn leprosa, (pulverulenta alba tamen ex ipso Decand.); apothecia tumida, elevata, elliptico-rotunda, juniora clausa, rima longitudinali simplici aut triradiata fissa, adultiora aperta, margine crasso, passim duplicato. Cum speciminibus anglicis 
præcipue convenit descriptio Schaereri cyusta amylacea, sæpe pulvinata, albissima.

* OPEGRAPHA rupestris, crusta tenui contigua nigro-limitata, demum leprosa efflorescente, apotheciis subrotundis ellipticisque demum plicatis deformatisque, marginem tumidum abscondendentibus.

O rupestris. Pers. in Ust. Ann. II. p. 20 ex Flotow. O. Persoonii Ach. syn. p. 71. . O. gyrocarpa. Flatow in Regensb. Bot. Zeit. 1825. p. 345. crusta rufescente.

Exs. Flatow Sil. 79 (in cortice n. 80).

Ad saxa arenaria aliaque formationis recentioris; etiam ad cortices rarius.

Hæc mihi numquam obvia difficilis est forma, prxcedenti utique nimis affinis, quam ad monita præcipue Cel. Flotowii distinximus. Sæpius prorsus acrustacea obviam venire videtur, \& in hoc statu ab. affinibus difficilis distinctu.

3i1. OPEGRAPHA varia, crusta subleprosa indeterminata, (raro hypophloeode), a potheciis superficialibus tumidis, excipuli integri marginibus demum distantibus tenuescentibus evanidisque, disco planiusculo, priaitus sulppruinoso, intus nigricante. Pers. in Ust. Ann. Bot. $7 \cdot p$. 3o. Cfr. Schaer. Flecht. p. 33.

a. pulicaris, apotheciis subellipticis, disco concaviusculo, margine inflexo. Lich. pulicaris. Hoffm. en. t. 3. f.2.c? Lich. spureatus \& vulvella. Acli. Proclr. O. vulvella (crusta hypophlocode), O. nimbosa $\alpha, O$. phra (crusta mycomatre fuscati) Ach. s: n. p. 77, 71, 78. O, pellicula. Duf.! revis. ex Auctore.

Exs. Lich. Su. n. 188. Flörk. n. 144. Maug. n.85\%. Flotow. $n$. 70 .

b. notha, apotheciis rotundatis. disco turgescente marginem sæpe obliterante. Graphis curvula. Ehrh. Engl. Bot. t. 1890. O. Lichenoides. Pers. l. c. t. 2. f. 4 . a. b. Lich., Opegrapha notha. Ach. - Syn. p. 76 . var. a Opegr. Verrucarioid. $\beta$. $\delta$., \& * Arthonia gibberulosa. Lich. univ.

Exs. Moug. n. 468. Flörk.n.27. - * Lich.Suec.n. 190. 
c. signata, apotheciis elongatis, disco 'lato plano, margine evanescente. Lich. hebraicus. Hoff $m$. en.t. 3. f. 2. f. O. signata Lich. univ. p. 201. (sub O. notha in Syn.; sub O. diaph. in Meth.) O. hebraica. Duf. ex spec.

Exs. Luich. Suec. n. 32. Flotow. n. 76.

d. diaphora, apotheciis elongatis utrinque attenuatis, margine subpersistente. Opegr. diaphora. Ach. - sub notha in Syn. p. 77. Engl. Bot. t. 2280. 0. tridens l. c. p. 79. O. cymbiformis. Flörke.

Exs. Lich. Suec. n. 189. Fl. Deutsch.n.165. Moug: n. 556. Schaer. n. 98. Flotow. n. 75.

Ad corticem crassiorem arborum ubique copiose, usque ad Sueciam mediam, ubi desistit. Magis degener ad ligna denudata, terram argillacearn \& saxa.

Maxime variabilis, nulla forma constante, hinc aptissimum nomen servandum, licet Schaereri ob accuratam limitationem magis classicum. Inter formas allatas nulli limites. Ob locum ad cortices crassiores crusta plerumque denudata, sæpeque prorsus deperdita, ad arbores vero lævigatas, v. c. Betulx, hypophloeodes. Apothecia hujus sequentium latiora, opaca, disco magis dilatato plano, nunc nudo, nunc cresio-pruinoso; in junioribus sporis eleganter xruginoso-pulverulentus, facie $\mathrm{Cal}$. roscidi!, qualem in nulla alia specie vidi. - Ad ligna ( $O$. ovaliformis Lich. univ.) varie degenerat, præcipue in truncis cavis Alni frequens, apotheciis pluribus sæpe in maculam radiatam aut contortam confluentibus; discus in his constanter fere cæsiopruinosus; a similibus speciminibus non discernere valeo 0 . elevatam Dec. Fr. 5. p. 169. secundum specimina ab inventore Dufour communicata. - Snb nomine $O$. argillicoloe Duby specimina formæ c. simillima ad parietes argillaceos in Gallia occidentali lecta. - Denique ad saxa, fotmationis præcipue recent. obviam venit \& a præcedente facile discernenda; a. eximiam habeo e Gallia sub O. saxicola Ach.! nomine; b. pro $O$. Persoonii passim venditur; d. est O.tridens b. Ach. 1. c. Huc quoque Flotow trahit suam O.hybridam Bot. Zeit. 1825.

ß. O. rimalis, crusta subhypophlœode, apotheciis superficialibus angustis linearibus, marginibus parallelis, disco lineari canaliculato nudo. 
O. chlorina Pers. in Act. Vett. (crusta peregrina) 0. rimal is. Ach.Syn.! O. vulgata. Auct. Var.

Exs. Lich. Suec. n. 31. p. p. (Fl. Deutsch. n. 87?)

Ad cortices magis æquabiles \& induratos v. c. Fagi, Populi \&c.

Rite segregatis formis ad $O$. variam \& $O$. atram pertinentibus, exstatne vera diversa $O$. rimalis? Talis mihi non obviam venit. Mea, ab Achario pro vera agnita, certo est angustissima prioris forma, a $d$. non rite limitabilis. Huc pertinet ex spec. misso Lich. hebraicus Ehrh. e. s. p., at nullibi synonymia difficilior quam inter Opegraphas ob diversissima, quæ sub singulo venduntur nomine.

* OPEGRAPHA saxatitis, crusta leprosa, apotheciis superficialibus angustis, excipuli integri marginibus parallelis subclansis, disco canaliculato nudo, intus nigricante. Dec. Fr. 2. p.3 32. e spec. Duf.

O. calcarea. Ach. syn. p. 72. Eingl. Bot. t. 179). sec. spec. ab Achario. data. O. lithyrga Ach. syn. p. 72. ex spec. Schleicheri. O. murorum. F'ée Dict. Class. ex spec. Desmaz. - Spiloma reticulatum. Chaubard! status deliquescens.

Exs. Desmaz. n. 288. (Schaer. Helv. n. 94.)

Ad saxa præcipue formationis recentioris \& ad muros. In Suecia non obvia.

Valde affinis $O$. atroe, at ne peregrina sub hac, quam ipse numquam nisi hypophloodem legi, immisceam, separavi. Apothecia nunc sparsa, nunc stellulato - aut maculæformi-congesta. - Moug. et Nestl. n. 856. O. rimalem magis refert. - O. lithyrga Flotow in Bot. Zeit. 1825. p. 343, quæ O. stenocarpa. v. lithyrga Exs. n. 83, a priori differt, ut $O$. rupestris ab $O$. cerebrina. Hæc omnia autoptorum examini commendo. Characteres hactenus dati non sufficiunt.

3ı. OPEGRAPHA atra, crusta hypophlœode, apotheciis emergenti-superficialibus gracilescentibus nitidis acutis, excipuli subintegri margiue tenui, disco lineari canaliculato nudo, intus corneo. Pers. in Ust. Alnn. 7. p. 3o. t. 1.f.2. B.b. 
O. atra Duf. in Journ. Phys. V. 8\% p.221. Schaer. spic. p. 48. Graphis atra. Wallr. Flecht. I. p.167.

a. stenocarpa, apotheciis longissimis semicylindricis flexuosis, nunc discretis nunc reticulatis \&c. Lich. denigratus Ach. Prodr. O. stenocarpa, denigrata \& vulgata. Ach. Lich. univ. Engl. Bot. t. 1753. O. stenocarpa, atra \& reticulata. Dec. Fr. 2. p. 310, 6. p. 170. - Subarthonioidea: O. epipasta. a. Ach. Lich. univ. O. dispersa. Decand.

Exs. Lich. Su. n. 65. Fl. Deutsch. n. 127, 126, 143. Desmaz. n. 386. Moug. n. 649. Schaer. n. 93.

b. abbreviata, apoth. abbreviatis, variis, sæpe radiatim dispositis. Flörk. - Gr. macularis. E/hrh. O. depressa, pedonta, stenocarpa $\beta$., denigrata $\gamma_{.}$, Verrucarioides $\gamma_{.}$, nimbosa $\beta$. Ach. Lich. univ. O. hapalea. Syn. Lich. p. 79. O. bullata, rimosa. Dec. Fr. 2. p. 309, 312. - Subarthonioidea: O. epipasta $\gamma . \delta$. Ach. $l$. c.

Exs. Fl. Deutsch. n. 128. Moug. et Nestl. n. 469. (in meo exempl. 468 \& 469 commutata).

* macularis, apotheciis in maculas varias subradiatas immarginatas dilatatis, confluentibusque. O. radiata. Pers. l. c. Lich. astroideus. Ach. Prodr. Arth. astroidea (s. radiata), \&, ex maxima parte, Swartziana Ach. - Engl. Bot. t. 1847. Arthonia vulgaris. Schaer. spic. p. 8. ex max. parte.

Exs. Lich. Suec. n. 24. Flörk. n. 121. Schaer, n. 16. Desmaz. $n .140$.

Ad cortices arborum, levigatos; b. ad teneros, *. in tenerrima ramorum epidermide, per omnem Europam.

Harum omnium formarum successivum transitum, ut quoque observarunt Wallroth \& Meyer, in eadem arbore facile persequimur. Species ipsa, neglecta apotheciorum forma mutabili, distinctissima est \& levi usu facillime recognoscenda. Inter hanc \& sequentem sectionem media est, apothecia ob crustam, quantum vidi, constantius hypophlocodem re ipsa per tenerrimam epidermidis pelliculam erumpunt, subinde quoque ab illa formatur tenuis spurius margo lirellas involucrans. Etiam disci, intus sæpe albidi aut cinerascentis, indole ad sequentes accedit. - Mihi ad ligna acrustacea raro, saxa non obvia. Cfr, priores. 
$\beta$. O. siderella, crusta obfuscata, apotheciis acutis opacis subinnatis, passimque erumpentibus. (Op. herpetica. Ach. - sub $\alpha_{0}$ in Synopsi, sed com-

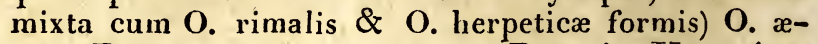
nea. Pers. -- Opegr. rufescens. Pers. in Ust. Ann. 7. p. 29. t. 2. f. 3. A. a. L. siderellus s. Opegrapha siderella. $A c h$. 0 . rufescens. $\alpha$. rubella. Schaer. spic. p. 50. crusta decolorata.

Exs. Schaer. Helv. n. 95.

Ad cortices arborum.

Verus Lichen rufescens \& siderellus Ach., exclusis omnibus peregrinis \& præcipue sequente admixtis, est forma macrior $O$.atrce, crusta obfuscata sublimitata, quo analoga cum $O$. cerebrina * rupestri; ceterum haud diversa. Si exstat alia a reliquis diversa species ut plurimi assumunt hæc mihi ignota est. Specimen O.herpet. a Laurero acceptum \& a Flörk eo probatum $O$, atrce forına est. 3r3. OPEGRAPHA herpetica, crusta hypophlœode dein verruculoso granulosa emergente, apotheciis emergentibus ellipticis obtuseve lanceolatis opacis, (verruca thallode alba subocellatis) excipuli integri marginibus tenuibus a disco canaliculato nudo, intus corneo, tumente demum obtectis. Ach. Lich. univ. p. 248.

Opegr. rubella. ß. Ach. Lich. univ. p. 250. O. herpetica. $\gamma$. Ach. syn. p. 73. Opegr. herpetica. Dec. Fr. 2. p. 309. Dufour Revis. Opegr. subocellata. Fl. Deutsch. X. p.7. Graphis insculpta. Wallroth. I. p. 351. (alia syn. ex spec. originalibus fidis ignota citare non ausus sum, v. c. Engl. Bot. t. 1785). Exs. Lich. Suec. n. 34. Flörken. 189. (Flotow S5. a.) b. apotheciis subpunctiformibus innatis, verruca thallode destitutis. Flörk. l. c. - O. fuliginosa. Lich. univ. p. 250. maxime inquinata.

'Exs. Lich. Suec. n. 191. Flörk. n. 190. Moug. n. 555. Flotow. 85. b.

Ad cortices arborum Europe facile totius, at tantum in provinciis meridionalibus campestribus Suecir. Ob apothecia hypophlneodia numquam ad saxa.

Rara est hæc species orusta extus haud inquinata \& 
apothecia vulgo admodum pusilla; est tamen species distinctissima $\&$ in statu perfecto facillima agnitu. Crusta vera sub epidermide latens. albissima, mox vero in verrucis granulosis albis erumpentibus collecta, unde crusta extus alboguttata, qualem in alia specie non vidi. In minus evolutis speciminibus tamen lævigata est. Apothecia juniora hypophloeodia, dein emergentia, cum verrucis thallodibus, a quibus subelevata $\&$ basi ocellata, vel omnino marginata ut in sequente sectione; passim plures verrucx confluunt \& Glyphidem Ach. (Asteriscam ex em. Meyer) offerunt. In b. vero hæc verruca desideratur \& apothecia punctiformi-innata persistunt. Præter crustam, apotheciis innatis, semper brevioribus, raro stellatis, intus omnino atris, in optimo vigore explanatis obtusis differt. Cfr. historiam apud Wallroth $l$. c.

Tot in his terris difficillimi generis rite distinguere potui species, non dubitans plures in Europa australiori obviam venire, videns quanta climace versus zonas calidiores augeatur specierum numerus. Nec plures invenio inter Acharianas; quasdam alias mihi missas, seposui. Restat Opegrapha rubella Pers. \& Ach., quæ siccitate abit in $O$. viridem Pers., quas respectu originis apto nomine O. herpetico v. disparatoe conjunxit Ach. syn.p. 73 , quæ æque ac 0 . rufescens Pers. (ex maxima saltim parte v. c. Decand.! Duf.! ad O. atram $\beta$. spectantes) rubella, ut observat Meyer, e Bysso, (e Chrysogonidio Wallroth.) oriuntur. Omnes præcedentes, numquam sequentes, hoc colore tinctas vidi \& revera nomina allata omnes complectuntur. O. rubella vera Persooniana (Lich. Suec. exs. n. 64. Duf.! Rev. Dec. Fr.') O. rufescens Flotow. n. 74. est O. varioe status; O.rubella Moug. et Nestl. n. 648. Flotow. n. 82. O. atroe, \& sane plurima specimina Flotow. Exs. 86, v. c. A. ab eadem dignoscere non valeo; $O$. rufescens $\psi_{0}$ rubella Schaer. n. 95. O. atra $\rho_{.} ; O$. rubella Fl. Deutsch. n. 166 est status Arthonioideus O. herpeticce. - In statu Arthonioideo vulgo sub nomine Arthonice obscurae Ach. syn. p. 6 (s. Opegraphae obscurae \& reniformis Pers.) æque disparata elementa comprehenduntur, v. c. $O$. herpeticae ex Flörkeo, $O$. atrae a Schaerero e. s. p., immo Verrucariarum ab Achario. Omnes ejusmodi degenerationes non ita describi possunt, ut ex hoc statu a tirone determinentur, nec utile esset, si in nomine quodam cognito acquiesceret, cum ipse nexum in natura per- 
séqui debeat. - Qui ceterum coloris crustæ mutati rationes acute expositas videre volunt, adeant Wallrothium, quem vero hoc loco nimis, longe deduceret sequi. Notandum tantum Opegrapharum apothecia etiam in Spilomata deliquescere v. c. Spiloma melaleucum-Syn. Lich. p. 2, cujus vero ut ommium specierum statu atypico fundatarum fons varius est.

* Apotheciis immersis, erumpentibus, excipulo proprio incompleto, margine thallode plerumque spurio coronatis. Graphis Ach. Absolute orticolæ.

314. OPEGRAPHA elegans, crusta hypophlœede, demum granulata, apotheciis erumpentibus prominulis, margine thallode spurio secedente, excipuli lateralis marginibus turgescentibus sulcatis, disco lineari primitus cesio-pruinoso. Engl. Bot. t. 1852 . .

Graphis elegans. Ach. syn. p. 85. Opegrapha sulcata! Dec. Fr. 6. $p .171$. nomen aptius.

Exs. Moug. el Nesîl. n. 360.

Ad contices arborum per Europam occidentali-meridionalem, Hispaniæ!, Galliæ copiose!, Anglix!

Simillima sequenti, ut nisi utile videretur formas evidentibus characteribus \& definitis geographicis limitibus distinctas servare, pro ejus statu luxuriante facile haberes. Margo proprius, qui in sequente sensim extenuatur, in hac incrassatur. Apothecia, plerumque simplicia, mutantur sequentis more; specimina nempe in Castanea \&c. sequentis a., in Betula ejusdem b., in Fago c. prorsus referunt.

315. OPEGRAPHA scripta, crusta hypophlceode, demum nuda leprosa, apotbeciis immersis erumpentibus margine thallode spurio secedente, excipuli lateralis marginibus tenuescentibus lævibus, aisco lineari primitus cæesiopruinoso. $A c h$. meith. p. 30.

Dill. Musc. t. 18. f. 1. Lich. scriptus. Linn. et Auct. Opegrapha. Fries. Vet. Ac. Hand. 1820. Sched. Crit. I. p. 12. Schicer. spic. p. 46. optime (etiam, ex spec. misso, $\xi$, a sequentibus diversa) Graphis pul- 
verulenta. Wallr. Flecht. I. acute. (inclusa subsequente.)

a. apotheciis emersis inordinatis variis. $O$. limitata \& O. pulverulenta. Pers. Ust. Ann. 7. t. 1. f.2. B.b. Lich. scriptus \& precinctus. Ach. Prodr. O. scripta \& pulverul. Ach. meth. Engl. Bot. t. 1754. Fl. Dan. $t$. 1242. $f .2$. Graphis scripta \& pulvernlenta. Ach. Lich. univ.

Exs. Lich. Suec. n. 124. Flörk. n 9. Schaer. n. 89. 90. Desmaz. n.3ss. Flotow. n.65, 67. Moug.n.650.

b. recta, apotheciis immersis rectis parallelis, disco magis dilatato. O. recta. Humb. O. Cerasi, betuligna, macrocarpa. Pers. l. c. c. ic. - Engl. Bot. t. 2301. Lichenes. Ach. Prodr. Graphis. Ach. Lich. uniw. O. montana. Schleich. Cat.

Exs. Lich. Suec. n. 314 (n. 33 transit ad a.)

c. serpentina, apotheciis immersis flexuosis prælongis, margine thallode tumido evanescente. Lich., Opegr," Graphis serpentina. Ach. - Engl. Bot. t. 1755. Lich. litterellus Ach. Prodr.

Exs. Lich. Su. n. 313. Schaer. n. 91. Flotow.n. 68. Moug. et Nestl. n. 361.

* apotheciis varie deformatis; speciosa, si in maculam dilatatam immarginatam abit. Arth. spectabilis Flotow ex ipso. (ad Arth. gyrosam Ach.)

Exs. Flot. n. 69.

Per omnem Europam, summo septentrione pro more generis excepto, ad cortices arborum b. ad Betulie, Cerasi, c. ad duriores v. c. Fagi.

Omnes hujus formæ luculenter ab epidermidis constructione pendent; ceterum ab omnibus præcedentibus facillime dignoscitur. Crusta præcipue ad cortices crassiores denudatur, pulverulenta fit (O. lactea Quibusdam), ad teneros innata persistit, quod in genere inter Opegraphas magis a loci natalis, quam ab ipsius stirpis indole pendet. Apothecia simplicia aut irregulariter ramosa, disco nudo \& pulverulento ubique mixta reperiuntur.

Inter priorem et sequentem ambigua cxemplaria adsunt e Saxonia, apoth.ramosissimis et divergentibus in pulvinulo latissimo plano paululum elevato immersis, qua ob thallum in ambitu depressum et hypophloeodem persistentem $G l$ y $p$ hin s. Aster $i$ s $c^{\circ} a m$ dixeris; ambitu vero sterili sublato a prioris c, dignosei nequit.

3.6. OPEGRAPHA Medusula, crusta hypophlo- 
ode, fertili in pulvinulos subrotundos erumpente, apotheciis pulvinulis immersis radiatin ramosis, excipuli lateralis margine levi, disco planiusculo primitus pruinoso. Pers. in Act. Vett. 2. p. 15. t. 1 $0 . f$. 1 .

Dec. Fr. 6. p. 171. Ach. syn. p. 334. $\mathrm{E}$ methodo Acharii Glyphidis species; e Féei Sarcographæ; ex Eschweileri Medusulæ; e Meyeri Asteriscæ; e sententia Schaereri prioris degeneratio.

Ád cortices arborum in Europa australi, Gallia!, rarius \& sporadice.

Præter crustam hypophloodem numquam fertilem, tantum in pulvinulos erumpentem, etiam divisione magis regulari apotheciorum, ad typum sequentis, a priori differt. 3I 7. OPEGRAPHA derdritica, crusta hypophlœode denudataque, apotheciis immersis, sæpius e centro radiatim pedatoque ramosis divaricatis, margine thallode tenui accessorio, proprioque tenuissimo evanidis, disco plano nudo. Ach. meth. p. 3 г. $t$. I. $f:$ ro.

Engl. Bot. t. 1756. Graphis. Ach. Lich.univ.p. 271. t. 3. f. 16. E m ethodo Dufouri Journ. Phys. V. 87. p. 206 Arthonia; e Meyeri Platygrammatis spec. Ex Schaerer \& W allroth status atypicus O. scriptæ. b. apotheciis brevioribus, parce \& irregulariter ramosis, subangulatis, apicibus obtusis. Arthonia obtusangula. Dufour $l$. c. ipso in addita schedula suadente.

Ad corticem arborum in Europa australioccidentali frequens, Hispaniæ!, Angliæ!, Galliæ!

Ramificatio apotheciorum in formis rite evolutis insignis, cui vero parum admodum fidendum est, occurrunt enim passim uno latere furcata, minus evoluta angulata tantum, immo prorsus simplicia \& subrotunda; notandum porro etiam simillima stellato-pedato-composita apothecia in $O$. scripta \& sulcata, licet rarius, obviam venire. Discus mox explanatus, dilatatus; margo proprius admodum tenuis, sed in perfectis individuis facile conspicuus, cum lamina connatus 1. si malis ab eadem formatus (nam excipulum non ut in præcedentibus discretuma est), sed disco madido hyalino-fuscescente niger 
persistens; hinc ad Opegraphas, eadem ratione ac Lec. albocorulescens, sang uinaria, sabuletorum, ad Lecideas, referri potest, quo vera affinitas \& geographicæ rationes, etiam in generibus limitandis respiciendæ, melius forsan servantur. In veris Ustaliis Nobis (Cfr. Ustal. speciosam Eschw. in Mart. Bras. t. 7. f. 5.) margo thallodes distans, proprius niger prorsus desideratus, discus velatus, sæpe angustissimus, (ut minus conveniat Platygrammatis nomen) \& habitus ab O. scripta adeo diversissimus, ut cum hac a nemine comparetur, pro cu jus statu (licet me judice diversissima sit) $O$. dendritica ab acutissimis Viris habita fuit. Hæc causa est, cur hanc \& sequentem, in Flora saltim Europæe, potius ut radium Opegraphæ ad tropicam Ustaliam, quam versa vice, receperim.

3 18. OPEGRAPHA Iyellii, crusta hypophlœode lievigata, apotheciis erumpentibus, margine thallode crasso pulverulento albo, proprio tenuissimo, disco plano primitus cæsio-pruinoso. Engl. Bot. ${ }^{2} S_{7} 6$.

Opegraph. scripta. Engl. Bot. t. 1813. ex Borrer. Graph. Lyelli. Ach. syn. p. 85. Platygramma. Meyer Arthonia marginata. Dufour Journ. Phys.l.c.p.205. Ad cortices arborum in Eurepa occidentalimeridionali Anglix Borrer, Gallix Dufour! \&c.

Præcedenti valde affinis, eisdemque vegetationis limitibus circumscripta. Apothecia vulgo quidem simplicia; subrotunda, oblonga, lanceolata; recta, curvata, flexuosa; at vidi simul ad prioris typum pedato-radiata. Precipua differentia pendet a thallo cum apotheciis magis elevatis erumpente, indeque denudato, quare apothecia margine vero thallode persistente (pulverulento in perfectis) cinguntur. Inde habitus Coniolomatis, sed plurimis stipatis Glyphid. magis refert. Ob marginem thallodem insignem ad Leioreuina (Graphid. S. O. V.) refert Eschweiler, verum hoc genus itidem mihi mere tropicum, relatis, ut l. c. indicavimus, omnibus Graphidibus Ach. Europæis ad Opegrapham.

1. Mihi quoad veras differentias et affinitatem dubia est non visa: 0 . venosa, thallo subtartareo determinato sordide albo, apoth. immersis sparsis elongatis ramosis flexis immarginatis, ramis obtusis. Pers. Vett. 2. p. 15. t. 10.f. 2. Eng gl. Bot. t. 2554 - Ad Fagos Gallia, Anglia. - Arthonia melanophthalma Duf.! ad O. -pegraphe genus non pertinet, potius pro statu. Arthonioideo Parmelia 
habeam. - In Chev. Fl. Par. ingrens allatus est $O_{p}$ e grapharum et Arthoni ar um numerus, mihi haud satis notus. Opegrapha n.1-2t o. atra nostre proxima, $n .12,22,29,25,26$ a. herpetica; $n$. 28-40 O. varia; n. 42-46 o. scripta. O. atra porra proxima affinitate junguntur Arth. $n .2-7,10$.

2. Ab Opegraphis prorsus elminanda et ad Fungos transferendic: a.) O. parallela Ach. = Stictis parallela. Fries Syst. M. II. p. 197, quam satis refert $\boldsymbol{Q}$. Prostia na e Gull. meridionali, sed est $O$. varice status lignatilis. b.) Opegrapha quercina, faginea et conglomerata Pers., s. O. macularis Ach. syn.p. 72. = Hysterium rugosum Fries. El. Fung. II. p. 141. - At Hysterium Opegraphoides Fl. Fr. 2. p. 30\%. s. Opegr. Hysterioides Dufour! Journ. Phys. 87. p. 215, a quo ipso monente non differt $O$. difficilis Duf. ib., mihi videtur $O$, u $t r u$ in ligno. denudata nata.

\section{LECANACTIS.}

Opegraphæ et Arthoniæ spec. Auct. Lecanactis Eschiv. Syst. Lich. p. 14. f. 7. Mart. Lich. Bras. t. VII. f. 2-4. Fries S. O. V. Graphidis spec. Meyer.

CHAR. Apothecia immersa, subrotundo-difformia, passim lirellæformia, semper aperta, excipula proprio carbonacea cupulari cum thallo (submarginante) connato. Discus corrueus, planiusculus, numquam connivens, primo a thallo pruinoso velatus, margine excipuli cinctus. Thallus crustaceus, apothecia nigra, albo-pruinosa.

Simillimum est hoc genus, specierum nimia affinitate admodum naturale, Opegraphis, ut admiratus $\operatorname{sim} E$ schweileri aciem in eisdem distinguendis; meo sensu præter vegetationem diversam essentialiter differunt excipt:lo semper aperto, margine jam primitns erecto (tenui) disco planiusculo, habitu Lecideæ v. c. L. corticolce. Forma apotheciorum magis polygona, guam lirellæformis. Excipulum valde differt. Opegraphæ genuinæ Verrucariarum instar ircipiunt, numquam vero Lecanactides. Hæ differentix etiam disci structuram mutant. Asci Lecanactidis ad Lecideas, Opegraphæ ad Verrucarias divergunt. Paucis, si Graphidearun tribus dissolveretur, neglecta apotheciorum forma, a qua pendet, Opegraphæ ad Limborieas, Lecanactides ad Lecideas pertinerent. Hanc quoque cum Lecideis affinitatem generis nomen iruponens in mente occulte habuisse vidctur Auctor. - Ceterum vegetationis historia hujus generis maxime insignis est; mihi vero illius species in natura satis observare non con- 
tigisse doleo, quam variorum dubiorum, præcipue Spilomatum in eisdem regionibus obviorum, clavem offerre spero. In specierum limitatione optimam auctoritatem, autoptam Dufour, plene sequi debui.

319. LECANACTIS grumulosa, crusta determinata undulata tartarea, facile amylacea candicante, apotheciis subrotundo-polygonis, disco plano albo-pruinoso, margine excipuli cupularis denudalo subflexuoso.

Opegrapha. Difour in Journ. Physa V. 8\% p. 216. Lecanactis, Fries, $S . O . V_{\text {. I. }}$. 288. Ab hujus crusta sorediorum instar fuligineo-luteorum oritur optimum Spiloma tricolor Ach. syn. p. 2. (saxicoluim) quod Spil. auratum Engl. Bot. t. 2078. In Turn. \& Borreri Lich. Br. p. 33 arboreum verum dicitur, \& tantum parasiticum in crusta $O$. calcarece in saxis occurrere. Num horum Auct, O. cal = carea præesens? Acharii minime est.

Ad rupès calcareas \& muros Angliz!-Galliæ accidentalis circa Rothomagum atibique frequens Le Prevost, in meridionali circa Massiliam Dufour!

Admodum spectabilis, attamen sequentibus valde affinis. Crusta crassissima tribus; undulato-plicata, inæquabilis, ambitu determinato; perfectissima ad Parmeliam repandam accedens. Vidi vere tartaream h. e. strato corticali non soluto; vulgo, autem amylacea est. Apothecia extus intusque atra, primo tota immersa ovatorotundata, excipulo cum crusta marginante connato, dein magis emersa, rotundato-angulosa, margine proprio tenui nuda erecto persistente, demum flexuoso. Passim e pluribus coalitis multilocularia fiunt, at rarissime subramoso-angulosa. Discus semper, etiam in elongatis, planus. 320. LECANACTIS lyncea, crusta effusa subtartarea inæquabili, mox amylacea candicante, apotheciis innato-emergentibus ovatis elongatisque, disco corneo plano-depresso cesio-pruinoso, demum convexo difformi.

Opegrapha cxsia, Dec. Fr. 2. p. 309. Lich. univ. p. 253. O. notha v. cxsia. Ach. syn. p. 76. .0. lyncea. Turn. et Borr. 
b. Arthonioidea, apotheciis applanatis subimmarginatis. Lichen lynceus. Engl. Bot.t. 809. Lecid. Ach. meth. p. 52. Ach. Lich. univ. p. 147.

c. Spilomatica, apotheciis in soredia fuliginosa fatiscentibus. - Hujus loci videntur: Spiloma microclonum. Engl. Bot. t. 2150. Sp. fuliginosum. Turn. et Borr. Lich. Brit. p. 37.

Exs. Lich. Suec. $n$. 313. variæ formx.

Ad cortices arborum, præcipue Quercus, raro ad ligna. Frequens in Europa occidentali v. c. Hispaniæ! Galliæ! Anglize!, ceterum rarissima v. c. Hallandire.

Planta mire polymorpha. Crusta indeterminata,primo tartarea, dein amylacea. A pothecia multo magis $\mathrm{O}-$ pegraphæ formam habent quam reliquarum specierum, sæpe valde elongata, semper vero obtusa, dein plerumque turgescentia, difformia \& rugosa. A proximis disco numquam papillato \& sporis, ex mente Meyeri, füliginosis, præcipue dignosci videtur.

321. LECANACTIS illecebrosa, crusta effusa subamylacea albicante, apotheciis elevatis subrotundis, margine tenuissimo, disco plano albo-pruinoso, demum papillato. S. O. $V$. I, p. 288. Opegr. illecebrosa Dufourr. l. c.

Exs. Lich. Suec. n. 193 (Pyren. farrea) var. videtur. Ad cortices velustos Quercus passim, optima in Europa australi.

Præcedenti nimis affinis, sed nec transitum nec in eadem regione legimus, \& notas varias peculiares servat. Apothecia priorum minora, magis regularia, suborbiculata, unde habitus formarum Pyrenothece incrustantis. Margo thallodes nullus distinctus, proprius admodum tenuis. Tam ex hoc, quam e centro disci demum erumpunt papillæ minimæ, subliberæ, atræ, quales in alia non vidi.

322. LECANACTIS urceolata, crusta innata rimulosa alba, apotheciis immersis subellipticis, disco planiusculo discreto nudo elabente urceolatis. S.O. $V$. l. c.

Ad cortices arborum in Europa australi. Herb. Achar.! 
Habitus a reliquarum diversus, unde ab Achario in mscr. ad Urceolarias relata est. Cirusta tenuis, effusa, indeterminata, haud pulverulenta. Apothecia crustæ plane \& persistenter impressa, per se plano-concaviuscula, sed disco soiuto facile elabente urccolata, opaca, atra, pruina mox evanescente. Margo proprius cum crusta adeo connatus, ut vix promineat. Specimen nunc ad manus non est.

Obs. LECANACTIS impolita. Cfr. Parmelia n. 66.

E toto habitu \& vegetatione hujus generis species sit, quo omnes deformatæ formæ sub Lec.dryina, Verrucaria byssacea \&c. comprehense in vicinia colliguntur; etiam illius status Spilomaticus (Spil. decolorans Engl. Bot.) priorum v. c. Spil. tricolori admodum similis est. - Ex obss. Cel. Meyeri Flecht. 1. p. 194. apothecia rite evoluta Opegraphæ esse generis hoc certius fit. Equidem vero tantum vidi Parmeliæ accedentia, quare ad interim inter Parmelias recipere coactus fui. Possent tamen et hæc excipulo imperfecto pro analogia $O$. Lyellii haberi.

USTALIE species proximas vide sub Opegr. n. 3 I 7,3 i 8.

\section{* CONIANGIUUM.}

Fries Vet. Ac. Handl. 1821. p. 330. Syst. Orb. Veg. CHAR. Apothecia adpressa, rotundato-difformia, oblongave semper aperta, excipulo destituta. Lamina contigua, persistens, parenchymate in sporos coloratos collabente. Thallus crustaceus, tenuis. Apothecia fusca, intus pulveracea fulva. Vix de alia planta magis diversa lata sunt judicia. Cum Calicio roscido, observantibus jam Flotow \&.Laurer, vix remotıssima adest affinitas ut, si sic placeret, to "male intellectum" facile repeterem. Sub Lecidece dryinoe nomine passim quidem venit, at vera Lecidea minime est; etiatn in Flörkeanis speciminibus Exs, n. 141 a meis diversam invenio structuram. Nec ad Sclerotia referri potest, natura evidenter Lichenosa. Mihi cum Ustalia, Coniolomate statibusque abortivis Graphidearum intime utique connexa videtur. Prope accedunt Spiloma tricolor Ach., auratum Engl. Bot.; recepi vero tantum unicam mihi notissimam speciem, quæ præter statum normalem rariorem etiam Arthonioideum profert. 
* CONIANGIUM vulgare, crusta contigua tenui albida, apotheciis diffarmibus fusco-nigris. Fries 7. c. p. $33 \mathrm{t}$.

Spiloma paradoxum. Ach. syn. p. 139. status perfectus. Arthonia lurida. Ach. syn.p. \% $_{\text {a }}$ Schaer. spic. p. 8. status Arthonioideus. Reg.Bot. Zeit.1828.p.597. Pro sua Lec. dryina specimina corticola vulgo determinavit Acharius. Verruc. gemmata. Reichenb. et Schubert Exs. n. 72. ex Laurero, at primitiva non est.

Exs., Lich. Suec. n. 1. Schaer. Helv.n.17.Reich.l.c.

Optima ad ligna vetusta Pini, Quercus; macrior ad cortices: Abietis, Alni, Betule \&c.

Crusta tenuissima, late effusa, indeterninata, contigua, membranacea, demum pulverulenta, alba, cinerascens, tandemque in pulverem ferruginascentem efflorescens; sæpe quoque deficiens. Apothecia convexa, mox planiuscula, irregularia, subrotubdo-difformia, elliptica \&c. ; juniora fere rubra, dein fusca, tandem nigra, normaliter semper in superficie lævigata, nuda nec pruinosa, sed in formas Spilomaticas more tribus præcipue ad cortices facile abeunt. At discus integer passion deciduus est, sporulas fulvas (vera sporidia enim non sunt) denudatas relinquens. Adest tanta cum Coniolomate affinitas, ut forsan inter se sub Coniocarpi Dec. nomine optime. conjungerentur. Interea nexus cum Opegraphis minus. evidens est.

\section{* CONIOCARPON.}

Coniocarpi spec. Dec. Coniocarpon. Sctuaer. N'at. Anzeig. 1821. p. 34. Meyer. Spilomatis, Apegvaphæ \& Axth. spec. Auet. Conioloma Flörk. Deutsch. Lich. II. p. 3. Eschw. Syst. Lich. Fries Syst. Orb. Yeg. CHAR. Apathecia adpressa, rotundato-difformia elongatave, aperta, immarginata, excipula destituta, demum lamina tenuissima membranacea rumpente aut fatiscente in soros spororum late coloratorum abeuntia. Thallus crustaceus, si quidem proprius nec Opegrapho mutatus.

Genus adhuc magis atypicum \& skispectum, quam Coniangium; at tam insigne \& eminens ut practico $\mathrm{Li}$ chenologo prorsus omittere non licuerit. Forma \& ha- 
bitus in perfectissimis omnino Opegraphæ, \& quin his etiam affinitate proxime conjunctum sit, mihi hand dubium videtur. Ad normam Wallrothii, multorum dubiorum clavem, facile dicas esse chrysogonidiorum acervum, qui histrionico Lichenum more vera apothecia Opegraphæ imitantur. Si arridet magis sententia Meyeri Spil.tricolor, azcratum \&c. esse fungos parasiticos, facile sequeretur Coniolomata etiam esse fungos in Lichenum crustis, inde personatis, nidulantes, Illasporio \& Scleracocco Syst. Myc. III. p. 257, 258 proximos. Sixpius Caniol. ochraceum in crusta Opegraploce scriptoe, sæpe $C$. cinnabarinum in $O$, atroe vidinus. Singulare vero hæc Coniocarpa in Scandinavia pxne desiderari, nam $C$. cinnabarinum ab amic. Ljungstedt tantum in extimo Scanix angulo lectum est; alia, quæ ipsi vidimus, ad suas species, v. c. Conioc. quoddam aruginosum ad Opegr. variam, tute referre potuimus. Possem equidem etiam reliqua descripta theoretice facile expungere, at cum nil facilius videam, quam theorias proponere \& ex his omnia deducere, has magis pænes me suffocare, quam alere studeo, expertum habens, veram sæpe accendi lucem magis quxrendo, quam apodictice respondendo. - Differentia a $\mathrm{Co}$ niangio unice pendet a Coniocarpi lamina tenuiori, membranacea, rumpente aut fatiscente.

* CONIOCARPON cinnabarinum, apotheciis difformibus subfuscis, primitus pruinosis, in soros. coccineos fatiscentibus. Dec. Fr. 2. p. 323.

Spil. tumidulum Ach. syn. p. 1. Engl. Bat. t.2151. Spiloma gregarium. Turn. et Borr. Lich. Brit. p. 42. Coniocarpon. Schaer. l. c. - status primitivus: Spilama tumidulum. Ach. meth. p. 11: t. 1. f. 5 . Arthonia Ejusd. in Schrad.Journ. - Bot.Fl. Dan. t. $1472 . f .1$. - status perfectior: Spiloma fallax Ach. meth. p. 10. S. rubrum. Pers. (Ach. Lich. u= niv. p. 137) Opegrapha coccinea. Schultz i'l. Starg. p. 375. Fl. Dan. t. 1352. Conioloma coccineum Flörke. - * Sphæria gregaria. Sow. Fingl. Fung.t.375. f. 5. Spiloma elegans. Ach. Lich. univ. p. 135. $\ell$. 1. f. 1. ex herb. \& spec. Schaer. (sed ab ipso habea veram Ustaliam).

Exs. Flörk. n. 21. Moug. Nestl. n. 851.

Ad cortices Coryli, Carpini \&c. Europe to- 
tius, excepta Suecia, ubi non nisi in extima Scania obvium fuit.

Crusta passim gaudet communi cum Opegrapha atra, scripta; sæpius autem propria, limitata, pædore rubente \&c. suffusa. Apotheciorum forma nulla constans, sæpius tamen in perfectioribus Opegraphæ, passim radiata, immo pedato-ramosa. Lamina in fuscum, Luridum, atropurpureum colorem vergit; ea rumpente aut disparente soris coccineis facillime dignoscitur. Occurrunt hi quoque Leprariæ instar æqualiter effusi. Eminentissimus est status Opegraphinus a Flörkeo descriptus, in quo lamina in ambitu rupta oblonga depressa aggercula pulveraceo cincta. De formis insuper conf. Lich. Brit. * CONIOCARPON ochraceum, apotheciis substellato-aggregatis sordide ochraceis, primitus concolori-pruinosis, in soros concolores fatiscentibus. Arthonia ochr. Duf. Rev.l.c. Opegrapha. Hepp. Lich. Wurtzb. p. 76. Con. Fries S. O. V. p. 76.

Exs. Moug. et Nestl. n. 470.

b.? soris ferrugineis.

Ad cortices in Europa australiori passim. Dufour! Aliique.

Crusta hujus plerumque eadem ac Opegraphas scriptoe, rarius b. $O$. dendritica - aut propria, ut scilicet apparet, nam si suspicio nostra confirmetur, forsan tam hujus quam prioris ab Opegrapharum personata orta est. Apothecia hujus constantius Opegrapham referunt quam prioris, vulgo $O$. atræ faciem præ se ferunt, magis tamen elevata; serius deliquescunt. Fide dignissimus observator Le Prevost limites certos inter hanc \& præcedentem fere deesse, per literas monuit.

O bs. Reliqua Coniocarpa aut Spilomata Auct., in statu primitivo lamina tegente destituta, in hoc aut præcedente genere minime recipi possunt. - Horum origo varia. Exclusis Mycetoideis v. c. Spilomate inusto (Sphæria Fr. El. Fung), Sp. microclono (dnbiæ originis, sæpe status degeneri Stictidis paralleloe Fr. S. M.) probe distinguendum inter I) SPILOMATA e sorediis crustarum sterilium órta v. c. Spiloma leucostigma, xanthostigma, Vitiligo Ach., quæ pro Variolariis, ut ultimum optime in Lich. Brit., habenda sunt, minime vero pro autonomis plantis, quorum originem locis natalibus facile persequimur, sed ob diversas matres ægre ci- 
tamus; v. c. Spil. Fitiligo non tantum ad P. variam, cui ab Achario adscribitur, pertinet, sed etiam ad Biat. vernalem, decolorantem e. s. p. Sp. xanthostigma variis locis jam citavimus, eademque ratio est plurimorum Spilomatum recentius descriptorum. - \& II) SPILOMATA ex apotheciis deliquescentibus orta; v. c. Spil.fuscatum Ach. a Parmelia subfusca cyrtella, $S p$. reticulatum Chaub. Sp. melaleucum \& versicolor Ach. a Turn. \& Borr. sub Spilomate nigro (Coniocarp. Decand.) conjuncta, $S p$. fuliginosum E. B. e. s. p. a variis Graphideis ortum ducunt. Sed aliud Spil. melaleucum Ach. potius a Lecideis ortum, æque ac Spil. tuberculosum E. B. t. 2556 (Spil. verrucosum Flörke Deutsch. n. 1) ex obs. Laureri e Lecid. canescente. Horum origo difficilius sæpe perspicitur, ut quædam insigniora sub Calicieis, ut genus inquirendum eadem ratione ac Coniocarpon sub Graphideis admittere cogamur. Spiloma Verrucaria Ach. est Coniangium, $S p$. effusum haud vegetabile.

\section{Trib. IV. CALICIEÆ.}

(Coniothalami. Syst. Orb. Veg.)

CHAR. Apothecia orbiculata aut globosa, semper aperta, excipulo proprio sporidia nuda pulveracea gerente. Thallus crustaceus, cum apotheciis cocetaneus aut serotinus!

Hypothallus plerumque fibrilloso-byssinus, canescens ligni fibris intertextus. Hujus indole \& colore jam affinitas cnm Fungis indicatur; ab eoque pendet, quod tam raro saxicolæ sint, vel in hoc loco plerumque in aliis $\mathrm{Li}-$ chenum crustis parasitentur, v. c. Calicium corynellum. Quædam omni propria crusta priva, v. c. C. turbinatum, potius fungis adnumeranda. At reliqua verissimi Lichenes sunt, intime cum Lecidinis \& Graphideis connexa, ut sæpe de limitibus dubitetur, præcipue cum Calicieæ veræ etiam ascigeræ visæ sint \& facile dicas reliquorum ascos ante ipsam evolutionem periisse. $M y-$ xogastres, cum quibus plurimi conjungere malunt, considerata eorum morphosi, qualem in Syst. Myc. III. exposui, non remotissimam habere affinitatem cuique facile patebit. Crusta enim vel granulata (leprosa superficialis etiam in hoc ordine est status deliquescens) 1. leprosa normaliter hypophloeodes, qualem in Cal. subtili, Conioc. 
nigricante, evidentissime vidimus. Hæc denudata ad ligna facillime disparet; sed crusta sxpe quoque deficit ob apothecia præcocia ante crustæ evolutionem e ligno \&c. erumpentia v. c. in Calic. pluceocephato, trichiali e. s. p.

\section{CONIOCYBE.}

Mucoris spec. Linn. Calicii Pers. et Auct. Coniocy- be. Ach. in Vet. Ac. Handl. 1816. p. 283. Fries. - Meyer. Sclerophora. Chev. par.

CHAR. Apothecia stipitata, sphærica, suberosa, immarginata, e vertice fatiscentia, demum undique pulverulenta, excipulum proprium abscondentia. Thallus crustaceus.

Evidentissime $\mathrm{ab}$ omnibus distinctum genus. A Calicio differt ut Bxomyces, cui analogum, a Lecidea. Stipes in hoc genere essentialis est.

323. CONIOCYBE furfuracea, crusta granulosofurfuracea sulphurea, apotheciis globosis demum fuscis, primitus stipilibusque gracilibus flavo-floccoso-pulverulentis. Fries - Ach. l. c. p. 288.

Mucor furfuraceus. Linn.-Batsch. El. Fung. C.1.f. 178. Lich. Swartz. Trichia. With. \&c. Calicium. Pers. - Turn. et Borr. L. Brit. p. 159. Wahl. Suec. n. 175\%. Scleroph. Chev. par. Lich. globular. Retz. Lich. capitatus. Schreb. - Engl. Bot. t. 1539. Bæom yces. Schum. Lich. Gatic,, Coniocyb. capitellat. Acli. Fl. Dan. t. 1792. f. 2.

Exs. Lich. Su. n. 3. Schaer. n. 14. Flot. n. 9.

b. fulva, crusta viridi-flava apotheciisque compactiobus, stipitibus brevioribus. Mucor. fulvus. Linn. Lich. Swartz. Lich. \& Cal. acicul. Ach. - Wahlenb. in $V$. A. H. 1806. t. 4. f. \%. Cal. capitell. $\beta$. Fl. D. Lich. n. 85.

c. sulphurella, crusta subleprosa e viridi incana, obsoletaque, apotheciis stipitibusque brevissimis læte flavis. Lich. sulphureus. Retz. in IY. A. H. 1769.p. 249. Calic. Decand. syn. Gall. Goniocybe brachypoda. Ach. V.A. H. 1816. p. 287. t. 8.f.16. Cal. cap. $\gamma$. rimarum. Flörke.

Exs. Lich. Su. l. c. Flörk. n. 103. Flot. n. 10. 
d. griseola, cinereo-pruinosa, minima, crusta nulla. Conioc. griseola Ach. l. c. 1817. p. 238. t. 8.f. 14. ad spec. ipsius. (at spec. mihi sic determinata C. pallidæ forma.)

Ad terram \& vegetabilia putrida locis silvaticis siccis occultis Europæe totius; b. præcipue ad saxa; c. d. in truncis cavis.

Crusta, facile deliquescens, leprosa fit; decolorans, indeterminate effusa. Stipites sæpe longissimi, at variant simul brevissimi, per ætatem nudi fusco-nigricantes. Sporidia fusca.

324. CONIOCYBE gracilenta, crusta e granuloso leprosa cinerascente, apotheciis oblongo-globosis carneis cinerascenti-pruinosis, stipitibus longissimis gracilibus nigricantibus. Ach. in Vet. Ac. Handl. l. c. p. 289 .

Calic. gracilentum. Lich. univ. p. 243. t. 3. f. 6. Ad terram ad arborum radices in Helvetia Schlezicher! alibique rarius.

Statura longissimarum prioris formarum, at color capitnli \& sporidiorum sequentis, absque omni lutescentia. Junior undique cinereo-pruinosa. Vereor ne pro hac saepius sumatur Cal. brunneolum.

325. CONIOCYBE pallida, crusta tenuissima leprosa albicante, apotheciis lentiformi-globosis pallidis albo-pruinosis, stipitibus nudis e hyalino-paltido fuscescentibus. Sched. Crit. I. p. 3. (C. stilbea Ach. l. c.)

a. firmior, e pallido-incarnato expallens. Trichia nivea. 1 offm. Veg. Cr. 2. t. 4. f. 1. Calic. pallidum. Pers. in Ust. Ann. 7. t. 3. f. 1, 2. Nees Syst. f. 36. Lich., Cal. peronellum. Ach. - Scleroph. farinacea. Chev. par. p. 315. t. 9. f.19. Fulgia, Ejusd. in Journ. Phys. 1822. t. 1.f. 2. ex spec. Auct.!

b. gracilior, e sulphureo expailens. Lich. cantharellus. Ach. Lich. Su. Calic. Meth. Lich. - Engl. Bot. t. 235\%. C. stilbeum Schaer. spic.p. 4. Calic.1eucocephalum Pers. misit Chaillet! Sclerophora minima. Chev. Par. p. 316.

Exs. a. \& b. Lich. Suec. n. 2. Schaer. n. 7. Sommerf. n. 54. Flotow. n. 30, 31 . 
Per omnem facile Europam; a. ad ligna putrida; b. ad cortices arborum. .

Quin optima sit Coniocybes species, non est quod dubitetur. Nullum verum adest excipulum carbonaceum, præcedentium modo fatiscens disciforme apparet, sed longa alia est ratio verorum Caliciorum. Formis mediis b. C. furfuraceoe c. d. ita obviam venit, ut sæpe non nisi ab adsueto discerni possit. Coniocybe griseola Ach. ad specimina mea est C. pallida, ex herb. Auctoris autem video ipsum ante oculos habuisse C. furfuraceæ formam. Præcipuæ, notæ sunt: stipes non pulverulentus, junior hyalino-pallidus demum vero fuscescens, capitulum expallens, cum C. furfuraceæ obscurius fit, sporidia subincarnata. In b. vidi crustam hypophloeodem; denudata vulgo disparet. - Allatæ formæ re ipsa constantes apparent, verum semio tam similes ut non rite discernendx.

326. CONIOCYBE nigricans, crusta tenuissima leprosa albicante, apotheciis globosis nudis nigris, stipitibus nudis ex hyalino-albido nigricantibus. Fr. Sched. Crit. l. c.

a. Cal. pusiolum. Ach. V. A. H. 181\%. p. 231. t. 8. $f$. 11 .

b. recedens ut prioris $b$, statura gracili.

Exs. F.otow. n. 11.

In Suecia, Silesia Flotow!, Saxonia Reichenbach ad quercus; a. in ligno; b. in cortice, rarior.

Stipitis colore, apotheciorum structura (jurenilia in C. nigricante fere carnosa) ad præcedentem accedit, at distinctissima species apotheciis junioribus glabris nec floccosis nec pruinosis, sporidiisque nigris. Crusta vix evidens nisi hypophlocodes. Cum Calic. subtili nulla vera adest affinitas.

\section{CALICIUM.}

Coralloid. spec. Dill. Mucoris sp. Linn. Trichiæ Hall. et Aluct. Calicii spec. Pers. Ach. Calicium \& Cyphelium. Ach. in Vet. Ac. Ha dl. 1815. p. 252. 1816 p. 110. Calicium. Fries. Meyer.

CHAR. A pothecia crateriformia, excipulo pro- 


\section{prio carbonaceo discum in sporidia coacervata} nuda collapsum marginante. Thallıs crustaceus.

1. Genus eximie naturale. Discus nunc jam primitus solutus pulveraceus, nunc primitus compactus, læevigatus v. c. in Cal. hyperello, trachelino. Stipes vulgo præsens; species eædem variant stipitatæ \& sessiles, \& constantius sessiles tam affines, ut non separandæ. Interea quædam harum disci structura recedunt, potius forsan Trachyliis adnumerandæ, v. c. C. tigillare.

2. Species ligna putrida præcipue incolunt. In silvis Sueciæ facile primævis, truncis putridis refertis, abundant. Hinc eis jam a primitiis studiorum meorum singularem dicavi attentionem. Non tantum omnes Caliciorum formas descriptas copiose quotannis in natura vidi, sed etiam multas haud notatas nec $h . l$, brevitatis studio insertas. Ad specimina a me potissimum collecta Acharius harum \& affinium monographiam in Vet. Ac. Handl. 1815-1817 elaboravit ; cum vero justo plures species distinctæ mihi viderentur, has strictius in Exs. Suec. 1. 1818 \&c. Sched. Crit. 1824 limitare studui, quæ studia minus attentione, quam vituperatione digna visa sunt. Licet gratius semper sit aliis concedere posse, quam propriis inhærere, doleo me in recentiora judicia, ceterum inter se plane divergentia, abire non potuisse. Videntur nempe ad analogam specierum morphosin \& notas primitivas non satis attendisse, \& sic analogas formas diversarum specierum conjungere (v. c. Cal. curtum cum C.trachelino, roscido e. s. p., cum verum luculenter $C$. 'lenticulari, observante Wahlenbergio, proximum), singulares vero locales aberrationes distinguere v. c. C.chlorellum. - Crusta, nisi typice hypophloodes, granulata, sæpe in lepram deliquescens (hæc vero status abnormis est) vel prorsus deficiens. Stipites ad ligna cariosa humida admodum gracilescunt, discus magis solutus \& tumescens, excipuli marginem obtegens, \& his locis, quibus optime luxuriant Coniocybr, has eximie referunt v. c. Cal. stemoneum Ach. Subinde his locis quoque stipites prælon gi, flexuosi omnino sterilescunt v. c. C. flexipes Ach. Locis vero occultis, siccissimis stipites tenelli, abbreviati, excipulum haud explicatum turbinatum, qualis status $\mathrm{Cal}$. phococephali certissime est Cal. chlorellum, C. trichialis Cal. glaucellum Ach. meth. \&c. ut in rimis aridis omnium fere parietum ligneorum vidimus. - Notas vero essentiales offerunt colores crustæ normalis, disci \& 
præcipue pruinæ excipuli \& sporidiorum. Species analogæ diversarum serierum sibi invicem plene respondent \& vulgo commutantur. Sic in omni sectione duæ priores species discum habent diu compactum, lævigatum, reliqua mox dissolutum. Series vero in his non indicantur crustæ colore (in singula serie \& sectione, ut etiam inter Coniocybas, species crusta sulphurea agmen ducit) sed excipuli iunioris \& sporidiorum. Singularem lusum disco exoleto albicante offerunt $C$. lenticulare, $C$.trichiale, $C$. hyperellum, $C$. roscidum.

Sect. I. A pothecia stipitata. Calicium Ach. 1. c. Cypkelium. Chev. par.

Duplici ratione harum apothecia sessilia \& abnormia occurrunt; vel diminuta, sessilia, punctiformia in ligno carioso, qualis v. c. C. subtilis status est Verrucaria stictica Fl. Deutsch. Lich. n. 168 - vel dilatata, difformia, subincisa, qualia tam C.melanophoei, quam C. trichialis Calicium ferrugineum Engl. Bot. t. 2473 referentia vidimus. Minime vero huc referas Coniangium vulgare, Pyrenotheam sticticam, Cliostomum corrugatum omnesque Limborias Ach.

* Glaucescentia. Excipulum extus e pruina glauca albido cinereum. Sporidia atra (ultima specie excepta).

327. CALICIUM viride, crusta granulosa flavoviridi, apotheciis turbinato-lentiformibus subtus albido-cinereis, disco plano stipiteque elongato atris. Pers. in Ust. Ann. 7. p. 20. ex Ach.

Lich. s. Cal. lygodes Ach. meth. p. 95. omnino, dein sub Cal. hyperello. - Cal. abietinum \& brevipes. Dec. Fr. 2. p. 344, 345 e descr.

Ad truncos siccos v. c. Pini, raro.

Sequenti proximum, diversum colore crustæ facile leprosæ, stipitibus gracilioribus; toto habitu vero gaudet C. hyperelli, at minus elatum, discus excipulumque subtus aliter colorata. Descriptiones Decandollei optime conveniunt, \& Cal. brevipedis crusta vel granulosa a "Lepr. citrina" Ach. non orta videtur.

328. CALICIUM lenticulare, crusta rugoso-granulata cinerascenti-alba, apotheciis lentiformibus, subtus albido-cinereis, disco plano-convexo, sti- 
piteque crasso rigido atris. Ach. V.A.H. 1816 . p. 262. t. 8. f. 4. 1817 . t. 8. f. 8.

Mucor Lichenoid. Linn. Suec. n. 1287. Lich. Web. spic. p. 198. Calic. Schumach. - Trichia lenticul. Hoffm. Veg. Cr. 2. t. 4. f. 3. Cal. Sched. Crit. 1. p. 5. Cal. quercinum. Pers. Dec. fr. pr. $p$. Lich. clavellus. Ach. Prodr. p. 83. Engl. Bot. t. 1465. Calic. Turn. et Borr. Lich.Br. p. 138. Cal. claviculare. Ach. cum aliis confusum. Cal. quercinum. Rec. non Ach.

Exs. Lich. Suec. n. 152. Fl. Deutsch. n.66. Flotow. n. 17. Moug. et Nestl. n. 473. a.

* disco soluto dealbato. C. discoidale Ach. l. c. p. 266. t. 8. $f$. 3 .

Ad ligna truncorum \& parietum, ubi optime explicatum, frequentius ad cortices.

Species glaucescentium centralis, reliquis robustior, ceterum adeo analogum $C$. trachelino, ut vix nisi notis sux seriei dignoscatur. Hinc a multis juncta sistunt v. c. C. clavellum Moug. \& Nestl. \& ut videtur a Wahlenbergio Cal. sphæroceph. Fl. Suec. $n$. 1752, nam Cal. clavellare Wahl. $l$. c. est Cal. roscidum. Crustæ granulæ sæpe obsoleta. b. est forma ad parietes sicciores nata, Cal. chorello quoddammodo analoga. - Forma lenticulari inter proxima optime distinguitur, hinc nomen antiquissinum \& optimum bene restituit Acharius. Cum hujus generis species nulli definito loco adscriptæ sint, sed quæ in altera regione hanc, in altera illam præcipue incolant arborem (cujus plurima notatu digna adsunt exempla), omnia inde desumta nomina rejicienda, eo magis cum in errores ducant, ut omnia similia nomina jam testantur.

329. CALICIUM curtum, crusta tenuissima (rarissime granulosa) cinerascente, apotheciis turbinato-cylindricis, margine coarctato albicante, disco demum protruso stipiteque brevi firmo aterrimis. Turn. et Borr. l. c. p. 148.

Calicium abietinum. Pers. - non Schum., nec Decand. Cal. sphæroc. $\gamma$. Ach. meth. p. 92. Wahl. Suec.n. 1752. Cal. clavicul. $\varepsilon$, glaucellum (exclus. syn. Methodi!) \& 5. Lich. univ. p. 236. Cal. curtuin Engl. Bot. t. 2503. Cal. cerviculat. Ach. V. A.A. 1816. 
p. 119. t. 5. f. 3. Fl. Dan. t. 1851. f. 3. Cal. pariet. $\delta$. $l$. c. p. 262. t. 8. f. 1.2. C. oblongum. Duf. Exs. Lich. Suec. n. 13. (Cal. cervic).

Ad ligna putrida silvarum Europæ borealis saltim copiosissime.

Præcedenti proximum, minime confundendum cum analogis formis sequentium serierum; insigne apotheciorum forma constante, margine coarctato juniori saltim albicante, discoque ob marginem constrictum peculiari modo protruso, qui in hoc essentialis, in sequentibus speciebus tantum in formis degeneratis rarius observatur. Hoc elapso oritur forma cyathella, ab Achario ipso cum simili Cal. phoeocephali juncta, at maxime diversa. Licet nulla alia species copiosius mihi obvia fuerit, excipulum numquam virescenti-, sed passim glauco-pruinosum obviam venit.

33o. CALICIUM subtile, crusta tenuissima leprosa albo-glaucescente, apotheciis lentiformi-globosis, primitus albo-pruinosis, dein cum stipite filiformi flaccido nudis. Sched. Crit. I. p. 6.

a. apotheciis e pruina albida cinerascentibus. Mucor sphærocephalus. Linn. Suec. n. 1286. Cal. subtile. Pers. - Ach. C. abietinum. Schum. C. debile. Schaer. Naturw. Anzeiger 1821. C. parietinum $\alpha$. Ach. in V.A.H.1816. p. 260. t. 8. f. $1 . a-$ b. apotheciis nudis atris. Cal. sphæroceph. d., Ach. meth. p. 92. Cal. clavic. $\eta$. Lich. univ.|p. 236. $\beta$. Syn. p. $5 \%$ Cal. debile. Turn. et Borr. l. c. p.151. Engl. Bot. t. 2462. Cal. subtile. Ach. in Vet. Ac. Handl. 1816. p. 117. t. 5. f. 1. C. pusillum. Fl. Deulsch. Lich. Exs. Lich. Suec. n. 14. Fl. n. 188. Sommerf. n. 55 .

* crusta perfecta leprosa hypophlooode. Calic. populneum. Brondau ex Le Prévost in litt.

Ad ligna vetusta \& parietes ubique. "ad cortices levigatos.

Inter affines gracillimum \& maxime subtile, stipite admodum debili \& flexibili, sed prioris vulgo longiori. Crusta ad ligna vulgo nil nisi hypothallus fibrillosus albus ligno innatus, sed ad cotices lævigatos evidenter hypophlooodes. Excipulum patens, haud coarctatum a disco tumente demum reflectitur. Sporidia atra. - Hujus degener \& elongatus status ad ligna cariosa suffocata ad 
terram est Cal. haustellare Ach. in $V$. A. $H .1816$. p. 122. $t$. $5 . f .6$, immixto vero Stillo rigido. Tode.

331. CALICIUM trichiale, crustæ granulis squamulosis crenatis pallidis, apotheciis turbinatis e disco tumente umbrino subglobosis, subtus albo-cinereis, stipite gracili. Ach. V. A.H. 1816 . p. 277, t. 8. f. 14 .

a. C. trichiale a. Ach. Lich. univ. p. 243. Schaer. spic.p. 5. - crusta deficiente: Cal.glaucellum. Ach. meth. p. 97 nec recent. script.

Exis. Lich. Suec. n. 15. Flotow 2\%. Schaer.n.10,11. b. crusta leproso-deliquescente. Calic. trich. $\beta$. Lich. un. l. c. C. stemoneum a. Ach. in $V . A$. H. l. c. p. 278. t. 8. $f$. 15. C. æruginosum. "Turn. et Borr." Schaer. Naturw. Anzeig. 1821.

Exs. Flotow. n. 28, 29. Schaer. Helv. n. 13.

* disco soluto dealbato: Calic. proboscidale. Ach. syn. p. 58.

\section{Ad ligna \& cortices, in primis pineos.}

Excipulo gaudet priorum, sporidiis sequentium, indeque inter utramque seriem medium, sed crustæ indole \& apotheciorum variatione cum $C$. phreocephalo plene convenit. Crusta locis siccissimis sæpe omnino deficit, in cryptis v. c. ad radices arborum leprosa. Stipites vulgo graciles \& elongati, sed etiam abbreviati firmiores occurrunt. Excipulum turbinatum, sed e disco, præcipue in cryptogenis, tumente apothecia subglobosa. - Cal. cinereum Pers. Ic. \& descr. Fung. t. 14. Ach. ll. cc. e descriptione non differt, verum specimen authenticum in Herb. Ach. nimis mancum est, $\&$ in genere specimina minuta male conservata in hoc genere difficile determinantur. Flotowii \& Schaereri Exs. hujus speciei potissimum auctorum fide citavimus.

** Fuscescentia. Apothecia plus minus ferruginea, disco ferrugineo aut umbrino, sporidia subfusca, sed in atrum, ferrugineum, umbrinum \&c. in diversis speciebus vergunt.

332. CALICIUM hyperellum, crusta granulosa viridi-lutea, apotheciis lentiformibus subtus ferrugineis, disco umbrino-nigro, stipite elongato firmo atro. Wahl. Lapp. p. 485. 
Lich. hyperellus. Ach. Prodr. - Engl. Bot.t. 1832. Cal. hyperellum \& baliolum. Ach.' meth. p. 93,94. t. 2. $f$. 4. Calic. hyperellum. Turn. et Borr. $l$. c. p. 140. Ach. in V. A. H. 1816. p. 273. t. 8. f.5. Fl. Dan. t. 1722. $f$. 1. C. baliolum Ibid. p. 123 . vetustum, atrum.

Exs. Lich. Suec. n. 8. Sommerf. n. 56. Flot. n. 20. * disco soluto dealbato. Calicium peltatum. Ach. in V. A. H. 1817. p. 235. t. 8. f. 9:

Ad cortices \& ligna, præcipue in montanis copiose.

Normaliter inter maximas \& robustissimas species, at etiam minus occurrit. Affinitate sequenti, habitu analogo $C$. viridi (Persoonii nomen forte et hoc complectitur) proximum. Sporidia demum ferme atra.

333. CALICIUM trachelinum, crusta lævigata cinerascente, apotheciis turbinato-lentiformibus, subtus rufo-ferrugineis, demum discoque ex umbrino nigricantibus, stipite elongato firmo atro. Ach. in V.A. H. 1816. p. 272. t. 8. f. 7 .

Dill. musc. t.14.f.3.A. Embolus sepulchralis Batsch. El. fung. C. 1. $f$. 113. Lich. sphærocephal. Engl. Bot. t. 414 ex Turn. et Borr. l. c. p. 153. (Calic.) Cal. salicinum. Pers. in Ust. Ann. Bot. \%. t. 3.f.3. Cal. clavellum. Dec. fr. 2. p. 344. C. clavicul. $\beta$. trach. Ach. meth. p. 91. C. trachel. Lich. univ. et Ŝyn. Cal. corylinum Schum. Ach. V. A. H. l. c. 1816. (Cal. sphæroidale Ib. 1817. p. 233 e mala figura E. B.)

Exs. Lich. Suec. n. 7. Flörk. n. 84. Flotow. n. 22. Moug. Nestl. n. 473. d.

- disco soluto hemisphærico umbrino occultante excipulum minutum fuscum. C. glaucell. $\beta$. epidryon. Ach. meth. p. 97. C. trichiale $\gamma$. Ach. Lich. univ. p. 243. C. stemoneum. $\beta$. V. A. H. 1816. p. 279. t. 8. $f_{.}$15. c. C. fagineum. Schum. Soell. 2.p.181. Cfr. Sched. Crit. p. 7.

** tenellum, excipulo turbinato-clavato.

Ad ligna \& cortices frequens, in campestribus in Salicibus passim, maxime vero abundat in montanis ad Abietes, Quercus \&c. * precipue in 


\section{arboribus cavis cariosis.} cissimis.

Simile analogo $C$. lenticulari, sed stipes longior \& tenuior, ceterum coloribus primariis facillime distinctum. Discus hujus \& prior is diu compactus \& levigatus, in sequentibus vero jam primitus solutus, etiam in C.trachelino *, quod xque ac ** Cal. chlcrelli analogon, e loco ortuin esse luculenter vidimus. Sporidia obscuriora quam in sequentibus. - De vexatis Mucore Lichenoide \& sphorocephalo indeque ortis synonymis plura sane, quam ut hoc loco recipiantur, afferenda essent. E locis vero natalibus, descriptionibus in Fl. Su. \&c. clarum omnino est $\boldsymbol{M}$. Lichenoidem sistere $\boldsymbol{C}$ al. lenticulare, ut quidem plurimi habent. M. spharocephalus Linn. I. c. ("triplo minor, stipite filiformi, capitulo globoso cinereo") non potest non esse vulgatissimum C. subtile, quod etiam confirmatur ex itinere Scan. p. 20, ubi suo more statura sim:lia conjungendi, eidem adnumerat Cal. chlorellum; illud vero in Mesembryanthemis est Fungus. Vulgo pro hoc sumtum fuit $C$. trachelinum, quod vero $C$. lenticulari triplo minus \&c. dici nequit. Hinc hoc nomen plane omittere necesse fuit. Acharii Lich. sphaerocephalus Prodr. est Linnzanus s. C. subtile; Cal. sphceroc. $\alpha$. et 8 . Methodi Lich. idem, sed ipsi ignota Cal. quercinum \& abietinum ut varietates addita; in Lich. univ. cum $C$. lenticulari prorsus coalitum, in $\mathrm{Sy}-$ nopsi tandem ex descr. Cal. sphcerocephali Wahlenbergii (alienæ stirpis, scilicet C. trachelini) restitutum, ut demum in Vet. Ac. Handl. 1816 ingenus Vir hoc suum synonymon e diversis elementis conflatum non citandum esse monuerit. - Lich. sphoroce, phalum suum ipsissimum pro sequente habendum esse docuit b. m. Swartz in litt., reliquos ut taceam. Ceterum multiplex orta est confusio a variis peregrinis crustis leprosis, quibus hujus præcipue ad cortices (ad ligna purior est, tum semper tenuis effusa contigua cinereo-albicans vix granulosa) suffusa est v. c. Lepraria flava, indeque pendet fig. citata ex Engl. Bot. ceterum quoque mala.

Singularis status monstrosus est Cal. xylonellum. Ach. meth. p. 92. et in V. A. H. 1816. p. 120. t. 5. f. 4. totum atrum, excipuli extus membrana fusca subdiscreta tecti margine inflexo.

334. CALICIUM melanophoeum, crusta granulatoconglomerata lactea, apotheciis turbinato-globosis, subtus margineque inflexo nitidis atris, 


\section{disco pulverulento umbrino-ferrugineo, stipite} brevi nigro. Sched. Crit. I. p. 5.

C sphæroceph. $\beta$. melanophæum. Fries olim in litt. C. melanophæum. Ach. in Vet. Ac. Handl. 1816. p. 276. t. 8. f. 8. imperf. sine crusta. Wahl. Suec. n. 1751. Sommerf. Lapp. p. 179. Flolow in Reg. Bot. Zeit. 1828., ex quo C. lygodes Hepp. Würzb. p. 78.

Exs. Lich. Suec, n. 9. Flotow. 21.

Ad ligna \& truncos quercinos, pineos \&c. Europæ septentrionalis saltim passim.

Inter præcedens \& C. roscidum quasi medium, insigne præcipue crusta eximie granuloso-conglomerata lactea, at pro more sæpe deficiente. Est vero vulgo in apotheciis monstrosum quoddam, quare, a me primo detectum, pro varietate diu habui, at Acharius sperie distinxit, nec in aliud umquam abire vidi. Disco excepio totum aterrimum nitidum, sed stipites passim basi fuscescunt. Sporidia ferruginea speciem ab omnibus distinguunt. - Passim occurrit monstrosum, sessile, dilatatum, excipulo inciso, disco ferrugineo bene respondens $C$. ferrugineo Turn. \& Borr. 1. c. p. 136. Engl. Bot. t. 2473. Ach. V. A. H. $181 \%$ p. 225.

335. CALICIUM physarellum, crusta granulatoverrucosa cinereo-viridi, apotheciis subturbinatis, extus fusco-nigris, margine tenui a disco pulverulento umbrino obtecto, stipite brevi nigro. Sched. Crit. I. p. 6.

C. physarellum. Fries - Ach. in Vet. Ac. Handl. 1816. p. 280.t. 8. $f$. 11. C. Prevostii. Duby e spec. invent. - nec differt ab hoc 1. C. trichiali Cal. $x-$ ruginosum. T'urn. et Borr. l. c. p. 156. Engl.Bot. t. 2502, Ach. l. c. $181 \%$ p. 236.

Exs. Lich. Suec. n. 11.

Ad parietes ligneos \& truncos rarius; ad terram argillaceam Gallize Le Prevost!

In statu perfecto granulis verrucosis in crustam subtartaream aggregatis bene $\&$ facile distinctum, sæpe vero locis suffocatis in lepram virescente-griseam deliquescit, in quo statu C. trichiale refert, ut syn. Turn. \& Borr. inter hæc ambigat. Hujus esse loci in litt. suasit optimus Schaerer, cujus, ipsi dubium, in Naturw. Anzeig. 
1821. potius C. trichiale. C. trachelino affinitate proximum; licet facies magis Coniocybes, verum Calicium excipulo exiguo quidem, sed carbonaceo. Stipites breves, crassiusculi, firmiores quam C. trichialis, nudi nisi crusta pulverulenta adspersa. Excipulum subtus numquam albocinerascens.

336. CALICIUM bruineolum, crusta tenuissima levigata albicante, apotheciis turbinato-globosis, extus umbrino-ferrugineis, disco concolori marginem excipuli exigui obliterante, stipitibus gracillimis nigris. Sched. Crit. I. p. 4 .

Cal. brunneolum. Fries - Ach. in Vet. Ac. Handl. 1816. p. 279. t. 8. f. 12. Calic. parietinum. Schaer. spic. p. 4 .

Exs. Lich. Suec. n. 4. Schaer. Helv. n. 9.

Ad ligua cariosa abiegna in silvis montanis septentrionalibus prope terram copiose; etiam in Gallia Dufour!

Admodum gracile \& microcarpon, crusta sæpius deficiente, passim granulis minutis pallidis leprosis adsporsa. Statura hujus omnino C. trichialis (aut Cal. chrysocephali tenuioris), sed ob excipuli colorem certe $C$. trachelino proximum; C. brunneolum Sommerf. Lapp. p. 182. ob excipulum albo-pruinosum ad C.trichiale referendum. Et consideranti mihi ejus vegetationis historia (sæpius enim occurrit in eisdem truncis ao Cal. trachelinum, ita vero, ut $C$. trachelinum plagas ligni indurati, præsens vero ligni mollis \& cariosi, definite occupent) vix dubium videtur $C$. brunneolum esse Cal.trachelini filiam e ligno carioso enatam, licet ceterum ob faciem diversissimam \& uberrimum proventum lubentius seorsim proponam. Numquam enim reperiuntur formæ intermcdiæ. - Ubi vero ligno carie plane dissoluto, locis udis ad terram prostrato, innascitur, adhuc magis gracilescit degeneratque, apotheciis vix rite evolutis \& tale est $C$. flexipes (C. brunneolum v. flexipes Fr. mscr.) Ach. in V. A. Handl. 1817. p. 232. t. 8. f. 12.! Statura affinitatem inter Calicia certe non indicat!

*** Flavo-virescentia. Apothecia flavo aut æruginosopruinosa. Sporidia subolivacea.

337. CALICIUM chrysocephahim, crusta granu- 
lato-conglomerata citrina, apotheciis turbinatolentiformibus, disco umbrino, stipitibus gracilibus nigris. Ach. meth. Suppl. p. 18.

Dill. musc. $t$. 14. $f$. 3. B. Lich. chrysocephalus. Turn. in Transact. Linn. Soc. VII. p. 88. t. 8. f. 1. Engl. Bot. t. 2301. Calicium. chrys. Turn. et Borr. l. c. p. 143. Ach. in V. Á.H.1S16.p. 269. Wahl. I.app. p. 487. Schaer. spic. p. 5. Fl. Dan.t.1851. f. 2 .

Exs. Lich. Suec. n. 6. Fl. Deutsch. n. 6. Schaer. Helv. n. 12. Flotow. n. 23.

Ad ligna \& cortices Pini, Quercus, Betulæ, copiose in silvaticis \& montanis.

Vulgo inter minora \& pumila, sed stipes gracilescens sæpe eximie elongatur, filaris, flexuosus. Crusta vix umquam deficit. Hujus \& marginis colore a sequente proximo facile dignoscitur. Sporidia aurantio-fusca, demum olivascentia. - Fiujus forma in aridis umbrosis nata cum $C$. hispzdulo aut chlorello sequentis analoga est C. fulvum Schaer. Naturw. Anzeig. 1821. sec. spec. oculatissimi quondam observatoris Chaillet, jain, proh dolor! subcocco.

sidcst stirps perquam similis, sed granula lıctea, similia C. me* lanophai. Sporadice tantum obviane venit, quare non separanus.

338. CALICIUM phoocephalum, crustæ grannis discretis e pallido fuscescentibus, demum squamulosis crenatis, apotheciis turbinato-lentiformibus flavoviridi-pruinosis, disco fusconigro, stijitibus gracilibus fusco-nigris. Turn. et Borr. Lich. Brit. p. 145.

Cal. chlorellum. Wahl. Suec. $n$. 1754 .

a. Lich. phæocephalus. Turn. in Transact. Linn. Soc. VIII. p. 260. t. 6. f. 1. G. sæpiculare. Ach. Lich. univ. p. 240. Vet. Ac. Handl. 1816. p. 271. t. 8 . $f .13$.

b. crusta imperfectiori: Calic. trabinellum Ach.meth. Suppl. p. 14. Vet. Ac. Handl. 1816. p. 270. t. 8. f. 2. Lich. trabinellus. Engl. Bot. t. 1540. C. chlorellum $\beta$. orochroum. Wahl. Lapp. p. 487. Ach. Syn. p. 60. Calic. claviculare. $\beta$. \& $\gamma$. cyathellum Ach. Lich. univ. p. 235. C. roscidum. B. Schaer. Sominerf. Flot. 
Exs. Lich. Suec. n. 5. a. et b.

* chlorellum tenellum, gracillimum, apotheciis obovatis, disco demum prominente. Calic. chlorellum. Ach. meth. p. 95. t. 2. f. 5. Lich. univ. p. 239. V. A. H. l. c. 1816. p. 267. - Turn. et Borr. l. c. p. 146. Cal. trachelin. $\gamma$. hispidialum. Ach. Lich. univ. p. 237. Cal. hispidulum. Vet. Ac. Handl. 1816. p. 268. t. 8. f. 9. Lich. acicularis. Engl. Bot. $t$. 2385. Calic. picastrellum. Ach. Vet. Ac. Handl. 1817. p. 237.

Exs. Flotow. n. 24. Flörk. n. 65.

Ad parietes ligneos, cortices arborum \&c. in silvaticis montosis abunde.

Species distinctissima crusta subsquamulosa, e pallido fuscescente, stipitibus gracilibus, pruina flavoviridi, qua specimina tenerrima undique, perfectissima margine tantum adsperguntur, excipulo e turbinato lentiformi, disco primitus compacto \& lævigato, sporidiis olivaceo-umbrinis. - Sed ad typum reliquorum, præcipue analogi Cal. trachelini, mutatur. Crusta ut serotina passim deficit, sed numquam leproso-deliquescens visa est; b. re ipsa nullo modo differt nisi crustæ granulis minutis aut nuilis, (ceterum promiscue obviam veniunt); nam discus cinerascens pendet e statu disci soluti degenerato cum C. discoidali, C. peltato \&c. Ach. analogo. Est quidem huic analogia structuræ \& magnitudinis cum $C$. curto, at nulla omnino affinitas, ut ex hujus excipulo cinereo-pruinoso, margine saltim albicante, sporidiis aterrimis \&c. facile patet. Nec umquam in natura promiscue vidi, ut non dubitem eorum unionem ortam esse ex speciminibus utriusque vetustis denigratis e solo natali divulsis comparatis. In $C$. chlorello hypothallus albicans pro vera crusta sumtus fuit. Hujus status, qui Cal. hisprdulum Ach., excipuli forma \& disco prominente, licet longe ceterun tenuior sit, $C$. curtum prorsus refert, ut ex hoc facile concluderes $C$. curtum esse analogam degenerationem, non C. phoeocephal, sed Cal. lenticularis, quod vero hujus genuina vegetationis historia dissuadet. Hoc Cal. chlorellum nil nisi formam tenellam imperfectam hujus speciei, e loco arido \& umbroso enatam, centies sane in rimis parietum ligneorum vidimus, atque omnis analogia probat. Hanc Wahlenbergianam \& nostram Sched. Crit. 1. c. limitationen omnes recentiores rejiciunt, distinguentes a. \& *, b. cum 
C. curto \& roscido conjungentes. Cujus rationes me plane non intelligere paucarumque specierum limitationem, quam præsentis, certiorem mihi videri fateor.

339. CALICIUM roscidum, crusta cartilaginea rugosa cinerascente, apotheciis lentiformibus, margine discoque demum nudo olivaceo primitus flavo-viridi pulverulentis, stipite brevi crasso uigro. Fl. Deutsch. Lich. 3. p. 3.

Cal. claviculare $\beta$. roscidum Ach. meth. p. 90 \& C. hyperellum b. roscidum. Ach. Lich. univ. p. 238. \& C. roscidum. Ach. Vet. Ac. Handl. 1816. $p$. 275. $t$. 8. $f .6$. hujus loci quidem sunt, at descr. erroneæ. C. roscidum. Sched. Crit. I. p. 6. Sommerf. Lapp. p. 181. Fl. Dain. t. 1851. f. 1. - var. $\alpha$. Schaer. in Naturw. Anzeig. 1821. Cal. claviculare. Wahl. Suec. C. mutabile. Ach. in V. A. IT. 1817. p. 234. t. 8. f. 13.

Exs. Lich. Suec. n. 10. Flörk. n. 42. Flot. n. 18. b. sessile, deformatum. Cal. adspersum Pers. ic. et descr. Fung. t. 14. f. 7. Ach. syn. p. 56. Cyphelium. $A c h$. in $\mathscr{V}$. $A$. rr. $^{1815}$.

- Ad ligna \& cortices passim.

Constanter curtum, robustum, magis quam statura ceterum proxinum C. lenticulare, cum quo olim frequenter commutatum, at maxime diversum est. Speciem primus rite proposuit Cel. Flörke, speciminibusque divulgatis fixit, quare hujus receptissimum nomen non potui non servare. Occurrit quidem minus, at cum C: $\operatorname{trc}-$ binello ex meis observationibus minime conjungere licuit. $C$. roscidi crusta superficiali-effusa contigua, mox rugosa \& inæquabilis, C. trabinelli, ubi præsens, semper granulis discretis erumpentibus, alia coloris mutatione, formatur. C. trabinelli stipites graciliores sunt \& excipuli forma diversa semper mihi visa. Discus in C. trabinello normalis compactus lævigatus umbrinus, margine regulari persistente, $\boldsymbol{C}$. roscidi semper discretus, primitus flavo-pulverulentus, hoc pulvere flavo, sporis ex Meyer, evanido sensim magis magisque æruginoso-olivaceus, immo nigrescens, margine cinctus subirregulari demumque evanido, a disco obliterato. Sporidia C. trabinelli umbrina, leviter olivascentia; $C$. roscidi seruginoso-olivacea. Quis discum flavo-pulverulentum a "Lepraria flava" ortum dixit? saltim Acharius in V.A. H. 181\%, nos in 
Sched. Crit. 1. e. s. p. discum primitus flavo-pulverulentum pro hujus primario habuimus charactere. (Cfr. insuper Lycop. Bovistam S. M. III. p. 31.)

340. CALICIUM disseminatum, crusta leprosa viridi albicante, apotheciis substipitatis globosolentiformibus atris, præcipue disco olivaceo-nigro, primitus obscure viridi-pruinosis. Fries Sched. Crit. I. p. 7 .

Cyphelium disseminatum. Ach. in Vet. Ac. Handl. 1817. p. 227. t. 8. f. 3. G. subpedicellatum. Schaer. Naturw. Anz. 1821. C. atomarium. Flotow in Regensb. Bot. Zeit. 1828. p. 600. ex maxima parte, sed forma 4 meo sensu ad speciem quandam seriei Glaucescentis, forma 5 Fuscescentis, \&c. ut status imperfecti pertinent.)

Exs. Lich. Suec. n. 16.

Ad ligna vetusta, truncos Abietis decorticatos \&c. in silvaticis montosis abundat.

P:imo obtutu pro forma mutila \& degenerata alius speciei facile sumitur, sed \& ipsa maxime protea est fornis bene evolutis \& multis; cum nullo præcedentium, e quàrum serie tamen luculenter est, conjungi potest; \& peculiari omnino vegetationis historia, sæpe Calic. trichialis, vix vero priorum societate, gaudet. Crusta hujus luculenter entoxyla est, per lignum argentato-decoloratum ut soredia virescenti-albida erumpit $\&$ hinc normaliter leprosa, non effusa. Apothecia re ipsa stipitata sunt, sed stipes plerumque ligno immersus est, passim vero etiam emersus gracilis, niger. Forma apotheciorum primaria globosa aut cum stipite globoso-turbinata est; margine obsoleto, disco semper soluto evidentius obscure - (nec flavo-) virescente-pruinoso; dein evanescente pruina varie explicata, disco sæe prominente. Sporidia viridi-olivaceo-nigra.

*w* Aterrima. Apothecia tota aterrima nuda aut atro-pruinosa.

Omnes hujns seriei species exigux \& breviter stipitatæ sunt, habituque proprio a prioribus diversæ, ut status priorum senio 1. pruina evanida nigrescentes, v. c. Cal. subtile $b_{\text {., huc non sint referendi. Inter se quo- }}$ que magis differunt, quam priorum serierum, nam hae xque inter se affines ac Cladonix ejusdem seriei, \& si has 
jungimus, etiam singulam Caliciorum seriem, excepta vero præsente, pro unica sumemus specie.

34r. CALICIUM corynellum, crusta tartarea leproso-deliquescente citrina, apotheciis turbinato-lentiformibus opacis aterrimis, disco planiusculo dilatato, stipitibus brevissimis. Ach. meth. p. 94 .

Lich. corynellus. Ach. Prodr. p. 94. Cal. Vet. Ac. Handl. 1816. p. 124.t.5.f.7. Wahl. Suec. n. 1750. Exs. Lich. Suec. n. 418 .

b. paroicum, apotheciis in Parmel. hæmatomma parasiticis. Ach. syn. p. 5\%. C. paroicum. Ach. meth. p. 89. $t$. 2. $f$. 3 .

In rupium fissuris, præcipue in Scandinavia montosa passim copiose.

Crusta insignis, sæpissime leprosa, conglomerata, floccis subintertexta, ut cum Leprar. chlorina Ach. syn. p. 329 , quam in eisdem regionibus, locis vero adhuc magis cryptis legimus, prope connexa videtur. Excipuli margo per ætatem obliteratur. Sporidia aterrima.

342. CALICIUM albo-atrum, crusta leprosa alba, apotheciis minutis turbinato-lentiformibus nudis, disco demum subimmarginato scabrido, stipitihus brevissimis tenuibus concoloribus. $F l$. Deutsch. 2. p. 46. e definitione.

C. minutellum. Ach. in Vet. Ac. Handl. 1816. $p$. 118. t. 5. f. 2. C. parietin. $\gamma$. Ach. l. c. p. 261. $t$. 8. $f$. 1. $d$. (pulvere crustæ apotheciis adsperso.) Exs. Flörk. l. c. n. 26. non vidi.

\section{Ad ligna \& cortices vetustos quercinos.}

Nostra stirps evidens est Calicium, excipulo marginante discum primo planiusculum compactum, dein tumentem marginem subexcludentem, \& inter affines crusta (typice hypophloode?) luculenter diversa. Nec de synonymis Acharianis dubitamus; Flörkei e definitione huc retulimus, cum fasciculum 2 Lich. exs. Flörkei numquam viderimus. Ceterum diversa sub hoc nomine accepitaus; in Flat. exs. n. 15. Calicium quoddam stipitatum in meo exemplari non invenio; Sonmerfeltii descriptio in Fl. Lapp. Supl. p. 176. Conic. nigricanti acce- 
dit, quod a nostro tam stipite primitus hyalino-pallido, quam excipuli defectu abunde diversum est.

343. CALICIUM byssaceum, (crusta byssacea opaca aterrima), apotheciis clavato-turbinatis nitidis aterrimis, disco impresso-punctiformi, stipitibus brevibus tenuibus. Fries Sched. Crit. I. p. 6.

Cal. pullatulum (ex errore!) Ach. in Vet. Ac. Handl. 1816. p. 121. t. 5. f. 5. Sommerf. Lapp. p. 178.

Exs. Lich. Suec. $n .12$.

Ad ramulos alneos, salicinos \&c. in silvis humidis umbrosis Scandinaviæ passim.

Distinctissima, licet minima, generis species. Nudo oculo Byssum quandam, v. c. Helmisporium, omnino refert, et apothecia sub lente evidentissime Calicii. Crusta nulla, nisi byssacea nigra, raro deficiens; hæc pro hypothallina habenda, hypothallo variorum Fungorum simillima. Est itaque omnino in limine Fungorum posita species, quam jam 1811 nomine proposito distinxi; Acharius dein 1816 cum $C$. pullatulo nostro in mscr. (Coniocybe nigricante) eonjungebat, ejusque nomen huc transtulit, quare non possumus non nomen nostrum servatum postulare.

344. CALICIUM microcephalum, crusta cartilaginea demum rugoso-verrucosa fuscescente, apotheciis turbinatis subsessilibus nudis aterrimis, margine subinflexo, sporidiis atris. Turn. et Borr. Lich. Brit. p. I 30.

Lich. microcephalus. Engl. Bot. t. 1865. Calic. Ach. syn. p. 57.

b. minus, crusta tenuiori, lævigata, pallidiori. Cyphel. Ach. in V. A. H. 1817. p. 227. t. 8. f. 3. Calic. Fries Sched. Crit. I. p. 8.

Exs. Lich. Suec. n. 17 .

Ad cortices truncorum vetustos.

Apothecia non nisi rarissime in stipitem attenuantur, sed tam ob veram affinitatem, quam ob apothecia crustæ non innata (ut in omnibus sequentis sectionis genuinis speciebus h. l, inserenda. A Cal. disseminato differt crista effusa, cartilaginea, in perfectissimis nuperius a me lectis speciminibus crassa \& rugoso-verrucosa, exci- 
pulo regulari turbinato, stipite numquam immerso, disco haud pruinoso, sporidiis aterrimis. - Est forsan Calicii turbinati, quod cfr., status crusta genuina.

Sect. II. Apothecia sessilia, crustæ innata - aut prorsus acrustacea parasitjca. Cyphelium. Ach. 1. c. Acolium Fée. Calicium. Cheval.

Probe separandæ a prioris sectionis speciebus apotheciis subsessilibus. Alia ratio insertionis apotheciorum illarum, quæ e ligno; alia earum, qux e crusta propria (aut peregrina) oriuntur.

345. CALICIUM tigillare, crusta areolato-verrucosa citrina, apotheciis innatis, disco primitus nudo atro marginem tumiduin aquante. Turn. et Borr. l. c. p. 132 .

Lich. tigillaris. Ach. Prodr. p.6\%. Engl. Bot.t.1530. Lecid. Ach. meth. p. 46. t. 2. f. 1. Wahl. Lapp. p. 468. Calic. Ach. syn. p. 55. Cyphel. $V_{0} A_{0} H$. 1815. Cal. citrinum Pers. in act. Wett. 2.

Exs. Lich. Suec. n. 151. Flotow. n. 12.

Ad ligna fabrefacta et truncos, præcipue locis frigidioribus ventosis.

$\mathrm{Ob}$ discum insolito compactum Lecideam, ne dicam Lecanoram refert.

346. CALICIUM viridulum, crusta areolato-verrucosa viridi-pallescente, apotheciis innatis, disco compacto virescenti-pruinoso marginem tenuem demum rquante. Sched. Crit. I. p. 8.

Cyphel. Ach. l. c. 1818. p. 226. t. 8. f. 5.

Ad ligna vetusta rarius.

Statura omnino prioris, sed margine tenui sequenti magis affine. Apotheciorum situ \& origine ab omnibus præcedentis sectionis abunde diversum.

347. CALICIUM saxatile, crusta tartarea rimosa alba, apotheciis innatis, disco pulveraceo atro marginem tenuem nigrum superante. Schaer. Naturu. Anzeig. 1821. Winterir. p. 35. Trachylia. Fries V. A. H. 1821. Ad saxa, locis irriguis, raro.

Sequenti generi, Trachylix, magis affine, sed ob a- 
pothecia marginata h. l. citandum, crusta tartarea \& apotheciis minutis a sequente differt.

348. CALICIUM tympanellum, crusta granulosotartarea glaucescente, apotheciis innatis, disco pulveraceo atro, marginem tenuem albicantem superante. Ach. meth. p.46.t.2.f.r.

Lich. inquinans. Engl. Bot. t. 810. Calic. Schaer. $l$. c. Cal. tympanellum, cembrinum, \& "leucomelas Pers.! in Act. Welt. 2." Ach. syn. p. 55, 333. Cyphelia. Ach. in Vet. Ac. Handl. 1815. t. 6.f. 7. 2. C. ollare (disco elapso) \& C. pileatum (disco protruso) l. c. $1817 . t$. 8.f.2,1. C. tympanell. Turn. et Borr. l. c. p. 134. Sched. Crit. I. p. 8. Fl. Dan. $t .1848 . f .2$.

Exs. Lich. Su. n. 18. Moug. Nestl. 859.

Ad ligna putrida \& truncos in regionibus silvaticis.

Crusta normaliter crassa, apotheciis" maximis foede atroinquinantibus inter proxima facillime dignoscitur. Nec C. cembrinum Ach., nec C. leucomelas Pers. nec reliquæ species Acharianæ secundum spec. archetypa tantum differunt ut peculiares sint formæ.

* Heteroclita, in aliis Lichenibus sine crusta propria parasitantia.

- CÁLICIUM stigonellum, parasiticum, excipulo cupulari innato atro, disco plano nigro-pulverulento, marginem tenuem erectum nigrum $æ-$ quante. Ach. syn. p. 56. ex ipso.

Calicium sessile. Pers. Disp. p. 59. ipso teste ap. Moug. et Nestl. Cyphelium stigonellum. Ach. in Vet. Ac. Handl. 1815. Cal. tympanell. $\beta$. Wahl. Suec. $n$. 1745. C. scutellaria. Duf.

Exs. Lich. Suec. n. 187. Moug. Nestl. n. 858.

In crusta Pertusariæ communis v. coccodis, nec umquam in forma normali.

Commixtum vulgo in herbar., etiam Achariano, cum minutis sequentis formis, cum quo igitur conjunctum fuit, at certissime diversum. Equidem semper pro prioris statu diminuto habueram, donec acutissimus Le Prévost ad diversam originem apotheciorumque naturam \& marginem concolorem primo conniventem attendi suasit. Cfr. Obs. sub sequente specie. 
* CALICIUM turbinatum, parasiticum, excipulo e globoso turbinato sessili libero atro-nitente, disco impresso margine crassiusculo inflexo cincto. Pers. Disp. Fung. p. 59 .

Sphærocarpus sessilis. Ehrh. - Lich. gelasinatus. With. arr. IV.t. 31.f. 1. Lecid. Ach. meth. p. 33. Cal. sessile. Dec. fr. 2. p. 365. Turn. et Borr. l. c. p. 128. Sphæria sphinctrina. Sowerb. Fung. t. 286. Gal. turbinatum. Ach. Lich. un. p. 232. t. 3. f. 5 . Gyphelium. Vet. Ac. Handl. 1815.

Ad crustam \& in verrucis apotheciorum Pertusariae communis ipsius, non autem in var. coccode, subinde vero in aliis Lichenibus.

A præcedentibus abunde differt apotheciis omnino elevato-liberis (vıdi stipitata), nitidis, primo clausis!, disco impresso punctiformi.

Locus hujus \& præcedentis varie dijudicatus: 1) Pro fungis veris, a Caliciis recedentibus ut Sphæria a Verrucaria, sumi possent: Hoc Systematicis limitibus \& characteribus, ipsorumque vegetationi optime respondet. 2) Pro statibus aliarum specierum, nempe C. stigonellum C. tympanelli \& C. turbinatum C. microcephali, facile habentur; quod habiius præcipue suadet, sed practice nondum demonstratum. 3) Pro ostiolorum Pertusariae degenerata luxurie ingeniose sumit Wahlenberg, quod etiam confirmatur a Spil. dendritico Ach. Cfr. Pertus.

C. cladoniscum et C. ventricosum Ach. syn. p. 61. sunt Sphceronamata S. M. II. - Veniunt vero sub his nominibus etium Calicia mutila, haud evoluta.

\section{* TRACHYLIA.}

Vet. Ac. Handl. 1821. p. 251. S. O. V.

CHAR. Apothecia sessilia, a thallo discreta, orbiculata, immarginata, corneo-carbonacea, scabrosa, sporidiis nudis pulverulentis adspersa. Thallus crustaceus. Apothecia atra.

Differt a Caliciis excipulo proprio haud marginante, licet sæpius adsit stratum carbonaceum, disco magis solido; a Lecideis scabrosis, quilus habitu simillimum, apotheciis pulverulentis; a Spil. verrucoso Fl., tuberculoso Engl. Bot. similibusque evidentius deformatis apotheciis haud floccoso-scabridis. Ceterum de specierum 
hujus generis autonomia minime convicti sumus, licet formas quasdam alio loco inserere non potuerimus, quare prorsus rejicere non licuit. Calicia quædam sessilia v.c. citrinellum h. l. potius inserenda, si marginem e char. excludas.

* TRACHYLIA Arthonioides, crusta contigua pulveracea ochroleuca, apotheciis convexis scabrido-pulverulentis, intus atris. Ach. Lich. univ.p. 178. Lecid.

Ad rupes Lusatiæ, raro. Herb. Ach.!

Habitus Parmel. lanuginosa, 'Lecid. farinosø forsan proxima, nec, quantum video, cum Biatora decolorante comparanda. "Crusta formatur a massa pulveracea albissima, cui superstrata est cuticula solidior pallide lutescens, iterum farina alba suffusa" $A c h$. mscr.

Reliquas hoc loco citandas, ut magis obscuras, omitto; observandum tantum Sclerococcum sphoerale Syst. Myc. III. p. 257. s. 'Spiloma spharale Ach. syn. p. 2. (Lecid. papillosa Lich. univ. p. 171. \& Lecan. micraspis Sommerf. Lapp. p. 102. sec. apoth.) ad Trachylias se habere ut Calicia parasitica ad vera Calicia.

\section{Ord. II. ANGIOCARPI.}

$\Lambda$ pothecia clausa, ostiolo pertusa aut irregulariter dehiscentia, nucleo incluso, subgloboso ascigero. Angiocarpi. Fr. Dian.Gasterothalami. S. O. V.

\section{Trib. I. SPEROPHORE $\mathbb{E}$.}

CHAR. Apothecia ex apicibus thalli intumescentibus formata, clausa, demum irregulariter \& lacero-dehiscentia. Nucleus subglobosus, cum ascis fatiscens aut disparens. Thallus verticalis, fruticulosus.

Alterum hujus tribus genus Usneam \& Stereocaulon, alterum Everniam \& Cladoniam refert, at cum ista genera serie contigua cum generibus thallo horizontali confluant, Sphærophoreæ ab Endocarpeis omnino abruptæ. - Eadem apotheciorum formatio rédit in Lichina - (Thamnomyce \&c. Pyrenomycetum). 


\section{SPHEROPHORON.}

Coralloid. spec. Dill. Stereocaulon. Hoffm. Sphærophoron. Pers. Ach. Decand. et Rec. omnium.

CHAR. Apothecia terminalia, sphærica, excipulo thallode clauso, lacero-dehiscente. Nucleus globosus, intus floccoso-cartilagineus, in ambitu sporidiis nudis (atris) pulveraceo-fatiscens. Thallus verticalis, fruticulosus, extus crustaceo-cartilagineus, intus solidus stuppeus. Apoth. serotina.

Male sub initiis studii mei Lichenologici cum Caliciis tribu conjunxi, cum quibus indole quidem nuclei demum disciformis pulveracei aliquantulum convenit, at ceterum nullo modo affine est. Lepraria, Coniocarpon, Calicium \& Spharophoron sub eadem sectione comprehensa sistunt exemplum generum adeo heterogeneorum $e$ methodo carpologica conjunctorum, ut magis diversa in thallinis copulata exquirere non valeamus. Ex hemisphærio australi adsunt hujus generis species thallo filamentoso pendulo, alia subtus dehiscente canaliculato-foliaceo e. s. p. - Alii Sphœerophorus scribunt, sed hæc sunt minutix, quas equidem in syn. non curo.

349. SP EROPHORON compressum, thallo fruticuloso vage ramoso, ramis compressis fibrillosis, apotheciis globoso-depressis demum disciformibus, margine reflexo. Ach. meth. p. 135 . (Dill. musc. t. 17. f. 34. ex Auct. Brit., sed icon \& descr. omnino cum Sph. fragili conveniunt) Lich. fragilis. Engl. Bot. t. 114. et Auct.var. Sph. compressum. Ach. Lich. univ. t. 12. f. 6. Turn. et Borr. p. 115. Dec. fr. 6. p. 178. Sph. melanocarp. Schaer. Naturw. Anzeig.

Exs. Fl. D. n. 39. ex Schaer., a me non vis.

In rupibus alpinis, etiam ad radices abietum \&c., Europæ fere totius, excepta Scandinavia; atque in saxis arenariis Britanniæ.

Apotheciis demum omnino disciformibus, marginibus reflexis, nucleo fibris albis copiosis intertexto, certissime dignoscitur a sequentibus, cum quibus frequenter com- 
mixtum fuit. Color vero incertam præbet differentiam; præsens vulgo albicat.

35o. SPHFROPHORON Coralioides, thallo fruticuloso vage ramoso, ramis teretibus laxo-divaricatis fibrillosis, apotheciis globosis, margine inflexo. Pers. Ust. Ann. 7 .

Mich. t. 39. f. 6. Dill. musc. t. 1\%. f. 35. Lich. globiferus. Linn. - Engl. Bot. t. 115. Fl. Dun. t. 960. Coralloid. Hoffm. Pl. Lich. t. 31. f. 2. Sphæroph. Dec. fr. 2. p. 327. Sph. coralloid. Ach. Lich. univ. p. 585. t. 12.f. 5. - var. a. laxum. Turn. et Borr. l. c. p. 110.

Exs. Lich. Suec. n. 60. Ehrh. Cr. 20. Moug. et Nestl. n. 262. Flörk. Deutsch. n. 98.

b. candicans, compressum, ramis teretiusculis.

In regionibus pineto-montanis, etiam alpestribus, ad rupes \& truncos Pini. - b. locis occultis irriguis; per Europam fere omnem; sed, ex Schaerero, in Helvetia desideratur.

Color vulgn castaneus, sed $\mathbf{b}$. passim omnino candicat, quale ab Achario, Flörkeoque Sph. compressum dictum fuit, unde has species olim conjungendas credidi. Rami acuti tenaces, sed fibrillæ fragillimæ sunt. Diffractis laciniis excipuli apothecia circumscissa apparent, at discus prioris magis convexus.

35r. SPHAROPHORON fragile, thallo cæspititio dichotomo-ramoso, ramis teretibus fastigiatis nudis, apotheciis turbinato-globosis, margine inflexo. Pers. 'l. c.

Linn. Lapp. t. 11.f. 4. Dill. musc. t. 14. f. 34. ex icon. Lich. fragilis Linn. - Jacq. misc. Il. t. 9. f. 6. male. Coralloid. Hoffm. Pl. Lich. t. 33. f. 3 . Sphæroph. fragile Ach. meth. t. 3. f. 5. Lich. univ. p. 585. Engl. Bot. t. 2474 . Schaer. spic. $p$. 7. Lich. sterilis. Ach. Prodr. Sph. cæspitosus. Dec. fr. 2. p. 327. Sph. coralloid. $\beta$. T'urn. et Borr. $l$. c. $p .111$.

Exs. Lich. Suec. n. 133. Ehrh. Cr. n. 128. Moug. et Nestl. n. 263. Schaer. n. 15.

Ad saxa locis alpestribus \& maritimis ven- 
tosis Europæ facile totius; per omnem vero Sueciam australinrem silvaticam prorsus desideratur.

Color plerumque cinerascens, raro fuscescens. Rami fastigiati, in crspites late effusos dense stipati, obtusi, fragillimi, fibrillis destituti. Apothecia magis clausa, unde sæpe deformantur.

\section{sibiona XXII. SIPHULA.}

- Fries V.A. H. 1821. Syst. Orb. Veg.pr.p.

CHAR. Apothecia in apicibus thalli tumescentibus inclusa, clausa, demum poro pertusa laceroque-dehiscentia. Nucleus globosus, dein explanatus, cum ascis disparens. Thallus verticalis, radiculosus!, fruticulosus, intus farctus stuppeus.

Bæomyces ceratites Wahl. ejusque status fructifer a Sommerfeltio inventus est maxime memorabile detectum in recentiori Lichenologia, cum nullo alio cognito genere conjungendum, quod jam plurimos ante annos pro typo Siphula generis proposui; sed ex habitu Evernia madroeporiformem \& similes conjungi posse credidi. Quamquam hæc adhuc sterilis tantum cognita est, majores suadent rationes eandem excludere. De vera Siphulæe affinitate lubenter abeo in ill. Sprengelii sententiam Sphærophoro eam esse proximam, quamquam cum eo ob nucleum numquam fatiscentem genere conjungi nequeat. Nucleus in discum passim explanatus non hoc genus magis quam Thelotrema, Pertusariam \& reliqua affinia ab Angiocarpis excludit, cum apothecia tamen magis quam in sequentibus clausa maneant \& nullo modo disciformia scutellatave evadant. A Pycnotheliis Duf. Rev. Pycnoth. omnino diversa est.

352. SIPHULA Ceratites, thallo ramoso, ramis fastigiatis rugosis obtusis, nucleo demum explanato tenui flavescente. Fries $V . A . H .1823$. p. 119 .

Bæomyces. Wahlenb. Lapp. n. 875. Cenomyce? Ach. syn. p. 279. Dufourea. Sommerf. in Vet. Ac. Handil. 1823. p. 118. Pycnothele. Ejusd. Lapp. p. 115. Sphærophoron. Spreng.

In terra nuda succosa alpium Nordlandia, rarius in subalpinis. Wahlenberg! Sommerfelt! 
Radix ramosissima, luto arcte adnata. A caule simplici subradicali brevissimo rami primum breves, partim erecti partim ad latera adscendentes, dein omnes erecti fastigiati arcte cæspitosi, per longitudinem rugosi usque ad 2 unc. longitudinem assurgunt. Sommerf. l. c. A pices incrassati, fertiles magis tumentes; diu clausi uucleo globoso, denique rumpentes tenuissimam disparentemque discretam urceolatain laminam includunt.

\section{Trib. II. ENDOCARPEA.}

CHAR. Apothecia thallo inclusa, clausa, ostiolo regulari discreto prominente pertusa, excipulo mere thallode aut thallode mutato. Nucleus deliquescens. Thallus horizontalis, foliaceus aut crustaceus.

Hre tribus Parmeliaceas ubiqne tangit; Parmelix haud explicatæ characteribus ab Endocarpo, Porina e. s. p., nisi ad ostiolum discretum attendatar, ægre dignoscuntur. Etiam in Stictis junioribus similis observatur nuclei facies, ut tantum ex tota evolutionis serie \& statu normali distingni possint. Adest v. c. End. arboreum Schwein. ex America boreali, e charactere huc referendum, at ex tota structura est Sticta haud rite evoluta. Sunt enim Parmeliaceæ quasi Lichenum series primąria, juxta quas ad alterum latus oriuntur Lecidinæ apotheciis magis liberatis \& superfieialibus, ad alterum Endocarpece apotheciis inclusis persistentibus. Exstat vero differentia primitiva in nucleo Endocarpeorum gelatinoso, deliquescente, cum perfectiori evolutione ascorum conjuncto, quo etiam status atypici diseiformes Endocarpeorum recedunt. - Fingi videtur Eudocarpeas ob excipulum proprium deficiens Verrucariis esse imperfectiores, quod vero omnino contrarie se habet, ut Parmelix, etiam prior ordo, testantur. Affinitas cum Hepaticis, quam alii videre volunt, nulla vera adest.

\section{ENDOCARPON.}

Lich. ord. 36. Mich. gen. p. 101. t. 54. Endocarpon. Hedw. - Schaer. spic. p. 58 ! - Ach. - Dec. Mieyer et Recent. omnium. Dermatocarpon. Eschw. CHAR. Apothecia thallo inclusa, globosa, 
nucleo gelatinoso colorato deliquescente, excipulo thallode membranaceo tenui pallido, ostiolis prominentibus. Thallus horizontalis, cartilagineofoliaceus, subpellatus.

Sunt, qui hoc genus cum Verrucariis conjungere malunt, sed perithecium verum omnino desideratur, excipulumque pro thallode Cel. Meyer optime explicasse mihi videtur. Interea, mediante Sagedia, series prorsus contigua est.

353. ENDOCARPON miniatum, thallo cartilagineo-coriaceo rigido e luteo cinerascente, subtus nudo fulvescente demum nigro, ostiolis prominulis fulvofuscis nigrescentibus. Ach.meth.p. 127 . Vaill. par. t. 31. f. 14. Mich. gen. t. 54. f.1. Dill. musc. $t$. 30. $f .127$. Hall. helv. $t$. 47. $f .2$. Lich. miniatus. Linn. et Auct. Wulf. in Jacq. misc. II. t. 10. f. 3. Engl. Bot. t. 593. Endoc. miniatum \& glaucum. Ach. syn.p.101. Sph. foliacea. Bolt. fung. t. 131.

b. complicatum, cæspitoso-polyphyllum, lobis adscendentibus imbricatis complicatisque. Fl. Dan. $t .532$. f. 1. L. polyphyllus. Wulf. l. c. III. t.2.f. 4. Lich. amphibius. With. L. miniatus $\beta$. Engl. Bot.l.c.f. inf. Lich. complicat. Swartz. Endoc. Ach.

Exs. a. \& b. Lich. Suec. n. 276. Schaer. n. 112. Ehrh. Phyt. n. 40. Moug. n. 57. Desmaz. n. 191. Sommerf. n. 59.

c. leptophyllım, diminutum simplex. Lich. leptoph. Ach. - Engl. Bot. t. 2012. f. 2. Endoc. Ach. meth. t. 3. $f$. 3 .

Ad saxa tam granitica quam calcarea Europæ totius, præcipue in regionibus magis campestribus \& maritimis. b. ad saxa magis irrigua. c. ad sæpius inundata.

Forma, ut plurimarum hujus generis specierum, adeo mutabilis est, ut ex ea nulla differentia petenda sit; in genere tamen hujus frondes maximx \& labi sequentis minus incisi sunt. In statu primario thallus monophylIus, orbicularis, integer, sæpe vero vel prolifero - I. e pluribus frondibus aggregatis polyphyllus; e Pyrenæis habeo pulvinulos latissimos e lobis angustissimis stipatis- 
simos. Colorem in optime vegetis $\&$ humidis apud nos semper vidi superne pallide luteolo-fulvescentem (numquam virescentem, ut alii petunt), in vetustis vero \& exsiccatis cinerascentem \& glaucopruinosum, subtus eximic fulvum (etiam in b. c.) per æatem vero in omnibus formis nigrescentem. Ostiola in regetis fulvescentia, sicca fusca \& nigra. - Descripsi hanc aliasque species quales mihi non ex paucis siccis, sed in innumeris vivis exemplaribus obviam venerunt, sine accomodatione ad aliorum recedentes descriptiones, quasi vero [Auctorum speciminibus congruas esse facile credam.

354. ENDOCARPON fluviatile, thallo cartilagi-t neo-membranaceo flaccido lobato læte viridi, sicco fuscescente, subtus nudo pallide flavo dein nigro, ostiolis prominulis nigris. Dec. $f r .2$. p. 4.13 .

Dill. musc. t. 10. f. 128. Lich. aquaticus. Linn.? anceps species. Weiss. - Engl. Bot. t. 594. Platisma. Hoffm. Pl. Lich. t. 45. f. 1-5. Lich. polylobus Wrulf. $l$. c. (III. p. 96) II. $t$. 16. fig: $g . h$. $i$. (a-f. ad præced.) Lich. fluviatilis. Web. spic. Endoc. Wahil. Lapp. p. 462. Endoc. Weberi. Ach. syn.p. 102. E. miniat. $\gamma$. Schaer. spic. p. 60.

Exs. Lich. Suec. n. 37. Ehrh. Cr. n. 39. Moug. et Nestl. 152. Schaer. n. 114.

b. diminutum, monophyllum. L. euplocus. Ach. Prodr. Endoc. Ach. meth. t. 3. f. 4 .

Ad saxa granitica, aqua suffusa, a. præcipue amnium, b. rupium irriguarum in regionibus pineto-montanis. Maxime abundat in agro Femsjonensi, ubi prius prorsus deficit.

Præcedentis forsan esse filiam, loco tamen \& regione diversis facile distingui, optime monet Wahl. Suec. $n$. 1740. Equidem transitum eo minus observare potui, cum in eisdem regionibus numquam legerim, licet præcedens æque aquaticum. Specimina hujus speciei monophylla semper minuta sunt, prioris eadem statura multo magis lobata ; adulta præcipue magis inciso-lobata \& semper complicata sunt. Facile dignoscitur, neglecta forma, frondibis tenuioribus, sæpe omnino membranaceis, flaccidis, in statu vegeto læte viridibus, siccis fuscis, raro pruinosis, subtus pallide flavis, ostiolis nigris. Nuclei perfecti minime desiderantur. 
355. ENDOCARPON Guepini, thallo cartilagineocoriaceo peltato integro e viridi olivaceo, subtus nudo carneo, apotheciis demum protuberantibus, ostiolis nigris. Moug.! in litt.

Lich. deustus. Wulf. in Jacqu. Coll. III, t. 1. f. 3 . forsan.

In rupibus schistosis \& calcareis Galliæ; circa Angers Guepin! Mougeot! Olbix Gallix australis IMoniagne!

Forma \& habitus Endoc. miniati, at similem hujus statum apud nos numquam vidimus. Multa, quæ vidi exemplaria, omnia monophylla, peltata, anguloso-repanda, haud vero lobata fuerunt, margine revoluto. Thallus supra lævis, glaker, humidus e luteo 1. olivaceo obscure viridis, siccus olivaceus aut fuligineo-olivacens; subtus lævis, glaber, obscure carneus, nec fulvescens. Sub strato corticali, strato evidentius distincto quam in prioribus, adest gonimon obscure viride, porro medullare album, demum paginæ inferioris carreum. Nuclei obscuriores, quam in prioribus, ostiolis minimis impressis. Cum vix probabile mihi videatur acutissimum \& practicum Lichenologum Wulfenium End. miniatum sub quattuor nominibus descripsisse eaque, habitu licet simili, vere diversa testari, huc potissimum referendum credidi Lich. deustum Auct., qui saltim in multis convenit.

356. ENDOCARPON phylliscum, thallo cartilagineo-gelatinoso foliaceo inciso-lobato fusco-atro, subtus nudo, apotheciis verruciformi-protuberantibus pertusis. Wahl. Lapp. n. 883. t. 29. f. 2. et Ach. syn. p. 100.

Exs. Sommerf. Norv. p. 58.

In rupibus irriguis graniticis Scandinaviæ alpinæ \& montosæ.

Species a ceteris adeo diversa, ut potius de genere, quam de differentia speciei dubitetur. Omnino foliaceum, licet 2-3 lin. tantum latum. - Nescio cum quo Lichene potius comparem Sphariam aciniformem Sowerb. t. 273, quæ novo examine dignissima.

357: ENDOCARPON reticulatum, thallo cartilagineo squamuloso-foliaceo rimoso reticulato glau- 
cescente, subtus albo, apotheciis areolis immersis pertusis. Dufour in litt.

Ad terram nudam Hispaniæ. Dufour!

Crescendi modus sequentis; hypothallo quantum video nullo, thallo hine subtus nudo albo, supra vero glauco, constanter rimis reticulatis elevato-areolato, strato gonimo atroviridi, apotheciis areolis inclusis, raro punctis nigris prominulis. - Accedit ad Sphoeriam Riccioideam Bolt. Fung. t. 182.

358. ENDOCARPON pusillum, thallo cartilagineo squamuloso-foliaceo levi olivaceo-subbrunneo, subtus pallido, ex hypothallo fibrilloso nigro oriundo, ostiolis nigris prominulis pertusis. Hedw. Stirp. Cr. II. p. 56. t. 20. f. A. Mich. gen.t. 54. f. 3. Dill. musc. t. 30.f. 133,135. Lich. tapeziformis. Zoeg. - Engl. Bot. t. 595. Lich. lachneus. Ach. Prodr. - Engl. Bot. t. 1698 Lich. Hedwigii Ach. Pr. End. Hedwigii, hepaticum, lachneum \& squamulosum. Ach. Lich. univ. p. 298, 299. End. Hedw. Schaer. spic. p. 60. optime! cum sequ. formis. - Ach. syn. p. 99. E. euplocum. Decand. syn.

Exs. Reich. n. 7. Schaer. n. 115. Moug. n. 441, 442. b. rufescens, rufescenti-olivaceum, thalli laciniis foliaceis elevatis undulato-flexuosis. E. rufescens. $A c h$. syn. p. 100. Lich. leptophyll. Engl.Bot.t. 2012.f.1. c. pallidım, tenuius, viridi-pallescens. Lich. pallidus. Engl. Bot. t. 2541. End. Ach. Lich. univ. p. 301. Syn. p. 100. E. muscorum. Lich. univ. p. 300. E. pallescens. Dec. ex spec. Montagne.

Ad terram \& saxa, formationis precipue recentioris, locis ventosis, ut in alpibus \& campestribus v. c. Scaniæ; sed in regionibus pinetomontanis Suecire saltim mihi non obvium.

Proteam hanc stirpem, pro more optime, primi cel. Schaerer l. c. \& Daffour in litt. limitarunt. Hypothallo nigro a præcedentibus facile dignoscitur; squamulæhuic adpressæ subtus nigro-villosæ, adultæ vero margine ele-

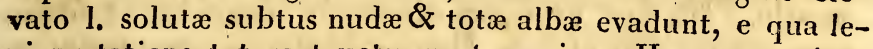
vi mutatione tot exstructæ sunt species. Hac vegetatione prope sane ad Biat. luridam cum affinibus accedit, speciesque citata etiam in statu abortivo profert apothe- 
cia Endocarpon mentientia. Hinc utique fieri potest ut Mich.t. 54. ord. 36. f. 4. \& Dill. t. 30. f. 134. ad eandem pertineant, licet citare non ausi simus, cum ille apothecia exacte Endocarpea describat. Squamularum forma mire quoque mutatur, ut etiam color e statione plus minus aprica \& umbrosa, sicca \& humida. Apotheciorum nucleus vegetus ruber.

End. turgidum Ach. Lich. univ. p. 305., quale equidem accepi, ab End. tephroide non differt; paululum recedunt specimina herb. Ach. \& adhuc magis descriptio.

Reliqua Europaa diversa originis sunt: End. sinopicum = P. ba dia status. E. smaragdulum Wahl, ipso observante $=P$. cervina-E. albatum. Ach. syn. p. 98. =E. pusillum a limacibus superne depastum. E. tephroides $A$. ad sequens genus potissimum referendum. - End. parasit. = Parmel. saxatilis status. - End. viride = thallus Cladoni ar um. - Solum End. viride s. Thunbergii ex exoticis Acharii dubiis caret. - End. eburneum Fl. Fr. 6. p. 192 ambigit inter Parmeliam Schaereri et Lecid. mamillarem.

\section{SAGEDIA.}

Sagedia. Ach. ex min. parte. Sagedia. Fries Syst. Orb. Veg. p. 259.

CHAR. Apothecia thallo inclusa, globosa, nucleo gelatinoso deliquescente, excipuloque membranaceo tenui demum nigrescentibus, ostiolis discretis in collum tenue attenuatis apice dilatatis pertusis. Thallus horizontalis, subcrustaceus.

Intima affinitate connexæ sunt species hoc genus ant subgenus, si singulam tribum ut genus superius consideremus, constituentes, undique bene limitatæ ut non possim non conjunctim tractare, etsi character minus palpabilis videri possit. Omnino jungunt Endocarpeas \& Verrucarias, illis affinitate, his habitu proximx. Excipulum enim in plerisque proprium apparet; vidimus tamen v. c. $S$. gibbosoe \&c. primitus luculenter thallodes pallidum, quamquam dein (cum nucleo) nigrescat. A Verrucariis præcipue facile confundendis, differt: defectu perithecii veri carbonacei, nucleo thallo omnino incluso, ostiolis vero discretis subcarbonaceis in collum attenuatis apiceque dilatato pro perithecio superficiali facile sumendo. Ob hoc ostiolum discretum etiam ad Endocarpeas referri debent. A Parmeliis degeneratis facile dignoscuntur nucleo \& ostiolo pertuso, cum in illis discus diminutus prominens punctiformis omnino astomus sit. 
- Solo inorganico innascentes.

359. SAGEDIA cinerea, crusta cinerea demum pruinosa, in ambitu subfoliacea, subtus spongiosa atra, ostiolis superficialibus sphæroideis. Endocarp. cinereum. Pers. in Ust. Ann. Bot. \%. p. 28. Lich. tephroides Ach. Prodr. - Engl. Bot.t. 2013. Endocarpon tephroides, Pyrenula microciba \& Verruc. polythecia. Lich. univ. p. 297, 315, 288. Verruc. cinerea. Schaer.!

Exs. Lich. Suec. $n$. 275.

Ad terrarn in regionibus alpinis aut campestribus formationis recentioris.

Crusta, licet arcte adnata sit, præcipue in ambitu subfoliacea (minime vero Endocarpi instar peltata), sed per æatatem rimosa, passim areolato-verrucosa, pruinosa, e fusco cinerascens. Pro End. turgido Ach. accepi formam crusta in strumas lævigatas aggregatas turgescente. Apothecia ob colorem. nigrescentem magis Verrucariam, quam Endocarpon referunt, sed perithecium discretum carbonaceum non adest, \& ostiola globoso-superficialia Sagediam, nec Verrucariam, indicant. Nuclei minuti discreti. In Pyrenula microciba, ut etiam $P$. gibbosa, nucleum ipsum pro perithecio descripsit Acharius.

36o. SAGEDIA fuscella, crusta tartarea rimosoareolata e fusco grisea, intus nigra, nucleis solitariis, ostiolis prominulis umbilicato-marginatis. Lichen fuscellus. Turn. in Transact. Soc. Linn. VII. p. 90. $t$ 8. f. 2. Verrucaria fuscella $\alpha$. Ach. Lich. univ. p. 289. Endocarpon $\alpha$. Ib. p. 675. (in Synopsi cum Sagedia cinerea $\beta$.' conjungitur, sed specimina missa pro Sagedia laevata determinavit, hinc Sag. lævata S. O. V.) Verrucaria glaucina. Botanicor. Gallia!!

Exs. Lich. Suec. ined.

$\beta$. crusta cervino-fusca.

Ad muros, saxa arenaria inque locis similibus Europæ occidentali-maritimæ facile tótius passim. $\beta$ ad saxa cotacea juxta litora maris prope Malaccam Cabrera!

A Sagedia cinerea meo sensu non potest non distingui. Crusta nullo modo foliacea, sed primitus ma- 
cularis, dein tartarea, saxo omnino innata, contigua, sed profunde rimoso-areolata, unde rimæ nigræe apparent; superficies nuda, nec pruinosa. Color junioris fuscus, adultæ cinereus, e rimis nigro-variegatus; hypothalli \& internus niger est, quæ notæ huic essentiales, quare $\beta$. colore fere sequentis non separavimus. Nuclei minuti, discreti, ostiolis superficialibus umbilicato-excavatis; in $\beta$. papillatis.

36ı. SAGEDIA viridula, crusta areolata e viridi cervino-castanea, intus alba, nucleis solitariis, ostiolis hemisphærico-prominulis.

Endocarpon viridulum. Schrad. spic. p. 192. t.2.f.4. Lich. placothallus. Ach. Prodr. p. 1s. Verrucaria fuscella. $\delta$. viridula. Lich. univ. p. 290. V. viridu-

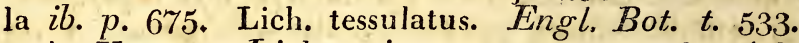
male. Verruc. Lich. univ. p. 289. Pyrenula Ach. syn. p. 126. (optima, nam valde diversa specimina sub his nominibus veniunt, v. c. cruc. margacea, muralis; nec differt P. areolata l. c. p. $122 \mathrm{e}$ spec. Schleicheri; Achariana spec. valde squalida sunt; descriptio priori magis accedit).

Exs. Lich. Suec, ined.

Ad saxa varia, præcipue formationis recentioris, locis humidis prope terram. Nos in Ostrogothia campestri in foveis calcareis cum amico Stcnhammar legimus.

Species hæc \& proximæ in diversis evolutionis statibus admodum mutantur, nec nisi in perfecto examinandæ; inde facile est ad infimas proles persequi. Crustæ areolæ perfectæ discretæ; dense aggregatæ, subangulatæ, aliæ planæ, aliæ convexæ, e viridi cervince l. castanex, humectatæ virescentes, intus sub strato gonimo omrino albæ. His notis a pracedentibus omnino differt. Crusta minus explicata granulosa, granulis ab hypothallo fuligineo infuscatis e. s. p. Nuclei minuti, in singula areola sæpius plures; ostiola semper simplicia, hemisphærica, dissecta intus juniora albo-furcta, ut facile pro perithecio superficiali sumantur. Affinis $S$. clopima \& Verrucarioidi.

362. SAGEDIA gibbosa, crusta areolis discretis fuscescentibus, hypothallo nigro insidentibus, 
nucleos confluentes includentibus, ostiolumque commune depressum marginantibus.

Pyrenula gibbosa. Ach. Lich. un. p.31\%.Syn.p.120.

Supra saxa montis Hochstein Lusatia. Mosig in herb. Ach.

Lichen admodum abnormis, habitu verrucoso Pertusariæ; a reliquis Sagediis differt ut Astrothelium Eschw. a Trypethelio Ejusd., at ob affinitatem genere separari non potest; etiam Pertusaria \&c. variat collis in os commune desinentibus. - Hypothallus late effusus, tenuissimus, niger. Ex hoc oriuntur areolæ discretæ, sed sæpe confertæ, verrucosæ, convexæ, læves, apice ob os commune nigrum prominulum pertusum depressæ \& hoc marginantes. Verrucæe includunt nuclenm amplum, gelatinosum, sed e pluribus confluentibus submultilocularem, primo totum pallidum (in hoc statu facillime pro Pertusaria sumitur, sed adest excipulum thallodes mutatum Endocarpeorum), dein omnino nigrescentem, absque omni perithecio carbonaceo.

363. SAGEDIA clopima, crusta tartarea granu-

loso-verrucosa castaneo-fusca, nucleis solitariis verrucis thalli marginatis inclusis, ostiolo prominulo depresso marginato.

Verrucar. clopima. Wahl. in Ach. meth. Suppl. $p$. 20. Lich. univ. p. 287. Wahl. Suec. n. 1726. Pyrenula. Ach. syn. p. 120.

Exs. Lich. Suec. $n .415$.

In rupibus granitoideis Scandinaviæ aqua suffusis, præcipue in alpibus Lapponicis, sed etiam pluribus Ostrogothice locis mihi monstravit Stenhammar.

Lichen admodum insignis, cum S. viridula \& Verrucaroide affinitate proxime connexus. Crusta late effusa, integra rupium latera obtegens, composita e granulis verrucosis plus minus concretis, ut contigua sæpius appareat. Verrucæ fertiles reliquis magis tument, ostiolum e fusco nigrum prominens, sed adultum in verruca depressum demum applanatum, indeque margine thallode obtuso cingentes. Interior verrucarum structura memorabilis est. Nucleus in singula verruca solitarius ex albo nigrescens, excipulo thallode generis communi cinctus, sed in perfectissimis ab ostiolo descendit excipulum accesso- 
rium proprium nigrum, thallodes superne obtegens inferne vero deficiens.

364. SAGEDIA Verrucarioides, crusta lævigata rimosa cinereo-fuscescente, ostiolis verrucæformibus immarginatis nigris, apice pertusis, nucleum pallidum obtegentibus. Ach. Lich. univ. p. 330 .

Ad saxa in Helvetia, ut videtur rarissima. Speciminulum archetypum dedit Acharius!

Habitu omnino Verrucariæ, hinc non cum Parmeliis abortivis confundenda, a quibus differt nuclei indole \& ostiolo pertuso. Color crustæ in nostro speciminulo humectatæ in lutescenti-cinereum vergit; intus subaurantius. Apotheciorum verrucæ minutæ perithecium Verrucariæ referunt, sed a nucleo discretæ sunt \& cum ostiolo Endocarpeorum omnino comparandx. Nucleus in hac specie magis elevatus est, proxime infra verrucam nigram prominulam collocatus, quare collum fere deest; globosus, pallidus, facile evacuatus, excipulo thallode Endocarpi.

Hujus porro generis: Pyrenula catalepta Ach. Syn. Lich. p. 120 (Endoc. Li ch. uni p. p. 676), at a jam allatis vix diversa; sub isto vero nomine etiam Verruc. marg a cea venit. - Ex habitu hujus generis videretur Pyrenula fuliginea 16. p. 121. (Verr.W ahl. Lapp. p. 465. V. lignyota Meth. Suppl.p. 20), sed ex obs. Sommerfelti Collema est.

** Hypophloeodes. Stigmatidii spec. Meyer.

365. SAGEDIA aggregata, crusta hypophlœode turgescente lævi, nucleis immersis, ostiolis prominulis nigricantibus demum in lirellas dendriticas confluentibus.

Opegrapha crassa. Dec. Fr. 2. p. 314. Porina aggregata \& taxicola. Ach. syn. p. 112, 113. Stigmatidium. Meyer. Lich. obscurus. Engl. Bot. t. 1752. excl. syn. Stigmatidium. Spr. St. crassum. Dub. Bot. Gall. p. 643. Arthonia Dufour. Arth. grammica. Herb. Ach.

Ad cortices arborum in Europa maxime occidentali: Hispania, regione atlantica Galliæ, Anglia.

Diversas induunt apothecia figuras, unde de genere tot dissensus, sed specimina perfecta omnino hujus gene- 
ris sunt \&, neglecta historia diversissima, Sagedice cinereoe turgescentis faciem eximie præ se ferunt. Ceterum summa adest affinitas cum Chiodecto, ut variæ exoticæ species v. c. Chiodecton monostichum Fée probant. Thallus verus leprosus, albus, sed epidermide strati corticalis vicibus gerente extus lævis, glaber, subcartilagineus, totus 1 . hinc inde turgescens, unde undulatus \& interruptus apparet; colore externo, hypophlæodium more, vario: albicante, virescente, cinereo, olivaceo-fuscescente. Nuclei rite evoluti crustæ, præcipue turgescenti, profunde immersi, minuti, confertissimi, globosi, juniores discreti, toti hyalini fuscescentes absque perithecio proprio!, vetusti confluentes, nigrescentes, qui evacuati excipuli membrauacei speciem gerunt, sed tota hæc morphosis exacte Endocarpearum. Ostiola prominula, minima, conferta, discreta, velusta vero in figuras dendriticas confluentia. - Occurrunt simul sæpe strumæ abortivæ, nucleis haud evolutis, ostiolis (pro peritheciis vulgo habitis) in lirellas dendriticas confluentibus, quæ Arthoriam grammicam Herb. Ach. sistunt \& acutiss. Meyerum ad hanc cum Strigula nostra conjungendam induxerunt. Hæc ad normalem statum accedunt, ut Spiloma dendriticum Ach. ad Pertusariam hymenæam, nec alia inter Endocarpeas desunt analoga exempla.

In bivio simul inter Sag gedia $m$ et Chiodect on posita est $P$ y. renula composita Syn. Lich. p. 124; sed ad exemplar minutulum in herb. Achariano determinare nolui.

\section{CHIODECTON.}

Ach. syn. p. 108. Transact. Linn. Soc. XII. I. p. 32. Ėschw. - Fée Cr. exot. et Monogr. - Meyer.

CHAR. Apothecia verrucæformia, e strato medullari pulverulento erumpente formata, includentia nucleos ceraceo-gelatinosos nigrescentes, demum confluentes, ostiolis discretis prominentibus. Thallus crustaceus.

Characterem hujus generis ad emendationem Cel. Meyeri mutavi ; observatur tamen in hoc, ut priori genere, species excipuli proprii in vetustis speciminibus. Apotheciis verrucæformibus Pertusariam refert (exstant enim Pertusariæ status abnormes verrucis apotheciorurn pulverulentis), sed nucleis nigrescentibus differt. Hac ratione ad Sagedias hypophloeodes tantopere accedit, ut 
dubium videatur an hæ non potius huc sint referendre. Ab his enim haud secus ac Opegr. medusula \&c. a veris Opegraphis differt, nempe verrucis crustæ hypophloeodis erumpentibus tantum fertilibus. - Genus ceterum tropicum, multis speciebus insigne, quarum eximiam monographiam in Ann. Scienc. Nat. 1820 Majo. dedit Fée, cui quoqne unica eximia Europæa species debetur.

366. CHIODECTON Myrticola, crusta farinosa alba (subhypophlœode), apotheciis subrotundo- difformibus planiusculis, ostiolis fuscescentibus in maculas subquadrangulas dilatatis. Fée Crypt. exot. p. 63. t. 18. f. $\mathbf{x}$.

Ad ramos emortuos, nec non in ligno denudato Myrti communis, in insulis Stoechadibus Cherniaëff ex Fée!, precipue de Pocquerolles Montagne!

Crusta inæquabilis, cum epidermide connata glaucopallescens. Verrucæ apotheciorum subrotundæ, angulatæ, elevatæ, pro more generis subfarinosæ \& niveæ. Nuclei ovato-globosi, nigricantes. Ostiola primitus punctiformia, fuscescentia, dein in maculas Arthonioideas dilatata. His non carbonaceis a speciebus tropicis insigniter differt. Abortiva Arthoniam subinde refert. - Adest quædam habitus \& præcipue historiæ convenientia cum Dirina, nec reticendum hoc genus a Parmeliaceis recedere, ut Chiodecton a reliquis Endocarpeis; vel potius Chiodecton se ad Dirinam, ut reliqux Endocarpex ad Parmeliam habere, nam Dirina junior Chiodecton refert, quamquam nuclei dein in discum Parmeliaceum explicantur. Cfr. F'ée l. c. t. 26. f. 1.

\section{PERTUSARIA.}

Dec. Fr. 2. p. 318. Turn. et Borr. Lich. Brit.191. Schaer. spic. p. 64. Duby. syn. 2. p. 672. Porina Ach. Lich. univ. p. 60. Endocarpi spec. Wahl.Sommerf:-Wallr. Porophora. Mey. Flecht. p. 326. CHAR. Apothecia verrucæformia, thalli strato corticali (normaliter) tecta, includentia nucleos nudos, ceraceo-gelatinosos coloratos. Asci maximi. Thalluis crustaceus, sape in soredia, Isidia abiens. 
I. A præcedentibus generibus dignoscitur præcipue nucleis omnino nudis (nulla membrana cinctis), inclusis, maximis, haud nigricantibus. At mira est characterum varietas non tantum in maxime affinibus, sed in eadem etiam specie. Verrucas similes formant Endocarpon reticulatum, Sagedia gibbosa e. s. p. \& pulverulentas Pertusariæ ipsæ in statu atypico. In hoc statu Variolarias nucleatas plurimas Auctorum efficiunt. Nuclei in his nunc inclusi globosi, Pertusariarum simillimi, nunc etiam explanati disciformes, ut caute a Variolariis simillimis Parmeliarum distinguendx. Alia exstat apotheciorum urceolato-apertorum degeneratio Thelotrema referens; id saltim constat horum generum characteres haud firmiores esse quam Parmeliacearum. - Nomen antiquissimum genericum i: plurimis receptum servavi, licet mihi minus placere fatear, sed si quid catholicum stabilietur, omnia placita, de quibus tot sensus quot capita, relinquere nécesse est.

II. Affinitatem omnium generum Endocarpeorum cum Parmeliaceis sæpius notavi, hujus vero tanta est, ut ad specimina normalia discerni solum possit. Ipsa species typica Pertusaria communis, ostiolis carbonaceis discretis prominulis a Parmeliis distinctissima, varias habet aberrationes nucleis confluentibus in discum denudatum Parmelix expansis, quod in Pertusaria hymencea fere normale est, qux specics tamen nucleo gelatinoso, denudato mox delabente aut deliquescente recedunt. De Parmelia verrucosa vero difficile est apodictice statuere, cujus generis absolute sit, nain altera forma est vera Pertusaria, altera Parmelia Thelotremoidea; cum hæc videatur perfectius explicata, ad Parmelias retuli. Ceterum plurimarum Parmeliarum occurrunt singulares lusus abortivi Pertusarias imitantes v. c. P. calcareo (Porina plana Duf.), $P$. cinerece (P. chionæa Ach.), $P$. badice, $P$. subfuscae, $P$. tartarea e. s. p. nec satis constat, an Porina xanthostoma Sommerf. (P. tornata Nobis olim) alte' non sit Parmelice parellac status.

III. Crusta vulgo hypophlocodes apparet, epidermide scilicet corticis cum strato corticali conuata; sed ad ligna, saxa, muscos, immo ad cortices vetustos \& crassiores, denudata, nihilo tamen minus externa facie \& structura non differt, unde insuper confirmatur hanc strati corticalis assimilationem parum essentialem esse. Magis memorabilis est crustæ multifaria metamorphosis; cru- 
sta sterilis nunc in optima Isidia Ach. degenerat; nunc e lævigata erumpunt soredia alba sterilia (fertilia supra sub apotheciis deformatis notavi) qualis P. communis optimam Variolariam communem Ach. efficit, licet saporem in hoc statu amarum, observantibus. T'urner et Borrer, Flörke, Meyer \& V. amara suæ (Verrucariæ discoideæ Hoffm. - En. Lich. t. 7. f. 5. Variolar. discoideæ Pers. - Ach meth. p. 14 a Parmeliis ortæ) perperam tribuat. Hæc Variolariæ \& præcipue Isidii formatio reliquis plerisque Angiocarpis peregrina (nam ad omnes Lichenes hæc metamorphosis incaute extenditur) etiam affinitatem cum Parmeliis confirmat. Non is sim, qui meis observationibus singularem vim dignitatemve tribuam, quare sine clangore enuntiata vulgo prætervidentur, nec qui jus prioritatis mihi vindicare velim, alios cocos judicans, at ne a Variolariis, Isidiis (jam 1817 a me deletis) appendicis loci memoratis concludatur, me ad Lichenum naturam observandam ineptum fuisse, haud morosum videatur, si observem, quod juridice demonstrari potest, me proprio marte Isidium \& Variolariam tantum status esse mutatos aliorum Lichenum observasse \& v. c. Variolariam communem ut sterilem formam cum Pert. communi conjunxisse in Stirp. Agr. Femsjonensis, priusquam Cell. Wallrothii \& Meyeri scripta, divulgata erant; minime tamen fingens veritatem tam apertam his acutissimis viris non patuisse, sed eisdem omnem assensum \& laudem eo lubentius tribuo, cum rem, in plerisque e mente mea sæpius quasi exscriptam, plene. exposuerint. - Species perquam affines, ut inferioris ordinis facile consideres; at cum in infinita formarum copia species quædam jam propositæ sint, in statu normali utique limitabiles, geographica distributione diversæ, ad infimas degenerationes Isidii, Variolariæ \&c, facile persequendæe, eas ut diverticula servare practicæ Lichenologix utile duxi.

367. PERTUSARIA communis, crusta cartilaginea glauca albicante, apotheciis hemisphæricis subclausis, ostiolis depressis discretis, perfectis nigro-papillatis. "Dec. Fr. 2. p. 320.

Mich. gen. t. 56. f. 1. Lichenoides. (male, tsonopyrena, ostiolo solitario) Dill. Musc. $t .18 . f_{.} 9$. Lich. pertusus. Linn. Fl. Dan. t. 766. Hoffin. en. t. 3. f. 3. Engl. Bot. t. 677. Sphæria. Weig. Schum. - Bolt. Fung, t. 126. Thelotrema. Ach. 
meth. p. 131. Porina. Lich. univ. p. 308.' Sphæria melastoma. Bernh. in Röm. Arch. Bot. IV. p. 10. $t$. 1. f. 1. Pertusar. communis. Turn. et Borr. p. 196. Schaer. Spic. p. 64 . Endoc. verrucosum. Wallr. - * crusta sterili, sorediifera: Lich. carpinens Linn.! Variolaria amara $A c h$. ex sapore, sed ad $V$. communem retulit (varietas alnea optima est ! Variol. griseovirens. Turn. et Borr. non obstat). * * in Isidium mutata: Lepra obscura Ehrh. ex Ach. Lich. s. Isidium coccodes Ach. ** * Leprarioidea: Is. coccodes b. $A c h$.

Exs. Lich. Suec. n. 93. Schaer. n. 118. Moug. et Nestl. n. 171. a. Flotow. n. 54. * Lich. Suec. n. 308. * * Lich. Suec. n. 186. Flotow. n. 55.

b. areolata, crusta crassiori rimoso-areolata verrucosa. Clement. Ens. Virl. p. 300. - * sterilis sorediifera. Variol. Flotowiana. Flörk.

Exs. * Reichenb. n. 34. Flotow. n. 56.

c. leucostoma, apotheciis (deficientibus papillis nigris) poris albis pertusis. Sphæria leucostoma. Bernh. $l$. c. Thelotrema \& Poriuá Ach.

d. leioplaca, crusta lævigata, apotheciis imperfectis rimose dehiscentibus Mich. l. c. $f .2$. Porina lejoplaca Ach. syn. p. 110. Schaer. spic. p. 66 -discoideo-apertis: Lich. melaleucus. Engl. Bot. t. 2461. Theiotrema. Turn. et Borr. Lich. Brit. p. 183.

Exs. Lich. Suec. n. 94. Sommerf. n. 5\% Flörk. n. 11. Schaer. n. 119.

Per omnem Europam, sed a * tantum in zona arctica. A ad cortices \& ligna ubique, raro ad muscos! c. similibus locis, at magis campestribus d. ad cortices lævigatos! b. sub multis formis ad saxa.

In statu normali facillime dignoscitur. Crusta glauca, raro in cinereum vergens, passim candicans. Apothecia depresso-hemisphærica, difformia, vulgo multos ovatos discretos nucleos (casu solitarium) includentia, impressione pro singulo ostiolo nigrescente papillæformi notata. At status degenerati plurimi; Tariolariam communem alneam in eadem crusta cum normali Lichene vidi, nec magis hæc recedit a Pert. communi, quam Ramalina farinacea a $R$. calicari; Isidium coccodes contra ad P. communem se habet ut Evernia furfuracea ad su- 
um statum politum. Variet. leioplacam in definitione haud respexi, cum evidenter sit status e loco degener, atypicus.

$\beta_{i} P$. sorediata, crusta tartareo-cartilaginea cinereo-albicante, in ambitu zonata, apotheciis in soredia farinacea fatiscentibus.

Lich. fagineus. Linn. et Auct. In statu perfecto nucleos habet prioris in verrucis farinosis, ostiolis nunc nigro-papillatis, nunc simpliciter pertusis, qui L. multipunctus Engl. Bot. t. 2061. Turn. in Transact. Linn. Soc. t. 10. f. 1. Lich. Brit. p. 73. Ach. syn. p. 129.

Exs. Lich. Suec. n. 248.

b. globulifera, verrucis compactis, farinosis, astomis, nucleis confluentibus inciusis. Lich. globuliferus. Engl. Bot. t. 2008. Variolaria Turn. l. c. t. 10.f. 2. Ach. syn. p. 130.

c. orbiculata, verrucis laxis explanatis, nucleis in discum submembranaceum denudatum carneum expansis, mox deciduis, soredia applanata marginata relinquentibus. Mich. gen. t. 53. f. 2. Lich. \& Variol. faginea. Vulgo. Engl. Bot. t. 1713. e. s. p. V. communis. a. Ach. syn. p. 130. - ad saxa: Variolar. gaditana. Clem. Ens. Vid. p. 295. Ach. syn.p. 133. sec. Dufour, autoptan. (Huc etiam minor pars Variolar. corallince Auct.; melior enim etiam, ut omne Isid. corall., Parm. sordida.)

Eisdem cum $\alpha$. locis, sed prius versus septentrionem desistic, vix supra terminum fagi bene evoluta in Suecia obvia; nam $V$. communis Flor. Suec. est a. * \& omnis $V$. corallina Suec. est Parm. sordida.

Porina omnino est; sed cum non tantum habitu, colore \& plurimis rationibus differat, sed etiam promiscue cum $P$. communi obvia facile semper distinguatur (etiam ubi utriusque crusta concrescat, limites inveni, nec tam directum transitum, quam sistit icon Meyeri) distinguant, quibus lubeat; equidem pro varietate atypica ob apothecia pulveracea ejusdem speciei habeo. Crusta simul acido carbonico oxidata. Probe distinguendum inter P. communis a. statum sorediiferum (cui crusta cartilaginea cinereo-glauca, soredia semper sterilia) \& hujus c., 
\& inter hujus c. \& sirniles formas a Parmeliis ortas. Fingo plures, omnes Variol. marginatas a Parmeliis ortas statuentes, forman orbiculatam ad has referre malle, sed nostra specimina lucentissime hujus loci sunt. Ex hac optime perspicitur nisus Angiocarporum in formam explanatam disciformern abeundi; sed hic discus, licet prorsus Parmeliaceus, in c. carneus, gelatinosus, ascis omnino Porinæ, \& mox deciduus, fundo excipuli haud cicatricoso ut in P. Wulfenii. Hæc metamorphosis $S_{i-}$ phulam in memoriam revocat.

368. PERTUSARIA Sommerfeltii, crusta cartilaginea cinerascenti-pallida lactea, apotheciis conoideis clausis, ostiolis (subsolitaris) elevatoprominulis nigricantibus. Flörke. - Sommerf. Lapp. p. 134. Endocarp.

Ad cortices arborum intra zonam arcticam; Lapponiæ hạd raro.

Refert præcedentis formam leioplacam, sed ista est forma degener, hre normalis, \& qua talis a P. communi differt crusta non glauca, apotheciorum verrucis conoideis, semper minoribus, fere acutis ob ostiola non depressa, sed papilla nigrescens demum deprimitur ut in "Pert. glomerata Schaer.," cui simul affinis videtur.

$=$ Pertus. glomerata Schaer. spic. p. 66, (muscicola) hoc loco simul memoranda, videatur sub Parm. verru$\cos a$ n. 169.

369. PERTUSARIA ceuthocarpa, crusta cartilagineo-tartarea subareolata fuscescente, linea obscuriori brunnea cincta, apotheciis subglobosis cæspitoso-confluentibus, ostioli papilla prominula nigra.

Lich. ceuthocarpus. Engl. Bot. t. 2372. Pertusaria. Turn. et Borr. p. 200 . e descript. tantum citavi. Exs. Lich. Suec. n. 247. Cfr. Obs. infra.

Ad saxa (Britanniæ, deest spec.) Sueciæ, Germaniæe ad Bayreuth Laurer!; etiam ad cortices crassiores rarius.

Crûsta magis inæquabili, fuscescente, linea obscuriori circumscripta sterilis vel in Isidium (Isidio Westringii simillimum) mutata quodammodo distingui potest, sed primaria differentia posita est in apotheciis, quorum 
singulum typice unicum nucleum tantum includit, sed plurima caspitose oriunda facillime confluunt in verrucas compositas, sed indeterminatas, forma varias, nunc 40-50 nucleos nunc perpaucos includentes, inter quas vero simul apothecia subglobosa sparsa \& simplicia occurrunt. Hinc verrucæ apotheciorum in $P$. communi perfecta pro ostiolis foveolatæ, in hac vero, ob singulum apothecium apice prominens tuberculatæ, numquam rimose dehiscentes visæ. Paucis: $P$. communis habitus Sphcerice Lignosa, hujus vero $S p h$. Caspitosce aut potius Confluentis. Ostiolum papilla nigra primo admodum prominet, dein ut in $P$. Sommerfeltii, "glomera$\boldsymbol{t} \boldsymbol{a}$ " deprimitur. Nuclei $\boldsymbol{P}$ communis minores. - Specimina hujus saxicola a $P$. communis adeo luculenter recedunt, ut non possin non separare. Corticola cum sequentis passim concrescunt, ut ejus statum crediderim, donec hunc transitum apparentem tantum inveni. Hinc video, in uno alterove exsiccator. exemplari sequentis status degeneres pro hac irrepsisse.

3 7o. PERTUSARIA Wulfenii, crusta cartilaginea sulphurea (olivacea decolorataque), linea nigra cincta, apotheciis hemispharico-depressis ostiolo nigricante communi pertusis, dein rimose dehiscentibus marginatis, fundo nucleis abortivis cicatricoso. Dec. fr. 2. p. 320.

Mich. gen. t. 52. ord. 32. Lich. pertusus. Wulf. in Jacqu. Coll. 1I. t. 13. $f$. 3. Schrad. spic. t. 1. $f$. 5. Lichen hymenius Ach. Prodr. - Engl. Bót. $t$. 1731. Thelotrema hymen. Ach. meth. p. 133. Turn. et Borr. Lich. Brit. p. 185. Porina leioplaca $\beta$. Ach. Lich. univ. p. 310. P. fallax, pustulata, rugosa. Ach. syn. p. 110. - * crusta sterili sorediifera, sorediis pallide sulphureis. Variolaria Schleich. - ** crusta in Isidium mutata. Isid. phymatodes. a. Ach. syn. p. 282.

Exs. Lich. Suec. n. 95. Fl. Deutsch. n. 147. Moug. et Nestl. n. 171. b. Flozow. n. 58.

b. rupicola, crusta crassiori plicato-rugosa. Sommerf. Lapp. p. 135.

c. carnea, verrucis astomis dehiscentibus, disco (Parmeliaceo) carneo-rubro. Turn. et. Borr. l. c.

d. decipiens, crusta tenui levigata, apotheciis imperfectis, nucieo abortivo disciformi nigricante. Turn. 
et Borr. l. c. Porina. coronata. Ach. syn. p. 111. P. melaleuca. Duby Bot. Gall. p. 673. (\& cum P. communis d. omnino analoga, ut etiam priores formix sibi respondentibus).

Per omnem fere Europam sub variis formis copiose; non vero in Suecia supra terminum $\mathrm{Fa}$ gi, cui arbori præcipue innascitur, tantum b. ad rupes occultas ad mare glaciale.

Ignoscant, precor, alii hanc aliter observantes \& dijudicantes, si erraverim, quod harc stirpem, qualis mihi oculis haud fugitivis lustranti obviam venerit, talem exposui; nucleum enim, quem deesse dicunt, video evidentem; quod ostiola dicunt, veris observatis, pro cicatricibus nucleorum elapsorum 1. abortivorum (quales cicatricés in analogis aliarum specierum non vidi) habeo e. s. p. In eodem trunco cum $\boldsymbol{P}$, communi nascens, immo concrescens, facilis in statu normali distinctu, at ob varias utriusque formas degeneres \& decoloratas rem facilius saltim absolvi, utramque conjungendo, lubenter concedo. Crusta cartilaginea in perfectis nigrolimitata, frequentissime \& normaliter (pallide 1. virescente -) sulphurea, passim olivacea; degenerata per xtatem in omnino album, sed colore lutescente hujus formæ Isidioideæ, Variolarioideæ \& leprosæ a $P$. communis dignoscuntur. Verrucæ clansæ minus elevatæ, ob nucleos (carneos) confluentes ostiolo solitario communi depresso terminatæ; at sæpius obviam vẹ́niunt apertæ, marginatæ nigro-punctatæ excipuli Parmelix facie; \& nucleo discum a verrucis marginatum offerente (c) facile pro Parmelia habetur. Tales formas numquam $P$. pertusa, nisi verrucis apotheciorum fatiscentibus, offert. Sapor insuper hujus speciei sterilis sorediiferæ non amarus, ut prioris.

ק. P. variolosa, crusta subtartareo-pulverulenta lutescente, apotheciorum verrucis in soredia farinacea fatiscentibus.

Formæ eædem redeunt ac sub $P$. communi $\beta$, at nucleatæ rarissimæ, qualis v. c. Lecan. lutescens Schaer.! cum P. comm. $\beta$. b. analoga. Prorsus sterilis: Lepra lutescens. Hoffm. Pl. Lich. t. 23. f. 1, 2. (Cfr. n. 150. Lich. Ach. Prodr. Isid. phymatodes. b. phragmæum. Ach. syn. p. 283.

Exs. Tich. Suec. n. 185. 
Cum priori, præcipue ad cortices Quercus, \& quousque hæc arbor versus septentrionem in Suecia adscendit, ideo longe supra limites $\alpha$.

Crusta intensius \& persistentius lutea, quam in forma primaria. Sapor non amaricans.

37 . PERTUSARIA xanthostoma, crusta tartarea indeterminata glauco-albicante, apotheciis elevatis depresso-hemisphæricis passim rimose dehiscentibus, ostiolis depressis discretis lutescentibus.

Porina. Sommerf. in Vet. Ac. Handl. 1823. p. 115. Endocarp. Fl. Lapp. Suppl. p. 136. End. pertusi. var. Wahl. Suec.

Ad cortices Juniperi, in muscis graminibusque destructis Nordlandia passim. Sommerfelt.! (simillimam legi tornatam formam ad ligna abiegna vix a $P$. parella diversam).

Inter Pert. communem, cujus formam, \& Parm. Parellam, cujus habitum exacte gerit, intermedia, in hoc genere ostiolis lutescentibus facile distincta. Monet Sommerf. 1. c., verrucas sæpe ruptas occurrere, nucleis tum excipulo sequentis generis simili cinctis, id quod rarius etiam in Pert. communi rupta vidi; ut non desint rationes T'helotrematis genus, sensu Acharii in methodo, restituendi.

372. PERTUSARIA nivea, crusta cartilaginea levigata candicante, apotheciis globularibus subliberis, nucleo ostioloque impresso solitariis rufescentibus. rissima.

Ad cortices arborum, v. c. Fagi Sueciæ ra-

Colorem hujus, licet omnino cartilaginex, omnino niveum semper vidi \& a præcedentibus eximie differt apotheciis longe minoribus, supra crustam elevatis \& fere liberis, granula globularia quasi adspersa offerentibus, ostiolo rubro impresso. Hujus apothecia dehiscentia nucleum, discum carneum eximie gelatinosum offerunt, ut non Parmeliæ statum sistere possit. Doleo hanc erninentissimam speciem adeo raram esse, ut hactenus in unico trunco tantum legerim. 


\section{PERTUSARIA Delisei, crusta cartilaginea pli-} cato-rugosa aurantio-rubra, apotheciorum verrucis confertis rotundatis difformibusque supra planis, ostiolis pluribus punctiformibus depressis subconcoloribus. Duby Bot. Gall. p. 672 .

\section{Ad rupes Galliæ prope Granville Delise.}

E recepto principio nullam speciem a me haud visam ut cognitam proponendi etiam hanc, characteribus licet maxime insignis sit, sine numero attuli fide libri laudati, quem maxima parte hujus opusculi absoluta ad me primum pervenisse doleo. Reliquarum novarum specierum, ibidem descriptarum, fere omnium ex incomparabili Botanicorum Gallix liberalitate jam prius mihi innotuerant, ut has suis locis sub Auctoris nominibus recipere licuerit.

\section{* THELOTREMA.}

Ach. Lich. univ. p. 62.! - Turn. et Borr. pr. p. Schaer. spic. - Fée - Fries et Auct. plur. Volvaria. Decand. Hymenoria Ach. Msr. Antrocarpum. Meyer.

CHAR. Apothecia verruceformia, a thallo formata, primo clausa, dein apice aperta marginata, includentia nucleum profunde detrusum, collo destitutum, demum in discum depressum, collapsum rigescentem, excipuloque interiori discreto membranaceo lacero-dehiscente velatum. T'hallus crustaceus.

Charactere ad Limborieas omnino recedit, verum tanta cum Pertusariis adest affinitas, ut non tantum limites varie ponantur; v. c. apud Turner \& Borrer etiam Pert. hymencea \& melaleuca huc referantur; sed etiam utrumque genus ab Achario in methodo, immo cum Endocarpis a Wahlenbergio conjungatur, quod utique fieri debet, nisi status normalis rationem tantum habeamus. Optime genus in Lich. univ. determinavit Acharius, ipse observans, T'helotr. exanthematicum ut aberrationem tantum subjunctum esse; ambiguurn hoc ens ad Gyalectam analogam Parmeliacearum retulimus. Dein vero in Vet. Ac. Handl. 1812. \& Syn. Lich. varias addidit species tropicas, omnino excludendas. Sed etiam e tro- 
picis plures veræ adsunt Thelotrematis species; unica Europæa tantum mihi cognita.

373. THELOTREMA lepadinum, apotheciis conoideis truncatis, demum urceolato-scutellæformibus, excipulo interno laxo concolori, disco nigricante primitus cæsio-pruinoso Ach. Lich. univ. p. 3 г 2. t. $6 . f$. .

Lich. lepadinus. Ach. Pródr. p. 30. Thelotrema Ach. meth. p. 322. Vet. Ac. Handl. 1812. Turn. et Borr. Lich. Brit. p. 160. Schaer. spic. p. 67. Endocarpon. Wahl. Suec, p. 874. Lich. inclusus Engl. Bot.t. 678. Volvaria truncigena Dec. Fr. 2. p. 374 .

Exs. Lich. Suec. n. 38. Flörk. n. 148. Schaer. $n$. 121. Moug. et. Nestl. n. 25\%. Flotow. n. 63.

Ad cortices arborum variarum frondosarum, etiam Abietis, per omnem Europam usque ad Sueciam inferiorem; tantum in maxime borealibus desideratur.

Crusta sæpius albescens, sed in Suecia saltim variat fusca, rufescens, \& hæc, in Fago abundans, præcipue trita aurea $\mathrm{h}$. e. e methodo Wallrothiana chrysogonimica. Excipulum interius junius omnino clausum ore simplici pertusum, dein lacero-ruptum, cum externo apertum Urceolariam Ach. etiam colore \& pruina disci refert.

Ignotum est: Thelotrema Hutchinsice, thallo albissimo, apotheciis depressis, demum apertis difformibus, ore irregulari lacero flocculoso, excipulo interno libero tenui lacerato inflexo, disco cæsio. Turn. et Borr. Lich. Brit. p. 178. Supra muscos \&c. lectum. An Parm. verrucosa?, cujus etiam exstat forma Thelotiema imitans.

\section{Trib. III. VERRUCARIE}

CHAR. Apothecia rotundata, excipulo proprio clauso (perithecio), ostiolo contiguo pertusa, nucleo gelatinoso subhyalino diffluente. Thallus crustaceus.

Plurima \& eximia sunt hujus tribus genera exotiea, si adnumeremus, ut decet, Trypetheliaceas perithe- 
cis excipulo thallode 1. tuberculo a strato medullari formato receptis, attamen inter se non magis differunt, quam tribus analogix generis Sphæriarum inter fungos; Trypethelium, Astrothelium, Parmentaria s. Pyrenastrum etc. inter se \& a Verrucariis haud magis differunt quam Sphoerioe-Lignosa, Incusa, Circinatoe e. s. p. a Sphæriis simplicibus. Sphæriæ Hypocreæ insuper Endocarpeis respondent. - Si inter fungos genera æque subtiliter distingueremus ac inter Lichenes, nullus finis foret illorum generum. Sunt itaque hujus tribus genera non altioris dignitatis quam relinquarum, \& facile ut unius superioris subgenera consideranda. Exstant enim directi transitus v. c. inter Verrucarias \& Trypethelia. Porothelium Eschweil., præ ceteris insigne, a pluribus peritheciis in tuberculum commune primitus coalitis ortum est, cum Sphoeriïs Confluentibus, v. c. S. melogramma, forsan potius quam Dothideis, quibus analoga est Arthonia Eschw., comparandum.

\section{SEGESTRIA.}

Fries Syst. Orb. Veg.p. 263.

CHAR. Perithecia solitaria, ceraceo-membranacea (colorata), ostiolo simplici subpapillato, nucleo gelatinoso-fluxili subhyalino. Thallus crustaceus.

A Verrucaria differt ut Biatora a Lecidea, perithecio ceraceo \& colorato, nec carbonaceo atro. Perithecia plus minus denudata, basi innata globosa aut hemisphærica, rarissime per ætatem nigrescentia, sed Verrucarix jam primitus atra \& carbonacea. Et ut Biatorce ad Parmelias, Segestrice ad Endocarpeas, præcipue Sagediam, simul accedunt. Eadem est excipuli ratio in utroque genere.

* SEGESTRIA thelostoma, crusta subtartarea tenuissime rimosa cinerea rufescente, peritheciis innatis hemisphæricis rufescentibus, ostio:o papillato nigrescente.

Verrucaria thelostoma. Horriman. - Winch. Engl. Bot. t. 2853. Pyrenula umbonata. Ach. Lich. univ. p. 316.

In saxis \& rupibus Scotia. Herb. Ach.! 
Crusta tenuis, determinata, lævigata, passim in umbrino-fuscum vergens. Perithecia a crusta ex magna parte obtecta, verrucas sistunt depressas, rufescentes, nucleo pallido. Mihi hand satis cognita; an varietas sequentis? 37.4. SEGESTRLA lectissima, crusta subcartilaginea contigua olivaceo-pallida, peritheciis prominulis hemisphæricis testaceis, ostiolo papillato concolori, nucleo albo. Syst. Orb. Veg. I. p. 287 .

In rupibus Saxonia metallifere $B o o k$ ! alibique Germaniz.

Lichen pulcherrimus. Crusta late effusa, haud determinata, contigua, lævigata, glabra, recens forsan magis virens \& gelatinosa, at sicca, qualem tantum vidi, subcartilaginea, olivaceo-pallida. Apothecia frequentia, majuscula, læte colorata, eisdem $S$. nuctulce (Porinæ nuculæ Ach.) similia; papilla passim deest, ostiolo tantum pertuso. - Ceterum varia hujus specimina sub nomine Verruc. testacece Wallr., ab ipso pro "Pyrenula umbonata" Ach. habeo, quæ licet longe minus speciosa, crusta cinerascente, apotheciis minoribus sordidis, haud distingui possunt.

375. SEGESTRIA rubra, crusta mucoso-gelatino-

sa lævissima sanguineo-rubra, peritheciis immersis globosis obscure rubris in presso-pertusis, nucleo hyalino. Sommerf!! Lapp. p. 240. In scopulis a fluxu maris inundatis in Europa boreali.

Lichen distinctissimus, in conterminis hujus familiæ \& Phycearum positus; a Palmella rubra Fl. Dan. t. similibus locis obvia, recedens præcipue crusta tenuiori, late effusa \& peritheciorum præsentia, ut facile pro alio ejusdem stirpis statu habeatur. Crusta recens mucoso-gelatinosa, in quartzo præcipue ruberrima, in lapidibus obscuris fusco-rubra, locisque occultis, ex Sommerfeltio, in sordide luteum vergens; sicca tenuissima, vernicis instar saxum obducens. Perithecia minima, admodum conferta, crustæ impressa, sed non obtecta, saturatius colorata, haud papillata; sicca collapsn-umbilicata.

XXIX. VERRUCARIA.

Pers. - Schrad. Ach.meth. - Decand. - Syst. Orb. 
Veg. 1.p. 264. et Auct. Recent. omnium. Pyrenulie spec. plur. Ach. syn.

CHAR. Perithecia solitaria, corneo-carbonacea (atra), ostiolo simplici papillæeformi aut pertuso, nucleo gelatinoso, fluxili aut deliquescente, subhyalino. Thallus crustaceus.

- Apothecia vulgo prominent, sed sæpe etiam crustæ immersa innatave, ostiolo tantum (in collum non attenuato) prominente. $\mathbf{E}$ nostræ regionis præcipue duæ species habitu recedunt, nempe $V$. papularis, peritheciis totis verruca thallode elevata clausa Porinæ instar inclusis, \& $V$. Hochstetteri tam perithecii tenuitate, quam verruca thallode apice aperta \& marginata, quare hæc species perithecio dehiscente aperto Thelotrema externa facie plane refert. - Species multas conjunxi - \& plures conjungere potuissem, nisi nostro scopo aptius visum esset singulas formas prominentes \& vegetatione \&c. insignes seorsim notare. - Dispositionem sumsi e loco natali, cum hunc hactenus omnino constantem invenerim.

\section{* Terrestres.}

376 . VERRUCARIA epigcea, crusta e gelatinoso leprosa tenui lutescente pallida, peritheciis semiimmersis integris globosis pertusis. Ach. meth. p. 123.

Sphæria. Pers. syn. fung, p. XXVII. Verruc. Lich. univ. p. 295. Lich. terrestris, Engl. Bot. t. 1681. Exs. Lich. Suec. n. 246. Schaer. Helv. n. 56. Fl. Deutsch. n. 146. Flotow. $n 42$.

\section{Ad terram humidam denudatam frequens.}

Crusta junior maculæ instar effusa, subgelatinosa, subito proveniens, demum leprosa. Apothecia minuta, demum emersa, collapsa scutella minima referunt. - Analoga cum Sag. cinerea, sed peritheciis omnino atris, denudatis, collo destitutis, ostiolo simpliciter pertuso abunde differt. - Crusta sæpe fibrillis peregrinis obducta virescens, a quo statu discernere non valeo Sphceriam velutinam Bernh. in Röm. Arch. Bot. 4. p. 11. t. 1. f. 3. s. Verruc. velutinam Ach. syn. p. 9\% - Unice crustæ colore recedit Verr. lateritic Pers. in Act. Vett. 2. 
- Ach. syn. p. 96. (in cujus herbario vidi); an hic color normalis sit, dubitamus.

Omnino vero diversa videtur, $S p h$. spongiosa Bernh. l. c. t. 1. f. 2. s. Verrucaria Ach. syn. p. 96. peritheciis ampulleformibus, forte potius cum Sagedia oinerea comparanda. A nemine Recentiorum observatam novi.

$\beta . V$ sabuletorum, crusta tartarea areolata granulosa lactea, peritheciis emersis subpapillatis. Ad terram glareosam Suecix, raro.

Præcedente major \& præcipue crusta insignior. Hæc vero tartarea est, crassiuscula, in areolas in superficie granulosas diffracta, haud leprosa. Perithecia etiam paulo majora, non collabentia, sed demum diffracta! Forte a precedente distinguenda, sed semel modo lecta.

377. VERRUCARIA muscorum, crusta effusa tenui cinerea, granulis minutis adspersa, peritheciis superficialibus integris hemisphæricis, ostiolis papillatis. Syst. Orb. Veg. i. p. 287.

b. crusta gelatinosa (albovirescente.) V. gelatinosa. Sommerf. Lapp. p. 140. (fusco-nigra) Ach. syn. p. 93. Misit ex Helvetia Schleicher!.

Supra muscos in montosis. Specimina nosira perfecta e Blekingia misit Aspegren!

Crusta indeterminata, late effusa, submembranacea (hypothallina), granulis minutis adspersa, grisea aut cinerea. Transitum b. in a. non quidem secutus sum, sed habitus ita omvino convenit $\&$ aliarum specierum analogia confirmat, ut de unione non dubitem. Apothecia omnino superficiali-adnata, depressa, sed e papilla subglobosa conoideo-hemisphærica.

* Saxatiles. Crusta subtartarea, denudata.

* Saxorum calcareorum aut aliortom formationis recentioris. Perithecia dimidiata (n. 377-381) l. integra (382-388). Color crustæ admodum mutabilis.

378. VERRUCARTA conoidea, crusta tartarea cinerascente, peritheciis dimidiatis, basi expan$s a$, denudatis subconicis persistentibus papillatis.

b. crusta albicante.

c. crusta rubella. V. rubella. Chaubard in St. Am. Fl. Ag.p. 483. Duby Bot. Gall. p. 646. 


\section{Ad saxa calcarea Pyrenæorum Dufour!, Gal.} lix ad Rothomagum Prevost! \&c. b. in Pyrenæis orientalibus Montagne! c. ad Agen Chaubard! \&c.

Crusta satis conspicua, sed sequentium more colore admodum mutabilis, nunc murino-fusca, nunc dilute cinerea; ceterum etiam albescens \& rubella, omnino ut $\boldsymbol{V}$. rupestris. Hæc omnino atypica est. Nomen itaque primi inventoris \& determinatoris ab invito mutandum fuit. A sequente, cum qua passim confusa, certissime differt: basi perithecii dimidiati haud inflexa, peritheciis haud politis, numquam collabentibus aut truncatis, sed papilla ipsa demum dilatata \& umbilicata. Apothecia ceterum maxima generis, denudata, opaca, subscabrida, nucleo hyalino-albicante; forma in perfectis eximie conica, in minus evolutis hemisphærica.

379. VERRUCARIA Dufourei, crusta subtartarea, peritheciis dimidiatis, basi inflexa, superficialibus politis globoso-hemisphæricis, collabescendo superne truncato-depressis. Dec. fr. 2. p. 3 i 8 . Schaer. spic. p. 54. Duby Bot. Gall. p. 646. Verruc. pyrenophora. Ach. Lich. univ. p. 285. t. 4. $f .3$.

Exs. Schaer. Helv. n. 101.

Ad rupes calcareas Helvetiæ Schleicher!, Germaniæ (Saltzburg) Laurer! (Würtemberg) Hochstetter!, Vogesorum IMougeot! Galliæ usque ad Pyrenæos! \& Rothomagum Le Prévost!

Crusta pro more colore nutabilis, normalis cinereofusca videtur \& nigrolimitata, sed occurrit cinerascens $\&$ sæpius albicans. Differentix itaque a peritheciis potıssimum petendx, qux insignes: sunt perithecia inter maxima generis, prorsus nuda \& polita (prioris a crusta, modo vero haud sensibili, tecta videntur $\&$ inde impolita), ob basin inflexam globoso-hemisphærica, (vix conica dicenda) raro papillata, sed plerumque collapsa, apice depresso truncato, ut facies Lecidex. Nucleus hyalinus, crustæ ad dimidium immersus. Ab Achario hujus specimen pro $L$. epipoloea accepi. - Singulare has Verrucarias macrocarpas in septentrione, quantum novimus, desiderari.

38o. VERRUCARIA talcacea, crusta subtartarea, 
peritheciis dimidiatis hemisphærico-depressis nudis nitidis pertusis, demum basi aequali circumscissis. Syst. Orb. Veg.p. 287 .

Ad saxa talcacea \& schistosa Galliz Persoon.

Perithecia magnitudine prioribus proxime accedunt; sed variant minuta; ceterum sunt superficialia, nuda, polita, nitida, hand papillata, nec collabentia, sed adultiora prope basin circumscissa decidunt, nucleo ocellam albam linea nigra (basi nec expansa néc inflexa) circumscriptam referente. Crusta hactenus interrupte effusa, indeterminata, subleprosa, sordida, e virescente grisea vișa est. Utrum forma admodum pusilla hujus characteribus sed habitu ceterum Verruc. rupestris gaudens, in schisto argillaceo Scaniæ obvia, hujus an alius sit status, ut numquam perfectius evoluta (subacrustacea), in medio relinquendum est.

38ז. VERPUCARIA argillacea, crusta tartarea albicante, peritheciis dimidiatis basi immersis conico-hemisphæricis umbilicato-pertusis (nucleo subrubro).

V. epipolæam Ach. syn. p. 95. ad hanc potissimum e descr. referrem, est vero species amphibola; ab ipso tuli $V_{.}$Dufourei, a recentioribus fes e omnibus $V$. muralis status rupestris pro $V$. epipolcea venditur.

Exs. Lich. Suec. ined.

Ad lapides argillaceos aliosque formationis recentioris in regionibus argillaceo-campestribus Gallize! \&c. copiose in Scania.

Crustam semper vidi effusam, indeterminatam; rugoso-inæquabilem, e glauco candicantem. Perithecia medix magnitudinis, re ipsa late conoidea, sed tam depressa, ut potius hemisphærica dicenda, bași a crusta indefinite, obtecta, parte denudata subnitida, intus nunc alba, nunc in centro nucleum insignem rubrum gerentia. 382. VERRUGARIA papularis, crusta tartarea cinereo-albicante, peritheciis dimidiatis conoideis, verruca thallode elevata hemispherica totis inclusis, papilla denudata nigra.

Ad rupes calcareas silvæ nigræ in regno Würtembergix. Hochstetter! 
Species pulcherrima, pustulis thalli regularibus \& eumorphis Pertusariam simplicem eximie referens. Crusta, in specc. visis, tenuis, contigua, indeterminata, lævigata, in superficie quasi pruinosa, e cinereo albescens. Pustulæ crustæ sparsæ, elevatæ, hemisphæricæ, sed papilla centrali prominente conoidex, semper clausæ \& immarginatæ, demum vero poro nigro depresso pertusæ. Perithecium vero conicum, carbonaceum, dimidiatum, nucleo globoso simplici sæpius evacuato collapso.

383. VERRUCARIA Hochstetteri, crusta tartarea determinata verrucosa pallida, peritheciis integris tenuibus globosis, verruca thallode aperta marginata immersis, demum urceolato-apertis. Pyrenula verrucosa. Ach. Lich. univ. p. 314. t. 5. f. 1.? Hochstetter in litt.

Ad rupes calcareas Blabyra in regno. Würtembergiæ Hochstetter!, in Pyrenæis orientalibus Montagne!.

Tam quoad crustam, insigniorem quam in alia specie, quam apotheciorum recedentem siructuram, species maxime memorabilis. Crusta admodum crassa, determinata, mollis, contigua, in superficie vero pruinosa elevato-verrucosa, albida, sed in griseum \& rosellum colorem simul yergens. Perithecia ampla, solito tenuiora, globosa, in foveolis crustæ determinate exsculptis nidulantia, simulque verruca thallode obtuse marginante sæpissime cincta, apice vero nuda sæpiusque dehiscentia evacuata \& urceolato-aperta. Exstat quidem quoad a potheciorum situm \& verrucas subsimilis $V$. rupestris forma (Pyrenula hiascens. Ach.); ceterum admodum diversa.

* VERRUCARIA actinostoma, crusta tartarea rimosa rugoso-areolata alba, peritheciis subglobosis immersis umbilicatis marginatis, papilla pulvere albo radiata. Ach. syn. p. $9^{5}$. Thelotrema radiat. Pers. Act. Wett. 2.

Ad saxa silaceo-calcarea Galliæ. Persoon in herb. Ach.

Specimen mihi deest; vidi quidem in Herb. Achariano Persoonianum, sed satis examinare ncti licuit. Videtur priori \& præcipue sequenti affinis; an re ipsa status normalis? 
384. VERRUCARIA muralis, crusta tartarea rimosa albicante, peritheciis integris rotundatis persistentibus, basi immerso-innatis, ostiolo albopruinoso, demum dilatato-marginatis. Ach. syn. p. 95 .

Lichen calcareus. Ach. Prodr. p. 60. Verruc. muralis \& lithina. Ach. Lich. univ. p. 287-288. Pyrenula lithina. syn. $p .127$. Verruc. ruderum \& concentrica. Dec. Fr. 2. p. 318. V. epipolæa (Ach.? ad spec. Schleich.) \& Rec. forsan omnium.

Exs. Flotow. n. 44. (in meo exempl. imperf.)

b. crusta rosea. Pyrenula titanophila Spreng.-Jahrb. d. Gewächsk. 1.3. p. 127.n. 43. ex Meyero.

Ad muros \& saxa calcarea passim.

Crusta utique genuina, subpulveracea, in perfectis crassiuscula, areolato-rimosa, passim vero obliterata. Apothecia minora, conoideo-globosa, globosa aut globosodepressa, basi matrici subimmersa \& a crusta plus minus obtecta, sed numquam verruca marginata cincta; ipsa vero vetusta scutelliformia evadunt. Pars denudata vulgo opaca \& scabrida. Nucleus hyalino-albidus, sed exoleta intus nigrescunt perithecia.

385. VERRUCARIA rupestris, a. calciseda, crusta tartareo-compacta contigua, peritheciis integris globosis impressis denudatis, ostiolo nudo umbonatis, dein collabentibus scutelliformibus, nucleo hyalino. Schrad. spic. p. $109 t$. 2. $f .7$.

a. crusta e viridi albicante. Sphæria mirabilis. Ehrh. ex spec. Ern. Meyeri, Lich. immersus Auct. Vet. (sed cum Lecid. albocærulesc. $\beta$. sæpissime confusus.) Verruc. immersa, Pers. in Ust. Ann. Bot. 7. p. 23. V. rupestris. Schrad. Dec. fr. 2. p. 317. Duby syn. p. 645. Turn. et Borr. Lich. Schraderi. Ach. - Engl. Bot. t. 1711. f. 2. Verruc. Ach. Schaer. spic. p. 54. V. mutabilis Wallr. Flecht. 1. p. 123. - peritheciis diminutis: V. calciseda. Dec. l. c. - perith. a crusta coronatis: Pyrenula hiascens. Ach. syn. p. 119. ex Laurer \& spec. Schleicheri. Exs. Lich. Suec. ined. - Schaer. Helv. n. 103, 104. Flörk. Deutsch. n. 28. Reichenb. - Flot. n. 46. 
b. crusta grisea aut murina. Verruc. Harrimanni. Ach. syn. p. 93. ipso teste. Lich. Engl. Bot. t. 2539.

c. crusta roseo-purpurascente ("ex oxido Mangani" Meyer) Verrucar. purpurascens. Hoffm. Pl. Lich. t. 19. $f .3$. Dec. Fr. 2. p. $31 \%$.

Ad saxa calcarea ubique; eliam in testis Lepadum \& Patellarum juxta litora maris (Sommerf. Lapp. p. 139); sed c. tantum in Europa australi. Dufour! Montagne!.

Crusta hujus speciei, aliarumque apotheciis simili modo saxo, ut apparet, insculptis calcareo, in quo sub hac forma tantum occurrunt, carbonatem calcicum assimilat, ut crusta senilis re ipsa gypsaceo-calcarea appareat (quod olim calcis crescentis rationem obtulit); sed in aliis saxis, etiam calce durissima, crusta a saxo magis discreta manet, \& perithecia crustæ tantum, nec saxo, impressa videntur. In hac specie ille status vulgatissimus est \& vario modo mutatur. Color crustæ eadem lege mutatur in $V$. conoidea, Dufourei \&c. ut certi simus eo diversas non indicari species, præcipue cum evidentes simul adsint transitus. In crustis crassioribus magisque a matrice discretis perithecia margine thallode semper aperto coronantur. Apothecia minuta, regularia, lævia, haud pruinosa ; collapsa Lecideam referunt, l. elapsa foveas relinquunt.

p. $V$. laevata, crusta demum tartareo-puỉveracea, apotheciis globosis integris denudatis semiimmersis, collabescendo umbilicatis.

Sphæria rupestris. Sowerb. fung. t.371. f.2. Verr. lævata (crusta adhuc juvenili lævigata virescenti-alba) \& V. trachona (crusta leproso-tartarea albida) Ach. syn. p. 94, 96. vix aptiori loco citandæ.

Exs. Lich. Suec. n. 416.

Ad saxa schistosa, cotacea \&c. formationis recentioris. In Suecia non raro.

Loco \& apotheciis minus arcte collabentibus a priori $\alpha$. differt, nec non crusta haud calcareo-compacta, sed hæ differentiæ a loco pendere videntur; adsunt saltim specimina nullo palpabili charactere separanda. In crusta tenuiori apothecia sessilia, in crassiori semiimmersa, numquam vero insculpta. 
386. VERRUCARIA plumbea, crusta tartareocompacta rimulosa plumbea, peritheciis integris globosis innatis, apice prominulis, nucleo hyalino-albido. Ach. Lich. univ. p. 285.

Lichen plumbosus. Engl. Bot. t. 2540. Verrucaria corulea. Dec. ex Dub. Bot. Gall. p. 645. (spec. mea a Mougeotio priori magis accedunt).

Exs. Schaer. Helv. n. 102.

Ad saxa calcarea Britanniæ \& Europæ australis copiose.

Possit omnino pro præcedentis filia haberi, at tam habitu, quam vegetatione ac: geographica distributione facile distincta. Crusta subdeterminata, crassa, turgescens, contigua, sed in superficie rimulosa, colore plumbeo ant coeruleo-cinereo insignis. Perithecia vulgo minuta, in crusta non tantum immersa, sed innata obtectaque, tantum adultiora semiemersa, - Sub Verrucaria purpurascentis nomine et hanc e Delphinatu recepi.

387. VERRUCARIA olivacea, crusta tartareo-cartilaginea levigata e viridi olivacea, peritheciis integris globosis subinnatis, apice prominente umbilicato, nucleo albido.

Ad saxa calcarea Galliæ inter Labouville \& Caumont. Le Prévost!.

Præcedentes dủas cum sequente fere conjungit, crustæ colore \& indole potissimum distincta. Crusta a saxo, cui arete ceterum adnata, bene discreta, effusa, haud admodum crassa, lævis, contigua aut vage rimulosa, olivacea, humectata magis virescens. Perithecia minuta, ex maxima parte immersa innataque, nec verrucoso-prominula, nec collabentia, sed apice umbilicato-pertusa. Nucleus sordide albus.

388. VERRUCARIA nigrescens, crusta tartareogelatinosa rimosa fusco-nigricante, intus alba, peritheciis integris globosis obtectis verrucosoprominulis subpapillatis, nucleo albido. Pers. in Ust. Ann. Bot. I 4. p. 36.

Lichen carbonarius. Wulf. in Jacqu. Coll. III. p. 118. t. 6. $f .2 . b, b$. Verrucar. antiquitatis. Flörk. in Berl. Mag. 180\% 1. p. 17. V. umbrina. $\beta$. ni- 
grescens. Ach. Lich. univ. p. 291. Pyrenula nigrescens. Ach. syn. p. 126. (cum Verruc. umbrina prorsus coaluit). Verr. nigrescens. Sommerf. Lapp. p. 1.38.

Exs. Fl. Deutsch. $n .43$.

Ad saxa calcarea aliaqne formationis recentioris Europa totius.

Crusta arcte adglutinata, statura \& forma varia, sed ambitus vulgo determinatus, color e fusco nigrescens, substantia subgelatinosa; junior macularis est, adultior crassiuscula rimosa. Nisi in meis speciminibus morbosum quoddam, deficit stratum gonimon viride, sub corticali intus nigro tota alba sunt. Infimæ hujus \& Verrucarioe umbrinoe proles ægre discernuntur, sed loco \& regione omnino differunt \& status perfectissimi luculenter diversi videntur.

389. VERRUCARIA macrostoma, crusta tartarea areolato-verrucosa fusco-olivacea, peritheciis integris amplis subampullaceis innatis, apice prominulis, nucleo albicante. Dec. Fr. 2. p.3ı. Ad muros vetustos (etiam rupes calcareas ex Dub. syn. p. 646) in Gallia, Hispania Dufour!

Tam crusta, quam apotheciis præcedentibus magis spectabilis. Crusta crassa, cohærens, sed areolato-verrucosa, passim nigro-limitata, habitu ad Parmel. badiam accedens. Apothecia inter majora geveris, immerso-innata, ipsa, nec verruca thallode, prominula, apice ostiolum magnum hemisphæricum pertusum referente. Nueleus re ipsa albus, sed perithecia vulgo ev́acuata intus nigra. Specimina Hispanica, teste Dufoureo, ad Pyren. nigrescentem ab Achario relata, hujus loci omnino sunt, tantum crusta magis fuscescente diversa.

** Saxorum granitoideorum aliorumque durissimorum formationis primitiva. Perith. subintegra. 39o. VERRUCARIA glaucina, crusta tartarea lævigata rimosa e fusco glaucescente, intus molli alba, peritheciis integris globosis politis semiimmersis, hemisphærio nudo pertuso. Ach. syn. p. 94.

Ad saxa durissima Scotiæ Herb. Ach., Helvetix Schleicher! n. 125. 
Crusta late effusa, crassiuscula, nunc omnino contigua nune areolato-rimosa, e fusco aut ferme nigricante glaucescens. Apothecia exacte globosa, hemisphærio altero crustæ immerso, altero omnino denudato; (crusta vero minime obtecta, ut in $\boldsymbol{V}$. margacea); apice poro simplici pertusa, nec papillata. - Externa facie Sagedicum fuscellam refert, at $\mathscr{V}$. glaucince crusta intus amylacea albissima, \& puncta nigra superficialia in hac vera perithecia, qux in Saged. fuscella tantum ostiola.

391. VERRUCARIA thelena, crustæ areolis verrucosis convexis lobato-crenatis virescenti-albis, peritheciis adnatis globosis, demum rugosis, apice planiusculis pertusis. Sommerf. Lapp. p. 240.

b. areolis confluertibus, subcontiguis $l$. c.

In rupibus granitoideis interdum stillicidio irriguis per Nordlandiam Saltensem. Sommerfelt!

Verrucis crustie subeffiguratis, interdum dispersis, siccitate pruina tenui alba cinerascentibus utique insignis est. Apothecia inter maxima hujus sectionis, semen Cannabis æquantia, gelatina fluxili referta.

392. VERRUCARIA margacea, crusta effusa con-

tigua e lete viridi cinerea, peritheciis integris e crusta subtectis hemisphærico-conoideis papillatis. Wahl. Lapp. p. 465. $\alpha$.

Thelotrema margaceum. Wahl. in Ach. meth. suppl. p. 30. Pyrenula. Ach. Lich. univ. p. 315.

b. diminuta, apotheciis hemisphæricis subnudis. Verruc. hydrela. Ach.! Syn. p. 94. \& V, chlorotica $l$. c. non differt.

Exs. Lich. Suec. n. 389. Flot. n. 53. (forma a. apoth. conicis denudatis).

c. crusta tenuissima, apotheciis subcylindricis apertis. Ad saxa \& rupes irriguas graniticas \& micaceas Sueçiæ totius; etiam Germaniæ, Helvetiæ Schleicher! (sub variis nominibus) Galliæ IMougeot! (pro V. mucosa) \&c.

Crusta infantilis, qualis locis magis aquosis persistit, loete viridis, mucosa; adulta \& rite explicata normaliter cartilagineo-tartarea, lævigata, cinerea, sed variat albescens, semper contigua \& vix nisi siccitate rimulosa. 
Perithecia e crusta prorumpunt ejusque verruca plus minus obtecta, (quod numquam in duabus præcedentibus), unde apothecia in perfectis conoidea, apice denudata, papillata, demum vero umbilicata. - Sed minus explicata admodum mutantur, in crusta tenuiori fere tota nuda, hemisphærica, plus minus diminuta, ut sæpe tantum punctiformia, qualis b., quam inclytiss. speciei detector hujus esse loci in litt. agnovit. Ob stationem humidiorem c. tantum habet crustam macularem, sed apothecia aperiuntur \& sub cylindrica fiunt.

393. VERRUCARIA umbrina, crusta verrucosogranulata (lavigataque) e fuscescente demum umbrina, peritheciis integris globosis e crusta subtegente prominulis papillatis. Wahl. Suec. p. 87 .

Verrucaria umbrina. Ach. meth. p. 122. exclusa V. nigresc. - Lich. univ. p. 291. $\alpha$. Sub Pyenul. nigrescente in Svn. Lich. p. 126.

b. crustæ granulis in crustam contiguam inæquabilem connatis. Verruc. xthiobola. Ach. meth. Suppl.p. 17. Lich. univ. p. 292. Pyrenula. Ach.syn. p. 125. c. crusta terso-lævigata turgida, apotheciis diminutis innatis. (Facies V erruc. plumbeoe!)

Exs. Lich. Suec. ined. var. formæ. Flotow. n. 49. A. Ad saxa granitica juxta aquas; b. locis ab aqua passim suffusis; c. in lapidibus rivulorum semper fere aqua tersis. In Scandinavia haud rara; minus evoluta Germaniæ Laurer! \&c.

Inter præcedentem \& sequentem media, \& si undique collecta specimina sicca comparaveris, vix limites invenies. Est tamen singulæ peculiaris vegetationis \& distributionis historia, e qua magis quam ad certos characteres distinximus. Omnes tres juvenilem locis humidis habent statum mucosum; hic vero in $V$. margacea late viridis, in adultiore Lichene expallens (cinereus aut albus); in $V$. umbrina viridi-fuscus, dein umbrinus; in V. maura atro-virens, adultus aterrimus. - V.umbrina perfecta verrucoso-granulosa, quales status reliquarum numquam vidi; perithecia hujus bullato-prominent, at non conica ut prioris fiunt. Ceterum, licet omnes tres uberrime, numquam promiscuas vidi. Originem vero b. ab $V$. umbrina ipsa evidentissime observavimus. 
Ubi hæc forma in foveis lapidum aquam diu servantibus nascitur, crusta magis turgescit, pulti fere similis, siccitate frustulosa, quam Verr. ceuthocarpam dixit Acharius (Lich. univ. p. 283), nec specimina Wahlenbergii Fl. Lapp. p. 467 discernere valeo; forsan tamen a sequente eadem ratione orta.

394. VERRUCARIA maura, crusta æquabili, demum rimosissima ex atro-viridi aterrima, peritheciis subintegris innato-prominulis, demum umbilicatis, nucleo albo. Wahlenb. Lapp. $n$. $889-892$.

Lichen terminalis. Fl. Dan. t. 879. Verr. mucosa (status junior), V. inaura (adultus), V. aractina (vetustissimus, elevato-punctatus, in Isidium tendens) Wahl. in Ack. Meth. Suppl. p. 23, 21, 17,:Ach. Lich. univ. p. 282, 293. Fl. Dan. t. 1852. f. 1.Pyrenul. aractina Ach. syn. p. 121. P. maura. Fl. Deutsch. Lich. n. 131. (inclusa V. umbrina). Exs. Lich. Suec. n. 388.

b. crusta viridi-nigra piceave, ambitu radiante, peritheciis nudis. Verrucar. striatula. $l l$. $c c$. Verruc. amphibia. Clem. Ens. Vid. p. 299., a Cabrera habeo. Ach. syn. p. 94. (hujus vero perithecia simillima c.!)

c. crusta tenuissima aterrima, peritheciis emergentibus urceolato-apertis. Gyalecta atrata. Ach. Lich. univ. p. 152. Lecid. Wahl. Lapp. p. 475. Ach. syn. p. 11.

In scopulis marinis graniticis, b. in Quartzo, Europæ totius a Nord-Cap ad mediterraneos $\mathrm{Ca}$ brera! ubique copiose.

Exstat sane prioris status nigrescens ab hac charactere in vetusto statu non separandus, quare haud sine ratione conjungi possint, at ne nimis contrahere videamur, in tanta formarum copia, separamus ob colorem primarium lævigatæ crustæ diversum, apothecia minus evoluta vix umquam papillata $\&$ præcipue proventum juxta aquas salinas; nam $V$. mauram ubique ad litora marina, $V$. umbrinam ad litora lacuum silvaticorum, nec vice versa, observamus. Utramque tamen ad litora Finmarkiæ legit Wahlenberg. Sphceria Licheniformis Sow. t. 220 ad V. mauram aut V. nigrescentem pertinet, sed ut plures eximii ceterum operis species nimis obiter tractata. 
Corticolce. Crusta hypophloode, sæpe deficiente. Affinitas summa cum Sphæriis; quando crusta deficit, non nisi loco in epidermide viva discerni possunt. Sed Sphceria Xylostei \&c. etiam in cortice vivo nascitur, huic vero crusta fungosa atra.

* Majores. Perithecia subintegra, primo obtecta, dein prominula persistentia, gelatina fluxili, hinc sicca cava. Analogæ Sphceriis Oblectis (Sph. Xylostei crustra atra tantum differt); degeneratæ in Spilomata, ut Sphæriæ citatæ in Stilbosporas, abeunt.

395. VERRUCARIA pinguis, crusta hypophlineode, peritheciis integris innato-obtectis, demum circumscissis, ostiolo subrimoso, nucleo fluxili. Cl.ev. par. p. 5ı8. Pyrenula.

Ad cortices arborum v. c. Fraxini, Tilize, Ilicis \&c.; in Gallia. Le Prévost aliique!

Habitus crustæ \& vegetatio omnino sequentis, sed perithecia tenuiora magis emergentia, demum prominula, epidermidem solventia, circumscissa, ostiolo haud papillato, sed in perfectis labiato-rimoso. Crusta hypophloeodes, olivaceo-luiescens oleoso-pinguis extus apparet; occurrit vero etiam denudata alba, peritheciis fatiscentibus, Spiloma quoddam melaleucum exhibentibus.

396. VERRUCARIA nitida, crusta hypophlœode, peritheciis integris obtectis, demum prominulis persistentibus, ostiolo subpapillato, nucleo fluxili. Schrad. Journ. Bot. 180 I. 1. p. 79. Sphæria nitida. Weig. Obs, p. 45. t. 2. f. 14. Sowerb. fung. t. 275. Lich., Verruc., Pyrenula. Ach. - Berl. Mag. 1812. p. 21. Sph. sanguinaria. Tod. Fung. Meckl. 2. t. 14. f. 112 . Lich. populneus. Ach. Prodr. p. 18. Pyrenula. Ches. Par. p. 518. Sphæria suffusa Rebent. Verruc. maxima Dec. fr. 2. p. 316 . -

Exs. Lich. Suec. n. 35. Ehrh. Cr. 60. Flörk. 130. Moug. n. 365. Reichenb. n. 9. Flotow.n. 37.

b. nitidella, minor. Flörk. exs. $n .10$.

Ad cortices Fagi, Carpini, Populi \&c.; b. Coryli, Europæ australis \& mediæ usque ad Sueciam meridionalem. 
Perithecia globosa, maxima, in cortice duriori, v. c. Fagi, magis prominula; in molliori magis immersa, Sphæriis simul affiniora, semper obtecta, apice prominulo dernum depresso. Crusta offert maculas virides, olivaceas, fuscas, lutescentes \&c. pro epidermidis diversa indole.

397. VERRUCARIA alba, crusta hypophloode demum denudata alba, peritheciis subglobosis integris denudatis persistentibus, basi immersis, ostiolo papillato pertusove. Schrad. Spic. $p$. I og. t. 2. f. 3. e spec. Kunzei!

V. melaleuca $A$ ch. meth. p. 117. si quidem syn. Schraderi certum. V. gemmata (Ach. pr. p.) Auctor, vulgo. V. farrea. Acl. syn. p. 96 certe!

Exs. Lich. Suec.

b. crusta cartilaginea, levisata (hypophlooode persistente), apotheciis minoribus. V. levigata. Pers. in Act. Wett.2. Verrucar. glabrata Ach. syn. p. 91 .

Exs. Schaer. Helv. n. 110. Flotow. n. 39.

Ad cortices arborum, $\alpha$. crassiorum scruposos; b. tenuiores levigatos, præcipue in regionibus campestribus; rarissime ad ligna denudata.

Inter proximas media, singularis crusta sxpe denudata leprosa alba, quam in reliquis indigenis quidem non vidimus, sed, ut inter Opegraphas, e loco ad cortices crassiores epidermide destitutos pendet. Nec ullo modo discernere possum specimina, quæ ad ligna denudata quercus legi, quæ ipsissimam $V$. ferream Ach. sistunt. Perithecia sequentis majora, emerso-denudata, ob basin immersam hemisphærica prominent \& adhuc magis in b., in qua subinde conoidea apparent. Variant ceterum magnit udine, lævigata \& scabrida, ostiolo papillato \& simpliciter pertuso. Nucleus fluxilis, siccus nigrescens, plerumque evacuatus. Nimis affinis $S p h$. mastoidea.

39 8. VERRUCARIA gemmala, crusta hypophlœode, peritheciis hemisphæricis dimidiatis (basi haud inmersis) innato-denudatis persistentibus, nucleo albicante. Ach. syn.p. 9o. (pr. p. sec. specc. determ.!)

Exs. Lich. Sulec. 


\section{Ad cortices arborum crassiores v. c. Fagi,} præcipue in silvaticis, ut videtur, rarior.

A præcedente tantum notis allatis dignoscenda, quibus sequenti subdivisioni accedit. Crustam in hac semper vidi hypophlocodi-effusam, lævigatam, albido-incanam. Perithecia minora sunt, subnitida, ob basin deficientem haud immersa; evacuata demum haud collabentia. - E grege illa Verr. gemmatae, glabrato \& cavatae Ach., quæe a prioribus differunt peritheciis emersis denudatis, difficile est species plures stabilire, nam crustæ indoles, ut in hypophloodibus solet, \& magtitudo apotheciorum mire mutantur. Duæ, quas copiosius legi, notis sane evidentibus \& loco diverso saltim discerni possunt, sed synonymia ob multas contradictiones difficilis est. Prior $a$. est quæ vulgo $V$. gemmata dicitur, sed e descriptione jam elucet hanc, cum prioris b. analogam, ab Achario potissimum respici. Videtur vero $V$. gemmata Fl. Deutsch. n. 167. huc quoque referenda, status cum prioris $\alpha$. adeo analogus; ut fere eadem ex habitur.

** Minores. Apothecia superficiali-adnata (tenerrima epidermidis pellicula secedente), nucleo firmiori albidofarcta, collapsa \& abortiva maculæformi-applarata \& in maculas Arthonioideas dilatata. Analoga Sphoeriis subtectis.

1. In infima hac grege, quæ ex parte simul regnum fungorum intrat (de qua re plenius ad Strigulce genus), e diversis videndi rationibus plures distingui possunt species 1. cum Wallrothio, ad Sphærias referente, in unam conjungi. Diversæ formæ habitu quidem differunt, at tantæ diversitates in eadem evidenter obviam veniunt, ut parum essentiales sint. Crusta nullas offert differentias, nisi $V$. rhypontce Ach., qux omnem Lichenosam indolem deposuit, citares. Peritheciorum forma parvi momenti; nullum omnino dubium mihi superest, ellipticam Verruc. epiclermidis \& Cerasi unice e peculiari harum arborum epidermidis constructione pendere. Magnitudo nullius momenti, nam apud citatam $V$. epidermidem plures hac ratione lusus videmus, quam omnes differentias. Unice fere restant perithecia dimidiata \& integra. Cum hæc differentia magnam partem historiæ Verrucariarum efficiat, paulo.plenius de illa disserendum. Typice eam quidem constantem habemus, sed varia ratione temperatur. Ubi basis perithecii dimidiati divergit, cujus evidentissi- 
mum exemplum offert Verrucaria conoidea, absolute constans est; ubi vero basis convergit, ut in $V$. Dufourei, sæpe in minus evoluto statu passim hiatus vix palpabilis ut fere contigua appareat. Cum perithecia integra a crusta rite evoluta recipiuntur, normalem suam structuram semper servant, verum crusta macilenta, peritheciis matrici ipsi adnatis, basis subinde obliteratur, tam in saxis durioribus (vix in calcareis laxioribus), quam supra epidermidem (minus in peritheciis primitus obtectis prioris sectionis).

2. Parum licet memorabiles sint status harum collapsi maculæformes \& abortivi Arthonioidei, quorum nexus cum formis normalibus facillime perseguimur ( $\&$ in Lich. Suec. Exs. semper fere juxta has traditi sunt), hoc loco necesse videtur eosdem etiam notare, cum ingens synonymorum turba ex his orta sit. Cfr. Meyer Flecht.' p. 161. Præer Arthoniam melanteram Ach. Lich. univ. Arth. obscura pr. p. Ach, syn., quæ a $V$. rhyponta oritur, non ad definitam speciem (ad epidermidem varie decoloratam distinguuntur) sed ad omnes sequentes referantur, quas re ipsa Arth. punctiformis Ach. syn. p. 4. complectitur, exclusa vero $\delta$, pro qua Stictis stecticue statum agnovit. (Arth. Sphcerula Ach. syn. p. 5. eadem ratione ad priorem subdivisionem referatur). Has diversæ originis status segregavit Cel. Dufour in Journ. Phys. v. 81. p. 205. sub Arth. galactite, $A$. ecrustacea, $A$. marginella. Plures addidit Chevallier Fl. par. p. 543. Jam optime III. Decandolle ad Verrucarias reduxerat: Verr. galactites Dec. fr. 2. n. 859. Possunt simul elongari, ut quædam formæ ad Opegr. epipastam relatæ etiam !njus loci sint.

399. VERRUCARIA biformis, crusta hypophloode, peritheciis emergentibus globosis integris, apice demum depressis umbilicatis. Turn. et Borr. - Schaer. spic. p. 56.

V. stigmatella. Auct. varr. Opegr. Verrucarioides. Ach.pr.p.

Exs. Schaer. Helv. n. 109.

Ad corticem arborum Europæ præcipue australioris.

Apothecia sequentium haud majora; sed emergentia aut erumpentia, juniora a thallo coronata, vel etiam pruinosa; adultiora superficiali-libera, omnino integra, disco 
depresso ferme lentiformia, intus evacuata nigricantia. Crusta sequentium insignior est, indeterminata, vetusta rimosa \& subpruinosa, etiam albissima visa. Pyrenothece sticticae affinis, variabilis, a primitiis Opegrapharum utique distincta.

40o. VERRUCARIA epidermidis, crusta hypophloode obsoletave, peritheciis dimidiatis basi patente innato-superficialibus, collapsis nucleoque applanato-depressis.

a. peritheciis majoribus, orbiculatis. V. analepta $A c h$. Lich. univ. p. 275.!' ex quo V. olivacea Pers. et Schrad. - spic. Germ. t. 2. f. 1 Engl. Bot. t. 1848. Exs. Lich. Suec. n. 184.

b. peritheciis majoribus, ellipticis. V. Cerasi Schrad. Ach. l. c. p. 276 . V. epidermidis. Ach. l. c. Lich. epid. \& ellipticus. Ach. Prodr.

Exs. Lich. Suec. n. 244. Schaer. n. 107. Flörk. n. 104. Flotow. n. 32.

c. peritheciis diminutis punctiformibus, habitu sequentis, ut vulgo commisceantur, sub $V$. stigmatella \&c. V. epid. o. Ach. etiam h. $l$.

Ad corlices arborum passim; b. in Ceraso \& Betula frequens; c. reliquis immixta.

Inter a. \& b. characteribus, magnitudine \& habitu omnino congruas nullam invenio differentiam præter formam, a peculiari epidermidis constructione in Betula \& Cercaso, quæ hinc varietatibus multis analogis, etiam inter Pyrenomycetes, conveniunt. Externus crustæ color varius. Apothecia normaliter prioris duplo triplove majora, plerumque opaca, perfecta papillata, in ambitu depressa, maculari-expansa; sæpe collapsa maculæformia. Diversa Auctorum judicia de affinium synonymis frustra conciliare studui; determinavi ad ectypa Achariana. Sunt quoque tot inter hanc \& sequentem formæ intermediæ, ut meo sensu unicam speciem facile efficiant.

40r. VERRUCARIA punctiformis, crusta hypophlœode obsoletåve, peritheciis innato-superficialibus semiglobosis subdinidiatis basi infle$x a$, nucleo globoso albo subfarctis. Pers. in Ust. ann. Bot. I1. p. 19.

Ach. Lich. univ. p. 274.! V. cinerea. Pers. \& V. - stigmatella Ach. pr. p. Engl. Bot. t. 1891. L. my- 
caporioides, Ehrh. V. Hippocastani, microcarpa. Dec. fr. 2. Sph. punctata. Sori. Eng. Fung. $t$. 375. f. 6 . Exs. Lich. Suec. n. 242. Flotow. n. 33-36.

Ad corticem lævigatam arborum, passim.

Cum præcedentis occurrant diminutæ \& abortivæ formæ omnino punctiformes, statura normaliter duplo triplove minor ad hanc discernendam haud sufficit. Primariam differentiam mihi offerre visa sunt perithecia semiglobosa, nec conoidea, typice integra, quales quoque obviam veniunt, sed basis innata sæpius obliteratur, tamen inflexa est nec ut vulgo in præcedente expansa, quare nucleus magis persistens globosus est. Ostiolum vulgo simplex.

* $V$. carpinea, peritheciis majoribus subintegris, ostiolo sæpe pa pillato. Pers. - Ach. l. c. p. 28 r. Exs. Desmaz. n. 190. Flörk. n. 145.

Ad corticem Carpini, eliam Scaniæ.

Forma suo loco satis constans, crustæ habitu fusconigricante simul insignis, at differentiam certam non invenio. Inter hanc \& squ. prorsus media specimina in Fraxino ad Lyon lecta misit Montagne.

* $V$. rhyponta, crusta tenuissima maculari nigra, peritheciis minutissimis. Ach. l. c. n. 282 .

Exs. Lich. Suec. n. 243. Flotow. n. 37.

In cortice Tiliz, Fraxini \&c.

Jam normalis planta in bivio inter Fungos \& Lichenes secuadum diversa exemplaria posita est; in hac demum nil Lichenosi in thallo restat, crusta omnino (ut apothecia) qualis in multis Sphæriis.

\section{Trib. IV. LIMBORIEE.}

CHAR. Apothecia rotundata, excipulo proprio carbonaceo clauso, dein varie dehiscente; nucleo subceraceo rigescente. Thallus crustaceus.

A priori tribu differt ut Phatidiacece a Sphariaceis, hinc Graphideas simul tangit $-\&$ forte Oxystoma Eschw. hujus loci sit. Quoad vegetationem vero Calicicis eximie analogæ sunt Limborieæ, tamen peritheciis clausis nucleique indole diversissimi. Ceterum Calicieis inferiores sunt, \& ultima genera epiphylla a Fungis vix acute limitandia. 


\section{XXIX: PYRENOTHEA.}

Fries Vet. Ac. Handl. 1821. p. 332. Syst. orb. $V e g$. Sphæriæ spec. Pers. Limboriæ \&c. Ach. Variolarix Decand. Leprantha. Dufour. Thrombium. Wallr., ex quo Gelatinaria. Flörk.

CHAR. Perithecia rotunda, carbonacea, clausa, ore simplici pertusa, nucleum globuli instar demum fatiscentis prolrudentia, demum dehiscentia explanata evacuata. (Unius speciei adest quoque status dișciferus). Thallus crustaceus.

Charactere essentiali optime distinctum genus, cum Thelebolo Fungorum analogum, inter Verrucarieas \& Limborieas intermedium, habitu \& vegetatione simul Caliciorum. Perithecia juniora clausa sunt, ostiolo simplici mox pertusa \& globulum protrudentia; demum passim magis déhiscunt, v. c. primæ speciei, \& $P$. sticticce fere semper, disciformi-aperta, sed verus discus ascigerus desideratur. Hunc statum Pyrenotheo leucocephalo sistit Cyphelium picastrum Ach., minime commutandurn cum Lecidea abietina Ach., quæ est alius ejusdem plantæ status, disco Lecidino. Ex hoc rarius obvio statu (mille sane exstant Pyrenothea leucocephalce ipsx pro singulo specimine s. d. Lecidea abietinae in plurimis regionibus campestribus prorsus desideratæ) ad Lecideas omnino referres, sed normales Pyrenotheæ, etiam $P$. leucocephala, dehiscentes ad Calicia potius pertineant, \& tota hæc metamorphosis adeo a veris Lecidinis diversa, ut non possim non separare. Nec desunt analoga metamorphoseos exempla inter verissimos Lichenes Angiocarpos; v. c. Lecidea atrata multæque similes a Verrucariis normalibus ortæ. Præcipue vero comparandus est hic status Lecidinus cum Pertusariis disciferis, \& ex his mihi major videtur ratio Parmelias \& Pertusarias conjungendi, quam Pyrenotheas cum Lecidea. Cum citatis Pertusariis disciferis quoque convenit crusta in hoc statu leprosa aut atypica; sed * "Lecidea abietina" simul potissimum occurrit locis cryptis, prope radices arborum \&c., ubi status normales non obviam veniunt. Præcipuam vero rationem, ob quam sub hoc genere servavi, offerunt reliquæ species, quibus etiam accedunt Am̄ericanæ, cum quibus vulgatissimus status prorsus convenit, ut ab illis genere non moveri possit. - Genus 
Pyrenotheis proximum, has cum Cliostomo \& Limboria tribu conjungens, sistit Gyrostomum, quod primitus licet prorsus omnino clausum, dein limbo orbiculari dehiscit, nec globiferum est, sed discum offert primo gelatinosum, dein rigescentem. Hoc extra tropicos nondum lectum novimus.

402. PYRENOTHEA leucocephala, $\alpha$. crusta lævigata glaucescente, perithecirs subglobosis emersis nudis atris, globulo subfarinaceo persistente albo. Fries Vet. Ac. Handl. 1821. p. 333! Sched. Crit. 1. p. 8! 9 .

Sphæria leucocephala Ehrh. (ex Flörke, \& sub hoc nomine ab E. Meyer accepi). Verrucar. s. Pyrenula leucocephala. Ach. sunt nomina hujus \& sequentis collectiva; huic, ut aptissimum, servavi. Cyphelium leucoceph. Ach. in Vet. Ac. Handl. 181\%. p. 228, speciatim var. $\beta$. elatinum. (T. 8. f. \%. 6. male). Variolaria leucocephala. Dec. Fr. 6. p. 176. Lecid. abietina b. leucocephala Flörk. Verruc. Jeucocephala $\beta$. Duby Bot. Gall. p. 645. - status dehiscens, disco orbus: Cyphel. picastrum. Ach. in Vet. Ac. Handl. 1815.

Exs. Lich. Suec. n. 19. Fl. Deutsch. n. 183.

* Lecidina. crusta subleprosa, disco scutelliformi-dilatato rigescente, plerumque densa pruina obtecto: Lich. abietinus. Ach. in Vet. Ac. Handl. 1795. t. 5. f. 7. Engl. Bot. t. 1682. Lecid. Lich. univ. p. 188. - vel omnino nudo: Limboria regularis. $A c h$. in Vet. A. H. 1815. p. 260.

Exs. Lich. Suec. n. 21. Flörk. l. c. n. 182.

Ad cortices arborum Quercus, Alni \&c. frequens; copiosisime ad truncos abiegnos in montosis silvaticis. * inter communem ad basin truncorum abiegnorum rarior.

Crusta late effusa, indeterminata, passim integros truncos obducens, tenuis. Perithecia clausa, poro pertusa, globulo mox farinaceo coronata. His magis dehiscentibus dilatatur discus, sed lamina ascigera caret; quæ adest in *, cujus apothecia undique plerumque pruina densa lutescenti-cinerea velata. Hujus analogiam cum Variolariis optime observavit Decandolle. - Nexum omnium huc relatarum formarum (quem a Flörkeo, Meyero \&c. con- 
firmatum vidi, licet proponendi modo leviter recedam) jam plurimis abhinc annis observavi, sub nomine Calicii variolosi (Cfr. Wahl. Suec. n. 1746) amicis mittens; dein in Commentariolo 1820 ad Reg. Soc. Scient. Holm. tradito sub Pyrenotheæ genere proposui. Hoc ostentationis vitio tædiosum, licet Auctores laudatos idem detexisse non dubitem, ideo tantum annotare coactus fui, cum ex eximia ceterum Meyeri expositione, Flecht. p. 210, 211, me de his tantum in errore versatum fuisse crederes. Lapsu potissimum calami dicitur me * denudatam sub nomine Limboriae regularis distinxisse; vera quidem ratio est, me hujus identitatem cum Lec. abietina, in V. A. H. 1817 etiam ab Achario agnitam, semper ursisse, etiam negante Flörkeo, cui hic status non obviam venisse videtur. Sancte quoque testor omnia ejusdem a me distributa specimina fuisse ejusdem individui partes; ut fallaciæ suspicio deleatur.

$\beta$. P. incrustans, crusta crassiori, peritheciis globoso-cylindricis, globulo gelatinoso luteo! annulo pulveraceo albo cincto $F r$. l. c. Cyphelium incrustans. Ach. Vet. Ac. Handl. 1817 . t. $8 . f .6$.

Exs. Lich. Suec. 20.

Ad rupes, præcipue absconditas, in Smolandia haud raro, Bohemia (Mann Lich. Boh.)

Priori adeo affinis, ut, observante Meyero, pro ejus varietate forsan melius sumatur. Crusta crassa, leprosa, sed cohærens; maxime diversa a s. d. Lepraria incana, quæ locis similibus occurrit. Perithecia majora, globoso-cylindrica, globulo gelatinoso-indurato luteo (Cfr. Ach. l. c. f. d.), passim spinulæ instar elongato ostiolo Spharioe chionoece simili!!, basi farina alba annulato. Perithecia dehiscentia discum offerunt ceraceo-gelatinosum; adest vero etiam alter status, cum prioris Lecidino analogus; sed in hac Parmeliam potius refert. 403. PYRENOTHEA vermicellifera, crusta lævigata glaucescente, peritheciis prominulis e crusta vestiente albis, nucleo filorum instar erumpente. Kunz. - Steud. Nomendl. Crypt. II. p. $36 \mathrm{r}$.

Lichen colliculosus Hoffm. En. Lich. t. 2. f. 2. teste Dufour. Leprantha Duf. Sphæria leucocephala. 
Pers. syn. p. XXVII. ad specimen ab ipso. Verrucaria, dein Thrombium vermicelliferum. Wallroth! Mscr.

Exs. Reichenb.

Ad cortices arborum in Hispania Dufour! Gallia Prèvost! Germania Wallroth! Kunze!; in Suecia numquam vidimus.

Crusta tenuis, byssaceo-macularis, glauco-candicans. Apothecia minuta, juniora a crusta omnino vestita, dein apice nigro-papillata, non globulifera, sed nuclei, ut in Sphæriis hypocreis, filorum instar erumpunt. T'helebolus conspersus Decand. valde similis. Wallrothius \& Dufour primi rite distinxerunt; Acharius suæ Pyrenula leucocephalce adscripsit. Licet aliquot momentis differat, huic subjungenda videtur habitu apotheciorum simillima: B. PYREN. fuscella, crusta cinereo-fuscescente, peritheciis subglobiferis. Ljungst. Sched. Crit.VII. Verrucaria, Pyrenula \& Cyphelium leucocephalum. Ach. pr. p. - Berl. Mar. 1812. t. 2.f. 24.

Exs. Lich. Suec. n. 194. Fl. Deutsch. n. 149.

Ad cortices arborum frondosarum Europa australioris, inque Scania copiose; sed in pinetomontanis Smolandia \&c., ubi myriades $P$. leucom cephalce, nullum hujus vestigium.

Tam hanc, quam var. a. ab omni Pyrenothea leucocephala distinctissimas esse, mihi saltim certissimum videtur; nam si junior ejus status putatur, non facile intelligitur, quare apud nos numquam in eadem regione observarentur; ceterum primitivum $P$. leucocephaloe statum omnino diversum reperi. - Variant Sphceria citrince \&c. \& vermicelliferæ \& globiferæ, quo convenientia inter $\beta$. \& $a$ confirmatur.

404. PYRENOTHEA stictica, crusta hypophlneode glaucescente, demum denudata (e chrysogonidio Wallr.) rufescente, peritheciis punctiformibus immersis nudis nigris, globulo albo ejecto deplanatis scutelliformibus. Fries Vet. Ac. Handl. i 821. p. 334 .

Sphæria byssacea. Weig. Obs. Bot. p. 42. t. 2. f. 9: Pers. syn. p. XX. Lich. sticticus. Ach. Prodr. p. 16. Verruear. byssacea \& stictica. Ach. meth. $p$. 
116,118 , quibus vero synonymis collectivum quoddam subest. - Plene hujus loci sunt \& ad mea specimina descripta: Cyphelium sticticnm: Ach. in Vet. Ac. Handl. 1815. p. 269. Limboria. Ach. l. c. 181\% p. 222. Ga:icium Wahl. Suec. n. 174\%. Thrombium punctiforme. Wallr. Flechtenk. 1. p. 170. eoque teste Gelatinarıa dryina Flörke - \& Verruc. rubens. Flörk. in Berl. Mag. 180\%.

Exs. Lich. Suec. n. 22.

* Lecidina. Lecid. Iilacina Ach. meth. p. 34. L. dryina. $\beta$. Ach. syn. p. 24.

Ad cortices truncorum vetustorum, præcipue Alni \& Quercus, passim copiose.

Crusta haud semper tenuis, passim enim turgeseens, habitu Sagediae aggregatce, cui hypophlocodes glaucescens hic Lichen similis est, sed præter perithecia diversissima, trita aurea fit; adultior denudata leprosa, semper fere rufescens. Est itaque sensu Wallrothii optime chrysogonimica, quale nullum vidimus Calicium. Perithecia puncta minima aterrima referunt, crustæ immersa, sed omnino denudata; primo globosa, clausa, dein globulum album generis fugacem protrudentia, tandem collapsa, aut discoideo-aperta scabrida habitu Calicii. Sed huic generi nullo pacto affinis est; verum suum $L_{i-}$ chenem sticticum cum Sph. byssacea (varie torta) Weigel identicum esse ipse agnovit 1. c. Acharius, \& ex fidis speciminibus confirmo. Monendum vero hvjus loci non essse specimina lignatilia, olim ab Achario memorata, sed una cum $V$. stictica Flörk. ad Caliciorum abortus pertinere. Pyrenothea stictica licet minima, certe maxime memorabilis species, a primordiis Opegrapharum præcipue cautius separanda.

Plures hujus generis, tam apotheciorum, quam thalli indole maxime insignis, etiam Europaca species nobis innotuerunt, quas vero, speciminibus exsiccatis distributis nondum fixas, deseribere parum utile duximus. - Ceterum inquirendum, an hujus generis sit Verrucari a epig a e a Ach., cum hujus habeumus statum Lccidinuin cum priorum optime comparandum. Acutissimus IV allr oth quóque eandem sub $T$ h rombi i nomine quodam loco memorat; admodum dotemus ab koc Auetore nullam suorum generum datam esse notitiam; e sparsis nominibus ideam de eis fingere frusta conati sumus.

\section{CLIOSTOMUM.}

Syst. orb. veg. 1. p. 116. Limboriz spec. Ach. in Vet. Ac. Handl. 1815. 
CHAR. Perithecium carbonaceum, integrum, rotundatum, clausum; collabescendo rugoso-plicatum, rugis demum rimose \& transversim dehiscens. Nucleus ceraceo-gelaiinosus, inclusus. Thallus crustaceus.

Unica hujus generis hactenus cognita species vàrie dijudicata fuit. Pro Lichene autonomo descripserunt primi determinatores; plurimi dein cum Achario pro Calicio deformato habuerunt. Hac sententiam ipse deseruit in Synopsi Lichenum \& Vet. Ac. Handl. I. c.; at Lecidea minime est, ut analysis, immo habitus, mox testatur. Ob singularem societatem cum "Lecid. Ehrhartiana" Ach. (Parmelia varia $\nu$. parasitica), cui hujus crusta semper adscripta fuit, pro fungo in hac parasitico (nam duo diversi Lichenes communi crusta gaudere nequeunt) cum Flörkeo, Albertini et Schweiniz diu habui, \& Rhytismati, cui generi inter Pyrenomycetes analoga est, subscripsi. Dein vero "Lecideam Ehrhartianam" argutius observans, inveni hanc tantum sistere apothecia parasitica Parmelice varioe, simili ratione etiam in aliorum Lichenum crustis vagantis; crustamque re ipsa ad "Lecid. corrugatam" Ach. pertinere. Vix umquam hujus, sæpe autem Parmeliae varice, apothecia desiderantur. Veritas hujus observationis, in Schred. Crit. IX propositæ, eximie confirmatur ab autonoma omnino congruente Wallrothii in Flechtenk. II. \& ut plane demonstrata a Flotowio recipitur. At ut verus Lichen hæc stirps, Limboriis licet proxima, cum alio genere, quantum video, conjungi nequit; Wallroth ad suum haud descriptum genus Thrombium refert. In statu perfectissimo dehiscente, quale locis humidis hieme miti tantum vidimus (Cfr. Ach. l. c. t. 6. $f .5$.), paucis obviam venisse videtur; sæpius tantum collapso-corrugatum, quale tam exoletum, quam locis siccioribus per totam vitam persistit. Hoc loco in memoriam revocare juvabit analogiam variorum Pyrenomycetum, qux ob fructificationem inter Fungos melius evolutam Lichenum eximie illustrat. Sic "Peziza pinastri" Pers. sæpissime \& in ramis siccis semper Pezizam rugoso-collapsam refert (analytice vero examinata maxime differt), sed locis humidioribus verno tempore rupta verum se esse Phacidium monstrat. Eadem ratio vulgaris "Sphoeriae Pezizoe" Tod.; hæc vero ut Phacidium rupta, h. e. in statu perfecto, 
tantum in subalpinis obviam venit. Ex his exemplis simul patet affinitas cum Limboriis, a quibus differt ut Rhytisma a Phacidio. - Denique inquirendum est an sub Cliost. corrugato plures lateant species. Certe plures insignes vidimus diversitates, unicam vero rite fructificantem. Plures se sub hoc nomine confusas distinguere posse etiam monuerunt Dufour, Stenhammar. Præcipue attentione digna huc vulgo relata forma in Caliciorum societate obvia (Engl. Bot. $t$. 464, Lich. graniformis), qualis numquam a me lecta, si hæc aliud sit quam status degener ipsius Calicii. Potius fingerem plures hujus exsistere exoticas species, nam quo magis generis Lichenosi fructificatio ad fungos deliquescens est v. c. Trypetheliorum, Limboriarum, eo magis tropicæ ejus species, cum sub arctica zona tantum occurrunt Lichenes habitus genuini.

405. CLIOSTOMUM corrugatum.

Lich. graniformis. Hag. Hist. Lich. p. 18. Ach. Prodr. t. 2. $f$. 1. cum apotheciis "Lichenis Ehrhartiani" immixtis, Peziza Hysterium Alb. et. Schwein. consp. p. 344. Fl. Deutsch. Lich. n. 24. in obs. Lecid corrugata Ach. syn. p. 18. Schaer. spic. p. 149. Limboria. Ach. in V.A. Handl. $l$. c. t. 6. f. 5. Rhytisma. Fries Syst. myc. II. p. 565. Thrombium graniforme. Wallroth. ined.

Exs. Lich. Suec. n. 254. Schaer. Helv. n. 192.

Ad parietes ligneos pineos vetustos in silvaticis; apud nos copiosissime - regionibus campestribus ad cortices Quercus, Tiliæ \&c.

Crusta late effusa, rugoso-verrucosa, eximie cartilaginea, é glauco albescens. Apothecia nuda, conferta, aterrima, subnitida; collapsa Lecideam referunt, sed quod in Lecideis discus nudus, in hoc perithecium clausum.

\section{LIMBORIA.}

Eschweil. Syst. Lich. p. 16. f. 16. Fries. S. O.V. Limboria Ach. ex min. parte.

CHAR. Perithecium corneo-carbonaceum, rotundatum, primo clausum, dein a centro stellatim dehiscens, nucleo subdisciformi e gelatinoso rigescente. Thallus crustaceus, leprosus aut hypophloeodes. 
I. Laudandum mihi videtur Cel. Eschweileri studium magis genera proposita acutius limitandi, quam novis nominibus salutandi. In Martii Lich. Bras. t. X.f. 4., quæ Verrucariam omnino sistit, videtur hoc genus cum Verrucariis conjungere, at veræ Limboriæ ab his omnino differunt ut Phacidium a Sphæria. Laciniæ perithecii, limbum Ach. offerentes, plerumque conniventes, sed in Limb. constellata Ach. etiam patentes. Plurimæ hujus generis species tropicæ sunt, ibidemque sequenti generi maxime accedunt, ut Alauxina Fée utrumque genus conjungere videatur. Totus enim habitus, vegetatio epiphylla \&c. sequentis generis ; apothecia vero exacte Phacidii Deltae Kunz., magnitudine minore tantum recedentia, huc revocare videntur.

II. Limboriæ indigenæ Ach. vel dubiæ 1. hujus generis non sunt. Limb. regularem A. sub Pyrenothea; Limbor. corrugatam sub Cliostomo citavimus; Limb. flexella est Peziza. (In genere, ut genus Calicieis accomodaretur, discum pulveraceum perperam describit). De loco Limb. sepincolae Ach. (Schizoxyli sepincolæ Pers. Moug. \& Nestl. exs. n. 174) adhuc dubitamus; crustæ Lichenosæ vestigium nullum umquam vidimus, tantum hypothallum ligni fibris intertextum normalem inter lignatiles Pyrenomycetes, dum Calicia vera in statu perfecto saltim veram Lichenosam habent crustam.

406. LIMBORIA sphinctrina, crusta innato-turgescente albida, peritheciis semiimmersis dimidiatis hemisphæricis in lacinias 4-5 æquales convergentes stellatim fissis. Dufour in litt.

\section{Ad saxa calcarea in Hispania. Dufour!}

Lichen admodum singularis, Crusta cum saxo calcareo turgescente coalita, ad typum Verrucarice rupestris, ut primo obtutu a saxo macula pallida differre videatur, licet satis insignis. Apothecia primo adspectu superficialia, hemisphærica ant depresso-hemisphærica apparent, sed dimidia nuclei pars crustæ immersa est, superne tantum tecta perithecio dimidiato, regulari, sæpe nitidulo, a centro versus ambitum radiatim fisso, ob lacinias $4-5$ obtusas æquales convergentes subclauso, discum cóllapsum in siccis saltim obtegentes. Unica generis species saxicola. Nisi perithecia cornea, ne dicam carbonacea, aterrima, facile cum Gyalecta? exanthematica comparares. 


\section{STRIGULA.}

Fries Vet. Ac. Handl. 1821. (nomen) Syst. orb. Veg. 1. p. 111. El. Fung. 1. p. 114. Squamariées épiphylles Fée Crypt. Exot. t. II. f. 1-8. ex maxima parte. Stigmatidii spec. Mleyer Flechtenk. p. 328.

CHAR. Perithecia carbonacea, subglobosa, farcta, clausa, ostiolo rimoso-inæquabili collabente, nucleo e gelatinoso rigescente, nigricante (in superficie subfatiscente). Thallis hypophloeodes, plerumque epiphyllus in foliis coriaceis perennibus tropicis.

I. Non dubito fore multos, qui, strictis systematicis limitibus addicti, vituperent $l$. mirentur hoc genus a me semper simul \& inter Lichenes \& Pyrenomycetes recenseri ; sed ita in conterminis utriusque familiæ positum est, ut sub utraque memorare, si naturam sequi velimus, necesse sit. Sunt enim aliæ species evidenter Lichenosæ, quare huic familiæ his tantum visis sine hæsitatione adscripsi (S. MIyc. 2. p. 535. licet præter formam peritheciorum colore tantum differat a Corynelia evidenti fungo, inter quam \& Strigulam accessit Tricharia Fée,) dein vidi alias species nec genere in præsenti a reliquis nec a Fungis jure separandas \& quam plurimas formas mycetoideas in foliis tropicis intime connexas. - Similia puncta, in quibus diversæ naturæ series in infimis prorsus se invicem contingant, ubique inter Plantas Homonemeas observamus. Sic, ut similium exemplorum decades omittamus, aliæ_Diatomearum generum species evidentius animalem, alia vegetabilem naturam offerunt. Strictos in his conterminis ponere limites magis in Systematicum nitorem optatur, quam in eorum studii commodum. Hinc h. $l$. ob contiguitatem cum Lichenum serie non possumus non hoc loco inserere; nec minus ob easdem rationes inter Pyrenomycetes iterum citare.

II. E jam allatis patescere videtur hỏc genus Lichenum infimum esse (Calicia prioris ordinis analoga, at melius evoluta), utpote jam facile ad Hysterophytarum (ut Fungos) seriem pertinens, cum omnes -species, quæ in tropicis abundant, absolute epiphytæ \& plurimæ in foliis vivis epiphyllæ. Sic quoque singula Pyrenomycetum series epiphyllis terminatur. In quibusdam spēciebus, facie licet Lichenosa, thallus omnino e folii substantia trans- 
formatus videtur. Sic in unica parum evoluta Europæa specie, quæ, optimæ Strigulae orbiculari Fries in Linn. 1830. p. 549 licet simillima, admodum fungis affinis \& sine crusta passim obvia ab eis neutiquam separari potest.

407. STRIGULA abietina, crusta epiphylla orbiculari lævigata flavovirente, perithecio centrali solitario.

In foliis Abietis in Helvetia. Chaillet!

Bullas sistit in folio vix lineam latas elevatas, omnino contiguas, orbiculares, flavovirides, quem colorem servat etiam languescente folio. In hujus centro perithecium adest solitarium, emersum, punctiforme, centro collabens; at similia perithecia in eisdem foliis absque crusta vidi. A Depazeis Pyrenomycetum potisssimum differunt folio in maculam arescente, cum in "Dothideis folii substantia in stroma fungosum mutatur; at in Strigula hoc stroma assimilat vegetationis primitivæ colorem viridem indeque thallum Lichenum menulatur. Hoc respectu Strigula a Fungis quodammodo recedit ut $V$ iscum a parasitis phanerogamis Fungosis. At ad magis imperfectam Lichenosam vegetationem quam hæc species offert, descendere non possumus, \& sic agmen claudit. 


\section{A D DENDA.}

p. 27. n. 12. Evern. villosa. - Ab hac diversa est, ex speciminibus Prostii, Borrera Solenaria Duby Bot. Gall. 2. p. 612, licet definitio Acharii-Cfr. p 76. p. 29. n. 14. Ram. pusilla. - Duby 1. c. p. 604.

p. 40. post n. 28. - Cetrar. complicata Laurer!, in truncis Pini \& Laricis lecta in alpibus Carinthiacis \& Tyrolensibus, videtur alia nova species ochrroleuca ex hac regione, at desunt apothecia.

p. 47. n. 37. Peltigera polydactyla b. - Cfr. Peltig. molesta. Delise apud Dub. l. c. p. 604 .

p. 70. Parmel. relicina. $\beta$. Parm. Despreauxii Jb. $p$. 602.

p. 103. n. 98. Parm. incisa. Lecanora pruinosa Chaubard! in St. Am. Fl. Ag. p. 495. Squamar. Duby Bot. Gall. p. 660. (Nomen antiquissimum, facile præferendum). A primo inventore jam habeo.

p. 119. n. 11\%. Parm. fulgens. Engl. Bot. t. 1867.

p. 202. n. 184. Stereoc. paschale. Proximum esse videtur Stereoc. Delisei. Bory in Dub. Bot. Gall. p. 619.

p. 256. n. 216. Biatora albilabra. Conferentes descriptionem ceterum non visæ Lec. cinereovirentis Schaer. (n. 252.) vix dubitamus eandem sistere speciem, quare p. 286 cum hac conjunximus, ut illo loco deleatur. Schaereri descriptioni fidimus esse Lecideam; qualis mihi missa, ex structura, licet denigrata, videbatur Biatora. Quod vero in viva plenius observandum.

p. 291. n. 259. Lecid. Wahlenb. Fl. Dan. 1720. $f .1$. p. 402. Calic. turbinatum.

Exs. Lich. Su. 63. Flörk. n. 125. M. et Nestl. 368. p. 406. n. 352. Siphula Ceratites.

Lichen coralloides fruticosus terrestris parvus flavescens, densissime ramificatus. Amman Stirp. Ruth. p. 176.

Coralloides Coralli minimi facie. Dill. Musc. $t .17$. $f .36$. (Sphærophoris quoque adnumerat nec Cladoniis). In montibus quoque Uralensibus locis nitrosis ad Jaicum fluvium.

Plurima reliqua nove species in Synops. Plant. Galliae a $D u b y$, ad specimina missa suis locis inserere licuit. Varia ceterum differentia nomenclatura e synonymis facile patent. De quibusdam Cladoniis judicium suspendo. Numerus quosdam neglectos Exs. Suec. possessores ipsi facile addent. 


\section{Errata typographica noiata:}

Pag. 20. I. 33. lege: $f$. 8. - p. 45. 1. 24. Waht. Suec. et ex part. Ach. - p. 46. 1. 11. Schleich. (pro Schaer.) - p. 49. 1. 4. L. S. 328. - p. 75. 1. 17. t. 36. - p. 84. l. 13. del. Lich. Su. - p. 139. 1. 19. t. 2154. - p. 240. 1. 2\%. distinguunt (loco dignoscitur) - p 260. 1. \%. $\beta$. (loco $\gamma$.) - p. 297. 1. 30. n. 409. - p. 308. 1. 4. n. 381. - p. 315. 1. 27. p. 130. - p. 316. 1. 9. n. 179. - p. 364. 1. 2\%. Schaer. $S p . p$. 50. (O. cymbiformis) et Mey. - . p. 394. 1. 22. subcoeci (pro subсоссо) - p. 418. l. 6. lege: 1828. p. 426. l. 37. lege: nucleum discoideum. p. 429. I. 19. XXVII. SEGESTRELLA. p. 430. lin. penult: XXVIII. 


\section{INDEX MICHELIANUS}

sistens species depictas in opere:

Nova genera plantarum.

Ord. 1. Tab. 36. f. 1. Ramalina fraxinea.

- - f. 2. prioris varietas apparet.

- - f. 3. Evernia prunastri.

- f. 4. Parmelia chrysophthalma b.

Ord. 3. T. 38. (Collema)

Ord. 4. - - f. 1. Evernia furfuracea.

$$
\text { - - f. } 2 . \quad \text { - } 3 . \quad \text { villosa. }
$$

Ord. 5. T. 39. f. 1.-4. Everniæ \&c. ægre definiendx.

- - f. 5. Usnea barbata. a.

- f. \%. Cetraria aculeata. $\beta$.

T. 53 f. 9. Stereocaulon denudatum.

- - f. 6. - vesuvianum.

- $-f . \%$ - alpinum b.

Ord. 6. T. 40. f. 1. Cladonia $\begin{aligned} & \text { nanum. } \\ & \text { rhangiferina. }\end{aligned}$

- - f. 2 - - uncialis.

Ord. 7. T. 41. f. 1 . -6 cornuta.

- ceteræ inter Cl. gracilem \& fimbriatam ambigunt.

Ord. 8. T. 41. f. 1, 2. Cladonia pyxidata.

$$
\begin{aligned}
& \text { - f. 3. - - Cornucopioides. } \\
& \text { - - f. 4. - - fimbriata. b. } \\
& \text { - f. } 5,6 \text {. - gracilis. b. } \\
& \text { - - f. } \% \text { - c carneola. } \\
& \text { - f. 8. - - deformis. } \\
& \text { T. 42. f. 1, 2. - alcicornis. }
\end{aligned}
$$

Ord. 9. T. 42. - - squamosa.

Ord. 10. T. 42. f. 1, 2. Biatora Cladonia.

Ord. 11. T. 43. - Sticta silvatica.

Ord. 12. T. 44. f. 1. Peltigera horizontalis.

- 2 . - r rufescens.

$-3,5 . \quad$ - venosa.

- - 6. - polydactyla. $b$.

- 4. Cetraria islandica. 
Ord. 13. T. 44. f. 1, 2. Peltigera resupinata.

Ord. 14. T. 45. Sticta pulmonacea.

Ord. 15. T. 45. Parmelia tiliacea.

Ord. 16. Collemata sine iconibus.

Ord. 17. T. 46. Parmelia glomerulifera.

Ord. 18. T. 47. Umbilicaria pustulata.

Ord. 19. T. 51. Parmelia olivacea.

Ord. 20. T. 48. f. 1. - caperata.

- f. 2 . - Acetabulum.

Ord. 21. T. 49. Sticta scrobiculata.

Ord. 22. T. 49. f. 1. Parmelia saxatilis. $\alpha$

Ord. 23. T. 43. f. 1. Parmelia plumbea.

Ord. 24. T. 50.

f. 3 .

- f. 2 .

- rubiginosa.

- f. 4. - (anceps, ad P. pulve-

rulentam vulgo citata)

Ord. 25. T. 50 .

Ord. 26. T. 50 .

Ord. 2\%. T. 50.

Ord. 28. T. 50.

Ord. 29. T. 51 .

f. 5 .

Ord. 30. T. 51, f. 1.

$$
\begin{aligned}
& \text { f. } 2 . \\
& =\quad \text { f. } 4 . \\
& =\quad \text { f. } 5 . \\
& =\quad \text { f. } 6 .
\end{aligned}
$$

Ord. 31. T. 52.

Ord. 32. T. 52.

Ord. 33. T. 52 .

Ord. 34. T. 52 .

T. 53. f. 1, 2. Variolarioidei status.

Parmelia perlata. parietina ** *

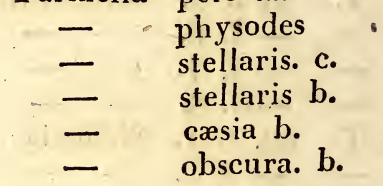

Parmelia gy"psacea.

- $\quad$ testacea

saxicola.

incisa.

aquila.

Peltigera saccata

Pertusaria Wulfenii.

Parmelia scruposa. b.

$$
\text { ocellata. }
$$

- f. 3. Parmelia vitellina

Ord. 35. T. 59. Bæomyces roseus.

Ord. 36. T. 54. f. 1. Endocarpon miniatum.

f. 2. Sticta herbacea infans.

- f. 3. Endocarpon pusillum.

- f. 4. Idem aut Biat. lurida.

Ord. 37. T. 54. Difficile absolute determinantur, immixtis Sphæriis \&c., ad has pertinent spe- 
cies quarum crusta nigra, nec farinacea dicitur; sint itaque

(f. 1. $\quad$ Sphæria mastoidea.)
(f. 2. Hysterium pulicare.)
f. 3. $\quad$ Verrucaria alba.
(f. 4. Sphæria pomiformis.)
(f. 5. Sphæria Laburni).
f. 6. Pyrenothea stictica.
f. 7. "Parmeliæ calcareæ var." Schaerer.

an potius e grege Verr. rupestris?

f. 8. Sagedia fuscella.

f. 9. Verrucaria nitida. $b$.

T. 59. f. 3. Opegrapha stenocarpa.

Ord. 38. T. 39. f. 6. Sphærophoron coralloides.
(n. 2 .
Lichina confinis.)

Lichenoides. T. 6. f. 1. Pertusaria communis. a.

2. - $\quad$ d.

Hoc \& sequente Dilleniano indice Patrum studium tironibus admodum me sublevasse spero; præter multa Micheliana synonyma reliqua Patrum Dillenius rara diligentia collegit. Sistant simul imaginem primæ Lichenum dispositionis tentaminis. Quoad thallum vidimus Auctorem, remoto tantum Sphcrophoro, (quod primum tamen tabulis ære jam incisis ex ordine V. exclusit), primo proponere species thallo primitus verticali aut pendulo (Ord. 1-5), dein thallo primario horizontali, secundario verticali (Ord. 5-10), demumque thallo mere horizontali (adscendenteve). Sed etiam, ut superius divisionis fundamentum, apothecia respexit. Ordines $1-30$ sunt Stereocarpi, qui inter se distinguuntur diversa prorumpendi ratione leprce s. gonidiorum, quæ Michelio semina (licet ascos etiam sporidia, Dillenio scandalon,) vidisset); hæc est ratio, cur Umbilicaria pustulata \& Parmelia glomerulifera comparentur e. s. p. Ordines $31-$ 34 sunt quoque Gymnocarpi sed urceolati; 35-38 Cenocarpi, quare 35 (Bceomyces) juxta Angiocarpos collocatur. Memorabile unicam tantum pictam esse Ope-. grapham \& unam Umbilicariam; nec inter Lichenes nec inter Fungos ne unicum quidem indicari Calicium. 


\section{INDEX DILLENIANUS}

secundum ordinem specierum in

\section{Historia Muscorum.}

USNEA. p. 36.

N:o 1. T, XI. Usnea barbata, c.

2. - Evernia ochroleuca c.

4. - Usnea barbata d. articulata.

N:o 5. T. XII. Evernia divaricata.

6. - Usnea barbata. d.

7. - Evernia jubata. c.

N:o 8. T. XIII. - jubata. a. in b. abiens.

9. - (Ephebe pubescens - Planta Byssacea)

10. - Evernia jubata. b.

11. - (Thamnomycetis spec.)

12. - Usnea barbata. b.

13. - - barbata. a.

14. - (Ex Auctore eadem ac t. 84. f. 10. Alector. Arabum. Ach. exotica)

15. - (Evernia lacunosa? exotica)

16. - - flavicans.

17. - Parmelia chrysophthalma.

CORALLOIDES. p. 75 . * Fungiformes.

N:o 1. T. XIV. Bæomyces roseus.

2. - Biatora Byssoides. a.

3. - A. Calicium trachelinum

B. - chrysocephalum.

4. - Biatora Byssoides. b.?

5. - (Onygena equina. Fungus)

** SCYPHIFORMES. a. Scyphis perfectis.

6. - A-C., A-M. Cladonia pyxidata. D-H. Cladonia gracilis. a.

\%. - Gladonia cornucopioides.

8. - - fimbriata. a.

9. - A. - pyxidata - B. gracilis.

10. - $\quad$ - macilenta.

11. - - pyxidata pygmæa

12. - - alcicornis. Cfr. p. 214. \&c.

13. - - gracilis. c.

N:o 14. T. XV. A-C. - cornuta. (D-E vermicularis).

F. - decorticata. 
N:o 15. T. XV. Cladonia cornuta. Cfro obs. p. 224.

16. - fimbriat. e.

1\% - A. macilentam b; B. C. Cl. carneolam referunt.

18. - A. deformis. B. \&

19. - A.B. digitatæ monstra.

C. Flörkeana.

20. - degenerans.

*** FRUTIGULOSI. a. Fistulosi.

N:o 21. T. XVI. Cladonia uncialis. a.

22. - - uncialis. b.

23. - (- verticillaris Raddi exotica).

24. - (- aggregata? - exotica).

25,26. - Cladonia furcata. c. \&c.

27. - - furcata \&c.

28. - - Papillaria.

29. - - rhangiferina. a. \&c.

30. - - rhangiferina. b.

- C.D. - furcata pungens.

b. Solidi.

N:o 31. T. XVII. Cetraria aculeata.

32. - (Racodium rupestre. Bvssacea).

33. - Stereocaulon denudatum.

34. - Sphærophoron compressum.

35. — - — coralloides.

36. _ - Siphula ceratites.

37. - Cetraria tristis.

38. - Ramalina scopulorum.

39. - Roccella tinctoria.

\section{LICHENOIDES. p. 124.}

I. CRUSTACEA. a. tuberculosa.

N:o 1. T. XVIII. Graphis scripta.

2. - (Hysterium rugosum. Fungus).

3. - Lecidea parasema.

4. - Biatora vernalis. (Coniocarp. cinnabarinum simul adest in Herb. Turn.)

5. - Lecidea geographica.

6. - (Tubercularia vulgaris. Fungus).

7. - (Spæria fusca, etiam S. bullata).

8. - Parmelia glaucoma isidioidea, commixta cum Lecidea contigua. 


\section{b. Scutellata.}

N:o 9. T. XVIII. Pertusaria communis.

10. - Parmelia pallescens.

11. - Variolariæ variæ.

12. - Parmelia sordida.

13. - - tartarea.

14. - - ventosa.

15. - A. - atra.

16. - - subfusca (specimina "sine limbo:" P. ferruginea ; "e muro" Lecidea albo-atra. ex Turn.)

17. - A. Lecidea canescens.

B. Parmelia circinata.

18.

\section{FOLIOSA.}

a. Gelatinosa (19-38. Collema).

b. Exsucca, scutellata; * scutellis pedicellatis.

N:o 39. T. XX. Parmelia perlata.

42.

43.

44.

45.

46.

47.

49 .

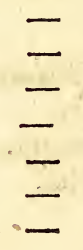
perforata.

hottentotta exotica). - perforata.

- ciliaris, at non bene.

- stellaris. b.

- obscura. b.

- phrsodes.

** scutellis sessilibus.

50. T. XXI. Parmel. Leucomela.

51. - Evernia intricata.

52. - - - fnrfuracea.

53. - - villosa.

54. - - prunastri. b.

55. - A. - prunastri. a. (peregrina admixta)

56. - A. Cetraria nivalis.

B. - cucullata.

5\%. - Ramalina pollinaria.

58. T. XXII. Cetraria glauca. a.

59. - Ramalina calicaris a. fraxinea.

60,61 - Roccella fuciformis.

62. T. XXIII.' Ramaliua calicaris. c. (in herbario quoque adsunt analogi status $R$. scopulorum).

63. - Eadem sterilis, sorediifcra. 
N:o 67. T. XXIII. Cetraria aculeata. b.

68. T. XXIV. Parmelia elegans, minor.

69. - - aquila. a.

70. - - c csia. a.

71. - - pulverulenta.

72 - - - obscura.

73. - - plumbea cum P. rubiginosa.

74. - - crassa.

75. - - conspersa.

76. - - parietina.

77,78. - - olivacea.

79. - - acetabulum.

80. - - $\quad$ saxatilis. $\beta$.

81. - - Fahlunensis. b.

82. - - Cetrariæ glaucæ monstrum.

83. - Parmelia saxatilis.

84-95. - Non pictæ, ex indice Micheliano cognoscentur.

N:o 96. T. XXV. Cetraria glauca. b.

97. - Parmelia caperata.

98. - Sticta herbacea.

N:o 99. T. XXVI. - glomerulifera.

100. - A. - fuliginosa.

c. Peltata.

B. - limbata.

N:o 101. T. XXVII. - silvatica. 102. - Peltigera canina,

103. - - rufescens.

N:o 104. T. XXVIII. - horizontalis.

105. - - $\quad$ - $\begin{aligned} & \text { resupinata. } \\ & \text { aphthosa. }\end{aligned}$

107,108. - - polydactyla.

109. - - venosa.

110. - "Endocarp. viride Ach." seu foliola

Cladoniæ.

111,112. - Cetraria islandica.

N:o 113. T. XXIX. Sticta pulmonacea.

114.

- scrobiculata,

115.

(- damæcornis exotica).

116.

N:o 117. T. XXX."

Umbilicaria ćylindrica.

118.

- vellea. $\gamma$.

119.

- erosa.

120.

Peltigera crocea.

proboscidea. c. 
N:o 121. T. XXX. Peltigera saccata.

122. - (sine icone) Umbilicaria vellea.

123-126. - Nomina Micheliana.

d. Fructificatione ignota.

N:o 12\%. T. XXX. Endocarpon miniatum.

128. - - fluviatile.

129. - Umbilicaria polyphylla.

130. - - - polyrhizos.

131. - - pustulata.

132-134. - Species Michelii, quas vide supra.

135. - Endocarpon pusillum.

APPENDIX. p. 544.

N:o 1. T. 82. Cladonia furcata. b.

2. - Parmelia triptophylla..

3. - - perforata.

4. - (Evernia ryssolen; exotica.)

5. - Umbilicaria vellea.

(6-9 Musci.)

N:o 10. T. 84. (Ramalina Tsneoides. exotica).

11. - (Parmelia hottentotta exotica).

12. - Sticta aurata.

N:o 13. T. 85. Evernia (I. Cetraria) furcellata (etiam nostra speeimina sterilia sunt ut genus dubium). 


\section{NOMINA SPECIERUM.}

Obs. Quare generica neglexerim in præfamine indicavi Quærendæ v. c. Lecid. ubietina \& Lemboria abietina Ach. sub Lichene abietino Ejusd., Squamaria, Lobaria, Pleyscia, Cetraria, Usnea juniperina, omnes sub L. juniperino Linn. Singulum nomen genericum repetendo hic index quadruplo \& ultra amplior factus esset, magis vere in confusionem, quam emolumentum. Nomina cursiva sunt nunc recepta.

Pag.

Abietinum, Cal. P. (C. curt.) $38_{7}$ Abietinus A. (Pyrenoth. leuc.) 450 - Ehrh. (Lcd. dolosa) 338 Pers. (Cld. Botr.) 235 Abietis, Strigula Fr. . . 457 Acetabulum Neck. Parm. - 65 Acharii Vstr. (P. ciner.) • 146 Acicularis A. (Cnc. furf.) : $33_{2}$ Engl. B. (Cal.phacoc) 395 Actinostoma, Verruc. Pers. . 435 Aculeatus, Ehrh. Cetr. . . 35 Adglutinat. Fl. (Prm. obsc.) Adspersum Pers. (Cal. rosc.) Aduncus A. (Cld. unc.) Adustus Dec. (Prm. sax.) . AEneu, Parmel. Df. . . 108 - Pers. (Opegr. utra.). - Schær. (Umbil.) . 353 Eneofusca Fl. (Biat. vern.) 262 Eruginos. Borr. (Calic.) 389, 392 Scop. (Biat.icmad.) 259 Ethalea A. (Prm. cin.) . 145 Æthiobola Wb. (Verr. umb.) $44 \mathrm{I}$ Affinis Dicks. (Prm. rubig.) 88 Afzelian. A. (Prm. circ.) ! 124 Agardhiana A. (Ead.) : 124 Agaricif. WIf. (Cld.) • 218 Agelæus A. (Purm.). . 184 Aggregata A., Saged. . . 416 Aglaea, Lecid. Smf. . . • 322 Aipolius Ehrh. (P. stell.) • 62 Aipospila, Parm. Whb. . . 109 Aitema A. (Prm. var.) . 156 Alabastrina Ach. 139, 156, 58 - rosella, B. 260,460 Hoffm. (Prm. pal.) 132 Alba Fl. Lecid. s. Lepr. . 33r Alba, Verrucur. Schr. • . 444 Albatum A. (End. pus.) : 412 Albescens Hoffm. (P'arm.) 11,104 Albellus Pers. (-subf.) 139 Albidocæsius Schr. (-sord.) 178 Albinea A. (Prm, casia) : 84
Pag.

Alboatrum Fl. , Calic. . . 398 Alboater Hoffm., Lecid. - 336 Albococrulescens, Wulf. Lcd. 295 Var. $(297,298)$ Alboflava Fl. Lepr. . . 279 Alboflavescens Wif. (P. pallcsc.) . . . . 132 Alboincarnat. Wif. (Biat. ros.) 260 Albozonaria Dec. (Lcd.paras.) 33o Alcicornis A., Cladon. 213, 212 Alzurites A., Purmel. • . 62 Allochrous Ehrh. (Prm. puiv.) 79 Allotropa, Cen. A. 219, 229, 23 r Alpestris A. (P. subf.) 138, 124 Alpestris Lecid. Fr. . . 306 Alpestris 'Sflt. (Prm. marit.) 108 Alpina Schær. (Lcd. biform.) 324 Alpina Sflt. (Prm. cin.) - 144 Alphoplaca Whlb. (P. mel.) 122 Amara A. Var. . . 420 Amaurocræa Fl. (Cl. grac.) 219 Ambigua A. (Lcd. atroalb.) 304 - b. A. (B. rivul.) 272 Ambiguus WIf., Parnel. $7 \mathrm{I}$ Ambiguus Ehrh. (P. stell.) 82 - Vill. (Clad. alcic.) 214 Ammiospilus Whlb. (P. ferr.) 172 Amniocola A., Parmel. . . 96 Amphibia, Lecid. . . . 307 Amphibia Clem. (Verr. maur.) 442 Amphibius With. (End. min.) 408 Amphibolius A. (Pyr. leuc.) 450 Ampliss. scop. (Stict. glom.) 54 Ampullac. Wulf. (Cetr. gl.) $\mathbf{3 9}$ Amylaceus A. (Lcd.) 297, 299 - Ehrh. (L. alboatr.) 336 Analeptus A. (Verr. epid.) 447 Anceps Rutst. (Biat. vern.) 260 Androgynus Hoffm. (P. tart.) 133 Angulosus Schr. (P. subfusc.) 139 Angustatus Hoffm. (P. pulv.) 79 Anomala A., Biatora . 269 - Ejusd. $₫ 38,156,158,176$ 
Anomæus A. (Cld. deg.) Pag. Antarcticus Jacqu. (Plt. arct.) 42 Anthelinus A. (Prm. stell.), 82 Anthracina A. Lecid. - 277 Anthracinus WIf. (Umb. atr.) $35 \mathrm{I}$ Antiquitatis L. Byssus - 121 - Fl. (Verruc. nigr.) 438 Aphthosus L. Peltigera. . 44 A pochroa A. (Prm. var.) . ${ }_{156}$ Apophysis Df. (Cl. dig.) . 240 Aquaticus L? Web. (End. fluv.) . . . . . 409 Aquilus Ach. Parm. . . $7^{8}$ Aractina Fr. (Prm. ferr.) . 173 - WhIb. (Verr. maur.) 442 Arctica A. (Umb. prob.) - 355 Arctica Smflt. Lecid. - - 342 Arcticus L. Peltigera . . 42 Arenaria Fr. Evernia . 23 Arenarius P. (Prm eryth.) 120 Retz. (Evern. prun.) 26 Areolata, Lecid. Schær. . 333 Pyrenul. Ach. : 414 Argenus, Ach. : $136,139,184$ Argillacea, Verrucar. Fr. - 434 Argillaceus, Bell. Lecid. . 346 Argillicola Duby (Opegr. par.) 365 Argopholis, Whlb. (P.frust.) $14 \mathrm{I}$ Armatus, Hoffm. (P. chrys.) 75 Armeniacus, Ram. Lecid. 320 Aromaticus, E. B. (Lcd.) 288,340 Arthonioides A. Trachyl. . 409 Artyta A. (Lcd. sabul.) . . 341 Aspergillus A. • . 144, 299 Asserculorum A. . . 332 Asteriscus, Ram. (Lcd. inf.) 3 เo Astroidea Clem. Parmel. Astroideus, Ach. (Op. atra) 367 - Fl. Dan. (Lcd. atroalb.) . . . . 310 Ater. Huds., Parmelia . . 142 Athrocarpus A. (Lcd. fusa.) 310 Atlantic. Ach. (Ev. intric.) 27 Atomaria DC. Verr. . 447 Atomarium Cal. Fr. n. 344. 3. 399 Atra, Opegrapha, Pers. - 366 Atrata A. (Verr. maur.) : 442
Atratus E. B. (Lod.) Atro-albus L. Lecid. . : 3 го - brunneuis Ram. Lecid. 319

- cinéreus Dick. Parm. . $15 \mathrm{I}$

- flavus E. B. (imperf.). 173

- ochrpus (Prm. subfusc.) 140
Atro-pruinos, Umbil. Schær . - rufus Dicks. Biatora . 255 - sanguin. Hoffm. • . 296 - sulphureus Whlb. Parm. 160 - virens L. . . 327, 277 - virens WIf. (P. varia) 158 Aurantiacus A. Parmelia . 165 Aurr. Auct. 162, 168 Aurantius P. . . . . 118 Auratus Sm. Sticta . - 50 - Vill. (Ev. vulp.) 23 Auratum Spiloma, Engl. B. 375 Aureola A. (Parm. par.) - 73 Aurea I'armel. Schær. . . 18 Axillaris Duf. Cl. brach. 229 Badia Lecidoa Fr. - . 289 - outra Lecid. Fl. . 315 Badius Pers. Parmel. 147, (127) Bacillaris A. (Cl. macil.) $24 \mathrm{r}$ Bæomyces Ehrh. (B. ros.) · 246 Balanina Fr., Parmel. . . 107 - Whlb. (P. aquil.) 78,79 Baliolus A. (Cal. hyp.) - 390 Baldensis Spr. (Biat. test.) 25 r Basaltigena, Lec. Fl. - - 300 Burbatus L. Usnea . . 8 Bellidiflorus A. Clad. : ${ }_{23} 3$ Betulignus A. (Op. script.) 370 Betulina, Op. Dec. (Ead.) $37 x$ Bicolor. Ehrh. (Evern. jub.) 20 Biformis Dec. Lecidea . . 324 - Fl. (Prm. imp.) - 324 Biformis, Verrucar. Turn. \& B. 446 Biuncialis Hoffm. (Cli unc.) 244 Blyttii, Parmelia Fr. . . 102 Bokii Rodig, Parm. . . 150 Borreri, Parmel, Turn. . . 60 Botryoides L. . . XX Botryosa Fr. (Biat. ulig.) . 275 Botrytis Hag., Cladon. - 234 Brachiatu, Cladon. Fr. . 228 Bracteatus A. (Prm. fulg.) 119 Brachypus A. (Con. furf.) $\quad 382$ Brevipes DC. (Cal. vir.) . 386 Brunneolum, Calic. Fr. - $\quad 393$ Brunneri, Lecid. . . . 333 Brunneus Sw., Parmel. . . $9^{3}$ - Engl. Bot. \&c. - $9^{\mathrm{r}}$ Bryophilus Ehrh. (P. scrup.) 192 Bryonthus A. (P. subfusc.) 137 Bullata DC. (Op. atra) : 367 Byssacea W. (Pyr. st.) 452, (184) 


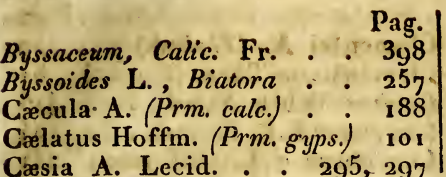
A. Lepr. - . 17r, 302 $\begin{array}{rr}\text { Dec. Op. (Lecn. lync.) } & 375 \\ \text { Cæsiella Spreng. (Parmel.) } & 88\end{array}$ Casio-alba, Purmel. Prev. $\quad 189$ - atra Schær. (Ld. arct.) 342 - rufa Schrad. (Prm. eryth.) 120 - pruinosa Schær. . 298 Casius Dicks. (L. atroalb.) 3 I Casius Hoffm. Parmelia 83 Cæspiticius Pers. (Clad.) 218 Cæspitosus Lam. (Cld. squam.) 23 I DG. (Spharoph.) • 405 Vill. (Prm. crass.) 100 Calamistrat. A. (Ev. prun.) 26 Calcarea A. (Opegr.) — 366 Calcareus A. Pr. (Verr. mur.) 436 - Lam. (P. Lagasc.) 102 Calcareus Linn. Parmel. 187 Weiss (Lch. contig.) 302 Calciseda Dec. (Verr. rup.) 436 Calcivorus Ehrh. (Lcd. alboc.) 296 Calicaris L. Ramal. . 3o, (32) Callosyne A. (Prm. hcem.) $\mathbf{1 5 4}$ Callopisma A. (Prm. mur.) 116 Calvus. Dicks. (P. aurunt.) $\mathbf{1 6 5}$ Campestris, Biatora Fr. . . 266 Camtschadalis A. (Ev. furf.) 26 Candelabrum Bor. (Cld.) ? 215 Candelaris L. Byssus ? . 164 Candelarius Auct. $73,115,164$ Candelarius L. (Prm. vitell.) 163 Candicans Dicks., Parmel. - 123 Candidissima, Sag. A. 302, 19x Candidus Web., Lecid. 285, (287) Canescens Dicks. Lec. - 284 Caninus L., Peltig. - . 45, (46) Cantharellus A. (Con. pall.) 383 Caperatus L., Parmel. Capitatus Schreb. (Con. furf.) 382 Capitellatus Ach. (Eadem) $\mathbf{3 8 2}$ Hoffm. (Lcd. sub.) 342 Carbonarius WIf. ( $\boldsymbol{V}$, nigr. $) 438$ Carcata A. (Cld. macil.) - 2 fr Caricæ Cl. (Prm. astr.) - 8I Cariosus A. (Cld, degen.) 221, (2 10) Carnea, Patell. Dec. . . 269 Curneola Ach. Biatora . 264 varr. . . $134, \times 38$
Pag.

Carneola Cladon. Fr. . . 233 Carneo-lutea, Parmel. Turn 136 - pallida Smflt. (Cld.) 264 Carneus Fl. (Biat. byss.) $\quad 258$ Carnosus Dicks. (P. musc.) 96 Carpinea, Verrucar. P. . 448 Carpineus L.: (Pert. comm.) $42 \pi$ Carphina A. (Led. atroalb.) 313 Carphina, Parmel. Fr. . . 110 Cartilagineus A. Parmel. 112 Lightf. (P. crass.) 100 Castaneola Lec. Ach. 128, 25 r Castanoola, Parm. Df. - 152 Castaneus Leers (Cetr. ac.) 35 Ram. Dec. (P. cervi) 12 ? Catalepta, Pyren. A. $\quad 4: 46$ Caucasica A. (P. ferr.) : -173 Cechumenus A. (Lcd. fusc.) $3 \times 6$ var. - (319) Cembrinum A. (Cal. tymp.) -40I Cenisea A. Parmelia ... 180 Cenoteus A. (Cld. brach.) 228 Centrifugus L. Parmel. • $7 \mathbf{~}$ varr. Auct. (Prm. consp.) . . . (.) go Ceranoides, Dec. (Cld unc.) 244 - Hoffm. (Cl.furc.) 229 Cerasi.P. (Opegr. script.) 37 I - Schrad. (Verr. epid.) 447 Ceratina A. (Usn. barb.) . 19 Ceratites Whlb. Siphula -406 Ceratonio A. Dirina . 194 Ceratophylla Wallr. (P.phys.) 64 Cerebrinus Ram. Opegr. . 363 Cereolus A. (Stereoc. cond.) 203 Cerinus. Hedw. Parmel. . $\quad 38$ Gervicornis A. (Cld. grac.) 219 Cerviculatum A. (Cal. curt.) 387 Cervinus I. Parmelia : 127 Cetrata A. (Parm. perf.) 58 Ceuthocarpa, Pertus. Borr. .. 423 - Verr: Wahl. - 442 Chalybira, Parmel. Fr. ‥ 125 Chalybæif. L. (Ev. jubat.) . $2 \mathbf{2}$ Fl. Dan. (E. div.) 22 Chaubardii, Parmel. Fr. . $16 \mathbf{6}$ Chauviniana DF. (P. musc.) 96 Chionæa A. (P. ciner.) : 144 Chloantha A. (P. obsc.) : $\$ 5$ Chlorellum Whl. (C. phreoc.) 394 Chlorina P. (Opegr, var.) \& 366 Chloroleucus E.B. ( $P$, cerin.) 169 - phæa Fl. (C. pyx.). 216 
Chlorophana, Parm. Whlb. - phylla (Cetr. sapinc.) Chlorótica A. (Verr. marg.) Df. (Cld. furc.)

Chondrotypa A. (P. var.) Chrysocephalus, Calic. Turn. Chrysoleucus Sm. Parmel. Chrysophthalmus L. Parmel. Ciliuris L. Parmel. . . . Ciliatus Hoffm. (P. obsc.) Cinerascens With. (P. calc.) Cinerea, Lecid. Schær. Cinerea, Sagedia Fr. . • Cincrea Verruc. Pers. (punct.) 447 Cinereoatra Ach. (Lcd. lapic.) 306 - - Hoffm. (Led. atr.) 311 - fusea W.(P.ferr.) . 170 - rufa, Schær. . . 289 - rufesceus, A. \&

- rufusWhlb. (Prm. cin.) 145 - sulphurea, Lepr. . . 155 Cinereo-virens, Lectd. Scharer. 286 Cinereum, Calic. P . 389 - Endoc. P. . 413 Cinereus L. Parmel. . . 142 - Smith. (Prm. calc.) 188 - Wulf. Prm. atr.) 142 Cineritia A. (Prm. astr.) $8 \mathrm{I}$ Cinnabarina A. Parmel. . • 165 Sflt. Biator. $\quad 266$ Cinnabarinum Dec. Conioc. 379 Cinnabarinus Bell. (Prm. el.) 814 Circinatus Pers. Parmel. $\quad 1_{2} 3$ Circumscriptus P. $(O p$. scr.) 371 Cirrhosa Hoffm. Umbil. 358 Cirrochroa A. (Prm. mur.) 115 Citrella P. (-pariet.) • - 115 Citrinellus A. Lecid. . . . 346 - E. Bot. (L. flavor.) Citrina, Leprar. Schær. : Citrinus A. $\beta$. (Parm. par.) :- Hoffm. (muror.) $\mathbf{1 5}$ - Ehrh. (Prm. fuly.) 115 - Pers. (Cal. tig.) 400 - Schrank (Ev. vulp.) 23 - Whlb. (Biat. luc.) 279 Cladonia, Biatora Fr. . . 256 Clausus Hoffm. (Gyal. exunth.) 198 Clavarioid. Df. (Cld. corn.) 225 Clavellus Ach. (Dcc. p. 39o) \& Clavieulare A. (Calicia) 387,388

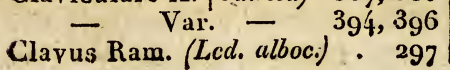

Clementei A. (Theleph.) Pag. Clementiana Turn. ( $P$. astr.) $8 \mathrm{z}$ Clopima Whlb. Saged. . 415 Coarctatus E.B. Parmel. . : 104 Cocciferus $\alpha$ L. (Cld. mac.) 241 - $\beta$ L. \& Auct. (Cld. cornuc.) $\beta .236$ Coccinea Clad. Hoffm. \& - I. Wallr. Pat. : 236 - II. - - 232 Coccinea Schultz (Cnc. cinn.) 379 Coccineus Pers. (P. hamat.) 154 Coccocephala (Cld. bellid.) - 237 Coccodes A. (Pert. comm.) - $42 \mathrm{Z}$ Conosum, Coll. A. (Biat. ul.) 275 Coerulea Dec. (Verr. plumb.) 438 - nigricans, Lightf. (Lcd. ves.) • • . . 287 Coerulescens DC. (Prm. rub.) 88 - Hag. (Prm. inc.) 176 - Huds. (P. plumb.) 87 - Pers. (mixta) 120,142 Collematif. Schl. (Prm, ol.). 66 Collicalos. Hoffm. (Pyr. verm.) 45 r Collinus A. (Pelt. polyd.) • 47 Colobina A. (Prm. soph.) : 149 Communis, Pertusar. Dec. - 420 - Variol. A. (Ead.) 420 Commutata A. (Biat. unom.) 269 Comosus A. (Usn. barb.) 18 Complicatus Sw. (End. min.) 408 Composita, Pyrenul. A. - 418 Compositus With. (Prm. sord.) 178 Compressus A. Spharoph. - 404 Compunctus Schl (P. calc.) 188 Concentrica DC. (Verr. mur.) 436 cus Dav. (Lcd. atr.) 3 r 3 Concolor Dicks. (Prm. par.) $7^{3}$ Conchylioides DC. (P. coarct.) 103 Condensatum, Stereoc. Hoffm. 203 Condyloides A. (Idem) . $\quad 203$ Conferta, Parmel. Dub. . . 155 Confervoides DC. (Lcd. atr.) $31 \mathrm{r}$ Confluens Web. Lecid. . . 318 - Varior.: 299, 318 - B. A. (Led. sab.) $34 \mathrm{r}$ Confragosus A. (Prm. atr.) 142 Conglobata A. (Prm. tart.) 133 Conglomerata, Lecid. A. - - 287 $\begin{array}{ccc}\text { Hoffm. (Bi. vern.) } & 26 \mathrm{r} \\ -\quad \text { Pers. (Fung.) } & 374 \\ \text { Coniocræa Fl. (Clad. cornut.) } & 325 \\ & 226\end{array}$ 
Pag.

Coniops A. (Lcd. sabul.) 340, 341 Conoidea, Verrucur. Fr. . 432 Conopleus Pers. (Prm. rub.) 88 Conspersus Ehrh. Parmel. . 69 Conspurcatus E. B. (Led. cont.) 337 Contigua, Lecidea Fr. • $29^{8}$ 305,318

Varior. 272, 299, 3 o3 Contortus Hoffm. (Prm. calc.) 188 Contortuplicata A. (Prm. chrysoph.) . . . . . $7^{5}$

Convolutus Lam. ( $\mathrm{Cl}$. endiv.) 219 Cooperta A. "(Prm. atrocin.) ${ }_{152}$ Coracinus Schacr, Auct. var. 293, 3 เo, 320

Corallinum, Stereoc. Schreb. 201 Corallinus L. . . 178, 422 Corullinsidec Hoffm. (Prm. trip(oph.). . . . . $9^{2}$ Coralloidea A. (Cld. pyx.) 217 Coralloides, Spheroph. 4405 Wallr. (Usn. barb.) 18 Corneus Diks. \&c. XIV, ${ }_{2} 64$ With. (Biat. mixt.) • 267 Corniculatus Lightf. (Cetr.tr.) 35 - Relh. (Ev. prun.) 26 Cornucopioides L. Cladon. - 236 - Varior. Hoffm. 214 Cornutus L Cladon. . . 225 varior. - 223, $24024 \mathrm{I}$ Coronata A. (Pert. Wulf.) 425 Coronatus A. Hoffm. (Prm. tript.).

Corrosus Ehrh. (Ümb. er.) 354 Corrugutus A. Cliostom. . . 455 Schr. (Umb. prob.) 355 Smith. (Prm. acet.) 65 Corticalis Relh. (Biat. vern.) 26o Corticola A. (Lcd. alboatr.) 336 Corylinum Schum. (Cal.trach.) 390 Corynellum A., Calic. . . . 398 Cotarius A. (Prm. coarct.) 105 Craspedius A. (Prm. erythr.) 120 Crassa Op. DC. (Saged. aggrr.) $4 \div 6$ Crassus Huds., Parmel. . 100 - Fl. Dan. (P. chrysol.) 113 - formis Hoffm. (P. cr.) 100 Crenata DC. (Lcd. cont.) 298 Crenularius With. (P. ferr.) 170 Crenulata Fl. (Cld. def.) - 239 Crenulatus Dicks.(Prm. sax.) 110 Cretacea A. Gyal.(Prm. scrup.) 192

Pag. Cretaccus Ehrh. (Lcd. cont.) 302 Cribrellum Relh. (Umb, er.) 354 Crinalis A. (Ram. calic.) • 22 Schleich. (Prm. cil.) 77 Crinita A. (Prm. perfor.) - 58 Crinitus Lightf. (Umb. cyl.) 356 Crispata A. (Cld. furc.) . 229 Cristata Hoffm. (Cld. degen.) 22 I Cristatum, Coll. DC. (P. aqu.) $7^{5}$ Crocatus E.B. Sticta - . 50 Crocea, Cornic. A. (E. flav.) 28 Croceus L. Peltigera . • 48 Crossophylla Whlb. (P. aqu.) 78 Cruentus.Web. (Prm. vent.) 153 Crustulata A. (Lcd. nitid.) 308 Crustulosa A. (Umb. vell.) . 357 Cucullatus Bell. Cetrar. - . 37 Culminalis Lapyl. (Prm. par.) 73 Cumatilis Rutstr. (Stict. glom.) 54 Cumulata Sflt. (Lcd. sab.) - 340 Cuprea Sflt., Biator. . • 265 Cupularis Hedw., Gyalecta , $19^{5}$ Curtum, Calic. Turn. - - 387 Curvula Ehrh. (Op. var.) : 364 Cyanea Dub. (Lcd. spilot.) . 298 - scens Hoffm. (Lcd. ent.) $33 \mathrm{z}$ Cyanolepra Desm. (P. cerin.) 168 Cyathellum A. (Cul. pharoc.) 394 Cyathoides A. (Biat. rivul.) 273 Cycloselis A. (Prm. obsc.) - 84 Cyrtaspis A. (Prm. cin.) : 146 Cyrtellus A. (Prm. sulffusc.) 138 Cylindricus L. Umbil. . . 356 Cymbiformis Fl. (Op, var.) 365

Dactylinus A. (Baom. ros.) 246 Dactyliferus Whlb. $\left(P\right.$. ocul.) $\iota_{35}$ Dactylophyllum Fl. (Stereoc. corall.) . . . . $20 \mathrm{I}$ Dædaleus E. B. (Biut.?) : $6 \mathrm{t}$ Damæcornis' (Cld. alcic.) . 213 Daphœena $\propto$ A. (Lcd. armen.) 321 . - B A. (Led. alboccer.) 295 Sflt. (Led. spilota) 297 Davallii Sm. (Lcd. Wahlenb.) $29 \mathrm{r}$ Dealbatus A. (Prm. sord.) $\quad 178$ Debile Turn. (Cal. subtil. P.) 388 Decipiens Ehrh. Biator. . 252 Decolorans Hoffm. Biat. - 266 Decolorans Turn. Spilom. $\quad 183$ Decorticata Fl. Cladon. . . 226 Deformis L. Cladon. . . 239 
Defraudans Olafs. (P.polioph.) 147 Degenerans Fl., Cladon. , 221 Delibuta A. (Lcd. alboc.) • 296 Delicatus Ehrh. (Cld. squam.) 23 r Delisei, Pertusar. Dub. . . . 427 Stereoc. . . 459 Demissus Rutstr. (Biat. atror.) 255 Dendritica, Opegraph. A. . 372 Parmel. Pers. . 68

- Spil. A. (Pert. ost.) 402 - Var, Auct.(L.inf.) 3 ro Denigrata, Biat. Fr. . 370 Denigrata, Op. A. (Op. atr.) 367 Denudatum, Stereoc. FI. . . 204 Denudatum H. (P. crysophth.) 75 Depressa, Opegr. A. (atr.) . 367 Sag. A. (P. ciner.) 143 - Umb. Sch. (U. vell.) 357 Desertorum A. (Biat. decol.) 267 Despreauxii Del.(Prm. relic.) 459 Detrita DC. (Prm. impol.) . 183 Hoffm. (Prm. subfusc.) 137 Deustus L. (Umb. polyph.) • 352 Diacapsis A. ('Prm. scrup.) 192 Diamartus Whib. (Prm. cin.) I 43 Diaphora A. (Opegr. par.) . 365 Diaspora A. (Verruc. stat.) 446 Dialrypa A. (Prm. phys.) . 64 Dichotomus Hoffm. (Ev. ochr.) 22 Dicksonii A. (Lcd.) 305, 3 r, 3 เ 5 Difficilis Df. (Opegr. atr.) . 374 Diffractus A. (Prm. suxic.) 111 Diffusus Dicks. (Prm. aleur.) 62 - Lam. DC. (Cld. turg.) 2r5 Web. (Prm. ambis.) 71
Digitatus L. Cludon. . . 240 E. B., Fl. D. $\left(\mathrm{Cl} . \mathrm{Fl}_{\text {. }}\right) 238$ Dilatata H. (Cl. grac.) $219,(\mathbf{2 2} 8)$ Dilleniana, Cl. Fl. .. . 230 Lcd. A. (L. cont.) 298 Discoidale A. (Cal. lent.) - 387 Discoides Chev. (Lcd. alboc.) 295 Discoideus A. Variolar . 420 Discolor Dub. (Prm. subf.) $\quad 137$ Dispermus Vill. (Biat. decip.) 252 Dispersa H. (Prm. acrust.) 175 Opegr. DC. (atr.) $36_{7}$ Disseminatum, Calic. Fr. . 397 Distans P. (Prm. subfusc.) • 139 Distorta A. (Prm. phys.) . Divaricatus L. Evern. . Dipergens Whlb. Evern. Diversicolor, Parm. A. .
Dolosa, Lecld, Whlb, 337, 263 . Dryina A. . . . 378 Varior. I 84, 45 r, 453 Dubius A. \& H. (Prm. c(es.) 84 - E. B. (Lcd. milliar.) 343 - Wulf. (Prm. perlat.) 59 Dufourei, Parmel. Fr. - 99 Verruc. DC. : 432 Dufresnii (Prm. rubr.) • 134 Duplicata A. (Prm. phys.) , 64 ,

Eburneum, Endocarp. DC. 4 412 Ecmocyna A. (Cld. gruc.) • 219 Ecrustacea Df. (Verr. status) 446 Effusus P. \& Auct. . 156, 262 Ehrhartianus A. (I', var.) 159, 454 Elacista A. (Prm. coarct.) 104 Elceinus, Parmel. Wahl. 86 Var. . . 84, 85 Eloochroma A. (Lcd. enter.) 33 r Elatina A., Parmel. . . 55 Elatinus A. (Hysterium) . 154 Electrinus Ram. (Prm. chlor.) I I Elegans, Opegraph. E. B. $\quad 370$ - Purmelia A. . . 114 Elegans, Spil. A. - 379,380 Elevata DC. (Opegr. var.), 365 Ellipticus A. (V crr. epia.) . $44^{\prime} 7$ Elongatus. Jaco. (Cld. gruc.) 219 Elvelloides Web. (Biat. icm.) 259 Wulf. (Biat. decip.) 252 Encaustus Sm. (Prm. phys.) 64 Endiviafolia A. Clad. 212, (213) Endocarpea, Parmel. Fr. - 128 Enteroleuca, Lecid. A. . 33x Flot. $(L c d . s a b)-.34 \mathrm{r}$ Epanora, Parmel. A. . - $16 \mathrm{r}$ Ephehea A. (Ev. villos.) . , 27 Epibryon A. (Prm. subf.) 138, 137 Whlb. (Prm. ocul.) 135 Epiphega A. (Hyst. rugros.) Epidermidis A. Verruc. . 447 Epigrea, Verrucar. A. . 43 I Epigaus, P. Lecid. - 290, (123) Epipastus A. (Op. atr.) $\quad 367$ Epiphyllus A. (Clad. status) 217 Epipolea Lcd. A. (L. alboat.) 337 Sflt. (Lcd. contig.) 298 Verruc. A. . 433, 436 Epixantha A. (Prm. vitell.) 162 25 Epulotica A. (Prm. cin.) . 146 21 Ereuticus Whlb. (P. molybrd.) 126 ${ }_{75}$ Ericetorum L. (Báom. ros.) 246 
Ericetorum sessilis L. (Biat. icmrad.)

Erosus, Web. Umbil.

Erysibe, Biatora Fr.

. 271

A. \& Auct. , . 26r, 296

Erythrellus A. (Prm. aurant.) 166 Erythrocarpa P., Parn. rio, 121 Erythrophiea FI. , 138, 290 Escharoides Ehrh. (Biat. dcc.) 207 Engl. B. (P. micr.) 91 Euphorea Sflt. (Biat. denigr.) $27 \mathrm{I}$ Enplocus A. (End. flup.) $409,(411)$ Eutypus A. (Spheria eut.)

Faranthernatic. Sm. Gyal.

Exasperatus Gunn. (U. Excapatus Relh. (Urc. scrup.) 191 Hoffm. (Stict. rudi).

Exigua Chaub., Biator. . 27s Exiguus A. (Prm. sophori.) 149,176 Exilis Hoffm. (Cld. pyxid.) 217 - Mich. (Prm. chingsophthi.) 75 Expallens A. 1. (P. s'ur. $) \quad 156,157$ Explicata Chaub. (Prm. cand.) 123 Extensa Hoffm. (Cld. cornuc.) 236

Fagineum Schum. (Cul. trach.) 390 Fagincus L. (Pert. conm.) • 422 Fahlunensis L. Parmel. . . 66 Fallax A. (Pert. Wilf.) : 424 - P. (Conioc. einub.) * 379 - Web. (Cetr. glauc.) 38 Falsaria A. (Biat. rivul.) . $27 \mathbf{1}$ Farinacea Chev. (Cneb. pall.) 383 Farinaceus L. (Ram. calic.) $3 \mathbf{r}$ Farinosa, Lecid. Stenh. . - 3/45 Farinosus Hoffm. (Varia) 79, i 33 Farrea A. (Verr. alb.) 444, $(376)$ - Turn. (Prm. pulver.)

Fasciculata H. (Led.fuscoatr.) 317 Fastigiatus P. (Ram. cal.) - 3o Femsjonensis, Parm. Fr. $\quad 9^{8}$ Ferrugineum, Cal. E. B. 386,392 Ferrugineus Huds. Parmel. . 1 70 Ferruginosus Turn. (B. mixt.) 267 Fertilis, Evernia Fr. . . . 24 Tibrosus E. B. (Prm. cin.) - $19 \mathrm{r}$ Fibula H.; A. (Cld. fintb.) $: 223$ Filaris A. (Usn. barb.). ${ }_{1} 8$ Filiformis Relh. (Cld. macil.) 241 Fimbriata A. (Prm, cin.) . 143 Schær. (Prm. orein.) I 3 Fimbriatus L. Cludon. Flabellum Df. Clad.
Flaccidus Hoffm. (Ev. divar.) 2.5 Flava Hoffm. (Prm. par.) $74,(164)$ Flavescens Huds. Sw. (P.mur.) i 5 Wulf. (P. venlos.) 153

Flavicans Sw, Evern. . . . 28 Flavicunda A. (Lcd. cont.) . 298 Flavocœrulcsc. FD. . 295,298 - fusca Schrad. (P. aur.) 167 - rubescens With. (Ead.) IG6 Fluvosirescens Dicks. Lecid. 29x - $\quad$ E. B. (Lcd.cilr.) 346 Wulf. (P. aur.) 166 Flavus Bell. (Prm. chloroph.) in - Schreb. Lepraria . 164 Flexipes A. (Cul. brunneol.) $3 \Omega 3$ Flexuosi, Biatora Fr. . 268 Flexuosa Fr. (Lcd. unargia.) 322 Flocculosus DC. (Umb, atr.) $25 \mathrm{x}$ Wulf.'(U.polyp $\left.h_{\text {. }}\right) 252$ Florkieana, Clad. Fr. . . 238 Lepr. A. (Biat.luc.) 279

Floridus L. (Usn. barb.) , 18 Flotowiana FI. (Pert. comm.) $42 \mathrm{I}$ Fluviatilis Web. Endoc. . . 409 Foliaceus Huds. (Ctd. alc.) 213, 212 Foliolosa Df. (Cld. furc.) * a3̃o Fovcolaris Whlb. (Gyal. cup.) 196 Fragilis L. Spharoph . . 405, 404 Scop. (Prm. gyps.) ? 101 Fraxineus L. (Ram. calic.) : 30 Friabilis Vill. (Prm. fulg.) I 19 Friesii A. (Lcd. myrm.) . 344 Frigidus Sw. (Prm. tart.). 134 Frondosus H. (Prm. hatemat.) 154 Frusiulosus Dicks. Parmel. $14 \mathrm{i}$ Fruticulosa Schær. (Cld.furc.) 229 Fuciformis L., Roccella . . 33 Fucoides Dicks. (Prior.) * 34 Wulf. (Cetr. trist.) 35 Futgons Sw. Parmel. . I I9 Fuliginea A. (Biat. ulig.) , 275 Verr. Wahl. : 4 i 6 Fuliginosa A. (Opeg. herp.) 368 Fuliginosum T. B. Spiloma 376 Fuliginosus Dicks. Sticta . 52 Fulvum Schær, (Cal. c/hrysoc.) 304 Fulvus Dicks. (Prm. eleg.) II - Neck. (Prm. par.). 73 - Schreb. (Prm. aurant.) r66 - Sw. L. (Cncb. furf.) 382 Fumosa A., Lcd. 3is, 316, 3 ז9 - Hoffm. (Lcd. fusc.) 316 y Fungicola A. (Biat, decol.) 26 
Fungiflorus Schrank.(B. byss.) 229 Fungiformis Scop.(Baom. ros.) 257 Furcatus Huds. Cladon. • . 229 Furcellata Hoffm. (Cld.brach.) 223 Furfuraceus L. Coniocyb. . 382 L. Evern. - 26, $(76)$ Fuscatum A. Spiloma 137, 38 ז Fuscatus Lam. (Prm. ferr.) 172 Schrad. (Prm. bud.) I 48 Fuscella Ljungst. (Pyren.) • 452 Fuscellus Turn. Saged. 413, (414) Fuscoater L. Lecid. . . 316 Varr. - $311,312,316$ Fuscoluteus Dicks.(Prm.ferr.) I 7 I Flörk. $\quad$ 7 1, 262, 263 Fuscorubella H. (Biat. vorn.) 275 FuscorubensWulf. (Gyal.cup.) 195 Fusca, Patellar. Wallir. 216,243 Fuscus Hoffm. (Cld. stat.) . 2 18 - Huds. Rutstr. (P. aquil.) $7^{8}$

Gaditana Clem. (Pert. comm.) 422 Gagates Lam. (Cetr.trist.) • 35 Gagei E. B. (Purm.) . . . 193 Gralactites Dec. (Verr. stat.) 446 Galactinus A. (Prm. sax.) i 1 1 , 15 Galbula Ram. (Lcd. Wahl.) 291 Gangalea A. (Prm. subf.) 138, 1 fo Gelasinatus With. (Cal. turb.) 402 Gelatinosa A. (Verr. musc.) 432 Fl. (B. vern.) - $26 \mathrm{r}$ Gelidus Huds. (Prm. vent.) 153 Gelidus L. Parmel. . . . 104 Gemmatus Ach. Verr. 444, $(378)$ Geographicus L. Lecid. - 326 Geoicus Whlb. Gyalecta . 196 Gibberosa A. (Biat. vern.) 260 Gibberulosa A. (Opegr. var.) 364 Gibbosa, Pyr. A. Sagred. . 414 Gibbosus A. (Prm. cin.) 143, 144 Gilva, Parmel. Pers. . 103 Glaber A. (Umb. polyph.) 35o, (351) Glabrata A. (Verr. alba) • 44́ Glabratus Dieks. (Prm. subf.) 139 Glacialis, Lecid. Schær. - $\mathbf{3}_{2} 3$ Schl. (Pl'g. polyd.) 47 Glauca Cld. Fl. (C. brach.) 229 Glaucella A. (P. var.) . 157 Glaucellum A. (Cal.var.) 387,390 Glaucescens Sw. (Prm. sord.) 178 Glaucinu, Verruc. A. $439,(4+3)$ Glaucocarpus Wblb. (P. cerv.) 127 Glaucoma Hoffm, (Prm. sord.) $17^{8}$
Glaucorufu Mart. (Prm. subf.) 38 Glaucuin A. (Endoc. min.) : 408 Glaucus L. Cetraria - 38, (59) Glebosa A. (Lcd.vesic.) • 287 Glebulosus E. B. Biat. - 252 Globifera A. Biator. . • 254 Globiferus L. (Sphceroph. Cor.) 405 Grobosa Clem. (Biat. vern.) 26 ' Globulare Sflt. (Prm. verr.) i 86 Globulàris Retz. (Cricb. furf.) $\mathbf{3 8 2}$ Globuliferus E. B. (Pert:com.) 422 Globulosa Fl. Lecid. • 338 Gromeratus Schl. (Prm. verr.) 423 Glomeruliferus Lightf. Sticta 54 Glomerulosa DC. (Lcd. sab.) $34 \mathrm{x}$ Gronatodes A. (Prm.' tartar.) 133 Gronorega, Cennm. A. 221, 228, 23 I Gracilenta, Conipcyb. A. : - 333 Gracilis L., Cludon. • • 229 - Usn. A. (U. barb.) 18 Granatina, Parmel. Sflt. . - $\quad \mathbf{1 5 2}$ Grandis P. (Stict. glomer.) 54 Graniformis Ehrh. (Lcd. ves.) 286 Hag. (Cliost.) • 455 Granulosus Ehrh. (Biat. dec.) 267 - Dicks. (Prm.tript.) 9r Graphica A. (Prm. ciner.) . $\$ 45$ Gregaria (Op. var. p. p.) \& 364 Gregariun E. B. (Conioc. cınn.) 319 Griffithii E. B. (Biat. mixt.) 268 Grisea Hoffin. (Prm. micr.?) 94 - Pers. (Verr. ripest.) 436 - Willd. (Lcd. vesicul.) 383 Griseoatra H. (Biat. rivul.) $37 \mathbf{x}$ Griseola A. (Cncb. furf) $\quad 383$ Griseovirens Turn. (Prt. com.) 42 r Griseus A. (Umb. vell.) • 358 Lam. (Prm. pulv.) . 79 Grœuland. F. D. (Pltog. arct.) 42 Grumosus P. (Prm. atr.) • 142 Grumulosa Df. Lecanact. : - 375 Guépini, Endocurp. Moug. - 4 10 Gymnocarpus P. (Lcd. ecrust.) 294 Gypsaceus Sm. Purmel. • 101 Gypsophilus Schr. (Bict. dec.) 252 Gyrocarpa Flot. (Op. rupest.) 364 Gyrosa A. (Op. scripta) $\quad 37 \mathrm{~s}$ Hæmatites Chaub. (Prm. cer.) 169 Hamatomma Ehih. Parmel. $\quad 154$ Hageni A. (Mixta) . . 138, 176 Halophæa A. (Prm. cerv.) . 127 Hamadryas A. (Biat. mixt.) 268 
Pag. Hamata D. (Cld.furc.) .

Hapalea A. (Op. atia)

Harrimanni A. (Verr. rup.)

Haustellare A. (Cal. subt.)

Hebraicus Ehrh. (Op. var.)

Heclæ Gunn. (Prm. gelid.) .

Hedwigii A. (Endoc. pus.) .

Halicopis Wahl. Purmel.

Helygæa A. (Prm. erythroc.) Helvetica A. (Plts. resup.)

Hepaticum A. (Endoc. pus.) Hepatizon A. (Prm. fahl.)

Herbuceus Huds. Sticta. .

Herpeticus A. Opegr. . . . 368

Heteroidea A (Umb. polyph.) 352

Heteromallus E. B. . - 21

Hiascens A. (Verr. rup.) • 436

Hippocastani DC. (V.punct.) 448

Hirsulus A. (Umb. vell.) • 358

Hirtus L. (Usn. barb.) . 18

Hispidula A. (Prm. saxat.) $\quad \mathbf{6}_{2}$

Hispidulum A. (Cal. phaoc.) 395

Hispidus Lightf. (Cetr. ac.) 36 - Scop. \&c. (I'rm.) 81, 82, 83

Hochstetteri, Verruc. Fr. .435

Hoffmanni A (Prm. calc.) $\mathbf{1 8 8}$ Df. (Cld. pyx.). 218

Hookeri E. B. Parmel. . 94

Holocarpus Ehrh. (Prm. vit.) 162

Holomelæna FI. (Led. stat.) 309

Holostea A. (Prma subfusc.) 138

Horizontalis L. Peltig. .

47

Horophthalm. A. (Prm. ocul.) \35

Humosus Ehrh. A. (Biat. ulig.) 275

Hutchinsix Turn. \& Borr. 428

Hyalina Mart. (Lcd. enterol.) $33 \mathrm{r}$

Hybrida Flot. (Op. var.) ? 365

Hydrela A. (Verr. marg.) . 440

Hydrophila Fr. (Lcd, cont..) 30 I Sflt. (Prm. frust.) $14 \mathrm{I}$

Hyloicus A. (Agyrium rufum)

Hymeninus A. (Pltg. polyd.)

Hymenius A. (Pert. Wulf.)

Hyperboreus A. Umbil. . 353

Hyperellus A. Calic. . . . 389

Hyperopta A. (Prm. amb.) $7 \mathrm{r}$

Hypnophila A. (Biat. vern.) 263 Hypnorum E. B. Purmel.

Hypn. Liljebl., A.Pr; (P. musc.) 96

- Wulf. (Prm subfusc.) 138

Hypoleuca Ach. (Prm.) ? 145

Hypopta A. (Biat. ulig.) \&. 275
Hysgina Whlb. (Prm. mol.) 126 Hysteroides Df. (Op. alr.) 374

Jacquini A. (Umb. probs) - 355 Icmudophilu Ehrh. Biator. • 258 Icmalea A. (Biat. ulig.) 275,276 Ileifarmis, Lecid. Fr. - . 334 llleccbrosa Df. Lecunact. . 3-6 Illimatus Whlb. (Prm. cin.) 144 Immersus Auct. (Verr. \& Lcd.) 296 Implexa Hoffm. (Ev. jub.) 2 I Implexus Lam. (Usn. barb.) 18 Impolitus Ehrh. Parmel. . 183 Impressus Sw. (Prm. scrup.) 191 Inalpina A. (Prm. aurunt.) $\quad 366$ Incana, Lec. - . 258, 259, 262 - \& Lepr. . . 89, 26i Incarnatus Thunb. (B. decip.) 252 Incisa, Parmel. Fr. . . 103 Inclusus E. B. (Thelotr. lep.) 428 Incolorata Fl. (Biat. decol.) 267 Incrassata Fl. (Cld. cornuc.) 237 Incrustans DC. (Prm. mur.) 115 Fr. (Pyren. leuc.) 45 z Incrustatum, Stereoc. Fl. - 203 Incurvus P. Parmel. . . 70 Incusa A. (Lcd. badioat.) : 316 Inflatus Schl. (Prm. melän.) 1 \& 2 Inquinans E. B. (Cal. tymp.) 4os Insculpta Wallr. (Op. herp.) 368 Insulatus Ram. (Prm. frust.) $14 \mathrm{r}$ Intermedius Schrad. (Lcd.) 336 Intestiniformis Bell. (P. phys.) 65 Intricutus Desf. Evern. . . 27 Schrad. (Prm. var.) 158 Inundata Fr. (Biat. vern.) $26 \mathbf{r}$ Irrubatả A. (Prm. aur.) - 168 Islandicus L. Cetrar. . - 36 Jubatus L. Evernia - 20, $2:$ Jungermanniæ Fl. Dan. : Iz: Juniperinus L. Cetr. . . 4a

Kochiana Hepp. (Biat. riv.) 272 Kœnigii (Lcd. Öder.) . . 3ix

Lachneus A. (Endoc. pus.) $4 \mathrm{it}$ Laciniatus Huds. (St. glom.) 54 Lactea Fl. (Lcd. atroulb.) - 305 Lacteus. L. (Prm pallesc \&c.) 133 - Schreb. (Lec: alb.) 33r - Vahl. (Prm. hamut.j 154 - Wulf. (Prm. sord.) 178 Lacustris With. (Prm. cin.) $14^{5}$ 
Pag.

Iærvata, Sag. A. (Prm. cin.) , 45 Verr. A. ( $V$. rup.)

Lævigata A. (Pltg. res.) .

Pers. (Verr gemmo 44

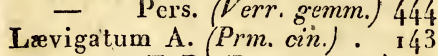

Lævigatus E. B. (Prm sinuos.) 6:s Lagasce A. Parmel. . . . 102 Lainea A. (Prm. subfusc.) . 140 Lalave Clemt. (Prm. eryth.) 121 Lamarkei DC. (Prm. Lagasc.) 102 Lamprocheila DC. (P. ferr.) 172 Lanatus L. \&c. (Prm. styg.) 68 Lanuginosus H. (Prm. pulv.) 79 Lanuginos. Schrad. Parmel. 88 Lapicida, Lecidea Fr. . • 306 A. . $294,295,297,303$ - - . 306-308,341

Laqueatus Wulf. (Prm. crass.) 100 Latebrarum A. Leprar. . 209 Lateritia Pers., Verrucar. $43 \mathrm{r}$ Latypea A. (Lcdl. nitid.) : 308 Lectissima, Segestrell. Fr. - 43o Lejocarpa DC. (Umb. atropr.) 35 ı Lejoplaca A. (Pert. comm.) $42 \mathrm{I}$ Leiphæmia A., Lepr. 154, 155 Lenticulare, Calic. A. . . 386 - Lec. A. . . 270 Lentigerus Web. Parmel. . 103 Lepadina Sfit., Parmel. . - $19^{3}$ Lepadinum A. Thelotr. . 428 Lepadolcmma Ehrh. (P. vent.) 153 Lepidora A. (Prm. Hypn.) $9^{8}$ Lepræformis Fl. (Prm. obsc.) 85 Leprosa, Urceol. P. . . 184 Schær. (Prm. scrup.) $19 \mathrm{I}$ Leptacina Sflt. (Prm. var.) 157 Leptalea A. (Prm. cces.) . 84 Leptoderma Dub. (Lcd. sab.) 34r Leptomera Sflt . . . 280 Leptophylla A. (Cld. grac.) 220 Leptophyllum A. (End. min.) 408 Leucinata A. (Prm. var.) - 158 Leucocephala Ehrh. Pyrenoth. 450 Leucococca Sfit. (Prm. var.) 158 Leucolepis Whlb. (-Hook) 94 Leucomelas L. Parmel. * 76, (80) Leucomelas P. (Cal. tymp.) 401 Leucophæus Dicks. (Microph.) 90 FI. D. (triptoph.) $9 \mathbf{1}$ Lcucopis A. (Prm. atr.) - 1/42 Leucoplaca DC. (Lcd. premn.) $329^{\prime}$ Leucorhiza Fl. (Plig. can.) 45
Leucostigma, Spil. A. . Pag. Leucostoma Bernh. (P. comm.) 421 Lichenoides L. (Cal. lent) . 387 Per's. (Opeg.var.) 36.4 Lightfoothii A. (Biat. riv.). 278 E. B. (Lod. paras. $33 \mathrm{t}$ Ligniaria A. (Lcd. mill.) 343,344 Ligny ota Whlb. (Coll. Sflt.) 4o6 Lilacina A. (Prnst. stict.). 453 Limbata Sift., Pelérg. . 49 Limbatus Sm. Sticta . . - $52_{2}$ Limitata P. (Opegr. script.) 3 go Limitatus Scop. (Lcd. pur.) 330 Limosa A. (Lcd. mill.) . . 342 Liparia A. (Prm. plures) 100, 113 Lithina A. (V Verr. mur.) ; 436 Lithophila A. (Lcd. alboc.) 295 Lithyrga, Lcd. A. (L. cont.) 302 Op. A. (Op. sax.) 366 Litterellus A. (Opegr. script.) $37 \mathrm{~F}$ Livida A. (Prm. sar.) . 158 Iobulata Fl. (Prm. par.) 43, (115) Longissima, Usn. A. . . 19 Lugubris, Lecid. Silt. - . 314 Lucidus A. Biator. . . 279 Ludwigii Schr. (Prm. frust.) $14 \mathrm{E}$ Lurida Arth. A (Conianr) 398 Luridus Fl. D. (Biat. globif.) 254 Luridus Sw. Biat. . . . ${ }_{2} 53$ Luteo-albus Turn. (Prm. cer.) 168 - Var. A. $777,162,168$ Luteolus Schrad. (B. vern.) 260 Var. A. $\quad 138,261,2,5$ Lutescens A. syn. (Prm. elat.) 155 DC. Flörk. (P. var.) 156 Hoffm. (Prt. Wulf.) 425 Pers. (Prm. sordid.) i 79 Luteus Dicks. (Gyal. eupul.) 108 Lutosa A. (Led. cand) - 285 Lyellii, Opegr. E. B. . . . 373 Lygæa, Lcd. Ach. 272, 273, 34 Lygodes A. (Cal. vir.) 386, (392) Lynceus E. B. Lecanact. - 375

Macilentus Ebrh. Cladon. - 240 Macrocarpa DC. (Led. cont.) 3or Macrocarpus A. (Op. script.) 3 ; 1 Macrostoma DC. Verruc. . 430 Maculacformis H. (Prm. var.) 156 Macularis A. (Hijst. rug.). 374 Ehrh. (Op. aitr.) 367 Madreporif. A. Evern
Hoffu. (Prm. sord.) $17^{3}$ 
Madreporif. (Cld. papill.) Pag. Madreporoides Rustr. (Ead.) 245 Malace , Peltig. A. . . 44 Mumillaris Gouan. Lecid. . 285 Mammosum 1). (Prm. verr.) I 86 Margueeu, Verruc. Whlb.

Margaritacea $\alpha$ A. (L. cont.) 298 Mar A A. (L. alboutr.) 337 Marginata, Lecid. Schær. . 322 (Opegr. Lyell.) Df. ${ }^{3} 7^{3}$

Marginella Df. (Verr. stat.) 446 Maritima Stlt. , Parmel. . 108 Marmorata Schl. (L. cont.) 299 Marmoreus Scop. (Gyal. cup.) 195 - Wulf. (Lcd. alboc.) 296 Mastrucatus Whlb. (Parm.) 142 Maura, Verruc. Whlb. 440 Maxima DC. (Verr. nitid.) $44^{\prime} 3$ Mazarinus Whlb. (Prm. cin.) 44 Medusula, Opesr. Pers. - 371 Meisnerianum Fl. (Ster. cond.) 203 Melaleuca A. (Verr. alb.) 444 Sflt. (Lcd. arm.) $32 \mathrm{I}$ - leuc. Wild. (Prm. perf.) 58 - leuc.,Spil. A. 369, 38 I, 443 - leuc. E. B. (Prt. comm). $42 \mathrm{I}$ - loma A. (Prm. cruss.) Iuo - mbola A. (Lecid. -) 328 Melanaspis, Parm. Whlb. 122 - nion. Spr. (Prm. obsc.) 85 Melanocarpus P. (Led. epig.) 290 - Sw. (Sphurer. consp.) . 404 - ceros. Wulf. (Ev. oclir.) 22 - chlora. Sflt. (Prm. soph.) 150 - chlorum DC. (Prm. calc.) I 88 - phæa. Fr. (Lcd. var.) 3 o3 (328) Melanophceum, Calic. Fr. - 392 - phthalm.Dc. (Prm. crass.) Ioo - - Df. Arth. $\quad 373$ Melantera A. (Verr. rhyp.) 446 -- stoma Bernh. (Prt. comm.) $42 \mathrm{I}$ Melizea Ach. 196 Membran. Dicks. (Prm. lanug.) 89 Mesarea A.

Mesenterif. Ehrh. U:b. prb. 355 Mesenteric. Schr.

Metabolica A. (Parm. soph.) 14.9 Micrasp. Sflt. (Prm. srd.) i $78(403)$ Microbola A. (Biut. vern.) . 264 - carpá DC. (Verr. punct.) 448 - celis A. (Parm. cin.). 143 Microcephal. E. B. Calic. 399 - ciba. A. (Sag. cin.) · 413
Pag. - clonum. A. Spiloma 380 - - E. B. (Lcnc. lync.) 376 Microphyllus A. Parm. . 90 - Schrad. (-tript.) $92\left(9^{3}, 275\right)$ - scopica E.B.(Verr. stat.) 446 Milliaria, Lecid Fr. . . 342 Milvinus. Whlb. (Prm. bad.) $\times 48$ Miniatus L. Endoc. . . 408 - Var. Auct. . 1 6, 114 Minima Chev. (Cnbc. pall.) 383 Minutellum A. (Cal. alboatr.) 398 - tissim. Hag. (Prm. var.) 256 - tula. A. (Biat. decol.) 267 Mirabilis Ehrh. (Verr. rup.) 436 Miscella Sflt. Biator • 279 - lus. A. (Led. sab.) . 339 Mniaroea A. (Prm. Hook.) . 94 Mixta, Biut. Fr. . . . 268 Molesta Del. • 459 Mollis Neck. (Ev. divar.) ${ }_{25}$ Molybdina, Parmel. Whlb. - 126 Monocarpus Th. (Cld. mac.) $24 \mathrm{r}$ Montagnei, Parmel Fr. . 107 Montana Schlch. (Op. script.) $37^{\circ}$ Moriformis Ách. (Dothidea)

Morio Ram., Lecid. . . . 3rg Morosa Df. (Biat. rivul.) : 272 Mortosa A. (Parm. soph.) . 19 Mougeotian. Dc. (Biat. decol.) 267 Mucosa Whlb. (Verr. maur.) 442 Multifid. Dicks. (Prm. incurv.) 70 - Horus Ehrh. (- brunn.) $9^{3}$ - puncta A. (- ciner.) 143 - punctata H. (Lcd. cont.) 299 - punct. E. B.(Prt. comm.) 422 - Ehrh. (Prm. phys.) 65 Muralis A. Verruc. . . 436 - Schreb. (Prm. saxic.) 110 Muricatus $\mathrm{S}_{w}$. (Cetr. acul.) $\cdot 36$ Murina A. (Lcd. atroalb.) $3_{3} 3$ - Schleich. (Prm. obsc) 84 Murinus A. (Umb., vell.) $\because 358$ Murorum A. Hoffm. Parmel. 115 - Féc (Opegr. sax.) • 366 Muscicola Sflt (Biat.) , 264 - geua A. (Prm. pulp) $79(96)$ Muscorum A. Syn. Parmel, . 95. - Endoc. A. (E. pus.) . 4 41 - Hoffm. (Prm. verr.) 187(263)

- Schleich. (Pltg. lioriz.) : 48

- Scop. (Prm. scrup.) . $19 \mathrm{r}$

- Web. \&c. (Brat. vern.) 263

- Wulf. (Lcd. sabul.) • 339 
Muscorum, Verruc. Fr. Pag. Mutabilis A. (Prm. verr.) - 186 - Ehrh. (Stict. herb.) . . 55 - Sfit. (Prm. var.) . 158 -- Wallr. (Verr. rup.) • 436 Mycopor. Ehrh. (Verr.punct.) 448 Myriocarpa DC. (Lcd. mill.?) 343 - Del: (Prm. plumb) . 87 Myrmecina Fr. Lecid. . . 344 Myrrhina A. (Prm. circin.) I 34 Myrticola, Chiodect. Fée. . 418

Nanum, Stereocaul. A. 205 (232) Nebulosa H. (Prm. brunn.) $\cdot 93$ Neglecta FI. (Cld. pyxid) . 216 Nephrea Sflt, Parnul. - . 15t Niger Auct. (Hypoth.) 92, 275 Nigrescens, Verrucur. 1. . 438 Nigricuns, Coniocyb. Fr. . 384 - Fl. (Prrn. obsc) . 85 Nigrita Schaer. (Lcd. urmen.)-321 Nigrum (Cfr. niger) Con.DC. 38 । Nimbosa A. (Opg. var.) 364 (367) Nimbosa, Parmel. Fr. . 129 Nitens P. (Prm. bad.) . 148 Nitidula, Lecirl. Fr. ? 308 Nitida Weig. Verruc. , , 443 Nivalis L. Cetrar. . . . 38 Nivea, Pertus. Fr. . . 426 - Trich. H. (Cncb. pall.) 383 Niveo-atcr.Dicks.(Lcd ulbnat.)337 Nobilis Sflt. (Led. cont.) . 301 Noäulosa, Parmel. Fr. . , 85 Normocric. Gunn. (Cetr. trist.) 68 Norvegica Sflt. (Led. squal) 288 Nothus. A. (Operpr. var.) $364(3 ; 5)$ Nuda P. (Lcd. sine crust.) 294

Obliter. P. (Prm.Mur.) \16(162) Oblongum Df. (Cal. curt.) . 388 Obscura, Lcd. A. (Prm.ferr.) 172 - Lepra E. (Prt. comm.) 4a I

- Opegr. P. (O. herpet.) 369

- Pltg. Schl. (P.rufesc.) 46 Obscurata Schær. (Lcd.pan.) 315 Obsciurus A. (Op. herp.) 369 (4/6) - E B. (Sag. aggr.) . 416 Obscurus Ehrh. Parmel . 84 - With. (Prm. aquil.) $\cdot 78$ Obsessa. A. (Prm. aleur.) 63 Obsoleta Sflt. (Prm. ocul.?) 135 Obtusatus F. D. ( Ocellata Hff. (- cintr.) $14^{3}$
- a. A. $(-$ calcar. $) \cdot 188$ Ocella'us Vill. Parmal. . 190 Ochracea Df. Conincarp. - 380 Ochracea Schaer. Parm. : 164 - Turn. Borr. Lepr. . 167 Ochrochlora, Led. A. , : 322 - Prm. A. . , 159 - ides. A (Prm sord.) 179 Ochroleucus Ehrh. Evern. 22 - Neck. (Prm. ham.) 154 - Wulf. ( - saxic.).110 Ocrinata, A. Parmel. . 159 Oculutus Dicks. Parm. . 135 Odontellus A. Cetr. . . 35 Odora, Gyalect. Schaer. - .197 Oederi Auct. . . 311 !, 326 - Auct. . . 291, 299 Olivacea Df Biatora . 255 - Hoffin. (Led. enterol.) 331 - Pers. (Prm. var.) • 159 - P. Verruc. Epid. . 447 Olivacea, Verruc. Fr. . . 438 Olivaceum Dec. Conioc. 38 I Olivaceus L. Parmel. . . 66 Ollare A. (Cal. tymp.) : 40 I Omphalodes L. (Prm. saxut.) 62 - Wulf. ( - pulv.) 79. Opaca, Lecid Df. - . 289 Opuntioides Vill. (Lcd. vesic) 287 Orbicularis Neck. (Prm. obsc.) 84 Orbicul. Schreb. (Prt. comm.) 422 Oreina A. Parmel. $113(145)$ - Variol. A. (P. sord) 178 Orostheus A. Parmel. . 180 - E. B. $(-$ var. $) \cdot 156$ Ostreata Hoffm. Parmel. $\cdot 94$ Ovaliformis A (Op. var.) . 365 Oxyceras A. (Cld grac.) 219, 2'4 Oxytona A. (Prm: cluloroph.) iIf

Pachycarpa Df. Biat. • $\quad 254$ Pxpalea A: (Prm, incpl.) 124, 182 Paleacea, Parmel. Fr.

Pallescens DC. (End. pus.) 4 it - Hoffm. (Prm. aleur.) 62 Pallescens L Purmel. . $\mathbf{1 3 2}_{2}$ - Weis, Wulf. (-subfusc.) 139 Pallida, Coniocyb. Fr. - 383 Pallideflava Schl. (-ocrin.) 160 Pallidus E B (End. pus.) $4 \mathrm{rr}$ - Pers. (Prm. tart.) . 134 - Schreb. \&c. ( - subfusc.) 139 
Panceola, Biator, Fr.

Pag.

Panceola, Lecid. Fr.

273

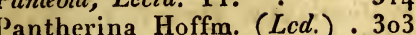

Pantospermus Vill. (B. decip.) 252

- śticta; A. Lcd. . . 307

a. L. alboccer. . . 296, 143

\& L. badioatra . . 316

\%. L. spilota. • • • 297

j. L. margin. . . . 322

Panyrgus A. (Prm. verruc.) 186

Papillaria, Cladon. Ehrh. 2/45

- DC. (Ev. madrep.) 25

Papillata, Lecid. Sflt. - . 336

Papillosa, Lcd. A. • 178, 403

- Verr. A. (V. mur.) .436

Papuluris, Verruc. Fr. .434

Papyracea. H. (Pltg. res.) . 42

Paradoxa A. (Lcd. vésic.) $\cdot 287$

- xum. A (Coniang.) $\cdot 378$

- xus. Ehrh. (Biat.) 253

Parsusemus A. Lecid. 330, (3o8)

- E. B. ( - enterol.) $) 33$ r

Parasiticus E. B. (Prm. saxat.) $6 \mathrm{r}$ Hoffm. (Cld. squam.) $23 \mathrm{I}$

Parechus A. (Cld. turg.) ? 215

Parallelus Ach (Stictis) 374

Parellus L. Mant. (Prm. pall.) i 33

Parietin. A. (Cal subt.) 388 ( 398 ) Schaer. (-brunn.) $\cdot 39^{3}$

Parietinus L. Parmel. ; 72

Parilis A. (Pllg. resup.) • 42

Parmeliar. Sflt. (Prm. saxat.) 6I

Paroicum A. (Cal. coryn.) 398

Paschalis L. Stereoc. 202 (201, 203)

Pedonta A. (Opeg. atra) . 367

Pelidna A. (Biat. pan.) $: 273$

Pelioscyph Whlb (Prm. cerv.) I27

Pellicula Df. (Op. var.) . 364

Pellitus A. (Umb. polyrrh.) 359

Pelobotryus Wahlb. Parm. . 189

Peltatum. A. (Cal. hyp.) - 390 - tus Lam. DC.(Prm. chrys.) 13 Peltifer Wulf (Biat. Byss.) 258 - phyllus Bell. (-decip.). 252

Pennina Sch. (Lecid. cand.) 285

PentaspermusVill. (End.pus.) 411

Percæna A. (Prm. cerv.) $\cdot 128$

Perforatus Jacqu. Pürmel. 58

Pericleus. A. (Lcd. dol.) 338 (149)

Perlatus L. Parmel. . . 59

Peronellus A. (Cncb. pall.). 383

Persooniana A. (Prm. cerin.) 169

- nii. A. (Op. rupest:) 364
Pertusus L. (Pertus. comm.) 420 - Schrank. (Prm, phys.) 64 - Wulf. (- scrup.) 190 - "Wulf." e Schrad. . 424 Petrcea, Opegrapha A. . . 362 Petræus. Wulf.\&c. (Mxt. spc.) 294 299, 3 13. Variet. Ach. - 325! Pezizoidea A. (Biat. vern.) 264 - des. Sw. ( - decip.) 252 - Web. (Prm. brunn.) $\cdot 9^{3}$ Phæa A. (Opegr. var.) . 364 Phæocarpa Fl. (Biat. ulig.) 275 Phacocephalus Turn. Calic. . 394 Pharcidia A. (Prm. soph) 0149 Pholidota. A. (Biat, gleb.) 252 Phycopsis A. (Rocc. fucif.) . 34 Phylliscum, Endoc. Whlb. 410 Phyllocarpa P. (Prm. spec.) - 80 - phorus. Ehrh (Cld.dg.) 22 r Phymat A. (Prt. Wulf.) 424, 425 Physarellum, Calic. Fr. - 392 Physodes L. Parmel. • 64 Picastrellum A (Cal.phacoc.) 395 - strum A. (Prnth. leucoc) 450 Piceus Dicks. (Prm. bad.) - 148 Picina, Led. A. (prior) ib. Picinus. A. (Prm. triptoph.) 92 Pileatum, Cal. A. (tympan.) $40 \mathrm{r}$ - Stereoc. A. (condens.) 203 Pilularis Dav. (Lcd. sabul.) $34 \mathrm{E}$ - Hoffm. (Lcd. mill.) . 343 Pinastri Scop. Cetrar. - 26 Pineti Schrad. (Biat. vern.) $26 \mathrm{r}$ Pinguis Chev., Verruc. \& 443 Pinicola Sflt. (Lcd. dolos.) 338 Pityrea A. (Prm. pulver.) 79 - DC. $(-$ rubig $) .88$ - Fl. (Cld.degen.)221(227) Placophyllus Whlh. Biat. 257 - thallus A. (Sag. virid.) 414 Platycarp A.(Lcd. cont.) 294(301) Platyna A. (Cetr. isl.) : $\quad 3$ ? Pleolepis' A. (Cld. squam.) 23 t Pleurota FI (Cld. ${ }^{-237}(239)$ Plicata Clem. Biat. . $\quad 274$ - Pers. (Prm. perlat.) • 59 Plicatus L. (Usn. barb.) 18 Plocina A. (Opegr. cerebr.) 363 Plumbea, Verrucar. A. $\quad 438$ Plumbeus Lightf. Parmel. . 87 - Roth. (Stict. scrob.). 53 Plumbos. E. B. (Verr. plumb.) 438 Pocillum A. (Cld. pyxid.) 216 
Polaris A. (Pltg. arce.) Pag. Poliopliaa, Parm. Whlb. . 146 Pollinaria, Ramal. A. - . 3 Polycarpa Fl. Lecid. . . . 305 - carpus Ehrh. (Prm. par.) $7^{3}$ - cephala Hoffm. Clad. ${ }^{23} 7$ - ceros Schrank. (Cld. fimb.) 222 - dactyla Fl. ( - macil.) $24 \mathrm{I}$ Polydactylus Neck. Pelugera . 46 Wulf. (P. rufesc.) ib. - gonus. Vill. (Prm culc.) 187 - lobus Wulf. (End. flup.) 409 Polymorpha, Ramal. A. . . 32 - Schaer. (Umb. prob.) 355 - Latour. (Lcd. ves.) 286 Polyphyllus, L. Umbil. . . 352 Wulf. (End.min.) 408 Polyrrlizus L. Umbilicaria 358 - Auct. (U. prob. \&c.) 355, 358 - thecia A. (Sag. cin.) . 413 - tropus Ehrh. (Prm.var.) 158 Populicola DC. (-subfusc.) 139 Populinus Ehrh. (Ram. cal.) 30 Populncum Brond. (Cal. subt.) 388 Populneus A. (Verr. nit.) 443 Porphyrins P. (Prm. ham.) 154 Porriginos. Turn. (Biat. vern?)260 Portentosa Df. (Cld. rang.) 244 Præcinctus. A (Op. script.) $37 \mathrm{r}$ Premnea, Lecid. A. . . . 329 Prevostii, Gyalect. Fr. . . 197 - Dub. (Cal. phys.) - 392 Privigna Ach. . . 294, $29^{5}$ Proboscidale A. (Cal. trich.) 389 Proboscideus Linn. Umb 354 (356) - Scop. (Prm. perf.) . 58 Prostiana: (Opegr. var) • 374 Protrusa, Lecid. Fr. . 324 Protuberans Whlb. (Prm. cin.) I $4 \%$ - Sag. A. (Ead.) . . 145 Pruinatus Dicks. (Lcd.alboc.) 295 - Pers. (Prm. impol.) 183 Pruinosa, Arth. A. (prior) 183 - Lcd. A. (L. alboccer.) 295 - Lcn. Ch. (Prm.incis.) 459 Prunastri, L. Evernia. Pseudo-corall. S. (Prm. scrup.) rgt - cornuta. Del (Cld. mac.)24r Psora Dicks. (Prm. cass.) • 83 Psoralis A. (- circin $)$. $\mathbf{2 4}$ Pubera c. A: (Ev. flavic.) . 28 Pubescens L. (Epleebe) Cf. p. 68 Pulchel. Schrad. (Lcd. W Whl.) 291
Pulchellus Wulf P Pag. Pulicaris Hoffm. (Op. cas.) 83 Pulicaris Pers.(Prm (Op. ar.) 364 Pullatulum A. (Cal. byss.) 399 Pullus A. (Prm. dendrit) . 68 $-\operatorname{Hoffm}(-$ physod. $) \times 65$ - Lightf. (-aquil.) . 78 - Schreb (- olivac.), 66 - Wúlf. (Umb. prob.) • 355 Pulmonarius, P. L. Sticta . 54 Pulveracea H. (sequens) \ 79 Pulverulentus Schreb. Parm. ib. Pulverulenta P. (Op. script.) 37 r Pulvinata, Lcd. Schaer. 255 Punctatus Dicks. (Is. Westring) - E. B. (Prm. subfusc.) 138 - F1 Led (paras.) . 330 - Hoffm. 296. 3o9, 33o - Scop (Lcd. enter.).33 Punctif. Wallr. (Prnth. stict.) 453 Punctiformis A. Verruc 447 (446) - DC. (Lcd.par.) 330 - DC. (Verr. epid.) • 447 Pungens A. (Cld. furc.) . 230 Purpurascens H. . $296,4^{3} 7$ Pusilla, Ramal. Dub. Prev. 29 - Parm A. . . 62 Pasillum, Calic. P. . . 388 Pusillum, Endoc. Hedw. • $4 \mathrm{ir}$ Pusiolum A. (Cncb. nigr.) 384 Pustulata A. Lcd. (alboc.) 296 A. Porin. (IVulf) $\cdot 424$ Pustulatus L. Umbilicaria • 35o Pygmæa Bory. (Prm. par.) 73 Pyrenophora A. (Verr. Duf.) 433 Pyrinus A. (Prm. soph.) ${ }^{\circ} 49$ Pyxidatus, L. Clad. . 216 (222)

Quadricol. Dicks. (Biat. dec.) 267 Quercifol.Wulf. (Prm. tiliac.) 60 Quercina P. (Hyst. rug.) . 374 Quercinum P. (Cal. lentic.) 387 Quercinus P. (Cld. squam.) $23 \mathbf{I}$ - Willd. side quercifol. Querneus Dicks. Biator. ${ }_{27} 8$ Quisquiliar. Leers (Ster. nan.) 205

Racemosus Schrad.(Cld. furc.) 230 Radians Lam. (Prm. circin.) 123 Radiata, Op. 1', Arth. 'A. ' 367 Radiatum P. (Verr. actinost.) 435 Radiatus Fl. Dan. (Cld.) 216, 219 - Huds. (Cetr. trist.) $\quad 35$ 
Radiatus Schreb. (Cld. fimb.) 223 Radiosus H. (Prm. circin.) 123 Ramulosa H. (Ev. jub.) : 2 t Rangifurinus L. Cladon. 243 (23r) Rangiformis $\mathrm{H}$. (Cld, furc.) 230 Recta Humb. (Op. script.) (27 I Recurvus, P. Parmel. ${ }_{2} 7 \mathrm{r}$ Rei Schacr (Cld. grac.?) - 210 Relicina, Parmel. Fr. . . jo Repanda, Parmel. Fr. - 177 Riesinæ, Peziza. . . 264 Resupinatus, L. Peltigera : 42 Reticulat. Df. Endocarp. -4to - Chaub. Spilon. - 366 - DG. (Op. atr.) . 367 - Hoffm. (Stict. pulver.) 54 - Wulf. . . . 68 Retiruga DC. (Prm. saxat.) 6r Retorida Chaub.(- courct.) 103 Rhagadiosa Ach. . . 18 Rhyponsa, Verruc. A. - 448 Rigidus Vill. (Evo ochrol.) $\quad 22$ - Wel. (Cetr. trist.) 35 Iiimalis A. (Op. var., atr.) 365 Rimosa, DC. (Cp. atr) $\cdot 367$ Rimosus R. (Prm. sord.) • 178 Rivulosa, A. Biator. • 271 Roccella (tinctoria) L. . . 33 Roscidum, Calic. F1. . 396 (394) Rosellus, P. Biat. . . . 259 Roseus, Bcromyc. P. . . 246 - Schreb. (Illospor.) . . Lxx - Rostrat. Scop. (Ram. cal.) $3 \mathbf{I}$ Rubella, Chaub. (Verr. con.) 432 . - P. (Opgr. spp.) 368, 369 Rubelliana A. (Prm. cinerea) 146 Rubellus Ehrh. (Biat. vern.) 260 Rubens FI (Pyren. stict.) 453 Ruber A. Hoffm. Purm. . ${ }_{132}$ Rubiformis Whlb.(Biat. glob.) 254 E. B. (Cld. init.) - 209. Rubiginosus Th. Parm. 88 Rubin. Vill. (Prm. chrysoph.) 113 - varr. A. . . 100, Ir3 Rubra, Sflt. Segestrella • 430 Rubricosa A. . . 120,128 Rubrum Pers (Conioc. cinn.) 379 Rudecta A. (Prm. Borr.) - 60 Ruderum DC. (Verr. mur.) 436 Rudeta A. (Led. mill.) . $\mathbf{3 4 2}$ Rufa, Pat. P. (Prm. mur.) 115 Rufescens Auct., Peltiges'a . 46
Rufcscens End. A. (E. pus.) 4 I I

- Opg.P.(O.atr.\&c.) 368,369 - Sag. A. (Prm. bad.) 148 - Yerr. H. (- aurant.) 167 - Wulf. (Pltg. polyd.) 47 Rufus Huds. (Biat. byss.) 257 Rugosa, Lcn. A. Parmel. . 182 - Por. A. (Prt. Wulf.) . 424 Rugosus L. Hysterium - 374 Rupestris, Opegr. P. . . 364 - Scop. \& Auct. . $\quad{ }^{67}$ Rupestris, Verruc. Schrad. $\quad 436$ Rupicola H. (Prm, calc.) 188 - L. $($ - sord. $) \cdot 178$ Rutilans A. ( - parietina) $\cdot 73$ Rutilus A. Lich, aurant, WIf. 176

Sabulctorum Schreb. Lec. 339 (342) Saccalus L. Peliigera . 49 - Umb. DC. (U. vell.) 357 Srepeculare A. (Cal. phacoc.) 394 Sapincola Ehrh. Cetrar. - 39 - Led. A. Prm. var. 156 - Pers., Limb. A. . 456 Salicina, Verr. DC. (Opegr. init.) - num., Cal. P. (C. trach.) 390 - nus. Schrad. (Prm.aur.) 156 Salignus Schrad. $C f r$. effusus Sanguinarius L. Lecid. . 335 - Var. Auct. $3 \dot{3} 0,443$ - nco-ater Wulf. $\quad 263$ Sarcoides Wulf, Bulgaria SarcopisWb. (Prm. var.) I56(138) Sarmentos. A. (Ev. ochrol.) 22 Saxatile, Calic. Schaer. $\quad 400$ Saxatilis L. Parmel. . - 6r _. L. sub Byss. ¿ 299 Saxatilis, Opegr. DC. • 366 Saxetana A. (Prm. ham.) 154 Saxicola Poll. Parmel. . I I - Psor. H. (- mur.) 115 - Schl. A. (Opegr.) 365, 366 Saxifragus $\mathrm{Sm}$. (Biat. test.) $25 \mathrm{r}$ Saxorum Fl. D. (Prm. tart.) 133 Scabra, Urceol. P. .. I8 8 Scabrosa A. (Lcd. flavov.) 29 r - E. B. (- eitrin. $)$. 346 - um, A.(Phacid. Caliciif.)

Scalaris A. (Prm. ostr.) $\quad 9^{5}$ Scalpod.Ehrh.(Unib, polyrh.) 359 Schuereri, Parmel. Fr, 106 (147) Schleicheri A. Parm. - . 130 Schraderi A. (Verr. rip. ${ }_{4}, 36$ 
Seiastra A. (Prm. Fahl.) - 67

Scolecinus A. (Cld. mac.). 241

Scopulorum A. Retz, Ramal. 32 - Fl D. (Prm. vent.) 153 Scorteus A.(Prm. til. \&c.) 6o (6r) Scriptus L. Opegr. . 3 7o $(373)$ Scrobiculatus Scop. Stict. $\quad 53$ Scruposus L. Parmel. . 190 - pulosa A. (Prm. stat.) 175 Scutatus E. B. (Pltg. polyd.) 47 - Wulf. (Cetr. scepinc.) • 39 Scutellaria Df. (Cal.' stig.) for Scytropus A. (Lcd. atroalb.) $31_{2}$ Sedifolius Scop. (- vesic.) 286 Segestria A. Lepr. • 144, 299 Sepulch r. Batsch, (Cal, truch.)39o Serpentinus A. (Op. script.) 37 r Sessilis Ehrh.(Cal.turb.) 402(401) Setiformis Ehrh. (Ev. jub.) 21 Sideralis, A. (Prm. astroid.) $8 \mathrm{I}$ Siderellus A. (Op.atr.) • 368 Signatus A. ( - var.) ${ }^{\circ} 365$ Silaceus A. \&c. 294, 295, 299 3o r Siliquosus Huds. (Ram. scop.) $\quad 32$ Silvatica Fl. (Cld. rang.) 243 Silvaticus L. Stict. • • 5 r Similaris Hoffm. . : 102 Simplex Dav. 148 (294) Sinapisperm. DC. (Bi, vern.) 263 Sinopicus Whlb. (Prm. bad.) 148 Sinuosus E. B., Parmel.) • 63 Smaragd. Whlb. (Prm. cerv.) 127 Smithii A. (Prm. gyps.) • 101 Solenaria A. (Ev. vill.) 27 (459) Sommerfeltiana Fl. - 179 Sommerfeltii Fl. Pertus. - 435 Sophod's A. Purmelia . . 149 Sordidus P. . . . . 178 Spadicea A. (Lcd. curneol. $\left._{.}\right){ }_{264}$ - Df. (Cld. furc.) ${ }^{23} \mathbf{I}$ - us Roth. (Ceir. acu'.) 36 Spadoch. Ehrh. (Umb.vell.) 357,8 Sparassus A. (Cld. squam.) $23 \mathbf{1}$ Speciosus Wulf, Parmel. 80 Spectabilis Flörk. (Lcd. arm.) 321 Speireus A. (Lcd. cont.) - 298 Sphærale A. Sclerococcum 403 Sphæralis, Fr. (Lcd.arctic.) 342 Sphærica Schaer. (- epig.) $29^{\circ}$ Sphrocephalus L. - 387,39 r Auct. - 338, 390 Sphæroid.Dcks.(Bt.vern.) 261 (263)
Sphinctrina, Limbor. Df. . 402 Spinosus Neck. (Cld. furc.) 230 Spilota, Lecirl. Fr. . . . 297 SplendensSchleich.(Ram. cal.) 31 Spodoph. Whl. (Prm. poliop.) 147 Spongiosa Bernh. Verruc. $\quad 432$ Sprengelii Fl. (Prm. dendr.) 68 Spurcatus A. (Op. var.) ${ }^{3} 6^{\prime}$ Spuria Schaer. (Lcd. lup.?) 307 - us A. (Pelt. can.) $\because 45$ Squalidus Sch. Lecid. . . 288 Squamat. Dicks. (Biat. lurid.) 255 Squamosa, Clad. Hoffin. 23 t Squamulosum A. (End. pus.) fir - sus Sch. Prm. cerv. 127 (25í) Squarrosus P. (Ram, poll.). 3, Stalactiticum (Prm, calc) $\quad 188$ Stannea, Parmel. Fr. . , 125 Steatina A. (1) rm. subfusc.) I 38 Stellaris L. Parmel. ․ 82 (80) Stellata Schaer. (Cld. unc.) $244^{\prime}$ Stemoneum A. (Cul. trich.) 389 Stenocarpa-A. (Op. atr.) . $36 \mathrm{~J}$ Sterilis A. (Spherph. frag.) 442 - Gouan (Cld. alcic.) - 213 Steriza Flot. (Lcd." stat.) 294 Stictæfor, Schleich. (Ram. cal. 3o Stictica Fl. (Cal. abort.) • 386 Slicticus A. Pyrenotli. . 452 Stictoceros E. B. ' $(E$ v. prun.) 26 Stigmatea A. (Lcd. sab.) • 34 I - tellus A. (Verr.) 446447 Stigonellum, A. Calic. - $40 \mathrm{I}$ Stilbea A. (Cncb. pall.) • 383 Stillicidior. Fl. D. (Prm.cer.) 169 Stonei A. (Prm. hemat.) . 154 Straminea, Clad. Sflt. - 234 Straminea, Parm. Whlb. 109 Striata, Parm. Dub. . 193 Striatul. Whlb. (Verr, maur.) 442 Strobilina A. (Prm. var.) 156 Stygias, L. Parmetia • • 67 Suaveolens A. (Gyal. od.) 197 Subcarneus A. ( - sord.) 179 Subfuscus L. Parmel. I36(140) - Var. Sflt. (- cenis.) 180 Subocellata Fl. (Op. herp.) 368 Subpedicel. Schaer. (Cal. dis.) 399 Subtile, Calic. P. . . . 388 Subulatus L. (Cld. furc.) 230 Subuliformis Ehrh. 221 (227) Suffusa Reb. (Verr. nit.) $44^{3}$ Sulcata Pers, (Op. ${ }^{\text {eleg. }}$ ) 370 
Pag. Sulphurea Lepr. Ach. • ${ }^{157}$ - us Dicks. (Prm•sord.) : 79 - Retz. (Cncl. furf.) . 382 Sulphureo-nig. Fl. (Prm. var.) I56 Superficialis, Lecid. Sch. • 325 Swartziana A. (Op. atr.) .367 Swartzii A. (Parm. sord.) 178 Sylvatic. vid, sill.

Symmicta A: (Prm. var.) 156 Sympageus A. (Prm. aurea.) 118 Symphicarp.Ehrh.(Cld,stat.) 218 Synothea A. (Biat. denigr. . $^{2} 270$

Tubacinus Ram. Biat. . . 253 Talcacea, Verruc. Fr. : 433 Talcophila A.'(Prm. scrup.) 19 i Turtureus, L. Purm. • \ 33 - Wulf. . 101, 102 Taxicola A. (Sag. aggr.) 416 Tauricus Wulf. $(\mathrm{Cld}$.$) , 221$ Tegularis Ehrh. (Prm. mur.) ${ }_{0} 6$ Tenagea A. (Biat. vern. $)$. 263 Tenel. Scop.(Prm. cas, \&c.) 84,82 Tephroid. A. (Sag. cin.) 4,3, Tephromel. Elirh.(Prm.atr.) 142 Terebrata Hoffm. (- phys.) 64 Terminal. F. D. (Verr. maur.) 4́2 Terrestris E. B. (Verruc.epig.) $4^{3} \mathrm{I}$ Terricola A. (Biat. ulig.) 275 Terrigena A. Ead. . . ib. Tersa A. (Lcd. paras.) • 330 Tesselata, Grph. A. (U. atrpr.)35 I - Licd. FI. (L. fuscoatr.) 317 - Lich. E. B. (Sag. virid.) 414 - Urc.DC. (Prm.cin.)143(188) - Verr. Hoffm. (-calc.) 388 Tesserata DC. (Op. petr.) 363 Tessulat, vid. tessel. .

Testucea Hoffm. Biat. . 25 r - Winch. $(-$ gleb. $) \cdot 252$ Theicolyta A. (Prm. eryth.) 120 Theiodes, Lecid. Sflt. - 325 Thelena, Verruc. Silt. : 4 'o Thelephora A. (Prm. cin。) I43 Thelostoma Harr, Segest. • 429 Thiodes Spr. (Prm. subfusc.) $14 \mathrm{I}$ Thrausta A. (Ram. calic.) 30 Tigilluris, A. Calicium 400 Tigrina Hoffm. . . . 303 Tilesii A. (Cetr. junip.) . 40 Tiliaceus Ehrh., Parm. . 59 Tiliæ Schleich. (Lcd. Sab.) 34r Tinctoria, Roccell. DC. . 33
Pag.

Tinctorius Web. (Ram. pol.) 32 Titanophila Spr. ( $V_{0}$ mur.) 436 Tomentosa H. (Pltg. res.) . 42 Tonientosum, Stereoc. Fr. - 201 Tornata A. (Umb. prob.) - 355 Torquata, Parm. Fr. . 1/47 Torrefact. Lghf. (Umb. prob.) 354 Trabinel., Wlb. (Cul. phoeoc.) 394 Trachelinum, Calicium A. 390 Trachona A. (Verr. rup. 437 Trachynus A. (Cld. degen.) $22 \mathrm{x}$ Trapelia A. (Prm. courct.) 105 Trapeziform.Dcks. (End.pus.) $41 x$ Tribrac.A. (Prm。ca's. \& c.) 84, 83 Trichiale, Calic. A. . . 389 Tricolor, With. (Biat. carn.) 264 - Spil. A. (Lenct. grum.) 375 Tridens, A. (Opegr. var.) 365 Triptophylla A. Parmelia - 9r Tristis Web., Cetraria $: 34$ Truncigena DC. (Thel. lep.) 428 Tuberculosa Sflt. (Biat, byss.) 258 - Hoffm. (Pert. com.) 422 - sum, Spilom. E. B. 38 I - sus E. B. 182 Tubiformis Lighf. (Cld. mac.) $24 \mathrm{x}$ Tubulatus Vill. (Cld vermic.) 221 Tumidulum A. (Conioc, cinn.) 285 - lus Pers. (Prm. pall.) i32 - Smith, (Led. manili.) 285 Tympanellum, Culicium A. $\quad 46 \mathbf{r}$ Turbinatum, Calicium P. . 402 - tus A. (Cld.grac.) 219, 229 Turfac. Whlb. (Prm. sophod.) 49 Turgida, Biat. A. (Lcd.cont.) 299 - dula, Led. Fr. . 337 - dum, Endoc, A. - 412 Turgidus Ehrh. Cladon. 214 Turneri A.(Prm, pall.) 132 (154) - riana, Lcd. . . ${ }_{1} 2^{3}$

Uliginosus Schrad. Biatora 275 Ulmi, Sw (Prm. rubra) . 134 - cola DC. (- cerin.) 168 Ulorrhiza Fr. (Pltg. rufesc,) 46 Ulotrix A. (Prm. obscura) 85 Umbilicatus A. ( - subfitsc.) 138 Umbonata A: (Segestr.) $\quad 429$ Umbrina A Verruc. 44 r (439) - , Led. A. . . 277 Umbrinum, Spiloma Fl. . I9 - nus Ehrh. (Prm. soph.) 149 Uncialis L. Cladonia . : 244 
Uncinata H (CI, brach) Pag. Unicolor A. (Prm, chloroph.) I17 Sflt. ( - sord.) 176 Upsaliensis L. (- pallese. $)^{\bullet} \mathbf{1}_{2}$

Vahlii Retz. (Prm. hemat.) 154 Vaillantii Df. (Cld, alcic.) 213 Vallesiacus (Prm. ocell.) . 190 Varia, Opegrapha P. . . 364 - abilis P. (Prm. circ.) 124 - ans Dw. ( - sord.,) 178 - - Led. A. (Biat. exig.) 278 Variegata, Lecid. Fr. . 3 o3 - olarioid. A. (Prm.) 136, 184 - olosum ( - Pyren.) $45 \mathrm{r}$ Varius Ehrh. Parm. ${ }_{156}$, 159 Velata Wallr. (- impol。) 183 Volleiform. Bell. (Umb. vell.) 357 Velleus I. Umbilicaria . - ib. - Hoffm. (U. polyrrh.) . 359 Velutina Bernh. (Verr.epig.) 43 I - nus. A. . . $9^{2}$ Venosa P. Opegrapha .. 3-3 Venosus L. Peltigera . . 48 Ventosus L. Parmelia - 153 Ventricos. (CI. squum.) 23 i (238) Cal. A. . . 402 Venusta A. (Parma pulver.) 79 Vermicellifer'a Wallr. Pyren. $45 \mathrm{I}$ Vermicular. Sw. (Clad. stat.) 220 Vernalis L. Biatora ' 260-4 Verruearioides A., Saged. 416 - Opegr. A. 364,367, 446 Verrucosa A. Parmel. . 186 -, Lcnor. A., . 36,184 -, Pyr. A $(V$. Hochst. $) 455$ Vcrrucosum, Endoc. Wallr, 421 - Spil. A. . 38 I Verrucosus Huds. (Stict, scrob.) 53 Web.(Plto. aphth، $) 44$ Verruculosus E. B. - . 278 Versicolor A. (Prm. circin.) 124 - DC. (- erythroc.) 120 - P. (- saxica) III
Versicolor, Spiloma A. . Pag. Verticillata H.(Clad. grac.) 219 Vesicularis, Lecid. A. . 286 Vesuvianum, Stereocaul. P. 204 Villarsii A. (Prm, ocell, $)_{0} \mathbf{1} 90$ Villosa, A. Evernia . • 27 Virellus A. (Prm, obscura) 85 Viride, Calicium Pers, . 386 - End, A. . . . 208 Viridescens Schrad. 262, 26 $;, 275$ Viridi-atra, Biat. Stenh. - 277 - Lcd. A. (L. armen.) : $32 \mathbf{2}$ - ater Wulf.. . 278 - flavesc. Wulf. $: 159$ - fusca Schleich. . . 84 - rufa A. Lcd. . . 172 - - Hoffm.' Verrucaria 166 Viridis, Lich. Schreb. (Chor.) xx - Op. Pers. (Mixta.) . 369 Viridulum, Calicium Fr. $\quad 400^{-}$ Viridul, End. Schrad, Saged, 414 - Hoffm. (Biat: dec.) 267 Vitellinus Ehrh, Parm, 162(115) Vitiligo A., Spiloma . 38 a Volvatus Vill, (Gyal, exanch.) igs Vulcani, Stereoc. Bory. - 203 Vulgare, Coniangium Fr. . 378 - ris, Arthon.Sch. (sq.) 367 - tus A. $(O p$. atr.) ? ih. Vulininus L. Evernia . . 23 Vulvella A. (Op. var.) - 364 Wahlenberg. A. (Gyal. cup.) 196 Wallenbergii, Lecid. A. - 291 Wallrothii Fl. 259 Spr. I4工 Weberi A. (End, flu. $\cdot 409$ Westringii. A. (Prm, scrup $)_{a} 19$ ! Wulfenii A. (Cld. alboces) 296 Wulfenii DC. Pertusiaria 424 Xanthococca, Lecid. Sfit. - 380 Xanthostigma A. Spiloma 345 Xantiostoma, Pert. Sflt. $\quad 426$ Xylonellum A. (Cal, trach.) 39, Zonata A. (Pr:m, ciner.) $143,145$.

Obs. Byssaceæ cum Collemaceis sepositæe sunt. Indicem gencrum omisit Typotheta. 





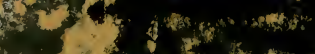

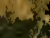

$\frac{3}{4}$

$y^{4} x^{4}$

ans as at

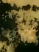

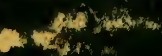

\section{$3^{2} y^{2}$}

$\infty \rightarrow$

被

被

.

se

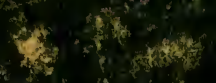

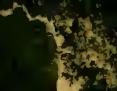

tor

(3)

tot

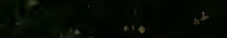

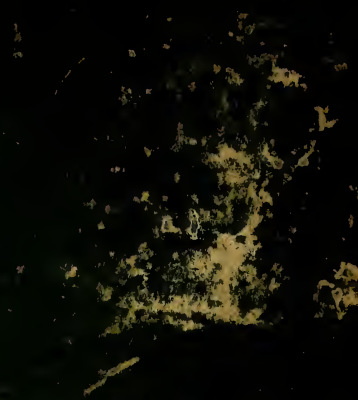

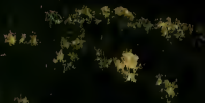

Hat $x^{4} x^{4} x^{4}$
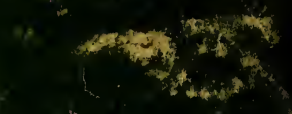

$$
0+\frac{x}{7}+\frac{3}{3}
$$
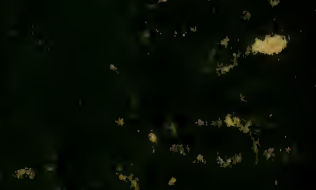

$+2 x^{2}+4$

$* \frac{1}{4} \cdot \operatorname{los}^{4}+4$

के

$+x+2$

$+6 t^{2}+\cos ^{2}, x_{0}$

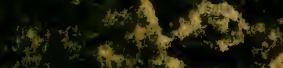

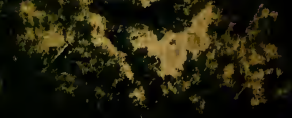

